Johanna Sophie Matzat

\title{
Die Energiewende in den eigenen vier Wänden
}

Alltägliche Heizpraktiken im Wandel 
Umweltsoziologie

herausgegeben von

Prof. Dr. Matthias Groß, Helmholtz-Zentrum für Umweltforschung, Leipzig und Friedrich-Schiller-Universität Jena Prof. Dr. Stefanie Hiß, Friedrich-Schiller-Universität Jena Prof. Dr. Harald Heinrichs, Leuphana Universität Lüneburg Prof. Dr. Ortwin Renn, Institut für transformative Nachhaltigkeitsforschung e. V. (IASS), Potsdam

Band 8 
Johanna Sophie Matzat

\section{Die Energiewende in den eigenen vier Wänden}

Alltägliche Heizpraktiken im Wandel

\section{Nomos}


Beitrag zum Exzellenzcluster „CLICCS - Klima, Klimawandel und Gesellschaft”

Die Deutsche Nationalbibliothek verzeichnet diese Publikation in der Deutschen Nationalbibliografie; detaillierte bibliografische Daten sind im Internet über http://dnb.d-nb.de abrufbar.

Zugl.: Hamburg, Univ., Diss., 2019

1. Auflage 2020

() Johanna Sophie Matzat

Publiziert von

Nomos Verlagsgesellschaft mbH \& Co. KG

Waldseestraße 3-5 | 76530 Baden-Baden

www.nomos.de

Gesamtherstellung:

Nomos Verlagsgesellschaft mbH \& Co. KG

Waldseestraße 3-5 | 76530 Baden-Baden

ISBN (Print): 978-3-8487-6309-2

ISBN (ePDF): 978-3-7489-0414-4

DOI: https://doi.org/10.5771/9783748904144

Onlineversion

Nomos elibrary

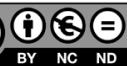

Dieses Werk ist lizenziert unter einer

Creative Commons Namensnennung - Nicht kommerziell Keine Bearbeitungen 4.0 International Lizenz. 
,Wenn es groß, kraftvoll und überzeugend werden soll, dann braucht es seine Zeit.

Aber auf dem Weg dorthin braucht man sich nicht verstecken. Im Gegenteil.'

- Ich bin stolz darauf, diese Arbeit fertiggestellt zu haben. 


\section{Inhaltsverzeichnis}

$\begin{array}{ll}\text { Danksagung } & 17\end{array}$

$\begin{array}{ll}\text { Danksagung } & 19\end{array}$

$\begin{array}{ll}\text { Zusammenfassung } & 21\end{array}$

$\begin{array}{ll}\text { Summary } & 27\end{array}$

1 Einleitung und Forschungsinteresse 31

1.1 Theoretischer und politischer Kontext: Klimawandel und Energieverbrauch

1.2 Energienutzung in Gebäuden: das Heizen als besonders relevanter Faktor der CO2-Produktion

1.3 Reduktion des Energieverbrauchs für Heizen - mehr als eine technische Frage

1.4 Die typische sozialwissenschaftliche Herangehensweise zur Erforschung des Energiekonsums in Privathaushalten

1.5 Der Ansatz sozialer Praktiken als forschungsleitende Perspektive

1.6 Die Anwendung des Praktiken-Ansatzes anhand von zwei Fallbeispielen: Heizen im Passivhaus und im SmartHome 44

1.7 Methodischer Ansatz: qualitative Interviews 46

1.8 Forschungsziele und konkrete Fragestellungen 47

1.9 Zum Aufbau der Arbeit 49

1.10 Zentrale Definitionen 50

1.10.1 Passivhaus - was ist der Passivhausstandard? $\quad 50$

1.10.2 Worum handelt es sich bei einem SmartHome? 54 
2 Soziale Praktiken als theoretische Forschungsperspektive 55

2.1 Der praxistheoretische Zugang 63

2.1.1 Gemeinsame Grundannahmen des praxistheoretischen Zugangs

2.1.1.1 Praktiken als elementare Einheit des Sozialen

2.1.1.2 Soziale Praktiken als koordinierte Einheit von Aktivitäten

2.1.1.3 Das besondere Verständnis von ,Materialität‘

2.1.1.4 Konzeption und Position des handelnden Subjekts

2.1.2 Begriffsbestimmung und Konzeption sozialer

Praktiken

2.1.3 Praktikentypologie

2.1.3.1 ,Dispersed' und ,integrative practices ${ }^{6}-$ verstreute, weit verbreitete und integrative Praktiken

2.1.3.2 ,Compound practices ${ }^{\varsigma}-$ komplexe, zusammengesetzte Praktiken

2.1.4 Merkmale sozialer Praktiken

2.1.4.1 Praktiken überschreiten raumzeitliche Grenzen

2.1.4.2 Die körperliche Darstellung und Verankerung von Praktiken

2.1.4.3 Praktiken als untrennbar verknüpfte routinisierte Formen körperlicher Performances und sinnhafter Verstehensleistungen

2.1.4.4 Die besondere Betonung der Materialität sozialer Praktiken

2.1.4.5 Die Geschichtlichkeit und kulturelle Kontingenz sozialer Praktiken

2.1.4.6 Die Stabilität und Wandel(barkeit) bzw. Offenheit sozialer Praktiken

2.1.5 Das Konzept sozialer Praktiken in der soziologischen Konsumforschung

2.1.6 Konsum als (Neben-)Folge von Praktikenvollzügen 
2.1.7 Energie als ein Bestandteil sozialer Praktiken und Energiekonsum als Nebenprodukt praktischer Vollzüge

2.2 Heizen als soziale Praktik

2.2.1 Energieintensive Gebäude- bzw. Raumheizung im Fokus

2.2.2 Die grundsätzliche Bedeutung von Wärme für Menschen - Heizen als essentielle Praktik

2.2.3 Heizen - eine geregelte Alltagsroutine

2.2.4 Die Bedeutung der Entwicklungsgeschichte häuslicher Heizung

2.2.4.1 Geschichte des Heizens

2.2.4.2 Sozialwissenschaftliche Reflexion der Geschichte des Heizens

2.2.5 Heizen als soziale Praktik - Versuch einer genaueren Bestimmung und Einordnung

2.3 Wandel und Veränderbarkeit von Praktiken

2.3.1 Die soziologische Debatte zum (Thema) Praktikenwandel

2.3.2 Praktikenwandel - grundlegende theoretische Differenzierungen

2.3.2.2 Ausmaß und Formen des Wandels von Praktiken

2.4 Praktiken - ein differenzierter und vielversprechender Forschungsansatz

3.1 Die Wahl eines qualitativen Ansatzes: Eine vom Erkenntnisinteresse geleitete Entscheidung

3.2 Dokumentarische Methode als methodologische (und methodische) Entsprechung zur gewählten theoretischen Perspektive

3.3 Methodisches Forschungsdesign 205

3.4 Begründete Auswahl der beiden Fallbeispiele 209

3.5 Auswahl der Interviewpartner*innen 211 
3.6 Interviews 214

3.6.1 Leitfadengestützte Interviews 214

3.6.2 Expert*inneninterviews 217

3.7 Feldzugang 218

3.8 Entwicklung und Erprobung der Interviewleitfäden 222

3.9 Materialbilanzierung 224

3.10 Dokumentarische Methode - konkretes

Auswertungsverfahren 225

3.10.1 Die formulierende Interpretation 226

3.10.2 Die reflektierende Interpretation 228

3.10.3 Sinn- und soziogenetische Typenbildung 233

3.11 Auswertungsschritte am Material 235

3.11.1 Zur formulierenden Interpretation 235

3.11.2 Zur reflektierenden Interpretation 238

3.11.3 Modifizierter Abschluss der dokumentarischen Interpretation

4 Wandlungsdynamiken im alltäglichen Heizen

4.1 Die prägende Kraft der Vergangenheit - am Beispiel von Entwicklungen rund um den Heizkörper

4.1.1 Heizen im Passivhaus

4.1.1.1 „[I]ch hab zusätzlich[e Heizkörper] ja. Die benutz ich jetzt nich ähm aber [...] wenn's richtig kalt ist [...]“ - Frau Rosental

4.1.1.2 „Äh also es war so klapperkalt es war so schrecklich im Winter dass ich mir das [ohne zusätzliche Heizkörper] nicht vorstellen konnte“ - Frau Schulze

4.1.1.3 „Also manchmal hab ich mich gesehnt wenn's draußen kalt war und ich kam hierher dass ich irgendwo meine kalten Füße an 'n Heizkörper halten kann" - Frau Köhler

4.1.1.4 „Also wenn ich bei meinen Kindern bin [...] die haben 'nen Ofen das finde ich dann immer herrlich“ - Frau Kirsch 
4.1.1.5 „Und na was ich super attraktiv fand tatsächlich [...] war dass sie gesagt haben dass es so was (klopft gegen den Heizkörper) nich mehr gibt" - Herr Frings

4.1.1.6 „Aber wir haben die [Heizkörper] überall und konnten die auch nicht wegdiskutieren" - Herr Thomsen

4.1.1.7 Einfluss und Lernen der Expert"innen im Prozess des Passivhausbaus (mit neuer Heizlösung) - Herr Frings, Frau Rosental, Herr Lehmann und Herr Meier

4.1.2 Heizen im SmartHome - vom (konventionellen) Heizen mit Heizkörper mit mechanischem Thermostat zum intelligenten Heizen mit Heizkörper mit Funk-Stellantrieb

4.1.2.1 [D]ass sich mir auch jetzt wo ich das nutze immer weniger erschließt warum es einfacher sein soll“ - Frau Huber

4.2 Gewöhnungsprozesse beim Wohnraumlüften

4.2.1 Die Befreiung von der „Last des Lüftens“ - Frau Möller

4.2.2 (Fenster-)Lüftung als „Wissenschaft“ - Frau Rosental

4.2.3 „[E]ntweder ich geh' auf die Straße zum Rauchen oder ich leb' mit dem Gestank jetzt" - Frau Fischer

4.2.4 Zum Umgang mit Regeln, die das Lüften im Passivhaus betreffen - Herr Frings und Frau Greiner

4.2.5 Von Fensterlüftung zu kontrollierter Be- und Entlüftung - ein „schleichender Gewöhnungsprozess" - Herr Lehmann

4.2.6 Vergleichendes Kapitelfazit

4.3 Veränderungen im Behaglichkeits- und Komforterleben

4.3.1 Im Winter komme ich mir oft vor "wie in 'nem Iglu“ - Frau Köhler

4.3.2 „Also dieses ganz Konstante [...] es ist nicht mein Ding" - Frau Köhler

4.3.3 Von „Leben mit den Jahreszeiten“ zu „’n bisschen raumschiffmäßig“ - Herr Thomsen 
4.3.4 „So 'ne Wärme [...] dass man [ sich] im gesamten Haus wohl fühlt [...] das ist so 'n Gefühl das hat so 'ne Gleichmäßigkeit im ganzen Haus. Das gibt so 'n Freiheitsgefühl“ - Frau Möller

4.3.5 „Es is [...] 'ne andere Wärme also 'ne gleichmäßigere“ - Frau Rosental 346

4.3.6 Trockene Raumluft im Passivhaus 347

4.3.7 Veränderungen im Behaglichkeits- und Komforterleben im Fall der SmartHomes 349

4.3.8 Vergleichendes Kapitelfazit 350

4.4 Das Gefühl von Kontrolle und Kontrollverlust 358

4.4.1 Eingeschränkte bzw. fehlende Regelbarkeit der Heizung

4.4.1.1 „Bis die [Heizung] auf das reagiert was ich gerne möchte bis dahin weiß ich schon nich mehr was ich gestern eigentlich wollte“ Frau Lutz

4.4.1.2 „[E]s macht's die Technik es macht's jetzt der Computer" - Frau Köhler

4.4.1.3 „Also ich sag ja mit dem Scheiß bin ich absolut unzufrieden“ - Herr Martens

4.4.2 Erlebte Störfälle und das daraus resultierende Gefühl zunehmender Technikabhängigkeit

4.4.2.1,$[\mathrm{M}]$ an ist halt jetzt auch so von dieser Technik so abhängig“ - Frau Fiedler

4.4.2.2 „Hab ich 'n bisschen-bisschen doller gedrückt. Und dann sagte es ,Knack““ - Herr Martens

4.4.2.3 „Und da hab ich gedacht wir sind komplett abhängig“ - Herr Frings

4.4.2.4 „Wir sind halt so 'n bisschen Versuchstiere und müssen mal gucken wie wir damit klarkommen“ - Frau Fiedler

4.4.3 Sicherheitsbedenken bezüglich des Datenschutzes

4.4.3.1 „, $[\mathrm{A}]$ lle von der Firma [haben] Einsicht [...] das sind ja nur 20, 30 Mitarbeiter $^{6}$ Da habe ich schon so gedacht, Oh das reicht mir eigentlich schon“" - Frau Fiedler 
4.4.3.2 „Äh wieso kann jetzt irgendwo in irgendeiner Zentrale die ich überhaupt nicht kenne $[\ldots]$ jemand $[\ldots]$ meine Heizungsnutzung [...] ablesen? Wozu? Mit welcher Berechtigung? Finde ich Scheiße“ Herr Martens

4.4.4 Vergleichendes Kapitelfazit

4.5 Wege, auf denen neue Heizpraktiken Verbreitung finden

4.5.1.1 „[D]ass das nun 'n Passivhaus wurde war nun gerade Zufall“ - Herr Werner (und seine zwei Töchter)

4.5.1.2 „Also das [Passivhaus] erlebe ich als dermaßenen Sprung in der Lebensqualität bezogen jetzt auf so 'n Altbau - Herr Barth

4.5.1.3 „Ja also ich würde wahrscheinlich jetzt nich in einen Altbau einziehen [...] würde ich jetzt nich mehr machen. Wenn ich es mir leisten könnte“ - Herr Frings

4.5.1.4 „@Und@ für meine Tochter war das ganz @witzig@. [...] Also die musste sich viel stärker umstellen“ - Frau Greiners Tochter

4.5.1.5 Die Rolle von Expert*innen im Entscheidungsfindungsprozess für ein Passivhaus

4.5.1.5.1 ,[D]er größte gemeinsame Wunsch dieser Gruppe war ein Sonnenhaus zu planen" Baugemeinschaft und Wohnprojektgruppe A

4.5.1.5.2 „[W]enn wir schon neu bauen dann für die Zukunft bauen und das sollte dann ein Passivhaus sein und auch nicht Niedrigenergie, sondern wirklich 'n Passivhaus" Baugemeinschaft und Wohnprojektgruppe B 
4.5.1.6 Öffentliches Image des Passivhauses und cleveres Marketing

4.5.1.6.1 „Und Passivhaus ist sowieso [...] so 'n blöder Name" - Herr Wirth

4.5.1.6.2 Der Name,Passivhaus' geht auf Wissenschaftler*innenkreise zurück, Marketingspezialist"innen waren an der Namensgebung sicher nicht beteiligt - Frau Schulze

4.5.2 Weg(e) zu einer intelligenten Heizungssteuerung oder wie intelligentes Heizen bisher Verbreitung findet

4.5.2.1 „So 'n bisschen von hinten durch die Brust [...] weil der direkte Weg funktioniert äh doch nicht so einfach" - Herr Thiel

4.5.2.2 „[S]o 'ne [...] Tupperparty [...] das würde die Zeit geben und wär 'n schöner Rahmen um das mal wirklich dezidiert vorzustellen“ - Herr Thiel

4.5.2.3 „[W]ir [als

Energieversorgungsunternehmen] sagen wir wissen [nicht] alles. Also wir sind sehr intensiv auch auf das Feedback der Kunden angewiesen" - Herr Thiel

4.5.2.4 „Wir suchen [...] aktiv nach Lead-Usern [...] das sind eher Nicht-Kunden [...] die sich dadurch auszeichnen dass sie selbst aktiv geworden sind" - Herr Koch

\subsubsection{Vergleichendes Kapitelfazit}

5 Theoretische und praktische Schlussfolgerungen sowie Ausblick auf weiteren Forschungsbedarf

5.1 Soziale Praktiken: Ein aufschlussreicher analytischer Rahmen zur Untersuchung des Energiekonsums in Privathaushalten

5.1.1 Arbeiten mit dem (Drei-)Elemente-Modell

5.1.2 Die (historischen) Entwicklungsverläufe von Praktiken

5.1.3 Die Verflechtung von Praktiken 
5.1.4 Die Klassifizierung von Praktiken

492

5.1.5 Unterschiedliche Formen und das Ausmaß von Praktikenwandel

5.2 Inhaltliche Erkenntnisse zur Praxis des Heizens 495

5.2.1 ,History matters' 496

5.2.2 Entkopplung und die Wandlung von Elementen mit unterschiedlicher Geschwindigkeit $\quad 502$

5.2.3 Koevolution 505

5.2.4 ,Distributed agency ${ }^{6}$ - (ungleich) verteilte Wirkmacht $\quad 507$

5.2.5 ,Heterogeneous engineers` und , heterogeneous engineering $^{6} \quad 509$

5.2.6 Nicht-intendierte Folgen 514

5.3 Ableitungen für politische Interventionen 515

5.3.1 Komplexität berücksichtigen $\quad 517$

5.3.2 Richtiges Timing und Gelegenheitsfenster schaffen 518

5.3.3 Die Bedeutung der Bedeutungen-Komponente $\quad 519$

$\begin{array}{ll}\text { 5.3.4 Allianzen aufbauen } & 519\end{array}$

5.3.5 Als Vorbild agieren $\quad 520$

5.4 Praktiken - die Transzendierung von Verantwortung 521

5.5 Bedarf und Potenzial für weitere Forschung 534

$\begin{array}{ll}\text { Literaturverzeichnis } & 539\end{array}$

Online-Quellen $\quad 569$

$\begin{array}{ll}\text { Anhang } & 573\end{array}$ 


\section{Danksagung}

Mein besonderer Dank gilt meiner Doktormutter Anita Engels. Ohne ihre vielfältige Unterstützung hätte diese Arbeit nicht ihren Weg in die Welt gefunden. 


\section{Danksagung}

Gefördert durch die Deutsche Forschungsgemeinschaft (DFG) im Rahmen der Exzellenzinitiative des Bundes und der Länder - EXC 177 „CliSAP - Integrierte Klimasystemanalyse und -vorhersage" - Projektnummer: 38787541, Beitrag zu dem Centrum für Erdsystemforschung und Nachhaltigkeit (CEN) an der Universität Hamburg. 


\section{Zusammenfassung}

Die Adressierung des Klimawandels stellt eine zentrale gesellschaftliche Herausforderung dar. Mehr als ein Drittel der gesamten Endenergie wird in privaten Haushalten genutzt, insbesondere für Raumheizung, wobei beträchtliche Mengen an klimaschädigenden $\mathrm{CO}_{2}$-Emissionen freigesetzt werden. Die vorliegende Arbeit befasst sich mit Dynamiken im alltäglichen Heizgeschehen in privaten Haushalten nach der Einführung von neuer Heiztechnik. Darüber hinaus wird der Frage nachgegangen, inwieweit sich hierbei ökologisch-nachhaltige Veränderungen gezielt anstoßen lassen. Dafür wird Heizen in Passivhäusern und so genannten SmartHomes untersucht.

Es wurde dabei ein praxistheoretischer Zugang gewählt, der umfassend dargelegt und für die anschließende empirische Anwendung aufbereitet wurde. Der Ansatz sozialer Praktiken (nach Schatzki und Reckwitz) wird in der Umwelt- und Konsumsoziologie häufiger als theoretischer Rahmen für Untersuchungen genutzt. Praktiken sind demnach eine Reihe von kollektiv geteilten, internalisierten körperlich-mentalen Routineaktivitäten, die von Materialität, Kompetenz und Sinn getragen bzw. zusammengehalten werden. Eine Praktik stellt eine jeweils spezifische Konfiguration dieser unterschiedlichen Elemente dar, sie integriert die Elemente zu einer Einheit. Es lassen sich insbesondere Wandlungen hinsichtlich der einzelnen Elemente, ihrer Zusammensetzung und ihren Verknüpfungen untersuchen. In dieser Arbeit wird entsprechend Heizen als eine soziale Praktik und der Wandel von Heizpraktiken im Übergang von konventionellen Wohnkontexten zum Passivhaus und zum SmartHome analysiert.

Methodisch wurde ein multiperspektivischer und prozessanalytischer Ansatz gewählt. Der qualitative Analyserahmen und das Untersuchungsdesign werden dezidiert dargelegt. Sowohl die Perspektiven von Passivhausund SmartHome-Bewohner"innen als auch von unterschiedlichen Expert"innen (Architekt"innen, (Haus-)Techniker*innen, Projektkoordinator*innen und Vertreter*innen von Energieversorgungsunternehmen) wurden einbezogen. So wird nicht nur deutlich, welche Fragen neue Heizformen im praktischen Alltag aufwerfen, sondern auch wer an der konkreten Ausgestaltung einer neuen Heizlösung beteiligt ist und wie diese Mitwirkung im Einzelnen aussieht. 
Für die Studie wurden insgesamt 33 Personen interviewt, davon $21 \mathrm{Be}-$ wohner*innen und zwölf Expert*innen. Mit den Bewohner*innen wurde über ihre alltägliche Heizpraxis vor und nach ihrem Übergang zum Passivhaus bzw. SmartHome gesprochen und die Expert*innen wurden vorrangig zu ihren beruflichen bzw. fachlichen Erfahrungen bezüglich der beiden Heizformen befragt. Zudem konnte ein Pilotprojekt zum smarten Heizen über knapp zwei Jahre wissenschaftlich begleitet werden. Die Interviews und das weitere Material wurden mit dem qualitativ-rekonstruktiven Interpretationsverfahren der Dokumentarische Methode nach Bohnsack (2014 [1991]) ausgewertet.

Empirisch werden - in jeweils eigenständigen Teilkapiteln - insgesamt fünf zentrale Aspekte bzw. Elemente alltäglicher Heizpraxis in den Mittelpunkt gestellt. Dies sind (1) der Heizkörper, (2) das Lüften, (3) das Behaglichkeits- und Komforterleben, (4) das Gefühl von Kontrolle und Kontrollverlust sowie (5) der Prozess der erfolgreichen Rekrutierung der Teilnehmer*innen. Anhand von relevanten Veränderungen bei diesen fünf Aspekten und Elementen werden verschiedene Wandlungsdynamiken im alltäglichen Heizgeschehen beschrieben und analysiert.

Anhand von Entwicklungen rund um den Heizkörper wird verdeutlicht, wie entscheidend sich die in vorherigen Kontexten meist über viele Jahre hinweg gesammelten Erfahrungen der Bewohner*innen auf ihre aktuelle Heizpraxis in Passivhäusern und SmartHomes auswirken.

Die Analyse des Lüftungsvorgangs im Kontext neuer Heizsettings zeigt, wie sich durch die Anwendung neuer Heiztechnik die Relationen zwischen (z. T. ehemals eigenständigen) Praktiken entscheidend wandeln können. Es lassen sich außerdem Verschiebungen in größeren Praktikengefügen nachzeichnen. Anhand der Thematik des Lüftens wird zudem der Unterschied zwischen Routine- und Gewohnheitsbildung deutlich gemacht.

Anhand von Veränderungen im Behaglichkeits- und Komforterleben im Übergang von konventionellen Wohnkontexten zum Passivhaus und SmartHome lassen sich die unterschiedliche Verwendung und Auslegung der Begriffe ,Behaglichkeit' und ,Komfort' sowie eine insgesamt gestiegene Erwartungshaltung an den thermischen Komfort aufzeigen. Außerdem werden nicht intendierte Effekte erfolgreicher Wärmedämmung und deren Auswirkungen auf das Wohlbefinden der Bewohner*innen verdeutlicht.

Durch die Analyse von Veränderungen im Kontrollerleben im Übergang von konventionellen Wohnkontexten zum Passivhaus und zum SmartHome wird verdeutlicht, dass sich das Gefühl des Kontrollverlustes und gesteigerter Technikabhängigkeit auf viele verschiedene Aspekte be- 
zieht und sich der Umgang mit (entsprechenden) Kontrollverlusterfahrungen dabei höchst unterschiedlich gestaltet. Ferner kann aufgezeigt werden, dass bei Expert*innen und Nutzer"innen auffallend unterschiedliche Deutungen neuer Technik und ihrer Einführung bestehen.

Es werden die z.T. sehr unterschiedlichen Wege, wie die Bewohner*innen zum Passivhaus und zur intelligenten Heizungssteuerung gekommen sind, nachgezeichnet. Somit liefert die Untersuchung wichtige Erkenntnisse (dazu), unter welchen Bedingungen neue Heizformen prosperieren.

Die Analyse des Interviewmaterials im theoretischen Kontext sozialer Praktiken hat insgesamt gezeigt, dass für ein umfassendes Verständnis und die Einordnung von Praktiken sowie von diesbezüglichen Wandlungsprozessen folgende Punkte zentral sind:

- Historische Aspekte sozialer Praktiken sind sehr bedeutsam und sollten stets in die Analyse von Praktiken einbezogen werden. Am Beispiel des Heizens zeigte sich dies in zweifacher Hinsicht: Zum einen wird das gegenwärtige Erscheinungsbild der Praktik des Heizens durch den historischen Verlauf der abstrakten Praktik bestimmt; zum anderen prägen die jeweiligen persönlichen Wohn- und Heizgeschichten die aktuellen Praktiken. Erst über die Einbeziehung der Historie lässt sich die Praktik umfassend erschließen und beide historischen Aspekte bedingen und begrenzen die Richtung des (weiteren) Wandels einer Praktik wie Heizen als kollektive Tätigkeit.

- Des Weiteren hat sich gezeigt, dass es sowohl durch zufällige Störung als auch aufgrund absichtsvoller Intervention häufiger zu Entkopplungen von ehemals stabil in einer Praktik integrierten Elementen kommen kann. Diese können sich daraufhin getrennt voneinander mit unterschiedlicher Geschwindigkeit weiterentwickeln und ändern. Die Untersuchung hat beispielhaft erbracht, dass sich im Falle des Heizens die Inhalte der Bedeutungen-Komponente merklich langsamer gewandelt haben als es die anderen zentralen Elemente der Praktik des alltäglichen Heizens getan haben.

- Außerdem konnte dargelegt werden, dass koevolutionäre Prozesse beim Wandel von Praktiken eine zentrale Rolle spielen. Am Beispiel der Analyse von Heizpraktiken in Passivhäusern und SmartHomes zeigte sich dies in zweierlei Ausprägung: Die dependente Entwicklung von Heizungstechnik und Behaglichkeitskonventionen ließ zum einen einen Prozess der Koevolution aufgrund von Abhängigkeiten zwischen den unterschiedlichen, zu einer einheitlichen Praktik integrierten Elementen sichtbar werden. Zum anderen ließen sich koevolutionäre Prozesse zwischen unterschiedlichen, mehr oder weniger lose gekoppelten 
Praktiken anhand der Verflechtung sowie wechselseitigen Anpassung des Heizens (und Lüftens) mit noch anderen Praktiken aufzeigen.

- Die Arbeit konnte zeigen, dass es unterschiedliche Auslöser für den Wandel von Praktiken gibt: Wandel kann innerhalb einer Praktik seinen Ausgangspunkt haben - hier kann jedes der zu einer Praktik gehörenden Elemente Ausgangspunkt sein. Wandel kann aber auch von außen angestoßen werden, z.B. durch Veränderungen im Elementegefüge, durch verschränkte Praktiken oder durch das Aufkommen gänzlich neuer, bisher nicht integrierter Elemente.

- Die gewählten Untersuchungsbeispiele zeigten unterschiedliche Ausmaße und Formen von Wandel: Mit dem Fall des passiven Heizens wird ein sehr grundlegender Wandel illustriert - es lässt sich hier von einer radikalen bzw. Basisinnovation sprechen und auf der Ebene des praktischen Handelns folglich von einer sozialen Innovation. Der Veränderungsprozess zum smarten Heizen stellt eher eine inkrementelle Wandlung bzw. eine rein technische (Verbesserungs-)Innovation dar.

- Darüber hinaus macht die Analyse deutlich, dass viele verschiedene Akteure am Wandel von Praktiken beteiligt sind. Es wird gezeigt, dass nicht nur die Aktivitäten der unmittelbar sich heizend betätigenden Bewohner*innen für das Erscheinungsbild alltäglichen Heizens entscheidend sind, sondern dass indirekt, etwa (vermittelt) durch die verwendete Technik, auch die Aktivitäten von vielfältigen anderen Akteuren wie Architekt*innen, Technik-Expert*innen, usw. in die Ausgestaltung einer Heizlösung und somit in das Heizen einfließen.

- Wichtig für die Analyse sozialer Praktiken sind nicht-intendierte (Neben-)Folgen und Rebound-Effekte. Dies konnte in der hier vorliegenden Arbeit am konkreten Beispiel nachvollzogen werden, was insbesondere für das Thema einer absichtsvollen Intervention in Hinblick auf Maßnahmen zur Energieeffizienzsteigerung und Ressourceneinsparung von zentraler Bedeutung ist.

Insgesamt konnten anhand der im Material evident gewordenen Wandlungen in der alltäglichen Heizpraxis auch geeignete Ansatzpunkte für politische Interventionen in alltägliche Praktiken identifiziert werden. Diese „Hinweise‘ bzw. Erkenntnisse können dabei behilflich sein, Interventionen umsichtig und effektiv zu gestalten. Sie werden in den Schlussbetrachtungen dargelegt. Zudem wird ein Ausblick für mögliche vertiefende Erforschungen von Heizpraktiken und die Anwendung des Ansatzes sozialer Praktiken gegeben.

Der Ansatz sozialer Praktiken lässt sich auf Basis dieser Arbeit als äußerst gewinnbringender theoretischer Forschungsrahmen für die Betrachtung 
und Analyse des alltäglichen Energiekonsums in Privathaushalten sowie die Untersuchung diesbezüglicher Wandlungsphänomene einschätzen.

Insgesamt zeigt die Arbeit somit am Beispiel des Wohnraumheizens, dass die qualitative Analyse des Interviewmaterials aus der Perspektive sozialer Praktiken wertvolle Erkenntnisse zum Energiekonsum liefern kann. Es wird somit auch deutlich, dass sozialwissenschaftliche Forschung einen wichtigen Beitrag zur Klimaforschung leistet. 


\section{Summary}

Addressing climate change is a central challenge to society. More than a third of the total final energy is consumed in private households, especially for heating, and this in turn emits substantial amounts of climate-damaging $\mathrm{CO}_{2}$. This dissertation focuses on the dynamics of everyday heating processes in private households after the implementation of new heating technology. Additionally, it addresses the question to what extent ecologically sustainable changes can be initiated in a targeted manner. For this purpose, heating in passive houses and so-called smart homes is investigated.

The research is based on a practice-theoretic approach, which is described in detail and has been refined for the subsequent empirical analysis. The Social Practices approach (according to Schatzki and Reckwitz) is quite frequently used as a theoretical framework for investigations in Environmental and Consumption Sociology. According to the approach, practices are a series of collectively shared, internalized, bodily-mental routine activities that are based on, and held together by, materiality, skills, and meaning. A practice represents a specific configuration of these various elements, integrating them into one unit. Changes can be detected particularly with regard to these individual elements, their composition and their links. Hence, this dissertation analyzes heating as a Social Practice and focuses on the transformation of heating practices in the transitional phase from conventional contexts of living to living in passive houses and smart homes.

The selected method comprises a multi-perspectival and process-analytical approach. The qualitative analytical framework and the investigative design are each described in detail. The perspectives of residents of passive houses or smart homes as well as those of various experts (architects, (building) technicians, project coordinators and representatives of energy supply companies) were integrated into this study. Thus, it becomes apparent that numerous questions emerge not only about heating forms in daily life, but also about who contributes to the specific design of new heating solutions and what that contribution looks like in detail.

33 individuals were interviewed for the study -21 residents and twelve experts. Residents described their daily heating practices before and after the transition to a passive house or smart home and experts were primarily 
interviewed regarding their professional experiences with both heating forms. In addition, a pilot project on smart heating was scientifically accompanied over the course of two years. The interviews and additional material were evaluated based on the Qualitative-Reconstructive Interpretation Process from the Documentary Method according to Bohnsack (2014 [1991]).

Individual, independent subchapters center on empirical discussions of five central aspects, or elements, of daily heating practices. They are (1) radiators, (2) ventilation, (3) the experience of coziness and (thermal) comfort, (4) the feelings of being in control and losing control, and (5) the process of successfully recruiting participants. Various relevant dynamics of change in daily heating habits are described and analyzed based on these five aspects and elements.

Based on developments surrounding radiators, it is emphasized in how substantial a manner experiences that were gathered over the years by residents affect their current heating practices in passive houses and smart homes.

An analysis of ventilation processes in the context of new heating settings shows how substantially the application of new heating technology can change the relations between (in part previously independent) practices. In addition, shifts in larger practice arrangements can be traced. Based on the theme of ventilation, the difference between the formation of routines and of habits is illustrated, as well.

Based on changes in the experience of coziness and comfort in the transitional phase from conventional living contexts to passive houses and smart homes, the varying usage and definitions of the terms 'coziness' (Behaglichkeit) and 'comfort' (Komfort) as well as overall increased expectations regarding thermal comfort are presented. In addition, unintended effects of successful thermal insulation and its impacts on residents' levels of comfort are highlighted.

The analysis of a changing experience of being in control in the transitional phase from conventional living contexts to passive houses and smart homes underlines that the feeling of losing control and of an increased dependence on technology is associated with various aspects and that coping with respective feelings of losing control can take on various forms. Furthermore, it can be illustrated that the interpretation of the role of new technology and its implementation differs significantly between experts and users.

Several very different paths of how users decided on passive houses and intelligent heat controls are uncovered. Thus, this investigation con- 
tributes to an understanding of the conditions under which new heating forms can thrive.

Overall, the analysis of the interview material within the framework of Social Practice Theory has shown that the following points are central to a comprehensive understanding of a classification of practices as well as of associated processes of change:

- Historical aspects of Social Practices are highly significant and should always be incorporated into analyses of said practices. The example of heating illustrates this in a twofold manner: Firstly, the current manifestation of heating practices is determined by the historical development of abstract practices; secondly, the respective individual living and heating biographies influence current practices. Only an incorporation of history allows for a comprehensive understanding of the current status and both historical aspects entail and delimit the direction of (further) change of a practice such as heating as a collective activity.

- Moreover, it turns out that elements that were formerly integrated in a practice in a stable fashion can frequently detach from that practice due to accidental disruptions or intentional interventions. From that point on, they can develop and change at different paces independently of another. In the case of heating, the investigation has shown that the contents of the meaning component have changed considerably slower than other central elements of the practice of daily heating.

- In addition, it could be shown that co-evolutionary processes play a vital part in the change of practices. The analysis of heating practices in passive houses and smart homes illustrates this in a twofold fashion: On the one hand, the dependent development of heating technology and (thermal) comfort conventions uncovers a process of co-evolution based on dependencies between the different elements integrated in a uniform practice. On the other hand, co-evolutionary processes are detected between different, more or less loosely linked practices in the form of intertwining and reciprocal adaptation of heating (and ventilation) to additional practices.

- This dissertation shows that there are different causes for the change of practices: Change can originate within a practice - in which case each element associated with that practice can be the cause. Change can also be affected externally, e.g., by means of shifts in the composition of elements, intertwined practices or the emergence of entirely new elements that were previously not integrated.

- The select examples that were investigated showed the different extents and forms of change: passive heating is representative of a fundamental 
change - we can speak of a radical, or basic, innovation and at the level of practical action we can therefore refer to a social innovation. The transition toward smart heating, by contrast, constitutes an incremental change or rather a purely technological innovation, or improvement.

- Beyond that, the analysis illustrates that many different actors contribute to a change of practices. It is shown that not only the activities of the residents that directly control the heating process are critical to the status of daily heating but also that the technology used as well as the activities of many actors such as architects and technical experts influence the design of a heating solution and therefore the heating process itself.

- Unintended side-effects and rebound effects are essential to the analysis of Social Practices. This is highlighted in the dissertation at hand by means of concrete examples that are highly significant to the topic of deliberate interventions with regard to measures that increase energy efficiency and conserve resources.

Overall, the changes that became evident in the material helped identify suitable starting points for political interventions in daily practices. These 'hints' or insights can help design interventions to be circumspect and effective. They are summed up in the conclusion. Moreover, the outlook discusses possible ways of investigating heating practices and the application of the Social Practices approach in more depth.

Based on this dissertation, the Social Practices approach can be evaluated as a fruitful theoretical framework for researching and analyzing daily energy consumption in private households as well as the investigation of associated change phenomena.

Overall, this dissertation uses the heating of residential spaces as an example to show that a qualitative analysis of interview materials from the Social Practices perspective delivers valuable insights into energy consumption. Thus, it also becomes clear that research in social sciences yields significant contributions to climate research. 


\section{Einleitung und Forschungsinteresse}

In Sachen Klimaschutz hat sich die deutsche Bundesregierung ambitionierte Ziele gesetzt: Bis Mitte dieses Jahrhunderts soll Deutschland weitgehend treibhausgasneutral werden, mindestens aber sollen bis zum Jahr 2050 die Treibhausgas-Emissionen um 80 Prozent gegenüber dem Niveau von 1990 gesenkt werden (vgl. Klimaschutzplan 2050). ${ }^{1}$ Um dieses Ziel zu erreichen, ist eine deutliche Reduzierung des gesamtgesellschaftlichen Energieverbrauchs und des damit einhergehenden $\mathrm{CO}_{2}$-Ausstoßes notwendig. Dies erfordert sowohl die allmähliche Verabschiedung von den nicht-nachhaltigen Energiequellen Kohle, Öl und Gas, als auch gleichzeitig den massiven Ausbau von erneuerbaren Energien wie Wind- und Wasserkraft, Solarenergie und Geothermie, von so genannten ,Flexibilitätsoptionen' wie Stromnetzen und Speichern (vgl. Bundesministerium für Wirtschaft und Energie (BMWi) 2018*) sowie eine sparsamere und effizientere Energienutzung.

Mit der ,Energiewende“ existiert für Deutschland bereits ein entsprechender politisch festgelegter, strategischer Plan, wie man als bedeutende europäische Industrienation diese große Transformation, die zudem von der Nutzung der Kernenergie wegführen soll, bis zur Mitte des Jahrhunderts bewerkstelligen will.

Die Energiewende bedeutet demnach eine grundlegende Umstellung in der Art und Weise, wie Energie in diesem Land produziert, verteilt und genutzt wird. Für das Gelingen der Energiewende sind Veränderungen in vielen Bereichen und auf allen gesellschaftlichen Ebenen erforderlich. So bedarf es einer weitgehenden Neu- bzw. Umgestaltung der größeren Infrastruktursysteme zur Energieversorgung. Genauso sind grundlegende Veränderungen und Umstellungen in der Mikroebene, im alltäglichen Konsum und in den Lebensstilen notwendig. Es geht darum, technische (Neu-)Entwicklungen und gesellschaftliche Transformationsprozesse sinnvoll zu verschränken.

1 „Der Klimaschutzplan 2050 - Die deutsche Klimaschutzlangfriststrategie“ der Bundesregierung abrufbar unter: www.bmu.de/themen/klima-energie/klimaschutz/nat ionale-klimapolitik/klimaschutzplan-2050/, zuletzt geprüft am 28.08.2018, sowie veröffentlicht als Broschüre (vgl. Bundesministerium für Umwelt, Naturschutz, Bau und Reaktorsicherheit (BMUB) 2016). 
Die vorliegende Arbeit betrachtet den umfassenden Wandel auf der Mikroebene. Wie kommt es zu Veränderungen in den alltäglichen (Energie-)Konsummustern? Darüber hinaus besteht ein zentrales Anliegen dieser Arbeit darin, mehr über Interventionsmöglichkeiten in grundlegende alltägliche Konsummuster zu erfahren, die eine Alternative zur klassischen staatlichen ,Top-down'-Intervention darstellen. Wie lässt es sich erreichen, dass sich die alltägliche Konsumpraxis privater Haushalte in Zukunft weniger energieintensiv gestaltet? Daher ist diese Arbeit der Frage nach dem Wandel alltäglicher Heizenergiekonsumpraktiken in Privathaushalten gewidmet.

Ein erheblicher Teil der Energiewende-Bemühungen und -Maßnahmen der Bundesregierung richtet sich auf den (Wohn-)Gebäudebereich. Nach Angaben des Bundesministeriums für Wirtschaft und Energie (BMWi) werden rund 35 Prozent der gesamten Endenergie in Deutschland in den ,eigenen vier Wänden` verbraucht - allen voran für Heizung und Warmwasser. ${ }^{2}$ Die Devise der Politik lautet: „Wo viel verbraucht wird, lässt sich auch viel einsparen." 3

Auf der Ebene der privaten Haushalte kann der Staat zwar ambitionierte und strenge Standards für Neubauten festlegen, den Verbraucher*innen ${ }^{4}$ umfangreiche Informationen zur Verfügung stellen und attraktive Förderprogramme anbieten, z.B. für energetische Sanierungsmaßnahmen; er hat jedoch nur begrenzt Einfluss darauf, was alltäglich im Privaten passiert und wie viel Energie dabei tatsächlich verbraucht wird. Dennoch können sich alltägliche Konsummuster bedeutend wandeln und das passiert mehr oder weniger ständig. Allerdings geschieht dies häufig zufällig und ungeplant; außerdem vollzieht sich dieser Wandel in der Regel eher langsam und kontinuierlich, meist handelt es sich um einen eher langwierigen Prozess. Wie der Wandel alltäglicher (Energie-)Konsumpraktiken in privaten

2 Vgl. www.bmwi.de/Redaktion/DE/Dossier/energiewende-im-gebaeudebereich.htm 1, zuletzt geprüft am 20.08.2018.

3 www.bmwi.de/Redaktion/DE/Dossier/energiewende-im-gebaeudebereich.html, zuletzt geprüft am 20.08.2018.

4 In dieser Arbeit wird auf eine gendersensible Sprache geachtet. Daher werden - da wo möglich und es passend erscheint - geschlechtsneutrale Ausdrücke, wie z.B. Akteure, Personen, Praktizierende, Mitglieder gebraucht. Ansonsten wird in der gesamten Arbeit durchgängig die Sternchenform verwendet, wenn von bestimmten Personengruppen geschrieben wird, um sichtbar zu machen, dass immer alle Geschlechter bzw. vielfältige Geschlechteridentitäten gemeint sind. Dafür wird der Stern an ein ganzes Wort angehängt, z.B. Bewohner*innen, Mieter*innen, Träger"innen. Durch diese Schreibweise wird die Vielschichtigkeit einer Positionierung im Hinblick auf das Geschlecht betont. 
Haushalten normalerweise vonstattengeht, ob und wenn ja, wie er sich gegebenenfalls durch gezielte politische Interventionen absichtsvoll initiieren und/oder sogar forcieren und beschleunigen lässt, wird in dieser Arbeit detailliert am Beispiel des Heizens untersucht.

\subsection{Theoretischer und politischer Kontext: Klimawandel und Energieverbrauch}

In diesem Abschnitt wird der Zusammenhang zwischen Energiekonsum in Privathaushalten und Klimawandel und Klimaschutz(bemühungen) deutlich gemacht.

Mittlerweile gilt es als allgemein anerkannt, dass (nicht-nachhaltiges) menschliches Handeln vielfältige Auswirkungen auf die globale Umwelt hat. Folgenschwere globale Umweltveränderungen wie zunehmende Luftverschmutzung, Ressourcenverknappung, Biodiversitätsverlust oder Klimawandel stehen demnach in engem Zusammenhang mit dem nichtnachhaltigen Charakter gewohnter Lebensweisen und Konsummuster vor allem der Menschen in reichen Industrieländern (vgl. Meadows et al. 1972; Meadows et al. 2016; Day et al. 2009: insbesondere 323-324). Welchen starken (negativen) Effekt die menschliche Weltbevölkerung und ihr ständiges Wachstum, die industrielle Produktion, die technischen Möglichkeiten sowie die materiellen Ansprüche insbesondere der reichen Menschen auf die globale Umwelt haben, hat besonders deutlich das 20. Jahrhundert gezeigt. In der zweiten Hälfte des letzten Jahrhunderts haben einige der globalen Umweltveränderungen, wie beispielsweise der Klimawandel, eine besonders dramatische Verschärfung erfahren und sind damit zu ernsthaften Menschheitsbedrohungen geworden.

Das Klima der Erde hat einen wesentlichen Einfluss auf die Lebensbedingungen von Menschen und belebter Natur. Der Umgang mit dem globalen Klimawandel und seinen Folgen stellt daher eine zentrale gesellschaftspolitische Herausforderung für die Zukunft (der gesamten Menschheit) dar (vgl. Edenhofer 2010). Die Etablierung nachhaltiger Produktionsweisen, Konsummuster und Lebensstile erscheint somit erforderlich. In Deutschland wie auch in den meisten anderen führenden Industrienationen besteht heute weitgehend gesellschaftlicher und politischer Konsens darüber, dass Entwicklungen in zentralen Bereichen und wichtigen Handlungsfeldern wie Wirtschaft, Landwirtschaft und Ernährung, Verkehr und Mobilität oder Bauen und Wohnen nachhaltig zu vollziehen sind (vgl. Bundesministerium für Umwelt, Naturschutz, Bau und Reaktorsicherheit 
(BMUB) 2016; Statistisches Bundesamt 2017: 3; Umweltbundesamt (UBA) $\left.2015^{*}\right)$.

Die weit überwiegende Mehrheit der Klimawissenschaftler*innen weltweit geht (,mit großem Vertrauen") davon aus, dass der Klimawandel mit dem Effekt globaler Erderwärmung in den letzten fünf Dekaden hauptsächlich durch den zunehmenden Ausstoß von Treibhausgasen verursacht worden ist. ${ }^{5}$ Während in der ersten Hälfte des 20. Jahrhunderts noch vor allem natürliche Faktoren wie die Zunahme des solaren Energieeinflusses und der Rückgang der Vulkanaktivität zur Erwärmung beigetragen haben (vgl. Brönnimann 2010*), halten führende Klimaforscher*innen es für ,extrem wahrscheinlich', dass der menschliche Einfluss die Hauptursache für die seit 1950 beobachtete deutliche globale Erwärmung ist (IPCC 20136; Latif 2006: 26). Dementsprechend herrscht mittlerweile wissenschaftlicher Konsens, dass der Ausstoß von Treibhausgasen deutlich reduziert werden muss, um den anthropogenen Klimawandel zu begrenzen.

Das mengenmäßig bedeutendste Treibhausgas ist das Kohlendioxid $\left(\mathrm{CO}_{2}\right)$ (vgl. Umweltbundesamt (UBA) 2018a: 69-71).7 Kohlendioxid $\left(\mathrm{CO}_{2}\right)$-Emissionen werden vor allem bei der Verbrennung fossiler Energieträger wie Erdöl, Kohle und Erdgas freigesetzt (vgl. Umweltbundesamt (UBA) 2018b*), weshalb Einigkeit besteht, dass vorrangig der Verbrauch fossiler Brennstoffe deutlich reduziert werden muss. „Der weltweite $\mathrm{CO}_{2^{-}}$ Ausstoß ist eng an den Welt-Energieverbrauch gekoppelt, da die Energiegewinnung vor allem auf fossilen Energieträgern basiert" (Latif 2006: 27). Die Konzentration von $\mathrm{CO}_{2}$ in der Atmosphäre war seit Jahrhunderttausenden nicht mehr so hoch wie heute. Wie sich durch Messungen zweifelsfrei belegen lässt, hat sich der $\mathrm{CO}_{2}$-Gehalt der Erdatmosphäre seit Beginn der Industriellen Revolution rasant erhöht. Es kann daher nicht mehr ernsthaft bestritten werden, dass in der Hauptsache der Mensch für diesen Anstieg verantwortlich ist (ebd.).

5 Tausende Expert*innen aus verschiedenen Disziplinen tragen mit ihren Forschungsergebnissen zu den so genannten Sachstandsberichten des IPCC (Intergovernmental Panel on Climate Change) bei. Im Deutschen wird der IPCC (,Zwischenstaatlicher Ausschuss für Klimaänderungen') oft auch als ,Weltklimarat' bezeichnet.

6 Der Fünfte IPCC-Sachstandsbericht, Haupterkenntnisse der Arbeitsgruppe I (Physikalisch-wissenschaftliche Grundlagen).

7 Vgl. auch https://de.statista.com/themen/2442/treibhausgasemissionen/ sowie www.umweltbundesamt.de/daten/klima/treibhausgas-emissionen-in-deutschland\#t extpart-1, beide zuletzt geprüft am 01.09.2018. 
Weltweit und in Deutschland kommen fossile Energieträger in allen gesellschaftlichen Bereichen in mehr oder minder großem Umfang zum Einsatz (vgl. AGEB 2017: Kap. 6). Soll die politisch angestrebte Transformation hin zu einer ,low-carbon' bzw. ,low-fossil-fuel' oder sogar zu einer, decarbonised society' gelingen, so erfordert dies Veränderungen auf allen gesellschaftlichen Ebenen. In Deutschland wird dieser sich bereits im Gange befindende gesamtgesellschaftliche Transformationsprozess, wie eingangs bereits erwähnt, zumeist unter der Bezeichnung ,Energiewende diskutiert - ein Begriff, der mittlerweile internationale Bekanntheit und Verbreitung erlangt hat (Hockenos 2012*).

\subsection{Energienutzung in Gebäuden: das Heizen als besonders relevanter Faktor der CO2-Produktion}

In Deutschland wie auch weltweit werden wesentliche Teile der $\mathrm{CO}_{2}$-Emissionen durch die Nutzung fossiler Energiequellen von Menschen in Gebäuden verursacht (vgl. Achtnicht 2011: 2191, Schaffrin und Reibling 2015: 1). Aus einer Konsumperspektive betrachtet, sind Privathaushalte in Deutschland für einen beträchtlichen Anteil energiebedingter Treibhausgasemissionen verantwortlich (im Jahr 2016 für ca. zehn Prozent). Bei einer Sektor spezifischen Betrachtung handelt es sich bei den privaten Haushalten - gemäß ihres Betrags an verursachten Emissionen - um den viertgrößten Treibhausgas-Emittenten. ${ }^{8}$

In Deutschland wurden im Jahr 201526 Prozent der gesamten Endenergie in Wohngebäuden mit privaten Haushalten genutzt. Davon werden wiederum mehr als zwei Drittel (im Jahr 2015 waren es 68,6 Prozent) für Raumwärme aufgewendet (AGEB 2016: 24). Innerhalb des Haushaltssektors ist demnach der größte Posten das Heizen. ${ }^{9}$ Im Zusammenhang mit

8 Aufgeteilt nach Sektoren (insgesamt acht Sektoren), standen private Haushalte in Deutschland bezüglich ihrer Treibhausgasemissionen im Jahr 2016 an vierter Stelle. Mit knapp 37,8 Prozent verursachte die Energiewirtschaft im Jahr 2016 die meisten Emissionen. Danach folgten - gemäß ihren Beträgen - die Industrie (knapp über 20 Prozent), der Verkehr (knapp 18 Prozent) sowie die privaten Haushalte (zehn Prozent). Deutlich niedriger lag der Anteil der Landwirtschaft (knapp acht Prozent), des Sektors Gewerbe, Handel und Dienstleistung (GHD) (vier Prozent) sowie der Abfallwirtschaft (ein Prozent) (vgl. BMU 2018: 28).

9 „Die Bewohnerinnen und Bewohner fast jedes zweiten Wohngebäudes in Deutschland heizen mit Erdgas. Dies ist unter anderem darauf zurückzuführen, dass in der Vergangenheit zahlreiche ineffiziente Kohle-Einzelöfen durch Erdgassysteme er- 
Klimaschutz ist daher die Umgestaltung des alltäglichen Heizens zu einer weniger energieintensiven Aktivität die wohl dringlichste Herausforderung. Das heißt, soll der Wohngebäudebereich in die deutschen Klimaschutzbemühungen mit einbezogen werden und sollen private Haushalte zur Energiewende in Deutschland mit beitragen, so ist (die) Gebäudebzw. Raumbeheizung ein entscheidender Ansatzpunkt.

\subsection{Reduktion des Energieverbrauchs für Heizen - mehr als eine technische Frage}

Bisher haben sich die Bemühungen, den Energiebedarf für Heizwärme und dadurch bedingte $\mathrm{CO}_{2}$-Emissionen effektiv zu reduzieren, vorrangig auf bauliche und energetische (Sanierungs- und Modernisierungs-)Maßnahmen und technischen Innovationen gerichtet. Ziel dabei ist, durch (gesteigerte) Energieeffizienz, erhöhten Wärmeschutz und Wärmegewinne die tatsächlichen Energieverbräuche von und in Gebäuden zu senken (siehe z.B. Castleton et al. 2010; Power 2010; Di Giulio 2012: insbes. $23-$ 96; Ma et al. 2012; Fokaides et al. 2013). ${ }^{10}$

So wurden etwa die Standards für die energetische Bewertung von Gebäuden (vgl. EnEV ${ }^{11}$ seit 2018 GEG $^{12}$ ) in ganz Europa in den letzten Jahren stetig verschärft. In Deutschland gelten insbesondere für Neubauten bereits heute strenge energetische Anforderungen (vgl. Achtnicht 2011:

setzt wurden. Erdgas-Zentralheizungen sind dabei das am häufigsten vertretene Heizungssystem in Deutschland. Öl-Zentralheizungen machen noch mehr als ein Viertel des Marktanteils aus. Fernwärme und besonders klimaschonende Heizungssysteme wie Elektro-Wärmepumpen versorgten 2015 lediglich fünf Prozent beziehungsweise zwei Prozent der Wohngebäude mit Wärme. Während Fernwärme insbesondere in Stadtstaaten eine Rolle spielt [...], ist deren Einsatz in den meisten Flächenländern sehr gering. Wärmepumpen könnten dort in Zukunft eine klimafreundliche Alternative bieten“ (BMU 2018: 44; siehe hierzu auch BDEW 2015 sowie Kapitel 2.2.4).

10 Vgl. hierzu auch die „Energieeffizienzstrategie Gebäude“ (ESG) (Bundesministerium für Wirtschaft und Energie (BMWi) 2015a) der Bundesregierung.

11 Bundesministerium der Justiz und für Verbraucherschutz 2007*: Die vollständige „Verordnung über energiesparenden Wärmeschutz und energiesparende Anlagentechnik bei Gebäuden (Energieeinsparverordnung - EnEV)“: www.gesetze-im -internet.de/enev_2007/BJNR151900007.html, zuletzt geprüft am 12.08.2018.

12 Im GebäudeEnergieGesetz GEG 2018 hat der Bund die folgenden Regeln zusammengeführt: Energieeinsparungsgesetz (EnEG), Energieeinsparverordnung (EnEV) und Erneuerbare-Energien-Wärmegesetz (EEWärmeG). 
2191f). Diese sollen in den nächsten Jahren schrittweise noch weiter verschärft werden. Spätestens ab dem Jahr 2021 soll dann europaweit das „Niedrigstenergiegebäude‘ bzw. das ,Nahe-Null-Energiehaus' (,nearly zeroenergy building') als Neubaustandard (für privatwirtschaftliche Gebäude) gelten (vgl. Schimschar et al. 2011; Annunziata et al. 2013; Hermelink et al. 2013; vgl. hierzu auch Bundesministerium für Umwelt, Naturschutz, Bau und Reaktorsicherheit (BMUB) 2016: 47; Tuschinski 2018: Kapitel 2). Neubauten (Baufertigstellungen von Wohngebäuden) und neu fertiggestellte Wohnungen machen in Deutschland allerdings jährlich nur einen äußerst geringen Anteil aus: so waren es im Jahr 2017 gerade einmal 0,58 bzw. 0,60 Prozent des gesamten Wohngebäude- bzw. des Wohnungsbestands. ${ }^{13}$ Das Neubauvolumen umfasste im Jahr 2017 demnach nur 245.300 Wohnungen (vgl. Statistisches Bundesamt (Destatis) 2018a: 82). Die viel größere Herausforderung im Hinblick auf Energieeinsparungen und Klimaschutz im Wohnbereich stellt daher der größtenteils noch unsanierte Gebäudebestand dar (vgl. Messari-Becker 2016: 28; vgl. auch Umweltbundesamt (UBA) und GdW - Bundesverband deutscher Wohnungsunternehmen e.V. 2003: 6f; Deutsche Energie-Agentur GmbH (dena) 2016; Deutsche Energieagentur GmbH (dena) 2017). „Da gerade im Gebäudebestand durch energetische Verbesserungen hohe Einsparpotenziale möglich sind, gerät dieser in Deutschland und in anderen Ländern zunehmend in den Fokus der Betrachtungen“ (Johann 2015: 172; vgl. hierzu etwa Adolf und Bräuninger 2012; Fokaides et al. 2013).

Unabhängig davon, ob es um mehr Energieeffizienz und Energieeinsparungen zu Heizzwecken schwerpunktmäßig bei Neubauten oder im Wohngebäudebestand geht, ist zu konstatieren, dass die meisten der hier bisher verwendeten Forschungsansätze dem gleichen, nämlich einem techno(logisch)-ökonomischen Paradigma folgen. Es handelt sich daher in der Hauptsache um bauphysikalische und energietechnische Betrachtungen häufig mit zusätzlicher Wirtschaftlichkeitsbewertung der Maßnahmen. Das heißt, diese Ansätze fokussieren meist einseitig die materiell-technischen Aspekte des Heizens und die energetische Gebäudeperformance (vgl. etwa Umweltbundesamt (UBA) und GdW - Bundesverband deutscher Wohnungsunternehmen e.V. 2003). Dafür untersuchen sie vornehmlich rechtliche Regelungen zu baulichen Energieeffizienz-Anforderungen,

13 Eigene Berechnungen auf der Grundlage aktueller Zahlen des Statistischen Bundesamtes (Destatis) zum ,Bestand an Wohnungen' und ,Bautätigkeit und Wohnungen' (vgl. Statistisches Bundesamt (Destatis) 2018a: 82 u. Statistisches Bundesamt (Destatis) 2018b: 7). 
Förderungen erneuerbarer Energien, sowie sämtliche bauliche (Veränderungs-)Maßnahmen und technische Innovationen (,technological fix ${ }^{6}$ ) (vgl. hierzu etwa Schulz und Rosenfeld 2011; Blazejczak et al. 2014). Technikwissenschaftler"innen und Technikökom*innen glauben fest an die Wirksamkeit von (innovativen) Technologien und daran, dass effiziente Technik allein ausreicht, den Energieverbrauch im Wohngebäudebereich bedeutend zu senken, weil entweder davon ausgegangen wird, dass die Technologien von den Bewohner"innen wie erwartet, das heißt genauso wie von den Technikkonstrukteur"innen und Designer"innen vorgesehen, genutzt werden oder weil die neuen Technologien in der Lage sind, beim Energiesparen den Faktor ,Mensch ${ }^{`}$ zu umgehen (vgl. Brand 2005: 7-16; sowie für eine Kritik an der Vorstellung von der ,Wunderwaffe' Technik, siehe Wilhite 2007).

Demzufolge steht bei den (rein) technikwissenschaftlichen Analysen die rechtliche und materielle Rahmung des menschlichen Energieverbrauchs in Gebäuden im Vordergrund. Das energiebezogene Handeln selbst, also das Energienutzungsverhalten von Menschen in Gebäuden wird von diesen Ansätzen weitgehend außer Acht gelassen, da es nicht für besonders wichtig bzw. entscheidend erachtet wird (vgl. Moezzi und Lutzenhiser 2010: 209f).

Allerdings handelt es sich bei der Reduktion des Energieverbrauchs zu Raumheizungszwecken um mehr als eine rein technische Frage (Hacke 2009b). Ohne Zweifel sind durch baulich-energetische Maßnahmen und technische Innovationen hohe Energieeinsparungen beim Heizenergiekonsum möglich und spielt (die eingesetzte) Technik für die Energieintensität des Heizens in Privathaushalten eine zentrale Rolle - allerdings immer nur insoweit als die betreffenden Technologien beim alltäglichen Heizen auch tatsächlich verwendet, das heißt von den Bewohner*innen aktiv in ihre alltäglichen Heizaktivitäten miteingebunden werden (vgl. Berker 2008; Lutzenhiser et al. 2010: 170). Auf die konkrete soziale (Handlungs-)Praxis kommt es an. Der Energieverbrauch zu Heizzwecken stellt nämlich vor allem auch ein Ergebnis sozialer Praktiken und individuellen Nutzer*innenverhaltens dar (vgl. Hacke 2009b: 6f; Gill et al. 2010). Daher werden baulich-energetische Maßnahmen sowie technische Neuerungen alleine nicht ausreichen, um substantielle Energieeinsparungen beim privaten Wohnraumheizen zu erzielen (vgl. Johann 2015: 172). In der alltäglichen Praxis wird allerdings immer wieder deutlich, dass durch Technik theoretisch mögliche Energieeinsparungen, aufgrund von eingefahrenen Gewohnheiten und unangepassten Routinen der Nutzer*innen, oft nicht erreicht werden (vgl. Gill et al. 2010: 501f; Majcen et al. 2013). 
Um besser zu verstehen, wie sich der private Energieverbrauch zu Heizzwecken tatsächlich senken lässt und wo dafür (im Bereich Gebäudeheizung) überhaupt mögliche effektive Ansatzpunkte für eine nachhaltige Veränderung des Heizens liegen, ist ein besseres bzw. genaueres Verständnis des Heizens erforderlich. Hier kann sozialwissenschaftliche Forschung einen wesentlichen Beitrag leisten, indem sie hilft, die das alltägliche Heizen formenden Verhaltensroutinen sowie das Heizgeschehen in Privathaushalten als Ganzes zu erfassen und dadurch besser zu verstehen. Sozialwissenschaftliche Forschung liefert interessante, relevante Erkenntnisse, auf welche Weise sich der Energieverbrauch zu Heizzwecken sowie die heizungsabhängigen $\mathrm{CO}_{2}$-Emissionen privater Haushalte tatsächlich deutlich vermindern lassen (vgl. Lutzenhiser et al. 2010: 172f).

\subsection{Die typische sozialwissenschaftliche Herangehensweise zur Erforschung des Energiekonsums in Privathaushalten}

Sozialwissenschaftliche Ansätze, die den (Heiz-)Energiekonsum in Privathaushalten näher erforschen, konzipieren ,Energieverbrauch' typischerweise als Ergebnis mehr oder minder bewussten menschlichen Handelns. Dementsprechend liegt der Fokus des überwiegenden Teils sozialwissenschaftlich ausgerichteter Forschung zum Thema ,Energieverbrauch in Wohngebäuden' zumeist auf dem individuellen Verbrauchshandeln sowie auf den unterschiedlichen Einflussfaktoren für Energiekonsum (vgl. etwa Kempton und Neiman 1987). Bei (stärker) soziologisch orientierten Analysen geht es häufig auch um die Erklärung von kollektiven (Energie-)Konsummustern sowie deren umfassende Einbettung, immer aber - und das haben alle klassischen sozialwissenschaftlichen Ansätze gemeinsam - wird auf (die Ressource bzw. das Verbrauchsgut), Energie‘ fokussiert, nimmt die Analyse beim tatsächlichen Energieverbrauch ihren Ausgang (vgl. die verschiedenen Beiträge in Gladhart et al. 1987b, z.B. Gladhart et al. 1987a; Gladhart und Roosa 1987; Gladhart und Tortorici 1987; Gladhart und Zuiches 1987). Demnach findet hier ebenso - wie schon bei den technikwissenschaftlichen Betrachtungen des Energieverbrauchs in Wohngebäuden - eine einseitige Verengung des Forschungsfokus statt, nur diesmal nicht zugunsten der technischen Hardware, sondern diese Ansätze konzentrieren sich stattdessen schwerpunktmäßig auf die sozio-strukturellen und kulturellen Dimensionen des Energiekonsums.

Den meisten dieser konsumtheoretischen Arbeiten, die sich mit dem Verbrauch der Energie für Heizwärme beschäftigen, liegt ein eher enges 
und vereinfachendes Begriffsverständnis zugrunde. ,Energie“ wird hier sehr häufig lediglich als Ressource, Betriebsmittel oder herkömmliches Verbrauchsgut verstanden und ,Konsum' wird meist als eine distinkte, eigenständige Tätigkeit bzw. Handlung begriffen. So wird ,Konsum` häufig entweder mit dem Kauf(akt) von Gütern und Dienstleistungen (,Marktentnahme ${ }^{6}$ ) gleichgesetzt oder die Bezeichnung Konsum wird für den (kurzzeitigen) Gebrauch oder vollständigen Verbrauch von Gütern und Diensten verwendet (vgl. Rosa 2011: 115ff). Mit diesem Begriffsverständnis wird vor allem in den Wirtschaftswissenschaften (hier insbesondere die Verhaltensökonomie) gearbeitet. Andere Sozialwissenschaften betonen dagegen eher die symbolische Bedeutung und die (andauernde) Verwendung sowie den Verwendungszweck von Gegenständen und Gütern (vgl. z.B. McCracken 1990; Featherstone 1991; Madigan und Munro 1996). Dementsprechend fokussieren Studien, die dieser Forschungsausrichtung entsprechen, meist direkt auf Energie(-verbrauch) und das Energieverbrauchshandeln (z.B. Fischer 2008; Lutzenhiser und Hill Gossard 2000).

Jedoch ist ,Energie bzw. der Verbrauch von Energie in der Regel nicht der handlungsleitende Faktor, beispielsweise, wenn Menschen ihre Wohnungen und Häuser mittels Gebäudeheizung erwärmen. Das primäre Interesse der Menschen gilt normalerweise nicht der genutzten Energie(menge) oder dem verwendeten Energieträger. Vielmehr ist ihnen in der Hauptsache an der durch den Verbrauch von Energie ermöglichten ,Serviceleistung' gelegen, im Falle von Heizung also ,Raumwärme' bzw. ,Wohnbehaglichkeit'. Energiekonsum erfolgt für die Menschen in ihrem Alltag also ,nur' indirekt; sie benötigen bzw. greifen auf Energie lediglich zurück, um bestimmte Dienste wie Gebäudeheizung oder ähnliches in Anspruch zu nehmen. Folglich sind für sie in erster Linie die jeweilig durch Energienutzung bereitgestellten Serviceleistungen und damit die Aktivitäten, die zur Erreichung dieser Serviceleistungen erforderlich sind - in die Energiekonsum eingelagert bzw. mit deren Ausführung die Nutzung von Energie verbunden ist - wichtig und bedeutungsvoll (Røpke 2009: 2490). Aus diesem Grund liegt der Analysefokus der vorliegenden Untersuchung auf sozialen Praktiken. Das heißt, es werden vorrangig die verschiedenen Maßnahmen und Aktivitäten analysiert, die Menschen in Privathaushalten ergreifen und (regelmäßig) ausüben, um ihre Gebäude bzw. Wohnräume ausreichend zu erwärmen sowie angenehm warm zu halten und die für gewöhnlich unter ,Heizen` subsumiert werden. Dafür wird in dieser Arbeit ,alltägliches Heizen' als eine soziale Praktik analysiert. Anstatt direkt auf Energie oder den Energiekonsum zu fokussieren, steht bei einer praxistheoretisch 
angeleiteten Analyse vielmehr das praktische Handeln, hier also das Heizen selbst im Mittelpunkt.

\subsection{Der Ansatz sozialer Praktiken als forschungsleitende Perspektive}

Wie oben ausgeführt, wird in dieser Arbeit ein praxistheoretischer Zugang zur Erforschung des Energiekonsums zu Heizzwecken in Privathaushalten gewählt. Die Entscheidung, in dieser Untersuchung auf Praktiken und nicht etwa auf individuelle Entscheidungen, symbolische Handlungen oder Interaktionen, technologische Gegebenheiten, Infrastrukturen, soziale Normen oder kollektive Wertordnungen zu fokussieren, impliziert einen Schwenk zu vollziehen, weg von Energie bzw. Energiekonsum und hin zu den alltäglichen Heizaktivitäten, deren Vollzug unter anderem auch den Konsum von Energie zur Folge hat. Diese Verschiebung des Forschungsfokus ergibt sich aus mehreren, miteinander zusammenhängenden Gründen, die im Folgenden ausführlicher dargelegt werden und die gleichzeitig begründen, weshalb der Praktiken-Ansatz zur Analyse des alltäglichen Heizgeschehens geeignet ist.

Besonderes Verständnis von ,Konsum' und ,Energieverbrauch' - von Energiekonsum zum routinisierten Vollzug alltäglicher energieintensiver Praktiken

Eine praxistheoretische Herangehensweise grenzt sich in mehrfacher Hinsicht deutlich von oben beschriebenen klassischen sozialwissenschaftlichen Ansätzen ab. Zunächst einmal liegt ihr ein gänzlich anderes Verständnis von ,Konsum' zugrunde. Aus praxistheoretischer Perspektive wird Konsum nicht als eine abgegrenzte, unabhängige (Einzel-)Aktivität begriffen, sondern es wird stattdessen angenommen, dass beinahe jede Alltagstätigkeit konsumtive Aspekte und Momente beinhaltet und umfasst. Diesem Verständnis zufolge ist Konsum integraler und elementarer Bestandteil von Alltagsaktivitäten, stets in diese eingelassen und geschieht mit deren Vollzug (vgl. Warde 2005: 137; Randles und Warde 2006). Folglich erscheint auch Energieverbrauch nur als ein Nebenprodukt des Alltagshandelns. Die praxistheoretische Perspektive knüpft hier an die Einsicht an, dass eine Ressource wie Energie nicht zum Selbstweck und meist auch ohne großes Nachdenken verbraucht wird (vgl. Shove und Warde 2002; Warde und Southerton 2012a: 6). Vielmehr geschieht Energiekonsum meist unmerklich und indirekt, in Form von so genannten Energiediensten: 
„People do not consume energy. They consume the services it makes possible“ (Wilhite et al. 2000: 118). Der größte Anteil des Energieverbrauchs durch Menschen in Wohngebäuden entfällt auf solch gewöhnliche Aktivitäten und Dienste, wie Kochen, Heizen oder Kühlung - beispielsweise wird Energie vermittelt als behaglich warmer Raum, als gekochte oder gekühlte Speise oder als betriebener Computer konsumiert. Menschen sind an diesen, aufgrund von Energieverbrauch möglichen Dienstleistungen und Aktivitäten interessiert; Energie an sich ist für sie dagegen relativ bedeutungslos (vgl. Warde 2005: 138; Røpke 2009: 2490, 2495).

„[C]onsumption, including energy consumption, is best understood as an outcome of the routine accomplishment of ordinary practices."

(Shove 2004b: 1056)

An genau diesem Punkt setzt eine praxistheoretische Betrachtung des Energiekonsums an, indem sie diese routinemäßigen Alltagsaktivitäten in den Fokus wissenschaftlichen Interesses und der Analyse stellt (vgl. Gronow und Warde 2001b; Randles und Warde 2006: 227). Und obwohl es diese gewöhnlichen Aktivitäten wie Waschen, Kochen, Fernsehen oder eben Heizen sind, in deren Rahmen auch beträchtliche Mengen an Energie verbraucht werden, sind diese bisher noch wenig umfassend konsumtheoretisch als soziale Praktiken analysiert worden (vgl. Shove und Warde 2002).

\section{Die integrative Betrachtung von Materialien, Kompetenzen/Know-how und Bedeutungsgehalten}

Der überwiegende Teil wirtschafts- und sozialwissenschaftlicher Analysen zur Senkung des häuslichen (Heiz-)Energiekonsums fokussiert mehrheitlich einseitig auf Technik und Effizienz - dann stehen Akzeptanz, Verbreitung und Verwendung neuer effizienter Technologien im Mittelpunkt (,technological fix ${ }^{6}$ ). Oder andere Studien konzentrieren sich in den Untersuchungen wiederum fast ausschließlich auf soziale Belange - hier geht es dann meist um Einstellungs- und Verhaltensänderungen bezüglich des privaten Heizenergieverbrauchs. Durch eine praxistheoretische Perspektive ist man hingegen entledigt, sich in der Analyse für nur eines (z.B. Annahme und Gebrauch von energieeffizienten technischen Geräten) und damit gegen anderes (z.B. einzelne Energiesparhandlungen, wie das Herunterdrehen des Heizkörperthermostats und kurzes Stoßlüften) entscheiden zu müssen. Eine praxistheoretische Herangehensweise ermöglicht es, diese vielen und äußerst unterschiedlichen Aspekte (einer so facettenreichen Alltagsaktivität wie) Heizen integrierend in den Blick zu nehmen. Wahrneh- 
men, Denken und Handeln stehen stets gleichermaßen im Fokus, wenn energiekonsumrelevante Phänomene erfasst werden. (Technologische) Artefakte, praktisches Wissen/Know-how sowie Sinndeutungen werden dabei nicht getrennt voneinander betrachtet, sondern sie alle werden als wichtige Komponenten von Praktiken angesehen und deshalb auch zusammenhängend analysiert. Das heißt, untersucht werden die sozio-technischen Verknüpfungen sowie komplexen (Energie-)Konsummuster und -dynamiken bestimmter Handlungsfelder wie etwa des Wohnraumheizens in Privathaushalten (vgl. Berker 2008).

Darüber hinaus stellt der praxistheoretische Ansatz die Konzepte ,Kontext' und ,Situation' zentral: die untersuchten Phänomene werden als ,gegenwärtige Vollzugswirklichkeiten' konzipiert, die entsprechend ihrem tatsächlichen Erscheinen und in ihrem aktuellen sozio-materiellen ,Setting' analysiert werden (vgl. Schmidt 2012: 32). Demzufolge werden routinemäßige Konsumaktivitäten wie der alltägliche Energieverbrauch zu Heizzwecken in praxistheoretischer Perspektive auch in ihrer Alltagseinbettung untersucht. Eine praxistheoretische Betrachtung hat somit den Vorteil, dass keine künstliche Herauslösung bestimmter Stufen des Konsumprozesses stattfindet, sondern es kann umfassend betrachtet werden, wie Materialien, Kompetenzen und (Sinn-)Deutungen in Konsumprozessen, wie etwa im Rahmen alltäglicher Heizpraktiken wechselseitig miteinander verknüpft sind.

Um die genannten Vereinfachungen anderer Ansätze zu umgehen, wurde daher entschieden, in dieser Arbeit eine Perspektive anzuwenden, die das Phänomen ,Heizen`als gewöhnliches Handlungsgeschehen und unreflektierte Routineaktivität in seiner Gesamtheit und seiner Eingebundenheit in den Alltag betrachtet.

\section{Die zentrale Bedeutung von ,Körperlichkeit' im Zusammenhang mit Hei- zen: Wärme - ein menschliches Grundbedürfnis}

Überdies ist der Ansatz sozialer Praktiken besonders geeignet, das alltägliche Heizen in Privathaushalten tiefgehend zu analysieren, weil er ,Körpern' bzw. ,Körperlichkeit' insgesamt besondere Bedeutung beimisst. Soziale Praktiken sind im Grunde nichts anderes als routinisierte körperliche Aktivitäten, sie sind ,immer auch sinnhafte, bedeutungstragende, gekonnte Körperbewegungen“ (Schmidt 2012: 55). Um eine Praktik zu vollziehen, muss der Körper, müssen Körperteile auf gekonnte Weise bewegt werden. Der Körper stellt somit die zentrale Vermittlungsinstanz zwischen Geist/Sinn, Aktivitäten und sozialen Prozessen dar (vgl. Brand 2011: 189). 
Im Hinblick auf alltägliches Heizen kommt ,Körperlichkeit' noch in anderer Hinsicht eine herausragende Bedeutung zu: Und zwar handelt es sich bei Wärme um ein körperliches Grundbedürfnis des Menschen (vgl. Teilkapitel 2.2.2). Für ihr Überleben sind Menschen auf ausreichend Wärme angewiesen. Aufgrund der in Zentraleuropa vorherrschenden klimatischen Bedingungen mit größtenteils recht niedrigen Außentemperaturen stellt die Versorgung mit ausreichend zusätzlicher Wärme mittels künstlicher (energieverbrauchender) Gebäudeheizung für die hier lebenden Menschen eine Grundvoraussetzung für ,normales‘ und ,gesundes (Über-)Leben' dar. Somit betrifft Gebäudeheizung weitestgehend alle hier lebenden Menschen; regelmäßig sind die in Häusern und Wohnungen lebenden Menschen mit dem Beheizen ihrer Wohnräume beschäftigt. Indem sich die Menschen heizend betätigen, sorgen sie für ihre körperliche Unversehrtheit und ihr körperliches Wohlergehen. Denn erst durch zusätzliche künstliche Gebäudeheizung sind Häuser und Wohnungen für hier lebende Menschen ganzjährig, also auch während der kalten Jahreszeit bewohnbar.

Davon abgesehen, dass jeder Mensch auf eine gewisse Grundversorgung mit Wärme zum Überleben angewiesen ist, können die persönliche, Wohlfühltemperatur' und das situative Wärmebedürfnis durchaus von Mensch zu Mensch zu einem gewissen Grad variieren, da jeder Mensch unterschiedlich auf Einflüsse aus der Umgebung reagiert. Je nach Alter, Körperbau, Ernährungszustand, körperlicher und psychischer Verfassung, Art der Bekleidung, Aktivitätsgrad usw. kann sich das Bedürfnis nach zusätzlicher Erwärmung unterscheiden und zudem über den Tag hinweg schwanken. Damit wird deutlich, wie stark (das Ausmaß von) Heizen und das konkrete individuelle Engagement in Heizen mit körperlicher Wahrnehmung zusammenhängen und vom individuellen, aktuellen körperlichen (Wohl-)Befinden des bzw. der jeweiligen Praktizierenden abhängen.

Diese drei Argumente entstammen dem Ansatz sozialer Praktiken, wie er jüngst von Schatzki (1996, 2002) und Reckwitz (2000b, 2002b) begründet wurde, wie in Kapitel 2 näher eingeführt.

\subsection{Die Anwendung des Praktiken-Ansatzes anhand von zwei Fallbeispielen: Heizen im Passivhaus und im SmartHome}

Die Arbeit möchte einen Forschungsbeitrag zum Wandel von Praktiken leisten, indem empirisch die Übergänge vom ,konventionellen` Heizen zu neuen Heizformen untersucht werden. Um mehr über Beständigkeit und 
insbesondere Wandel von energieintensiven Heizpraktiken in Privathaushalten zu erfahren, wurden zwei neuere und möglicherweise zukunftsweisende Heizformen zur Analyse ausgewählt: Heizen in Passivhäusern und in so genannten SmartHomes. ${ }^{14}$

Die für diese Arbeit gewählten Untersuchungsfälle sind bislang noch wenig aus konsumsoziologischer Perspektive unter Anwendung des Ansatzes sozialer Praktiken untersucht worden (siehe aber allgemein zur Praktik des Heizens: Gram-Hanssen 2010, 2011; Brunner et al. 2011: insbesondere Kapitel 4.2.; speziell zum Passivhaus: Foulds et al. 2012; Foulds 2013; sowie am Rande in Sonnberger und Zwick 2016: 10f; zu SmartHomes: in Ansätzen Nyborg und Røpke 2011; sowie ausführlicher z.B. Hargreaves et al. 2015). Im Wesentlichen sind es drei Aspekte, die die ausgewählten Fälle zur Erforschung des Wandels von Praktiken besonders aufschlussreich erscheinen lassen:

Erstens handelt es sich bei der Passivhaustechnik und der intelligenten Heizungssteuerung um Veränderungen von unterschiedlicher Reichweite. So kann man bei der Passivhaustechnologie von einer "Basisinnovation" sprechen, weil sie das Heizgeschehen grundlegend verändert - eine konventionelle Gebäudeheizung wird obsolet. Bei der intelligenten Heizungssteuerung handelt es sich um eine klassische Nachrüsttechnologie: der konventionelle Heizvorgang wird automatisiert - die Intervention ist damit deutlich weniger radikal. Vom Neuheitsgrad entspricht die smarte Heiztechnologie demnach einer, Verbesserungsinnovation'. Somit werden durch die gewählten Fallbeispiele zwei unterschiedliche Wandlungsformen abgebildet. Dementsprechend sind auch die zu erwartenden Einsparpotenziale bei Heizenergie und $\mathrm{CO}_{2}$-Emissionen für beide Fälle sehr unterschiedlich.

Zweitens stehen die beiden zur Untersuchung gewählten Fälle für unterschiedliche Stadien von Neuerungs- bzw. Wandlungsprozessen. Während Passivhäuser in der Praxis schon länger regelmäßig gebaut werden, befindet sich die SmartHome-Technologie noch in der Erprobung. So gibt es erste größere Pilotprojekte, jedoch hat die SmartHome-Technik über die Pilotprojekte hinaus noch relativ wenig Verbreitung gefunden.

Drittens verbinden sich mit den ausgewählten Fallbeispielen auch unterschiedliche Vorstellungen über die Rolle des bzw. der Verbraucher*in in der zukünftigen Energiewelt. Während im Passivhaus kaum mehr geheizt

14 Worum es sich bei einem Passivhaus handelt und was genau unter einem SmartHome zu verstehen ist, wird am Ende der Einleitung, in Abschnitt 1.10 näher definiert. 
werden muss und die verbleibenden Heiz- und Lüftungsaktivitäten nahezu vollständig durch die Technik erledigt werden, steht die SmartHome-Technologie gerade dafür, dass sie den Verbraucher*innen (wieder) die vollständige Kontrolle und Verantwortung über ihren (Heiz-)Energiekonsum ermöglicht und zurückgibt. Demnach findet im Passivhaus der Energiekonsum zu Heizzwecken auch weiterhin weitestgehend,im Verborgenen statt bzw. er läuft im Hintergrund $a b$ und relativ unabhängig vom individuellen Nutzer*innenverhalten: Passivhausbewohner*innen müssen sich weder intensiv mit ihrem (nunmehr nur noch äußerst geringen) Heizenergieverbrauch auseinandersetzen, noch wird ihnen abverlangt, dass sie sich selbst aktiv um effektive Senkung des Energieverbrauchs zu Heizzwecken bemühen. Was ihren alltäglichen Heizenergiekonsum anbelangt, befinden sich die Verbraucher"innen somit in einer weitgehend passiven Rolle. Hingegen ist die SmartHome-Technologie so konzipiert, dass die Verbraucher*innen durch Visualisierung ihres täglichen Energieverbrauchs (etwa für Heizung) sowie direktes Feedback (z.B. zu den aktuellen Kosten) aktiviert und motiviert werden sollen, sich bewusst mit ihrem Energieverbrauch auseinanderzusetzen; das heißt, sie werden dazu angeregt, ihren Energiekonsum selbst aktiv zu verwalten und durch bewusstes Handeln effektiv zu senken.

Insofern ist mit den ausgewählten Fallbeispielen ein weites Spektrum von Heizformen sowie Dynamiken und Wandlungsprozessen von (Heiz-)Praktiken abgedeckt.

\subsection{Methodischer Ansatz: qualitative Interviews}

Methodisch wird ein multiperspektivischer Ansatz angewendet. Innovativ ist hier insbesondere, dass sowohl die Perspektiven ,gewöhnlicher' Nutzer*innen (Passivhaus- bzw. SmartHome-Bewohner"innen) als auch von Expert*innen (Architekt"innen, (Haus-)Techniker"innen, Projektkoordinator"innen sowie von Vertreter"innen großer Energieversorgungsunternehmen) miteinbezogen werden. So wird nicht nur deutlich, welche Fragen neue Heizformen im praktischen Alltag aufwerfen, sondern auch wer am erfolgreichen Zustandekommen und der konkreten Ausgestaltung einer neuen Heizlösung beteiligt ist und wie diese Mitwirkung im Einzelnen aussieht. Da es in dieser Arbeit vorrangig um die Erforschung von Praktikendynamiken und -wandel geht, wurde zudem eine prozessanalytische Perspektive angewendet. Die gewählte Methode ist besonders dazu geeignet, Veränderungsprozesse zu untersuchen, da die interviewten Bewoh- 
ner*innen von Passivhäusern zuvor alle in konventionellen Wohnungen gewohnt haben und nun somit einen Vorher-/Nachher-Bericht abgeben können. Im Fall der SmartHomes wurde der Prozess über eineinhalb Jahre hinweg begleitet; das heißt, hier konnten sowohl vor, während als auch nach der Intervention Daten erhoben werden - der Wandel konnte somit direkt beobachtet werden. Die Arbeit basiert in erster Linie auf Einzel- und Kleingruppeninterviews. Zur Ergänzung wurden kleine Rundgänge und Besichtigungen in Privathaushalten und Musterhaushalten, so genannte ,LivingLabs‘, durchgeführt sowie weitere Materialien, wie z.B. die Protokolle der Baubesprechungen ausgewertet.

Zur Auswertung des Materials wurde die dokumentarische Methode nach Ralf Bohnsack verwendet (Bohnsack 2014 [1991]). Es handelt sich dabei um einen rekonstruktiv arbeitenden methodologischen Ansatz, der in der qualitativen Sozialforschung mittlerweile gut etabliert ist (Przyborski und Wohlrab-Sahr 2013).

\subsection{Forschungsziele und konkrete Fragestellungen}

Auf Basis dieses methodologischen Designs verfolgt die vorliegende Arbeit drei Ziele: Erstens besteht ein zentrales Erkenntnisinteresse der Forschungsarbeit darin, zu einem besseren Verständnis von der Beschaffenheit des alltäglichen Heizgeschehens in Privathaushalten beizutragen. Zweites Ziel ist es, eine umfassende Analyse und Darstellung verschiedener typischer Praktiken-Wandlungsprozesse zu leisten. Dies geschieht, indem für Wandlungen relevante Phänomene identifiziert und diese dann in ihren jeweiligen Entwicklungsverläufen untersucht werden. Auf Basis von Bewohner*innen- und Experten"inneninterviews werden wichtige Aspekte und Elemente des Wandels herausgearbeitet und dargestellt. In der $\mathrm{Zu}$ sammenschau wird so deutlich, wie sich die Praktikenelemente, Technologie', ,praktische Kompetenzen` und ,Bedeutungszuschreibungen' jeweils für sich und in ihrem Zusammenspiel ändern bzw. stabil bleiben. Das dritte Ziel der Arbeit ist es, aus den zuvor erarbeiteten Detailanalysen Ansatzpunkte für mögliche absichtsvolle Interventionen auszumachen, um Heizpraktiken energiesparender zu gestalten.

Das Design der Studie ermöglicht es, verschiedene Aspekte und Facetten des Wandels (und dementsprechend auch der Beharrlichkeit) von Praktiken empirisch aufzudecken und zu beschreiben sowie sie über die beiden Fälle hinweg systematisch zu vergleichen. 
In der vorliegenden Arbeit stehen die Erzählungen ,gewöhnlicher' Menschen über ihr alltägliches Heizen in Passivhäusern und SmartHomes im Mittelpunkt. Sie werden ergänzt durch die Erzählungen und Berichte von Expert"innen aus ihrer Berufspraxis. Am Beispiel des Heizens in Privathaushalten wird den folgenden drei Fragestellungen nachgegangen:

1) Wie gestaltet sich das alltägliche Heizgeschehen in privaten Haushalten? Aus welchen konkreten Elementen konstituieren sich alltägliche Heizpraktiken?

2) Wodurch kommt es zu Dynamiken und Veränderungen im alltäglichen Heizgeschehen? Das heißt, wie wandeln sich alltägliche Heizpraktiken?

3) Was sind bzw. lassen sich geeignete Ansatzpunkte und Interventionsmöglichkeiten ausmachen, um alltägliches Heizen in eine weniger energieintensive Tätigkeit zu transformieren?

Und konkret auf die zwei Fallbeispiele bezogen, lauten die forschungsleitenden Fragen:

1) Wie sieht ,alltägliches Heizen' in Passivhäusern und so genannten SmartHome-Haushalten aus? Wie läuft es ab? Welche verschiedenen Elemente sind hier jeweils im Einzelnen involviert und durch die Praktizierenden sinnhaft zu einer Tätigkeit integriert?

2) Wie wandelt sich ,Heizen' im Übergang von konventionellen Wohnkontexten zum Passivhaus bzw. SmartHome? Was hat sich an der jeweiligen Elementezusammensetzung verändert? - Welche Elemente sind neu dazugekommen, weggefallen oder wurden ersetzt? Wie sehen die neuen bzw. gewandelten Elementearrangements nun aus? Wie wandeln sich Deutungen des Heizens bei den Bewohner*innen, die gewählt oder unfreiwillig mit den neuen Heiztechnologien konfrontiert sind?

3) Und konkret auf das dritte zentrale Ziel dieser Arbeit bezogen, einen echten Forschungsbeitrag zu leisten, wie der Heizenergieverbrauch in Passivhäusern und SmartHomes zukünftig gesenkt werden kann, ist zu fragen: Welche Schlüsse lassen sich aus den Fallanalysen bezüglich absichtsvoller Intervention in das alltägliche Heizgeschehen bzw. hinsichtlich effektiver Ansatzpunkte für eine Veränderung alltäglicher Heizpraktiken in Privathaushalten ziehen, so dass diese in Zukunft weniger Energieverbrauch implizieren? 


\subsection{Zum Aufbau der Arbeit}

Die Arbeit ist wie folgt aufgebaut: Kapitel 2 ist der Darlegung der eigenen Forschungsperspektive gewidmet. Zunächst wird hier eine Abgrenzung des gewählten theoretischen Ansatzes (Theorie sozialer Praktiken) von anderen möglich anzuwendenden Theorieansätzen zur Untersuchung des (Heiz-)Energiekonsums in Privathaushalten vorgenommen und die Entscheidung für die Verwendung einer praxistheoretischen Perspektive wird fundiert begründet. Nach einer genaueren Verortung des gewählten Ansatzes sozialer Praktiken innerhalb der breiten praxistheoretischen Strömung erfolgt eine Klärung wichtiger theoretischer Grundannahmen sowie eine Erörterung zentraler Begrifflichkeiten und die Ausarbeitung wichtiger Analysekonzepte, die für die eigene Forschung fruchtbar gemacht werden sollen.

In Kapitel 3 geht es um den methodischen Zugang und das eigene konkrete Forschungsvorgehen.

Daran schließt der eigentliche Hauptteil der Arbeit an, in dem die empirischen Ergebnisse der Untersuchung dargelegt werden: Kapitel 4 setzt sich aus fünf eigenständigen Teilkapiteln zusammen, in denen jeweils unterschiedliche Aspekte und Elemente von Praktiken-Wandlungsprozessen im Mittelpunkt stehen. Präsentiert werden die kleineren und größeren Veränderungen von Praktiken sowie Verschiebungen in Praktikengefügen beim Übergang von konventionellem Heizen zum Heizen im Passivhaus bzw. SmartHome, die anhand des empirischen Materials evident wurden.

Im letzten Kapitel 5 erfolgt abschließend eine Zusammenschau und Diskussion der Ergebnisse. Dafür werden die Ergebnisse zur bereits vorhandenen Literatur zum ,Wandel von Praktiken“ in Bezug gesetzt, um zu eruieren, welche Schlussfolgerungen aus den Analysen in die Theoriedebatte eingebracht werden können. Darüber hinaus sollen im Schlusskapitel einige Hinweise und praktische Anregungen für politische Entscheidungsträger*innen gegeben werden, die planen, steuernd in die alltäglichen Praktiken einzugreifen, um diese in Richtung, Nachhaltigkeit ${ }^{6} \mathrm{zu}$ lenken. Des Weiteren wird noch einmal die Frage nach der Verantwortung für nachhaltigen Konsum aufgegriffen und diskutiert. Zuletzt wird ein kurzer Ausblick für mögliche vertiefende Erforschungen von Heizpraktiken und die Anwendung des Ansatzes sozialer Praktiken gegeben. 


\subsection{Zentrale Definitionen}

Im Rahmen dieser Arbeit wird zum einen ,Heizen“ im Wohnkontext ,Passivhaus' und zum anderen ,Heizen' im Wohnkontext ,SmartHome', genauer: mittels smarter bzw. intelligenter Heizungssteuerungstechnik analysiert. $^{15}$

\subsubsection{Passivhaus - was ist der Passivhausstandard?}

Für die folgenden Ausführungen zum Passivhauskonzept habe ich mich im Wesentlichen an den Erörterungen Schnieders' und Hermelinks (2006: 152-155) orientiert.

Genau genommen handelt es sich bei einem ,Passivhaus“ nicht um einen bestimmten Haus- oder Gebäudetyp. Vielmehr bezieht sich die Bezeichnung ,Passivhaus' auf einen spezifischen Konstruktions- und Energieeffizienz-Standard für Gebäude, der durch die Verwendung vieler verschiedener Technologien, Designs und Materialien erreicht werden kann. Im Prinzip stellt das Passivhaus eine (weitere) Verfeinerung des Niedrigenergiehaus-Standards dar. Passivhäuser sind Gebäude, die sommers wie winters ein behagliches Innenraumklima garantieren, ohne dafür ein konventionelles Wärmeverteilsystem zu benötigen. Hierfür ist es erforderlich, dass die maximale Heizlast des Gebäudes 10 Watt pro Quadratmeter $\left(\mathrm{W} / \mathrm{m}^{2}\right)$ nicht übersteigt (Schnieders und Hermelink 2006: 152). Die extrem hohe Energieeffizienz, welche beim Passivhaus(standard) erreicht wird, entspricht in etwa einem jährlichen Heizwärmebedarf von 10 bis maximal 15 Kilowattstunden (Energiegehalt von etwa 1,5 Litern Heizöl) pro Quadratmeter $\left(\mathrm{kWh} /\left(\mathrm{m}^{2} \mathrm{a}\right)\right)$. Folglich ist der Verbrauch für Heizung in einem Passivhaus äußerst gering - er beträgt nur rund ein Zehntel des sonst üblichen Verbrauchs. Dieser relativ geringe (verbleibende) Raumwärmebedarf kann in der Regel durch eine leichte zusätzliche Erwärmung der Zuluft über das Lüftungssystem abgedeckt werden. Darüber hinaus ist ein Passivhaus

15 Zur Vereinfachung wird beim zweiten Fall im Weiteren vom ,Heizen' in so genannten ,SmartHomes' $(\mathrm{SH})$ gesprochen, auch wenn es sich bei den untersuchten Haushalten im definitorischen Sinne nicht um ,echte' SmartHomes, also komplett „informations- und sensortechnisch aufgerüstete, in sich selbst und nach außen hin vernetzte Zuhause" (Bendel 2017*) handelt. Vielmehr ist in den betreffenden Haushalten lediglich der Heizvorgang vollständig automatisiert; das heißt, nur das Heizgeschehen wird mittels vernetzter Computertechnik intelligent gesteuert, was für diese Untersuchung jedoch vollkommen ausreichend ist. 
durch Grenzwerte im Bereich des Primärenergiebedarfs von maximal 120 $\mathrm{kWh} /\left(\mathrm{m}^{2} \mathrm{a}\right)$, hinsichtlich der Luftdichtheit sowie der maximalen Wirkungsgrade definiert (ebd.).

Der Standard hat den Namen ,Passivhaus' erhalten, weil der überwiegende Teil des Wärmebedarfs zu Heizzwecken aus ,passiven` Quellen wie Sonneneinstrahlung und der Abwärme von den sich im Haus befindenden Personen und technischen Geräten gedeckt wird. Die auf diese Weise ,passiv' gewonnene Wärmeenergiemenge reicht in der Regel aus, um das Gebäude (nahezu) während der gesamten Heizperiode auf behaglicher Innenraumtemperatur zu halten (ebd.). Das Ergebnis besteht in einer positiven Raumwahrnehmung, verbunden mit einem niedrigen Energieverbrauch.

Bleibt nun die Frage, was ein Gebäude letztlich genau zu einem Passivhaus macht. Die verschiedenen Hauptkomponenten des Passivhausansatzes können wie folgt klassifiziert werden: drei Elemente sind von entscheidender Bedeutung für das Passivhauskonzept - dies sind (1.) eine hochgradig effektive Wärmedämmung, (2.) Wärmerückgewinnung und (3.) passiver Solarenergiegewinn. Um die Umweltbelastungen möglichst weitestgehend zu minimieren, gibt es darüber hinaus noch zwei Elemente, die für dieses Ziel notwendig (elektrische Effizienz) bzw. sinnvoll (Deckung des verbleibenden Energiebedarfs durch regenerative Energieressourcen), aber zur Erreichung des Passivhausstandards nicht zwingend erforderlich sind. Im Folgenden wird daher nur auf die drei erst genannten elementaren Passivhaus-Komponenten kurz näher eingegangen.

Die Grundidee des Passivhauses, die darin besteht, die Wärmeverluste so weit zu minimieren und die Solarenergiegewinne so weit zu maximieren, dass ein zusätzliches separates Heizungssystem überflüssig wird, erfordert als ersten Schritt eine hervorragende Wärmeisolierung aller äußeren Bauelemente. Das heißt, die äußere Gebäudehülle muss praktisch komplett luftdicht sein und Wärmeverluste durch so genannte Wärmebrücken sind, so gut es geht, zu vermeiden (ebd.: 152f). Das zweite wesentliche Kernelement des Passivhauskonzepts stellt die besondere Lüftungsanlage dar, die effiziente Wärmerückgewinnung mit ergänzender Zuluftheizung in einem vereint. Um die Wärmeverluste über die Lüftung zu begrenzen, benötigen Passivhäuser eine kontrollierte Wohnraumlüftung, die in der Regel mit Wärmerückgewinnung gekoppelt ist: Über die Lüftungsanlage wird das Passivhausinnere kontinuierlich mit frischer Luft versorgt; gleichzeitig sorgt die Lüftungsanlage für den permanenten Abtransport von verbrauchter Luft und Wasserdampf - auf diese Weise wird ein ständig behagliches Raumklima und damit ein hoher Wohnkomfort sichergestellt. Damit ist für den notwendigen Luftaustausch gesorgt, ohne dass dafür ein Fenster geöffnet 
werden muss. Etwa alle drei Stunden ist die gesamte Luft im Haus ausgetauscht. Bei den dazu erforderlichen Luftvolumenströmen sollten normalerweise keinerlei Luftbewegungen, Zugluft oder Geräusche wahrnehmbar sein. Mit einem Wirkungsgrad von (mindestens 80) bis zu 95 Prozent kann die Passivhauslüftungsanlage die Wärme aus der Abluft zurückgewinnen, welche dann wiederum genutzt wird, um die gesondert einströmende $\mathrm{Zu}$ luft zu erwärmen. Dadurch verfügt die einströmende Zuluft bereits über eine gewisse Mindesttemperatur von etwa 14 bis 16 Grad Celsius (vgl. Grobe $2016^{*}$ ).

Da in Passivhäusern ein großer Teil des Heizwärmebedarfs von inneren Gewinnen - durch die Wärmeabgabe von Personen und elektrischen Geräten, sowie von solaren Erträgen beim Wärmeeintrag über die Fenster - gedeckt wird, besteht meist nur noch ein sehr geringer Restwärmebedarf. Dieser geringe Heizwärmebedarf kann in der Regel durch eine Beheizung der Zuluft der Lüftungsanlage abgedeckt werden. Dafür wird ein kleines elektrisches Heizregister (Elektrozusatzheizung) vor den Einströmungsschacht der Lüftung geschaltet. Diese so genannten Kompaktgeräte, in denen eine kontrollierte Wohnräumlüftung, (Warmwasserbereitung, eine Mini-Wärmepumpe) und eine Elektrozusatzheizung integriert sind, die aber keine klassische Gebäudeheizung darstellen, kommen häufig in kleineren Passivhäusern zum Einsatz. Bei größeren Passivhäusern, beispielsweise bei Mehrfamilien-Passivhäusern und größeren Wohnanlagen, kann es sein, dass die Beheizung alleine über die Zuluft nicht ausreicht. In gröBeren Passivhäusern wird der noch bestehende Restwärmebedarf meist über ein zusätzliches (konventionelles) Heizungssystem bzw. durch eine weitere Heizwärmequelle bereitgestellt, zum Beispiel eine Gasheizung, über Fernwärme, eine Wärmepumpe, eine thermische Solaranlage, einen Pelletofen oder auch durch eine Ölzentralheizung. Das heißt, größere Passivhäuser werden üblicherweise (meist noch zusätzlich) wie herkömmliche Gebäude über statische Heizflächen beheizt, die dann jedoch von deutlich geringerer Größe sind. Mittlerweile zeichnet sich ab, dass statische Heizflächen im Wohnungsbau mehr und mehr durch integrierte Heizflächen verdrängt werden, hier allen voran durch Fußbodenheizungen, die einen erhöhten Wärmekomfort versprechen.

Der tatsächliche Heizwärmebedarf kann jedoch sehr unterschiedlich sein, ist er doch wesentlich vom Verhalten der Nutzer"innen abhängig. Wichtige Einflussgrößen hierbei sind unter anderem die gewünschte Raumtemperatur, das Lüftungsverhalten (Stoßlüften oder dauerhafte Fensterkippstellung) und die Verschattung der Fenster. Im Extremfall beträgt 
der tatsächliche Wärmebedarf dann ein Vielfaches des optimal Möglichen und die Energieeinsparung fällt entsprechend geringer aus.

Schnieders und Hermelink räumen allerdings ein, dass sich in der Praxis gezeigt hat, dass in Zentraleuropa strukturelle Maßnahmen alleine oft nicht ausreichen, um den Raumwärmebedarf bis unter die Obergrenze von $15 \mathrm{kWh} /\left(\mathrm{m}^{2} \mathrm{a}\right)$ zu senken (vgl. Schnieders und Hermelink 2006: 153). Dies kann meist nur durch den Einsatz besonders energieeffizienter Passivhaus-Wärmerückgewinnungssysteme erreicht werden. Gelingt dies nicht, so ist auch in diesen Fällen eine zusätzliche Heizmöglichkeit erforderlich zum Beispiel ist hier der Einsatz eines Erdreichwärmetauschers zur zusätzlichen Vorerwärmung der Frischluft möglich, wodurch der Nachheizbedarf weiter gesenkt wird (ebd.). Oder es besteht immer die Möglichkeit, eine zusätzliche konventionelle Gebäudeheizung zu installieren.

Das dritte unverzichtbare Element des Passivhauses sind die passiven solaren Gewinne. Nach Ausschöpfung der Effizienzpotenziale, deckt die passive Sonneneinstrahlung, die durch die besonders beschichteten und für eine ausreichende Belichtung ausgelegten Fenster eingefangen wird, etwa ein Drittel des verbleibenden Restwärmebedarfs des Hauses (ebd.). Das bedeutet, die Fenster eines Passivhauses müssen, über ihre herkömmlichen Beleuchtungs- und Lüftungsfunktionen hinaus, solare Zugewinne ermöglichen. Wichtige Voraussetzungen dafür sind: einerseits sehr geringe Wärmeverluste über die Fenster, was durch eine entsprechende Verglasung (Dreifach-Isolierverglasung, gefüllt mit schweren Edelgasen) erreicht wird; und andererseits - wenn möglich - eine südliche Ausrichtung sowie eine möglichst geringe Verschattung der Fensterfront-Hausseite. Gleichwohl sind Passivhäuser heutzutage nicht mehr dringlich angewiesen auf Baugrundstücke, die besonders große Solareinträge ermöglichen (ebd.: 153f).

Über diese drei elementaren Komponenten muss ein Gebäude mindestens verfügen, um als Passivhaus gelten zu können bzw. diese drei Kriterien sind in jedem Falle zu erfüllen, wenn ein Gebäude den Passivhausstandard erreichen soll.

Wie die größeren implementierten Heizlösungen in den für die vorliegende Arbeit untersuchten Passivhausprojekten konkret aussehen, ist in einer Übersichtstabelle dargestellt, in der die vier untersuchten Passivhausprojekte hinsichtlich ihrer zentralen Merkmale sowie ihrer technischen (Heizungs-)Ausstattung in Kurzform beschrieben sind (siehe Anhang A). Wie wiederum in den einzelnen Haushalten der interviewten Passivhausbewohner*innen der Restwärmebedarf gedeckt wird, welche Wärmequellen sowie welche technischen Geräte zur Wärmeverteilung hier jeweils verwendet werden, darauf wird im empirischen Teil dieser Arbeit, im Rah- 
men der einzelnen thematischen Fallanalysen und jeweils an entsprechender Stelle näher eingegangen (vgl. Kapitel 4).

\subsubsection{Worum handelt es sich bei einem SmartHome?}

Das zweite in dieser Arbeit untersuchte Beispiel ist „Heizen` im Wohnkontext des so genannten SmartHomes. Die Bezeichnung, SmartHome' dient als Oberbegriff für Wohnhäuser bzw. private Haushalte, die mit modernen informations- und kommunikationstechnisch vernetzten und fernsteuerbaren Geräten ausgestattet sind. Mittels der SmartHome-Technologie können einerseits Alltagsvorgänge wie Heizung oder Beleuchtung automatisiert werden, andererseits lassen sich direkt mit dem Haus verbundene Einrichtungen wie Alarmanlagen, Heizung, Fenster, Jalousien oder ähnliche Komponenten sowohl zentral von zuhause aus als auch von unterwegs steuern. Das heißt, die Geräteeinstellungen, z.B. der Heizung, Lüftung und von Unterhaltungselektronik können per Computer oder via Smartphone schnell an die individuellen Bedürfnisse der Bewohner"innen angepasst werden. Die technischen Systeme und Anwendungen des SmartHomes zielen demnach auf eine Erhöhung des Wohnkomforts und der Lebensqualität, auf Sicherheit sowie eine effiziente Energienutzung ab (vgl. BaltaOzkan et al. 2013: 364; Hargreaves und Wilson 2017: 1-3).

$\mathrm{Da}$ in dieser Arbeit alleine das alltägliche Heizgeschehen in Privathaushalten analysiert wird, liegt der ausschließliche Fokus auf smarter bzw. intelligenter Heizungsteuerungstechnologie, andere SmartHome-Technologien und -Anwendungen werden im Rahmen dieser Studie nicht analysiert.

Da sich alle SmartHome-Haushalte, die im Rahmen dieser Arbeit untersucht wurden, im selben größeren Wohngebäudekomplex befinden und die konkrete Ausgestaltung der smarten Heizlösung somit in allen untersuchten SmartHome-Haushalten gleich aussieht, erfolgt eine ausführliche Beschreibung des technischen Heizsettings der SmartHome-Haushalte im ersten Kapitel des Analyseteils (vgl. Teilkapitel 4.1.2). 


\section{Soziale Praktiken als theoretische Forschungsperspektive}

In diesem Kapitel wird die eigene theoretische Perspektive auf das alltägliche Heizen in Privathaushalten als Untersuchungsgegenstand erarbeitet. Der zu entwerfende Blickwinkel wird ein praxistheoretisch angeleiteter Forschungsstandpunkt sein. Mit Lindemann gesprochen, handelt es sich dabei um eine sozialtheoretische Perspektive (vgl. Lindemann 2008: 109), denn mit der Entscheidung, in der empirischen Forschung auf Praktiken zu fokussieren, ist festgelegt, was im Rahmen der Forschung ein soziales Phänomen überhaupt darstellt: „Bei sozialtheoretischen Annahmen handelt es sich um grundlegende Theorien über die Beschaffenheit des Gegenstandes sowie um methodologische Konzepte“ (ebd.).

Theoriearbeit ist kein Selbstzweck. Vielmehr kann Theorie als eine Art ,Sehhilfe‘ oder ,Brille‘ begriffen werden (vgl. ebd.: 114). Theorie stellt einen mehr oder weniger konkreten Vorschlag dar, auf soziale Wirklichkeit zu blicken und diese auf eine bestimmte Weise zu begreifen. Zudem geht es darum, wie diese empirischen Daten zu verstehen und zu interpretieren sind. Dementsprechend lässt sie bestimmte soziale Phänomene präzise erkennen, andere wiederum bleiben undeutlich oder weitgehend im Verborgenen. Mit allein einer Theorie kann man die soziale Wirklichkeit nie in Gänze erfassen und verstehen. Die Schwächen und ,blinden Flecken', die ebenso offenkundig werden, wenn sich für die Verwendung einer bestimmten Theorie entschieden wurde, welche dann auf empirische Objekte und Gegenstände bezogen wird, lassen sich jedoch produktiv nutzen: Aufkommende Irritationen können als Anregung verstanden werden, über die Begrenztheit der gewählten theoretischen Perspektive nachzudenken und daraufhin betreffende theoretische Konzepte empirienah zu verändern und weiterzuentwickeln (vgl. Kalthoff 2008: 20f).

In dieser Arbeit wird daher einem Verständnis des Verhältnisses von Theorie und Empirie gefolgt, das für qualitative Sozialforschung adäquat ist und z. B. von Herbert Kalthoff und Gesa Lindemann vorgeschlagen wird (vgl. Kalthoff 2008; Lindemann 2008). So ist es Kalthoff zufolge besonders wichtig, dass sich die eigene theoretische Perspektive als „empiriefähig" (Kalthoff 2008: 14) erweist. Damit ist gemeint, dass sie keinesfalls vorab oder völlig losgelöst von der empirischen Forschung entwickelt wird, sondern sie entfaltet sich im Verlaufe des Forschungsprozesses. In der konkreten Auseinandersetzung mit dem empirischen Material wird sie 
ausgearbeitet. Andererseits ist es weder erklärtes Ziel qualitativer Forschung, noch ist es realistisch möglich, vollkommen theorieneutral in den empirischen Forschungsprozess einzutreten und Material zu generieren (vgl. ebd.: 20). „In die Erhebung von Daten gehen prinzipiell schon theoretische Annahmen ein“ (Lindemann 2008: 110). Also geht es vielmehr darum, sich die vorhandenen und angestellten beobachtungsleitenden Vor-Annahmen (vorab) bewusst zu machen, sie offenzulegen - etwa im Sinne einer eigenen Positionierung - und kritisch zu reflektieren. Denn die theoretische Haltung bestimmt schließlich wesentlich, was als relevant wahrgenommen wird und damit überhaupt als Datum erscheinen kann und wie dieses Soziale folglich begriffen wird. Diesem Verständnis zufolge können die Daten mittels Theorie(n) gelesen werden bzw. erst durch aktive Verwendung von Theorie(n) wird „das empirische Material zzum Sprechen ' gebracht" (Kalthoff 2008: 20). Erst bei der empirischen Analyse zeigt sich somit das Potenzial von Theorien.

In dieser Arbeit wird eine Forschungshaltung eingenommen, die die in der Soziologie weit verbreitete gedankliche Teilung von Theorie und Empirie ablehnt und stattdessen von einem stetigen „Ineinanderverwobensein von theoretischer und empirischer Forschung“" (ebd.: 10) ausgeht. Idealerweise lässt sich die Beziehung von Theorie und Empirie als ein dialektisches Verhältnis bzw. als einen integrierten Prozess denken, in dem Theoriearbeit und das empirische Forschen permanent ,Hand in Hand' gehen und wodurch dauerhaft die Möglichkeit aufrechterhalten wird, dass beobachtungsleitende theoretische Annahmen und Konzepte stets vom Empirischen her irritierbar sind (vgl. Schmidt 2012: 28-33). Das gelingt durch eine angemessene Balance zwischen erforderlicher Verengung der eigenen Forschungsperspektive sowie einer Vorreflexion damit verbundener theoretischer Annahmen und der nach wie vor notwendigen Offenheit (im Umgang mit dem empirischen Material) - die theoretischen Konzepte sind also durch empirische Daten herauszufordern, immer wieder in Frage zu stellen und gegebenenfalls abzuwandeln (vgl. Kalthoff 2008: 12).

Der Fokus liegt auf sozialen Praktiken, genauer: im Rahmen dieser Arbeit soll das alltägliche Heizen als eine soziale Praktik analysiert werden. Die Entscheidung, Praktiken und nicht etwa Diskurse, symbolische Interaktionen, individuelle Entscheidungen oder Handlungen zentral zu stellen, wurde nicht vorab getroffen, sondern sie ist erst im Laufe des theoretischen und empirischen Forschens gefallen.

Ausgehend von dem Problem, die Reduktion von $\mathrm{CO}_{2}$-Emissionen resultierend aus privaten Konsumaktivitäten $\mathrm{zu}$ untersuchen, wurde zunächst ganz offen recherchiert, welche Alltagsaktivitäten in privaten Haus- 
halten mit einem hohen Energieverbrauch in Verbindung gebracht werden können. Schnell wurde dabei deutlich, dass Heizen damit der entscheidende Ansatzpunkt ist, soll der Energiekonsum in Privathaushalten effektiv gesenkt werden. Daraufhin wurde entschieden, dass eine nähere Beschäftigung mit diesem offenbar besonders relevanten Forschungsproblem erfolgen soll. Die Entscheidung, Heizen in Privathaushalten aus einer praxistheoretischen Perspektive zu analysieren, war zu diesem frühen Zeitpunkt allerdings noch nicht getroffen; sie kristallisierte sich dann aber in der Auseinandersetzung mit möglichen alternativen Forschungsperspektiven unerwartet schnell heraus.

Es gibt mehrere theoretische Forschungsperspektiven, aus denen das Heizhandeln bzw. der Energiekonsum zu Heizzwecken in Privathaushalten häufig analysiert wird. Im folgenden Abschnitt werden die geläufigsten dieser alternativen Forschungsansätze in ihren zentralen Annahmen kurz vorgestellt. Dabei wird jeweils auch gleich deutlich gemacht, wo Schwächen bei diesen anderen Ansätzen gesehen werden. Anschließend wird aufgezeigt, inwiefern sich eine praxistheoretische Herangehensweise von diesen anderen Ansätzen unterscheidet und wie Heizaktivitäten und der alltägliche Heizenergiekonsum in Privathaushalten aus einer praxistheoretisch angeleiteten Forschungsperspektive zu analysieren und interpretieren sind.

\section{Alternative disziplinäre Forschungsperspektiven}

Die verschiedenen möglichen Forschungsperspektiven, die Energie aus einer Konsum- bzw. aus Konsument*innenperspektive betrachten und sich intensiver mit der Thematik, (Effizienter) Energiekonsum in Privathaushalten' auseinandersetzen, sind im Wesentlichen drei wissenschaftlichen Disziplinen zuzuordnen. Bei den drei Disziplinen, die sich mit verschiedenen Forschungsansätzen bisher sowohl theoretisch als auch empirisch mit Energiekonsum in Haushalten beschäftigt haben, handelt es sich um die Wirtschaftswissenschaften (hier insbesondere die Verhaltensökonomie), die Psychologie (einschließlich die marketingbezogene Literatur zum Konsument*innenverhalten (vgl. Andreasen 1995; McKenzie-Mohr 2000)) und die Soziologie (hier hauptsächlich die Wissenschafts- und Techniksoziologie, in Ansätzen die Umweltsoziologie sowie - bisher noch in weitaus geringerem Maße, aber durchaus vielversprechend - die Konsumsoziologie (Brohmann et al. 2009: 8f; Shove et al. 1998: 293f)). Im folgenden Abschnitt wird die Arbeit mitsamt ihrer Theorie und Methodologie in diesem Forschungsfeld verortet. 
Bei den ökonomisch-rationalistischen Ansätzen stehen die in Zahlen erfasste (Heiz-)Energiekonsummenge von Individuen oder Haushalten sowie deren Energieverbrauchsentscheidungen als zu erklärende Größen im Mittelpunkt der Analysen. Gestützt von der grundlegenden Annahme, dass sich das Entscheidungsverhalten von Menschen vorrangig an der Maximierung ihres Nutzens orientiert und entsprechend modellieren lässt, betonen diese Ansätze die Bedeutung von Marktkräften und -mechanismen (insbesondere Preisen) sowie die Verfügbarkeit moderner (Umweltschutz- und Energiespar-)Technologien zur Effizienzsteigerung (Ferguson 1993; Dubin und McFadden 1984). Dementsprechend wird in verhaltensökonomischen Studien vom ,homo oeconomicus' als Handlungsmodell ausgegangen. Das heißt, es werden autonom und rational handelnde, umfassend informierte und mit eindeutigen Präferenzen ausgestattete Individuen angenommen, die mit ihren (energiebezogenen) Entscheidungen, nach Abwägung ihrer begrenzten (finanziellen) Mittel und den aktuellen Marktpreisen (z.B. für ein neues energiesparendes Gerät), ihren persönlichen Nutzen zu maximieren versuchen (z.B. Energiekosten minimieren) (Long 1993; Vaage 2002; Groba und Traber 2010: 4; Burgess und Nye 2008). ${ }^{16}$

Allerdings weist diese Perspektive einige bedeutende Nachteile auf. So können etwa die z.T. träge verlaufenden, verzögerten oder nicht stattfindenden Verhaltensanpassungen an steigende Energiepreise mithilfe des ökonomisch-rationalistischen Ansatzes nicht gut erklärt werden (Lutzenhiser 1993: 256ff). Auch erklärt dieses Modell nicht, wie überhaupt erst bestimmte Präferenzen entstehen oder wie diese sich wandeln (Nemoz 2010: 6), geschweige denn werden die den Reaktionen auf Preisänderungen unterliegenden kognitiven und evaluativen Prozesse thematisiert (vgl. Stern 1986). Aus diesen Gründen ist die Beschreibung des bzw. der ,rationalen Konsument"in' nicht ohne weiteres aufrechtzuerhalten. Die Frage nach der „non-rationality“ (Lutzenhiser 1992: 52) des Energieverbrauchs wird dann als Gegenstand zur psychologischen Erklärung übergeben.

Eine große Anzahl an Beiträgen zum Thema ,Energie(spar)verhalten in Haushalten' stammt aus der Psychologie, und zwar besonders aus a) der kognitiven Psychologie, b) der behavioristischen Psychologie und c) der

16 Mit derlei Annahmen und Modellen wird auch in der energiebezogenen sozialwissenschaftlichen Forschung gearbeitet. Ein anschauliches Beispiel für diese Art der Herangehensweise, die so genannte ,Rational-Choice-Theorie', und den möglichen Ablauf einer solcherart geleiteten Untersuchung, liefert für den Energiebereich Diekmann mit seiner Darstellung „Die Untersuchung einer Hypothese zum Energiesparverhalten“ (Diekmann 2003: 174-199). 
Sozialpsychologie. Neben zahlreichen Unterschieden, die zwischen diesen Ansätzen bestehen, teilen sie den Fokus auf individuelles Verhalten (Brohmann et al. 2009: 5).

Die typische Herangehensweise psychologischer Forschung an die Themen ,Energiekonsum' und ,Energieeinsparung' in Haushalten besteht darin, zu klären, welche individuell-persönlichen Anreize und Intentionen (Motive, Motivation und Emotionen) sowie Restriktionen und Hemmnisse die Akteure in ihrem (Energieverbrauchs-)Verhalten beeinflussen, welche mentalen Prozesse diesem Verhalten unterliegen und welche Verhaltensmechanismen dabei wie zur Wirkung kommen. Hierfür entwickelt die Psychologie Modelle kognitiver Prozesse, in denen Variablen wie die Wahrnehmungen von Individuen, ihre Bewertungs- und Einschätzungsprozesse, ihre Risikoabwägungen, allgemein ihre kognitiven Aktivitäten, ihre Persönlichkeitsstrukturen, sowie ihre Einstellungssysteme und Norminternalisierungen zur Erklärung von Verhalten herangezogen werden (Klusendick 2011). Persönlichkeitsmerkmale und auf der Wahrnehmung der ,Betroffenen' beruhende Eigenschaften sowie persönliche Einstellungswerte und die Wertorientierungen der Haushaltsmitglieder werden mit dem gezeigten Energiekonsumverhalten in eine kausale Verbindung gebracht (vgl. hierzu exemplarisch Leonard-Barton 1981a, 1981b; Olsen 1981; Black et al. 1985; Brandon und Lewis 1999; Staats et al. 2004; Barr et al. 2005; Abrahamse et al. 2005). ${ }^{17}$

Die umfassendste Kritik an der psychologischen Herangehensweise besteht darin, dass ihre Ansätze und Modelle eine klare und zudem linearprogressive Kausalbeziehung zwischen subjektiven Einstellungen und dem individuellen Verhalten unterstellen. Es gibt jedoch klare Evidenz dafür, dass Umweltwissen und umweltbewusste Einstellungen oft nicht in umweltschonenden und -bewussten Verhaltensweisen münden (vgl. Peattie 2010: 216f). ${ }^{18}$ Und nur in seltenen Fällen ließen sich anhand allgemeiner Einstellungen tatsächliche Energieeinsparungsverhaltensweisen prognostizieren (Olsen 1981; Ester 1984).

17 Paul C. Stern $(1985,1992,2000)$ und Stern et al. (1981; 1999) sind die Pioniere dieser mit Energie und Verhalten befassten psychologischen Arbeiten gewesen (Barr et al. 2005: 1427).

18 Das Phänomen bzw. die Beobachtung, dass bei manchen Menschen umweltbezogene Werte und Einstellungen nicht mit entsprechenden Verhaltensweisen einhergehen, wird in der wissenschaftlichen Literatur schon seit vielen Jahren intensiv unter dem Stichwort, attitude-behaviour-gap“ bzw. ,value-action-gap“ diskutiert (siehe etwa Blake 1999; Kollmuss und Agyeman 2002; Barr 2006; Flynn et al. 2009; Kennedy et al. 2009; Valkila und Saari 2013). 
Den wirtschaftswissenschaftlichen und den psychologischen Ansätzen ist gemein, dass sie den Fokus eindeutig auf individuelles Verhalten bzw. Konsumentscheidungen legen. Genau diese Konzentration auf den bzw. die einzelne"n Konsument"in wird aus soziologischer Sicht als die größte Schwachstelle dieser Ansätze angesehen (vgl. Brulle und Dunlap 2015: 8ff). Zudem beziehen sich beide Herangehensweisen in erster Linie auf reflektierte, geplante Tätigkeiten, die mit (bewussten) Handlungsentscheidungen verbunden sind. Das Konzept der informierten und verantwortungsbewussten Wahl wird hier zentral gestellt. Jedoch ist es nicht plausibel, alle Konsumaktivitäten als absichtsvoll geplant oder als bewusste Wahlentscheidung aufzufassen. So kann gerade der alltägliche Heizenergiekonsum als Paradebeispiel einer unreflektierten Routineaktivität gelten.

Da wirtschaftswissenschaftliche und psychologische Paradigmen jedoch weiterhin sehr einflussreich bzw. dominant sind - beispielsweise in der Politikberatung (vgl. UNEP 2015) - scheint ein weiterer Ausbau gerade der soziologischen Forschung zum Thema wichtig zu sein (Dunlap und Brulle 2015).

Eine soziologische Herangehensweise an die Energiethematik besteht grundlegend darin, Energiekonsum als soziales Handeln zu begreifen. Statt individuelle Konsumentscheidungen zu erklären, liegt der Analysefokus auf kollektiven (Energie-)Konsummustern. Das grundlegende Argument ist: Energiebezogenes Handeln findet niemals isoliert und vollkommen losgelöst vom räumlich-materiellen, soziokulturellen und zeitlichen Kontext statt, sondern wird vielmehr von einem komplexen Bündel an vielfältigen Einflussfaktoren bestimmt. Solche elementaren Faktoren sind z. B. natürliche und technologische Gegebenheiten, die vorhandene Infrastruktur, der kulturelle und soziale Kontext, soziale Normen, soziale Interaktionen und Akteurskonstellationen, sowie Behaglichkeitsvorstellungen und Komforterwartungen, vorhandenes oder lokal gebundenes Wissen, die soziale Strukturierung von Entscheidungsprozessen, usw. (Szerszynski und Urry 2010: 3; siehe hierzu auch Guy und Shove 2000; Wilhite et al. 2000; Vliet 2002; Vliet et al. 2005).

\section{Forschungsfokus: soziale Praktiken}

Diese Dimensionen beziehen insbesondere neuere kulturtheoretisch-praxeologische Ansätze mit ein (vgl. Reckwitz 2002b, 2003; Schatzki 1996, 2002). Aus dieser Perspektive wird der Haushaltskonsum von Energie als gewohnheitsmäßiges praktisches Alltagshandeln beschrieben und untersucht (vgl. zu Konsum allgemein: Gronow und Warde 2001b, 2001a; Shove und Warde 2002; Warde 2005; Randles und Warde 2006; Røpke 2009; 
Warde und Southerton 2012b und speziell zu Energiekonsum: Shove 1997a, 1997b, 2004b; Shove und Chappells 2001; Chappells und Shove 2005; Shove 2010b; Shove und Walker 2014). Diesem noch recht jungen und ausbaufähigen Forschungsstrang rechnet sich auch die vorliegende Arbeit zu.

Der praxeologische Zugang betont im Gegensatz zu anderen soziologischen Ansätzen die gleichzeitige Bedeutung von (1) (technologischen) Artefakten, (2) (Be-)Deutungen und von (3) Know-how. Der Analysefokus liegt mit dieser theoretischen Perspektive nicht auf Individuen oder individuellem Verhalten, sondern auf sozialen Praktiken (Schatzki 2012). Entsprechend werden Individuen in dieser Sicht nicht als rationale Entscheider*innen betrachtet, sondern gelten als ,Träger"innen'von Praktiken (vgl. Reckwitz 2002b: 256). Privathaushalte werden verstanden als ein besonderer Kontext bzw. als ein spezifisches Alltags-Setting, in dessen Rahmen bestimmte Energiekonsumpraktiken stattfinden (vgl. Shove et al. 2007; Butler et al. 2014).

Eine praxistheoretische Perspektive auf (Energie-)Konsum erlaubt es, ressourcenintensive Tätigkeiten wie Autofahren oder Heizen umfassend und detailliert zu analysieren.

Erstens können kulturell spezifische Wertvorstellungen und gesellschaftliche Konventionen mithilfe des Praktiken-Ansatzes entschlüsselt werden (Shove 2003). So hat sich in den letzten Jahrzehnten 22 Grad Celsius als angenehm empfundene Innenraumtemperatur durchgesetzt - ein weit verbreiteter, damit akzeptierter und mittlerweile auch erwarteter ,Normalitätsstandard' im Hinblick auf Raumwärmekomfort, der einen erheblichen Energieverbrauch impliziert (vgl. Shove 2004a: 122; Shove 2014: 421).

Zweitens kann dieser kulturelle Erwartungsstandard nur durch den Einsatz und die Verwendung von Technologien, hier etwa von Klimaanlagen und Heizungssystemen, weiter fortbestehen. Der Praktiken-Ansatz betrachtet Materialität als einen notwendigen und hochgradig relevanten Bestandteil von Praktiken und hat deshalb die materiellen Dimensionen gesellschaftlichen Lebens in seine theoretischen Modelle standardmäßig integriert (vgl. Reckwitz 2002a; Schatzki 2010).

Drittens wird in dieser Sicht technologischer Wandel bzw. energieeffiziente Technologie nicht per se als, Wunderwaffe' zur Erreichung von Energieeinsparungen begriffen; vielmehr wird Technik als Mitgestalterin und genauso als Mitgestaltete von selbstverständlich erscheinenden Konventionen, alltäglichen Praktiken und gewohnten Lebensweisen aufgefasst (Shove et al. 1998). Denn wie die technischen Geräte im Rahmen von Alltagsaktivitäten eingesetzt und ob die mit ihnen möglichen Effizienzpotenziale 
tatsächlich ausgeschöpft werden, hängt entscheidend davon ab, über welche Kompetenzen die Praktizierenden verfügen und welches praktische Wissen sie im Umgang mit diesen Technologien zur Geltung bringen (Wilhite 2008). Die praxistheoretische Sichtweise impliziert, dass sich soziokulturelle, organisationale und technologische Elemente gemeinsam und in ständiger Wechselwirkung herausbilden, dass sie sich also ko-evolutionär entfalten und dementsprechend Technologie- und Gesellschaftsentwicklung nur zusammenhängend analysiert werden können (vgl. Shove et al. 1998; Elzen et al. 2004; Elzen und Wieczorek 2005). Demnach vermag die praxistheoretische Analyse bisher einseitige Fokussierungen auf (effiziente) Technik (,technological fix ${ }^{6}$ ) und/oder (technisches) Wissen oder Einstellungen zu überwinden.

Der Praktiken-Ansatz ist bereits erfolgreich in ersten Fallstudien erprobt worden. So sind ressourcenintensive Routine-Praktiken in Privathaushalten wie beispielsweise der Gebrauch von Klimaanlagen (Shove 2003), Wäschewaschen (Shove 2004c), tägliches Duschen (Hand et al. 2005) und die standardmäßige Verbreitung und Verwendung von Gefrierschränken (Shove und Southerton 2000; Hand und Shove 2007) bereits umfassend praxistheoretisch analysiert worden.

Jedoch liegen bislang nur vereinzelte Studien zur Praktik des Heizens vor (vgl. Gram-Hanssen 2010, 2011). Im deutschsprachigen Raum wurden für den Gegenstandsbereich des privaten Heizens bisher noch keine praxistheoretisch orientierten empirischen Untersuchungen vorgenommen. Im Kontext der Transformationsforschung zur ,low carbon' bzw. ,decarbonized society ${ }^{6}$ handelt es sich beim Heizen aufgrund des hohen Energieverbrauchs um einen besonders relevanten Untersuchungsfall. Darüber hinaus lag der Schwerpunkt soziologischer Forschung bisher generell eher auf der Reproduktion sozialer Ordnung; zur Erforschung von gesellschaftlichen Transformationsprozessen und sozialem Wandel generell hat die Soziologie hingegen bislang verhältnismäßig wenig beigetragen. Auch wurde von verschiedenen Seiten die Kritik geäußert, das Konzept der Praktiken sei wenig geeignet, um Wandel und Veränderungsprozesse zu erfassen (vgl. Warde 2005: 136). Im Kontrast dazu wird in dieser Arbeit die gegenteilige These vertreten, nämlich, dass der theoretische Ansatz sozialer Praktiken sogar besonders geeignet für die Analyse von Veränderungsprozessen ist. Es wird angenommen, dass Alternation und die Fähigkeit zu Wandel typische Eigenschaften und inhärente Merkmale von Praktiken sind und diese deshalb auch von Anfang an in den theoretischen Analysekonzepten konzeptionell mitgedacht und mit entworfen worden sind (vgl. Reckwitz 2003: 294f; Warde 2005: 140; Hargreaves 2011). 
Im Folgenden soll zunächst die in dieser Arbeit eingenommene praxistheoretische Perspektive innerhalb der heterogenen Strömung praxistheoretischer Zugänge verortet werden. Im Anschluss werden die zentralen, die eigene empirische Forschung leitenden Annahmen und Konzepte dargelegt und es wird aufgezeigt, welche der praxistheoretischen Konzepte im Rahmen dieser Arbeit in den Mittelpunkt gestellt und für die eigene empirische Forschung aktiviert werden.

\subsection{Der praxistheoretische Zugang}

Der Ausdruck ,Praxistheorie' (,practice theory') hat in den letzten Jahrzehnten weite Verbreitung gefunden. Insbesondere in den Kultur- und Sozialwissenschaften erfreuen sich praxisanalytische Zugänge seit einigen Jahren immer größerer Popularität und kommen dort immer häufiger zur Anwendung. In Zusammenhang mit diesem Trend wird von einem ,practice turn in contemporary theory“ (Schatzki et al. 2001, Hervorh. im Original) gesprochen (hierzu kritisch Bongaerts 2007).

Obwohl die häufig verwendete Bezeichnung ,Praxistheorie' dies vermuten lässt, handelt es sich bei der praxistheoretischen Strömung keineswegs um ein einheitliches Theoriegebäude. Auch gibt es keine klar definierte "Theorie sozialer Praktiken“ (Reckwitz 2003: 282). Beim praxistheoretischen Zugang handelt es sich vielmehr um eine heterogene, weit aufgefächerte theoretische Strömung mit sehr verschiedenen Ansätzen (vgl. Schatzki et al. 2001; Ebrecht und Hillebrandt 2004; Hörning und Reuter 2004; Reckwitz 2003: 282-284). Von daher wäre es sinnvoll bzw. angemessener von Praxistheorie im Plural zu sprechen.

\section{Das Spektrum praxistheoretischer Ansätze}

Eine generelle Welle erneuten Interesses an ,Alltag', ,Lebenswelt' und ,sozialer Praxis' (vgl. Reckwitz 2002b: 244) und damit auch an "Praxistheorie‘ kam im Rahmen verschiedener akademischer Disziplinen im letzten Drittel des 20. Jahrhunderts auf. „The Practice Turn in Contemporary Theory“ (Schatzki et al. 2001), wie diese Denkströmung zuweilen bezeichnet wird, hat ihre Wurzeln demnach in mehreren unterschiedlichen Wissenschaftsdisziplinen (vgl. Reckwitz 2002b: 243). Zuletzt waren es der Philosoph Theodore R. Schatzki und der Soziologe Andreas Reckwitz, die bedeutende Versuche unternommen haben, die verschiedenen Stränge zu systematisieren und stärker zu einer, Theorie sozialer Praktiken` zu verdichten. Ihre 
Zusammenführung und Fundierung eines praxistheoretischen Ansatzes basiert darauf, dass sie das Praktiken-Konzept erstmals explizit zentral stellen und dieses als theoretische Grundlage zur Analyse von Sozialwelt ausarbeiten. In diesem Sinne ist es erklärtes Ziel, die soziale Welt und das in ihr stattfindende soziale Geschehen als ein Gefüge vieler verschiedener, zum Teil auch aufeinander bezogener sozialer Praktiken zu analysieren. Dafür greifen sie auf die Arbeiten von Theoretiker*innen zurück, die bereits der ersten Generation von Praxistheoretiker"innen zugerechnet werden. Wichtige Referenzen sind etwa die Philosophen Ludwig Wittgenstein, Hubert Dreyfus und Charles Taylor, aber genauso gehören Soziologen wie Pierre Bourdieu und Anthony Giddens, sowie auch Kulturtheoretiker wie Michel Foucault und Jean-François Lyotard dazu (vgl. Schatzki 2001: 1; Schatzki 2012: 13; Reckwitz 2003: 282f). Diese Sozialtheoretiker haben wichtige Grundlagen geschaffen. In ihren Arbeiten finden sich bereits Elemente, die für eine Theorie sozialer Praktiken fruchtbar gemacht werden können und auf die Schatzki und Reckwitz ihren Theorieansatz aufbauen (hierzu ausführlich Schatzki 1996: insbes. Chapter 1 bis 3; Reckwitz 2000b: insbes. Kapitel 7, 2002b: 246-250). Es sind vor allem die neueren Arbeiten Schatzkis (1996, 2002) und Reckwitz' (2002b) gewesen, die zur Formulierung eines stärker einheitlichen Ansatzes zur Analyse sozialer Praktiken geführt haben. In seinem programmatischen Aufsatz „Toward a Theory of Social Practices" aus dem Jahre 2002 spricht Reckwitz gar davon, „an idealized model of practice theory“ (Reckwitz 2002b: 244), also ,einen Idealtypus von Praxistheorie‘ entwickeln zu wollen. Sein Ziel ist es, eine neue Denkströmung zu begründen, die den Rang eines eigenständigen und umfassenden sozialtheoretischen Ansatzes erreicht und damit als eine echte Alternative zu anderen idealtypischen Theorieansätzen, wie etwa der zweckrationalen und der normorientierten Handlungstheorie oder auch strukturtheoretischen Ansätzen gesehen werden kann (vgl. ebd.). Die in dieser Arbeit eingenommene theoretische Perspektive knüpft im Wesentlichen an diese Ausarbeitungen an. Dies soll im Folgenden begründet werden.

Auch wenn es sich (noch) nicht um einen einheitlichen Ansatz handelt, kann ,Praxistheorie dennoch als eine zwar lockere, aber abgrenzbare Denkströmung bezeichnet werden (Schatzki 2001: 13f). Neben zum Teil erheblichen Unterschieden zwischen den verschiedenen praxistheoretischen Ansätzen gibt es nämlich ein paar wichtige einende, das heißt gemeinsame Grundannahmen und Merkmale praxistheoretischer Zugänge (vgl. Reckwitz 2002b: 244, 2003; Brand 2011: 178; Schatzki 2012: 13f). 
Diese einenden, theoretischen Basisannahmen stehen im Mittelpunkt des folgenden Abschnitts und werden dort näher erläutert.

\subsubsection{Gemeinsame Grundannahmen des praxistheoretischen Zugangs}

Im Wesentlichen sind es vier grundlegende Annahmen, auf denen die im Detail unterschiedlichen Ansätze der praxistheoretischen Strömung fußen.

\subsubsection{Praktiken als elementare Einheit des Sozialen}

Praxistheoretische Ansätze verorten das Soziale nicht in individuellen Handlungen, normativen Ordnungen, Zeichen- und Symbolsystemen, nicht in mentalen Strukturen oder Prozessen rekursiver Kommunikation, sondern in sozialen Praktiken. Bei einer Praktik handelt es sich um eine bestimmte geordnete Konstellation verschiedener körperlich-mentaler Aktivitäten. Eine Praktik ist ein soziales Phänomen in dem Sinne, dass sie immer mehrere Menschen betrifft bzw. erfasst (vgl. Reckwitz 2000b: 611616; Schatzki 2012: 13). Praktiken werden als grundlegende und kleinste Einheit des Sozialen betrachtet und sind die relevanten Untersuchungseinheiten. In praxistheoretischer Perspektive werden gesellschaftliche Phänomene wie Sprache, kollektive Wissensordnungen, Deutungs- und Sinnsysteme, menschliches Handeln und Handlungsrationalitäten, Normen, Machtgefüge, aber auch Organisationen und soziale Institutionen, die sonst als gegebene Tatsachen betrachtet und bestimmt durch eigenlogische soziale Strukturen erklärt werden, demgegenüber als Hervorbringungen, Bestandteile, Verknüpfungen oder Sequenzen unterschiedlicher ,Felder sozialer Praktiken' aufgefasst: „The field of practices is the total nexus of interconnected human practices" (Schatzki 2001: 11).

Aus praxeologischer Perspektive stellt demzufolge die soziale Welt ein Gefüge aus „sehr konkret benennbaren, einzelnen, dabei miteinander verflochtenen Praktiken (im Plural)“ (Reckwitz 2003: 289, Hervorh. im Original) dar. Somit sind praxistheoretische Erklärungsansätze weder individua- 
listisch ${ }^{19}$ noch holistisch ${ }^{20}$ : Sie folgen keiner individualistischen Erklärungslogik, weil Praktiken weder Eigen- noch Errungenschaften einzelner Individuen sind, sondern Praktiken sind überindividuelle Phänomene, in dem Sinne, dass sie den Individuen vorausgehen. Sie sind schon vor den einzelnen Tätigkeitsvollzügen da und ,gehören' niemandem. Soziale Praktiken existieren einerseits unabhängig von individuellen Handlungsentwürfen und bestehen andererseits nur fort, weil sie von vielen individuell vollführt werden. Praxistheoretische Erklärungen folgen aber wiederum auch keiner holistischen Logik. Das Praktiken-Konzept entspricht keiner ,strukturalistischen' Betrachtung, weil Praktiken nicht als einfach gegebene, statische Phänomene betrachtet werden, die die individuellen Handlungsvollzüge weitestgehend bestimmen. Praktiken haben keine starren Grenzen, sondern sind zu einem guten Teil offen und unbestimmt; und sie bestehen nur fort, wenn sie immer wieder aktiv und individuell, aber im Gesamtresultat eben von einer größeren Gemeinschaft, vollzogen werden. Dabei können sie entweder reproduziert oder transformiert werden. Praxistheoretische Betrachtungen bieten demnach, so drückt es Schatzki aus, eher pluralistische und flexible Bilder und Beschreibungen vom Aufbau bzw. der Verfasstheit gesellschaftlichen Lebens, die generell in Opposition stehen $\mathrm{zu}$ (Vorstellungen von) starren verdinglichten Einheiten, die soziale Ordnung eher in lokalen Kontexten verankern und/oder die Komplexitäten, Unterschiede sowie Besonderheiten erfolgreich (in sich) aufnehmen bzw. unterbringen (Schatzki 1996: 12).

Praktiken liegen gleichsam quer zu Struktur und Handlung, sie bilden somit „eine emergente Ebene des Sozialen“ (Reckwitz 2003: 289). Schatzki folgert daraus als wesentliche Erkenntnis, dass „both social order and individuality $[\ldots]$ result from practices“ (Schatzki 1996: 13).

19 Die mit dem methodologischen Individualismus verbundene Erklärungsstrategie beinhaltet, dass Strukturmerkmale der höheren Ebene zurückzuführen sind auf Prozesse der Ebene des Individuellen und ,Kleinen`. Soziale Phänomene (Makroebene) werden demnach erklärt, indem man aufzeigt, dass sie aus bzw. von Einzelhandlungen her (Mikroebene) resultieren (vgl. Heintz 2004: 3).

20 Mit dem methodologischen Holismus bzw. Kollektivismus, der das logische Gegenstück zum methodologischen Individualismus darstellt, verbindet sich die Auffassung, „dass die höhere Ebene eigenständige Gesetzmäßigkeiten aufweist, die ohne Rückführung auf die tiefere Ebene analysierbar sind“ (Heintz 2004: 3). Gesellschaftliche Phänomene stehen demnach für sich und sind in dieser Sicht aus sich selbst bzw. ihrer Eigenlogik heraus zu erklären. Es gilt demnach der Grundsatz: ,Soziales durch Soziales‘ zu erklären. 
Das Praktiken-Konzept stellt demnach einen theoretischen Versuch dar, den Makro-Mikro-Dualismus zu überwinden bzw. zwischen dem Gegensatz von Struktur und Handlung perspektivisch zu vermitteln. Dies ist der Kerngedanke, der ebenso im Mittelpunkt der Strukturationstheorie Giddens' steht. Gemäß dieser stellen soziale Praktiken den zentralen Untersuchungsbereich der Sozialwissenschaften dar:

„The basic domain of study of the social sciences, according to the theory of structuration, is neither the experience of the individual actor, nor the existence of any form of social totality, but social practices ordered across space and time. Human social activities [...] are recursive. That is to say, they are not brought into being by social actors but continually recreated by them via the very means whereby they express themselves as actors." (Giddens 1984: 2, Hervorh. im Original)

\subsubsection{Soziale Praktiken als koordinierte Einheit von Aktivitäten}

Eine weitere geteilte Annahme der praxistheoretischen Denkströmung ist, dass das Sozialleben als ein großes Netz von verschiedenen, dabei miteinander verknüpften Praktiken zu verstehen ist und dass Menschen sich in ihrem alltäglichen Leben in zahlreichen Praktiken betätigen. Bei Praktiken handelt es sich demzufolge um menschliches Tun. Sie stellen eine koordinierte Einheit von körperlich-mentalen Aktivitäten dar, die regelmäßig in mehr oder weniger routinisierter Weise von vielen Menschen vollzogen werden. Praktiken sind also repetitive Verhaltensmuster - mehr noch: sie sind routinisierte Muster des Wahrnehmens, Bewertens, Denkens und Handelns.

Überdies teilen Praxistheoretiker*innen die Vorstellung, dass menschliches Handeln wesentlich auf einem Wissen basiert, das von den Handelnden selbst nicht verbal expliziert werden kann: ein ,einverleibtes/inkorporiertes', kollektiv geteiltes ,praktisches Verstehen' und Handlungswissen, ein tief verinnerlichtes Know-how, das die jeweiligen Praktiken zusammenhält und durch welches sie organisiert sind. In sozialen Praktiken sind Handeln und Wissen gekoppelt. Routinisierte Formen körperlich vollzogener Aktivitäten sind untrennbar verknüpft mit sinnhaften Verstehensleistungen. Demgemäß begreifen, genauer konzipieren Praxistheoretiker*innen Praktiken als „embodied, materially mediated arrays of human activity centrally organized around a shared practical understanding" (Schatzki 2001: 11). Vor allem der Körper wird dabei als zentrale, Vermittlungsinstanz' zwischen Geist/Sinn, Aktivitäten/physischem Handeln und 
sozialen Prozessen angesehen (vgl. Brand 2011: 189). In praxistheoretischer Sicht beruhen Reproduktion wie auch Transformation sozialen Lebens auf der erfolgreichen ,Performance' dieses einverleibten, also körperlich verankerten und vermittelten praktischen Wissens:

"the maintenance of practices, and thus the persistence and transformation of social life, rests centrally on the successful inculcation of shared embodied know-how. [...], the skilled body commands attention in practice theory as the common meeting point of mind and activity and of individual activity and society.” (Schatzki 2001: 12)

\subsubsection{Das besondere Verständnis von ,Materialität ${ }^{\star}$}

In neueren praxistheoretischen Ansätzen wird die wichtige vermittelnde Rolle ,Materialität ${ }^{`}$ ganz allgemein zugesprochen. Demnach wird dem impliziten Handlungswissen im Rahmen von Praktiken sowohl durch die sinnhafte, erfahrene und gekonnte körperliche Ausführung bestimmter Handgriffe und Tätigkeiten als auch durch einen geschickten Umgang mit Dingen und technischen Artefakten sowie die geübte An- und Verwendung von Alltagsgegenständen Ausdruck verliehen (vgl. Reckwitz 2002a; Schatzki 2010). Diesem Verständnis folgend, ist zu betonen, „that within practices not only bodies but also artifacts are sites of understanding in the form of materialized understanding“ (Reckwitz 2002a: 212, Hervorh. im Original). Das heißt, es sind stets sowohl Körper und Geist in Form eines menschlichen Akteurs als auch Dinge erforderlich, um eine bestimmte soziale Praktik aufrechtzuerhalten (vgl. Schmidt 2012: 55-71).

\subsubsection{Konzeption und Position des handelnden Subjekts}

Bei einer Praktik handelt es sich um eine relativ beständige, relativ gut wiedererkennbare Entität. Solch eine Einheit kann aber nur fortbestehen, wenn die dazugehörigen, sinnhaft miteinander verbundenen mentalen und körperlichen Aktivitäten auch tatsächlich regelmäßig von Menschen vollzogen werden; und zwar nicht nur von ein paar wenigen Einzelpersonen, sondern von größeren Gruppen von Menschen - „without practitioners there would be no practice” (Shove und Pantzar 2007: 164). Durch ihre Praktikenperformances sorgen die Individuen dafür, dass die Entitäten im Laufe der Zeit reproduziert und damit entweder stabilisiert oder eben umgestaltet werden. Das einzelne Individuum agiert folglich als ,Trä- 
ger*in' einer sozialen Praktik bzw. von vielen verschiedenen Praktiken, die nicht notwendigerweise miteinander koordiniert oder verknüpft sein müssen. Reckwitz fasst diese alternative Sicht auf das Individuum bzw. das praxistheoretische Subjektverständnis folgendermaßen zusammen:

„In practice theory, agents are body/minds who 'carry' and 'carry out' social practices. Thus the social world is first and foremost populated by diverse social practices which are carried by agents. Agents, so to speak, 'consist in' the performance of practices (which includes - to stress the point once more - not only bodily, but also mental routines)."(Reckwitz 2002b: 256, Hervorh. im Original)

Als Träger*innen einer Praktik, so betont Reckwitz weiter, sind und handeln Akteure weder vollkommen autonom, noch verhalten sie sich wie ,voreingenommene Trottel' (,judgmental dopes“, ebd.), die einfach nur irgendwelchen gesellschaftlich anerkannten Normen folgen bzw. entsprechen. Vielmehr interpretieren und verstehen sie die Welt und auch sich selbst. Sie nutzen ihr praktisches Wissen/Know-how und ihr Motivationswissen entsprechend der jeweiligen, bestimmten Praktik. Da es viele verschiedene soziale Praktiken gibt und da jedes Individuum eine Vielzahl verschiedener sozialer Praktiken ausübt, stellt aus praxistheoretischer Sicht jedes Individuum einen ganz besonderen ,Kreuzungspunkt' bzw. eine einzigartige ,Schnittmenge' von Praktiken, also körperlich-mentalen Routinen dar (ebd.).

Die übereinstimmende Festlegung praxistheoretischer Ansätze auf soziale Praktiken als Grundeinheit soziologischer Analyse impliziert folglich ein ,dezentriertes ${ }^{6}$ Verständnis sowohl von Subjektivität, als auch von Rationalität und Normativität (Brand 2011: 190). Das heißt, es wird nicht vom einzelnen Akteur und seinem Handeln ausgegangen, sondern vorranging und zuallererst wird sozialen Praktiken nachgeforscht - sie bilden den Ausgangpunkt jedweder praxeologischer Analyse. Körper und materielle Artefakte kommen dabei als (Sinn-)Träger und Mitwirkende an Praktiken und menschliche Akteure im Sinne körperlich-geistiger Wesen kommen als Praktikendarsteller*innen in den Blick - aber eben immer erst, wenn sie sich in Form bestimmter Praktiken aktiv betätigen. Gleiches gilt für Entscheidungsmotive, Zwecke, Werte, Normen oder Intentionen sowie Ideen und Überzeugungen: sie werden im Rahmen von Praktiken hergestellt bzw. sie sind selbst schon Bestandteile spezifischer Praktiken (und nicht etwa dauerhafte persönliche Eigenschaften von Individuen).

Hiermit enden die zentralen Gemeinsamkeiten praxistheoretischer Ansätze. Im Detail fußen die einzelnen praxistheoretischen Ansätze auf teil- 
weise recht unterschiedlichen Annahmen und es wird dementsprechend mit unterschiedlichen Konzepten gearbeitet. Im Folgenden soll daher nun näher auf die Begriffsverständnisse und Analysekonzepte des jüngst von Schatzki und Reckwitz begründeten Ansatzes sozialer Praktiken eingegangen werden, da dieser in der vorliegenden Studie zur Analyse von Heizaktivitäten in Privathaushalten verwendet wird.

\subsubsection{Begriffsbestimmung und Konzeption sozialer Praktiken}

Um sich alltäglichen Heizpraktiken empirisch angemessen nähern zu können, ist vorab zu klären, was theoretisch unter einer sozialen Praktik zu verstehen ist. Dafür wird in diesem Abschnitt das forschungsleitende Konzept ,soziale Praktiken' konkretisiert, damit klar umrissen ist, welcher Gegenstand zu beobachten ist.

Was im analytischen Sinne genau gemeint ist, wenn von ,Praktiken' die Rede ist, wird von Reckwitz prägnant geklärt, indem er zunächst eine Unterscheidung zwischen ,Praxis' und ,Praktiken' vornimmt und beide Begriffe in Abgrenzung zueinander definiert. Bei ,Practice“ im Singular - auf Deutsch ,Praxis - handelt es sich demnach um einen besonderen Ausdruck, der (im Deutschen) dafür verwendet wird, um (mit Nachdruck) jegliches menschliche Handeln zu beschreiben, und zwar ist hiermit wirklich das praktische Handeln, also körperliche Tun gemeint, im Gegensatz zu Theorie(arbeit) und bloßem Denken. Mit ,Practices' im Plural - auf Deutsch ,Praktiken' -, im Sinne der Theorie sozialer Praktiken, ist hingegen etwas anderes gemeint. In diesem Verständnis dient der Ausdruck ,Praktik' (,practice') zur Bezeichnung eines routinisierten Verhaltens bzw. eines wiederkehrenden Handlungsmusters, das aus mehreren, miteinander verbundenen Elementen besteht, also aus körperlichen Aktivitäten bzw. bestimmten Körperbewegungen, spezifischen mentalen Aktivitäten, Dingen/Gegenständen und ihrem Gebrauch, einem Hintergrundwissen in Form von Verstehen, Know-how, Gefühlszuständen und auch einem Motivationswissen/Beweggründen, usw. (Reckwitz 2002b: 249).

Praxissoziolog*innen interessieren sich für beide Belange. So steht Bourdieu, dessen Theorie explizit den Namen „Theorie der Praxis“ (Bourdieu 1976) trägt, mit seinen Arbeiten tendenziell eher für ersteres Begriffsverständnis (vgl. auch Bongaerts 2007: 254-257). Er verwendet den Begriff der Praxis vor allem dafür, die theoretische Praxis des bzw. der Wissenschaftler*in von der Alltagspraxis, gewöhnlicher' Menschen zu unterscheiden 
(vgl. ebd.: 254). ${ }^{21}$ Für die Konsumsoziologie scheint hingegen eher letzterer Begriff bzw. das Konzept der Praktik aufschlussreich und geeignet zu sein. Dies ist so, weil es einerseits sehr differenzierte Analysen ermöglicht: Die zahlreichen Elemente jeglichen Konsumhandelns sowie ihre Verknüpfungen können in den Blick genommen werden. Andererseits ist das Konzept, das Praktiken als eine kohärente Einheit fasst, hinreichend abstrakt. Es eignet sich, um sehr unterschiedliche Phänomene zu betrachten: zum Beispiel ,Heizen', aber auch ,Tanzen' und ,Unterrichten'. Dadurch erscheinen Praktiken als klar benennbare, distinkte soziale Phänomene, die aber keinesfalls mit Einzelhandlungen gleichgesetzt oder verwechselt werden können (vgl. Warde 2005: 133). Deshalb wird in der soziologischen Konsumforschung, wie auch in dieser Arbeit, bei letzterer Begriffsbedeutung, nämlich der von sozialer Praktik angeknüpft.

\section{Soziale Praktik(en) als abstrakte koordinierte Einheit(en) und als konkre- te Performance(s)}

Schatzki unterscheidet zwischen zwei zentralen Auffassungen einer sozialen Praktik: zum einen begreift er ,Praktik ${ }^{`}$ als eine abstrakte koordinierte (Seins-)Einheit, zum anderen fasst er ,Praktik' als konkrete Performance bzw. tatsächliche Handlung auf.

Mit dem ersten Begriffsbild beschreibt Schatzki die Praktik als kleinste ontologische Entität des Sozialen, die immer aus mehreren, sinnhaft miteinander verknüpften Aktivitäten besteht. In dieser Auffassung spricht er von "practice as a temporally unfolding and spatially dispersed nexus of doings and sayings" (Schatzki 1996: 89). Beispiele für solche sich über die Zeit entfaltenden und räumlich weit verbreiteten Gefüge von, doings and sayings' wären etwa Praktiken des Kochens, Erklärens, Aufräumens und Ordnens, des Arbeitens, Erholens usw. Und weiter heißt es bei Schatzki:

„To say that the doings and sayings forming a practice constitute a nexus is to say that they are linked in certain ways. Three major avenues of linkage are involved: (1) through understandings, for example, of what to say and do; (2) through explicit rules, principles, precepts and instructions; and (3) through what I will call 'teleoaffective' structures embracing ends, projects, tasks, purposes, beliefs, emotions and moods." (ebd.)

21 Genau genommen oszilliert Bourdieu in seiner Herangehensweise permanent zwischen den beiden Bedeutungen von Praktik und Praxis (vgl. Warde 2005: 136). 
Praktiken setzen sich demnach stets aus konkreten Taten und verbalen Äußerungen zusammen, was beinhaltet, dass man sich im Rahmen einer umfassenden Analyse von Praktiken mit beidem, sowohl mit dem praktischen Handeln als auch mit den gedanklichen und sprachlichen Repräsentationen dessen beschäftigen muss (vgl. Warde 2005: 134). In diesem ersten Praktikenverständnis liegt das Hauptaugenmerk auf den Verknüpfungen der verschiedenen, zu einer Praktik gehörenden Aktivitäten, also den sinnhaften Verbindungen. Und zwar beschreibt Schatzki (in obigem Zitat) drei wesentliche Pfade, über die die ,doings and sayings' zu einem einheitlichen Gebilde in Form einer Praktik verknüpft sind: Erstens wird die Kopplung über (stillschweigende) Übereinkünfte, also ein implizites, geteiltes Verständnis hergestellt, beispielsweise davon, wie eine Situation zu interpretieren, wie in ihr (adäquat) zu handeln ist und was in diesem Rahmen gesagt werden kann oder darf. Zweitens findet laut Schatzki eine Kopplung über so etwas wie explizite Regeln, Grundsätze, Vorschriften, Normen und Anweisungen statt. Und drittens stellt Schatzki sich vor, dass so etwas wie eine ,teleo-affektive Struktur' für Verbindung sorgt. Damit ist ein komplexes Gefüge bzw. eine große Gemengelage bestehend aus Zielen, Plänen, Absichten, Vorhaben, Aufgaben und Pflichten, Zwecken, Vorstellungen und Überzeugungen, sowie Empfindungen, Leidenschaften und Stimmungen gemeint, die sich im Wie des praktischen Handelns und Sprechens erkennbar niederschlägt (vgl. Schatzki 1996: 89). Erst diese sinnstiftenden Verknüpfungen machen Praktiken zu eindeutig identifizierbaren Einheiten. Denn letztendlich sind solche Bündel oder Blöcke von Aktivitäten nur dann als ,Praktiken-Entitäten' deutlich identifizierbar, wenn die einbezogenen Aktivitäten bedeutungsvoll koordiniert und sinnhaft aufeinander bezogen sind.

Solcherlei Entitäten bestehen nur fort, wenn betreffende Aktivitäten tatsächlich von Menschen vollzogen, also (immer wieder) aktualisiert werden. Die Reproduktion des geordneten Zusammenhangs erfordert regelmäßige Durchführung. Hier knüpft Schatzki mit seiner zweiten Vorstellung von ,Praktik als Performance' oder Ausführung an (vgl. ebd.: 90). Erst durch den konkreten Vollzug der mit einer Praktik verbundenen Tätigkeiten wird deutlich, welche Aktivitäten tatsächlich zur Praktik gehören. Gleichzeitig wird die Praktik wiederum erst durch die Ausführung der betreffenden Aktivitäten als Praktik konstituiert: „Each of the linked doings and sayings constituting a practice is only in being performed" (ebd.).

Das zusammenhängende Vollführen der ,doings and sayings“ „actualizes and sustains practices in the sense of nexuses" (ebd.). Hier wird deutlich, wie Schatzki die beiden von ihm unterschiedenen Praktikenkonzepte in 
Verbindung bringt. Und zwar sehen sich Einzelpersonen Praktiken als Einheiten gegenüber, wie sie historisch entstanden und zu einer kollektiven Errungenschaft geworden sind. Das heißt, eine „performance presupposes a practice“ (Warde 2005: 134). Beispielsweise sehen Menschen sich mit dem Erfordernis konfrontiert, im Winter ihr Haus zu beheizen, damit sie nicht frieren, sondern sich in ihren Räumlichkeiten wohl und behaglich fühlen (können). Sie wissen, wie sie ihre Wohnräume angenehm erwärmen können; ihnen ist klar, was sie in dieser Situation machen müssen und sie beherrschen die entsprechenden Handlungen und Handgriffe, wie etwa die Heizung anstellen, die Heizkörperthermostatventile weit aufdrehen, Fenster und Türen überwiegend geschlossen halten und nur kurzes Stoßlüften praktizieren oder den Kamin anfeuern, usw. Durch ihre tatsächlichen Praktikenperformances reproduzieren und/oder verändern die Einzelnen dann die abstrakten (Praktiken-)Einheiten im Laufe der Zeit. Indem die Menschen entweder immer wieder die Heizkörper aufdrehen, reproduzieren sie das, was als ,Heizen' aufgefasst und verstanden wird; oder, indem sie etwa auf neue Heiz- und Lüftungstechniken umsteigen, tragen sie dazu bei, dass andere, neue Aktivitäten unter Heizen subsumiert werden und sich dadurch mit der Zeit eventuell das Verständnis des Heizens sowie die Tätigkeit selbst grundlegend wandeln. Demzufolge sind die Konzepte von einer ,Praktik-als-Einheit ${ }^{\star}$ und einer ,Praktik-als-Performance rekursiv aufeinander bezogen - und Gleiches gilt für die konkreten verschiedenen körperlich-mentalen Aktivitäten, die sich dann im Einzelnen hinter den jeweiligen Praktiken verbergen.

\subsubsection{Praktikentypologie}

Mittlerweile zeichnet sich ab, dass sich drei Typen von Praktiken unterscheiden lassen, wie im Folgenden näher ausgeführt wird.

2.1.3.1 ,Dispersed ' und ,integrative practices ${ }^{\text {- }}$ - verstreute, weit verbreitete und integrative Praktiken

Zusätzlich zu der im vorangegangenen Abschnitt beschriebenen Unterscheidung weist Schatzki mit einer weiteren Unterscheidung, nämlich der zwischen ,dispersed practices' ${ }^{6}$ und ,integrative practices ${ }^{6}$ auf den weiten Anwendungsbereich des Praktikenkonzepts hin. 
Mit „dispersed practices“ (vgl. Schatzki 1996: 91f) sind Tätigkeiten gemeint, die in vielen Bereichen des Gesellschaftslebens vorkommen bzw. Anwendung finden. Praktiken des Erklärens, Beschreibens, Fragens, Berichtens, des Anordnens und des Befolgens von Regeln - all das sind typische Beispiele für ,verteilte' bzw. ,weit verbreitete Praktiken'. Ihr Vollzug erfordert hauptsächlich ein kollektiv geteiltes, praktisches Verstehen. Das Befolgen einer Regel beispielsweise, beinhaltet, dass man ein Verständnis davon hat, was es bedeutet, den Handlungsakt der Regelbefolgung angemessen auszuführen, darüber hinaus die Fähigkeit, den Akt des Regelbefolgens bei sich selbst und bei anderen identifizieren und benennen $\mathrm{zu}$ können sowie das Vermögen, regelkonformes Handeln auslösen und auf Regelbefolgung in adäquater Weise reagieren zu können. Es geht darum zu wissen, wie - im Sinne von „knowing how to" (Schatzki 1996: 91) eine Tätigkeit auszuführen ist. Dabei handelt es sich um ein (Leistungs-) Vermögen, das eine kollektiv geteilte Praxis voraussetzt, die den situationsgerechten konkreten Vollzug auf Basis eines sozial standardisierten und von den Einzelnen verinnerlichten Wissens umfasst und zur Folge hat.

„Zentral für das praxeologische Verständnis des Handelns ist, [...] dass Handeln im Rahmen von Praktiken zuallererst als wissensbasierte Tätigkeit begriffen werden kann, als Aktivität, in der ein praktisches Wissen, ein Können im Sinne eines, know how' und eines praktischen Verstehens zum Einsatz kommt.“ (Reckwitz 2003: 291f, Hervorh. im Original)

Das kollektiv geteilte spezifische praktische Können bzw. Verstehen sorgt letztlich dafür, dass eine bestimmte Handlung bzw. Darbietung beispielsweise als (Akt der) Regelbefolgung erkennbar wird.

Diese rein theoretischen Ausführungen sollen anhand eines Beispiels verdeutlicht werden: Ein Gesellschaftsbereich, in dem die verteilte, das heißt häufig vorkommende Praktik der Regelbefolgung zur Anwendung kommt, ist der Straßenverkehr. Beim Autofahren gelten offizielle Verkehrsregeln. Diese sind von den Kraftfahrzeugführer*innen zu beachten, damit weder sie selbst noch andere Verkehrsteilnehmer“innen gefährdet werden; und auch, weil ein Regelverstoß meist streng sanktioniert wird: So droht bei kleineren Geschwindigkeitsüberschreitungen meist ,nur ein Bußgeld, hingegen kann es bei drastischen Überschreitungen eines festgelegten Tempolimits sogar zum temporären Entzug der Fahrerlaubnis kommen. 
Eine andere Tätigkeit, bei der die Praktizierenden Regeln befolgen, ist das Kochen. Gerade Anfänger*innen folgen beim Kochen eines neuen, ihnen noch unbekannten Gerichts meist sehr genau den detaillierten Angaben und Anweisungen eines Rezepts, damit selbiges gelingt. Später, wenn sie das Gericht bereits einige Male gekocht haben, brauchen sie meist kein Rezept mehr, weil das Rezept(-wissen) dann bereits in ihrem Gedächtnis verankert ist und durch das mehrmalige Wiederholen zudem noch mit praktischem Erfahrungswissen angereichert wurde. Auch bei kleinen Abweichungen kommt dann normalerweise am Ende ein wohlschmeckendes Gericht heraus. Oftmals wird das Rezept von den Praktizierenden sogar bewusst leicht abgewandelt, weil sie allmählich aus der Erfahrung wissen, wie es ihnen am besten gelingt und am besten schmeckt.

Diese beiden Anwendungsbeispiele für das Auftauchen der generellen Praktik des Regelbefolgens zeigen, dass diese Praktik allgemeine und eher abstrakte Aktivitäten umfasst, die es einerseits möglich machen, konkrete Handlungsvollzüge in sehr unterschiedlichen Bereichen bzw. Kontexten als Ausführungen ein und derselben verteilten Praktik zu identifizieren, nämlich der Regelbefolgung. Andererseits machen die gewählten Beispiele deutlich, dass die konkreten Performances der Regelbefolgung in den verschiedenen Bereichen (Verkehr und Essenszubereitung) nicht nur sehr unterschiedlich aussehen können, sondern im Einzelnen auch ganz andere, für den jeweiligen Bereich spezifische Fähig- und Fertigkeiten erfordern und jeweils für den Tätigkeitsbereich typische Handlungsvollzüge beinhalten.

Mit „integrative practices“ bezeichnet Schatzki „the more complex practices found in and constitutive of particular domains of social life" (Schatzki 1996: 98). Zu den ,integrativen' oder ,spezifischen Praktiken' werden beispielsweise landwirtschaftliche Tätigkeiten, Kochaktivitäten, Geschäftspraktiken und Lehrtätigkeiten gezählt. Diese beinhalten sehr häufig auch weit verbreitete Praktiken wie Fragen, Erklären oder das Befolgen von Regeln (vgl. die oben beschriebenen Beispiele). Es ist aber wichtig, integrative Praktiken nicht nur als eine Ansammlung von verteilten Praktiken zu verstehen, sondern sie wirklich als einen anders gearteten, eigenständigen Praktikentypus zu begreifen. Verbreitete Praktiken, sofern sie im Rahmen von integrativen Praktiken auftauchen, erscheinen dann meist in spezialisierter Form, weil sie durch die Eingliederung in einen bestimmten größeren Tätigkeitszusammenhang abgewandelt oder den anderen noch in dieser Praktik enthaltenen Aktivitäten angepasst wurden: „Although multiple dispersed practices wander through and meet within integrative ones, they are sometimes transformed through their incorporation" 
(vgl. ebd.: 99). So umfasst die allgemeine Tätigkeit des Regelbefolgens ganz andere ,doings and sayings' und ist mit einem ganz anderen sinnhaften Verstehen verbunden, je nachdem ob ihr im Rahmen von Kochaktivitäten oder beim Führen eines Kraftfahrzeugs im Straßenverkehr nachgegangen wird.

„For instance, such dispersed practices as describing and requesting course largely unaltered through numerous domains of social life, regardless of how much they might be transformed within specific domains. What is true is that people usually, though not always, are also engaged in an integrative practice when carrying on a dispersed practice." (ebd.)

Ganz generell interessiert sich die Soziologie vorrangig für integrative bzw. spezifische Praktiken und dies gilt ausdrücklich in gleicher Weise für die Konsumsoziologie, wie an späterer Stelle noch ausführlich darzulegen sein wird.

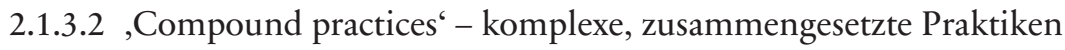

Warde argumentiert, dass es sinnvoll ist, neben den zwei von Schatzki beschriebenen Praktikenarten, den weit verbreiteten, eher allgemeinen und den integrativen, eher spezifischen Praktiken, noch einen weiteren Typus von Praktiken zu unterscheiden: die „composite or compound practices“ (Warde 2013). Warde zufolge handelt es sich bei einer ,compound practice' um eine besonders komplexe, weil aus mehreren Teilen, genauer: aus mehreren integrativen Praktiken zusammengesetzte Praktik. Die zu einer ,compound practice‘ gehörenden integrativen Praktiken könnten zwar jeweils für sich alleine stehen; wenn sie allerdings in spezifischer Weise angeordnet sind und dementsprechend sinnhaft miteinander verschränkt erscheinen, sind sie, so argumentiert Warde, als Teilelemente einer „composite or compound practice" (ebd.: 25, Hervorh. im Original) zu betrachten. $\mathrm{Ob}$ es sich um solch einen geordneten Komplex mehrerer integrativer Praktiken, also um eine so genannte ,compound practice ${ }^{6}$ handelt, wird demnach erst mit Blick auf ihre konkrete Verknüpfung und ihr wirkliches Erscheinen in einem sozialen Kontext erkennbar.

Warde hat sich in Anbetracht des für ihn nicht klar einzuordnenden Falls ,eating' (Essen) die grundlegende Frage gestellt, wie eine Praktik überhaupt als Praktik zu identifizieren ist. Wie lassen sich Aktivitäten möglichst eindeutig, als zu einer Praktik gehörend, gegen andere Aktivitä- 
ten abgrenzen? - Wo liegen die Grenzen einer Praktik? Daran anschließend wirft er die grundsätzliche Frage auf: Was sind eigentlich die wesentlichen Charakteristika einer Praktik? Anhand welcher Merkmale lässt sich eine Praktik deutlich als solche erkennen?

Um diese theoretisch-methodologischen Fragen genauer zu erkunden, knüpft Warde an Schatzkis anfängliche Ausarbeitungen zu verteilten und integrativen Praktiken an (vgl. Warde 2013: 20). Schatzki benennt mehrere Kriterien anhand derer integrative Praktiken relativ präzise auszumachen sind (vgl. Schatzki 1996: 98-110). Davon erscheinen Warde drei Grundannahmen für seine eigene weitere Argumentation relevant: Erstens müssen Praktikenperformances, auch wenn sie stark abweichend und neu erscheinen, dennoch hinlänglich altbekannte Aspekte enthalten. Sie müssen also genügend an Gemeinsamkeit(en) mit der bisher vorhandenen Praktik aufweisen, so dass sie auch weiterhin, trotz ihrer Anders- bzw. Neuartigkeit, als korrekte und annehmbare Ausführungen dieser betreffenden Praktik erkennbar bleiben (Warde 2013: 20). Zweitens die Annahme, dass Praktiken über sozialen Charakter verfügen und dies kraft der Tatsache, dass sie an verschiedenen Orten und zu unterschiedlichen Zeiten oder auch zeitlich parallel von unbegrenzt vielen anderen Praktizierenden vollzogen werden. Und drittens die Annahme, dass irgendeine spezifische (Art von) Praktikeneinheit existiert, die nicht nur in den Vorstellungen der Individuen vorhanden ist: „the organization of an integrative practice is out there in performances themselves not in the minds of actors" (ebd.). Die ersten beiden Annahmen gelten sowohl für verteilte als auch für integrative Praktiken; die letzte Annahme sei aber nur im Fall von integrativen Praktiken gültig.

Das entscheidende Kriterium zur Identifikation einer Praktik als integrative Praktik sei demnach die grundsätzliche und klare Geordnetheit der zu einer Praktik verknüpften Aktivitäten. Das heißt, die abstrakte Gliederung einer Praktik schlägt sich in den tatsächlichen Vollzügen nieder und wird damit immer wieder aufs Neue sichtbar, weil die zu einer integrativen Praktik gehörenden Aktivitäten eben nicht vollkommen beliebig, sondern stets in einer bestimmten Handlungsabfolge und -anordnung vollzogen werden. ,Organization' scheint, so versteht Warde Schatzki, das entscheidende Merkmal integrativer Praktiken zu sein - eine Gliederung, die immer auch ,out there', in den Darstellungen selbst wiederzuentdecken sei (vgl. ebd.: 20). Warde zieht daraus die Schlussfolgerung: „Social organization is a necessary condition of the existence of a practice" (ebd: 23, Hervorh. im Original). 
Wardes Antwort auf die Frage, wie Praktikenperformances trotz ihrer Einzigartigkeit geregelt und organisiert sein können, ist, dass die normativen Standards, nach denen eine Praktikenausführung als richtig und angemessen beurteilt wird, öffentlich ersichtlich sind. Dies komme in einer expliziten Formalisierung und Kodifizierung entsprechender Praktiken zum Ausdruck. Formalisierung und Regulierung sind häufig das Resultat der Tätigkeit entsprechender formaler Organisationen. So geben beispielsweise das Umweltbundesamt und die Verbraucherzentrale regelmäßig sehr detaillierte Flyer und Merkblätter zum ,richtigen` Heizen und Lüften heraus. $^{22}$

„Indeed, one of the ways in which we might recognise a practice is through the existence of formalized processes, procedures or artefacts directed towards specifying adequate performances." (ebd.)

Ein gebräuchliches Mittel hierzu sind schriftlich festgehaltene Tätigkeitsbeschreibungen - hierbei handelt es sich um detaillierte Erläuterungen, wie die betreffende Praktik richtig zu vollziehen ist. Beispiele hierfür sind Betriebs- oder Bedienungsanleitungen, Einführungen oder Leitfäden, Regelwerke, erste Selbstlernbücher oder Handbücher zur Performanceverbesserung. Formale Anleitungen sind demnach als deutliche Hinweise für die Existenz einer Praktik anzusehen:

„For practices only exist where performances can attain to some standard of excellence and thus, for most individuals, be improved. Manuals also seem to provide solid evidence of the facticity (and common recognition) of the existence of some underlying foundations to correct or acceptable performances of a complex and widely shared practice." (ebd.)

Warde zieht eine Parallele zu Selbstlernangeboten und stellt die These auf, dass es grundsätzlich möglich sein sollte, jede Tätigkeit, die als integrative Praktik angesehen werden kann, in die "Teach Yourself series" (ebd.) einzubeziehen. Selbstlern-Bücher und -Trainingshefte verfügen seiner Ansicht nach über mehrere definierende Merkmale, die sich auch als Kriterien für die Identifizierung integrativer Praktiken eignen: So bieten diese Bücher

22 Vgl. Flyer „Gesundes Raumklima. Heizen, Lüften, Feuchtigkeit und Schimmel“ der Verbraucherzentrale (Verbraucherzentrale Bundesverband e.V. (VZBV) 2017*); Website-Artikel zu den Themen „Richtig Heizen, Schimmelbildung vermeiden“ und „Richtig Lüften, Schimmelbildung vermeiden“ des Umweltbundesamtes (Umweltbundesamt (UBA) 2013, 2017.*). 
normalerweise einen einfachen und vorläufigen Überblick über Inhalt und das einschlägige Wissen (zu) einer bestimmten Tätigkeit. Meist wird dieses Wissen in Form von Regeln und Fakten sowie klaren Handlungsanweisungen präsentiert, also in einer für Anfänger*innen geeigneten Weise, damit diese erfahren bzw. nach der Lektüre wissen, wie die entsprechenden Praktiken auszuführen und zu verbessern sind. Anleitungsbücher zum Selbstlernen skizzieren demnach die Art und Weise sowie die Mittel zur Erlangung der betreffenden Kompetenzen, um eine Performance abliefern zu können, die von einem fachkundigen Publikum als angemessen anerkannt werden würde. Darüber hinaus präsentierten diese Selbstlernbücher die Aktivität als eine Praktik, im Sinne einer koordinierten Einheit, d.h. mit geteilten Normen für die Ausführung (vgl. Warde 2013: 24).

Warde beschreibt es als ,Paradox ${ }^{6}$ des Formalisierungs- und Kodifizierungsprozesses, dass sich kompetente Praktizierende beim Vollzug einer Praktik zwar niemals streng an die Vorschriften und Regeln halten oder zur praktischen Betätigung meist nicht auf eine Betriebsanleitung Bezug nehmen, dass aber dennoch die genaue Kodifizierung und Formalisierung einer anspruchsvollen Praktik üblich, selbst schon eine Formsache sei. Zwar gebe es oftmals eine starke Formalisierung, diese habe aber keineswegs zur Folge, dass dadurch alle Praktikenvollzüge gleich aussähen. Handbücher und Anleitungen für bestimmte praktische Tätigkeiten dienten vielmehr lediglich als gute Belege dafür, dass die betreffenden Aktivitäten den Status anerkannter, gut ausgereifter und damit gut ausgearbeiteter Praktiken erreicht hätten. Demnach können sich solche Handbücher dann als besonders nützlich und hilfreich erweisen, wenn es um die abstrakttheoretische Bestimmung bzw. Spezifizierung und genaue Einordnung von Praktiken geht (vgl. ebd.).

Als Veranschaulichung für solch einen Bestimmungsprozess arbeitet sich Warde an der Praktik des „eating“ (ebd.: 24f) ab. ${ }^{23}$ Warde prüft zunächst, ob ,eating' angemessen als eine verteilte, also eher allgemeine oder als eine integrative Praktik beschrieben werden kann. Er kommt aber zum Schluss, dass mit beiden Praktikenkonzepten ,eating' in der britischen Gegenwartsgesellschaft nicht plausibel dargestellt werden kann, sondern dass es dafür eines anderen Konzepts bedarf. Warde begründet dies folgendermaßen: Zwar existiere ein weit verbreitetes praktisches Verständnis, was

23 Beim Nachvollzug des Beispiels wird überwiegend die englische Bezeichnung, eating' beibehalten, da sich mit den deutschen Übersetzungen ,Essen' oder ,Nahrungsaufnahme' die verschiedenen, sich hinter dem Begriff , eating'verbergenden umfassenden Tätigkeiten nur unzulänglich erfassen lassen. 
man sich unter ,eating' vorzustellen habe, aber es fehlten eben gemeinsam geteilte normative Standards, die die Aktivität sowie ihre konkrete Ausführung formal regulierten: „Most immediately, in Britain at present there exists no shared understanding of what it means to eat well“" (ebd.: 22). Stattdessen lässt sich für ihn, eating ${ }^{6}$ am plausibelsten als eine eigenständige, aber sehr umfassende Praktik beschreiben, die auf mehreren integrativen Praktiken basiert. ,Eating', so wie es die Briten zurzeit kennen würden, setze die Verschränkung von mindestens vier integrativen Praktiken voraus: die Versorgung mit Lebensmitteln, das Kochen, die Organisation und der geregelte Ablauf von Mahlzeiten sowie ästhetische Geschmacksbeurteilungen. Diese integrativen Praktiken sind gemäß Warde allgemein als ,Ernährung', ,Kochkunst', ,Tischmanieren' oder ,Umgangsformen bei Tisch und ,Gastronomie‘ bzw. ,Esskultur' formalisiert. Von daher könnte man ,eating' als eine außergewöhnlich komplexe Praktik betrachten:

"Conceived as an entity, one option would be to conceptualize it as emergent from a number of these other integrative practices. Even better, perhaps, would be to treat it as a composite or compound practice with multiple organizational underpinnings. Performances of eating are, in the latter view, a complex corollary of the intersection of four, relatively autonomous integrative practices.” (Warde 2013: 24f, Hervorh. im Original)

Das Vorhandensein von vier Teilpraktiken mache es äußerst schwierig, ,eating' als Gesamtpraktik zu koordinieren, sowohl auf der Ebene individueller Performance als auch auf Ebene der kollektiven Institution. Daraus ergibt sich für Warde, dass ,eating performances' gesellschaftlich nur wenig geordnet, ja regelrecht unorganisiert seien. Denn schließlich habe jede zu ,eating' gehörende integrative Teilpraktik ihre eigene Logik und ihre eigenen unterschiedlichen Koordinierungsinstanzen (vgl. ebd.: 25).

Demnach geht es bei zusammengesetzten Praktiken vorrangig darum, zu klären, wie die verschiedenen zu einer ,compound practice‘ verschränkten integrativen Praktiken im Einzelnen aufeinander abgestimmt sind.

Welche Schlüsse zieht Warde nun aus seiner Analyse? Er hat festgestellt, dass man mit dem bisher für komplexere Praktiken verwendeten Konzept der integrativen Praktiken im Falle von ,eating' nicht weit kommt. ,Eating ${ }^{6}$ stellt sich als ein besonderer, bislang noch nicht näher bestimmter Typus von Praktiken dar. Von daher erscheint es sinnvoll, ein neues Praktikenkonzept für solch komplexe und ,heteronome' Praktiken wie ,eating' zu entwickeln. Den Ausgangspunkt für eine präzisere Bestimmung und Einordnung dessen, um welchen Praktikentypus es sich bei ,eating' handelt, 
bildet für Warde „the fundamental axiom that performances and practices [as entities, JM] stand in a recursive relationship to one another" (Warde 2013: 27). Demnach erscheint ,eating' in seiner gegenwärtigen Ausgestaltung als Beispiel für eine zusammengesetzte Praktik:

„That is to say, the practice is recognizable through its performances, but judgement of their correctness (their conformity with standards) cannot be made with reference to a single integrative practice. The normative forces governing eating are divergent in their injunctions, even mutually contradictory." (ebd.)

Für diese Arbeit ist es aufschlussreich, diese (kleine dreiteilige) ,PraktikenTypologie‘ zu kennen, da es in Kapitel 2.2.5 darum gehen wird, herauszuarbeiten, um welchen Typus von Praktik es sich beim Heizen handelt - das heißt, welche Aktivitäten zum Heizen dazugehören, in welchem Verhältnis sie zueinander stehen und wie sie miteinander koordiniert sind. So ist ,richtiges ${ }^{6}$ Heizen in der Praxis untrennbar mit der Aktivität des Lüftens verbunden (und diese Verknüpfung wird größtenteils auch in der Theorie gemacht). Handelt es sich beim Heizen und Lüften nun um zwei zwar eng miteinander in Zusammenhang stehende bzw. aufs engste verbundene, aber dennoch getrennte, eigenständige, so genannte, integrative Praktiken'? Oder ist es angemessener von Heizen als einer ,komplexen Praktik“ zu sprechen, also Heizen (im Sinne Wardes) als eine ,zusammengesetzte Praktik` zu betrachten, die die Operation des Lüftens immer schon enthält bzw. mit umfasst? Und inwiefern verschieben bzw. verändern die in dieser Arbeit analysierten neu eingeführten (Heizungs-)Technologien (noch einmal) das Verhältnis von Heizen und Lüften in der praktischen Performance bzw. der alltäglichen Handlungspraxis? Dies sind zentrale Fragen, die vor allem in Kapitel 4.2 des empirischen Teils dieser Arbeit vertiefend behandelt werden sollen.

\subsubsection{Merkmale sozialer Praktiken}

In diesem Abschnitt sollen die zentralen Eigenschaften von Praktiken zusammengefasst werden, um ein klares Bild von dem Untersuchungsgegenstand dieser Arbeit zu erlangen und ein verständliches Konzept zur empirischen Anwendung zu haben. Insgesamt werden sechs Merkmale von Praktiken ausgeführt: ihre raumzeitliche Ausdehnung, ihre körperliche Verankerung, ihre Verknüpfung von körperlichen und sinnhaften Eigenschaf- 
ten, ihre materielle Komponente, ihre geschichtliche und kulturelle Verankerung sowie ihre Stabilität bzw. Wandelbarkeit.

\subsubsection{Praktiken überschreiten raumzeitliche Grenzen}

Räumliche und zeitliche Grenzen zu transzendieren, ist eine vielfach beschriebene Eigenschaft von Praktiken (Reckwitz 2004: 321; vgl. bereits Giddens 1997 [1984] und Schatzki 1996: 89). Damit ist gemeint, dass die zu einer Praktik gehörenden Aktivitäten von verschiedenen Individuen (oder auch Personengruppen) zu verschiedenen Zeitpunkten und an verschiedenen Orten immer mal wieder, meist mit einer gewissen Regelmäßigkeit vollzogen werden. Soziale Praktiken sind demnach (über Raum und Zeit hinweg) relativ beständig und stabil. Sie weisen somit ,Routinecharakter' auf. Bei sozialen Praktiken handelt es sich typischerweise um einen Komplex bzw. Zusammenhang von körperlichen und mentalen Routineaktivitäten (vgl. Reckwitz 2002b: 252, 256). Das Besondere an routinisierten Handlungsvollzügen ist, dass in ihrem Fall die Entscheidungsfindung keine wesentliche Rolle (mehr) spielt. Alternativen werden nicht (mehr) bewusst in Betracht gezogen und gegeneinander abgewogen; dadurch laufen die entsprechenden Aktivitäten nahezu unverändert, stets in gleicher Art und Weise ab. Das Resultat sind relativ stabile und damit leicht zu identifizierende, weil ständig wiederkehrende Tätigkeitsvollzüge (vgl. Bauman 2000: 153). Das gesamte (Alltags-)Leben setzt sich demnach aus einer Vielzahl von Gewohnheiten und Routinen zusammen.

Die Akteure sind sich über ihr alltägliches Handeln und die entsprechenden Handlungsgründe zwar meistens in dem Sinne bewusst, dass, wenn sie danach gefragt werden, sie „die Absichten ihres Handelns und dessen Gründe fast immer diskursiv darlegen können" (Giddens 1997 [1984]: 57). Jedoch seien den Akteuren die Motive ihres Handelns - Reckwitz spricht hier etwas allgemeiner von der ,sinnhafte[n] Orientierung der Träger der Praktiken“ (Reckwitz 2004: 322) - meist nicht wirklich bewusst, da „Motive [dazu] neigen, nur unter relativ ungewöhnlichen Umständen eine direkte Auswirkung auf das Handeln zu haben, d.h. in Situationen, die in gewissem Sinne von der Routine abweichen" (Giddens 1997 [1984]: 57). Vielmehr „sorgen Motive“, so führt Giddens weiter aus, „[hauptsächlich] für Gesamtpläne oder Programme - "Entwürfe« in Schütz' Worten -, innerhalb derer eine Reihe von Verhaltensweisen ausgeübt werden“" (ebd., Hervorh. im Original). Die meisten alltäglichen Aktivitäten werden allerdings in Form von Routinen vollzogen, die keiner be- 
wussten Reflexion mehr bedürfen (vgl. ebd.: 36). In ihnen ist ein praktisches Bewusstsein eingelagert, ein stillschweigendes Wissen, wie in verschiedenen Kontexten angemessen zu handeln ist (ebd.). Wie das Handeln (selbst), so ist in praxistheoretischer Perspektive demnach auch ,Intentionalität ${ }^{\star}$, also die motivationale Begründung von Handeln, nicht atomistisch und individualistisch, sondern aus einer Prozessperspektive zu betrachten (ebd.: 54). Die Sinngrundlage einer Praktik ist somit oft implizit, wird gemeinsam geteilt und situativ im Vollzug der Praktik mobilisiert (Reckwitz 2004: 322, vgl. hierzu auch Giddens 1979: 49-95; Schatzki 1996: 19-132).

Dabei können repetitive Handlungsmuster unterschiedlich fundiert sein: Auf der einen Seite gibt es bewusst eingeübtes Handeln, also Wiederholungen von Handlungen, die zumindest zu Anfang bestimmten bewussten Reflexionsprozessen unterlagen. Die Routinisierung hat dann den Zweck, diese bewussten Überlegungen nicht wiederholen zu müssen, sie wirkt also entlastend und reduziert die Komplexität von Handlungsentscheidungen (vgl. Ilmonen 2001). Auf der anderen Seite kann es sich um Wiederholungen von Handlungen handeln, über die nie bewusst nachgedacht und die nie absichtsvoll eingeübt wurden, sondern eher einem von vornherein unreflektiert erlernten Tun gleichkommen. Repetitive Handlungsmuster lassen sich demnach in Routinen und Gewohnheiten unterscheiden:

„Es lässt sich leicht feststellen, dass ,Routine ${ }^{6}$ offenkundig ein ursprünglich bewusst trainiertes Handeln bezeichnet, während, Gewohnheiten' ihrem Bedeutungsgehalt nach auch und gerade auf der Aneignung von Verhaltensweisen beruhen, die nicht das Bewusstsein im Sinne eines Entwurfs, Ziels oder Plans durchlaufen haben müssen, die also auch nicht die Form propositionalen Wissens annehmen müssen." (Bongaerts 2007: 256)

Der Aneignungsmodus impliziten Wissens gibt zudem auch Auskunft darüber, auf welcher Form von Wissen ein repetitives Handlungsmuster jeweils basiert. So handele es sich bei dem in Routinen zum Ausdruck kommenden Wissen um ein propositionales Wissen im Sinne von ,wissen, dass' (knowing that). In diesem Verständnis bedeutet ,wissen' so viel wie ,über eine bestimmte Information verfügen' oder, einen bestimmten Sachverhalt kennen'. Demgegenüber sei ein im Wesentlichen nicht bewusst angeeignetes Wissen, wie es bei einem von Gewohnheiten getragenen Handeln zum Ausdruck komme, auch nicht-propositional (vgl. ebd.). Hier gehe es eher um Wissen im Sinne von,wissen wie' (knowing how), so habe 
,wissen' die Bedeutung von ,etwas können`oder ,eine bestimmte Fähigkeit besitzen'.

$\mathrm{Ob}$ es sich bei einem sich wiederholenden Handlungsmuster nun um eine Routine oder eine Gewohnheit handelt, lässt sich demnach feststellen, indem man versucht, nicht nur das dem Handeln zugrundeliegende Wissen zu rekonstruieren, sondern auch wie, also die Art und Weise bzw. den Prozess, in dem der betreffende Akteur sich dieses Wissen angeeignet hat.

Die Inkorporation von Wissen führt dazu, dass die Akteure über ihr Tun oft nur noch begrenzt bzw. kaum mehr Auskunft geben können, wenn sie zu diesem befragt werden (vgl. Giddens 1997 [1984]: 36) und dazu, dass häufig (und oft beharrlich) an Handlungsroutinen festgehalten wird, auch wenn dies gegebenenfalls nicht (mehr) funktional ist (Ilmonen 2001: 17).

Durch ihren repetitiven Charakter und das in sie eingelagerte Wissen ergeben sich relativ stabile und damit leicht zu identifizierende, weil ständig wiederkehrende Tätigkeitsvollzüge (vgl. Bauman 2000: 153). Und obwohl jede Gewohnheit und jede Routinetätigkeit für sich genommen häufig relativ wenig bedeutet, haben sie in der Gesamtsumme enorme Auswirkungen auf unsere Gesundheit, unseren Ressourcenverbrauch, unsere finanzielle Situation, unsere Produktivität und unser Wohlbefinden (vgl. Duhigg 2012).

Praktiken transzendieren somit raumzeitliche Grenzen. Auf den Untersuchungsgegenstand des Wohnraumheizens bezogen, lässt sich dieses Merkmal sehr einfach darlegen: Routinen rund um das Heizen werden in der Ferienwohnung des Winterurlaubs ebenso angewendet, wie sie gegebenenfalls früher, in einer heiztechnisch ähnlich ausgestatteten Wohnung praktiziert wurden.

\subsubsection{Die körperliche Darstellung und Verankerung von Praktiken}

Ein zweites wichtiges Merkmal sozialer Praktiken ist ihre ,Körperlichkeit ${ }^{6}$ (vgl. z.B. Schmidt 2012: 55-62):

„Aus praxeologischer Perspektive ist auf basaler Ebene jede Praktik eine körperliche ,performance': Wer eine Praktik erlernt, lernt, seinen Körper auf bestimmte, sozial als angemessen perzipierte Weise zu bewegen; [...] die Praktik ist zunächst nichts anderes als eine regelmäßige, kompetente (,skillful') Bewegung des Körpers." (Reckwitz 2004: 322, Hervorh. im Original). 
Demzufolge sind soziale Praktiken immer auch „sinnhafte, bedeutungstragende, gekonnte Körperbewegungen“ (Schmidt 2012: 55). Ohne Körper bzw. körperliche Beteiligung gibt es demnach keine Praktiken. Entsprechend erhält der Körper bzw. Körperlichkeit in praxistheoretischen Analysen besondere Aufmerksamkeit, wodurch sie sich deutlich von mentalistischen Kulturtheorien sowie von den beiden traditionellen Formen der Handlungstheorie (der zweck- und der normorientierten Handlungserklärung) abgrenzen. Diese Ansätze tendieren dazu, den Körper allenfalls als ,Werkzeug' oder ,Ausführungsinstrument' von Motiven, Normen oder kognitiven Schemata aufzufassen - der Körper bzw. körperliches Tun wird in dieser Logik als dem Geist bzw. dem Denken/Mentalen nachgeordnet angesehen, das öffentlich sichtbare Handeln werde demnach von der inneren Sphäre des Geistes angeleitet. Dementsprechend finden Körper und Körperbewegungen in diesen Erklärungsansätzen auch begrifflich - wenn überhaupt - nur am Rande Erwähnung. Hingegen verstehen und konzipieren die Theorien sozialer Praktiken ${ }^{24}$ den Körper als elementaren Bestandteil jedweder Praktik: Der Körper erscheint als ,Träger' bzw. ,Medium' des impliziten Wissens und Verstehens - durch Bewegung in Routinen bringt er implizite, gemeinsam geteilte Wissensordnungen zum Ausdruck (vgl. Schatzki 1996: 23; Reckwitz 2000a: 177ff). Dem Körper wird „als Speicher vergangener Praktiken sowie als Medium und Agens in gegenwärtigen Praktiken eine zentrale Rolle zu[erkannt]" (Schmidt 2012: 55). Durch entsprechend praktikentheoretisch angeleitete Analysen von Tätigkeiten, wie etwa das wissenschaftliche Arbeiten oder das Programmieren, die normalerweise als kognitive Domäne gelten (ebd.), wird zu zeigen versucht, dass der Körper auch in solchen Tätigkeiten entscheidend involviert ist (vgl. hierzu auch Wallenborn und Wilhite 2014: 57). Praktikentheoretiker*innen gilt der geschulte, trainierte (,skilled') Körper als zentrale Vermittlungsinstanz, als Schnittstelle von Geist/Verstand und Aktivität sowie von individueller Tätigkeit und Gesellschaft (Schatzki 2001: 12). Man könnte diesen gesamten Punkt auch mit Postill wie folgt zusammenfassen: "practice theory is a body of work about the work of the body" (Postill $2010: 8$, Hervorh. Im Original).

Die körperliche Komponente ist somit ein charakteristisches und wichtiges Merkmal sozialer Praktiken. Bezogen auf das Untersuchungsthema wurde bereits einleitend (vgl. Kapitel 1.5) auf die zentrale Bedeutung von

24 Reckwitz (2000b) spricht meist von „praxeologische[r] Kulturtheorie“ oder von den „Theorien sozialer Praktiken“ (vgl. auch Reckwitz 2004: 322). 
,Körperlichkeit' im Zusammenhang mit Heizen hingewiesen (vgl. auch Wallenborn und Wilhite 2014).

\subsubsection{Praktiken als untrennbar verknüpfte routinisierte Formen körperlicher Performances und sinnhafter Verstehensleistungen}

In sozialen Praktiken treten Handeln und Wissen stets gekoppelt auf. Jedwede Praktik enthält immer beide Elemente. Routinisierte Körperbewegungen und sinnhafte Verstehensleistungen gehören untrennbar zusammen:

"Ohne entsprechende Wissens- und Verstehensformen wären die Handelnden nicht dazu in der Lage, die entsprechende Gleichförmigkeit von Körperbewegungen (dies schließt intellektuelle ,ausgezeichnete' Bewegungen wie die des Sprechens oder Schreibens ein) hervorzubringen. Umgekehrt ist der Ort dieser kollektiven Wissens- und Verstehensformen nirgendwo sonst zu finden als in den ,öffentlichen' Verhaltensweisen: Wissensordnungen ,drücken' sich damit in Bewegungsmustern ,aus'." (Reckwitz 2004: 322)

Bei diesen in den praktischen Vollzügen zum Ausdruck kommenden Sinnmustern handelt es sich nicht primär um ein theoretisch-intellektuelles als vielmehr um ein praktisches Wissen und Verstehen. Damit ist gemeint, dass dieses praktisch-interpretative Wissen tief in der Handlungspraxis verwurzelt ist: Wir verfügen über dieses Wissen in der Praxis, das heißt wir wenden es wie selbstverständlich im Handeln an. Dies wird unter anderem erkennbar, wenn unsere Praktikenperformances in der Praxis auch wiederum von anderen Teilnehmer*innen erkannt und als kompetente Darbietungen entsprechender Tätigkeiten wahrgenommenen werden. Dies geschieht jedoch alles mehr oder weniger, stumm', das heißt, ohne dass dieses Wissen von den Akteuren expliziert werden müsste, weshalb manchmal auch von einem ,stillschweigenden Wissen ' die Rede ist, das in den Praktikenvollzügen zum Ausdruck kommt: „Die Praxistheorie betont die körperlich-leibliche Mobilisierbarkeit von Wissen, die häufig gar nicht mit einer Explizierungsfähigkeit oder Explizierungsbedürftigkeit dieses Wissens einhergeht“ (Reckwitz 2003: 290).

Körperliche Performances und sinnhafte Verstehensleistungen sind dabei untrennbar verwoben: Erkennen und Verstehen ist nur möglich, wenn sich mentale Schemata körperlich ausrücken. Und umgekehrt lassen sich (körperlich vollzogene) Routinen nur aufgrund der mentalen Sinnmuster, 
die ihnen zu Grunde liegen, erkennen und verstehen (Reckwitz 2000a: 178).

Diese untrennbare Verknüpfung von Körperlichkeit und Sinnhaftigkeit ist ein weiteres wichtiges Merkmal sozialer Praktiken und ihrer Analyse. Auf den konkreten Fall des Wohnraumheizens bezogen, ließe sich beispielhaft die Routine anführen, dass Thermostat heraufzuregeln, wenn der Raum als kalt wahrgenommen wird. Es werden hierbei nicht jedes Mal neu Überlegungen zur damit verbundenen Technik und ihrer Funktionsweise angestellt und auch für andere Familienmitglieder ist der körperliche Akt des Betätigens des Thermostats ohne verbale Erläuterung normalerweise verstehbar.

\subsubsection{Die besondere Betonung der Materialität sozialer Praktiken}

Während die Soziologie ,Materialität' im Allgemeinen bisher nur wenig Beachtung geschenkt hat - die materiellen Dimensionen gesellschaftlichen Lebens (Natur bzw. natürliche Gegebenheiten, Technik, Alltagsgegenstände) wurden von ihr traditionell entweder ausgeklammert oder lediglich als äußeres Beiwerk sozialer Akte begriffen -, werden aus praxistheoretischer Perspektive Dinge und Artefakte als wichtige und notwendige Bestandteile vieler bzw. der allermeisten Praktiken angesehen (vgl. Reckwitz 2003, 2004: 323). Wie (schon) körperliche und mentale Aktivitäten sind auch materielle Objekte und technische Artefakte so gut wie immer erforderlich, wenn es um die Betätigung menschlicher Akteure in Form von Praktiken geht: Eine Praktik zu vollziehen, impliziert sehr häufig den Gebrauch bestimmter Gegenstände auf eine ganz bestimmte Art und Weise (Reckwitz 2002b: 252f).

Die praxistheoretische Perspektive geht in ihrer Betrachtung von Gegenständen und Artefakten als integrale und konstitutive (Teil-)Elemente sozialer Praktiken noch einen Schritt weiter: So geht sie davon aus, dass in sozialen Praktiken Dinge und Artefakte häufig nicht nur auf kompetente Weise in Gebrauch genommen werden, sondern dass sie eine Voraussetzung für die Entstehung und Reproduktion bestimmter Praktiken sind (Reckwitz 2004: 323):

„not only human beings participate in practices, but also non-human artefacts form components of practices. The things handled in a social practice must be treated as necessary components for a practice to be "practiced". In fact, one can say that both the human bodies/minds and artefacts provide "requirements" or components necessary to a 
practice. Certain things act, so to speak, as "resources" which enable and constrain the specificity of a practice." (Reckwitz 2002a: 212)

Materielle Artefakte tragen somit zur Bildung sozialer Ordnung bei (vgl. Schmidt 2012: 63f). Es lässt sich daraus ableiten, dass Subjekt-Objekt-Zusammenhänge für die praxistheoretische Analyse sozialer Ordnungsbildung mindestens ebenso wichtig sind wie rein intersubjektive Beziehungen:

„The stable relation between agents (body/mind) and things within certain practices reproduces the social, as does the 'mutually' stable relation between several agents in other practices. Moreover, one can assume that most social practices consist of routinized relations between several agents (body/minds) and objects. At any rate, the social is also to be located in practices in which a single agent deals only with objects (besides, also in practices in which a single agent deals only with himself, with neither other subjects nor objects) and in this sense also the objects - television sets, houses and brownies - are the place of the social insofar as they are necessary components of social practices." (Reckwitz 2002b: 253)

In Abgrenzung zur ,Akteur-Netzwerk-Theorie‘ (ANT), die den Subjektstatus auf Objekte ausweitet und damit den Dingen und Artefakten Handlungsfähigkeit zuspricht, hält die Theorie sozialer Praktiken an einer ,asymmetrischen' Beziehung zwischen Artefakten und menschlichen Akteuren bewusst weiter fest (vgl. Reckwitz 2002a: 213f). Es besteht demnach aus „praxissoziologischer Perspektive zwischen den acts von Artefakten und dem doing von menschlichen Teilnehmern [weiterhin] ein entscheidender Unterschied: Artefakte und non-humans artikulieren ihre acts nicht" (Schmidt 2012: 69, Hervorh. im Original). Gemeint ist, dass Artefakte nicht selbst mitteilen bzw. indizieren (können), wie ihre Aktivität zu verstehen ist und was sie mit ihr anstreben. Die praxissoziologische Sicht auf das (Mit-)Wirken der Dinge in sozialen Zusammenhängen ist hier folgende:

„[S]ie [gemeint sind die Dinge, wie Objekte und Artefakte, JM] tragen nicht aus sich selbst, sondern nur im Zusammenspiel mit den menschlichen Teilnehmerinnen dazu bei, das soziale Geschehen, an dem sie beteiligt sind, als dieses oder jenes soziale Geschehen zu identifizieren und damit sinnhaft zu verwirklichen. Non-humans sind keine Träger impliziten Wissens, sie leisten keinen eigenständigen Beitrag zur sinnhaften Integration und zur Intelligibilität von Praktiken - solche Beiträge 
bleiben den teilnehmenden bumans vorbehalten" (ebd., Hervorh. im Original).

Anders als klassische Handlungstheorien wird in der Theorie sozialer Praktiken somit Materialität als Bestandteil von Praktiken gesehen, ohne eine Gleichsetzung von Dingen und menschlichen Akteuren vorzunehmen (vgl. Reckwitz 2004, 2002a: 213f). Dabei wird gesehen, dass Artefakte nicht beliebig einbezogen werden können, sondern dass die materiale Kultur der Artefakte die Ausgestaltung von Praktiken weitgehend bestimmen kann, ohne sie jedoch gänzlich vorzuschreiben (Reckwitz 2003: 291).

Darüber hinaus erhält ,Materialität ${ }^{\star}$ auch noch in Form von materiellen (naturalen und infrastrukturellen bzw. technischen) Rahmungen Einzug in praxistheoretische Betrachtungen. So spricht Schatzki vom Sozialen beispielsweise als "nexuses of practices and material arrangements“ (Schatzki 2010: 123). Unter solchen Arrangements versteht er ein ,Set von miteinander verbundenen Einheiten'(ebd.). Menschliche Akteure, materielle Artefakte und Organismen bzw. physische Teile der Natur bilden einen Zusammenhang, können dabei in diesem Gefüge changieren und unterschiedliche Bedeutungen annehmen (vgl. Brand 2011: 183). Schatzki beschreibt vier unterschiedliche Wege, wie diese Einheiten miteinander verknüpft sein können (vgl. Schatzki 2010: 139ff): Es kann erstens ein kausaler Wirkzusammenhang bestehen. Es kann zweitens ein Zusammenhang bestehen, der zukünftige Entwicklungen präfiguriert. Es kann drittens ein Zusammenhang dahingehend bestehen, dass die Einheiten konstitutive Voraussetzung für bestimmte Praktiken sind. Und viertens können die Elemente einen für die menschlichen Akteure sinnhaften Zusammenhang bilden, der ein Verstehen ermöglicht. Solche ,Arrangements` erhalten allerdings nur im praktischen Handeln Bedeutung.

Bleibt man eher bei den Begriffen ,Rahmung' und ,Rahmen', so sind damit meist der ,natürliche' Kontext, das ,Habitat' und/oder das materielle Setting gemeint, in dem sich bestimmte bzw. die zur Beobachtung ausgewählten sozialen Praktiken abspielen:

„Artefakte wie Gebäude, Wände, Türen, Fenster und Ähnliches stellen zunächst materielle Rahmen für Praktiken bereit, indem sie diese lokalisieren, umgrenzen und als operative Inseln, situierte Vollzüge oder als Interaktionen in exklusiver Ko-Präsenz von den Interferenzen des sozialen Prozesses isolieren." (Schmidt 2012: 64)

Auf die in dieser Arbeit interessierenden Heizpraktiken in Privathaushalten bezogen, sind demnach alle privaten Wohn- und Nutzräume wie Wohn-, Schlaf- und Arbeitszimmer, aber auch Küche, Bad und Flur, mit 
ihrer jeweiligen Möblierung sowie ihren jeweiligen technischen (Wärmeverteilungs-)Infrastrukturen konstitutiv. Zudem sind im Falle von Heizpraktiken meist auch noch etwas abgeschiedene oder ausgelagerte spezielle Technikräume oder der (Heizungs-)Keller relevant, in dem sich meist der Großteil der technischen Infrastruktur zur Beheizung sowie kontrollierten Be- und Entlüftung der Wohnräume befindet.

Das materielle Moment als ein wichtiges Merkmal sozialer Praktiken ist somit anschaulich verdeutlicht.

\subsubsection{Die Geschichtlichkeit und kulturelle Kontingenz sozialer Praktiken}

In praxistheoretischer Perspektive wird davon ausgegangen, dass soziale Praktiken und ihre Wissensgrundlagen immer eine ,Geschichte' haben etwa wie sie entstanden, sich verbreitet und etabliert haben oder wie sie auch wieder verschwunden sind. Aus praxissoziologischer Sicht lässt sich für jedwede soziale Praktik ein solcher, ihr eigener Entwicklungsgang nachzeichnen.

Aber aus praxistheoretischer Perspektive gibt es immer auch einen starken Gegenwartsbezug, einen ,Ereignischarakter' (Schmidt 2012: 52). Dabei ist entscheidend „dass es sich bei sozialen Praktiken um ein konkretes Geschehen handelt, das sich fortlaufend, immer wieder aufs Neue und immer wieder neu im Hier und Jetzt konkreter Gegenwarten vollzieht“" (ebd.: 51). Praxistheoretisch angeleitete Analysen nehmen ihren Ausgang in der Regel bei einer gegenwärtig sichtbaren Handlungspraxis. Gleichwohl geht die praxistheoretische Perspektive davon aus, dass soziale Praktiken nicht ,einfach so' aus dem Nichts heraus entstehen, sondern dass sie und ihre Wissensbasis stets Vorläufer und spezifische Ursprünge haben, die erst bzw. nur ex post beschrieben werden können. Die praxistheoretische Herangehensweise unterstellt nicht nur, dass es immer möglich ist, die jeweils spezifische Verlaufsbahn (,trajectory') einer sozialen Praktik sowie ihrer Wissensgrundlagen zu rekonstruieren, sondern der Nachvollzug der Historie erscheint ihr für ein umfassendes Verständnis und die sinnvolle Einordnung einer in der konkreten Gegenwart beobachteten Handlungspraxis geradezu unerlässlich.

Darüber hinaus werden soziale Praktiken als kulturell kontingent angesehen. Damit ist gemeint, dass soziale Praktiken, in der Form, wie sie gegenwärtig auftauchen und bestehen, immer (auf das engste) mit dem kulturellen Kontext, in dem sie auftauchen und entstanden sind, verbunden 
sind. Demzufolge können sie und das in ihnen zum Tragen kommende (implizite) Wissen nicht losgelöst von diesem kulturellen Kontext betrachtet, oder besser gesagt angemessen eingeordnet und verstanden werden (vgl. Reckwitz 2004: 323).

Für das Thema des Wohnraumheizens wird die hier vorliegende Arbeit unter anderem aufzeigen, dass umgenutzte Heizkörper in Passivhäusern nur aufgrund ihrer geschichtlichen (und kulturellen) Verankerung in vorausgegangenen Heizerlebnissen und Heizpraktiken sinnvoll ,entschlüsselt ${ }^{\star}$ werden können (vgl. Teilkapitel 4.1.1.5). Das Merkmal der Geschichtlichkeit sozialer Praktiken hat insgesamt dazu geführt, dass in dieser Arbeit ein systematischer Einbezug der Entwicklungsgeschichte häuslichen Heizens erfolgt (vgl. Teilkapitel 2.2.4).

\subsubsection{Die Stabilität und Wandel(barkeit) bzw. Offenheit sozialer Praktiken}

Ein weiteres Merkmal sozialer Praktiken ist, dass sie gleichzeitig relativ stabil und offen für Wandel sind. Gerade die Stabilität von Praktiken ermöglicht durch ihren repetitiven Routinevollzug Möglichkeiten für Wandel:

„Die Praxistheorien eröffnen eine andere Perspektive auf den ,Struktur'- und den ,Prozess'-Charakter des Handelns: Die Strukturiertheit des Handelns ist nun in der Routinisiertheit von Praktiken, die Prozessualität in der ,interpretative work' der Situation suchen [sic!], in denen interpretative Mehrdeutigkeit und damit das Durchbrechen von Routinen potentiell ständig möglich sind.“ (Reckwitz 2004: 323, Hervorh. im Original)

Durch ihre Repetitivität hat die alltägliche Handlungspraxis starken Routinecharakter und erscheint vollkommen selbstverständlich, in Wirklichkeit aber sind soziale Praktiken - da von einem spezifischen Know-how abhängig - höchst voraussetzungsreich. Denn der Vollzug sozialer Praktiken verlangt von den Praxisträger*innen gleichzeitig eine fortwährende Interpretationsleistung in der Aufeinanderfolge der Handlungen und Situationen (ebd.). Ein Durchbrechen der Routinen und damit die Destabilisierung der Struktur erscheint nun nicht mehr überraschend, sondern „[d]ie Entstehung neuer Handlungsformen und Sinnelemente, die ,Kreativität des Handelns' (Joas) erscheint dann vielmehr als Ergebnis der praktischen Problemlösung angesichts von interpretativer Mehrdeutigkeit und Unsicherheit in der Handlungssituation" (ebd.). Die Iteration von Handlungsvoll- 
zügen provoziert sozusagen immer auch Wandlungsoptionen. Das heißt, jede Praktikenperformance bzw. jedwede konkrete Handlungssituation trägt auch ein gewisses Potenzial in sich, kleinere oder größere Veränderungen hervorzubringen, die sich auf längere Sicht durchaus als stabil erweisen können. Daraus lässt sich ableiten, dass Anpassung und Wandel im Theorieansatz sozialer Praktiken grundlegend mitkonzipiert sind.

Das besondere Spannungsverhältnis zwischen fortwährender Reproduktion und gleichzeitig ständig möglicher Transformation sozialer Praktiken ist entscheidend im Hinblick auf die Beantwortung der in dieser Arbeit zentral behandelten Fragestellung. Es wird deshalb noch einmal in Teilkapitel 2.3.2 aufgegriffen, in dem es um (die) unterschiedlichen Formen von Praktikenwandel und deren absichtsvolle Initiierung geht, und dort ausführlich diskutiert.

Abschließend zu den dargelegten verschiedenen Merkmalen sozialer Praktiken lässt sich zum theoretischen Analysekonzept sozialer Praktiken mit Reckwitz zusammenfassend festhalten:

"A practice is thus a routinized way in which bodies are moved, objects are handled, subjects are treated, things are described and the world is understood. To say that practices are 'social practices' is indeed a tautology: A practice is social, as it is a 'type' of behaving and understanding that appears at different locales and at different points of time and is carried out by different body/minds." (Reckwitz 2002b: 250)

Diese höchst abstrakten, zum Teil philosophischen Betrachtungen und Überlegungen zu Praktiken können allerdings nicht einfach in die Praxis übertragen oder problemlos in empirischer Analyse umgesetzt werden.

Praxistheoretische Ansätze sind generell sehr abstrakt. Häufig wird mit stark idealisierten Annahmen und anspruchsvollen Konzepten gearbeitet. Derweil werden die genauen und tatsächlichen sozialen Prozesse, die für die Schaffung, Gestaltung und Reproduktion sowie Abwandlung von Praktiken eine Rolle spielen, in praxistheoretischen Betrachtungen oft nur vage mitbedacht. Dem Soziologen Alan Warde erscheint dies jedoch verständlich, waren die Hauptanliegen vieler Praxistheoretiker"innen (der ersten ,Generation') meist anderer Art. Demnach waren ihre Überlegungen von Anfang an eher metatheoretisch, denn empirisch ausgerichtet (vgl. Warde 2005: 135f). Warde sieht in der praxistheoretischen Perspektive neueren Ursprungs mit dem ausgearbeiteten Konzept ,sozialer Praktiken ${ }^{6}$ aber viel Potenzial, alltägliche Konsumaktivitäten sowie deren Implikationen, etwa für die Umwelt und das Klima, einmal alternativ in den Blick zu 
nehmen, als andere soziologische Ansätze dies bisher getan haben. Dies soll im Folgenden kurz dargestellt werden.

\subsubsection{Das Konzept sozialer Praktiken in der soziologischen Konsumforschung}

Die praxistheoretische Perspektive wurde in den vergangenen Jahren für die soziologische Konsumforschung neu entdeckt (siehe z.B. Gronow und Warde 2001b; Shove und Warde 2002; Warde 2005; Randles und Warde 2006; Shove und Pantzar 2005, 2007; Shove et al. 2009; Warde und Southerton 2012b; Shove und Spurling 2013). Die aktuelle Konsumforschung grenzt sich dabei gezielt von älteren praxistheoretischen Ansätzen ab. So begründet Warde in seinem wegweisenden Aufsatz des Jahres 2005 „Consumption and Theories of Practice“ (Warde 2005) die Abgrenzung von der ersten Welle praxistheoretischer Arbeiten - prominent vertreten durch Pierre Bourdieu (1977, 1984, 1990) und Anthony Giddens (1979, 1984, 1991) - mit deren geringeren Analysekraft für Alltagskonsumaktivitäten (vgl. Warde 2005: 136). Als äußerst nützlich für diesen Untersuchungsgegenstand erscheint Warde dagegen das von Schatzki vorgeschlagene Praktikenkonzept von Praktiken als koordinierte Einheiten, in dem sich Schatzki auf die Verbindungen zwischen den zu einer Praktik gehörenden,doings and sayings' konzentriert (Schatzki 1996: 89f, 2002). Warde greift diese Idee der Verlinkung von Schatzki für seine eigene Arbeit auf und befasst sich mit den Möglichkeiten, wie die verschiedenen, zu einer Praktik gehörenden Aktivitäten im Einzelnen zusammenhängen können und wie sie miteinander koordiniert sind (vgl. Warde 2005, 2013, 2016).

Für diese Arbeit ist die Erkenntnis Wardes zentral, dass ,Konsum' selbst keine eigenständige Praktik ist, sondern vielmehr „a moment in almost every practice“ (Warde 2005: 137) darstellt. Daraus lässt sich für eine praxissoziologische Analyse von Konsum als zentrale Annahme ableiten, dass die Menschen in ihrem Alltag in zahlreichen Praktiken engagiert sind: sie schlafen, kochen, essen, gehen einkaufen, arbeiten, hören Musik und treiben Sport. Praktiken sind für die Menschen bedeutungsvoll und sinnstiftend. ,Konsum' verstanden als Ressourcenverbrauch, der aus ökologischer und umweltsoziologischer Perspektive vorrangig interessant erscheint, kommt im Rahmen einer praxistheoretischen Betrachtung als Teilaspekt oder Nebenprodukt von praktischer Betätigung ins Spiel. Konsum ist den Praktiken bzw. dem praktischen Vollzug demnach untergeordnet und spielt in der Analyse somit eine nachrangige Rolle (Røpke 2009: 2490). 
Neben Warde ist es vor allem Elizabeth Shove, die den Ansatz sozialer Praktiken in der soziologischen Konsumforschung etabliert hat. Shove et al. haben den Praktiken-Ansatz nicht nur in zahlreichen empirischen Studien (zu nachhaltigem Konsum und weiteren Themen) angewendet, sondern in ihren praxistheoretisch orientierten Analysen haben sie den Praktikenbegriff auch konzeptionell weiterentwickelt, indem sie das Konzept sozialer Praktiken zur empirischen Anwendung konkretisiert haben. Sie verfolgen dabei das Ziel, den Ansatz sozialer Praktiken zu einem umfangreichen soziologisch fundierten Forschungsprogramm vor allem für nachhaltigen Konsum weiterzuentwickeln, was sich in einer großen Anzahl von Publikationen widerspiegelt (siehe hierfür u.a. Shove 2004a; Hand et al. 2005; Chappells und Shove 2005; Shove und Pantzar 2005, 2006, 2007; Hand und Shove 2007; Shove und Walker 2007, 2014; Shove et al. 2007; Shove et al. 2008; Shove et al. 2012; Shove und Spurling 2013).

Im Unterschied zu Warde legt Shove ein etwas anderes Praktikenkonzept zugrunde. Und zwar knüpft ihre Systematisierung stärker an die Definition sozialer Praktiken von Reckwitz an. Praxistheoretiker*innen, die den Ansatz sozialer Praktiken zur Analyse alltäglicher Konsumaktivitäten anwenden, gehen demzufolge von unterschiedlichen Praktikenbestimmungen aus.

Während einige Praktikentheoretiker*innen auf die Verbindungen (vorrangig innerhalb) von Praktiken fokussieren und demzufolge primär analysieren, was Praktiken (im Inneren) zusammenhält (vgl. Schatzki 1996, 2002; Warde 2005), gibt es eine zweite Gruppe, die sich schwerpunktmäBig mit der ,Brückenfunktion“ bzw. der vermittelnden Rolle von (Alltags-)Praktiken zwischen individuellen Lebensstilen und sozio-technischen Versorgungssystemen befasst (z.B. Spaargaren und Vliet 2000; McMeekin und Southerton 2012; sowie mehrere Beiträge in Southerton et al. 2004 und Vliet et al. 2005). Derweil gibt es noch einen dritten Vorschlag, das Konzept sozialer Praktiken für die Analyse alltäglicher Konsumaktivitäten zu aktivieren. Es handelt sich hierbei um die Idee, dass Praktiken aus verschiedenen Elementen bestehen (vgl. z.B. Reckwitz 2002b; Shove und Pantzar 2005; Gram-Hanssen 2010). Im Folgenden wird auf die letztgenannte Forschungslinie vertieft eingegangen, da an diese für die vorliegende Arbeit wesentlich angeknüpft wird.

In seinem richtungsweisenden Aufsatz „Toward a Theory of Social Practices" (Reckwitz 2002b) hat Reckwitz den Versuch unternommen, wesentliche Einflussgrößen bzw. Ingredienzien von Praktiken zu benennen, die er als ,Elemente' von Praktiken bezeichnet. Er schreibt hier: 
"A 'practice' [...] consists of several elements, interconnected to one other: forms of bodily activities, forms of mental activities, 'things' and their use, a background knowledge in the form of understanding, know-how, states of emotion and motivational knowledge. A practice - a way of cooking, of consuming, of working, of investigating, of taking care of oneself or of others, etc. - forms so to speak a 'block' whose existence necessarily depends on the existence and specific interconnectedness of these elements, and which cannot be reduced to any one of these single elements." (Reckwitz 2002b: 249f, Hervorh. im Original)

Eine Praktik erscheint hier als ein Gefüge von logisch und konsistent miteinander verknüpften, heterogenen Elementen. Auch wenn Reckwitz dies nicht explizit erklärt, so ist davon auszugehen, dass er mit dieser Aufzählung von Bestimmungsgrößen weder eine vollständige Liste aller Praktikenbestandteile liefert, noch gibt er eine Empfehlung, welche spezifischen Merkmalskategorien weitergehend zu untersuchen wären. Reckwitz diskutiert in seinem Aufsatz lediglich einige dieser zu Praktiken integrierten Elemente etwas eingehender, um aufzuzeigen, mit welcher Art von grundlegenden Fragen Praktikentheoretiker*innen beschäftigt sein sollten (vgl. ebd.: 250ff). Ein zentraler Aspekt auf der von ihm dargelegten praxistheoretischen Forschungsagenda ist die stärkere Beachtung und Miteinbeziehung von ,Materialität' bzw. ,Dingen“ (ebd.: 252) als ein konstitutives Element von Praktiken. So weist er ausdrücklich darauf hin:

„objects are necessary components of many practices [...]. Carrying out a practice very often means using things in a certain way. It might sound trivial to stress that in order to play football we need a ball and goals as indispensable 'resources'." (ebd.: 253)

In diesem Zusammenhang betont Reckwitz noch einmal explizit, dass aus (neuerer) praxistheoretischer Perspektive Subjekt-Objekt-Verhältnissen die gleiche Bedeutung beizumessen ist wie Subjekt-Subjekt-Beziehungen (vgl. ebd.), was nicht nur im Widerspruch zur allgemeinen soziologischen Literatur steht, sondern vor allem auch zu dem, was prominente Praxistheoretiker*innen der ersten Welle vorher behauptet hatten (vgl. etwa Bourdieu 1982; Giddens 1984).

Diese Erkenntnis, dass Gegenstände und technische Artefakte, Materialien jeglicher Art, im Rahmen von Praktiken eine wichtige Rolle spielen, findet Shove entscheidend. Ihre Argumentation baut wesentlich auf dem grundlegenden Argument auf, dass Dinge zur Ausführung von Alltagstä- 
tigkeiten fast immer erforderlich sind und praktische Aktivität, und somit auch Konsum, stets materiell vermittelt stattfindet.

Shove und Pantzar machen diesen Punkt ebenfalls als Forschungslücke in der bisherigen Literatur zu sozialen Praktiken aus: „there is a material dimension to practice that deserves and that is now beginning to receive attention in its own right" (Shove und Pantzar 2005: 44). Die Erkenntnis, dass insbesondere die Relation zwischen Materialien und Praktiken bisher kaum theoretisch behandelt wurde, nehmen sie daher zum Anlass und setzen sich das programmatische Ziel, den sozialtheoretischen Praktiken-Ansatz als empirisches Forschungsprogramm zu ,materialisieren' (ebd.: 45). Dafür knüpfen sie, wie dargelegt, an das von Reckwitz vorgeschlagene Praktikenmodell an, vereinfachen bzw. verschlanken dieses jedoch bewusst für empirische Zwecke.

Die konkrete Analyse und Diskussion von ,Nordic walking' als einer Praktik hat Shove und Pantzar (2005) darauf gebracht, einen bewusst gestrafften Ansatz zur Analyse von (Alltags-)Praktiken vorzuschlagen, der auf (nur noch) drei Kategorien von Elementen basiert, aus denen eine bzw. jedwede Praktik konstituiert ist (vgl. Shove et al. 2012: 24). Dies sind (vgl. Shove und Pantzar 2005: 46ff; sowie in konkret ausformulierter Form in Shove et al. 2012: 14, 23f):

- Materialien, einschließlich alles Physische und Dinglich-Greifbare, also Objekte und Artefakte, neue Technologien, Infrastrukturen, aber eben auch Körper (= leibliche Akteure),

- Kompetenzen, im Sinne von verkörperten Fähig- und Fertigkeiten sowie einem praktischen Know-how, und

- symbolische Bedeutungen und (Sinn-)Bilder, wozu sozial geteilte Deutungen und Verstehensweisen, kulturelle Konventionen, soziale Erwartungen, Wünsche, Zielsetzungen, usw. gehören.

Seither werden meist genau diese drei Begrifflichkeiten verwendet, manchmal werden auch noch andere, aber ähnliche Bezeichnungen gebraucht; dann ist etwa von Ausrüstungsgegenständen/Equipment, erlernten Techniken/Verfahrensweisen und Ideen/Sinndeutungen die Rede (vgl. z.B. McMeekin und Southerton 2007: 7-13; Røpke 2009: 2492). Demnach handelt es sich bei einer Praktik als Einheit um eine Reihe von körperlichmentalen Aktivitäten, die von Materialität, Kompetenz und Sinn getragen bzw. zusammengehalten werden; oder anders ausgedrückt: Eine Praktik stellt in diesem Verständnis eine jeweils spezifische Konfiguration unterschiedlicher Elemente dar, die den drei Sammelkategorien ,Materialien', ,Bedeutung(en $)^{6}$ und ,Kompetenz(en)' entstammen. 


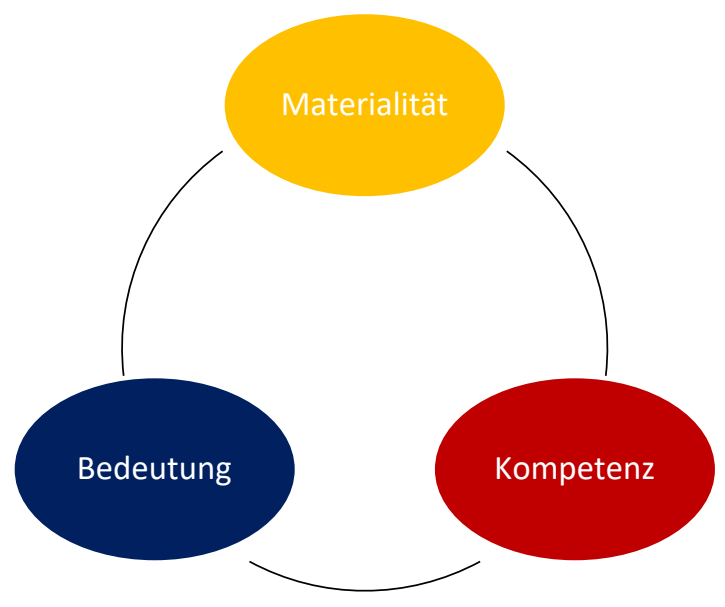

Vereinfachtes Praktiken-Modell (nach Shove et al. 2012):

Wichtig zu beachten ist, dass für die Bildung einer Praktik immer Elemente aus allen drei Kategorien erforderlich sind. In jeder Performance einer Praktik werden diese verschiedenen Elemente zusammengebracht. Es ist nicht möglich, eine Praktik zu performen, wenn nicht alle erforderlichen Elemente vorhanden sind. Alltagsaktivitäten sind nicht auf eine oder zwei dieser Komponenten reduzierbar. Die Verbindungen zwischen den verschiedenen Elementen werden von den Praktiker*innen hergestellt; sie integrieren die heterogenen Elemente zu einem sinnhaften Ganzen in ihren Praktikenperformances. Bei diesem Formungsprozess von Praktiken als erkennbar vorhandene Einheiten handelt es sich also um eine Art ,Verschweißen' von Aktivitäten zu sinnhaften Tätigkeitsvollzügen.

Jede der drei Praktikenkomponenten kann als eine breit angelegte Kategorie verstanden werden, die jeweils viele verschiedene Aspekte und Elemente abdeckt bzw. beinhaltet. Auch verfügen die Komponenten nicht über klare Grenzen, sie sind nicht immer eindeutig von- und gegeneinander abgrenzbar und teilweise sind sie auch verkörpert durch die Praktizierenden. Im Folgenden werden die drei Praktikenkomponenten kurz beschrieben und dabei wird auch auf Überschneidungen eingegangen (vgl. hierzu auch Teilkapitel 2.3.2.1 zu den Ausgangspunkten für Praktikenwandel).

Die Materialien-Komponente bezieht sowohl Gegenstände, technische Geräte als auch Körper(lichkeit) mit ein, die an der Performance einer Praktik beteiligt sind. Es kann sich sowohl um allgemeine als auch um spe- 
zifische Gegenstände handeln. Im Rahmen der Materialkomponente ähnelt der Körper einem ,Werkzeug', das für den Vollzug der Praktik benötigt wird. Der Körper steht aber genauso mit den anderen Komponenten in Zusammenhang, spielt auch für diese eine wichtige Rolle, etwa als verinnerlichtes Wissen oder praktisches Können, als körperliche Erfahrung sowie verkörperte Gefühle. Die Ausführung von Praktiken trägt zur Formung des Körpers mit bei: „Practice theorists [...] typically believe, further, that bodies and activities are 'constituted' within practices" (Schatzki 2001: 2).

Die Kompetenzen-Komponente umfasst die Kenntnisse und Fertigkeiten sowie das erforderliche Wissen, um die Praktik angemessen auszuführen. Die Fertigkeiten und Kenntnisse resultieren häufig aus gemachten Erfahrungen, sie sind durch (gezielte) Ausbildung sowie ständiges Üben (Handlungspraxis) erlernt. Mit der Zeit werden sie von den Praktizierenden mehr und mehr verinnerlicht, so dass sie als inkorporiertes, praktisches Wissen schließlich untrennbar mit ihnen als körperlich-mentale Akteure verknüpft sind. Ein Teil des Wissens und Könnens ist festgehalten und kodifiziert in offiziellen, formalen Vorschriften, Richtlinien und Grundsätzen, in Regeln und Anweisungen, wohingegen andere Wissensbestandteile implizit bleiben und lediglich in der Form eines unbewussten stillschweigenden Know-hows vorhanden sind. Bei manchen Kompetenzen handelt es sich um eher allgemeine Kenntnisse, in dem Sinne, dass sie im Rahmen vieler verschiedener Praktiken Anwendung finden, wie beispielsweise die Fähigkeit zu lesen und die zu schreiben. Andere Kompetenzen sind wiederum stärker spezialisiert, wie etwa das Beherrschen einer Fremdsprache oder das Spielen eines Instruments. Obwohl die Kenntnisse und Fertigkeiten von den Praktizierenden zum Teil stark verinnerlicht und somit stark mit ihnen als Individuen bzw. ihren persönlichen (Erfahrungs-)Werdegängen verknüpft sind, impliziert die praxistheoretische Perspektive, dass diese nicht als persönliche Eigenschaften der Praktizierenden, sondern als genuine Bestandteile der Praktik bzw. von Praktiken gesehen werden, die wiederum nur durch die Performances fortbestehen. Das heißt, nur, wenn ich regelmäßig heize und die zu Heizen gehörenden elementaren Aktivitäten wiederkehrend ausführe, behalte ich auch das Wissen, wie Gebäude bzw. Räume adäquat zu erwärmen sind und bleibt dieses Know-how mit mir als Person und meinem persönlichen Werdegang verknüpft. Somit sind (auch) die Kompetenzen sozial, in dem Sinne, dass sie (von vielen) geteilt werden bzw. viele Menschen über sie verfügen.

Bei der Bedeutungen-Komponente geht es darum, die Aktivitäten zu verstehen und Sinn in ihnen zu erkennen. Dies beinhaltet beispielsweise 
Vorstellungen davon zu haben, wozu bzw. wofür die zu einer spezifischen Praktik gehörigen Aktivitäten taugen, was man mit ihnen beabsichtigt oder warum sie als problematisch gelten (können). Darüber hinaus beinhaltet die Bedeutungen-Komponente die mit den jeweiligen Tätigkeiten verbundenen Gefühle und Empfindungen, die Ansichten und Überzeugungen sowie ein einvernehmliches Verstehen. Auch die Bedeutungen und Sinngehalte können insofern generischer Art sein, als sie Teil vieler verschiedener Praktiken sind. So spielt die Idee der, Gesundheit' in vielen verschiedenen Praktiken eine zentrale Rolle: Sportlich aktiv zu sein, beispielsweise Schwimmen oder Joggen gehen, wird als ,gesund' erachtet; genauso werden ein hoher Obst- und Gemüsekonsum sowie ausreichender Schlaf und Entspannungspausen als, gesund' beurteilt. Der bzw. die Praktizierende wird zum bzw. zur Träger*in bestimmter prktikenbezogener Überzeugungen, Empfindungen, sowie spezifischer Intentionen und Zwecke bei der Durchführung einer bestimmten Praktik. Auch hier gilt wieder, dass die einzelnen Bedeutungsaspekte als ,zur Praktik gehörig ' begriffen werden, statt als aus eigenständig handelnden Individuen hervorgehend betrachtet. Dies verdeutlicht, inwiefern Sinngehalte und Bedeutungszuschreibungen als soziale Phänomene zu verstehen sind (vgl. Reckwitz 2002b: 252).

Während die in Kapitel 2.1.4 dargelegten sechs charakteristischen Merkmale sozialer Praktiken eher eine theoriegeleitete Annäherung an Praktiken darstellen, ist das hier vorgestellte Drei-Elemente-Modell ein reduktives Schema für die empirische Analyse sozialer Praktiken.

Die hier vorliegende Untersuchung von Heizpraktiken in Privathaushalten orientiert sich an diesem von Shove und Pantzar (2005) erstmals vorgeschlagenen und in weiterer intensiver Forschungszusammenarbeit mit noch anderen Kolleg*innen weiter ausgearbeiteten Konzept der drei elementaren Komponenten. Dafür gibt es im Wesentlichen drei Gründe: Erstens ist aus einer forschungspragmatischen Sicht dieses vereinfachte Analyseschema sehr gut anwendbar und trotzdem durchdacht. Es gilt die von Shove et al. selbst formulierte Einschränkung bezüglich solch eines forschungspragmatischen Vorgehens (vgl. Shove et al. 2012: 15): Sie räumen ein, dass es durchaus möglich ist, dass es sich bei ihrem Praktikenschema um ein stark vereinfachendes bzw. abstrahierendes Modell zur Beschreibung von Sozialleben handelt. Gleichzeitig argumentieren sie aber, dass mit diesem simplifizierten Konzept (die das Sozialleben wesentlich bestimmenden Prozesse von) Stabilität und Wandel praxistheoretisch sehr gut zu konzeptualisieren sind, und zwar deswegen, weil sich mittels ihres vereinfachenden Elemente-Ansatzes das permanent rekursive Verhältnis zwi- 
schen ,practice-as-performance“ und ,practice-as-entity ' hervorragend erfassen lässt (ebd.). Auf diesen Punkt kommt es bei einer praxistheoretischen Untersuchung von (Praktiken-)Veränderungsprozessen meines Erachtens wesentlich an, weshalb in Kapitel 2.3.2, in dem es um die theoretische Konzeption von Praktikenwandlungsprozessen geht, noch einmal genauer auf die Unterscheidung zwischen der , practice-as-entity' und der ,practiceas-performance eingegangen sowie deren wechselseitige Beeinflussung aufgezeigt wird.

Der zweite Grund für die Arbeit mit dem vereinfachten Praktikenschema von Shove et al. ist, dass dieses Drei-Komponenten-Modell mittlerweile schon erprobt ist. Insbesondere im Nachhaltigkeitsbereich wurde das Elemente-Modell bereits vielfach von Shove et al. erfolgreich angewendet (vgl. etwa Shove und Pantzar 2006, 2007; Pantzar und Shove 2006, 2010; Shove 2010a, 2010b, 2014; Shove et al. 2012). Für Forschungen zu nachhaltigem Konsum haben die praxistheoretisch orientierten Arbeiten Shoves (et al.) mittlerweile zentrale Bedeutung erlangt, und an die in diesen zahlreichen Untersuchungen erzielten Ergebnisse lässt sich mit dieser Arbeit hervorragend anknüpfen. Bei dem von Shove auf der Ebene von Alltag und Konsum verfolgten Ansatz (z.B. Shove 2003; Shove et al. 2007) steht die (generelle) Frage im Mittelpunkt,

„wie sich ,Normalitätsstandards ${ }^{6}$ bestimmter Konsumpraktiken in der Verknüpfung von neuen Geräten, Techniken und Materialien, von ökonomischen Interessen und politischen Regulierungsinstanzen, von infrastrukturellen Systemen, sozialen Alltagsarrangements und kulturellen Erwartungsstandards ko-evolutionär herausbilden." (Brand 2011: 184f)

So ist davon auszugehen - und erste Untersuchungen haben dies bestätigt -, dass „[d]ie sozio-technischen Kopplungen je nach Gegenstandsbereich (Einführung von Klimaanlagen, Waschmaschinen und Convenience-Produkten; Verbreitung von Automobilität etc.) andere Muster und Dynamiken auf[weisen]“ (ebd.: 185). Dementsprechend lässt sich daraus die von Brand treffend formulierte methodische Forderung ableiten,

"die für die jeweiligen Handlungsfelder typischen sozio-materiellen Verknüpfungen und Konsumdynamiken zu rekonstruieren, um effektive Ansatzpunkte für eine Veränderung von Konsumpraktiken identifizieren zu können.“ (ebd.)

Diese Analyse ist für das Handlungsfeld ,alltägliches Heizen' in Privathaushalten in detaillierter Form bislang noch nicht erfolgt - insbesondere der 
Wandel von Heizpraktiken beim Übergang von konventionellen zu modernen Wohnkontexten wurde bisher wenig aus praxistheoretischer Perspektive untersucht (siehe aber bezüglich des Heizens allgemein GramHanssen 2010, 2011; bezüglich neuer Wohnkontexte siehe Foulds et al. 2012; Foulds 2013; Hargreaves et al. 2015; Hargreaves et al. 2016 sowie in Ansätzen Nyborg und Røpke 2011; Sonnberger und Zwick 2016). Diese Forschungslücke soll mit der vorliegenden Arbeit geschlossen werden.

In dieser Forschungsarbeit geht es folglich darum, die für das private Wohnraumheizen typischen sozio-technischen Kopplungen von Heizungsund/oder kompakten Lüftungsanlagen, Heizkörpern, Wohnraummanagern bzw. Touchpads, von (fossilen und/oder regenerativen) Wärmeenergieträgern, von Energieversorgungsinfrastrukturen, von Raumnutzungsund Lüftungsgewohnheiten, von Anwesenheits- und Abwesenheitszeiten, von Thermostateinstellungen, von sozialen Behaglichkeitsvorstellungen und individuellen Wohlfühltemperaturen, usw. aufzuzeigen sowie die daraus resultierenden Energieverbrauchsdynamiken nachzuvollziehen, um auf dieser Basis mögliche effektive Ansatzpunkte für eine Veränderung des alltäglichen Heizgeschehens in Richtung ,Nachhaltigkeit‘ identifizieren zu können.

Und drittens wird mit dem Elemente-Ansatz als leitendes Analyseschema noch einmal unmissverständlich zum Ausdruck gebracht, wo eine praxistheoretisch angeleitete Analyse sämtlichen Sozialgeschehens grundsätzlich ihren Ausgang nimmt:

„This 'elemental' approach is unusual in provisionally de-centring the human actor (as integrator) but it is, at the same time, consistent with the argument that in the moment of doing, practitioners (those who do) simultaneously reproduce the practices in which they are engaged and the elements of which these practices are made. [...]. By paying attention to the trajectories of elements, and to the making and breaking of links between them, it is, we suggest, possible to describe and analyse change and stability without prioritizing either agency or structure." (Shove et al. 2012: 22)

Damit hebt sich die praxistheoretische Perspektive mit ihren grundsätzlichen Konzeptionen, beispielsweise vom menschlichen Akteur, von Handlung und Struktur, von sozialer Sinngebung, sozialer Ordnung(sbildung) und Wandel, sowohl von handlungs- als auch von strukturtheoretischen Ansätzen deutlich ab, die für gewöhnlich zur Erforschung von Alltagskonsumaktivitäten angewendet werden. 
Was dieses reduktive Praktikenschema in der konkreten Anwendung auf die Alltagstätigkeit des Heizens bedeutet, wird in den nun folgenden zwei Teilkapiteln (2.1.6 und 2.1.7) erläutert.

\subsubsection{Konsum als (Neben-)Folge von Praktikenvollzügen}

In diesem Abschnitt werden noch einmal kurz die grundlegenden Implikationen einer praxistheoretischen Perspektive für das Verständnis sowie die Analyse von Konsum erörtert. Im Weiteren geht es dann etwas spezifischer um den Energiekonsum im Rahmen von Alltagsaktivitäten in Privathaushalten. Energie(verbrauch) stellt hier den ,Link ${ }^{6}$ zur Umwelt und zum Klima dar, da der Verbrauch fossiler Energieressourcen mit erheblichen negativen Konsequenzen für die natürliche Umwelt und das Klima verbunden ist.

Aus praxistheoretischer Sicht ist Konsum ein Teilaspekt bzw. Bestandteil von Praktiken und erfolgt demnach im Rahmen von Praktiken. Das heißt, im Vollzug der meisten Praktiken ist in irgendeiner Form ,Konsum erforderlich und vermutlich haben fast alle Praktiken den Ge- und/oder Verbrauch von Gütern und Diensten zur Folge, ganz gleich, ob diese Praktiken nun als zur Produktion oder Konsumtion gehörig eingestuft werden. Gewöhnlich wird der Umwandlungs- bzw. werden der Verarbeitungs- und Veredlungsprozess von Ressourcen und Zwischenprodukten für nutzenbringende Zwecke als ,Produktion' bezeichnet, während der endgültige Verbrauch und der Abbau nützlicher Produkte als ,Konsumtion' verstanden werden. Zum Teil deckt sich diese Unterscheidung mit der Trennung zwischen den Gesellschaftsbereichen ,Wirtschaft ${ }^{\star}$ bzw. dem Unternehmenssektor und ,privaten Haushalten'. In diesem Verständnis wird ,Konsum' häufig einseitig dem Sektor der privaten Haushalte zugeordnet und dann mit ,Nachfrage‘ oder ,Bedarf‘ an Gütern gleichgesetzt. „,B]ut productive activities also take place in households, and activities usually considered to be consumption also occur at the workplace“ (Røpke 2009: 2495). Produktion und Konsumtion lassen sich aus praxistheoretischer Perspektive nicht eindeutig gegeneinander abgrenzen. In der praxistheoretischen Forschungslogik wird vielmehr davon ausgegangen, dass beinahe alle Tätigkeiten sowohl produktive als auch konsumtive Momente enthalten und dementsprechend Konsum(aktivität) in allen Gesellschaftsbereichen zu finden und zu verorten ist: „Consumption cannot be reduced to demand, requiring instead its examination as an integral part of most spheres of daily life" (Warde 2005: 137). 
Praxistheoretisch wird ,Konsum“ als ein sozialer Prozess aufgefasst, „whereby agents engage in appropriation and appreciation, whether for utilitarian, expressive or contemplative purposes, of goods, services, performances, information or ambiance, whether purchased or not, over which the agent has some degree of discretion" (ebd.). Allerdings wird in dieser Auffassung Konsum nicht als (eine) distinkte, vollkommen unabhängige und eigenständige Aktivität begriffen, sondern als stets in Praktiken eingelagert konzipiert (vgl. ebd.). So kommt beim Vollzug der Praktik des,Autofahrens' in jedem Falle ein Auto zum Einsatz. In diesem Prozess werden sowohl das Fahrzeug als auch Straßen (ab-)genutzt, genauso wird Benzin verbraucht. Die Praktizierenden engagieren sich in der Praktik, um sich fortzubewegen oder um etwas zu transportieren. Dass im Zuge dessen auch Sachgüter genutzt und Ressourcen verbraucht werden, ist für sie meist zweitrangig. Dennoch sind diese Gegenstände und Betriebsmittel zwingend erforderlich, um die Praktik (z.B. des Autofahrens) zu vollführen. Hier wird auch verständlich, warum sich Konsum nur unzureichend auf Basis rationaler Entscheidungsmodelle erklären lässt: So hängt etwa die für die Fahrtstrecke benötigte Spritmenge entscheidend davon ab, welches Auto dem Praktizierenden zur Verfügung steht. Wieviel Benzin dann letztendlich für die Fahrt verbraucht wird, hängt zudem vom Fahrtstil des bzw. der Fahrzeugführenden, den Verkehrsverhältnissen und der Großwetterlage sowie von der Beschaffenheit der Strecke ab. Fakt ist allerdings, dass das Auto ohne Benzin gar nicht fährt und im Prozess des Autofahrens immer auch Benzin verbrannt wird.

Eine praxeologische Betrachtung fokussiert demzufolge nicht direkt auf den Gebrauch von Gegenständen oder den Verbrauch von Ressourcen, sondern ist stattdessen auf die Praktiken konzentriert, mit denen (der) Konsum (von Sachmitteln und Ressourcen) einhergeht. Konsum erscheint in dieser Forschungslogik vielmehr als Konsequenz von Praktiken und wird somit als Praktiken nachgeordnetes Phänomen in den Blick genommen:

„We see practices as preceeding individuals, consumption and lifestyle, on the one hand, and preceeding systems of provision on the other. This suggests that the basic ontological unit for analysis is the practice." (Randles und Warde 2006: 223) 
2.1.7 Energie als ein Bestandteil sozialer Praktiken und Energiekonsum als Nebenprodukt praktischer Vollzüge

Um zu entscheiden, welche Praktik bzw. welche alltäglichen Aktivitäten im Rahmen dieser Arbeit von Interesse sind, ist es wichtig, zunächst zu spezifizieren, um welche Art des Konsums bzw. um welches Verbrauchsgut es geht. Diese Arbeit hat umwelt- bzw. klimarelevanten Konsum zum Gegenstand. Der Ausgangspunkt ist der private Konsum von Gütern und Diensten, der sich ganz erheblich negativ auf die Umwelt auswirkt und die globale Erwärmung antreibt. Dabei läuft die Verbindung zwischen Praktiken und der Umwelt bzw. dem Klima(wandel) grundsätzlich über die Materialien-Komponente - über die Produktion, den Ge- und Verbrauch sowie die Entsorgung all der Roh- und Werkstoffe, Gerätschaften und Infrastruktureinrichtungen, die zur praktischen Durchführung betreffender Tätigkeiten benötigt werden. Diese Arbeit beschäftigt sich mit dem Konsum fossiler Energieressourcen, weil bei der Verbrennung fossiler Energieträger wie Erdöl oder -gas große Mengen klimaschädigender Treibhausgase freigesetzt werden. Dies hat zu der Entscheidung geführt, in dieser Arbeit besonders energieintensive Aktivitäten von und in Privathaushalten genauer zu analysieren. Häusliche Aktivitäten sind in der Hinsicht umwelt- und klimawirksam, als dass die Praktizierenden beim Vollzug zahlreicher Alltagstätigkeiten indirekt (auch) große Mengen an Energie verbrauchen. Es sind vor allem banal erscheinende Routineaktivitäten, wie etwa das alltägliche Duschen, Wäschewaschen, Kochen, Heizen, Kühlen, Beleuchtung, Fernsehen oder am Computer arbeiten, auf die der Großteil des Energieverbrauchs in Privathaushalten entfällt. Viele der häuslichen Alltagsaktivitäten, mit denen ein substanzieller Energieverbrauch einhergeht, werden von den Praktizierenden meist unreflektiert, das heißt ohne großes Überlegen und bewusstes Entscheiden, also routinemäßig vollzogen (vgl. Shove 2012: 110).

Obwohl diese Routinetätigkeiten unter ökologischen Gesichtspunkten besonders interessant und relevant erscheinen, standen sie bislang selten im Fokus konsum- und umweltsoziologischer Forschung. Bisher hat sich die soziologische Konsumforschung übermäßig den ,spektakulären' und sichtbaren Aspekten von Konsumaktivität zugewendet. So waren konsumsoziologische Studien fast ausschließlich mit Phänomenen wie Musikgeschmack, Kleidermoden, dem privaten Kauf von Autos und Einrichtungsgegenständen befasst; und die Aufmerksamkeit war vor allem auf kulturellen Konsum, wie beispielsweise Theater-, Musical- und Museumsbesuche gerichtet. Diese einseitige Fixierung auf ,schillernde`, eher außergewöhnli- 
che Konsumereignisse hat dazu geführt, dass ein großer Teil des aus ökologischer Sicht substanziellen Konsums zu wenig beachtet wurde - Praktiken, die vielleicht weniger auffallend und sichtbar, für die Alltagsgestaltung der Menschen aber mindestens genauso relevant sind. Dazu gehören alltägliche Verrichtungen wie der Konsum von Lebensmitteln, der tägliche Gebrauch von Klimaanlagen, Heizungen und Kühlschränken, die morgendliche Dusche oder das Radiohören beim Frühstück (vgl. Gronow und Warde 2001a: 1-4). Diese meist völlig banal erscheinenden Alltagsaktivitäten folgen jedoch einer anderen Logik als es die demonstrativen und symbolisch aufgeladenen Konsumformen tun und sie erfordern dementsprechend auch eine spezifische, ihrer Charakteristik angemessene Herangehensweise in der Analyse (vgl. Warde und Southerton 2012a: 6).

Etwa zu Beginn der 2000er Jahre hat sich in der soziologischen Konsumforschung deswegen eine Art Gegenbewegung zur ,Mainstream'-Forschung gebildet, deren Vertreter"innen propagieren, dass es notwendig ist, den unscheinbaren Alltagskonsum zu verstehen und zu erforschen. Diese Forschung firmiert unter dem Schlagwort „ordinary consumption“ (Gronow und Warde 2001b) oder ,inconspicuous consumption“ (Shove und Warde 2002).

„[T]he idea of ordinary consumption refers to those items and practices which are neither highly visible nor in any way special and which often stand in a subsidiary relation to some other or primary or more conscious activity.” (Gronow und Warde 2001a: 4)

,Gewöhnlicher Konsum' lässt sich demnach am besten mit Konzepten wie Routine, Gewohnheit, notwendige Randbedingung, Nebenfolge usw. erfassen und beschreiben. Gleichzeitig wird mit diesem Ausdruck der konventionelle Charakter des Konsums deutlich betont. In dieser Sicht wird angenommen, dass ,Konsum' ebenso auf Gewohnheit wie auf bewusster Entscheidung und Wahl basieren kann (vgl. Warde und Southerton 2012a).

„By considering consumption behaviour as 'conventional', it is implied that people mostly consume in a rather routine, habitual, unreflective way, in accordance with sets of shared aspirations, requirements and expectations." (Randles und Warde 2006: 227)

Nicht jede Konsumaktivität lässt sich gleichermaßen gut mithilfe solch einer Konventionenperspektive analysieren. Für eine Analyse alltäglichen Energiekonsums in Privathaushalten scheint diese Betrachtungsweise 
gleichwohl in besonderer Weise geeignet zu sein, was im Folgenden genauer begründet wird.

\section{Das besondere ,Konsumgut‘ Energie und der, gewöhnliche Konsum'von Energie}

Der Verbrauch von Energie unterscheidet sich in signifikanter Weise vom Kauf und Gebrauch alltäglicher Konsumgüter wie etwa Kleidung und Einrichtungsgegenstände, die häufig unter der Perspektive des symbolischen und des demonstrativen Konsums analysiert worden sind. Energie wird zwar als notwendiger Einsatzfaktor, jedoch als eine insgesamt ,unspektakuläre' Ressource betrachtet: „[Energy] is hardly a product to be proud of, to show around, or to worry about" (Fischer 2008: 80). Oder wie Shove und Warde es ausdrücken: „Water quality is more or less standardized as is the 'quality' of electricity, so there are no distinctive edges to play with in that respect" (Shove und Warde 2002: 239f). Ihrer Ansicht nach hängt das damit zusammen, dass Energie(konsum) außerordentlich vielfältig, meist nicht unmittelbar ersichtlich bzw. erkennbar ist und dadurch schwer durchschaubar erscheint (vgl. ebd.: 240).

Energie wird meist routinemäßig, ,nebenbei' konsumiert. Dass die Praktizierenden ihren Energiekonsum im Alltag oftmals nicht bewusst steuern und kontrollieren, ist demnach darauf zurückzuführen, dass ihr Energieverbrauchsverhalten größtenteils auf alltäglichen Routinen beruht (vgl. Guy und Shove 2000; Shove und Chappells 2001; Lutzenhiser 2002: 348f; Shove 2003: 395f).

Energieflüsse sind in den modernen Industriegesellschaften allgegenwärtig: in den Lebensstilen, in den alltäglichen Mustern der Kommunikation und Interaktion, in den Produktionsstrukturen und im alltäglichen Konsum sowie in den umfassenden Mobilitäts- und Reisemustern (vgl. auch Rosa et al. 1988: 149; Lutzenhiser 2002: 348). Dies hängt neben dem konventionellen Charakter auch mit den besonderen ,Eigenschaften' des alltäglichen ,Konsumgutes' Energie zusammen: Energie ist abstrakt, im Sinne von ,gegenstandslos, sie ist unsichtbar und physisch nicht direkt (an-)fassbar (vgl. Shove 1997b).

Dazu kommt, dass die meisten Hinweise auf Energieflüsse in modernen Gesellschaften aktiv verborgen werden: Die Orte und Anlagen zur Energiegewinnung und -produktion liegen für gewöhnlich weit weg von den Stellen der Endnutzung. Aber auch die Elemente der Energiesysteme wie etwa Verteilerwerke oder Steuerungszentralen stehen abgesondert in Industriegebieten, Randbezirken oder Vororten. Gleiches gilt für die Wohnstätten der Menschen: Hier verlaufen die Kabel und Leitungen der Elektrizitäts-, 
Gas- und anderer Versorgungssysteme hinter Wänden, unter Fußböden und über den Zimmerdecken. Selbst die Stromzähler befinden sich zumeist versteckt im Keller oder in der Abseite - sorgfältig vor dem täglichen Anblick verborgen (Lutzenhiser 2002: 349).

Darüber hinaus wird Energie von den Menschen nicht direkt, sondern indirekt konsumiert, wie beispielsweise als Raumheizung oder Beleuchtung, oder in Form bestimmter Leistung(en), etwa als laufender Kühlschrank oder betriebener Computer (Shove und Chappells 2001: 48, 57). Daraus lässt sich folgern, dass die Menschen nicht an Energie an sich interessiert sind, sondern an den Leistungen und Diensten, die ihnen der Einsatz des Betriebsmittels Energie ermöglicht: „consumers do not consume resources, they consume the services those resources make possible. In buying electricity, consumers are really buying lighting, heating, comfort and convenience and more" (Southerton et al. 2004: 5).

Ins Bewusstsein gelangt das Thema ,Energiekonsum' meist durch Irritationen, etwa wenn die Heizung ausfällt oder wenn die jährliche Heizkostenabrechnung deutlich angestiegen ist (vgl. ebd.).

Heute findet sich im Haushalt für eine Vielzahl an Aktivitäten ein entsprechendes Gerät, das mithilfe von Energie, meist in Form von Elektrizität, betrieben wird: „In practice, people use things that depend on energy consumption: refrigorators, fan heaters, fluorescent light, and so on" (Shove und Warde 2002: 240). Alltagstechnologien wie Heizung und Beleuchtung und elektronische Haushaltsgeräte wie Kühlschrank oder Toaster bestimmen demzufolge mit, wie und in welchem Umfang Energie im Haushalt verbraucht wird (Shove et al. 2007; Shove und Walker 2014: 55; Gerber et al. 2012). Die energiebetriebenen technischen Geräte zählen zu den ,klassischen' auffälligen und sichtbaren Konsumgütern, auf die die soziologische Konsumforschung und umweltsoziologische Untersuchungen aus den oben genannten Gründen bisher überwiegend ihre Aufmerksamkeit gerichtet haben.

Die Analyse des privat-häuslichen Energieverbrauchs als ,ordinary consumption' erscheint noch aus einem weiteren Grund sinnvoll: Der unscheinbare, indirekt-vermittelte und in Routinetätigkeiten eingebettete Energiekonsum in Privathaushalten wird ein Problem in Hinblick auf Nachhaltigkeit, weil dieser für große Mengen an klimaverändernden $\mathrm{CO}_{2}$-Emissionen verantwortlich ist.

Energieverbrauch in Privathaushalten ist einerseits eingebettet in unscheinbare Alltagsroutinen wie beispielsweise die tägliche Dusche am Morgen, das mehrmalige Wäschewaschen pro Woche oder die durchgehende Inbetriebnahme von Klimaanlagen. Andererseits wird der häusliche Ener- 
giekonsum in modernen Gesellschaften wesentlich durch gesellschaftliche Konventionen und Normen bestimmt. Als Konventionen werden solche Verhaltensmuster bezeichnet, die allgemeinen gesellschaftlichen Erwartungen entsprechen. Bei Normen handelt es sich ebenfalls um sozial akzeptierte und relativ konkrete, aber dennoch informelle Verhaltensstandards oder -regeln. Normen können zudem formalen Charakter haben bzw. annehmen. Dann erscheinen sie als verbindliche Vorschriften, die das Sozialverhalten konkret regeln (z.B. Gesetze und Vorschriften).

Es gibt einige weit verbreitete Erwartungsstandards, die sich entscheidend auf die Inanspruchnahme von Energiedienstleistungen auswirken. So liegt die als ideal und angemessen empfundene Innentemperatur im Sommer bei etwa 21 Grad Celsius und 22 bis 23 Grad Celsius im Winter - Erwartungsstandards, die in hiesigen Breiten häufig nur durch den intensiven Einsatz von energienutzenden Technologien erreichbar sind (vgl. Shove 2003; Chappells und Shove 2005; Shove et al. 2008; Shove 2014: 421). Eine weitere konventionelle Vorstellung ist, dass mittels Raumwärme und intensivem Licht bzw. besonderer Beleuchtung im Haus eine gemütliche Atmosphäre geschaffen wird (vgl. Wilhite und Lutzenhiser 1999). Alle diese gesellschaftlichen Konventionen und Normen bedingen Verhaltensmuster, die mit enormem Energieverbrauch verbunden sind (vgl. Wilhite et al. 2000: 116). Demnach haben soziale Konzepte von Komfort, Annehmlichund Bequemlichkeit sowie Vorstellungen davon, was zu einem ,normalen Leben' gehört, einen erheblichen Einfluss darauf, wie energieintensiv die alltäglichen Praktiken sind (vgl. Wilhite und Lutzenhiser 1999; Shove 2003, 2004b: 1062).

Durch das Engagement in Praktiken kommt zum Ausdruck, welchen Konventionen die Praktizierenden folgen. Allerdings determinieren Konventionen die Praktiken nicht vollkommen, sondern die konkrete Art und Weise der Praktikenausführung ist entscheidend. Beispielsweise kann man, wenn man in den eigenen Wohnräumen leicht friert, entweder die Heizung aufdrehen oder sich einen Pullover anziehen. Oder eine gemütliche Wohnatmosphäre lässt sich mittels aufwendiger Beleuchtung(stechnik) oder auch mit einfachem Kerzenlicht erzeugen. Es stehen meist mehrere Handlungsalternativen zur Wahl und mit diesen verschiedenen Aktivitäten verbinden sich meist jeweils bestimmte Deutungen, spezifische Fertigkeiten sowie ein besonderes Know-how und Equipment. Auch ist wichtig, über welche praktischen Kompetenzen die Praktizierenden verfügen; ob sie beispielsweise wissen, wie entsprechende technische Geräte, wie z.B. moderne Heizungs- und Lüftungsanlagen effizient zu nutzen sind. Denn die Energiedienste und dementsprechend der Energieverbrauch sind in die 
kontinuierliche Ausführung und damit Reproduktion dieser alltäglichen Vollzüge eingebunden.

Demzufolge ist die Perspektive zu erweitern: Statt eng auf Energie und Energieverbrauch zu fokussieren, gilt es den Blick zu weiten und auf den Konsum von Energiedienstleistungen zu schauen (vgl. Wilhite et al. 2000: 115). Mit anderen Worten: „it is the outputs that energy consumption makes possible that should be the focus of attention" (Shove und Warde 2002: 240; vgl. auch Shove und Walker 2014). Es sind vor allem tagtäglich in Anspruch genommene Energiedienstleistungen wie Raumheizung, Beleuchtung und ,Meta-Energiedienste' wie Komfort und Behaglichkeit (Wilhite et al. 2000: 115) für die die meiste Energie im Alltag aufgewendet wird. Sie sind dabei eingebunden in zahlreiche Alltagsaktivitäten wie Kochen, Wäschewaschen und das allgemeine Temperieren von Wohnräumen. Dies sei abschließend noch einmal mit einem prägnanten Zitat verdeutlicht:

„The demand for energy is from this perspective a secondary outcome of demands for energy services, which are in turn a consequence of how everyday practices are constituted and performed." (Walker 2014: 50)

Das heißt, auch wenn man vom Energieverbrauch her argumentiert, gelangt man wieder zu den Praktiken - sie sind der Dreh- und Angelpunkt des ,normalen“ alltäglichen Geschehens. Praktiken bilden somit die Schnittstelle von infrastrukturellen Systemen, (Haushalts-)Geräten, Techniken und Materialien (wie z.B. Energieressourcen), sozialen Alltagsarrangements sowie gesellschaftlichen Konventionen und Normalitätsstandards. Energieverbrauchsmuster werden hervorgebracht durch historisch spezifische Verknüpfungen von Technologien und Praktiken sowie Konstellationen von Praktiken (vgl. Shove und Walker 2014: 49).

Möchte man Näheres über den Konsum von Energie erfahren, wird man sich ausführlich mit den Praktiken befassen müssen, in deren Vollzugsmuster und Ausführungsstrukturen Energieverbrauch eingelagert ist. Man wird sich detailliert mit ihrer Beschaffenheit, ihren einzelnen Bestandteilen, mit ihrem gegenwärtigen Gesamterscheinungsbild, ihrer Entwicklungsgeschichte sowie ihrer möglichen Weiterentwicklung beschäftigen müssen. Nur in seiner Verwobenheit mit unzähligen Alltagsaktivitäten lässt sich ermitteln und verstehen, welche Relevanz die Bewältigung des Alltags und die moderne Lebensweise etwa für den Heizenergieverbrauch haben: 
„From this point of view, understanding energy is first and foremost a matter of understanding the sets of practice that are enacted, reproduced and transformed in any one society, and of understanding how material arrangements, including forms of energy, constitute dimensions of practice." (Shove und Walker 2014: 48)

\subsection{Heizen als soziale Praktik}

Im letzten Teilkapitel 2.1.7 wurde herausgearbeitet, dass der Fokus zur Untersuchung privaten Energiekonsums auf Praktiken liegen sollte, weil Energie als ein materiell vermittelter Bestandteil von Praktiken zu betrachten ist und sich Energieverbrauch in Privathaushalten erst durch den Vollzug alltäglicher Praktiken ergibt. In diesem Kapitel soll nun eine dieser Alltagsaktivitäten genauer analysiert werden, im Rahmen derer beträchtliche Energiemengen verbraucht werden. Im Folgenden soll das alltägliche Heizen als soziale Praktik untersucht werden.

Dieses Kapitel ist im Weiteren wie folgt strukturiert: In Teilkapitel 2.2.1 wird als erstes dargelegt, welches Verständnis des Begriffes ,Heizen“ dieser Arbeit zugrunde liegt. Dafür werden zunächst die Aktivitäten eingegrenzt, die in dieser Arbeit unter ,Heizen' subsumiert werden und es wird argumentiert, warum sich für die Bezeichnung ,Heizen` entschieden wurde. Dann wird genau aufgelistet, welche Aktivitäten in dieser Arbeit als zu „Heizen' gehörig verstanden werden und dementsprechend im Fokus der Analyse stehen. In den Teilkapiteln 2.2.2 und 2.2.3 soll dann weiter argumentiert werden, weshalb das Heizen im Hinblick auf die zentrale Fragestellung einen besonders interessanten und relevanten Untersuchungsfall darstellt. Hierfür wird zunächst auf die grundlegende Bedeutung von Wärme für Menschen eingegangen (Teilkapitel 2.2.2), woraus sich auch die Relevanz regelmäßigen Engagements in Form von Heizen ableiten lässt (Teilkapitel 2.2.3). In Teilkapitel 2.2.4 wird die Entwicklungsgeschichte des häuslichen Heizens ausführlich dargestellt, um die zentrale Bedeutung, vor allem aber die historische Bedingtheit heutiger künstlicher Gebäudeheizung deutlich zu machen. Nachdem dargelegt worden ist, was ,Heizen grundsätzlich zu einer sozialen Praktik macht, soll dann abschließend in Teilkapitel 2.2.5 etwas detaillierter ergründet werden, um welche Art von Praktik es sich bei ,Heizen' genau handelt. Im Anschluss an die in Teilkapitel 2.1.3 erörterten Unterscheidungen zwischen verteilten, integrativen und zusammengesetzten Praktiken ist zu fragen, wie sich ,Heizen“ einordnen lässt. 
Insgesamt dient Kapitel 2.2 also dazu, um einerseits schlüssig zu begründen, weshalb gerade ,Heizen' als Untersuchungsfall ausgewählt wurde. Und andererseits geht es darum, ,Heizen` als soziale Praktik näher zu bestimmen und genauer einzuordnen.

\subsubsection{Energieintensive Gebäude- bzw. Raumheizung im Fokus}

Mit ,Heizen' sind in dieser Arbeit erst einmal generell alle Aktivitäten gemeint, mit denen geschlossene Wohnräume aktiv beheizt und warmgehalten werden. Es geht also um all jene Tätigkeiten, die die Praktizierenden vollführen, um in ihren Häusern und Wohnungen in Zeiten geringer AuBentemperaturen thermisch Behaglichkeit zu schaffen und sie auch warm zu halten. Der Fokus liegt somit vorrangig auf all jenen Maßnahmen zur Erreichung und Sicherung von thermischer Behaglichkeit, die am Gebäude und den Räumlichkeiten ansetzen. Diese Heizaktivitäten werden in der Literatur als ,building', ,room' oder ,space heating' bezeichnet. Davon unterschieden werden Heizbetätigungen, die wesentlich an der ganzen Person bzw. am menschlichen Körper oder an einzelnen Körperteilen ihren Ansatz nehmen, wie z.B. das Tragen warmer Kleidung, der Gebrauch einer Wärmflasche oder der Verzehr warmer Speisen und Getränke. Hier spricht man entsprechend von ,person heating' (vgl. Kuijer und Jong 2012). Letztere Heiz- bzw. Aufwärmhandlungen sollen in dieser Arbeit allerdings

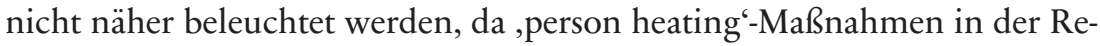
gel mit nur einem sehr geringen Verbrauch an fossiler Energie verbunden sind oder sogar gänzlich ohne die Inanspruchnahme fossiler Energieressourcen auskommen. So wird beispielsweise durch das Tragen von Wollkleidung nur während des Herstellungsprozesses der Kleidung (fossile) Energie verbraucht.

Bisher wurde das Heizen weniger als eigenständiger Handlungsbereich begriffen, sondern unter dem Stichwort, (accomplishing, consuming and sustaining) thermal comfort" untersucht (Brager und Dear 2003; Shove et al. 2008). Hierunter werden in der sozialwissenschaftlichen Literatur sowohl das Innenraumklima rein mechanisch beeinflussende Aktivitäten gefasst, als auch personenbezogene Heiz- und Kühlungsstrategien. Dabei widmet sich die Literatur in letzter Zeit verstärkt dem mechanisch-technologischen und damit energieverbrauchenden und $\mathrm{CO}_{2}$-Emissionen verursachenden Heizen und Kühlen. Durch die zusätzliche Konzentration auf die diesbezügliche Situation und Entwicklung in den USA bzw. in den angloamerikanischen Ländern ist darüber hinaus ein vorrangiges Interesse an 
„Kühlung' in Form von ,Air-conditioning' festzustellen (vgl. etwa Brager und Dear 2003: 179f; Chappells und Shove 2005; Healy 2008; Strengers 2008).

Wie bereits eingangs erwähnt, wird in dieser Arbeit eine andere Fokussierung vorgenommen, indem sich primär auf gebäude- bzw. raumbezogene Heizaktivitäten konzentriert wird, die zusammenfassend mit ,Heizen“ bezeichnet werden. Dafür gibt es vier plausible Gründe, die im Folgenden dargelegt werden.

Erstens lässt sich die Fokussierung auf Heizaktivitäten damit begründen, dass in dem gewählten landesspezifischen Untersuchungskontext (Deutschland) die für Raumwärme aufgewendete Energiemenge die zur Innenraumkühlung verwendete deutlich übersteigt. Zwar lässt sich auch in Deutschland der Trend feststellen, immer mehr Wohngebäude, vor allem Neubauten standardmäßig mit Klimaanlagen zu Kühlungszwecken auszustatten, doch das Heizen ist und bleibt weiterhin mit Abstand der größte Posten beim Endenergieverbrauch deutscher Privathaushalte (vgl. Statistisches Bundesamt und Umweltbundesamt 2015: 34).

Zweitens stellt ,Heizen', so wie es in dieser Arbeit verstanden und an späterer Stelle noch genauer ausgeführt wird, bereits einen größeren Aktivitätenkomplex dar, so dass eine fokussierte Betrachtung sinnvoll ist. Unter dem Stichwort ,(accomplishing, consuming and sustaining) thermal comfort $^{`}$ wird dagegen gleich ein ganzes Bündel sehr heterogener Praktiken in den Blick genommen, neben raum- bzw. gebäudebezogenen Heizaktivitäten auch Kühlungs- und Ventilationsaktivitäten sowie alle personenzentrierten Betätigungen. Hierzu ist anzumerken, dass bei der Passivhaustechnologie nicht mehr eindeutig zwischen Heizungs-, Lüftungs- und Kühlungsanwendungen unterschieden werden kann, da hier alle Raumklimatisierungsanwendungen miteinander verknüpft und in einem Gerät, der Passivhauskomfortlüftung, weitestgehend zusammengeführt worden sind. Und im SmartHome sind die unterschiedlichen Anwendungen zur Innentemperaturregulierung mittlerweile häufig mittels der computergestützten Steuerungstechnologie aufeinander abgestimmt und im System in Form der Raumprofileinstellungen zusammengeführt. Lüftungs- und Kühlungsaktivitäten werden in dieser Arbeit aber nur als relevant betrachtet, wenn sie einen eindeutigen Zusammenhang mit dem Beheizen von Wohnräumen aufweisen. Auch personenbezogene Heizaktivitäten, die ich im ,thermal comfort'-Konzept stärker verankert sehe, sollen nicht gänzlich unbeachtet bleiben. ,Person heating ' bildet allerdings nicht den Ausgangspunkt der Analyse, findet aber als Alternativ-, Ersatz- und Komplementärmaßnahmen, als Ergänzungs- und Unterstützungsaktivitäten, oder auch als 
Umgehungsstrategien für idealtypisches Wohnraumheizen Einzug in die Betrachtung. So zum Beispiel, wenn eine Bewohnerin, der es in ihrem Passivhaus zu kühl erscheint, sich eher einen Pullover anzieht oder in eine Decke einwickelt, anstatt die Passivhauslüftung (mit integrierter Zuluftheizung) anders einzustellen.

Ein dritter Unterschied zwischen den Konzepten ,achieving thermal comfort' und ,Heizen' betrifft das Gegensatzpaar Subjektivität/Objektivität. Was damit gemeint ist, wird im Folgenden erklärt: Indem das Konzept „Heizen' von den tatsächlichen Handlungsvollzügen ausgeht, verfügt es über einen starken Tätigkeitsbezug. Durch den klaren Fokus auf das praktische Tun, auf die öffentlich sichtbaren Aktivitäten, wird vom Denken einzelner Praktizierender sowie von (ihren) individuellen Erwartungen und Motivationen weitestgehend abstrahiert. In folgendem Zitat beschreibt Warde dies als einen Minimalkonsens unter Praktikentheoretiker*innen:

„However, how best to examine practices remains controversial. Agreement among advocates of the practice approach is limited, although in general all give precedence to practical activity as the means by which people secure their passages through the world thereby emphasizing doing over thinking, practical competence over strategic reasoning, mutual intelligibility over personal motivation and body over mind." (Warde 2013: 18)

Dafür rückt das Handlungssetting, der situative Kontext stärker in den Blick. Dagegen fokussiert das Konzept ,achieving thermal comfort'stärker auf die subjektive Komponente unternommener Heiz- (und Kühlungs-)Aktivitäten. So verweist , achieving thermal comfort' nicht lediglich auf ein immer schon an eine Person gebundenes Handeln, sondern stellt ein durch persönliche Motive und subjektives Behaglichkeitsempfinden (an-)geleitetes Tätigsein in den Vordergrund. Dieses Ausüben kann in der Praxis so unterschiedliche Aktivitäten wie das Aufdrehen des Heizungsthermostats oder die Verwendung einer Wärmflasche bedeuten, immer aber ist es personenbezogen, und zwar in dem Sinne, dass subjektive Behaglichkeitsvorstellungen für das aktive Agieren als zentral bedeutend angenommen werden. Wohnraumheizen bezieht sich dagegen stärker auf das Erwärmen von Räumen, ohne dass dabei (persönliche) Behaglichkeitserwägungen eine große Rolle spielen oder dass sich überhaupt Personen in den zu beheizenden Räumlichkeiten aufhalten (müssen). Dies trifft - wie auch Mietrechtstexten zum Heizen zu entnehmen ist (siehe Kapitel 2.2.3, die Fußnoten 29 und 30) - beispielsweise zu, wenn Wohnräume (auch un- 
genutzte) in vorgegebener Weise beheizt werden, um Schimmelbildung oder Frostschäden zu vermeiden. Darüber hinaus wird die subjektive Prägung des Konzepts auch daran deutlich, dass sich ,thermal comfort ' kaum ohne Bezug auf menschliches Empfinden beschreiben lässt. Vielmehr wird mit ,achieving thermal comfort' ein subjektiv empfundener und persönlich gedeuteter Zustand umrissen. Aus diesem Grund präferiere ich das tätigkeitsbasierte und weitaus neutralere, weil stärker beschreibende Konzept ,Heizen'.

Ein viertes wichtiges Argument, Heizaktivitäten zentral zu setzen, habe ich aus meiner empirischen Forschung gewonnen. Bei ,Heizen` handelt es sich um ein sehr praxisnahes Konzept: ${ }^{25}$ Die Praktizierenden, die für diese Erhebung interviewt wurden, sprechen selbst fast alle ausschließlich von „Heizen'. Und auch in den Anleitungen und Empfehlungen etwa des Umweltbundesamtes und der Verbraucherzentrale wird fast ausschließlich die Bezeichnung ,Heizen` verwendet. Lediglich in den Gesprächen mit den betreffenden Expert"innen war häufiger von der Herstellung (optimaler) thermischer Behaglichkeitszustände die Rede. Anhand dieser Beschreibungen wird deutlich, dass es sich bei ,(achieving) thermal comfort ${ }^{\star}$ eher um ein wissenschaftliches Konstrukt handelt, das seine Wurzeln in den damit ursprünglich beschäftigten Fachdisziplinen hat - hier allen voran den Ingenieurswissenschaften (vgl. Fanger 1970). Da in dieser Arbeit eine praxistheoretische Perspektive eingenommen wird und dabei die Betätigungen der Praktizierenden im Mittelpunkt stehen, erscheint es geboten, auch für die empirische Forschung an die in den Köpfen der Beforschten vorhandenen sowie in ihrem Handeln und in ihrem Sprechen (in ihren ,doings and sayings $\left.{ }^{6}\right)$ Niederschlag findenden Sinnzuschreibungen, Bilder und Konzepte anzuknüpfen. Dem entspricht der für die qualitative Sozialforschung zentrale Anspruch, „dass sozialwissenschaftliche Konstruktionen auf den Konstruktionen des Alltags aufgebaut werden und die gedanklichen Gegenstände der Sozialwissenschaften mit jenen vereinbar bleiben müssen, die von Menschen im Alltag gebildet werden“ (Rosenthal 2011: 39). Auch deshalb wird in dieser Arbeit ,Heizen“ als Konzept zentral gestellt und im Folgenden für ein spezifisches Aktivitätenbündel von ,Heizen' gesprochen.

Dennoch bildet ,(accomplishing) thermal comfort' oft einen Motivationshintergrund für Heizbetätigungen und stellt ein zentrales Element von der Praktik des Heizens dar. Komfortvorstellungen bzw. Konzepte und

25 Das Argument der Praxisnähe wird in Kapitel 3 zum methodischen Vorgehen noch einmal aufgegriffen und dort in aller Ausführlichkeit diskutiert. 
Vorstellungen von thermischer Behaglichkeit werden als solches deshalb an späterer Stelle noch einmal aufgegriffen.

Bei einer Praktik handelt es sich, wie in Kapitel 2.1.2 ausführlich dargelegt, immer um ein Bündel von Aktivitäten: „an organized nexus of actions" (Schatzki 2002: 71). Eine Praktik stellt demnach einen in sich geordneten Aktivitätenkomplex dar, der mit bestimmten materiellen Arrangements in Zusammenhang steht. Materielle Arrangements erlangen ihre Bedeutung allerdings erst im praktischen Tun. Die Praktik des Wohnraumheizens, um die es in dieser Arbeit zentral gehen soll, konstituiert sich wesentlich durch folgende a) Aktivitäten, die mit folgenden b) materiellen Arrangements gekoppelt sind:

a) 1. Nutzung und Bedienung einer konventionellen Gebäudeheizung oder einer Komfortlüftungsanlage (mit integrierter Zuluftheizung) oder einer intelligenten Heizungssteuerungstechnologie, usw.

2. Regulierung der Raumwärme mittels Öffnung und Einstellen der Heizkörperthermostat(ventil)e; Heizkörper entlüften

3. (Fenster-)Lüftung

4. Türen zwischen unterschiedlich beheizten Räumen geschlossen halten (oder gezieltes Öffnen der Türen, um für eine Verteilung von Wärme zu sorgen)

5. Kontrolle der Luftfeuchte

b) 6. Bauliche Maßnahmen und Gegebenheiten, wie z.B. Außenwanddämmung, Fensterisolierverglasung, Gebäudeheizung, usw.; allgemein die bauliche Substanz und technologische Ausstattung sowie diesbezügliche Renovierungs- und Sanierungsunternehmungen

7. Zimmermöblierung bzw. -einrichtung und Anordnung der Gegenstände im Raum

Hierbei handelt es sich um eine vorläufige Auflistung von Aktivitäten, die sich unter Wohnraumheizen subsumieren lassen. Dies sind die weitläufig bekannten und vorherrschenden Heizaktivitäten, wie sie etwa in Anleitungen zum ,richtigen' Heizen und Lüften zu finden sind. Es kann aber durchaus sein, dass noch wichtige gängige Tätigkeiten in dieser Liste fehlen. Deshalb soll dieser Katalog nach Auswertung des empirischen Materials noch einmal kritisch überprüft und gegebenenfalls ergänzt und verändert werden. Qualitative Forschung, die dem Prinzip der Offenheit folgt (vgl. Hoffmann-Riem 1980), ist darauf angelegt, das sie beiträgt, diese Liste zu erweitern. So kann die konkrete Fallanalyse des Heizens in Passivhäusern und in SmartHomes zur Entdeckung und Benennung neuer, weiterer Heizaktivitäten führen. 
Mit dem Beheizen von Wohnräumen verbindet sich in aller Regel ein hoher Energieverbrauch und ein dementsprechend großer $\mathrm{CO}_{2}$-Ausstoß, da die allermeisten Heizungsanlagen in Privathaushalten heutzutage (noch) mit Energie aus fossilen Brennstoffen wie Erdgas oder Heizöl betrieben werden, bei deren Verbrennung ehemals gebundenes $\mathrm{CO}_{2}$ freigesetzt wird (vgl. Clausnitzer 2014: 30). ${ }^{26}$ Ein hoher Energieverbrauch und $\mathrm{CO}_{2}$-Ausstoß sind somit eher unbeabsichtigte Nebenfolgen bei der Erzeugung der gewünschten Serviceleistung, Raumwärme‘ mittels Heizen.

Der durch das Beheizen privater Wohnräume verursachte Energieverbrauch und das dabei freigesetzte $\mathrm{CO}_{2}$ schädigen das globale Klima. Die in die Atmosphäre entlassenen $\mathrm{CO}_{2}$-Emissionen wirken entscheidend daran mit, dass sich die Erdatmosphäre immer mehr aufheizt (vgl. Latif 2006: 26). Der mit Abstand größte Anteil der von privaten Haushalten verursachten $\mathrm{CO}_{2}$-Emissionen ist auf das Beheizen von Wohnräumen zurückführen. Mehr als zwei Drittel der gesamten in privaten Haushalten genutzten Energie wird zum Heizen, also zur Erzeugung von Raumwärme verwendet (vgl. Deutsche Energie-Agentur GmbH (dena) 2016: 31). Vom Standpunkt umwelt- und klimarelevanten Konsums aus betrachtet, stellt sich Heizen als besonders relevante Alltagstätigkeit dar, weil sie außerordentlich folgenschwer für Umwelt und Klima ist.

In den meisten Privathaushalten industrialisierter Gesellschaften der nördlichen Hemisphäre stellt Wohnraumheizen mit Abstand die energieintensivste Praktik dar. Dementsprechend sind hier auch die Einsparpotenziale enorm. Es gilt somit: Sollen der private Energiekonsum und mit ihm die energiebasierten $\mathrm{CO}_{2}$-Emissionen effektiv gesenkt werden - was angesichts des globalen Klimawandels erklärtes Ziel ist - dann erscheint Wohnraumheizen als sehr aussichtsreicher Ansatzpunkt für Interventionsmaßnahmen. In jedem Fall hätten neue Routinen in diesem Bereich weitreichende ökologische Konsequenzen. Insofern ist es eine spannende Frage, ob und inwiefern das Heizen in eine weniger energieintensive bzw. eine energiesparsame Aktivität transformierbar ist.

Die Möglichkeiten, das Heizen in Privathaushalten zu verändern, sind allerdings nicht vollkommen unbegrenzt, da Menschen grundsätzlich ein gewisses Maß an Wärme zum Überleben brauchen. Im gesamten zentraleuropäischen Raum liegen die Außentemperaturen an vielen Tagen des Jahres um und bei 12 Grad Celsius oder deutlich niedriger (siehe

26 Vgl. auch Forschungsstelle für Energiewirtschaft e. V. (FfE) 2017** 
www.dwd.de). ${ }^{27}$ Die in Deutschland überwiegend vorherrschenden Außentemperaturen - das Klima in Deutschland gehört zur kühlgemäßigten Klimazone - machen es somit erforderlich, dass sich die Menschen an vielen Tagen des Jahres noch zusätzlich erwärmen, dass sie also ihre Häuser und Wohnungen durch (künstliche) Gebäudeheizung bewohnbar machen.

\subsubsection{Die grundsätzliche Bedeutung von Wärme für Menschen - Heizen als essentielle Praktik}

Bei welchen Temperaturen sich Menschen in Gebäuden wohl und behaglich fühlen, kann zwar von Situation zu Situation stark variieren und von Mensch zu Mensch sehr unterschiedlich sein, jedoch ist das jeweilige individuelle Spektrum nicht allzu groß. Es nicht ausreichend warm zu haben, empfinden die allermeisten Menschen nämlich nicht nur als höchst unangenehm, sondern auch sehr schnell als einen existentiell bedrohlichen $\mathrm{Zu}$ stand. Menschen brauchen Wärme und sind außerordentlich kälteempfindlich. Hitze wird recht gut ertragen, Kälte dagegen nur sehr begrenzt. So hat eine aktuelle Studie zu temperaturbedingter Mortalität ergeben, dass nicht etwa Hitze oder Extremtemperaturen, sondern moderate winterlich-kalte Temperaturen die meisten Todesopfer fordern (vgl. Gasparrini et al. 2015). Immerhin haben die Menschen gelernt, sich durch Kleidung, Behausung und Heizung gegen starke Kälte zu schützen und ihre lebenswichtige Körperwärme dadurch zu bewahren; allerdings sind diese Möglichkeiten begrenzt. Ausreichende Versorgung mit Wärme stellt demnach ein akutes menschliches Bedürfnis dar.

Klar ist, dass in westlichen Gesellschaften nicht einfach auf künstliche Gebäudeheizung verzichtet werden kann: die Tätigkeit des Beheizens von Wohnräumen lässt sich nicht ersatzlos abschaffen und ist auch nicht ohne weiteres durch eine andere - neue oder alte - Praktik zu substituieren. Die in Industrieländern wie Deutschland lebenden Menschen sind mittlerweile an zusätzliche Erwärmung in Form von künstlicher Gebäude- bzw. Raumheizung gewöhnt und zumindest während der kalten Wintermonate

27 Siehe exemplarisch für verschiedene Städte Deutschlands: www.dwd.de/DE/leistu ngen/klimadatenwelt/europa/ae/deutschland/deutschland_node.html, zuletzt geprüft am 11.10.2018. So lag beispielsweise die mittlere tägliche Maximaltemperatur in Hamburg in der Periode von 1961 bis 1990 mindestens während sechs Monaten (Oktober bis April) unter 12 Grad Celsius. 
angewiesen. Wärme ist ein körperliches Grund- bzw. Existenzbedürfnis des Menschen. Menschen benötigen (äußere) Wärme, also eine gewisse Umgebungstemperatur, damit die wärmeabhängigen Vorgänge in und am menschlichen Körper, die einerseits das körperliche Überleben sichern und andererseits für das Wohlbefinden von ausschlaggebender Bedeutung sind, aufrechterhalten werden und ungehindert ablaufen können (Gekle und Singer 2014: 567).

Die normale Körperkerntemperatur, womit in der Regel die Temperatur des Körperinneren bzw. der inneren Organe, manchmal aber auch die Bluttemperatur gemeint ist, liegt beim Menschen zwischen 36,3 und 37,5 Grad Celsius. Von Mensch zu Mensch kann die ,Normaltemperatur' also etwas variieren. Darüber hinaus sind geringe Körperkerntemperaturschwankungen durch Faktoren wie Tageszeit, körperliche Aktivität, Kälteexposition, Emotionen, usw. natürlich und zu berücksichtigen. Die Kerntemperatur ist bei gesundem Körper normalerweise nur sehr geringen Schwankungen unterworfen - bereits eine Temperatursteigerung um wenige Grad (z.B. bei heftigen Fiebererkrankungen) kann schon den Tod verursachen und eine geringe Ab- bzw. Auskühlung bedingt bereits schwere Erkältungskrankheiten; kühlt sich der Körper auf unter 20 Grad Celsius ab, stirbt er den ,Kältetod‘ (ebd.: 568).

Der Körper versucht diese Solltemperatur im Körperkern von ungefähr 37 Grad Celsius ständig bzw. so lange wie möglich aufrecht zu erhalten. Aufgrund dessen, dass sie eine konstant hohe Körperkerntemperatur aufweisen, sind Menschen temperaturtechnisch als ,gleichwarme' (homöotherme) Lebewesen (Säugetiere, Vögel) zu betrachten - diese Eigenschaft macht den menschlichen Körper gleichzeitig unabhängiger von der Umwelt und deren Temperaturschwankungen. Dagegen kommt es in den peripheren Geweben (Körperschale) regelmäßig zu größeren Temperaturschwankungen. Zusammengefasst bedeutet das: während die Körperkerntemperatur konstant bleibt, „wenn die Umgebungsbedingungen sich von einer milden Wärmebelastung zu einer leichten Kältebelastung oder umgekehrt ändern, $[\ldots]$ nähert sich die Temperatur der Körperschale von ihren kernnahen Schichten nach außen immer mehr der Umgebungstemperatur an" (ebd.: 567).

Dies führt dazu: wenn auch die Oberflächentemperatur der Haut - die mittlere ideale Hauttemperatur (Körperschale) liegt derweil bei 27 bis 32 Grad Celsius - keineswegs die Körperkern- bzw. die Bluttemperatur erreicht, so ist der menschliche Körper in der Regel doch wärmer als seine Umgebung, so dass eigentlich permanent ein Wärmeverlust stattfindet. 
Gleichzeitig und mit einer gewissen Unabhängigkeit von der jeweiligen Umgebungstemperatur produziert der menschliche Körper ständig Wärme (Thermogenese), um die von ihm abgegebene Wärmemenge auszugleichen. Demzufolge passt sich die (menschliche) Körpertemperatur nicht einfach der jeweiligen Umgebungstemperatur an. Würde der Körper die übermäßige Hitze jedoch nicht via Wärmeabgabemechanismen wie Konduktion (Wärmeleitung), Konvektion (Wärmeströmung), Radiation (Strahlung) und Evaporation (Verdunstung) abgeben, entstünde ein Wärmestau - der Körper würde überhitzen und schließlich sterben (ebd.: 570573, sowie 580-582). Je größer der Unterschied zwischen der menschlichen Körpertemperatur und der Umgebungstemperatur ist, desto schneller erfolgt die Wärmeabgabe. Die meisten Menschen empfinden eine Umgebungstemperatur von 20 bis 25 Grad Celsius als ideal bzw. besonders angenehm. Das ist dadurch begründet, dass der menschliche Körper in diesem Temperaturbereich die überschüssige Wärme etwa in dem gleichen Tempo an seine Umgebung abgeben kann, wie er sie selbst neu erzeugt. Bei dieser so genannten ,Behaglichkeitstemperatur' fühlen sich die meisten Menschen deshalb durchschnittlich am wohlsten (vgl. Fanger 1970: insbesondere Kapitel 2: 19-67; Richter 2003: 14f; Gekle und Singer 2014: 577; Dentel und Dietrich o. J.: 4-12).

$\mathrm{Da}$ in Nord- und Mitteleuropa die durchschnittlichen Außen- bzw. die Umgebungstemperaturen die überwiegende Zeit des Jahres unterhalb der oben genannten ,Behaglichkeitstemperatur' liegen - in den Wintermonaten sogar erheblich von dieser abweichen -, sind die hier lebenden Menschen auf zusätzliche künstliche Erwärmung angewiesen - künstliche (Gebäude- bzw. Raum-)Heizung stellt für sie somit ein notwendiges Erfordernis dar.

In Deutschland gehört eine Wohnung zu den ,unverfügbaren Grundrechten', die durch das Grundgesetz gesichert sind (vgl. Art. 13 des GG). Das Recht auf (menschenwürdiges) Wohnen ist ein Menschenrecht der zweiten Generation, das allerdings nicht im Grundgesetz verankert ist. Es hat seine Grundlage im internationalen Recht $^{28}$ (vgl. hierzu auch Krennerich 2018*). Demnach geht es im Wesentlichen darum, mittels künstlicher Gebäudeheizung in den Wohnräumen solche Temperatur- und Feuchtig-

28 Dies sind Artikel 11 des Internationalen Pakts über wirtschaftliche, soziale und kulturelle Rechte (ICESCR), Artikel 16 der Europäischen Sozialcharta vom 16. Dezember 1966 sowie Artikel 31 der revidierten Europäischen Sozialcharta (vgl. de.wikipedia.org, Artikel zum Thema ,Recht auf Wohnen', zuletzt aktualisiert am 08.02.2018, zuletzt geprüft am 11.10.2018). 
keitsverhältnisse zu schaffen, durch die der menschliche Körper keine unangenehme oder gar ungesunde bis lebensbedrohliche Entwärmung (Auskühlung) erfährt. Vorübergehend bzw. in gewissen Grenzen verträgt der menschliche Organismus zwar ungünstige raumklimatische Verhältnisse und passt sich in solchen Fällen - wie oben beschrieben - „selbsttätig einer notwendigen Verschiebung in der Art der Wärmeableitung an" (Recknagel 1915: 87). Allerdings ist ein Großteil der in Industrieländern lebenden Menschen mittlerweile in solchem Maße an Raumtemperaturverhältnisse gewöhnt, wie sie eigentlich nur durch den intensiven Gebrauch von zusätzlicher künstlicher Heizung im Winter erreicht werden können. Diese Menschen sind buchstäblich als abhängig von künstlicher Gebäudeheizung zu betrachten. Aufgrund des intensiven Gebrauchs künstlicher Heizung haben es viele Menschen verlernt, sich auf eine größere Vielfalt bei den Raumklimaverhältnissen einzustellen; sie können es sich kaum vorstellen oder es kommt für sie kaum mehr in Frage, auf niedrige (Innenraum-)Temperaturen, anstatt wie gewohnt mit dem sofortigen vollen Aufdrehen des Heizungsthermostats, anders oder auch nur einmal (wieder) in etwas geringerem Maße als sonst üblich zu reagieren (vgl. Chappells und Shove 2005: 38). Künstliche Gebäudeheizung ist nunmehr zu einer essentiellen Praktik geworden, die nicht mehr aus dem Alltag wegzudenken ist und auf die nicht mehr vollständig verzichtet werden kann.

Insgesamt lässt sich daraus folgern, dass ausreichende Raumwärme ein wichtiges Bedürfnis von in (modernen) Gebäuden wohnenden Menschen ist und dass das alltägliche Wohnraumheizen somit (vorläufig) weiterhin eine zentrale, relevante Tätigkeit im Alltag der Menschen sein wird. Daher erscheint das alltägliche Heizgeschehen (zumindest zum jetzigen Zeitpunkt) nur in begrenztem Maße transformierbar. Das heißt, Veränderungen - auch sehr große bzw. gravierende - bei den einzelnen in das alltägliche Heizgeschehen involvierten Komponenten sind möglich und gut vorstellbar, wie etwa die weitgehende Umstellung der Beheizung von fossilen auf regenerative Energieträger. Allerdings sind genauso deutliche Kontinuitäten im privaten Heizen zu erwarten, wie bespielweise, dass der Grad an Technisierung und Automatisierung weiter zunehmen wird, Heizen also in Zukunft in noch stärkerem Maße von Technik abhängen und an Technik delegiert wird als dies bereits heute der Fall ist.

Dadurch, dass zusätzliche künstliche Gebäudebeheizung vielerorts an zahlreichen Tagen des Jahres erforderlich ist und Heizen demnach von vielen Menschen regelmäßig praktiziert wird, stellt es eine soziale Routine dar. Einmal bewusst erlernt, sorgt die dauernde Betätigung im Heizen dafür, dass die entsprechenden dazugehörigen Aktivitäten in hohem Maße 
routinisiert sind (vgl. Wilk 2009). Das heißt, Menschen, die Heizen eine Zeit lang öfters ausgeführt haben, die sich regelmäßig oder sogar alltäglich heizend betätigen, haben sich ein routinisiertes Verhaltensmuster antrainiert - deren Gehirn hat ein automatisches Verhaltensmuster zur Meisterung dieser Aufgabe im Unterbewusstsein abgespeichert.

\subsubsection{Heizen - eine geregelte Alltagsroutine}

Heizen konnte somit im vorangegangenen Teilkapitel als essentielle Praktik beschrieben werden. Demnach handelt es sich beim Heizen weder um eine reine Willensfrage oder ideologische Entscheidung, noch stellt Heizen eine vollkommen freie Wahlhandlung dar. Stattdessen handelt es sich vielmehr um eine mehr oder weniger notwendige Routineaktivität. Dass Wohngebäude in Nord- und Mitteleuropa zumindest während der so genannten ,Heizperiode ${ }^{6}$ - der Zeitraum, in dem die Heizanlage in Betrieb genommen werden muss, um die Innenraumtemperatur auf mindestens 18 Grad Celsius zu halten - beheizt werden (müssen), ist rechtlich geregelt. So haben in Deutschland Mieter*innen einer Wohnung mit Zentralheizung nicht nur ein gesetzlich verankertes Recht auf Wärme; gleichzeitig sind sie auch verpflichtet, die von dem bzw. der Vermieter"in bereitgestellte Heizleistung abzunehmen. ${ }^{29}$ Ist ein*e Mieter*in hierzu beispielsweise aus wirtschaftlichen Gründen nicht in der Lage, so kann er bzw. sie zwar

29 Während es derjenigen Person, die ein Eigenheim bewohnt, freisteht, ihre Heizung ganzjährig auf vollste Stärke einzustellen oder auf Beheizung ganz zu verzichten, haben Mieter*innen ein gesetzlich geregeltes Recht auf Wärme. Im Mietrecht ist die ,Heizperiode“ für Deutschland klar vorgeschrieben: sie gilt allgemein vom 01. Oktober eines Jahres bis zum 30. April des Folgejahres (Urteil des LG Düsseldorf BlGBW 55, 31; Urteil des AG Düsseldorf ZMR 56, 332), und zwar unabhängig davon, wie hoch die Außentemperatur ist. In dieser Zeit muss die Heizanlage durch den bzw. die Vermieter*in wieder vollständig angeschaltet werden und er bzw. sie muss sicherstellen, dass von der mietenden Person tagsüber eine durchschnittliche Raumtemperatur von 20 bis 22 Grad Celsius generell tatsächlich erreicht werden kann. Nachts darf die Heizanlage nur so weit gedrosselt werden, dass in den Räumlichkeiten immer noch eine Temperatur von mindestens 18 Grad Celsius herrscht.

Die Heizperiode ist zusätzlich temperaturabhängig. Auch außerhalb der offiziellen Heizperiode trifft den bzw. die Vermieter*in eine Heizpflicht, und zwar, wenn die Raumtemperaturen tagsüber auch nur zeitweise unter 18 Grad Celsius fallen und abzusehen ist, dass diese Kälteperiode länger als einen Tag andauern wird. Sinken die Temperaturen in der Wohnung auf tagsüber unter 16 Grad Celsius, so muss die zentrale Sammelheizung sofort in Betrieb genommen werden, 
auf eine Beheizung der Wohnräume verzichten - im Gesetz sind keine konkreten Raumtemperaturen vorgeschrieben. Allerdings hat der bzw. die Mieter*in grundsätzlich dafür Sorge zu tragen und zumindest in dem MaBe zu heizen und zu lüften, dass keine Schäden an der Wohnung oder am Gebäude entstehen (z.B. Einfrieren der Wasserrohrleitungen, Schimmel oder Schäden durch Feuchtigkeit). Auch ist es dem bzw. der Mieter*in grundsätzlich nicht gestattet, die Wohnung eigenmächtig und gegen den Willen des bzw. der Vermieter*in auf eine andere Art und Weise, zum Beispiel durch Einzelöfen zu beheizen..$^{30}$ Wie und in welchem Ausmaß geheizt wird, ist also nicht zwingend festgelegt. Welche Art des Heizens sich in bestimmten sozio-kulturellen und rechtlichen Kontexten als gängige Praxis herausbildet, hängt zusammen mit den materiellen und sonstigen Gegebenheiten vor Ort und verfügbarer Technologie, sowie mit Geschichte, Kultur und vorherrschenden gesellschaftlichen Konventionen - entscheidend sind die spezifische Zusammensetzung und das Zusammenspiel der beteiligten Elemente sowie der jeweilige sozio-kulturelle Gesamtkontext, in dem Wohnraumheizen stattfindet und betrachtet wird (vgl. Walker et al. 2014: 1f).

Eine warme Wohnung erscheint den allermeisten Menschen in Europa heute so selbstverständlich wie eine Toilette mit Wasserspülung. Während früher und noch deutlich bis ins 20. Jahrhundert hinein große Mengen an

da hier der Gesetzgeber die Grenze zur Gesundheitsgefährdung bereits als überschritten sieht (Urteil des LG Kassel WM 64, 71). Da die Innentemperaturen aber auch stark von den individuellen Wohngewohnheiten und vom Heiz- und Lüftungsverhalten des bzw. der jeweiligen Mieter*in abhängen, erscheint es sinnvoll, sich wie das Amtsgericht Uelzen auf den objektiven Wert der Außentemperatur zu beziehen. Dieses hat in einem Urteil aus dem Jahr 1986 (AG Uelzen WM 86, 212) entschieden, dass die volle Heizleistung auch außerhalb der Heizperiode gewährleistet sein muss, wenn die Außentemperatur für einen Zeitraum von mindestens drei Tagen weniger als 12 Grad Celsius beträgt. Die Vorschriften bezüglich der Raumtemperaturen, die mindestens zu erreichen sind, werden in der DIN 4701 festgehalten. Die dort aufgeführten Mindesttemperaturen dürfen grundsätzlich nicht unterschritten werden.

Mieter*innen müssen eine Wohnung grundsätzlich nicht beheizen, sie haben keine Heizpflicht. Allerdings müssen sie dafür sorgen, dass die Wohnung frostfrei bleibt und keine Wasserrohre einfrieren können. Sie sind also verpflichtet, die Wohnung zumindest so minimal zu heizen und zu lüften, dass keine Schäden etwa durch Schimmelbildung oder Feuchtigkeit am Gebäude entstehen können (vgl. Mietrechtslexikon.de - Redaktion 2014*; Deutscher Mieterbund e.V. (dmb) o.J.*).

30 Vgl. Online-Redaktion von mietrecht-lexikon.net o.J.*: „Zentralheizung (Miete)“ (pdf-Dokument). 
Holz, Kohlebriketts oder Koks zur Befeuerung von Kamin oder Kachelofen herangeschafft werden mussten, genügt heutzutage ein Drehen am Heizkörperthermostat, um in kurzer Zeit eine als behaglich empfundene Wärme im Raum zu erreichen. Selbst bei Minusgraden können heutzutage durch moderne Heizungstechnologie Innenraumtemperaturen weit über $20 \mathrm{Grad}$ Celsius erreicht werden. Und dies hat sich als gesellschaftliche Konvention etabliert: So ist es heutzutage ,normal' und weit verbreitet, dass Innenräume im Winter auf 22 Grad Celsius oder mehr beheizt werden (vgl. Shove 2004a: 121; Chappells und Shove 2005) Diese Entwicklung zur heute gängigen Praktik des Heizens mittels moderner Zentralheizung auf etwa 22 Grad Celsius Raumtemperatur dauerte allerdings viele Jahrhunderte. Die gesellschaftlichen und technischen Entwicklungsschritte, die sich bis dahin ereigneten, sind Thema des nächsten Teilkapitels.

\subsubsection{Die Bedeutung der Entwicklungsgeschichte häuslicher Heizung}

Für diese Arbeit ist es sowohl in theoretischer als auch empirischer Hinsicht relevant, die historische Entwicklung des Heizens zumindest in groben Zügen zu kennen. Zwar handelt es sich bei sozialen Praktiken immer um ein Geschehen, das sich „im Hier und Jetzt konkreter Gegenwarten vollzieht“ (Schmidt 2012: 51). Diese gegenwärtigen Ereignisse tauchen jedoch nicht, einfach so' aus dem Nichts auf, sondern sie haben immer schon Vorläufer, knüpfen immer an bereits vergangene Aktivitäten an. Soziale Praktiken sowie ihre Wissensgrundlagen haben eine jeweils eigene irreduzible Geschichte (vgl. Reckwitz 2004: 323), die kontinuierlich im praktischen Vollzug aktualisiert wird - soziale Praktiken sind stets historisch gewachsen. So betont Schmidt, dass mit dem Konzept der Praktiken „ein zeitliches Kontinuum [bezeichnet wird:] die Teilnehmerinnen befinden sich in einem Strom sich entfaltender Aktivitäten. Diese Aktivitäten folgen als Jetztzeiten sequentiell aufeinander" (Schmidt 2012: 52). Dementsprechend können soziale Praktiken, so erläutert Schmidt weiter, „erst ex post - und indem über ihren gegenwartsbasierten Ereignischarakter hinweggesehen wird - in ihrer charakteristischen Verlaufsbahn (trajectory) beschrieben werden" (ebd., Hervorh. im Original). Nimmt man die Gegenwart als Ausgangspunkt, so lassen sich „[d]ie spezifischen Beziehungen, die soziale Praktiken zur Vergangenheit und zur Zukunft unterhalten“ (ebd.: 54), anschaulich beschreiben: „In ihrem gegenwartsbasierten Vollzug fungiert immer auch Vergangenes; es wird vergegenwärtigt, und zugleich wird dadurch Zukünftiges präformiert" (ebd.). Diese Kontinuierungsar- 
beit, also die Tatsache, dass Aktivitäten nicht nur zeitlich aufeinanderfolgen, sondern auch sinnhaft aneinander anknüpfen, wird insbesondere von den Träger*innen von Praktiken erbracht: den beteiligten Körpern und den materiellen Artefakten. „Durch die Mitwirkung dieser gegenständlichen und körperlichen Speicherformen und Trägerschaften wird die in sie eingegangene Geschichte aktualisiert“ (ebd.: 54f). Demnach beeinflusst die über die Trägerschaften in Praktiken immer auch präsente Vergangenheit nicht nur die Praxisgegenwart, sondern von ihr hängt zu einem gewissen Grad die Richtung zukünftiger Verläufe ab (vgl. ebd.: 55).

Demzufolge gilt auch für das Heizen, dass es sich um eine geschichtlich gewordene Praktik handelt. Ihre Vorgeschichte ist unbedingt in die Analyse miteinzubeziehen, will man gegenwärtige Erscheinungsformen des Heizens interpretieren und einordnen, also angemessen verstehen. Aber auch für die Zukunft des Heizens ist die Kenntnis der besonderen Entwicklungsgeschichte des Heizens unerlässlich: So ist davon auszugehen, dass in und durch vergangene und gegenwärtige Tätigkeitsvollzüge schon teilweise vorgezeichnet ist, wie sich Heizen zukünftig entwickeln wird bzw. kann, ohne dass die weitere Entwicklungsgeschichte des Heizens damit bereits komplett vorbestimmt wäre.

Auch im Hinblick auf das in dieser Arbeit zentrale Thema ,Praktikenwandel' sind diese Überlegungen in mehrfacher Hinsicht relevant: Über Wissen zu verfügen, wie sich Wandel im Heizen in der Vergangenheit vollzogen hat, kann sehr aufschlussreich sein, um erstens die gegenwärtige Situation des Umbruchs besser verstehen und deuten zu können. Ist ein neuer, abweichender, etwa in Richtung mehr Nachhaltigkeit weisender Pfad beim Heizen bereits eingeschlagen? Oder wird weiterhin an den altbekannten, etablierten Heizformen und -techniken festgehalten? Zweitens kann das Wissen von vergangenen Veränderungen und Umbrüchen im Heizen hilfreich sein, um daraus abzuleiten, welche gesellschaftlichen Trends Veränderungen im Heizen hin zu mehr Nachhaltigkeit möglicherweise begünstigen (vgl. Wilhite und Lutzenhiser 1999: 286); oder womöglich lässt sich aus der Vergangenheit lernen, welche politischen Entscheidungen es braucht, um die vermehrte Reproduktion und weitere Verbreitung bereits bestehender Heizpraktiken mit nur geringen negativen Auswirkungen für Umwelt und Klima zu befördern (vgl. Shove 2012: 110f).

Welches sind interessante und relevante Trends im Heizen, die bereits in der Vergangenheit angelegt sind oder die womöglich wichtige historische Vorläufer haben, an die sich eventuell anknüpfen lässt? Unter welchen Umständen kam es bereits früher zu zentralen Veränderungen oder Umbrüchen im Heizen? Aus welchen, bereits in der Vergangenheit gemachten 
Fehlern lässt sich für die Zukunft lernen? Wie und wohin wird sich das Heizen vor dem Hintergrund vergangener Umgestaltungen zukünftig höchstwahrscheinlich entwickeln? - All diese Fragen verdeutlichen noch einmal, wie wichtig für das Verständnis der Gegenwart die Kenntnis der Vergangenheit ist. Deshalb folgt nun als Nächstes ein Überblick über die Verlaufsgeschichte des alltäglichen Wohnraumheizens. Im Anschluss wendet sich diese Arbeit wieder gegenwärtigen Erscheinungsformen des Heizens zu - diesmal allerdings vor dem erhellten Hintergrund vergangener Heizentwicklungen.

\subsubsection{Geschichte des Heizens}

Das Erwärmen von ganzen Gebäuden oder von einzelnen Räumen in Gebäuden hat eine lange Geschichte. Noch weit bis ins Mittelalter hinein wurden die meisten Häuser lediglich durch ein offenes Feuer beheizt. Um 1900 heizte man in westlichen Industrieländern die Häuser vor allem aus Kostengründen noch bevorzugt mittels Kamin und Kachelofen, welche mit Holz bzw. Kohle befeuert wurden. Erst nach dem Zweiten Weltkrieg, mit der gleichzeitigen Umstellung von Festbrennstoffen auf Öl und Gas, verbreiteten sich Zentralheizungen in westlichen Industriestaaten (vgl. Schwartz Cowan 1976: 7). In den späten 1960er Jahren setzten sich Warmwasser-Zentralheizungen auch in den deutschen Wohnungen durch. Bis heute ist dies die gängige Form der Gebäudeerwärmung in deutschen Haushalten, Gas- und Ölheizungen sind nach wie vor weit verbreitet (vgl. Clausnitzer 2014: 30). Im Folgenden soll dargestellt werden, wie es dazu gekommen ist, dass Wohnraumheizen mittels Gas- oder Ölzentralheizung in den 1970er Jahren zur konventionellen Art des Heizens in deutschen Privathaushalten geworden ist.

Um die Etablierung dieser Normalität zu erklären, erscheint es hilfreich, analytisch zwischen den materiellen, konventionellen sowie kultur- bzw. zeitgeschichtlichen Dimensionen des Heizens zu unterscheiden; wohl wissend, dass in der Praxis die verschiedenen beteiligten Komponenten in permanenter Wechselwirkung stehen und stets eng miteinander verflochten, eben immer zeitgleich in und zu einer einheitlichen Praktik integriert sind. Wenn das heutzutage typische Heizen in seiner gegenwärtigen Erscheinungsform erklärt werden soll, dann sind die Beziehungsverhältnisse zwischen den Dimensionen zu theoretisieren. Im Folgenden soll deshalb verdeutlicht werden, wie die Elemente zu unterschiedlichen Zeitpunkten jeweils spezifische Verbindungen eingegangen sind. 
Die Geschichte des Heizens soll gegenstandsbezogen als eine Geschichte von ständigen Innovationen in der Befeuerungs- und Heizungstechnik, von Neuentwicklungen im Anlagenbau der Wärmeverteilung sowie der Versorgung(slage) mit Brennmaterialien erzählt werden. In der vorhandenen historischen Literatur zur Entwicklungsgeschichte des Heizens wird nur begrenzt auf kulturelle Aspekte, soziale Konventionen und Bedeutungen eingegangen; dies auch, weil die Geschichtsschreibung schon immer stark auf die Herrschenden konzentriert war und alltägliche Praktiken von ,gewöhnlichen' Menschen kaum in den Blick genommen hat. Allerdings lässt sich die Geschichte des Heizens gut anhand von materiellen Artefakten nachvollziehen, die als gegenständliche Speicherformen und Trägerschaften sozialer Praktiken begriffen werden können (vgl. Schmidt 2012: 55-69). Wo dies aufgrund der Quellenlage möglich ist, werden betreffende kulturgeschichtliche Entwicklungen, soziale Konventionen und entsprechende Sinnzuschreibungen sowie deren Wandel mit in die Darstellung einbezogen.

\section{Das offene Feuer als erste künstlich-direkte Heizung}

Lange Zeit ist Heizen eine aufwendige und schmutzige Angelegenheit gewesen. Über viele Jahrtausende und bis ins Mittelalter hinein waren Lagerfeuer bzw. offene Feuer die einzige Form künstlicher Heizung, die den Menschen zum Beheizen ihrer Behausung zur Verfügung stand (vgl. Loewer 1968: 1; Roberts 1995: 773). Das meist in der Raummitte platzierte offene Feuer - bei der Feuerstelle handelte es sich meistens um ein einfaches Loch im Boden in der Mitte des Raumes, das mit Steinen umrandet wurde - verrußte die Innenraumluft stark (vgl. Recknagel 1915: 76). Ein weiterer Nachteil des offenen Feuers bestand darin, dass es nur so lange wärmte, wie es tatsächlich brannte und die Wärme verflüchtigte sich schnell in alle Richtungen. Das heißt, die Energieeffizienz dieser Heizmöglichkeit war äußerst dürftig. Darüber hinaus strömte und strahlte die Wärme nur in die unmittelbare Umgebung aus, weshalb es nur in dem Raum warm wurde, in dem sich die Feuerstelle befand. Dementsprechend wurde das wärmespendende Feuer, das meist gleichzeitig auch Kochstelle war, zum Mittelpunkt des häuslichen Lebens; und das blieb es viele Jahrhunderte. 


\section{Die römische Fußbodenheizung - der erste, Vorläufer' der modernen Zen- tralbeizung}

Im ersten Jahrhundert vor Christus entwickelte der Römer Gaius Sergius Orata ein kompliziertes Heizsystem, das als frühe Form einer FußbodenZentralheizung angesehen werden kann (vgl. Roberts 1995: 773). Die so genannte Hypokausten-Heizung fand im römischen Reich und seinen nördlichen Provinzen zuerst und vor allem in öffentlichen Thermen Verwendung. Später ließen einige reiche Römer*innen und Griech*innen einzelne Räume ihrer (Land-)Villen mit diesem aufwendigen und komfortablen Heizungssystem ausstatten (vgl. Loewer 1968: 2). ${ }^{31}$ Es gab dreierlei Arten von Hypokausten-Heizsystemen: 1) die reine Fußbodenheizung, 2) eine Fußboden-Wand-Heizung und 3) eine Warmluftheizung, bei der die warme Luft über Löcher im Fußboden direkt in den Raum gelangte (vgl. Roberts 1995: 773). Die Konstruktion bestand aus einem Brennofen, einem unter dem Fußboden liegenden Hohl- bzw. Heizraum sowie Abzügen für die heiße Luft und die Rauchgase. Der Hohlraum entstand dadurch, dass Türmchen von Ziegelplatten den Fußboden (Estrich) trugen (vgl. Bean et al. 2010: 50). Bei dieser ,Warmluftheizung' wurde zunächst die Luft in einem separaten, außerhalb des Hauses gelegenen zentralen Brennofen (Heizkammer) auf ca. 250 Grad Celsius erhitzt. Die aufsteigende Warmluft wurde dann über Tonrohre in einen Zwischen- bzw. Hohlraum unterhalb des Fußbodens (Hypokaustum) und/oder in Hohlziegel der Raumwände geleitet. Von dort aus erwärmte die durchströmende Luft die Bodenplatte und/oder die Wände, die einen Teil der Wärme in die darüber liegenden bzw. eingeschlossenen Räume abgaben und diese somit erwärmten (vgl. Faber 1957: 70; Loewer 1968: 2). Als massive Wärmeträger, die mit warmer Luft durchströmt und dadurch erwärmt wurden, dienten vor allem Fußböden oder Wände, die aber im Vergleich zu einem Heizkörper nur eine deutlich niedrigere Oberflächentemperatur erreichten. Auf dem Fußboden erreichte man auf diese Weise ungefähr $35 \mathrm{Grad}$, im Raum etwa 21 Grad Celsius. Allerdings dauerte es mehrere Tage bis ein Raum auf diese Temperatur erwärmt war. Demnach war die Energieeffizienz dieses Heizsystems eher gering, der Brennstoffverbrauch dafür aber entsprechend hoch (vgl. Roberts 1995: 773f). Mit der Hypokausten-Heizung verband sich unter anderem der Vorteil, dass die Luft in den Wohnräumen sauber blieb, da die Verbrennungsgase über Rohre und Schächte

31 Die Bezeichnung Hypokauste bzw. Hypokaustum (Singular) stammt aus dem Griechischen und setzt sich zusammen aus hypo = von unten und kauein = brennen. Es bedeutet so viel wie ,Heizen von unten her`, von unten beheizt'. 
in den Wänden nach draußen strömten, nachdem sie ihre Wärme an die Wände und Pfeiler abgegeben hatten (vgl. Faber 1957: 70). Darüber hinaus war das Hypokaustum durch einen besonderen Frischluftkanal mit dem Freien verbunden, durch den man der durch den Feuerraum einströmenden heißen Luft kalte Luft zumischen konnte - diese Heizung ließ sich also bereits regulieren (vgl. Recknagel 1915: 80f). Recknagel schreibt hierzu:

„Die Einrichtung [also die Hypokaustenheizung, JM] stand ohne Zweifel auf einer sehr hohen Stufe. Man war in der Lage, den angestrebten Zweck der Raumheizung gleichzeitig mit guter Lüftung zu erreichen.“ (ebd.: 81)

Einen kleinen Nachteil hatte die Hypokaustenheizung laut Recknagel jedoch: Zu ihrer Befeuerung musste Holzkohle verwendet werden, weil sich andernfalls unangenehm riechender Glanzruß gebildet hätte. Dies hatte zur Folge, dass „,[d]er Betrieb teuer [wurde], da der mit der Heizung verbundene reichliche Luftwechsel sowohl als auch die Herabsetzung des Wirkungsgrades der Feuerung gegenüber der Heizung mit Feuerbecken viel Holzkohlen erforderte“ (ebd.: 81).

Mit dem Untergang des Römischen Reiches verschwanden allerdings auch die meisten technischen Einrichtungen der Römer*innen, so auch ihre anspruchsvollen Heizvorrichtungen. Recknagel zufolge haben die von den Römer*innen entwickelten Hypokaustenheizsysteme den German*innen nicht als Ausgangspunkt für ihre Heizanlagen gedient (vgl. Recknagel 1915: 82), sondern man findet bei ihnen in den ersten Jahrhunderten wieder den Herd mit dem offenen Holzfeuer, als nächste Stufe den Kamin und im 10. Jahrhundert dann die Ofenheizung. Erst viele Jahrhunderte später wurden ähnlich funktionierende Heizsysteme in Ländern wie England und Frankreich entwickelt. Das alte römische Heizungssystem wurde erst im Europa des 18. Jahrhunderts wieder neu entdeckt (vgl. Bruegmann 1978: 144; Roberts 1995: 774).

\section{Die Feuerstelle wird zum Kamin}

$\mathrm{Ab}$ dem 8. Jahrhundert entwickelten sich im Laufe der nächsten Jahrhunderte aus der offenen Feuerstelle die unterschiedlichsten Öfen und gemauerten Herde. Diese ersetzten schließlich zunehmend die offene Feuerstelle und verlegten sie von der Mitte des Raumes in eine Wandnische. Immer häufiger wurden Häuser mit Holzfußböden ausgestattet, so dass offene Feuerstellen eine ständige Brandgefahr bedeuteten. So entstand die Idee des gemauerten Herdes aus der Absicht heraus, diese Gefahr zu reduzieren. „Die ersten Öfen dieser Art wurden im frühen Mittelalter aus gebrannten 
Hohlziegeln oder aus Lehm gebaut“ (Loewer 1968: 3). Von nun an konnte das Feuer in einem geschlossenen Behälter entzündet werden, der für die Erwärmung des Raumes sorgte. Diese gemauerten Öfen wurden im 13. und 14. Jahrhundert zu dem noch heute bekannten Kachelofen verbessert.

In Europa kam zwischen dem 10. und 12. Jahrhundert der Kamin(ofen) auf - eine Heizungsart, bei der das Feuer sowohl an den Seiten als auch von hinten durch einen Rauchabzug umbaut wurde. War der Rauch der offenen Feuerstelle bis dahin einfach über ein Loch im Hausdach ins Freie entlassen worden, wurde aufgrund der sich langsam durchsetzenden mehrgeschossigen Bauweisen eine andere Handhabung erforderlich: Das Feuer musste an die Wand des Raumes rücken und wurde mit einem Kamin verbunden. Die Erfindung des Kamins veränderte schließlich grundlegend, wie Familien ihre Häuser heizten. Waren Häuser bis dahin stets verraucht gewesen, sorgte nun die neue Kamintechnik für sauberes Heizen in den Wohnräumen: Die Luft wurde vom Kamin aus dem Raum ins Feuer gezogen und die Abluft bzw. der warme Rauch wurde dann über einen Rauchfang und einen Schornstein direkt nach draußen geleitet (vgl. Roberts 1995: 774). Mit der Kamintechnik wurde es möglich, auch auf mehreren Etagen Feuer zu betreiben, also mehrere Ebenen zu beheizen, und dennoch den Raum frei von Rauchgas zu halten - ein bedeutender Schritt nicht nur im Hinblick auf den Wohnkomfort, sondern auch für die Sicherheit. Im Zuge dessen wurde auch ,richtiges' Lüften wichtig, damit der Kamin gut arbeitete.

Zwar machte die Kamintechnik die Luft der Wohnräume erträglich; allerdings ging dabei, obwohl der Kamin schon eine deutlich höhere Heizleistung und bessere Wärmespeicherung als die offene Feuerstelle erzielte, immer noch ein Großteil der erzeugten Wärme verloren. Grund hierfür war: Kamine wurden bis ins ausgehende Mittelalter - bis man effizientere Baumaterialien entdeckte und bessere Bautechniken entwickelte - von dicken Steinen umringt, die kaum Wärme aufnehmen und abgeben konnten. Die Hitze wurde demnach nur über das Feuer selbst abgestrahlt. Dies machte es notwendig, in jedem Raum Kamine - und damit auch entsprechend komplexe Rauchabzugsnetzwerke - zu bauen; bis im 14. Jahrhundert dann die ersten Kachelöfen entstanden. Oftmals reichte „die mäßige einseitige Wärmeabgabe des üblichen Kamins“ (Faber 1957: 67) in strengen Wintern gar nicht aus, um das Zimmer angenehm und gleichmäßig zu erwärmen, so dass der Kamin manchmal durch andere zusätzliche Heizanlagen wie Einzelöfen unterstützt werden musste. 
Ungeachtet der genannten Vorteile der damals neu entwickelten Kamintechnik benötigten gemauerte Rauchschlote bzw. Schornsteine hierzulande noch bis zum 15. Jahrhundert, bis sie großflächig verbreitet waren.

Trotz ihrer für das mitteleuropäische Klima schon damals häufig zu geringen Wärmeleistung erfreuen sich Kaminöfen in Deutschland heute noch wie damals großer Beliebtheit. Dies hat vor allem ästhetisch-dekorative Gründe: das lodernde Kaminfeuer steht nach wie vor sinnbildlich für (häusliche) Gemütlichkeit (vgl. Faber 1957: 65ff):

„So anheimelnd das flackernde Kaminfeuer mit seinem wechselnden Flammenspiel, den knisternden funkensprühenden Holzscheiten, seinem trautlichen Lichtkreis im Raum sein mag, eine so schöne Augenweide und gemütlicher Platz zum Plaudern und Träumen in der Dämmerstunde, so schlecht heizt der Kamin, so völlig unzureichend ist er in feuerungstechnischer Hinsicht.“ (ebd.: 67)

\section{Kachel- und Eisenöfen entstehen}

Als Nachfolger des im Haus eingebauten Back- bzw. Küchenofens entstand der Kachelofen. Neben dem Kamin wurde der Kachelofen ab dem 13. Jahrhundert zu einer zweiten, ähnlich üblichen Art des Heizens (vgl. Loewer 1968: 3). Im Unterschied zum Kamin, der von dicken Steinen umringt war, die kaum Wärme speichern und abgeben konnten, waren die neu entstandenen Kachelöfen mit gebrannten Steinen ummauert, die viel Hitze abgaben. Die einzelnen Ofenkacheln wurden aus einer speziellen Tonmischung gefertigt, die über eine große Wärmespeicherfähigkeit verfügte. Damit erreichte man, dass die beim Verfeuern von schnell niederbrennenden Festbrennstoffen wie Holz oder Holzkohle kurzzeitig anfallende große Wärmeenergiemenge von den massigen Kacheln zunächst aufgenommen wurde. Anschließend gaben die Kacheln diese gespeicherte Wärme dann über einen längeren Zeitraum in den zu beheizenden Raum ab. Hierzu lässt sich festhalten: „Bis zum 14. Jahrhundert war der Ofen nur für das niedere Volk, von da ab wurden auch in den Burgen architektonisch ausgebildete Kachelöfen verwendet“" (Recknagel 1915: 83).

Der Kachelofen fand insbesondere im nördlichen Deutschland und in Skandinavien weite Verbreitung bzw. überall dort, wo ein gemäßigtes bis kühles Klima vorherrscht (vgl. Roberts 1995: 775). ${ }^{32}$ Im Süden Deutschlands und im Rest Europas verbreitete sich eher der Eisenofen. Durch die

32 Vgl. de.wikipedia.org, Artikel zum Thema ,Kachelofen', zuletzt aktualisiert am 05.01.2018, zuletzt geprüft am 06.08.2018. 
Erfindung der Eisengusstechnik wurde im 15. Jahrhundert die Entwicklung von geschlossenen Eisenöfen möglich. Die ersten eisernen Öfen waren aus mehreren gusseisernen und meist reichlich verzierten Platten zusammengesetzt und verfügten häufig über einen steinernen Aufsatz, welcher deutlich besser als das Metall die Wärme speichern konnte (vgl. Loewer 1968: 3).

Die ersten Feuerungen von Kamin und Kachelofen bestanden aus einfachem Holz, später benutzte man eher Kohle oder Koks zur Befeuerung. In der Mitte des 18. Jahrhunderts wurde Holz von Kohle als beliebtester Brennstoff abgelöst. Wegen ihres aufwendigen Heizstils hatten schon die Römer*innen die um Siedlungen liegenden Wälder weitestgehend gerodet. Im 16. Jahrhundert wurde Holz in Europa zu einem knappen Rohstoff. Diese Entwicklung hatte ihre Ursachen nicht nur im stetigen Bevölkerungszuwachs, sondern auch in dem in dieser Zeit einsetzenden Entdeckungsdrang und den dafür benötigten Schiffen. „Die immer drängendere Holznot hatte schließlich dazu geführt, sich nach einem anderen Brennstoff für Gewerbe und Haushalt umzutun“ (Faber 1957: 208). Alternativen für das mehr und mehr zur Neige gehende Holz fand man in Form der zuvor als minderwertig angesehenen Stein- und Holzkohle. Damals war Kohle noch leicht verfügbar: viele Kohleflöze ragten an die Erdoberfläche. Doch je mehr diese anfangs noch leicht zugänglichen Lagerstätten ausgebeutet wurden, in desto tiefer liegende Gesteinsschichten musste man vordringen. Damit steht die Geschichte der Heizung auch in engem Zusammenhang mit der des Bergbaus. ${ }^{33}$ Darüber hinaus erschien Kohle komfortabler, da bei ihrer Verbrennung mehr Wärme produziert werden konnte als bei der Holzverfeuerung.

Der Kamin und der Kachelofen blieben lange, noch bis ins 19. Jahrhundert hinein, die bevorzugten Arten private Wohnräume zu heizen (vgl. Roberts 1995: 775).

\section{Die erneute Entdeckung der Zentralheizung im 18. Jabrhundert}

Nach dem (zeitweiligen) Verschwinden der Hypokausten-Heizung zusammen mit dem Untergang des Römischen Reichs wurde die Technologie der Zentralheizung in Europa erst im 18. Jahrhundert wieder bzw. neu entdeckt. Wie bereits erwähnt, diente das anspruchsvolle Heizprinzip der

33 Vgl. o. A. 2000-2018*: www.wissen.de/heizung-eine-brennend-heisse-geschichte (Online-Artikel auf wissen.de - das Wissensportal von bild der wissenschaft), zuletzt geprüft am 06.08.2018. 
Römer*innen hierbei nicht als Vorbild (vgl. Recknagel 1915: 82). Und erst im frühen 19. Jahrhundert wurden Zentralheizungen erneut verstärkt in Betrieb genommen.

Die ersten Zentralheizungssysteme neueren Typs wurden hauptsächlich während der Industriellen Revolution, also in der zweiten Hälfte des 18. und im (frühen) 19. Jahrhundert in England und Frankreich entwickelt (vgl. Loewer 1968: 3). Es gab drei grundlegende Verfahren, auf denen moderne Gebäudezentralheizungen im Wesentlichen basierten: auf der Zirkulation von heißer Luft, von (Wasser-)Dampf und von heißem bzw. warmem Wasser (vgl. Bruegmann 1978: 143). ${ }^{34}$

Dabei ist bemerkenswert, dass diese wiederentdeckten oder neu entwickelten Heizverfahren ursprünglich alle nicht für private Zwecke, das heißt zur Beheizung privater Wohnräume, sondern zunächst für andere, in der Regel für wirtschaftliche Zwecke entwickelt wurden. Nicht die Erhöhung des privaten Wärmekomforts, sondern vielmehr die Aufrechterhaltung, Fortführung oder sogar Erhöhung der Produktion(serträge), etwa von Nahrungsmitteln oder Textilien standen damals bei der neuerlichen Erfindung der Zentralheizungstechnik im Vordergrund. Die Kunsthistorikerin und Architektin Emmanuelle Gallo schreibt in ihrem Buchbeitrag mit dem Titel „Lessons Drawn From the History of Heating: A French Perspective“ (Gallo 2008) hierzu:

„During the modern period, there was another productive field where new heating methods were experienced long before it was applied in

34 Die Heißluftzentralheizung entwickelte sich aus dem gebräuchlichen geschlossenen Küchen- bzw. Kachelofen. Bruegmann zufolge war dafür lediglich erforderlich, den Ofen nach außerhalb der zu heizenden Räume zu verlegen und stattdessen nur die vom Ofen erwärmte Luft in die Räume strömen zu lassen (Bruegmann 1978: 144). Die Heiß- bzw. Warmluftzentralheizung verwendete die Raumluft als Wärmeträger. Sie erforderte weder besondere Investitionen noch spezielle ingenieurswissenschaftliche Kompetenzen. So wurden in den ersten Jahrzehnten des 19. Jahrhunderts etliche solcher Heizungen installiert (vgl. ebd.: 146). Insgesamt fanden Heißluft geführte Heizsysteme in Europa aber nie wirklich großen Anklang (vgl. Nagengast 2001*).

Die Dampfzentralheizung bestand aus einem zentralen Dampferzeuger und einem Rohrleitungssystem, in welchem der heiße Dampf unter hohem Druck zirkulierte. Kohlebefeuerte Kessel lieferten den heißen Dampf, der über aufgestellte Heizkörper somit indirekt in die Räume gelangte und diese hierdurch erwärmte (vgl. Bruegmann 1978: 146f). In ähnlicher Weise funktionierten die ersten Heißbzw. Warmwasser-Zentralheizungen, nur, dass hier statt heißem Dampf tatsächlich das erhitzte Wasser im Rohrleitungssystem und in den daran angeschlossenen Heizkörpern zirkulierte. 
living spaces: this is the case of greenhouses. From the early $17^{\text {th }}$ century, there were several types of systems: indirect smoke heating underneath vaults or in hallow walls. At the end of the $18^{\text {th }}$ century and the early $19^{\text {th }}$ century there was also steam heating or hot water heating systems to heat greenhouses. [...] The conservation of exotics [sic!] plants and the production of vegetables or fruit came before domestic comfort. Sometimes in winter, wine froze in glasses inside the Versailles castle, heated by chimneys, while pineapples shrubs were properly heated in the castle`s greenhouses." (ebd.: 269f)

Die älteste bekannte Warmwasser-Zentralheizung wurde demnach bereits im Jahre 1716 von dem in England lebenden Schweden Marten Trifvald entwickelt. Jedoch baute er diese, wie erwähnt, nicht in ein Wohnzimmer ein, sondern sie diente der Beheizung eines Gewächshauses im englischen Newcastle (vgl. Roberts 1995: 775f). Auch Dampfzentralheizungen, die eine englische Erfindung sind, wurden anfangs fast ausschließlich in Treibhäusern eingesetzt. ${ }^{35}$ Später wurde die Dampfheizmethode dann noch in Mühlen und Fabrikräumen eingesetzt, um diese an kalten Tagen zu erwärmen. Dies geschah allerdings ebenfalls nicht aus der (vorrangigen) Absicht heraus, die Behaglichkeit bzw. den Komfort der Arbeiter*innen zu erhöhen, sondern um die Produktion zu erleichtern (vgl. Recknagel 1915: 83; Gallo 2008: 270). Und in ihrem Text zur Entwicklungsgeschichte der Heizung beschreibt Gallo noch ein weiteres anschauliches Beispiel, zu welchen wirtschaftlich-industriellen Zwecken die ersten Heißwasser-Zentralheizungssysteme während der Industriellen Revolution entwickelt wurden:

„In France, during the same period [at the end of the $18^{\text {th }}$ century and the early $19^{\text {th }}$ century, JM], hot water central heating was firstly developed by Jean-Simon Bonnemain (1743-1830). In 1777, this clever man built a system for hatching eggs and rearing chickens artificially. The purpose was clearly to produce chickens throughout the year, and that is what he did until the French revolution.” (Gallo 2008: 270)

35 Matthew Boulton und James Watt gelten als Pioniere auf dem Gebiet der Dampfmaschinentechnik in den letzten Dekaden des 18. Jahrhunderts. Mit entscheidender Weiterentwicklung und Verbesserung der Dampfmaschine revolutionierte der Engländer Watt im Jahr 1769 die Industriegesellschaft. Fünf Jahre später, so wird berichtet, beheizte er nicht nur seine Fabrikräume, sondern auch sein Wohnhaus in Birmingham mit Dampf (vgl. Faber 1957: 3). 
Laut Recknagel stellte diese erste Wasserzentralheizung, die vor allem zum künstlichen Ausbrüten von Hühnereiern diente, „schon in ihrer ersten Ausführung eine sehr vollkommene Einrichtung mit selbsttätigem Temperaturregler dar" (Recknagel 1915: 84). Allerdings, so merkt er kritisch an, hatte sie auch „nur einen einzigen aus fortlaufenden Rohrschlangen gebildeten Heizkörper mit Wärme zu versorgen“ (ebd.). Erst im Jahre 1819 errichtete der Pariser Marquis de Chabannes, der als einer der französischen Pioniere auf dem Gebiet der Zentralheizungstechnik gilt, die erste Warmwasserheizung für mehrgeschossige Wohngebäude - dies allerdings in London (ebd.). Und laut Gallo unternahm er nach seiner Rückkehr in sein Heimatland nie den Versuch, seine Heizungsinnovationen auch in Frankreich einzuführen (vgl. Gallo 2008: 272).

Dieses nun mehrfach beschriebene Muster in der Entwicklungs- und Verbreitungsdynamik moderner Zentralheizungstechnik in Europa ist im Übrigen auch für den Bereich moderner Klimatisierungs- und LüftungsTechnik in den USA deutlich erkennbar: Gail Cooper zitiert in ihrem Buch „Air-conditioning America“ (Cooper 1998) Stuart Cramer, einen der Pioniere moderner Klimatisierungstechnik, der während der ersten Dekade des 20. Jahrhunderts nach eigenen Angaben intensiv darum bemüht war, durch die Einführung moderner Raumklimatisierungssysteme in Produktionsgebäuden der Textilindustrie im Süden Amerikas für die besten Bedingungen während der Textilproduktion zu sorgen. Die Kontrolle der Luftfeuchte half demnach, verschiedene Prozesse der Textilienherstellung aus Baumwolle oder anderen Wollgeweben zu erleichtern (vgl. Cooper 1998: 17-23). Demzufolge ging eine umfassendere industrielle Entwicklung von Klimaanlagen in den USA ebenfalls vom Produktionsbereich aus, wurden Klimaanlagen zuerst nur in Produktionsgebäuden verwendet, bevor sie schließlich auch in Büros, in öffentlichen Gebäuden wie Theatern oder Museen und schlussendlich in privaten Wohngebäuden zum Einsatz kamen (vgl. Gallo 2008: 270). Und genauso wurden (Warmwasser-)Zentralheizungen nach ihrer Erstanwendung im Produktionsbereich zunächst für die Verwendung in öffentlichen Gebäuden weiterentwickelt, bevor die neue Heiztechnik in den Privatwohngebäudebereich diffundierte (vgl. ebd.: 274). Für Gallo machen diese unterschiedlichen Fallbeispiele deutlich, „that [in all these cases, JM] comfort, especially home comfort, never came first“ (ebd.: 271).

Wesentlicher Treiber für die Entwicklung der ersten Zentralheizungssysteme für den Privatbereich im Verlauf des 18. Jahrhunderts war der Wunsch von Adels- und Fürstenhäusern, ihre Häuser mit einer möglichst geringen Anzahl an Feuerstellen optimal zu beheizen. Die neue Art des 
Heizens mit heißem Dampf oder warmem Wasser fand demnach zunächst vor allem bei reichen Adelsfamilien Anklang (vgl. Bruegmann 1978: 147). In Deutschland ließen sich ab etwa 1850 einige Fürst*innen und wohlhabende Bürger*innen Dampf- oder Warmwasserzentralheizungen in ihre Schlösser und Villen einbauen. So gründete der Ingenieur Johannes Haag 1843 in Kaufbeuren eine, Werkstätte für allgemeinen Maschinenbau und für die Herstellung von Zentralheizungen' und kann somit als erster Heizungsbauer Deutschlands gelten. Sein erster Auftrag galt dem baden-württembergischen Hohenzollern-Schloss in Sigmaringen, das somit die erste Heißwasser-Heizanlage, eine Dampfzentralheizung, Deutschlands erhielt (Häußler 2008). Im späten 19. Jahrhundert fand die Zentralheizungstechnik dann Eingang in die bürgerlichen Wohnungen. „But during the entire nineteenth century, the domestic use of central heating was generally delayed“ (Gallo 2008: 273). So stellt Nagengast in der Rückschau fest, dass die Europäer*innen sehr zurückhaltend, ja regelrecht abgeneigt waren, speziell Dampfheizungssysteme in ihren Wohnungen zu verwenden: „A few installations were made, but steam was generally not accepted in Europe for another decade or more" (Nagengast 2001*). Dies ist zum einen sicherlich auf die grundlegende Skepsis zurückzuführen, mit der Menschen größeren Neuerungen anfangs häufig begegnen. Zum anderen hatten sich die neuen Heizmethoden, insbesondere die mit Heißluft bzw. heißem Wasserdampf, als nicht ganz ungefährlich erwiesen, so dass Nachrichten von verletzten oder sogar getöteten Personen bei Hausbränden infolge von explodierten Heizungsboilern zusätzlich für einen schlechten Ruf moderner Zentralheizungen sorgten (vgl. Gallo 2008: 275).

Ab etwa 1830 begann man die Vorteile von Warmwasser gegenüber heißem Dampf als Wärmeträgermedium zu erkennen: So hat Warmwasser eine viel niedrigere Vorlauftemperatur und damit einen sanfteren Gesamteffekt als Dampf. In weiten Teilen Europas hat sich deshalb Warmwasser gegenüber Dampf als bevorzugtes Heizmethode durchgesetzt - unter anderem aufgrund des hier vorherrschenden gemäßigten Klimas; Heißluft führende Heizsysteme fanden in Europa dagegen nie großen Anklang (The Editors of Encyclopædia Britannica 1998*).

"Schneller als in Deutschland verbreitete sich die Zentralheizung in den USA“ (König 2000: 237). Zwar wurde die neue Zentralheizungstechnik üblicherweise auch von hiesigen technischen Experten wie Ingenieuren schon frühzeitig mehrheitlich befördert und unterstützt. Allerdings zeigten sich damals einige Ingenieure zurückhaltend, insbesondere was den Einsatz von Zentralheizungen im privathäuslichen Bereich anbelangte. So schrieb beispielsweise der Ingenieur Paul Planat in der zweiten Hälfte des 
19. Jahrhunderts ausführlich über die weite Verbreitung von Zentralheizungen in amerikanischen Privathaushalten, nahm zugleich aber an, dass diese Technik nicht für den Einsatz in französischen Wohnungen geeignet sei (vgl. Gallo 2008: 274f). Und so dauerte es noch bis zum Beginn des 20. Jahrhunderts bis die (Warmwasser-)Zentralheizung schließlich auch in Ländern wie Deutschland und Frankreich den Ofen als weitverbreitetste Art des Heizens ablöste. Die Erfindung der effizienteren (Zentral-)Heizung setzte sich in Europa demnach nur langsam durch.

Zwar hatten die Menschen auch schon in den Jahrhunderten zuvor nach mehr (Wohn-)Komfort gestrebt, etwa, dass weniger Rauch aus den Kaminöfen kommt, und sie waren zu dieser Zeit schon bemüht gewesen, die damals verwendeten Brennstoffe Holz und Kohle möglichst sparsam einzusetzen. Jedoch war im Laufe des 19. Jahrhunderts auch bei unteren Bevölkerungsschichten die Anzahl der Räume stetig gestiegen, wodurch sich der Heiz- bzw. Raumwärmebedarf und damit unweigerlich auch der Verbrauch an Brennstoffen immer weiter erhöht hatten. Mit der Zeit waren es einfach zu viele Räume geworden, um jeden mit einem einzelnen offenen Kamin zu beheizen, so dass diese allmählich mehrheitlich durch kleine geschlossene Zimmeröfen (mit einem eigenen, verhältnismäßig kleinen Kaminanschluss) ersetzt wurden. Während Zimmeröfen genauso wie (die ersten) Zentralheizungen mit Kohle befeuert werden konnten, traf dies auf die traditionellen Kamine in der Regel nicht zu (vgl. ebd.: 274):

"Before the $18^{\text {th }}$ century, townhouses had only a few chimneys, some times [sic!] just one. After this period, there was almost one chimney or stove for each room, and this significantly increased the consumption of fuel. At the same time, the master of the house was not the only one to access warmth; the servants began to be interested as well." (ebd.: 277f)

„A real evolution in the growth of democratisation of thermal comfort" (ebd.: 277) ereignete sich in den westlichen Industrieländern allerdings erst im Verlauf des 20. Jahrhunderts - dafür war die Umstellung der Beheizung von Festbrennstoffen auf Öl und Gas entscheidend.

Um Heizkosten zu sparen, blieben viele Haushalte zunächst noch bei Kohle-Einzelöfen. Die Nutzung der Kohle als Hauptbrennstoff war zwar nicht sehr ökologisch: die ersten Kohlekraftwerke verschmutzten durch Ruß und Abgase die Luft und nutzten die im Brennstoff Kohle gespeicherte Energie nur unzureichend aus. Jedoch war Kohle vor Ort in großen Mengen vorhanden und deshalb relativ kostengünstig. Hinzu kam, dass 
der Transport von Energieträgern früher deutlich aufwendiger war als heute. Dementsprechend spielten regionale Aspekte, wie das lokale Vorkommen der zur damaligen Zeit hauptsächlich verwendeten Festbrennstoffe Holz, Braun- oder Steinkohle damals eine viel größere Rolle. Beispielsweise heizte man im Ruhrgebiet - einem Ballungsraum mit relativ wenig Waldfläche, aber reichlichen Kohlevorkommen - schon früh viel mit Kohle; hingegen wurde in waldreichen Gegenden wie in Süddeutschland und in vielen ländlichen Gebieten überwiegend mit Holz geheizt.

So ist die Zentralheizung zwar seit dem 18. Jahrhundert bekannt, aber aus oben genannten Gründen ein Luxus, den sich zunächst nur wohlhabende Bürger*innen leisten konnten. Sie blieb zunächst - und so auch während des gesamten 19. Jahrhunderts hindurch - ein seltenes Statusbzw. Luxusobjekt. In den ärmeren Haushalten war dagegen weiterhin, das heißt bis in die Zeit nach dem Zweiten Weltkrieg, die dezentrale und damit direkte sowie selektive und temporäre Beheizung von Räumen während der Heizperiode die gängige Praktik.

Neue Impulse für die technische Weiterentwicklung der Zentralheizung im deutschen und allgemein im europäischen Raum gingen von den USA aus, wo sich die Zentralheizung insgesamt deutlich schneller verbreitete als in Deutschland und Europa (vgl. Schwartz Cowan 1983: 89ff): dort gefertigte und patentierte Gussheizkessel und Radiatoren wurden gegen Ende des 19. Jahrhunderts zum neuen Standard; sie lösten die alten Heizkessel und Wärmetauscher ab (vgl. Gallo 2008: 278). ${ }^{36}$

36 Wie die alltägliche Heizsituation in der breiten Bevölkerung und speziell in den ärmeren Haushalten Deutschlands (sowie in den USA) vor und zwischen den beiden Weltkriegen aussah, beschreibt sehr anschaulich der (Technik-)Historiker Wolfgang König in seinem Buch „Geschichte der Konsumgesellschaft" (König 2000): „In den Jahrzehnten vor dem Ersten Weltkrieg besaßen die allermeisten Wohnungen eine Heizmöglichkeit. In den winterkalten Klimaten Deutschlands und der USA ließ es sich in Wohnungen ohne Kamin oder Kohleofen schwerlich aushalten. In den Wohnungen der Ärmeren beschränkte sich die Heizung allerdings auf einen gußeisernen Herd in einem Raum, das heißt meist auf die Wohnküche. Im Winter bot einzig die Küche wohnliche Wärme, die anderen Zimmer bekamen je nach der räumlichen Lage zur Küche oder zum Kamin ein mehr oder weniger großes Quantum an Wärme ab. In den Schlafräumen krochen die Bewohner unter Decken oder das Federbett, in den Arbeitsräumen arbeitete man sich warm. Problematisch war ein sitzender Aufenthalt im Winter in unbeheizten Räumen. In der Zwischenkriegszeit schafften die beliebten Heizdecken, Heizkissen und sonstige elektrische Heizgeräte einen gewissen Ausgleich. Mit der Zeit dürfte die Zahl der Zimmer in der Wohnung zugenommen haben, ohne daß es hierzu genaue Zahlen gibt. Eine flächendeckende Wärmeversorgung fand aber 


\section{Öl- und Gas-Zentralheizung - Standard im 20. Jahrhundert}

Anfang des 20. Jahrhunderts setzte sich in Deutschland wie auch in anderen Ländern Europas zunehmend die Warmwasser- gegenüber der Dampfzentralheizung durch (vgl. ebd., vgl. auch The Editors of Encyclopædia Britannica 1998*). Nagengast verweist darauf, dass in Europa Dampfheizungssysteme zum Wohnraumheizen ohnehin nie wirklich beliebt waren, da sie als komplex und laut wahrgenommen wurden und man Explosionen aufgrund des hohen Drucks fürchtete (vgl. Nagengast 2001*). Wohl auch aus diesen Gründen bürgerten sich warmwasserbetriebene Zentralheizungen immer weiter ein. Insbesondere durch den Einsatz von Heizungspumpen fanden Warmwasserzentralheizungen immer weiter Verbreitung. Im Jahre 1920 produzierten die Brüder Buderus - Pioniere im Heizungsbau - die ersten Pumpen-Warmwasserheizungen. ${ }^{37}$ Diese neue Technik ermöglichte es, auch größere Wohnanlagen mit Warmwasser-Zentralheizungen auszustatten - es entstanden die ersten Etagenheizungen in (neugebauten) Mietshäusern (vgl. König 2000: 237). In dieser Zeit stieg das Kaufinteresse an Warmwasser- und Niederdruckdampfheizungen enorm und immer leistungsstärkere Heizkessel, Heizkörper und Rohrleitungssysteme wurden nachgefragt.

Parallel zur Entwicklung der Kesseltechnik veränderten sich somit auch die Heizkörper. Wie schon bei der Dampfheizung wurden anfangs Rohrschlangen und -register verwendet, danach kamen die schweren, meist aufwendig verzierten Rippenrohrheizkörper zum Einsatz. Mit der (starken) Verbreitung der Warmwasser-Heiztechnik entwickelten sich auch neue

erst mit dem Übergang zur Zentralheizung statt, das heißt in der Zeit nach dem Zweiten Weltkrieg“ (König 2000: 236f).

37 Anfangs erfolgte die Verteilung der Wärme im Rohrleitungssystem noch alleine durch die Schwerkraft. Man machte sich hier den Dichteunterschied des Wassers bei unterschiedlichen Temperaturen innerhalb des Heizsystems zu Nutze (vgl. Roberts 1995: 776). Eine Schwerkraftheizung benötigt demnach keine Umwälzpumpe. Im Westen Deutschlands wurden Zentralheizungen bis Ende der 1960er Jahre noch regelmäßig als Schwerkraftheizungen ausgeführt. In Ostdeutschland hat man Schwerkraftheizungen sogar noch bis zur Mitte der 1980er Jahre installiert. „Heutigen Ansprüchen an Heizkomfort und Energieeffizienz wird die Schwerkraftheizung allerdings nicht mehr gerecht. Man tauscht sie deshalb aus beziehungsweise rüstet das Heizsystem um, zumeist in eine Pumpenwarmwasserheizungsanlage." (Redaktion von energie-experten.org 2016*, Blog-Artikel zum Thema ,Schwerkraftheizung'). 
Bauformen für Heizkörper wie etwa Konvektoren, Plattenheizkörper, Strahlplatten oder Fußbodenheizungen. ${ }^{38}$

Ihren großen Durchbruch erlebte die Zentralheizung in Deutschland aber erst in den Jahrzehnten nach dem Zweiten Weltkrieg. Verschiedene sowohl wirtschaftliche und technisch- materielle als auch soziokulturelle Entwicklungen kamen in den Nachkriegsjahrzehnten zusammen, beförderten sich gegenseitig und sorgten im Verbund für den bahnbrechenden Erfolg der Zentralheizung(stechnik): Der Krieg hatte in Deutschland und in weiten Teilen Europas zu verheerenden Zerstörungen geführt. Ganze Städte mitsamt ihren Infrastrukturen waren in den Kriegsjahren dem Erdboden gleichgemacht worden. So furchtbar diese großflächigen Verheerungen für die Menschen auch waren, so hatten sie auch etwas Gutes: Dadurch war es möglich, dass die Infrastrukturen ganzer Innenstädte und Stadtviertel auf einen Schlag erneuert wurden - dazu gehörten auch Gasleitungen und in Neubauten moderne Heizungen. ${ }^{39}$

Als in den Jahren nach 1945 in Deutschland wie in ganz Europa der große Wiederaufbau begann, nutzten Hauseigentümer*innen und Wohnungsbaugesellschaften die einmalig günstige Gelegenheit, in die neu gebauten Häuser dann auch gleich moderne Heiz(ungs)formen zu integrieren. Mit dem wirtschaftlichen Aufschwung der 1950er und 1960er Jahre stieg in der Bevölkerung zudem auch der allgemeine Wunsch nach höherem Wohnkomfort. „Zusammen mit der entsprechenden Entwicklung der Heizungstechnik führte dies zu einer immer stärkeren Verbreitung der Zentralheizung" (GMSH 2013: 9). Die erfolgreiche Verbreitung der Zentralheizung begann demzufolge als Europa durch den Krieg weitgehend zerstört war.

Und obwohl solche frühen Formen von Zentralheizungen noch teilweise mit Kohle befeuert wurden, waren die Menschen es zunehmend leid, schwere und schmutzige Briketts heranschleppen zu müssen. So gerieten Festbrennstoffe für Einzelfeuerungsöfen mit jedem weiteren Neubau ins Hintertreffen. Gleichzeitig war mit dem Wiederaufbau der Nachkriegszeit die Möglichkeit dafür gegeben, dass Rohrleitungssysteme für Versorgungsnetze ganz neu verlegt werden konnten. Dadurch war es möglich, ganze Städte mit neuen bzw. oftmals bisher noch nie vorhanden gewesenen Gas-

38 Vgl. www.baunetzwissen.de/standardartikel/Heizung_Standard-Warmwasser-Zen tralheizung_161064, zuletzt geprüft am 15.08.2018.

39 o. A. 2000-2018*: www.wissen.de/heizung-eine-brennend-heisse-geschichte (Online-Artikel auf wissen.de - das Wissensportal von bild der wissenschaft), zuletzt geprüft am 06.08.2018. 
leitungen auszustatten, über die moderne Zentralheizungen betrieben werden konnten. ${ }^{40}$

Und gleichfalls wurde Öl immer mehr zur wichtigsten Energieressource auf der Welt: Durch die Nachfrage nach Öl als Treibstoff hatte der Krieg die Erschließung unzähliger Ölquellen erforderlich gemacht. Doch nun gewannen die Nebenprodukte der Raffination an Bedeutung. „Allen voran: Heizöl. Als Nebenprodukt der Benzinherstellung war es günstig und bot sich als Heizmaterial für Haushalte an - nicht zuletzt weil es so komfortabel wie Gas war" ${ }^{41} .42$

Das heißt, nachdem über viele Jahrhunderte fast ausschließlich Holz und Kohle als Heizbrennstoffe gedient hatten, vollzog sich im Laufe des 20. Jahrhunderts eine Umstellung in der Beheizung von Festbrennstoffen auf Öl und Gas nun relativ rasant. Bereits zu Beginn des 20. Jahrhunderts kamen die ersten Öl- und Gasbrennkessel auf den Markt (vgl. Schwartz Cowan 1976: 7). Aber auch (hier) bei dieser Technik - wie schon bei der Umstellung von den Einzelfeuerungsöfen auf die Zentralheizungstechnik

40 Vgl. o. A. 2000-2018*: www.wissen.de/heizung-eine-brennend-heisse-geschichte (Online-Artikel auf wissen.de - das Wissensportal von bild der wissenschaft), zuletzt geprüft am 06.08.2018.

41 o. A. 2000-2018*: www.wissen.de/heizung-eine-brennend-heisse-geschichte (wissen.de Artikel; wissen.de - das Wissensportal von bild der wissenschaft), zuletzt geprüft am 06.08.2018.

42 „Die Wärmeversorgung eines Gebäudes mit dem Energieträger Heizöl hat den großen Vorteil, dass er leicht an jedes Gebäude angeliefert werden kann. Dem steht gegenüber, dass Heizöl vor Ort bevorratet werden muss. Dieser Nachteil relativiert sich allerdings dadurch, dass durch die Speicherung eine gewisse zeitliche Unabhängigkeit vom Ölbezug erreicht wird“ (https:/www.baunetzwissen.de/ heizung/fachwissen/brennstoffe/heizoel-161108, zuletzt geprüft am 15.08.2018).

„Die Versorgung eines Gebäudes mit dem Endenergieträger Gas erfolgt meist durch einen Anschluss des Gebäudes an das Gasnetz des Gasversorgers. Durch diese leitungsgebundene Energieversorgung entfällt eine Speicherung des Energieträgers vor Ort. Der Anschluss an das Gasnetz wird in der Regel über eine Stichleitung zum Haus die von der Hauptleitung hergestellt. [...]. Im Gebäude besteht der Gasanschluss im Wesentlichen aus einem Haupt-Absperrhahn, dem Gaszähler und einem Gasdruckregler. Durch den leichten Überdruck strömt das Gas automatisch zum Wärmeerzeuger. Eine Versorgung eines Gebäudes mit Gas hat

neben der Raumersparnis durch den Wegfall der Brennstoffbevorratung noch die Vorteile, dass sich der

Brennstoffverbrauch leicht kontrollieren lässt und dass bei der

Verbrennung von Gas relativ wenig $\mathrm{CO}_{2}$ frei gesetzt wird" (https://www.baunetz wissen.de/heizung/fachwissen/brennstoffe/gas-161110, zuletzt geprüft am 15.08.2018). 
- lagen wieder mehrere Jahrzehnte zwischen Markteinführung und allgemeiner Verbreitung.

Zentralheizungen setzten sich vor allem ab den 1960er Jahren durch. Der Anteil, der mit Zentralheizung ausgestatteten Wohnungen stieg von 1960 bis 1970 in der Bundesrepublik von 12 auf $40 \%$; bis 1991 stieg der Wert auf 79,5\% (König 2000: 238). Kohle verlor als Brennstoff zunehmend an Bedeutung (von 1960 bis 1991 von 80 auf 5\%, ebd.). Mit Heizöl wurde bis 1970 mehr als die Hälfte der Wohnungen in Deutschland beheizt, später sank der Wert etwas ab, da Fernwärme, Elektrowärme und Gas hinzukamen. Gas erreichte 1991 einen Marktanteil von $31 \%$ und lag somit an zweiter Stelle der eingesetzten Energieträger (ebd.). Hintergrund dafür war preiswertes Erdgas aus der Sowjetunion und den Niederlanden. „Die privaten Wohnungen in der Bundesrepublik steigerten bis zur Mitte der 1970er Jahre ihren Anteil am gesamten Energieverbrauch auf etwa $25 \%$. Am Energieverbrauch der Wohnung besitzt das Heizen einen Anteil von mehr als drei Viertel“" (ebd.; vgl. auch GMSH 2013: 9).43

Die zunehmende Motorisierung des Verkehrs und der verstärkte Einsatz von Ölzentralheizungen, insbesondere ab den 1960er Jahren hatten, neben dem ebenfalls vermehrten Einsatz von Öl in der chemischen Industrie (z.B. zur Herstellung von Kunststoffprodukten), einen stetig steigenden Ölbedarf zur Folge. Und diese Entwicklungen wurden durch den in diesem Zeitraum äußerst niedrigen Ölpreis noch begünstigt. Die Themen Energiesparen und Energieeffizienz „spielte[n] daher politisch auch weiterhin kaum eine Rolle“ (GMSH 2013: 9). Die Ära sehr billiger Energie hatte zudem dazu geführt, dass in den 1950er und 1960er Jahren beim Hausbau praktisch kaum auf eine energiesparende Bauweise geachtet wurde. In den 1960er Jahren stand vielmehr im Vordergrund, Komfortsteigerungen durch automatische Heizungen für flüssige und gasförmige Brennstoffe zu

43 Gallo konstatiert für Frankreich eine ähnliche Entwicklung: „Heating systems burning oil became the modern way of heating even if oil refineries were rather rare in France. We found this energy in several modern buildings in towns or in the countryside, with better energy efficiency and a reduced workforce." (Gallo 2008: 278). Und an späterer Stelle führt sie weiter aus: „In 1954, the average lodging with central heating reached $10 \%$. But this rate was distributed very differently in France. In the country, the average reached $3 \%$, small towns $12 \%$ and Paris and its suburbs had $26 \%$. [...]. The rich suburbs of the West of Paris had $50 \%$ of lodgings with central heating. Ten years after World War II, central heating was still rare in France and a sign of special wealth" (ebd.: 279). 
erreichen. ${ }^{44}$ In den 1970er Jahren konnte sich der größte Teil der deutschen Bevölkerung bereits eine Zentralheizung leisten. Parallel zu diesen technisch-ökonomischen Veränderungen kam es auch zu einem deutlichen Wandel bei den gesellschaftlichen Komforterwartungen, die mit Wohnen, Heizung und Raumwärme zusammenhängen: So stieg mit der Etablierung der Zentralheizung in deutschen Privathaushalten die durchschnittliche Raumtemperatur von 18 auf 22 Grad Celsius (Shove 2004a; Shove 2014: 421).

\section{Exkurs: Fernwärme ${ }^{45}$}

Vornehmlich in der Nähe von Industriezentren, in denen viel Hitze etwa in Form von Abwärme aus Industrieprozessen erzeugt wurde, entwickelte sich im Deutschland der Nachkriegsjahre neben der (Gas- und Öl-)Zentralheizungstechnik noch eine weitere Heizform: Fernwärme. Zwar begann „[d]ie Versorgung eines ganzen Stadtviertels per Fernwärme [bereits] in der zweiten Hälfte des 19. Jahrhunderts, erreichte aber erst nach dem Zweiten Weltkrieg relevante Größenordnungen“ (König 2000: 237). Bei dieser Form der Gebäudeheizung wird die (außerhalb der Verbrauchsstätten erzeugte) Wärme in Form von Dampf oder heißem Wasser über wärmegedämmte Rohrleitungen vom Erzeuger oder einer Sammelstelle direkt zu den Verbraucher*innen, das heißt in die einzelnen Haushalte geleitet. Wenn auf diese Weise ganze Städte oder Stadtteile erschlossen werden, spricht man von Fernheizung. Fernwärme versorgt die angeschlossenen Wohngebäude neben Heizung meist auch gleichzeitig mit Warmwasser. Damals wurde das Heißwasser für das Fernwärmesystem vor allem in Kohle- und Ölkraftwerken mit Kraft-Wärme-Kopplung erzeugt und durch einige, ebenfalls fossil befeuerte Heizkessel ergänzt. Auch die Wärmelieferanten in heutigen Fernwärmenetzwerken, Heizkraftwerke und Blockheizkraftwerke, werden häufig noch mit fossilen Brennstoffen betrieben, allerdings werden sie in vielen Fällen auch schon mit Biomasse oder Müll befeuert (vgl. Deutsche Energie-Agentur GmbH (dena) 2016: 41). In modernen Fernwärmesystemen kommen als Wärmequelle immer häufiger erneuerbare Energien zum Einsatz (vgl. Bundesministerium für Wirtschaft und Energie (BMWi) 2017*). Und in Zukunft sollen vorrangig bzw. fast

44 Vgl. www.baunetzwissen.de/standardartikel/Heizung_Standard-Warmwasser-Zen tralheizung_161064, zuletzt geprüft am 15.08.2018.

45 Gilt ähnlich auch für Nahwärme, wobei hier abweichend die Übertragung von Wärme zu Heizzwecken nur über relativ kurze Entfernungsstrecken erfolgt. Die Übergänge zwischen den Bezeichnungen Fern- und Nahwärme sind fließend. 
ausschließlich erneuerbare Energien oder die Abwärme aus Industrieprozessen als Wärmelieferanten dienen.

Bisher konnte sich das Heizkonzept Fernwärme in Deutschland allerdings nicht breit durchsetzen - dies vor allem wegen der nach wie vor unvermeidbaren Wärmeverluste beim Transport der thermischen Energie über die in der Regel erdverlegten Leitungen. Die neueste (vierte) Generation von Fernwärmesystemen, die sich derzeit noch in der Erforschung und Erprobung befindet und ab ca. 2020 großflächig zum Einsatz kommen soll, verspricht hier deutliche Verbesserungen. Aktueller Stand der Forschung ist, dass die Bedeutung von Fernwärme in den letzten Jahren deutlich zugenommen hat und Fernwärmesysteme zukünftig bei einer nachhaltigen Energiewirtschaft eine wichtige Rolle spielen werden (vgl. Bundesministerium für Wirtschaft und Energie (BMWi) 2015b*).

In Deutschland befinden sich die größten Fernwärmenetze zur Wärmeversorgung privater Haushalte zurzeit in Berlin, Hamburg und München. Mit einem Anteil von ca. $98 \%$ Fernwärme am gesamten Wärmemarkt (d.h. Raumwärme und Warmwasserbereitung) gehört Flensburg zu den Städten mit dem höchsten Marktanteil bei Fernwärme. ${ }^{46}$

\section{Durch die Ölkrisen zum ökologischen Heizen}

Im Rückblick können die beiden ersten Nachkriegsjahrzehnte durchaus als "goldenes Zeitalter der Heizung “47 bezeichnet werden: erstmalig war zu ihrem Betrieb praktisch keine menschliche Interaktion mehr notwendig. Heizen war mehr und mehr zu einer ,Nebenbei-Tätigkeit‘ und zu einer einfachen Selbstverständlichkeit geworden. Dank der sich damals gerade etablierenden und zum allgemeinen Standard werdenden Zentralheizungstechnik, verbunden mit der meist gleichzeitig erfolgenden Umstellung der Befeuerung von Festbrennstoffen auf Öl und Gas, bedeutete Heizen für die Menschen keinen großen Arbeitsaufwand im Alltag mehr und es erforderte nur noch wenig von ihrer Aufmerksamkeit (vgl. Lewis 2011: 282).

Doch dann kam es im Jahr 1973 zur ersten Ölkrise: Sie „löste in den Industrieländern einen [gewaltigen] Schock aus und machte den Menschen ihre enorme Abhängigkeit von fossiler Energie bewusst“ (GMSH 2013: 7).

46 Vgl. de.wikipedia.org, Artikel zum Thema ,Fernwärme', zuletzt aktualisiert am 26.07.2018, zuletzt geprüft am 07.08.2018.

47 o. A. 2000-2018*: www.wissen.de/heizung-eine-brennend-heisse-geschichte (Online-Artikel auf wissen.de - das Wissensportal von bild der wissenschaft), zuletzt geprüft am 06.08.2018. 
Auch führte sie der deutschen Bevölkerung deutlich vor Augen, wie groß aufgrund des enormen gesellschaftlichen Energieverbrauchs mittlerweile die Abhängigkeit Deutschlands von Energieimporten geworden war - insbesondere von Rohöllieferungen aus der damals politisch zunehmend instabil werdenden Golfregion. Die zweite Ölkrise 1979/80, in deren Folge es zu einem weiteren drastischen Anstieg des Ölpreises kam, verstärkte diese Eindrücke noch weiter (vgl. ebd.: 9).

Bereits die erste Ölkrise bewirkte ein deutliches Umdenken in Bezug auf Heizen und (alltäglicher) Energieverbrauch. Die Themen ,Energieeinspa-

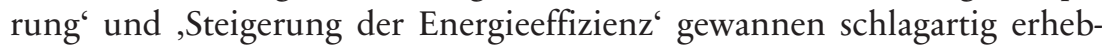
lich an Bedeutung und rückten immer stärker ins Zentrum politischer Tagesordnung. In Deutschland und in anderen Ländern sind durch den ,Ölpreisschock ${ }^{6}$ Mitte der 1970er Jahre in den darauffolgenden Jahren viele wichtige Entwicklungen angestoßen worden, so z.B. im Bereich der Gesetzgebung und der Technik, die bis heute andauern und sich wohl auch in Zukunft noch weiter fortsetzen werden (vgl. ebd.: 8).

In Bezug auf (Wohnraum-)Heizen und dem damit verbunden Energieverbrauch haben die erste Ölkrise und der dadurch bedingte drastische Anstieg der Energiepreise zu einer rasanten Entwicklung in der Heizungstechnik geführt und einen wichtigen, wenn nicht gar den entscheidenden Anstoß zu modernen energiesparsamen Heizformen gegeben - weshalb manchen (aus heutiger Perspektive) 1973 als „das wichtigste Jahr für die gesamte Heizungsentwicklung" gilt. ${ }^{48}$

Im Folgenden werden die für den Bereich des alltäglichen Heizens wichtigsten Entwicklungen dargestellt, die damals durch die beiden Ölpreiskrisen in den 1970er Jahren angestoßen wurden und sich noch bis heute auswirken. Die zur Darstellung ausgewählten Entwicklungen und Trends sind zum Verständnis der hier vorliegenden Studie deshalb besonders interessant und relevant, weil sie zum einen direkt zu den zwei für diese Studie ausgewählten Fallbeispielen führen. Zum anderen werden in den aufgezeigten Entwicklungstrends bereits die zentralen Fragen und Themen deutlich, die für die gegenwärtige alltägliche Heizpraxis der Menschen noch eine Rolle spielen und daher auch von den Beforschten regelmäßig in den Interviews thematisiert wurden.

Eine der ersten längerfristigen Reaktionen, die auf die beiden Ölpreiskrisen folgte, war die Entstehung eines allgemeinen Trends, Weg vom Öl':

48 o. A. 2000-2018*: www.wissen.de/heizung-eine-brennend-heisse-geschichte (Online-Artikel auf wissen.de - das Wissensportal von bild der wissenschaft), zuletzt geprüft am 06.08.2018. 
„Wo möglich und sinnvoll wurde versucht, schrittweise Öl zu substituieren. Als Beispiel hierfür ist der verstärkte Ersatz von Heizöl durch Erdgas als Primärenergieträger für die Raumbeheizung zu nennen.“ (GMSH 2013: 9)

Eine weitere bedeutende Entwicklung infolge der Ölkrisen in puncto Heizen war, dass Nachtspeicherheizungen unattraktiver wurden. In den 1950er und 1960er Jahren waren strombetriebene (Nacht-)Speicherheizungen noch als probate Alternative zu kohle- oder heizölbefeuerten Einzelöfen und Zentralheizungen propagiert worden. Zentrale Argumente für den bevorzugten Einsatz elektrischer Nachtspeicherheizungen in Wohnungen und Wohnhäusern damals waren eine verringerte Staub- und Geruchsbelästigung am Nutzungsort, eingesparter Lagerraum für Brennstoff, eine insgesamt einfachere Haustechnik und auch eine einfachere Installation. So waren für elektrisch betriebene Nachtspeicherheizungen im Gegensatz zu Warmwasserzentralheizungen mit Heizkörpern anstelle von Rohrleitungen (zu den Heizkörpern) nur Stromleitungen erforderlich, die (bei nachträglichem Einbau in ein Gebäude) zudem deutlich leichter nachzurüsten waren als Heizungsrohre. ${ }^{49}$

Der Hauptbeweggrund für die Energieversorger, den Gebrauch von elektrischen Nachtspeicherheizungen in Privathaushalten damals zu forcieren, war, dass sie auf diesem Wege eine stetigere Auslastung ihrer Grundlastkraftwerke - zunächst handelte es sich ausschließlich um Kohlekraftwerke, später dann ebenso um Kernkraftwerke - erreichen wollten. Als eine Maßnahme, um eine ausdauerndere Auslastung zu bewirken, versuchten die Stromversorger deshalb, nachts für eine höhere (Strom-)Nachfrage zu sorgen. Nachtspeicherheizungen ermöglichten relativ unabhängig von den Bedarfs- bzw. Nachfragezeiten der Endverbraucher"innen zu agieren. Politische Förderprogramme sowie besonders niedrige Stromtarife zu typischen Schwachlastzeiten, so genannte Nachtstrom- oder Niedertarife, förderten den Einsatz von (Nacht-)Speicherheizungen in Wohnungen und Wohnhäusern, insbesondere während der ersten beiden Nachkriegsjahrzehnte (vgl. Paschotta 2010*).

Als die Energiekosten infolge der ersten Ölkrise im Jahr 1973 drastisch anstiegen, relativierten sich die Subventionen der Niedertarife (z.B. für Nachtstrom). Elektrische Nachtspeicherheizungen verloren gegenüber

49 Vgl. de.wikipedia.org, Artikel zum Thema ,Nachtspeicherheizung', zuletzt aktualisiert am 16.05.2018, zuletzt geprüft am 07.08.2018. 
konventionellen Zentralheizungen dadurch zunehmend an Wirtschaftlichkeit; vielmehr entpuppten sie sich nun als ,Stromfresser'.

Nach den enormen Energiepreisanstiegen wirkte sich nun zusätzlich der im Vergleich zu konventionellen Heizungen niedrige Gesamtwirkungsgrad von Nachtspeicherheizungen negativ aus. Gleiches galt für die insgesamt deutlich höhere Umweltbelastung sowie die deutlich schlechtere $\mathrm{CO}_{2}$-Bilanz - beides wesentlich verursacht durch die (immer noch überwiegend konventionelle) Stromerzeugung. ${ }^{50}$

Überdies machte die Ölpreiskrise erstmals einer breiten Öffentlichkeit deutlich bewusst, dass fossile (Brenn-)Rohstoffe nicht in unbegrenztem Maß zur Verfügung stehen und der Verbrauch deshalb reduziert werden muss. ,Energiesparen' wurde zum großen Thema. In Deutschland und auch in einigen anderen europäischen Ländern begann in den 1970er Jahren ein regelrechter Energiespar-Trend, der bis heute anhält.

Bis in die 1970er Jahre hinein hatte es in Deutschland praktisch keine Gesetze und Verordnungen zur Energieeinsparung gegeben. Dies änderte sich bedingt durch die erste Ölpreiskrise ab 1973. Die immensen Energiepreissteigerungen infolge der beiden Ölkrisen sorgten dafür, dass Energieeinsparung in den 1970er Jahren zu einem zentralen Thema wurde. Dies schlug sich auch im Erlass neuer Gesetzen und Verordnungen nieder. Im Laufe der 1980er Jahre kamen dann weitere Themen hinzu: der Umweltschutzgedanke, das Bewusstsein über die Endlichkeit fossiler Energieressourcen sowie der mit beiden Themen verbundene Nachhaltigkeitsgedanke. Ab den 1990er Jahren rückte der Klimaschutz zunehmend in den Fokus des Bewusstseins, der bis heute ein zentrales Argument zur Energieeinsparung darstellt (vgl. GMSH 2013: 10).

Vor diesem Hintergrund wurde auch die Forschung zu alternativen Heizmöglichkeiten verstärkt forciert. In besonderem Maße profitierte davon die Solar(energie)technik. Zwar reichen die Anfänge der Solarenergieforschung bis ins 19. Jahrhundert zurück, aber erst durch die Ölpreiskrisen wurden die Entwicklung und Nutzung dieser Technik (wieder) intensiviert. In Deutschland war es vor allem „,[d]ie Klimaschutzdebatte[, die] neben einer Forcierung der Aktivitäten auf dem Gebiet der Energieeinsparung auch verstärkte Überlegungen hervor[brachte], die fossilen Energieträger so weit als möglich durch regenerative und damit klimaneutrale Energieträger, wie z.B. Wind und Sonne, abzulösen“ (ebd.).

50 Vgl. de.wikipedia.org, Artikel zum Thema ,Nachtspeicherheizung', zuletzt aktualisiert am 16.05.2018, zuletzt geprüft am 07.08.2018. 
Im Bereich der Heizungstechnik ist seit der Ölpreiskrise (die Steigerung der) Energieeffizienz das dominante Thema. Angestoßen durch die Ölpreissteigerungen ist es in den folgenden Jahren in der Heizungstechnik zu einer besonders schnellen Entwicklung gekommen: Resultate sind hier unter anderem die moderne Brennwerttechnik und Wärmepumpen. Darüber hinaus wurden auch die Gebäude an sich verbessert. So ist für moderne (Neubau-)Gebäude heutzutage eine energetische Wärmedämmung inzwischen gesetzlich vorgeschrieben (vgl. EnEV 2014 bzw. GEG 2018). Und auch immer mehr Altbauten werden nachträglich wärmegedämmt.

Ein weiterer Entwicklungstrend in Hinblick auf den Energieverbrauch zu Heizzwecken sind Häuser, die ganz ohne konventionelle Gebäudeheizung funktionieren: so genannte Passivhäuser. Dies gelingt in der Regel durch eine besonders gute Dämmung der Außenhülle, die Verwendung wärmesammelnder Bauteile wie Fassadenkollektoren sowie hochkomplexe Lüftungsanlagen, die der Abluft Wärme entziehen und auf diese Art für die weitere Raumbeheizung rückgewinnen. Im Idealfall wird ein Passivhaus von der Sonne aufgeheizt, entlässt gleichzeitig seine Wärme wegen der hocheffektiven Dämmung nicht nach außen und führt beim Abpumpen der verbrauchten Luft die Wärme über die eingeschleuste Zuluft wieder zurück.

Im Zuge der Energiewende könnten auch die elektrischen Nachtspeicheröfen ein ,Comeback ${ }^{6}$ erleben. Wie bereits weiter oben geschrieben, galten elektrische Speicherheizungen, allgemeiner bekannt unter der Bezeichnung Nachtspeicherheizungen, lange Zeit als unwirtschaftliche und wenig umweltfreundliche ,Energieverwerter'. Im Zuge der Energieeinsparverordnung von 2009 (EnEV 2009) sollten Nachtspeicherheizungen nach einer Übergangsfrist sogar vollständig verboten werden. Dieser Beschluss wurde im Mai 2013 jedoch wieder aufgehoben - damit begann für die zuvor bereits als überholt geltende Technologie eine neue Ära. Denn auch elektrische Speicherheizungen können mit Strom aus erneuerbaren Energiequellen betrieben werden. Darüber hinaus stellen sie gleichzeitig einen hervorragenden Speicher für aus Sonnen- und Windenergie erzeugten Strom dar, der unregelmäßig produziert wird und dessen Erzeugung sich nicht an Bedarfszeiten koppeln lässt.

Die wechselvolle Geschichte des Heizens wird an verschiedenen Stellen der Untersuchung immer wieder aufgegriffen, da sie - wie noch gezeigt wird - einen wichtigen Kontext für das Verständnis gegenwärtiger Heizpraktiken darstellt. 


\subsubsection{Sozialwissenschaftliche Reflexion der Geschichte des Heizens}

Obwohl die wesentlichen Elemente der technischen Infrastruktur der Warmwasser-Zentralheizung bereits zu Beginn des 20. Jahrhunderts - teilweise sogar schon deutlich früher - vorhanden und auch Öl und Gas als besonders komfortable Brennstoffe zur Befeuerung bereits bekannt waren, wurde Heizen mittels Öl- oder Gaszentralheizung in deutschen Haushalten erst in den 1970er Jahren zum Standard - und ist dies bis heute. Wie an verschiedenen Stellen der Geschichte des Heizens angemerkt, ist dieser Wandel nicht alleine durch technische Entwicklungen erklärbar. Eine ausschließlich auf materielle Artefakte fokussierte Geschichte des Heizens hat offensichtliche Grenzen; sie vermag nur die Verfügbarkeit der Zentralheizungstechnologie sowie neuer Brennstoffe, nicht aber ihren zunehmenden Gebrauch, ihren soziokulturellen Bedeutungsgehalt und ihre gesellschaftliche Relevanz erklären.

Die bislang beschriebenen enormen materiellen und technologischen Veränderungen, insbesondere der Wechsel in der Heizungsbefeuerung von Holz und Kohle hin zu Gas und Öl als wichtigste Energieträger sowie der Wandel von der Einzelraumheizung zur Zentralheizung, wurden von ebenso zentralen soziokulturellen und ideengeschichtlichen Entwicklungen begleitet, wenn nicht sogar wesentlich vorangetrieben (vgl. Schwartz Cowan 1976). In Deutschland war in den Nachkriegsjahrzehnten mit dem Einsetzen einer allgemeinen Wohlstandsentwicklung die Steigerung des Komforts ein zentrales Leitthema, das sich praktisch durch alle Bereiche privater Lebensführung zog und den privaten Konsum wesentlich beförderte. Auch im Bereich des privaten Wohnens und Heizens machte sich dieses ausgeprägte Komfortstreben deutlich bemerkbar (vgl. Clausnitzer 2014: 30). Die Zentralheizung(stechnik) wurde den gestiegenen Erwartungen der Menschen hinsichtlich Wohn- und Wärmekomfort gleich in mehrfacher Hinsicht gerecht: Im Gegensatz zur Wohnraumbeheizung mittels Einzelöfen erlaubt eine Zentralheizung die gleichzeitige Beheizung mehrerer Zimmer bzw. die einheitliche Wärmeversorgung ganzer Gebäude mit unzähligen Räumen. Indessen muss der baulich-technische Aufwand für die Wärmegewinnung mittels Zentralheizung nur einmal, an einem zentralen Ort im Wohngebäude, wie beispielsweise dem Keller betrieben werden.

Zusammen mit der Umstellung der Befeuerung von Holz und Kohle auf Gas und Öl verringerten sich mit zunehmender Verbreitung der Zentralheizungstechnik sowohl der mit Heizen verbundene körperliche als auch zeitliche Aufwand in ganz erheblichem Maße. Musste vorher ständig 
neuer Brennstoff herangeschafft und manuell nachgelegt werden, so war es nun ausreichend, wenn man den Öl- oder Gastank im Keller ein- bis zweimal jährlich befüllen ließ. Zudem boten die für Gas- und Ölheizungen eigens entwickelten Thermostatregelungen eine weitgehende Automatisierung des Heizvorgangs, was den Wohnkomfort noch einmal deutlich steigerte. Und auch die Wartung der neuen Heizungsanlagen übernahmen nun die Versorgungsunternehmen, die Gerätetechnikhersteller oder selbständige Dienstleister (vgl. König 2000: 237). Das heißt, mit der Verdrängung der Brennstoffe aus der Wohnung und der umfassenden Automatisierung des Heizvorgangs wurde Heizen immer sauberer, sicherer und auch immer einfacher bzw. das Heizen wurde den Menschen immer mehr von der Technik sowie von entsprechenden Technik-Expert"innen abgenommen. Ein Großteil der für Gebäudeheizung erforderlichen (technischen) Infrastruktur und auch viele alltägliche Heizaktivitäten verschwanden mit dem Übergang zur Zentralheizung immer mehr aus dem täglichen Blickfeld sowie Handlungsrepertoire und damit letztendlich aus dem Bewusstsein der Menschen. Dadurch gewannen die Menschen Zeit, die sie ehemals für die aufwendige Beheizung ihrer Häuser und Wohnungen aufgewendet hatten und die sie nun in andere Beschäftigungen und Tätigkeiten investieren konnten. Behagliche Raumwärme wurde mehr und mehr zu einer kaum mehr bewusst wahrgenommenen Selbstverständlichkeit ständig vorhanden und nahezu mühelos erreichbar -, da eine Zentralheizung bald schon zum Standard in den allermeisten Privathaushalten gehörte (vgl. ebd.: 243f). Seither ist Heizen etwas, das weitgehend im Hintergrund abläuft, nahezu unsichtbar operiert und kaum mehr Aufmerksamkeit auf sich zieht - entsprechendes gilt für den mit Raum- bzw. Gebäudeheizung einhergehenden Energiekonsum. Es sei denn, die Heizung funktioniert einmal nicht, dann wird einem - insbesondere während der kalten Jahreszeit - mit einem Schlag (wieder) deutlich bewusst, von welch zentraler Bedeutung eine stabile und vor allem ausreichende Wärmeversorgung für das alltägliche Wohlbefinden ist. Zugleich wird einem durch solche (auch nur vorgestellten) Krisensituationen und -szenarien, wie z.B. eine längere Unterbrechung der häuslichen Wärmeversorgung im Winter oder ein größerer Stromausfall (insbesondere bei Verwendung moderner, sehr umfassender Heizungs-, Lüftungs- und Klimaanlagentechnik) deutlich vor Augen geführt, welche Abhängigkeiten private Haushalte eingegangen sind, um den heute gewohnten (technischen) Standard, etwa beim Heizen, Kühlen, Waschen oder Kochen zu erreichen. Voraussetzung für diese umfassende Technisierung des Haushalts, die ein mittlerweile kaum mehr hinterfragtes Maß an Bequemlichkeit und Komfort bedeutet, war ein An- 
schluss an technische Ver- und Entsorgungssysteme für Wasser, Abwasser, Müll, Gas und Elektrizität (ebd.: 246). Im Allgemeinen bedeuteten all diese Abhängigkeiten keine Beeinträchtigung, vorausgesetzt die Familien konnten die entstehenden Kosten aufbringen. Mit der Eingliederung privater Haushalte in technische Infrastruktursysteme verband sich zudem eine weit reichende Externalisierung von Belastungen:

„Die kommunale Abwasserentsorgung und die Müllabfuhr übernahmen die Verantwortung für die anfallenden Abfallstoffe, welche vorher beim Hausbesitzer oder Haushaltsvorstand gelegen hatte. Gas- und Stromversorgung reduzierten die im Haushalt entstehenden Aschemengen, Luftschadstoffe und die im Sommer unerwünschte zusätzliche Wärme. Die Wohnungen wurden sauberer - und die Schadstoffe häufig weiträumig in die Umwelt verlagert. Damit eröffnete sich den Haushalten der Weg zur Konsumexpansion - die negativen Folgen waren für die Bewohner nicht mehr sicht- und spürbar." (König 2000: 246)

Das heißt, die Menschen beschäftigten sich in ihrem Alltag immer weniger mit den beträchtlichen negativen Auswirkungen, die ihr alltägliches Konsumhandeln auf die Umwelt hatte und verloren dadurch mehr und mehr den Bezug dazu. Heute sind es genau die aus diesen selbstverständlich gewordenen Produktions- und Versorgungsstrukturen, Konsummustern und ,normalen` Lebensstilen resultierenden Mentalitäten wie ,Aus den Augen, aus dem Sinn', die nun - bei gestiegener umweltpolitischer Sensibilität Schwierigkeiten dabei bereiten, einen Teil der Verantwortlichkeiten für diese Konsumexpansion und ihre negativen Folgen wieder in die Haushalte zurückzuführen (ebd.).

In Deutschland wie auch in anderen Industrieländern mit vergleichbaren Jahresdurchschnittstemperaturen stellt das Heizen mittels moderner Zentralheizung(stechnik) mittlerweile eine weit verbreitete und in hohem Maße routinisierte Handlungspraxis dar.

Im Folgenden wird der Versuch unternommen, die alltägliche Handlungsroutine des Wohnraumheizens, wie sie in praktisch allen deutschen Privathaushalten beinahe tagtäglich zu beobachten ist, als soziale Praktik genauer einzuordnen. 


\subsubsection{Heizen als soziale Praktik - Versuch einer genaueren Bestimmung und Einordnung}

Nachdem in den vorangegangenen Teilkapiteln - insbesondere anhand der Geschichte des Heizens - ausführlich dargelegt wurde, dass es schlüssige Argumente dafür gibt, das Heizen (mittels Zentralheizung) als eine gängige soziale Praktik zu charakterisieren, geht es nun darum, die Praktik des Heizens genauer zu spezifizieren. Dafür ist es erforderlich, ihre Grenzen ausmachen und benennen zu können (vgl. Warde 2005: 18). Um was für eine Art von Praktik handelt es sich beim Heizen? Lässt sich das Heizen mit einem der bereits bekannten und in Teilkapitel 2.1.3 eingeführten Konzepte von ,dispersed', ,integrative' und ,compound practice' angemessen beschreiben? Ziel dieses Teilkapitels ist es, die Charakteristika und die Eigenständigkeit des Wohnraumheizens als Praktik aufzuzeigen und zu begründen.

Es gibt zwei gewichtige Argumente dafür, Heizen mindestens als ,integrative practice' zu begreifen: Erstens ist Heizen nicht als anderen Tätigkeiten untergeordnet oder nachrangig anzusehen, sondern Heizen stellt eine unabhängige, eigenständige Praktik dar. So kann man schlafen oder im Wohnzimmer mit Freund"innen zusammensitzen und fernsehen, ohne die entsprechenden Räume zwangsläufig zu beheizen. Umgekehrt ist es genauso möglich und manchmal zwingend erforderlich, dass in Räumen geheizt wird, in denen sich gerade niemand aufhält, diese also währenddessen ungenutzt sind. Zweitens verfügt Heizen über eine eigene immanente sinnhafte Strukturierung, die trotz des verstreuten und unregelmäßigen Aufkommens von Heizaktivitäten dafür sorgt, dass Heizen als eine in sich geordnete und einheitliche Tätigkeit anzusehen ist und auch als solche wahrgenommen werden kann.

Jenseits dieser offensichtlichen Argumente lohnt es, noch einmal genauer zu betrachten, inwieweit Heizen als, integrative practice ${ }^{6}$ angemessen beschrieben ist oder ob es sich beim Heizen nicht doch - wie gelegentlich vermutet - nur um eine, dispersed practice' handelt. Es stellt sich die Frage, ob es nicht sogar über eine, integrative practice' hinausgeht und ob Heizen gemäß seinen zentralen Eigenschaften nicht sogar schon als eine ,compound practice' anzusehen ist.

Als zentrales Charakteristikum von ,dispersed practices' (,verteilte Prak-

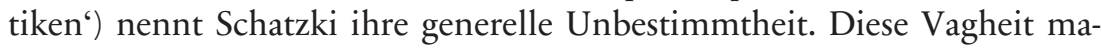
che es demzufolge möglich, dass Praktiken dieser Art in vielen verschiedenen Lebensbereichen auftauchen und je nach Bezugsrahmen dementsprechend unterschiedliche Ausgestaltungen erführen (vgl. Schatzki 1996: 91). 
Eher allgemeine, grundlegende Aktivitäten wie beispielsweise Schreiben, Lesen, Fragen und Erklären gelten demnach als typische ,dispersed practices'. Erst in Verbindung mit anderen Praktiken, mit diesen verzahnt zu komplexen und in sich geordneten Tätigkeitsgefügen, sowie durch ihren spezifischen Vollzugszusammenhang (Kontext) nehmen verteilte Praktiken konkrete Gestalt an. So kann z.B. Schreiben Teil von Bewertungspraktiken an der Universität (Gutachten), aber auch von Einkaufen (Einkaufszettel) sein. Über den Kontext sind die das Schreiben konstituierenden körperlichen und mentalen Aktivitäten mit weiteren Aktivitäten sinnhaft verschränkt und koordiniert und zu umfassenderen Tätigkeiten integriert; erst dadurch erhält die grundlegende Praktik des Schreibens ihre jeweilige Bestimmtheit und Eindeutigkeit.

Wäre Heizen als eine ,dispersed practice' anzusehen, würde das bedeuten, dass Heizen lediglich im Verbund mit anderen Praktiken Form annimmt. In diesem Fall wäre Heizen nur ein Teil(aspekt) anderer Praktiken wie Wohnen, Schlafen, geselliges Zusammensein, von Wohlfühlen, Entspannung und Sich-zurückziehen ins Zuhause. In der Tat erscheint Heizen ebenso elementar wie auch wieder nur sekundär. Daher könnte man geneigt sein, Heizen als eine ,dispersed practice‘ zu beschreiben.

Heizen ist elementar, denn offenbar hängt das Heizen von Wohnräumen tatsächlich häufig mit dem Vollzug anderer Aktivitäten zusammen und ist oft mit anderen Tätigkeiten verschränkt. Teilweise scheint es erforderlich, dass geheizt wird, damit Wohnen, Arbeiten, Schlafen oder das Empfangen von Gästen in privaten Räumlichkeiten bzw. in der eigenen Wohnung möglich ist. Beinahe tagtäglich sind die Menschen damit beschäftigt, für angemessene Innenraumtemperaturen zu sorgen und ihre Wohnräume behaglich zu temperieren. Eine entsprechend regulierte Innenraumtemperatur erscheint somit als eine wichtige Grundlage für vielerlei andere Praktiken.

Heizen wirkt gleichzeitig auch wieder sekundär: Die Aktivitäten, die mit dem Beheizen von Wohnräumen verbunden sind, nehmen meist nur wenig Zeit in Anspruch und werden von den Praktizierenden oft zwischendurch und nebenbei, ohne großes Nachdenken gewohnheitsmäßig vollzogen. Häufig sind es sogar nur kurze Momente, in denen beispielsweise die Raumthermostate aufgedreht oder neu reguliert werden, in denen die Fenster zur Stoßlüftung geöffnet und anschließend wieder geschlossen werden. Nimmt man diese mittlerweile geringe vordergründige Bedeutung und Präsenz des Heizens im Alltag und das hohe Maß an Verstreutheit bzw. Uneinheitlichkeit von Heizaktivitäten als zentrale Unterscheidungsmerkmale bzw. als Entscheidungskriterien für ,dispersed practices', 
so wirkt Heizen nebensächlich und zweitrangig. Dann erscheint Heizen als Teil länger andauernder Betätigungen, wie etwa im Wohnzimmer Fernsehen oder sich um seine Gäste kümmern und wiederum liegt die Vermutung nahe, dass es sich bei Wohnraumheizen nicht um eine eigenständige Praktik handeln kann.

Dennoch gibt es gute Gründe dafür, Heizen als, integrative practice' zu begreifen. Die zwei entscheidenden Kriterien für eine, integrative practice sind erstens die sinnhafte Einbindung und Strukturierung von mehreren, durchaus auch verstreuten Aktivitäten zu einer einheitlichen Praktik, und zweitens, dass von einer Tätigkeit als eigenständiger, das heißt von anderen Tätigkeiten deutlich zu unterscheidender Tätigkeitsbereich gesprochen wird. Diese Kriterien sind im Falle von Heizen beide erfüllt. Daher wird im Folgenden argumentiert, dass, obwohl Heizaktivitäten sehr in den Hintergrund geraten sind und heute meist nur noch in Verbindung mit anderen Tätigkeiten auftauchen und sie dadurch als an diese gekoppelt oder sogar als fester Bestandteil dieser anderen Tätigkeiten erscheinen, es sich beim Heizen trotzdem um eine eigenständige und somit mindestens integrative Praktik handelt.

Wie in dem Teilkapitel 2.1.3.1 bereits dargelegt, bestehen, integrative practices' (,integrative Praktiken') aus mehreren (kleineren) Einzelaktivitäten, die sinnhaft aufeinander aufbauen bzw. aufeinander bezogen sind. Eine inhärente Ordnung kann demnach als definierendes Merkmal integrativer Praktiken angesehen werden. Die sinnhafte Strukturierung ist es, die letztendlich dafür sorgt, dass zum Teil sehr unterschiedliche sowie auch zeitlich und räumlich getrennt vollführte Tätigkeiten dennoch als zu einer Praktik gehörig wahrgenommen, eben als eine sozial koordinierte Einheit erfasst werden (können). Oft sind einzelne, dispersed practices auch in komplexere integrative Praktiken mit eingeflochten.

Blickt man in die Historie und vergleicht früheres Wohnraumheizen zu Zeiten des offenen Kamins oder des Kohleofens (Stubenofens) mit dem Heizen heutiger Tage mittels moderner Zentralheizung, so wird ersichtlich, welch drastischen Wandel das häusliche Heizen bis heute erfahren hat - nicht nur die Zusammensetzung der zum Heizen gehörigen Aktivitäten hat sich über die Jahrhunderte deutlich gewandelt, sondern auch der Inhalt der einzelnen Heizaktivitäten, ihre Dauer, Häufigkeit, der mit ihnen verbundene Arbeitsaufwand sowie ihr Ausführungsort haben sich stark verändert. Während die Befeuerung von Kohleöfen noch einen erheblichen und sehr regelmäßigen Arbeitsaufwand für die privaten Endverbraucher*innen bedeutete, bedarf es bei einer modernen Öl-Zentralheizung meist lediglich einer Betankung des im Keller befindlichen Öltanks 
im Jahr durch einen professionellen Heizöllieferanten. Ansonsten beschränken sich die alltäglichen Heizbetätigungen heutzutage meist auf ein kurzes Drehen am Thermostat. Folgendes Zitat fasst die eindrucksvolle Wandlung, die das private Heizen über die Jahrhunderte erfahren hat, noch einmal prägnant zusammen:

"The history of domestic heating shows how deeply the way we heat our houses has been transformed since the appearance of central heating. From stoves that have to be filled regularly by hands to electronic control, the delegation of action to machines has dramatically increased, while energy became invisible. [...]. Compared to the fireplace or the stove, central heating ensures even temperature throughout the house and does not require daily maintenance." (Wallenborn et al. 2011: 47f)

Vor diesem Hintergrund erscheint gegenwärtiges Heizen tatsächlich als eine nebenbei und zwischendurch vollzogene Tätigkeit: die Heizung läuft häufig ,im Hintergrund' (weiter), während sich die Praktizierenden anderweitig aktiv betätigen (können). Jedoch bedeutet das Ausführen von Heizaktivitäten (am Thermostat drehen, Fenster oder Türen öffnen und schlieBen, die Lüftung regulieren) - heute noch genauso wie damals - immer eine Unterbrechung sonstiger Beschäftigungen. Auch wenn heutzutage im Schnitt kürzer oder weniger oft Heizaktivitäten wie das Regeln des Thermostats performt werden, macht es faktisch keinen Unterschied, dass diese Aktivitäten von den Praktizierenden weiterhin als Wohnraumheizen wahrgenommen werden und überdies von diesen Betätigungen auch als Heizen gesprochen wird. Dies zeigt, dass die verschiedenen, zum Teil isoliert vollzogenen Aktivitäten vom Sinn her zusammenhängend als Heizen verstanden werden, dass die Einzelaktivitäten demnach als Bestandteile einer umfangreichen Tätigkeit erkannt wurden. Es lässt sich daraus ableiten, dass die Praktizierenden Heizen sinnhaft als eine einheitliche (und damit eigenständige) Praktik begreifen. Das entscheidende Kriterium, was das Bündel an Aktivitäten zusammenhält, ist damit der einvernehmlich zugeschriebene Sinn; nur die (kollektiv geteilte) Deutung stellt sicher, das zeitlich und räumlich getrennt voneinander vollzogene Körperbewegungen als Teil einer (einheitlichen, also zusammenhängenden) Praktik gesehen werden.

Darüber hinaus lässt sich feststellen, dass es einen gesellschaftlichen Konsens darüber gibt, welche Handgriffe und Körperbewegungen zu Heizen gezählt werden. Wenn es um Wohnraumheizen geht, so ist stets nur von ganz bestimmten Tätigkeiten die Rede, wie zum Beispiel Drehen am Thermostat, Nachtabsenkung der Heizung, Geschlossen halten von Türen 
und Fenstern, Stoßlüften durch das geöffnete Fenster (statt Dauerkippen), Entlüften der Heizkörper, Wärmedämmung, usw. Das Entscheidende aber ist, dass über Heizen als ein eigenständiger Tätigkeitsbereich gesprochen wird. Dafür sind die Regeln und Anleitungen zum ,richtigen' Heizen ein deutliches Zeugnis. Sie sind Ausdruck eines kollektiv geteilten Verständnisses über den notwendigen bzw. ,korrekten' Praktikenvollzug. So sind alle Aktivitäten, die Wohnraumheizen zugerechnet werden in den Ratgebern ausführlich besprochen. Es ist ein großes Vokabular vorhanden, das sich auf Heizen bezieht. In Fachgruppen und Expert*innenkreisen wird viel über Heizen nachgedacht und es wird dementsprechend viel zum ,richtigen' Heizen geschrieben und veröffentlicht. Dies schließt konkrete Deutungs- und Verstehensweisen, bestimmte Bewegungsabläufe und typische Handlungsmuster sowie ein besonderes technisches Equipment mit ein, das speziell auf Heizen ausgelegt ist. Damit ist Heizen als Praktik gut erkennbar; die Aktivitäten, die Heizen ausmachen, sind bei Erscheinen sofort als solche identifizier- und zuordenbar.

Es gibt also gute Argumente dafür, das Heizen als eine, integrative practice' zu begreifen.

Im Vergleich mit typischen, integrative practices ${ }^{6}$ wie Autofahren oder Kochen stellt sich allerdings die Frage, ob Heizen nicht sogar noch mehr ist als ,nur' eine, integrative practice', ob es sich bei Heizen nicht schon um eine, compound practice' handelt.

,Compound practices' (,komplexe, zusammengesetzte Praktiken') sind in ihrem Aufbau und ihrer Struktur noch einmal komplexer als, integrative practices'. Sie setzen sich meist aus mehreren bereits umfassenderen, eigenständigen Praktiken zusammen. Das heißt, einzelne integrative Praktiken sind häufiger zu einer größeren ,compound practice‘ integriert. Dies wird gut am Beispiel der umfassenden Praktik des Reisens deutlich, die in der Regel mehrere andere - mehr oder minder umfangreiche - eigenständige Praktiken (Reiseziel aussuchen, Flug, Unterkunft, usw. buchen, Hinund Rückflug, Ausflüge vor Ort planen und unternehmen) in sich vereint.

Für Heizen gilt Ähnliches. Auch beim Heizen handelt es sich nicht lediglich um ein einheitliches Bündel von mehreren kleinen Aktivitäten. Heizen umfasst vielmehr Tätigkeiten, von denen man zumindest das Lüften und wahrscheinlich auch das Beschaffen von Brennmaterial sowie das energetische Dämmen/Sanieren des Wohngebäudes als (weitgehend) eigenständige Tätigkeiten, also selbst als, integrative practices' betrachten kann. Mit Blick auf die Liste der im Rahmen dieser Arbeit zum Wohnraumheizen gezählten Aktivitäten (siehe Teilkapitel 2.2.1) wird deutlich: Neben den alltäglichen Handgriffen und kleineren Aktivitäten gehören 
auch größere und/oder temporäre Maßnahmen, wie die Schornsteinreinigung oder das Aufstellen zusätzlicher Heizlüfter, sowie seltene und/oder einmalige Entscheidungen, wie z.B. die (nachträgliche) Dämmung der AuBenfassade, die Erneuerung der Heizungsanlage oder das Austauschen der Fenster, mit zu der Praktik des Heizens dazu. Somit wird deutlich, dass Heizen die Kriterien für eine ,compound practice' erfüllt.

Besonders deutlich wird diese Verschränkung bzw. Eingliederung von eigenständigen Tätigkeiten zu einer umfassenderen Praktik (wie Heizen) am Beispiel der ,integrative practice' des Lüftens, welche einerseits in sich geschlossen und damit eigenständig ist, zugleich aber auch eine unabdingbare Teilaktivität des Heizens darstellt: So wurde mit Einführung des Kamins zwischen dem 10. und 12. Jahrhundert in Europa ,Lüften` zu einem notwendigen und damit festen Bestandteil des Heizens. Der Kamin zog die Raumluft ins Feuer und das Rauchgas wurde dann über den Schornstein direkt nach draußen abgeführt. Damit diese raumluftabhängige Heizform funktionierte, war regelmäßiges Lüften der betreffenden Räume und damit das Sorgen für ausreichend Frischluftnachschub unbedingt erforderlich. Auf diese Weise hat die neue Kamintechnik das Heizen zu einer sauberen Angelegenheit gemacht. Seitdem sind Heizen und Lüften fest miteinander verknüpft bzw. sind Lüftungsaktivitäten fest ins Heizen integriert. Diese Tätigkeitsverschränkung hat sowohl in den ,doings' als auch den ,sayings' deutlich Niederschlag gefunden, so zum Beispiel in der Anforderung des regelmäßigen Stoßlüftens statt des Dauerlüftens mit gekipptem Fenster (wenn die Heizung aufgedreht ist) oder etwa in der regelmäBig erforderlichen Aktivität des Entlüftens der Heizkörper. Und auch in den Anleitungen und Ratschläge-Katalogen zum ,richtigen` Heizen findet man die beiden Tätigkeiten stets als gekoppelt. So ist, wenn von Heizen die Rede ist, immer auch Lüften gemeint, was sich in Aussagen und Ratschlägen wie ,Richtig lüften heißt auch richtig heizen“ und ,Richtiges lüften geht nur bei angemessenen Raumtemperaturen' niederschlägt. ${ }^{51}$

Darüber hinaus tragen im Passivhaus viele andere eigenständige Praktiken zur Erwärmung der Wohnräume entscheidend bei. Im Passivhaus können alltägliche Praktiken, wie beispielsweise Kochen, Staubsaugen und Fernsehen, die definitiv ,integrative practices' darstellen, gezielt dafür ,genutzt ${ }^{`}$ werden, um die Innenraumtemperatur zu erhöhen. Das Prinzip des Passivhauses beruht gerade darauf, dass unter anderem die bei solchen Be-

51 Siehe Utopia Team 2018*, Ratgeber-Artikel auf utopia.de mit Tipps zum richtigen Lüften gegen Schimmelbildung in der Wohnung, zuletzt geprüft am 07.08.2018. 
tätigungen ,nebenbei` freiwerdende Wärmeenergie besonders effektiv zu Heizzwecken genutzt wird. Diese Gegebenheit spricht somit ebenfalls dafür, Heizen bereits als eine, compound practice' zu betrachten.

Gleichzeitig ist klar, dass theoretische Konzepte und Kategorien lediglich analytische Hilfskonstrukte sind und die Einordnung , lebendiger' sozialer Phänomene wie Heizen in bestimmte Konzepte letztendlich immer nur eine Momentaufnahme und eine analytische Vereinfachung darstellen. Wie der Blick in die Geschichte des Heizens zeigt, hat sich die Elementezusammensetzung des Heizens über die Jahrhunderte stark gewandelt und haben sich dementsprechend auch die zu Heizen begriffenen Aktivitäten deutlich gewandelt. Und diese Ausfüllung der Kategorien wandelt sich weiterhin bzw. sie ist permanent im Wandel begriffen.

Für die ausgewählten Fallbeispiele zeichnen sich im Hinblick auf die zu Heizen gebündelten Aktivitäten interessante Entwicklungen ab: So stellt beispielsweise das Passivhausprinzip die Verschränkung des Heizens und Lüftens nun (wieder) teilweise in Frage bzw. die Funktionsweise des Passivhauses verändert diese Tätigkeitsverflechtung in gravierender Weise, denn im Idealfall geht im Passivhaus nunmehr umgekehrt das Heizen vollkommen im Lüftungsvorgang auf.

Und auch im SmartHome sind durch die funkbasierte (Heizungs-)Steuerungstechnik Heiz- und Lüftungsaktivitäten neuerdings untrennbar miteinander verknüpft. Mit der Anwendung der intelligenten Heizungssteuerung nehmen sowohl die Ausführung des Heizvorgangs als auch die an das Heizen gekoppelte Lüftungstätigkeit neue Gestalt an, und zwar in dem Sinne, dass im SmartHome beide Tätigkeiten nur noch in geringem Maße in menschlicher Hand liegen, sondern weitestgehend automatisiert sind, das heißt von der Computertechnik gesteuert und erledigt werden.

Demnach stellt die Betrachtung von Heizen als ,compound practice' ein interessantes Hintergrundschema zur Analyse dar, um beispielsweise zu ermitteln, in welchem Verhältnis die eigentlich eigenständigen, und nun gleichzeitig zu einem komplexen Tätigkeitsgebilde wie Heizen verschränkten Aktivitäten zueinander stehen und welche Verschiebungen sich diesbezüglich (z. B. in der An- und/oder Rangordnung) über die Zeit, etwa durch die Hereinnahme einer neuen Heiztechnologie, immer wieder ergeben.

Es stellt sich die Frage, ob sich diese Veränderungen in der Elementezusammensetzung, der Aktivitätenverzahnung sowie hinsichtlich der Ausführung(sverantwortung) der Praktik des Heizens auch (dauerhaft) in den konkreten alltäglichen Heizpraktikenperformances niederschlagen und zu tatsächlichen Re-Arrangements und/oder Auflösungen in bzw. bei der 
,practice-as-entity führen. Die Frage nach Wandel und Veränderbarkeit von Praktiken ist Thema des nächsten Kapitels.

\subsection{Wandel und Veränderbarkeit von Praktiken}

Nachdem in Teilkapitel 2.1.7 herausgearbeitet wurde, dass der Rückgriff auf Energieressourcen im Rahmen von Alltagshandlungen erfolgt - Energiekonsum stellt demzufolge das Resultat praktischer Vollzüge dar -, wurde in Teilkapitel 2.2.1 die Fokussierung auf besonders energieintensives Wohnraumheizen begründet. In diesem Teilkapitel steht nun die Frage nach dem Wandel und der generellen Veränderbarkeit sozialer Praktiken im Mittelpunkt. Mit der Erkundung von Stabilität und Wandel werden wichtige Grundfragen der Sozialwissenschaften gestellt, die insbesondere die Soziologie berühren. Seit jeher beschäftigen sich Soziolog*innen mit Prozessen sozialen Wandels auf allen gesellschaftlichen Ebenen. So wird etwa gefragt: Wie kommt es zur Transformation von ganzen Gesellschaften bzw. Nationalstaaten? Wie wandeln sich Organisationen und Institutionen? Wie kommt es zu Veränderungen bei alltäglichen Lebensstilen und Konsummustern? Daher liegt es im genuinen Interesse der Soziologie, auch den Wandel sozialer Praktiken zu untersuchen:

„Since social change constitutes core business for the social sciences, one might expect these disciplines to be taking centre stage - generating lively popular and policy debate about what such transformation [in consumption patterns towards a low carbon society, JM] might entail and how it might come about." (Shove 2010a: 1273)

Erstaunlicherweise ist dies bisher nur eingeschränkt der Fall. Dies ist aber auch gerade im Begriff, sich deutlich zu wandeln (vgl. z.B. Shove et al. 2012; Schatzki 2013). So stellt Røpke fest:

„The dynamics of changing practices attracts increasing interest; in particular, Shove and her collaborators have achieved new insights through empirical studies.“ (Røpke 2009: 2494)

Die Frage nach dem Wandel alläglicher (Heiz-)Praktiken ist auch aus empirischer Sicht interessant: Aus politisch-regulatorischer und genauso aus kultureller Perspektive ist es bedeutsam, sowohl die Persistenz als auch die Veränderung von Alltagsaktivitäten zu verstehen, insbesondere wenn eine Neugestaltung des Alltagsgeschehens aus bestimmten Gründen dringend erforderlich erscheint und auch willentlich angestrebt wird (vgl. Shove et 
al. 2012: 1f). Aktuell besteht von Seiten der Politik ein besonderes Interesse, den häuslichen Konsum besser zu verstehen, um den privaten Energieverbrauch zu reduzieren.

Theoretisch und empirisch motiviert geht es somit aus konsumsoziologischer Sicht um die Analyse umweltrelevanter Konsequenzen von ressourcenintensiven Konsumaktivitäten. Vor diesem Hintergrund wird nach dem möglichen Wandel und der Veränderbarkeit von Praktiken gefragt, denn dies ist eine Voraussetzung der Änderung des Energieverbrauchs beim Heizen. Energieverbrauch ist in Praktiken eingebettet und somit stellt sich für Energieeinsparungen die Frage nach der Veränderbarkeit von Praktiken:

„The understanding of energy demand [...] requires a different approach to revealing and explaining change. Its foundation is provided by seeing social order and social arrangements [...] as an emergent product of social practices. It follows then that as changes in energy demand arise from changes in social practices, the task becomes to track and understand the longer term dynamics of practices and complexes of practices - taking practices themselves as the central unit of analysis." (Walker 2014: 50; vgl. auch Shove 2010a: 1279)

Es können folgende allgemeinere Fragen abgeleitet werden: Wie wandeln sich Praktiken? Und lassen sie sich absichtsvoll verändern bzw. inwiefern sind Praktiken überhaupt intendierten Änderungen zugänglich? Wenn ja, worin bestehen die möglichen Ansatzpunkte? Wie lässt sich der Wandel von Praktiken dann konkret initiieren und wie lässt er sich beschreiben?

Anschließend ist dies genauer für das Heizen zu erkunden: Wie und wodurch ändert sich Heizen? Lässt sich Heizen gezielt umgestalten, so dass es sich von einer - zurzeit meist noch - besonders energieintensiven zu einer energiesparsamen oder energieeffizienten Tätigkeit wandelt? Was kann man anhand der Analyse von Heizaktivitäten sowie ihrer Dynamiken über Praktikenwandel erfahren?

In der Literatur wird regelmäßig auf das besondere Beharrungsvermögen von Praktiken hingewiesen (vgl. etwa John 2013: 107) und die Kritik wird geäußert, dass der Schwerpunkt des Praktiken-Ansatzes auf dem routinisierten Vollzug von Praktiken und ihrer Repetitivität, das heißt auf der gleichförmigen Reproduktion sozialer Handlungsvollzüge liege. Routine, Kontinuität und Stabilität würden im Konzept sozialer Praktiken überbetont, wohingegen Wandel und das Veränderungspotenzial von Praktiken nur unzureichend erfasst seien. 
In dieser Arbeit wird ein davon abweichender Standpunkt eingenommen: Ich bin der Ansicht - und schließe mich damit der Position zentraler Praxistheoretiker*innen an -, dass der Ansatz sozialer Praktiken sich gut zur Analyse von Wandel eignet. Überdies soll deutlich gemacht werden, dass Veränderung und Wandlungsfähigkeit typische Merkmale, ja sogar inhärente Eigenschaften von Praktiken sind und das Veränderungspotenzial deshalb von Anfang an in den theoretischen Ansätzen konsequent inkludiert wurde. Dies soll im Folgenden dargelegt werden.

Dieses Teilkapitel ist im Weiteren folgendermaßen strukturiert: In einem ersten Schritt wird der spezifische Beitrag der praxistheoretischen Perspektive zum Verständnis von Wandlungsprozessen herausgearbeitet. $\mathrm{Zu}$ diesem Zweck ist zunächst die praxistheoretische Literatur im Hinblick auf die Thematisierung und Konzeptualisierung von, Wandel und Veränderbarkeit von Praktiken' aufzuarbeiten (Teilkapitel 2.3.1 und 2.3.2). In einem nächsten Schritt geht es um zentrale Ausgangspunkte für Wandel (Teilkapitel 2.3.2.1), um anschließend in einem dritten Schritt mögliche Wandlungsformen und Veränderungsresultate darzustellen (Teilkapitel 2.3.2.2). In theoretischer Hinsicht geht es hierbei insgesamt auch um die Frage, inwiefern sich der derzeitige Stand praxistheoretischen Denkens dafür eignet, den Wandel von Praktiken angemessen zu analysieren. Gegebenenfalls gilt es zu ermitteln, wie das theoretische Analyseinstrumentarium weiterzuentwickeln ist, damit Veränderungsprozesse sozialer Praktiken adäquat zu verstehen und zu erklären sind.

\subsubsection{Die soziologische Debatte zum (Thema) Praktikenwandel}

Die Aufarbeitung der Literatur zum Thema,Wandel ${ }^{\star}$ geschieht auf Basis der einschlägigen Texte derjenigen Theoretiker*innen, in deren Arbeiten das Konzept sozialer Praktiken explizit zentral gestellt ist. Dies sind im Wesentlichen die theoretischen Grundlagenarbeiten von Schatzki (1996, 2002) und Reckwitz (2000b, 2002b, 2003) sowie einzelne ausgewählte Beiträge aus der Konsumsoziologie, wie etwa von Warde (2005) und Shove (2012) sowie von Shove et al. (z.B. Shove und Pantzar 2005; Shove et al. 2012), die sich ebenfalls dem Thema, Wandel von Praktiken' widmen.

Praxistheoretisch ausgedrückt stellen soziale Phänomene zunächst nichts anderes als Zusammenhänge von Praktiken und materiellen Arrangements dar (vgl. Schatzki 2013: 31), bestehen das Alltagsleben und die gesamte Sozialwelt aus einer komplexen Ansammlung unterschiedlicher, zum Teil aufeinander bezogener und miteinander verknüpfter Praktiken 
(vgl. Reckwitz 2003: 295). Entsprechend wird „[s]ozialer Wandel als weitgehend ungesteuertes Produkt der Dynamik sozialer Praktiken, ihrer Verknüpfungen und Nebenfolgen gesehen" (Brand 2011: 190).

Während in Schatzkis Frühwerk "Social Practices. A Wittgensteinian Approach to Human Activity and the Social“" (Schatzki 1996) Wandel nicht ausdrücklich thematisiert wird, befasst er sich in seinem Folgewerk, das den Titel „The Site of the Social“ (Schatzki 2002) trägt, zwar in einem Kapitel explizit mit den Themen ,Werden' und ,Wandel' (ebd.: 189-264), allerdings bleiben die Inhalte eher von allgemeiner und abstrakter Art. Der wesentliche Punkt ist hier, dass Wandlungsprozesse omnipräsent sind, wobei ,agency' als der zentrale Motor für Veränderungen anzusehen sei. Das Besondere hierbei ist, dass Schatzki mit seinen Überlegungen nicht auf den Annahmen der klassischen Handlungstheorie aufbaut, nämlich, dass Handlungen in der Regel bewusst motiviert seien und auf eine klare Absicht bzw. einen Zweck hin erfolgen würden, sondern er legt ihnen ein verändertes, eigenes Verständnis von ,agency zugrunde: „it is no longer possible to presume that agency is intentional human action. (...). All I mean by 'agency' in the following, consequently is doing" (ebd.: 190f, Hervorh. im Original).

In seinen Arbeiten jüngeren Datums kommt das Thema ,Praktikenwandel' ebenfalls nur am Rande vor. So merkt Schatzki beispielsweise in einem 2005 erschienenen Aufsatz, in dem er ein praxistheoretisches Analyseprogramm für Organisationen vorschlägt, an einer Stelle an: „Of course, practices are not static" (Schatzki 2005: 475). Auch hier bleiben die Überlegungen zum Wandel von Praktiken allgemein:

„They evolve as circumstances change, opportunities and problems arise, personnel changes, new ideas arise, and so on. Changes in practice-arrangement bundles can be intentional or unintentional and known or unknownst to participants. Changes are also typically piecemeal and gradual, alterations in any component of a bundle being accompanied by continuity in others. Practices can, however, be changed more wholesale, when conscious intervention (from the inside or outside) reworks goals, alters rules, and redesigns projects. These comments apply mutatis mutandis to a department's material arrangements and to the mesh between practices and arrangements." (ebd.: 475f, Hervorh. im Original) 
An späterer Stelle erwähnt Schatzki noch - dies jedoch eher beiläufig -, worin er die Hauptquelle für Wandel sieht:

„Because, furthermore, human action is the primary source of change in practice-arrangement bundles and nets, investigators interested in change will pay particular attention to the chains of action that link and pass through bundles and nets." (ebd.: 476)

In diesen Textstellen stecken bereits viele Hinweise zu Wandel und Veränderungsanlässen. Diese Ideen werden an späterer Stelle noch einmal aufgegriffen, wenn es darum geht, mögliche Wandlungsanlässe und unterschiedliche Wandlungsformen systematisch aufzulisten.

Erst deutlich später beschäftigt sich Schatzki dann selbst ausführlicher mit der Frage nach dem Wandel und der Veränderbarkeit von Praktiken. In einem Essay setzt sich Schatzki mit dem Phänomen des Praktikenwandels intensiv auf theoretischer Ebene auseinander. Ziel dieses Beitrags ist es, „the locus and basic dimensions of change in social practices“ (Schatzki 2013: 31) zu identifizieren. Dafür beleuchtet und beschreibt er den gesamten Lebenszyklus von Praktiken: von ihrer Entstehung und ihrem ersten Auftauchen, über ihr längeres Fortbestehen und ihre Weiterentwicklung, bis hin zu ihrer Auflösung und ihrem endgültigen Verschwinden. Der Aufsatz endet mit einer allgemein-abstrakten Aufzählung von „loci and forms that change can take" (ebd.: 44), die Schatzki zufolge (aber auch) als sachdienliche Hinweise für den Umgang mit den Herausforderungen des Klimawandels zu sehen sind.

Hingegen hat Reckwitz den Wandel von Praktiken in seinen Arbeiten konsequent thematisiert. Bereits in dem 2003 erschienen Aufsatz „Grundelemente einer Theorie sozialer Praktiken“ (Reckwitz 2003) äußert er sich differenziert zum Veränderungspotenzial sozialer Praktiken sowie dazu, wie aus seiner Sicht das Verhältnis von Routine und Veränderung zu sehen ist. So betont er zunächst ebenfalls die Routinisiertheit als ein grundsätzliches Strukturmerkmal von Praktiken. Genauso müsse aber die „Unberechenbarkeit von Praxis“ (ebd.: 284) als konstitutives Merkmal von Praktiken verstanden werden. Reckwitz zufolge ist mit „der Unberechenbarkeit interpretativer Unbestimmtheiten“ (ebd.: 294) das den sozialen Praktiken immer auch inhärente Potenzial zur Transformation beschrieben. Es handele sich keineswegs um einen Widerspruch, dass diese beiden scheinbar gegensätzlichen Aspekte betont würden, sondern vielmehr markierten Routinisiertheit und Unbestimmtheit „zwei Seiten der ,Logik der Praxis““ (ebd., Hervorh. im Original). Die soziale Welt der Praktiken entfalte sich in eben jenem Spannungsfeld von routinisierter Reproduktion 
typisierter Praktiken einerseits und ihrer Unberechenbarkeit andererseits. Und weiter heißt es: „die Praxis [bewegt sich] zwischen einer relativen ,Geschlossenheit' der Wiederholung und einer relativen ,Offenheit' für Misslingen, Neuinterpretation und Konflikthaftigkeit des alltäglichen Vollzugs" (ebd., Hervorh. im Original). Der entscheidende Punkt dabei sei, dass die Offenheit und Veränderbarkeit der Praxis - genauso wie ihr Routinecharakter - gerade aus den verschiedenen Eigenschaften der sozialen Praktiken selbst resultieren. Laut Reckwitz sind hier insbesondere „vier Eigenschaften einer ,Logik der Praxis' [zu nennen], die ihre Unberechenbarkeit und damit Offenheit für kulturellen Wandel zum Normalfall werden lassen“ (ebd.): So können erstens „sämtliche mögliche Eigenschaften des Kontextes, in dem die Praktik vollzogen wird“ (ebd., Hervorh. im Original) Anlass für Wandel sein. Die Konfrontation mit unerwarteten Ereignissen, fremden Personen, neuen Handlungen und Objekten, aber auch Selbstreaktionen, all solche „Überraschungen des Kontextes“ (ebd.) können eine Abweichung von der bisherigen Praxis provozieren. Als einen besonderen Fall „eines derartigen ,neuen Kontextes““ (ebd.: 295) beschreibt Reckwitz „das Aufkommen neuer Artefakte, denen noch keine eingespielte Praktik entspricht und die - unter Einbeziehung ,alter ' Wissens- und Praxiselemente - die Entwicklung partiell neuer sozialer Praktiken (...) herausfordern" (ebd., Hervorh. im Original).

Zweitens verlange "die Zeitlichkeit des Vollzugs einer Praktik“ (ebd., Hervorh. im Original) zwingend eine gewisse Offenheit und Wandelbarkeit in der Routine. Der Aspekt der Zeitlichkeit, mit dem die zeitliche Gebundenheit praktischer Vollzüge gemeint ist, beinhaltet sowohl den Moment der Zukunftsungewissheit als auch den des Potenzials der Sinnverschiebung. So ist zum einen nie ganz sicher, „inwiefern ein weiteres Handeln im Rahmen der Praktik gelingen wird und die Praktik fortzusetzen ist“" (ebd.). Gleichzeitig besteht für gewöhnlich ein Druck zum Handeln, so dass oft unter Zeitdruck entschieden werden muss (vgl. ebd.). Zum anderen ist mit der Möglichkeit der Sinnverschiebung das Phänomen beschrieben, dass auch die repetitive Anwendung einer Praktik nie eine vollkommen identische Wiederholung bedeutet; der wiederholte Vollzug „enthält vielmehr das Potenzial ,zufälliger - sprunghafter oder schleichender - Verschiebungen im Bedeutungsgehalt der Praktik und ihres Wissens, die sich in bestimmten Kontexten ereignen“" (ebd.).

Drittens betrifft das Transformationspotenzial der Praxis den Sachverhalt, dass soziale Praktiken nicht als vereinzelte, abgesonderte und für sich alleinstehende Phänomene in der sozialen Welt existieren; vielmehr erscheinen sie meist in mehr oder weniger lockeren Praktiken-Verbünden. 
Sie hängen also häufig mit anderen Praktiken zusammen, können mitunter aber auch zueinander in Konkurrenz stehen. Demnach „bildet die soziale Welt lose gekoppelte Komplexe von Praktiken, die häufig nur bedingt und widerspruchsvoll aufeinander abgestimmt oder gegeneinander abgegrenzt sind“ (Reckwitz 2003: 295, Hervorh. im Original). Diese lose Kopplung erzeugt Offenheit und kann damit Ausgangspunkt für Wandel sein.

Die vierte und letzte Grundlage der Unberechenbarkeit und Wandlungsfähigkeit von Praktiken liegt „in der praxeologischen Struktur des Subjekts als eines lose gekoppelten Bündels von Wissensformen“ (ebd.) begründet. Aus praxistheoretischer Sicht überschneiden und schichten sich in denselben Akteuren und Subjekten verschiedene Wissensformen, so dass jedes einzelne Subjekt einen einzigartigen „Kreuzungspunkt unterschiedlicher Verhaltens/Wissenskomplexe sozialer Praktiken darstellt" (ebd.: 296). Theoretisch gesprochen partizipiert das Subjekt in seiner Alltags- und Lebenszeit an zahlreichen sozialen Praktiken, die jeweils ein sehr spezifisches Wissen voraussetzen. Dies bedeutet jedoch umgekehrt für das einzelne Subjekt, „dass es gleichzeitig unterschiedliche, heterogene, möglicherweise auch einander widersprechende Formen praktischen Wissens inkorporiert hält, die es in seiner Lebensführung zum Einsatz bringt“" (ebd.). Wie mit den verschiedenartigen Verhaltensroutinen und deren heterogenen Sinngehalten umgegangen wird, ja wie die Kombination und Integration unterschiedlicher sozialer Praktiken dann im Einzelnen bewerkstelligt wird, ist individuell sehr verschieden. Dadurch schließlich erscheint das Subjekt als wichtige „Quelle von Unberechenbarkeit und kultureller Innovation" (ebd.).

Damit wird deutlich, dass Reckwitz der Veränderbarkeit sozialer Praktiken sowohl in empirischer Hinsicht als auch auf theoretisch-konzeptioneller Ebene die gleiche hohe Bedeutung beimisst wie ihrem allseits besonders hervorgehobenen Routinecharakter.

Warde knüpft in diesem Punkt an die Arbeiten von Reckwitz an. Er argumentiert, dass man sich genauso intensiv mit der Frage nach Wandel wie mit der nach der Regelmäßigkeit sozialer Praktiken beschäftigen muss und stellt ebenfalls die Frage, wie der Wandel von Praktiken angemessen zu verstehen ist. Dabei sieht er das Konzept sozialer Praktiken als gleichermaßen geeignet, um die relative Reproduzierbarkeit, also die (endlose) Wiederholung von Praktiken, sowie deren Wandel und Veränderungsvermögen zu erfassen:

"The principal implication of a theory of practice is that the sources of changed behavior lie in the development of practices themselves. The 
concept of practice inherently combines a capacity to account for both reproduction and innovation." (Warde 2005: 140)

Warde geht demnach wie Reckwitz davon aus, dass (ständige) Verschiebungen und Erneuerungen feste Bestandteile der internen Verfahrenslogik sozialer Praktiken sind (vgl. ebd.: 141).

Im Verlauf seines Aufsatzes nennt Warde zahlreiche Formen von Beständigkeit und möglicher Umgestaltung sozialer Praktiken. So kommen für ihn interne Differenzierungen hinsichtlich der verschiedenen Dimensionen von Praktiken als Treiber für Wandel infrage. Diese Unterschiede können sich beispielsweise in der Auslegung einer Praktik, den gewählten Abläufen und der konkreten Ausführung zeigen, bedingt durch den (persönlichen) Erfahrungsschatz, besondere Fachkenntnis, die vorhandenen bzw. begrenzten Möglichkeiten sowie verfügbare Ressourcen (vgl. ebd.: 138). Auch den Sozialstatus und unterschiedlich starkes Engagement betrachtet Warde als mögliche treibende Kräfte für Veränderung, denn alle diese Aspekte führten letztendlich zu voneinander abweichenden Verstehensweisen und Handlungsroutinen (vgl. ebd.: 139). Darüber hinaus hätten die Größen Zeit, Raum sowie sozialer Kontext Einfluss auf Praktiken und könnten dadurch Ausdifferenzierungen und Änderungen in den Performances nach sich ziehen (ebd.). Genauso kann die Übertragung von einzelnen Aspekten oder Elementen einer Praktik auf andere Praktiken, Warde zufolge, zu Neuregelungen und Umstellungen sowohl innerhalb einer Praktik als auch zu einer abgewandelten Koordination zwischen den verschiedenen, miteinander zusammenhängenden Praktiken führen (vgl. ebd.: 141). Schließlich macht Warde, wie schon Reckwitz, das Individuum als eine besonders bedeutende Quelle für Wandel aus (vgl. ebd.: 143ff).

Wardes besonderer Verdienst ist es, den Aspekt sozialer Differenzierung von Praktiken sowie ihrer Performances in die Debatte um Wandel und Kontinuität sozialer Praktiken eingebracht zu haben.

Die Arbeiten Shoves et al. befassen sich noch einmal sehr viel stärker mit der Veränderung sozialer Praktiken. Durch zahlreiche empirische Studien haben Shove et al. neue Einsichten in die Dynamiken sich wandelnder Praktiken gewinnen können. Beispielsweise untersuchen sie die Entstehung neuer Praktiken bzw. das Aufkommen ein und derselben neuen Praktik in verschiedenen Kontexten (vgl. Shove und Pantzar 2005): Dafür gehen sie der Frage nach, wie Praktiken neue ,Träger"innen' rekrutieren und diese an sich binden, um dadurch ihr Fortbestehen zu sichern (Shove und Pantzar 2007). Hierfür haben sie die Interdependenz von Praktikenverläufen (,practice trajectories ${ }^{6}$ ) und Praktizierenden beleuchtet, was sie zu der grundlegenden Frage gebracht hat, inwiefern sich soziale Praktiken 
auch aus sich selbst heraus wandeln (können). Die zentrale Erkenntnis, die Shove und Pantzar aus diesen Analysen haben gewinnen können, ist, dass aus Praktikenperspektive das Rekrutieren von neuen Teilnehmer*innen und das Verlieren von Praktizierenden bereits Wandel bedeutet. An diese Überlegungen anknüpfend haben sich Shove et al. in einem Buch den möglichen Dynamiken sozialer Praktiken umfassender gewidmet. In „The Dynamics of Social Practice“ (Shove et al. 2012) beschäftigen sie sich zunächst mit den abstrakt denkbaren Veränderungen sozialer Praktiken, um diese unterschiedlichen theoretischen Wandlungsprozesse innerhalb einer einzelnen Praktik sowie zwischen mehreren Praktiken dann anschließend anhand konkreter Beispielen zu verdeutlichen.

Für eine systematische Auflistung von Wandlungsquellen und -formen wird im Folgenden insbesondere an dieses größere Werk angeknüpft.

\subsubsection{Praktikenwandel - grundlegende theoretische Differenzierungen}

Nachdem im letzten Teilkapitel die wichtigsten Beiträge und Positionen zum Thema ,Wandel' aus der praxistheoretischen Literatur zusammengetragen wurden, wird sich nun zwei für den Wandel von Praktiken besonders relevanten Differenzierungen zugewendet: Dabei handelt es sich erstens um die Unterscheidung zwischen Praktiken und ihrem Kontext und zweitens um die Unterscheidung zwischen der ,practice-as-entity" und der ,practice-as-performance.$^{52}$ Beide Unterscheidungen sind wichtig, um Ausgangspunkte und das Ausmaß von Wandel einzuschätzen und somit unterschiedliche Wandlungsarten voneinander unterscheiden und verstehen $\mathrm{zu}$ können.

Alle bisher besprochenen Theoretiker"innen (Schatzki, Reckwitz, Warde, Shove et al.) vertreten die Position, dass Praktikenwandel sowohl von innen heraus als auch von außen, durch Impulse aus dem Umfeld veranlasst, erfolgen kann: „Generally speaking, changes can be generated within a bundle or induced or caused from outside it" (Schatzki 2013: 42). Häufig würden Veränderungen durch externe Bedingungen und Faktoren erklärt; Shove und Pantzar geben jedoch zu bedenken, „that practices also develop

52 Im Folgenden wird ,practice-as-entity ${ }^{6}$ mit ,Praktik-als-Einheit ${ }^{\star}$ und ,practice-asperformance' mit ,Praktik-als-Performance' übersetzt. Teilweise werden auch die englischen Originalbezeichnungen beibehalten, um die Mehrdeutigkeit der jeweiligen Begriffe (,entity' und ,performance') für den Verwendungszusammenhang zu wahren. 
from within or, more accurately, as a consequence of continual re-positioning of practitioners with respect to the entity or practice they sustain and reproduce" (Shove und Pantzar 2007: 165). Sie sind der Ansicht, dass sogar der überwiegende Teil der Veränderungen in Praktiken auf interne Dynamiken zurückzuführen ist, dass sich soziale Praktiken also vor allem aus sich selbst heraus wandeln (vgl. ebd.: 154). Dies sehen sie in der besonderen Struktur sozialer Praktiken begründet. Ihre Position ergibt sich, so Shove und Pantzar, aus der für Praxistheorie zentralen Annahme, dass soziale Praktiken zwar über eine relativ dauerhafte Existenz in Raum und Zeit verfügen, dass ihr dauerhaftes Bestehen aber von ihrer wiederholten Reproduktion in Form von zwangsläufig raumzeitlich situierten Performances abhängt (vgl. Shove und Pantzar 2005: 61).

\section{Die Abgrenzung einer Praktik von ihrem jeweiligen Kontext}

Die Unterscheidung von dem, was zur Praktik gehört und ihrem jeweiligen Kontext kann hilfreich sein, um mögliche Wandlungsquellen und daraus resultierende Formen von Praktikenwandel zu systematisieren. Da die Differenzierung zwischen internen und externen Veränderungsursprüngen bezogen auf Praktiken nicht ganz einfach zu verstehen ist, soll sie anhand des praktischen Beispiels neuer Heizungstechnik kurz verdeutlicht werden: Allgemein ausgedrückt kommen als interne Wandlungsanlässe alle Elemente und Aspekte in Frage, die bereits Bestandteil der betreffenden Praktik sind. So stellt der Einbau einer neuen Zentralheizung, wenn etwa eine 30 Jahre alte Gas- oder Öl-Zentralheizung durch eine moderne, energieeffiziente Heizungsanlage ausgetauscht wird, eine Veränderung innerhalb der bestehenden Praktik ,Heizen' dar. Denn der Heizkessel war schon vor dem Austausch eine zentrale Komponente. Die Inbetriebnahme der neuen Anlage würde demnach ungebrochen als Heizen gedeutet werden. Das heißt, auch wenn sich durch den Heizkesselaustausch kleinere oder für manche Praktizierende auch größere Verhaltensänderungen (auf der Performanceebene) beim Heizen ergeben, wäre dies trotzdem als ein Wandel zu betrachten, der auf interne Entwicklungen zurückzuführen ist. Die Praktik des Heizens wird in ihrer Existenz oder ihrem grundsätzlichen Erscheinungsbild jedoch nicht infrage gestellt oder gar umgebildet.

Eine neue Technologie kann allerdings genauso als externe Veränderungsgröße auftreten. Dann muss es sich jedoch um ein technisches Artefakt und Verfahren handeln, welches vorher noch kein fester Bestandteil besagter Praktik war. Dieses neu aufgekommene technische Element befindet sich somit zunächst außerhalb der Praktik, gehört vorerst nur dem Kontext an. Auf Heizen bezogen galt dies etwa für die im 18. Jahrhundert 
neu eingeführte Zentralheizungstechnologie, die später die Beheizung mittels Kohle-Einzelöfen ablöste und heute Standard ist; oder aktuell wäre hier zum Beispiel an die neuartige Technologie der Eisheizung zu denken. ${ }^{53}$ Anfangs stellt eine neu entwickelte Technologie lediglich eine Irritation von außen dar bzw. zu diesem frühen Zeitpunkt fehlt (noch) eine korrespondierende Praktik. Erst wenn das neue technische Element in eine bestehende Praktik fest integriert wird oder wenn sich eine auf die technische Neuerung hin abgestimmte soziale Praktik neu herausgebildet hat, ist von Praktikenwandel aufgrund eines externen Einflusses zu sprechen. In diesem Fall ist der Wandel deutlich tiefgreifender, denn er betrifft diesmal nicht nur den praktischen Vollzug, sondern auch die Praktik als abstrakte Einheit verändert sich. So wandelte sich mit Einführung und zunehmender Verbreitung der Zentralheizungstechnologie und der gleichzeitigen Umstellung der Beheizung von Festbrennstoffen auf Öl und Gas neben dem technischen Zubehör bzw. den zentralen materiellen Elementen auch das Bündel der dazugehörigen körperlich-mentalen Aktivitäten ganz grundlegend: Nun musste beispielsweise nicht mehr Feuerholz oder Holzkohle beschafft, dafür aber mindestens einmal im Jahr der Öl- oder Gastank befüllt werden; und statt der Befeuerung von Einzelöfen in verschie-

53 Beim Prinzip der Eisheizung handelt es sich um eine effektive Methode, um auf günstige Weise Energie (zu Heizzwecken) zu erzeugen. Das Konzept geht auf den Energieerhaltungssatz zurück, wonach keine Energie verloren geht, wenn ein Medium, wie beispielsweise Wasser, seinen Aggregatzustand von flüssig zu fest verändert. Die beim Übergang frei gewordenen Energieeinheiten werden mittels Wärmetauschern und Wärmepumpen aufgenommen und weitergeleitet. Die Technologie der Eisheizung ist relativ einfach: Als Speicher fungiert ein in die Erde eingegrabener Betonbehälter, der mit Trinkwasser befüllt wird. Im Verlauf des technischen Vorgangs friert dieses Wasser zu Eis und taut wieder auf. Das Aufheizen des Wassers übernimmt eine auf dem Hausdach installierte Solaranlage bzw. übernehmen so genannte Solar-Luft-Kollektoren und die dabei gewonnene Energie wird über eine Wärmepumpe zur Verfügung gestellt. Beim Übergang in den entgegengesetzten Aggregatzustand, wenn also das Wasser im Winter zu Eis gefriert, wird ebenfalls Energie freigesetzt, die genutzt werden kann. In diesem Fall wird Energie frei, die das sich am Gefrierpunkt befindende Wasser auf $80 \mathrm{Grad}$ Celsius aufheizen kann. Die umliegende Erde (des eingegrabenen Wasserbehälters) dient als zusätzlicher Energiespeicher. Auf diese Weise nutzt diese Heizbzw. Energieanlage gleich fünf regenerative Quellen (Eis, Wasser, Sonne, Luft und Erde), um Energie zu erzeugen, die dauerhaft und ohne Schwankungen zur Verfügung steht. Das Prinzip der Energieerzeugung aus Solareis kann auch umgekehrt zu Kühlungszwecken, sprich im Sommer zur Raumkühlung, genutzt werden (vgl. www.eisheizung.com/eisheizung.html, zuletzt geprüft am 07.08.2018). 
denen Räumen bedarf es bei der Zentralheizung nur noch eines zentralen, meist im Keller aufgestellten Heizkessels. Demnach hat sich mit der Zentralheizungstechnologie sowohl der Bedeutungsgehalt des Heizens grundlegend gewandelt, als auch kam es zu einer Neufassung und Neustrukturierung der zu Heizen gehörenden Tätigkeiten.

Hieran schließt sich die Frage an, ob wir gegenwärtig mit der Passivhaustechnologie und der intelligenten Heizungssteuerungstechnik wieder an solch einem Wendepunkt stehen: Haben die Passivhaustechnologie und/oder die intelligente Heizungssteuerungstechnik das Potenzial, Heizen ein weiteres Mal von Grund auf zu verändern? Im empirischen Teil dieser Arbeit, vor allem aber im Schlusskapitel wird es wesentlich um die Auseinandersetzung mit dieser Frage gehen.

Bei der Differenzierung interner und externer Wandlungsausgangspunkte handelt es sich um eine zweckmäßige Vereinfachung. In der Praxis ist der ausschlaggebende Anlass für Veränderung oft nicht eindeutig zu identifizieren; häufig handelt es sich um eine Mischung bzw. ein Zusammenspiel unterschiedlicher Faktoren, die sowohl intern wie extern verortet werden (können). Darüber hinaus lässt sich nicht pauschal beantworten, ob Änderungen im Inneren oder im Äußeren ihren Ausgang genommen haben, dies kann oft nur die konkrete Analyse der Handlungspraxis bzw. einzelner praktischer Handlungsvollzüge ergeben.

\section{Die Unterscheidung zwischen, practice-as-entity' und ,practice-as-perfor- mance' sowie das Verhältnis der beiden Konzepte zueinander}

Daneben spielt eine zweite Differenzierung für die angemessene Untersuchung und Einschätzung von Praktikenwandel eine wichtige Rolle: dies ist die Unterscheidung zwischen der ,Praktik-als-Einheit' (,practice-as-entity') und der ,Praktik-als-Performance' (,practice-as-performance').

Praktiken sind für viele Gesellschaftsmitglieder erkennbar, unabhängig davon, ob sie die Tätigkeit selbst vollziehen oder nicht. Zum Beispiel können die meisten Menschen Autofahren, Rauchen oder einen Kinobesuch beschreiben, und die Elemente, aus denen sich diese Tätigkeiten zusammensetzen, egal ob sie diese Tätigkeiten nun selbst praktizieren oder nicht. Aufgrund dessen, dass diese routinisierten Tätigkeitsvollzüge unabhängig von bestimmten Einzelpersonen existieren, ist es möglich, von Praktikenals-Einheiten zu sprechen. Von daher ist es hilfreich, analytisch zwischen einer Praktik-als-Einheit und einer Praktik-als-Performance zu differenzieren (Spurling et al. 2013: 20).

Praktiken-als-Einheiten haben eine Geschichte, das heißt sie verfügen über einen Verlauf bzw. spezifischen Entwicklungsweg. Wie in Teilkapitel 
2.2.4.1 ausführlich dargestellt, existiert die Alltagstätigkeit des Gebäudebzw. Raumheizens schon seit vielen Hundert Jahren. Allerdings haben sich sowohl die involvierten Elemente als auch das Heizsetting über die Jahrhunderte stark gewandelt, so dass sich Heizen auch hinsichtlich seiner Form und Ausgestaltung stark verändert hat.

Praktiken-als-Performances sind die konkret beobachtbaren Handlungen bzw. Vollzüge, die häufig auch als Verhalten(sweisen) bezeichnet werden (ebd.: 21).

Während mit der Praktik-als-Einheit also eher das abstrakte Modell einer Praktik gemeint ist - zu verstehen als ein über eine bestimmte Spanne von Raum und Zeit hinweg stabile Aktivitätenkonstellation (vgl. Schatzki 1996: 89) -, stellt die Praktik-als-Performance den tatsächlichen Tätigkeitsvollzug, die konkrete Ausführung spezifischer ,doings and sayings' dar (vgl. ebd.: 90). Vereinfacht gesprochen, handelt es sich bei individuellen Verhaltensweisen um Performances sozialer Praktiken, in denen aber immer überindividuelle Phänomene zum Ausdruck kommen. Bezüglich des Heizens wären hier z.B. sozial geteilte Behaglichkeitsvorstellungen zu nennen.

Im Folgenden wird noch einmal darauf eingegangen, in welchem Verhältnis die beiden Konzeptionen zueinander stehen. Die Dualität der Praktik-als-Einheit und der Praktik-als-Performance soll hier mittels Giddens ${ }^{6}$ Theorie der Strukturierung (1997 [1984]) deutlich gemacht werden. Im Prinzip geht es hierbei um das Verhältnis von ,agency“ (hier verstanden als Handlungsmacht bzw. -trägerschaft) und ,structure' (Struktur) und dessen praxistheoretische Konzeptualisierung (vgl. Shove et al. 2012: 2ff).

Den Praxistheoretikern Schatzki und Reckwitz zufolge sind soziale Praktiken Routinen: „routines of moving the body, of understanding and wanting, of using things, interconnected in a practice" (Reckwitz 2002b: 255). Routinen zeichnet aus, dass sie - einmal erlernt - ohne bewusstes Nachdenken in nahezu gleicher Weise Tag für Tag vollzogen werden (können); in ihrer fortlaufenden Reproduktion bilden sie soziale Strukturen. Beide Theoretiker erkennen hierin den rekursiven Charakter von Praxis: Praktikals-Einheit und Praktik-als-Performance stehen in einem rekursiven, sich gegenseitig konstituierenden Verhältnis zueinander, wobei Praktik(en)-alsEinheit(en) gewissermaßen mit ,Struktur' gleichzusetzen sind und Praktikals-Performance dem ,agency'-Konzept Giddens' nahe kommt. Reckwitz bringt die Dualität von Praktiken zum Ausdruck, indem er erklärt, dass eine Praktik als ein ,Block' bzw. ein Muster existiert, „which can be filled out by a multitude of single and often unique actions reproducing the practice" (Reckwitz 2002b: 250). Insofern bleibt eine Praktik (als Einheit) 
auch zwischen und über einzelne, konkrete Vollzüge (Performances) hinweg bestehen. Dahinter steht das Argument, dass „sich die Akteure [in ihrem Alltagshandeln] immer und notwendig auf die strukturellen Momente übergreifender sozialer Systeme [beziehen], welche strukturellen Momente sie so zugleich reproduzieren“ (Giddens 1997 [1984]: 76). Dabei handelt es sich um ein zentrales Element der Giddens'schen Theorie der Strukturierung: Aktivitäten werden durch Strukturen - im Wesentlichen Regeln, Bedeutungen und Ressourcen - geformt, gleichzeitig werden genau diese Strukturen, die das Handeln erst ermöglichen, im kontinuierlichen Strom menschlichen Handelns immer wieder aufs Neue hervorgebracht und dabei reproduziert oder transformiert (vgl. ebd.: 77).

Um die Möglichkeiten von Praktikenwandel zu erörtern, ist daher zunächst zu klären, welche Ebene von Veränderung betroffen ist. Auf welcher Ebene ereignen sich die Wandlungen jeweils und wie hängen die Ebenen miteinander zusammen? Während die Praktik-als-Performance analog zum ,agency'-Konzept gedacht werden kann, kann die Praktik-alsEinheit eher mit abstrakter ,Struktur' identifiziert werden. Auf Wandel bezogen geht es um die Unterscheidung von Wandel auf der Handlungsebene und Wandel auf der Strukturebene - um einfache Verhaltensänderungen auf der einen Seite und konstitutive, das heißt sich auch strukturell manifestierende Veränderungen auf der anderen Seite. Während Praktikenwandel auf Performanceebene ständig stattfindet, ist die Praktik-als(abstrakte)-Einheit deutlich seltener von Wandel betroffen. Denn nicht jede Veränderung in der Performance führt zu Umbildungen bei der Praktik als abstraktes Modell. Umgekehrt geht aber jeder Feststellung eines Wandels einer Praktik-als-Einheit ein (multipler) geänderter Handlungsvollzug voraus. Nur im letzten Fall ist von einem grundlegenden Veränderungsprozess zu sprechen. Daher ist aus praxistheoretischer Perspektive vor allem der Wandel der Praktik-als-Einheit interessant:

"For practice theory, then, the 'breaking' and 'shifting' of structures must take place in everyday crises of routines, in constellations of interpretative interdeterminacy and of the inadequacy of knowledge with which the agent, carrying out a practice, is confronted in the face of a 'situation'." (Reckwitz 2002b: 255)

Die beiden Konzepte stellen allerdings, wie bereits ausgeführt, keinen Gegensatz dar. Vielmehr sind die beiden Ebenen - ,agency' und ,structure', um mit Giddens zu argumentieren - über das vermittelnde Konzept sozialer Praktiken miteinander verknüpft: 
„Konstitution von Handelnden und Strukturen betrifft nicht zwei unabhängig voneinander gegebene Mengen von Phänomenen - einen Dualismus -, sondern beide Momente stellen eine Dualität dar. Gemäß dem Begriff der Dualität von Struktur sind die Strukturmomente sozialer Systeme sowohl Medium wie Ergebnis der Praktiken, die sie rekursiv organisieren. Struktur ist den Individuen nicht "äußerlich «: in der Form von Erinnerungsspuren und als in sozialen Praktiken verwirklicht, ist sie in gewissem Sinne ihren Aktivitäten eher »inwendig « als ein [...] außerhalb dieser Aktivitäten existierendes Phänomen.“ (Giddens 1997 [1984]: 77f, Hervorh. im Original)

Für Giddens ist damit klar, dass soziale Praktiken die zentralen Untersuchungseinheiten abgeben, da lediglich über die Analyse von Praktiken sowohl an das alltägliche Handeln als auch an soziale Strukturen heranzukommen ist.

Was bedeutet das wiederum für die empirische Untersuchung von Praktikenwandlungsprozessen? Fest steht: Praktiken können in der Form von Praktiken-als-Einheiten nicht direkt beobachtet werden, wie dies auch für soziale Strukturen im Allgemeinen gilt. Stattdessen braucht es Indikatoren bzw. Konkretisierungen, etwa in Form materieller Darstellungen, die die abstrakten Muster sicht- und messbar machen. Demnach ist von den raumzeitlich situierten Praktikenvollzügen auszugehen, nur sie sind der empirischen Erschließung zugänglich: „practices can only be studied in the form of practice-as-performance“ (Røpke 2009: 2494). Aufgrund des rekursiven Charakters sozialer Praktiken kann von den Performances auf die Praktikals-Einheit rückgeschlossen werden, denn Kontinuitäten wie auch Veränderungen schlagen sich zwangsläufig zuallererst in den praktischen Handlungsvollzügen nieder.

Das heißt, soll sich nachhaltig etwas auf der Handlungsebene verändern, soll es auf lange Sicht und auf Dauer zu nachhaltigen Verhaltensweisen kommen, so ist dafür das Erschließen und ein grundlegendes Verständnis der jeweils zugrundeliegenden Praktiken-als-Einheiten erforderlich, denn für einen nachhaltigen Wandel von Praktiken muss an den, entities' interveniert werden. Um die Beziehung von Praktik-als-Performance und Praktik-als-Einheit anschaulich zu beschreiben, verwenden Spurling et al. die bekannte Metapher des Eisbergs:

"Observable behaviour is just the tip of the iceberg: the performance of socially shared practices. It is the entity - the socially embedded underpinning of behaviour - which we argue forms a better target for sustainability policy.” (Spurling et al. 2013: 21) 
Entsprechend spiegelt die Praktik-als-Einheit die den einzelnen (Heiz-)Praktikenvollzügen zugrundeliegenden, konstitutiven Elemente und Strukturen wider. Anhand dieses Bildes lässt sich dann auch gut erschließen, welches die Ausgangspunkte für einen grundlegenden Praktikenwandel sein können, um die es im folgenden Teilkapitel geht.

\subsubsection{Ausgangspunkte für Wandel}

Nachdem nun die grundlegenden Differenzierungen, die zur Untersuchung und Einordnung von Praktikenwandlungsphänomenen relevant sind, erläutert wurden, sollen im Folgenden die wichtigsten Punkte dargelegt werden, von denen Praktikendynamiken ihren Ausgang nehmen können. Dies soll als theoretische Grundlage der empirischen Analyse von (Heiz-)Praktikenperformances dienen, um mehr über deren Aufbau, Struktur sowie Wandlung(spotenzial) in Erfahrung zu bringen.

\section{Die Elemente und ibre Integration}

Wie in den Teilkapiteln 2.1.2 und 2.1.5 bereits erläutert, bestehen soziale Praktiken aus verschiedenen Elementen. Diese werden von den Praktizierenden im Rahmen ihrer praktischen Handlungsvollzüge sinnvoll miteinander kombiniert und zu einheitlichen Tätigkeiten integriert.

An dieser Stelle soll noch einmal daran erinnert werden, dass in dieser Arbeit das vereinfachte Praktiken-Modell Shoves et al. zugrunde gelegt wird. In diesem sind die zahlreichen verschiedenen Elemente in drei Kategorien zusammengefasst: dies sind 1) Materialien, 2) Kompetenzen und 3) Bedeutungen/Sinn (Shove et al. 2012: 14 und 23f). Daraus ergibt sich, „that practices are defined by interdependent relations between materials, competences and meanings" (ebd.: 24). Folglich kann der Wandel von Praktiken verstanden werden als das neuerliche Herstellen, das Bestätigen, das Aufbrechen oder das Kappen von Verbindungen zwischen den definierenden Elementen einer Praktik. Veränderungen können demnach von jedem der zu einer Praktik integrierten Elemente ausgehen. Die Variation einzelner Elemente bzw. jegliche Änderung hat immer Auswirkungen auf das Gesamtgefüge der Praktik, zumindest auf die Praktik-als-Performance, da in jeder Praktik stets alle Elemente zusammenwirken. Das bedeutet, die Verknüpfungen sind von zentraler Bedeutung: „if specific configurations are to remain effective, connections between defining elements have to be renewed time and again" (ebd.). Durch das Verknüpfen von Elementen 
oder das Kappen von Verbindungen kommt Bewegung in Praktiken, dann entwickeln, wandeln sie sich oder lösen sich gar ganz auf (vgl. ebd.: 21-62) - all dies geschieht im ,doing', also in der konkreten Handlungspraxis und ist somit beobachtbar.

In Bezug auf die Materialien-Komponente ist zum Beispiel denkbar, dass neue Objekte oder Werkzeuge hinzukommen oder es kann sich die zu einer Praktik gehörende Infrastruktur verändern. Zur Materialität sozialer Praktiken gehört neben technischen Artefakten und Objekten auch der menschliche Körper. Die Körper bzw. sämtliche körperliche Konstitutionsmerkmale der Praktizierenden können ein entscheidender Ausgangspunkt für Wandel sein. Deshalb wird an späterer Stelle noch einmal gesondert auf Individuen als Quelle für Veränderungen von Praktiken eingegangen.

In der Kompetenzen-Komponente sind vielfältige Wissensformen und praktische Kenntnisse zusammengefasst. Von dieser Komponente können Veränderungen in vielgestaltiger Weise angestoßen werden, zum Beispiel kann Neues gelernt und in bekannte Abläufe integriert werden, Erfahrungswissen kann angereichert oder bereits vorhandene Fertigkeiten können durch Einübung bzw. Wiederholung erweitert werden. Ständig sehen sich die Praktizierenden mit neuen Erkenntnissen konfrontiert und werden ihnen neue Informationen zur Verfügung gestellt, die sie aufnehmen und in ihr alltägliches Handeln einfließen lassen (können). Darüber hinaus erwerben die Praktizierenden im Laufe ihres Lebens ständig neue Kompetenzen, entweder durch professionelle Anleitung, im intensiven Selbststudium oder im direkten Umgang mit neuen Gegenständen oder durch die überraschende Konfrontation mit unbekannten Situationen oder Aufgaben. Ebenso ist es möglich, dass durch Anregungen aus dem Umfeld, etwa durch einzelne Mitstreiter*innen oder Konkurrent"innen, an bereits vorhandenen Fertigkeiten gefeilt wird. Umgekehrt können Kompetenzen auch (wieder) verloren gehen oder in Vergessenheit geraten, um dann vielleicht nach vielen Jahren wieder reaktiviert zu werden (vgl. Shove und Pantzar 2006: 61; Shove et al. 2012: 34).

Die Bedeutungen/Sinn-Komponente umfasst sämtliche mentale Aktivitäten, Emotionen wie auch Motivationen. Der Ausdruck, meaning' steht Shove et al. zufolge stellvertretend für "the social and symbolic significance of participation at any one moment" (Shove et al. 2012: 23). Shove et al. behandeln Bedeutungen/Sinn als ein Praktikenelement, für sie stellt der Bedeutungsgehalt ein notwendiger Bestandteil jedweder Praktik dar, „not something that stands outside or that figures as a motivating or driving force" (ebd.: 24). Nehmen Veränderungen von hier aus ihren Ausgang, so kann dies die Form neuer Sinnzuschreibungen oder Zielinterpretationen 
annehmen, ebenso vorstellbar sind geänderte Einstellungen, veränderte Gefühlslagen oder Motive. Insbesondere neue Ideen und Konzepte sowie ihr Eingang in alltägliche Handlungsvollzüge kann ein bedeutender Impuls für umfassenderen Praktikenwandel sein, so dass es zu einer sprunghaften Verschiebung im Bedeutungsgehalt einer Praktik kommt. Die tiefgreifendste Form von Wandel, die diese Entwicklung provozieren kann, wird meist unter dem Schlagwort ,Paradigmenwechsel ${ }^{6}$ diskutiert und im Schlusskapitel noch einmal aufgegriffen.

Alle genannten Verschiebungen (in der Elementezusammensetzung) führen im Endeffekt mindestens zu Wandlungen in den praktischen Vollzügen. Umgekehrt wirken sich die abgewandelten Vollzüge aber immer auch wieder auf die involvierten Elemente aus:

„Moments of doing, when the elements of a practice come together, are moments when such elements are potentially reconfigured (or reconfigure each other) in ways that subtly, but sometimes significantly change all subsequent formulations." (Shove et al. 2012: 13)

Darüber hinaus argumentieren Shove et al., dass die einzelnen Elemente einer Praktik eine Art ,Eigenleben' führen. Sie begründen diesen Standpunkt mit der Feststellung, dass sich Elemente im Vergleich zu Praktiken relativ frei in Raum und Zeit bewegen können. Als raumzeitlich strukturierte und situierte Aktivitätenkomplexe seien Praktiken gewissermaßen ständig im Prozess des Auf-, Um- oder Abbaus begriffen. Demgegenüber seien Elemente verhältnismäßig stabil und somit fähig, zwischen verschiedenen Orten und Kontexten zu zirkulieren und länger in gleichbleibender Manifestation fortzubestehen (vgl. ebd.: 44). Obgleich „materials, meanings and forms of competence circulate in characteristically different ways" (ebd.: 132), beurteile ich die grundsätzliche Annahme, dass Elemente eigene Verläufe haben, für die praktische Analyse von Praktikenwandlungsprozessen als hilfreich. Dadurch bietet sich die Möglichkeit, den Werdegang einzelner, für Heizen elementar wichtige Elemente zu verfolgen, um derart auf Veränderungen im Heizen zu schließen. So argumentieren auch Shove et al., dass es vor allem für die Analyse und den Vergleich von Praktiken durchaus sinnvoll und nützlich sein kann, „to think of elements as if they had relatively autonomous trejectories" (ebd.: 62, Hervorh. im Original), auch wenn gleichzeitig klar ist, „that elements are nothing unless integrated in practice“ (ebd.).

Der Wandel von Erwartungen und Konventionen, die vorrangig mit Heizen und Kühlen bzw. der Herstellung thermischer Behaglichkeit innerhalb von Wohnräumen zusammenhängen - und die dementsprechend der 
Bedeutungen/Sinn-Komponente zuzuordnen sind -, ist bereits praxistheoretisch untersucht worden. In ihrem Aufsatz „Debating the future of comfort" (Chappells und Shove 2005) diskutieren Chappells und Shove die Zukunft von (thermischer) Behaglichkeit bzw. Komfort (in Abhängigkeit vom thermischen Raumklima), sowohl als ideelles Konzept als auch als materielle Realität. Für ihre Studie, die sich auf den britischen Kontext bezieht, führten sie Interviews und diskutierten mit politischen Entscheidungsträger*innen sowie zahlreichen Gebäudeexpert*innen, wie z. B. Architekt"innen, Bauingenieur*innen, Gebäude- und Anlagentechniker*innen, Energieberater*innen, die alle an der Bestimmung und baulichen Gestaltung eines zukünftigen Wohnraumklimas beteiligt sind. Auf Basis dieser Gespräche konnten vier mögliche Szenarien zukünftigen (thermischen) Komforts identifiziert werden, jedes mit unterschiedlichen Konsequenzen für den Energieverbrauch. Diese vier Szenarien sollen an dieser Stelle kurz vorgestellt werden, da sie für die Auswertung des empirischen Materials relevant sind. In Kapitel 4.3 des empirischen Teils dieser Arbeit zu Veränderungen im Behaglichkeits- und Komforterleben werden sie noch einmal aufgegriffen.

Im ersten vorstellbaren Szenario wird erwartet, dass sich die gültigen Konventionen für Komfort und Bekleidung weiter stabilisieren und standardisiert werden. Wenn man diese Entwicklung annimmt und das Klima erwärmt sich weiter, dann wird sich zukünftig vor allem der Bedarf für ,Kühlung' erhöhen (vgl. Chappells und Shove 2005: 37).

Eine zweite mögliche Entwicklung wäre, dass die Komfortansprüche noch weiter anstiegen und sich dementsprechend auch der Energieverbrauch für Raumwärme und -kühlung in Zukunft noch weiter erhöhte. Chappells und Shove werfen hier die Frage auf, was geschehen würde, wenn die Menschen es in ihren Wohnungen künftig im Winter noch wärmer und im Sommer noch kühler haben wollten als heute schon üblich und weisen darauf hin, dass erste Ergebnisse aus Haushaltsbefragungen zeigen, dass derartige Entwicklungen in Ländern wie Großbritannien und den USA bereits im Gange sind. Unter Umwelt- und Klimagesichtspunkten, so argumentieren sie weiter, würden Trends dieser Art die Suche nach effizienteren technologischen Lösungen noch dringender und notwendiger machen (ebd.).

Alternativ könnte sich der Behaglichkeits- bzw. Komfortbereich auch dergestalt ausweiten, dass sich der Energiekonsum verringert, statt sich zu erhöhen.

Aus Expert"innensicht ist ebenfalls vorstellbar - dies ist das dritte Szenario -, dass sich die Menschen, anstatt das ganze Jahr über standardisierte 
klimatische Bedingungen innerhalb von Gebäuden zu verlangen, (wieder) an eine breitere Vielfalt gewöhnen, so dass sie im Winter etwas niedrigere und während der Sommermonate höhere Raumtemperaturen als gegenwärtig erwarten und akzeptieren. Wäre dies der Fall, so könnte saisonale Kleidung ein wichtiges Mittel zum Umgang mit klimatischen Schwankungen darstellen. Die Kombination ,Bekleidung und deutlich dehnbarere Definitionen von Komfort bzw. breitere Komfortzonen' könnte den Energiebedarf erheblich reduzieren und womöglich eine geeignete Strategie darstellen, sich an den Klimawandel anzupassen bzw. ihm zu begegnen, ohne zum Problem selbst weiter beizutragen (vgl. ebd.: 38).

Das vierte Szenario, das die Expert*innen zwar für nicht sehr wahrscheinlich, jedoch nicht für unmöglich halten, beinhaltet die ,Neuerfindung' und positive Bewertung lokaler kultureller und klimatischer Vielfältigkeit, auf die mit der Entwicklung regional angepasster ökologischer Baupraktiken reagiert werden könnte (vgl. ebd.).

Chappells und Shove betonen, dass die vier skizzierten möglichen Entwicklungen keine sich gegenseitig ausschließenden Alternativen darstellen und es in jedem Falle wichtig sei, daran zu erinnern, dass ein Großteil der in den Szenarien antizipierten Gebäude(konzepte) und viele der für die Zukunft vorgestellten sozialen Konventionen bereits heute schon existierten.

Im empirischen Teil dieser Arbeit soll untersucht werden, welche der von den Expert*innen identifizierten möglichen künftigen Entwicklungstrends in den Behaglichkeits- und Komforterwartungen der Bewohner*innen von Passivhäusern und SmartHomes bereits wiederzufinden sind und/ oder sich zumindest schon abzeichnen.

Das Fortbestehen sozialer Praktiken als Ganzes hängt wiederum wesentlich von ihrer ständigen Reproduktion $\mathrm{ab}$, also davon, dass die betreffenden Praktiken regelmäßig von größeren Personengruppen wiederholt bzw. vollzogen werden. Soziale Praktiken müssen quasi eine größere ,Träger"innenschaft ${ }^{\star}$ dauerhaft an sich binden. Shove und Pantzar beschreiben dieses besondere Verhältnis von Praktiken und ihren Träger*innen folgendermaßen: „On the one side of the coin, practitioners are captured by practices. On the other, practices are defined and constituted through participation" (Shove und Pantzar 2007: 156). Die Entwicklungspfade von Praktiken hängen demnach eng mit den Werdegängen ihrer Träger*innen zusammen; vielmehr noch: beide hängen wechselseitig voneinander $a b$.

Im Folgenden wird es um diese spezielle Beziehung gehen, da hier ein weiterer wichtiger Ausgangspunkt für Wandel liegt (vgl. Shove und Pantzar 2007: 165; Shove et al. 2012: 63-79). 


\section{Das Subjekt als Ausgangspunkt für Praktikenwandel}

Im Praktiken-Ansatz wird zuallererst von sozialen Praktiken ausgegangen, die die Sozialwelt ,bevölkern'. In dieser Analyseeinstellung erscheinen Subjekte lediglich als ,Träger“innen' sozialer Praktiken: ,agents are body/ minds who 'carry' and 'carry out' social practices" (Reckwitz 2002b: 256, Hervorh. im Original). Demnach existieren die Subjekte nur innerhalb des Vollzugs von Praktiken, sie werden gewissermaßen im Prozess des Ausführens konstituiert (vgl. Reckwitz 2002b: 256, 2003: 296), wobei genauso soziale Praktiken nur aufgrund der wiederholten Performances der handelnden Subjekte fortbestehen. Der zentrale Ort, an dem sich Wandel manifestiert, ist demnach in den ,doings' handelnder Subjekte zu suchen - in bzw. mit ihren Praktikenperformances transformieren die Akteure die sozialen Praktiken.

Doch genauso gilt: „Social practices do not present uniform planes upon which agents participate in identical ways" (Warde 2005: 138). Vielmehr sind Praktiken im Inneren stark ausdifferenziert, setzen sie sich doch aus verschiedenen Elementen zusammen, die selbst wiederum sehr unterschiedlich gestaltet und auf vielfältige Weise zu einer Tätigkeit integriert sein können. Und genauso unterscheiden sich die an Praktiken teilnehmenden Subjekte hinsichtlich ihrer körperlich-mentalen Ausstattung. Demzufolge sind für jedes Subjekt in seiner jeweiligen Situiertheit immer nur bestimmte Praktiken attraktiv und so betätigen sich die Subjekte in ihrem Alltag und ihrem Leben in ganz unterschiedlichen Praktiken (vgl. Reckwitz 2002b: 256). Sie bilden jeweils einzigartige heterogene Wissensbündel (vgl. Reckwitz 2003: 295f).

So können sich Heiz-Performances nach bisherigen Erfahrungen, individueller Fachkenntnis, dem allgemeinen technischen Verständnis, Bildungsniveau, Lernen, Rahmenbedingungen und Gelegenheiten, verfügbaren Ressourcen und vorhandenem Equipment, persönlichem Kälte- und Wärmeempfinden, der Tagesform der teilnehmenden Subjekte usw. unterscheiden. Alle diese Aspekte fließen in die Ausübung mit ein, wodurch jede Performance unweigerlich eine ,individuelle Note' erhält. Die sehr unterschiedlichen körperlich-mentalen Ausstattungen und die einzigartige Wissensstruktur jedes Akteurs beeinflussen die Performance (vgl. Reckwitz 2002b: 256). Zudem wandeln sich die vom Subjekt verkörperten Verhaltens- und Wissenselemente mit der Zeit. Hierin liegt der Ausgangspunkt für subjektinduzierten Wandel begründet. Denn das Subjekt, überträgt ${ }^{\star}$ diese Änderungen (in den von ihm inkorporierten körperlich-mentalen Routinen) unvermeidbar auf sein Handeln, wodurch sich eben auch die 
Praktiken selbst ändern (können), an denen das im Fokus stehende Subjekt jeweils beteiligt ist.

Der Praktikenwandel kann dabei eher durch die individuelle Ebene (z.B. Lernen) oder durch die Strukturebene (,Praktik-als-Einheit ${ }^{\top}$ ) motiviert sein. So führt etwa Könnerschaft zu Praktikenwandel. Je öfter Praktizierende eine Praktik wiederholen und je mehr praktische Erfahrung sie dabei mit der ,richtigen' Ausführung sammeln, desto sicherer werden sie in der Performance. Letztendlich verschmelzen sie immer mehr mit der Praktik und werden auf diese Weise zu „full practitioners“ (Lave und Wenger 2011 [1991]). Dies hat häufig zur Folge, dass die Praktizierenden, frei$\mathrm{er}^{\mathrm{r}}$ in der Anwendung werden und dass sie sich in ihrer Performance weniger streng an Regeln und Vorgaben bzw. den formal vorgegebenen Verlauf einer Praktik halten (müssen) (vgl. Warde 2013: 24). Stattdessen beginnen sie, bei ihrer Performance zu improvisieren und zu experimentieren. Eventuell entfalten sie sogar eine eigene Auslegung der Praktik. Auch kommt es darauf an, um welche Art von Praktik es sich handelt. So ist bei vielen Praktiken, wie etwa im Sport, die Möglichkeit gegeben, durch kontinuierliches Üben und hartes Trainieren die Performance immer weiter zu optimieren. Wo immer sich die Chance zur Steigerung bietet, gibt es Praktizierende, die einen besonderen Ehrgeiz entwickeln, in der betreffenden Tätigkeit Professionalität zu erlangen (vgl. Warde 2005: 141): „new levels of practice come within reach as competence develops" (Shove et al. 2012: 71). Ein zentrales Prinzip ist somit der Wettbewerb. So kann Wettbewerb dazu führen, dass die zahlenmäßige Beteiligung an und das Engagement in bestimmten Praktiken deutlich steigen und es dementsprechend $\mathrm{zu}$ Variationen in den betreffenden Betätigungen kommt. Genauso möglich ist aber, dass sich Individuen, etwa aufgrund von Wettbewerbsdruck, ganz von der praktischen Betätigung zurück- und ihre bisher eingebrachten Ressourcen von der betreffenden Praktik abziehen (Stebbins 1992, 1999; vgl. auch Shove et al. 2012: 71).

Zusammenfassend lässt sich sagen, dass sich aufgrund des unterschiedlichen Engagements und der allgemeinen Leistungsfähigkeit der Akteure zahlreiche unterschiedliche ,Positionierungen' der Akteure im Hinblick auf die Weiterentwicklung einer Praktik zeigen bzw. es ergeben sich zahlreiche Relationen, in denen Partizipierende und Praktik zueinander stehen können (vgl. Warde 2005: 138). Berücksichtigt man die unterschiedlichen Niveaus von Engagements, so wird deutlich, dass es Gruppen von Partizipierenden gibt, die vor allem zur Reproduktion der Praktik in bisheriger Form beitragen, während andere Gruppen von Partizipierenden stärker die Weiterentwicklung forcieren: 
„Patterns of participation matter not only for who gets the opportunity to do what, but for who it is that shapes the future of a practice, and for how individuals are shaped by the experience." (Shove et al. 2012: 73)

Nicht zuletzt findet sich ein Potenzial für Veränderung in der jeweiligen Einzigartigkeit der Mischung und Kombination unterschiedlicher Verhaltens/Wissensgefüge sozialer Praktiken, die jedes Subjekt verkörpert (Reckwitz 2003: 296). Wie mit diesen verschiedenartigen Verhaltensroutinen und deren oft uneinheitlichen Sinngehalten im Einzelnen umgegangen wird, welches praktische Wissen in konkreten Situationen und spezifischen Kontexten aktiviert wird, kann jeweils sehr unterschiedlich aussehen und sich auch ständig ändern.

Dies leitet zu einem weiteren wichtigen Ausgangspunkt für Wandel über: gemeint ist der Kontext bzw. das Setting, in dem eine Praktik vollzogen wird. Zwar kann „die Kontextualität, die Situativität des Vollzugs von Praktiken [...] unter vielen Umständen routinisiert bewältigt werden“ (ebd.: 294); sie kann gegebenenfalls aber auch zur Krise, zum Scheitern körperlich-mentaler Routinen führen und daher Abwandlungen in den praktischen Vollzügen auslösen.

In diesem Zusammenhang ist wichtig zu erwähnen, dass einige Praktikentheoretiker*innen, wie beispielsweise Shove, der Vorstellung bzw. dem theoretischen Konzept des ,Kontextes' eher kritisch gegenüberstehen. Ihrer Meinung nach ist eine klare Trennung zwischen (gerade im Mittelpunkt stehender) Praktik und diese Praktik umgebende, aber bisher (noch) nicht direkt an ihr beteiligte Einflussfaktoren in der sozialen Wirklichkeit in der Regel nicht gegeben und ergebe deshalb auch theoretisch wenig Sinn (vgl. Spurling et al. 2013: 7). Aus diesem Grund vermeiden Shove et al. es weitgehend, von ,Kontext' und ,Kontextintervention' zur Initiierung von Praktikenwandel zu sprechen. Von grundlegendem Interesse ist stattdessen, wie verschiedene Praktiken, die etwa um die gleichen Ressourcen konkurrieren, (günstig oder ungünstig) ineinandergreifen und wie sich diese Verzahnungen und Kopplungen gegebenenfalls durch absichtsvolle Intervention verändern lassen, so dass die betreffenden Tätigkeitsformen und Konsummuster stärker in Richtung Nachhaltigkeit transformiert werden (vgl. ebd.: 12).

Das Argument Shoves et al., dass es sich meist um eine künstliche und oft auch willkürliche Trennung zwischen Praktik(-Elementen) und Umgebung(-sfaktoren) handelt, ist nachvollziehbar. Dennoch wird für die vorliegende Untersuchung weiterhin mit dieser analytisch-theoretischen Unterscheidung gearbeitet und es wird damit an die Argumentationen Schatzkis 
und Reckwitz' angeknüpft, da diese Unterscheidung wichtige Vorteile für die Analyse von Praktikenwandel mit sich bringt. So lässt sich mit der Rede von ,Kontext(-faktoren)' und dem ,Kontext'-Konzept gut deutlich machen, dass es durchaus (äußere) Einflüsse gibt, die sich erst neuerdings oder nur selektiv in einzelnen Fällen auf die (gerade im Fokus stehende) Praktik auswirken. Auf alltägliches Heizen in Privathaushalten bezogen sei hier beispielsweise an das gesetzliche Verbot von Nachtspeicherheizungen in der EnEV 2009 erinnert, das - wenn es denn eingetreten wäre - für die betroffenen Haushalte eine größere Herausforderung dargestellt hätte. ${ }^{54}$ Bei dem Thema ,Kontext' bzw. ,Verzahnung von Praktiken' geht es also um eine eher indirekte Beeinflussung von Praktiken durch (umgebende) Faktoren, welche weder zwingend noch generell mit der fokussierten Praktik in Zusammenhang stehen müssen. So gestaltet sich der Alltag, sind die Tagesabläufe der Bewohner*innen eines großen Mehrfamilienhauses, die zwar alle die gleiche Heiztechnik zur Verfügung haben, sehr unterschiedlich. Und diese Termin- und Zeitpläne sowie die dahinterstehenden konkreten Tätigkeitsinhalte wirken sich auf das Heizen aus. Demnach soll es im Folgenden um eine umfassendere Betrachtung von Veränderungsanlässen gehen.

\section{Der Kontext einer Praktik - andere Praktiken und ibre Elemente}

Zunächst lässt sich ganz allgemein konstatieren, dass als externe oder so genannte kontextuelle Wandlungsanlässe alle Ereignisse, Elemente und Eigenschaften fungieren können, die sich (zum Zeitpunkt der Betrachtung)

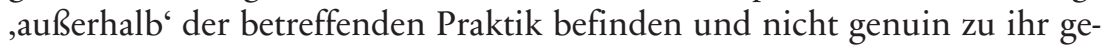
hören. Da in dieser Arbeit das Aktivitätenbündel ,Heizen' im Fokus steht, ist es hilfreich, ,Kontext' unmittelbar von dieser Praktik aus zu denken.

Ändert sich überraschend der Kontext einer Praktik, dann beeinflusst dies in der Regel auch ihre praktische Ausführung. Wenn aber Dinge, Technologien, Infrastrukturen, Körper, Kompetenzen, vielfältige Wissensformen sowie Bedeutungen und Sinnelemente bereits Bestandteile von Praktiken sind, worin - so könnte man fragen - kann dann (noch) der Kontext einer sozialen Praktik bestehen? Die Antwort lautet: in vielfältigen anderen Praktiken und deren zahlreichen Elementen. Wie Randles and Warde richtig anmerken: „Practices do not float free of technological, institutional and infrastructural contexts" (Randles und Warde 2006: 229).

54 Mittlerweile hat der Bundestag das eigentlich ab 2020 geplante Verbot für Nachtspeicherheizungen wieder gekippt. 
Vielmehr werden alle soziale Strukturen wie die gesellschaftliche Arbeitsteilung, Geschlechterverhältnisse und der ungleiche Zugang zu Ressourcen, wie auch politische, ökonomische, rechtliche und kulturelle Institutionen durch Praktiken gebildet; gleichzeitig stellen diese Praktikenkonglomerationen und -gefüge wiederum immer auch den Kontext für den Vollzug von Praktiken dar (vgl. Røpke 2009: 2493). Wichtig ist hier der Gedanke, dass soziale Praktiken nie als einzelne, isolierte Phänomene auftreten, sondern stets mit (zahlreichen) anderen Praktiken lose gekoppelt bzw. mehr oder minder fest verflochten sind (vgl. Reckwitz 2003: 295; hierzu ausführlicher, siehe Shove et al. 2012: 81-96). Die wohl bekanntesten manifesten Verschränkungsformen von Praktiken sind Infrastruktur(systeme) und Institutionen:

„Infrastructure - which influences where activities take place, and institutions - which influence when activities take place, play a vital part in how practices interlock, and are therefore important targets for interventions.” (Spurling et al. 2013: 12, Hervorh. Im Original)

Im Hinblick auf gezielte Interventionen in Praktikenkomplexe in Richtung Nachhaltigkeit im Alltag spielen laut Spurling et al. vor allem zwei Arten der Praktikenverzahnung eine zentrale Rolle: Dies sind zum einen Praktikensequenzen, also typische zeitliche Abfolgen von Praktiken:

„Our daily schedules are in-part determined by institutions and organisations: such as school timetables, the working day, and shop opening hours. Such sequences have differing implications for sustainability." (ebd.)

So hat eine Reduzierung der Arbeitszeit in den meisten Fällen eine Erhöhung der Anwesenheitszeit im Zuhause zur Folge, was in der Regel wiederum zu einem vermehrten Beheizen der privaten Wohnräume führt.

Zum anderen ist die Synchronisation von Praktiken zentral und kann somit vielfältige Auswirkungen auf angrenzende Alltagspraktiken haben. Bestimmte Praktiken sind (gut) aufeinander abgestimmt, fallen zeitlich zusammen oder hängen voneinander ab. Bleibt man bei obigem Beispiel, so wird deutlich, dass Heizaktivitäten in Privathaushalten bzw. die individuellen Heizprofile stark an den persönlichen An- und Abwesenheitszeiten der Subjekte orientiert sind. Oder ein weiteres typisches Beispiel ist die in vielen Haushalten schon standardmäßig eingestellte Nachtabsenkung der Heizung. Auch im Schlafzimmer sind normalerweise während der Nacht eher niedrige Temperaturen eingestellt, da die meisten Menschen zum Schlafen etwas niedrigere Temperaturen als tagsüber bevorzugen. Verkürzt 
sich die Schlafdauer, beispielsweise, weil vermehrt gearbeitet wird oder die betreffende Person unter Schlaflosigkeit leidet, so kann sich dieser geänderte Schlaf-Wach-Rhythmus auch entscheidend auf die Heizaktivitäten auswirken.

Bestimmte Formen von Praktiken-Synchronisation und -Koordination können demnach mehr oder weniger nachhaltig sein und diese zeitliche Abstimmung lässt sich gezielt beeinflussen (vgl. Shove et al. 2012: 86f):

In jedem Falle stellt der Kontext einer Praktik bzw. die Abstimmung von Praktiken tagtäglich wieder eine neue Herausforderung dar. Das Problem liegt dabei vor allem in der Menge von Praktiken, die die Menschen (im alltäglichen Leben), tragen' bzw. vollführen sowie bei den Anforderungen und Erfordernissen, die all diese Praktiken hinsichtlich Dauer, ,Timing' und Abfolge an die Praktizierenden stellen (vgl. ebd.: 96).

\subsubsection{Ausmaß und Formen des Wandels von Praktiken}

Praktikenwandel kann sowohl von innen beginnen als auch von umgebenden Einflüssen ausgehen und er kann von den Praktizierenden wahrgenommen werden oder von ihnen unbemerkt bleiben. Ob eine Veränderung bewusst bemerkt wird, hängt wesentlich von ihrem Umfang ab, sowie davon, wie gravierend der Einschnitt ist, der die Instabilität bzw. Änderung verursacht hat und dementsprechend wie deutlich die Abweichung von der eingeübten Routine ist. Wandel geschieht permanent. Die meisten Veränderungen vollziehen sich graduell und kleinteilig. Änderungen bei einzelnen Komponenten eines Aktivitätenbündels gehen in der Regel mit Kontinuität und Stabilität bei den anderen Komponenten desselben Bündels einher. Ein solch inkrementeller (schleichender) Veränderungsprozess wird üblicherweise als relativ stabiles Fortbestehen einer Praktik wahrgenommen und gedeutet; letztlich wird dadurch die Existenz der Praktik als Einheit abgesichert. Schatzki beschreibt dies folgendermaßen:

"What enables such a system to remain the same system over time is the piecemealness of this reshuffling: Changes in particular elements are accompanied by continuity in others." (Schatzki 2002: 244)

Hingegen kommt es im Falle externer Veränderungsanlässe häufig vor, dass sie größere Dynamiken auslösen, die im Resultat zu sehr drastischen Wandlungen in den Tätigkeitsvollzügen führen. Für diese Art von Veränderung(en) hat sich - aus den Wirtschaftswissenschaften kommend - in der Wissenschaft allgemein der Begriff bzw. das Konzept vom ,disruptiven 
Wandel' durchgesetzt. Vielfach wird auch von ,disruptiver Innovation' gesprochen, wenn eine Neuerfindung eine bestehende Technologie, ein bestehendes Produkt oder eine bestehende (Verfahrens-)Praktik möglicherweise vollständig verdrängt (vgl. Christensen 1997). Woran ist aber zu erkennen, dass es sich immer noch um dieselbe Praktik handelt bzw. dass die neu entwickelte Lösung an einen bereits bestehenden und auch weiterhin vorhandenen praktischen (Handlungs-)Problembereich anknüpft? Schatzki hat sich diese Frage ebenfalls gestellt und sie direkt selbst beantwortet. Er gibt den Hinweis: ,the unity of a practice is secured by its organization" (Schatzki 2002: 244). Auf das Beispiel alltäglichen Heizens angewendet, bedeutet das: man würde eine neue oder stark abgewandelte Praktikperformance auch weiterhin als ,Heizen' erkennen, auch wenn die in ihr gebündelten Teil-Aktivitäten für sich genommen zwar deutlich verändert sein können, sich aber die grobe (An-)Ordnung der insgesamt zu Heizen gehörenden Aktivitäten nicht oder nur geringfügig gewandelt hat. Das heißt, etwas an der Tätigkeit „Heizen“ - und hier ist jetzt die ,practice-asentity' gemeint - muss relativ gleichgeblieben sein. Es sind in der Regel die grundlegende Ausgestaltung und Gliederung der zu Heizen integrierten Aktivitäten, die relativ beständig bestehen bleiben (müssen). Nur so, aufgrund einer solchen minimalen Verbindung zur altbekannten Handlungspraxis, ist eine Neuerung oder deutliche Abweichung von der bisherigen Verfahrensweise für eine*n außenstehende*n Betrachter"in überhaupt als (gravierender) Wandel von einer bereits bestehenden Handlungspraxis wahrnehmbar (vgl. Matzat 2008: 24f). Die Frage nach dem Grad der Abweichung von der bisher gängigen Praxis wird an späterer Stelle noch thematisiert, hängt sie doch eng damit zusammen, zu welcher Einschätzung und Klassifizierung von Wandel man gelangt - was ein zentrales Thema dieser Arbeit ist.

Im Folgenden soll es daher detailliert um verschiedene mögliche Wandlungsformen gehen, die als Folge oder Reaktion auf die unter Punkt 2.3.2.1 aufgezählten Veränderungsanlässe begriffen werden können. Dahinter steht die Frage, in welche Praktiken-Metamorphosen die einzelnen beschriebenen Anstöße jeweils münden (können) und wie sich diese Änderungen am besten beschreiben und einordnen lassen. Die Darstellung der Wandlungsprozesse erfolgt entlang des ,Lebenszyklus' von Praktiken (vgl. Schatzki 2013). Man könnte sagen, dass die folgenden Überlegungen nach dem ,Radikalitätsgrad' der Veränderungen strukturiert sind: Begonnen wird mit der fundamentalsten Form von Wandel, der kompletten Neuschöpfung sowie der kompletten Abschaffung oder Zerstörung einer Praktik: der so genannten Ex-Novation - dem direkten Pendant zur Inno- 
vation. Dann werden weniger drastische Änderungsformen unter den Begrifflichkeiten ,evolutionärer' oder ,inkrementeller Wandel' zusammengefasst, um schlussendlich bei sich auflösenden bzw. (natürlich) vergehenden Praktiken anzugelangen.

\section{Radikale oder Basis-Innovation(en)}

Das Aufkommen einer neuen Praktik setzt einen Innovationsprozess voraus, in welchem „agents configure a set of bodily-mental activities by integrating elements of meaning, material and competence" (Røpke 2009: 2494). Demnach handelt es sich bei einer Praktikeninnovation um eine Neuschöpfung oder Neugestaltung eines körperlich-geistigen Aktivitätenkomplexes. Dies wird durch neuartiges Verknüpfen von entweder bereits existierenden oder erst neu aufgekommenen Elementen erreicht. ${ }^{55}$ Wenn solch ein neuartiges Aktivitätenarrangement hinreichend Verbreitung findet, das heißt, wenn ausreichend andere Akteure die neu entwickelte Tätigkeit aufnehmen, dann ist eine neue Praktik als eine vorläufig stabile und erkennbare Einheit im Entstehen (ebd.). Demnach gilt für soziale Praktiken: erst Verbreitung, dann Innovation. So befindet im gesellschaftlichen Bereich „soziale Akzeptanz darüber, ob eine Idee, ein bestimmter Gegenstand oder ein bestimmtes Ereignis mit dem Attribut ,Innovation' versehen wird" (Aderhold 2005: 31). Soziale Innovationen sind somit abhängig davon, inwieweit die Mitglieder einer Gesellschaft sie sich zu eigen machen (Neuloh 1977: 22). Aus diesem Grund argumentiert Neuloh, „daß bei neuen Ideen auf [sozialem] Gebiet die Diffusion der Innovation und der Institutionalisierung vorausgeht" (ebd.: 25). Von einer Innovation auf sozialem Gebiet lässt sich demnach erst dann sprechen, wenn die neue Praktik schon eine gewisse Verbreitung erfahren hat, wenn sich eine Diffu-

55 Bereits der Nationalökonom Joseph Schumpeter (1883-1950), auf den die Einführung des Begriffs ,Innovation' in die Wissenschaft höchstwahrscheinlich zurückgeht und der als Gründungsvater der Innovationsforschung gilt, bezeichnet Innovation als "the doing of new things or the doing of things that are already been done in a new way" (Schumpeter 1947: 149). Für den amerikanischen Anthropologen Homer Barnett reicht ebenfalls eine neuartige Verbindung bereits vorhandener Elemente aus, um von Innovation zu sprechen. So heißt es bei ihm: "When innovation takes place, there is an intimate linkage or fusion of two or more elements that have not been previously joined in just this fashion, so that the result is a qualitatively distinct whole. [...]. Fundamental to this point of view is the assumption that any innovation is made up of preexisting components" (Barnett 1953: 181). 
sion der Innovation abzeichnet (vgl. Neuloh 1977: 25; Deutsch 1985: 20; Aderhold 2005: 31).

\section{Exnovation}

Meist wird in Wissenschaft und Politik einseitig auf das Neuartige fokussiert, löst es doch eine besondere Faszination aus. Dabei wird häufig außer Acht gelassen, dass die intensive Beschäftigung mit dem Gegenstück zur Innovation - die so genannte ,Exnovation' - mindestens genauso bedeutend ist, wenn es um ein angemessenes Verständnis der Abkehr vom bisherigen Pfad und der Aufgabe nicht-nachhaltiger Praktiken geht. Der Begriff der Exnovation beschreibt die Abkehr bzw. den Ausstieg aus bisherigen, meist nicht-nachhaltigen Strukturen, Technologien, Produkten und (Handlungs-) Praktiken (vgl. Arnold et al. 2015: 7).

Der Politik- und Umweltwissenschaftler Dirk Arne Heyen bringt dieses bestehende Missverhältnis in der bisherigen Erforschung von Transformationsprozessen pointiert zum Ausdruck:

„Politik und Forschung beschäftigen sich bevorzugt mit der ,schönen Seite' von Transformationen: dem Neuen. Doch reichen Innovationen und ihre Förderung häufig nicht aus, um etablierte nicht-nachhaltige Strukturen zu ersetzen, die ökonomisch noch funktionieren (teilweise verzerrt durch Subventionen). So reicht beispielsweise die Förderung erneuerbarer Energien nicht aus, um die klimaschädliche Kohle aus dem Strommarkt zu drängen. Der bisherige Fokus auf Innovationen sollte daher ergänzt (nicht ersetzt) werden durch eine stärkere Beschäftigung in der Politik und Forschung mit ,Exnovation': dem Ausstieg aus nicht-nachhaltigen Infrastrukturen, Technologien, Produkten und Praktiken." (Heyen 2016: 5; vgl. auch Paech 2006: 31)

Häufig stellt das Neue keine Ersetzung, sondern nur eine Ergänzung des Alten dar und führt somit zu „fortdauernden Parallelstrukturen“ (Heyen 2016: 10). Daraus lässt sich ableiten, dass „Transformation auch die zielgerichtete Beendigung von nicht-nachhaltigen Infrastrukturen, Technologien, Produkten, Praktiken sowie den sie fördernden Politikinstrumenten, z.B. umweltschädliche Subventionen [braucht]“ (ebd.). Dementsprechend sollten sich die Sozialwissenschaften auch Exnovationsprozessen und -maßnahmen widmen.

Auch unter Praktikentheoretiker*innen gibt es seit etwa Mitte der 2000er Jahre eine Debatte darüber, dass die Prozesse, die zum erfolgreichen Auslöschen oder Aussterben, also einem Verschwinden von nicht- 
nachhaltigen Praktiken führen, stärker in den Blick genommen werden sollten (vgl. Shove und Pantzar 2006).

Mit der Zeit sterben Praktiken aus, wenn es ihnen nicht mehr gelingt, neue Teilnehmer*innen für sich zu gewinnen, also weiterhin Praktizierende zu rekrutieren, die sie aktiv vollführen:

"artifacts, ideas and forms of competence only have meaning and effect (they only live) when integrated into practice. [...] it is through the integrative work of 'doing' that elements are animated, sustained and reproduced. When that stops, fossilisation sets in.” (ebd.: 59)

Auch wenn eine Praktik als ,ausgestorben' gilt, das heißt, sie aktuell praktisch nicht mehr aktiv performt wird, so gibt es meist (noch) Spuren und Belege, die ihre einstige Existenz erkennen lassen. Häufig sind Reststücke oder Überbleibsel, in der Biologie und Archäologie so genannte ,Relikte', der alten, erloschenen Praktiken auffindbar, etwa in Form von nicht mehr verwendeten Artefakten oder veraltetem Wissen. Shove und Pantzar charakterisieren diese ,Reste' vergangener Praktiken als ,social fossils` (,soziale Fossilien'), anhand derer die (zeitweise) verschwundenen Praktiken in der Regel gut rekonstruiert werden können (vgl. Shove und Pantzar 2006). Røpke bezeichnet diesen grundlegenden Zerstörungs- bzw. Abschaffungsprozess als „killing of practices“ (Røpke 2009: 2495), der nichts anderes beschreibt als das Auf- bzw. Zerbrechen des Gefüges, das die Praktikenelemente zusammengehalten hat. Auch sie betont in diesem Zusammenhang: "The killing of practices can be important, not least in an environmental perspective“(ebd.).

Die Konzepte der ,Exnovation` oder ,Zerstörung von Praktiken` und von ,sozialen Fossilien' erscheinen sehr hilfreich für die Rekonstruktion und Analyse vergangener Heiz-Praktiken sowie dafür, mittels der Analyse früherer und gegenwärtiger Heiz-Praktiken aussichtsreiche Maßnahmen in Richtung mehr Nachhaltigkeit abzuleiten.

\section{Evolutionärer oder inkrementeller Wandel}

Schatzki fasst kleinere Veränderungen bzw. sich allmählich ereignenden Praktikenwandel unter dem Begriff ,persistence' zusammen (Schatzki 2013: 39ff). Normalerweise wird diese Stabilität in der Charakteristik von ,Seiendem' als ,Identität' (von jemand oder etwas) gedacht und „as the perpetuation of the same; that is, as the absence of change" (ebd.: 39) verstanden. Schatzki zeigt aber, dass sich diese Konzeption von ,Identität ${ }^{\star}$ nicht wirklich für die Beschreibung der „persistence of practice-arrangement 
bundles“ (ebd.) über eine längere Zeit eignet. Er versteht „Persistenz und ,Fortbestehen' im Zusammenhang mit Praktiken(wandel) etwas anders:

„The persistence of a bundle over time is, instead, a kind of unity in difference. The subsistence of a bundle is compatible with the multiplication and metamorphosis of its activities, alterations of its arrangements (including connections among arrangements), transformations of interwoven timespaces and practice organizations, and changes in how practices link to one another and to arrangements. What is required for a bundle to persist through these kinds of changes is that the changes generally hang together and that they are neither too frequent nor too large.” (ebd.)

Daraus abgeleitet, lässt sich ,persistence“ in Bezug auf alltägliche Praktiken als „the same bundle existing before and after change“ definieren (ebd.: 40) und zwischen zwei Arten von längerem (Praktiken-)Fortbestehen unterscheiden: Stabilität und Evolution:

„Stability exists when changes are minute, isolated, and non-ramifying. Evolution occurs when bundles survive larger or multiplying changes." (ebd.)

Evolutionärer bzw. inkrementeller Wandel beschreibt demnach eine laufende, schrittweise Anpassungs- oder Verbesserungs-Veränderung einer Praktik, beispielsweise initiiert durch die (Neu-)Einführung eines technischen Artefakts.

Technischer Fortschritt spielt tatsächlich häufig eine zentrale Rolle, wenn es um den Wandel von Praktiken geht. So untersuchen Shove et al. die (Entstehung und Entwicklung der) Digitalfotografie sowie den Trend zu ,Do-it-yourself‘ (DIY)-Aktivitäten als prägnante Beispiele für Praktikenwandel, bei denen technische Neuerungen und Weiterentwicklungen ein wichtiger Teil(aspekt) für die Umgestaltung betreffender Tätigkeiten gewesen sind (vgl. Shove et al. 2007). Durch die Integration kleiner oder größerer technologischer Innovationen in bereits bestehende Praktiken findet häufig eine kontinuierliche Optimierung und/oder Effizienzsteigerung in den Praktikenperformances statt.

Neben Änderungen der materiellen Komponente von Praktiken, ist ebenso möglich, dass neue Informationen, ein neu angeeignetes Wissen, neu erlernte Fertigkeiten oder die Anwendung bzw. Integration neuer Ideen, Leitbilder oder Paradigmen in bestehende praktische Handlungsvollzüge zu einem allmählich voranschreitenden Wandel von Praktiken führen. Allerdings macht die Beobachtung der Entwicklung alltäglicher 
Handlungspraxis immer wieder deutlich, dass „understandings and [bodily] repertoires [hiermit sind internalisierte Denkmuster und lang einstudierte Körperbewegungen, also mentale und körperliche Routinen gemeint, JM] tend to inertia; indeed, their inertia is crucial to the pervasive persistence of bundles, a conservatism which is inherent to social life" (Schatzki 2013: 40).

Im Zuge eines solchen, sich kontinuierlich und schrittweise ereignenden Wandels kann es mit der Zeit auch zur Aufspaltung bzw. Verzweigung einzelner Praktiken kommen. Aus einer (ehemals) einheitlichen Praktik entwickeln sich allmählich mehrere, zwar weiterhin ähnliche, aber dennoch hinreichend unterschiedliche neue Praktiken. Diese besondere Form von allmählichem Praktikenwandel, auch als ,Bifurkation' bezeichnet (ebd.: 38), stellt ebenfalls eine Art von Praktiken-(Neu-)Entstehung dar. Laut Schatzki entwickeln sich neue Sportarten häufig auf diesem Wege. Und genauso ist die gegenteilige Entwicklung möglich, nämlich, dass bisher eigenständige, aber bereits mehr oder weniger eng miteinander zusammenhängende Aktivitätenbündel allmählich fusionieren bzw. zu einer einzigen Praktik verschmelzen: „Bundles can also hybridize, yielding new (though not necessarily more complex) bundles" (ebd.). Diese Entwicklung, also solch eine ,Hybridisierung' lässt sich für die beiden Praktiken des Heizens und Lüftens durch die Passivhaustechnologie beobachten (vgl. Kapitel 4.2).

In manchen Fällen erweisen sich einige Praktiken trotz massiver Einwirkungen von außen als sehr beharrlich, wenn nicht gar wandlungsresistent. Manche Praktiken erstarren förmlich in einer bestimmten Gestalt. Sie erscheinen dadurch mit der Zeit anachronistisch. Dennoch bleiben sie weiterhin in gleicher Gestalt bestehen, werden nur äußerst selten vollführt, dümpeln ansonsten aber mehr oder weniger vor sich hin.

\section{Auflösung}

Zum (natürlichen) Zerfall von Praktiken schreibt Schatzki:

„Bundles dissolve when overwhelming, frequent, or large-scale changes occur to them. Dissolution does not equal destruction. External causes, such as the climatic, geological, military, and also biological ones just mentioned, often destroy bundles [...]. More often, however, dissolution is a matter of smooth development from predecessors of bundles that embrace large, rapid, or cascading changes. Such cases are ones of linked simultaneous dissolution and emergence." (Schatzki 2013: 42) 
Den Unterschied zwischen dem Prozess einer (natürlichen) allmählichen Praktiken-Auflösung und für den entsprechenden Bereich sich gleichzeitig ereignenden Praktiken-Neuentstehung sowie dem Prozess einer ,echten ${ }^{6}$ Praktiken-Innovation mit notwendig dazugehörender Praktiken-Exnovation - verstanden als absichtsvolle Abschaffung bzw. Zerstörung -, den Schatzki sieht, veranschaulicht er anhand von zwei Beispielen moderner Automobilentwicklungen:

„Hybrid cars look and are operated much like internal combustion cars. Although driving them is different, the bundle formed by driving practices, hybrid automobiles, and street arrangements is not new. Electric automobiles, by contrast, will require larger changes in practices and design and, when more affordable and widely available, will be part of a new bundle of driving practices, automobiles, and supporting arrangements." (ebd.: 43)

Lässt sich diese Unterscheidung womöglich übertragen auf die in dieser Arbeit näher untersuchten neuen bzw. veränderten Heiz-Praktiken? Auf den ersten Eindruck ,revolutioniert' die Passivhaustechnologie Heizen regelrecht - das heißt, das neu entstandene ,passive Heizen' hat kaum noch etwas mit der Art und Weise zu tun, wie sich Heizen bisher gestaltete. Demnach wäre die Passivhaustechnologie und das hierdurch entstehende (überwiegend), passive Heizen' als ein Prozess von (sozialer) Innovation mit zugehöriger Exnovation zu charakterisieren - ein zweiseitiger disruptiver Prozess, den der österreichische Nationalökonom Joseph Schumpeter erstmals 1942 als ein Grundmotiv der Dynamik kapitalistischer Wirtschaftsentwicklung äußerst treffend mit dem Konzept der ,schöpferischen Zerstörung' beschrieben hat (vgl. Schumpeter 1943).

Das Heizen im SmartHome infolge der Implementierung von smarter Heizungssteuerungstechnik knüpft hingegen in vielen Punkten an bisheriges Heizen an. Die Einführung intelligenter Heizungsregelungstechnik und die damit einhergehende Weiterentwicklung bzw. Transformation bisherigen Heizens hin zu smartem Heizen stellt sich somit eher als ein kontinuierlicher, schrittweiser Wandlungsprozess dar und kann von daher (recht passend) mit den Konzepten einer allmählichen Auflösung und einer damit gleichzeitig verbundenen Praktik(en)-Neuentstehung beschrieben werden.

Diese ersten theoretischen Überlegungen und Interpretationsideen zur Einordnung und Klassifizierung der Untersuchungsfälle müssen allerdings noch empirisch überprüft werden, was im Rahmen des Empiriekapitels erfolgen wird. 
Bei der Einteilung der Wandlungsformen sind die Grenzen nicht immer eindeutig, sondern zum Teil verschwimmen sie und sind im Einzelfall zu definieren. Zunächst einmal ist diese erste theoretische Kategorisierung möglicher Praktikendynamiken und Wandlungsarten für die Analyse konkreter, das heißt empirisch vorfindbarer Praktiken sowie ihrer Veränderungsprozesse von Relevanz. Darüber hinaus kann die Klassifikation von grundlegenden Wandlungsformen für eine absichtsvolle Intervention in Praktiken im Rahmen eines umfassenderen Veränderungsmanagements dienlich sein - etwa von Seiten der Politik, die versucht, mit vielfältigen Maßnahmen dem Problem des Klimawandels auf allen gesellschaftlichen Ebenen zu begegnen. Denn eine kleine, inkrementelle Veränderung (beispielsweise im Bereich des alltäglichen Heizens) erfordert sicherlich einen anderen Impuls und eine andere Herangehensweise sowie eine andere Bearbeitung als die Initiierung und erfolgreiche Bewerkstelligung einer radikalen Innovation.

\subsection{Praktiken - ein differenzierter und vielversprechender Forschungsansatz}

In diesem Kapitel konnte ein gut anwendbarer theoretischer Rahmen dargelegt werden, um sich der ausführlichen Analyse von Heizpraktiken zu widmen. Wie gezeigt werden konnte, stellen, soziale Praktiken' eine geeignete theoretische Perspektive dar, um sowohl Kontinuitäten als auch (sich ereignende) vielfältige Wandlungsdynamiken im alltäglichen Heizgeschehen zu erfassen, zu beschreiben und zu interpretieren.

Die theoretische Grundlage, um die alltägliche Heizpraxis tiefergehend und umfassend empirisch zu analysieren, wurde im Rahmen dieses Kapitels geschaffen: Herausgearbeitet wurden die verschiedenen an Praktiken beteiligte Elemente sowie ihr spezifisches Zusammenspiel - dies geschah zum einen auf theoretisch-abstrakter Ebene, zum anderen wurden die wichtigsten historischen Heizformen sowie deren jeweilige Elementekonstellationen rekonstruiert, die Vorläufer und Grundlage für aktuell vorfindbare Heizansätze sind (vgl. Kapitel 2.2). Im Anschluss wurde der zentralen Frage nach Wandel und Veränderbarkeit von Praktiken nachgegangen: Nebst der Einführung wichtiger theoretischer Differenzierungen, wurde hier eine umfassende Darstellung sowohl der Hauptausgangspunkte für Dynamiken in Praktiken als auch möglicher Formen des Wandels von Praktiken geleistet (vgl. Kapitel 2.3).

In der Auseinandersetzung mit wichtigen praxistheoretischen Konzepten und Kategorien sowie (beim Versuch) einer ersten, noch vagen Anwen- 
dung auf den gewählten Untersuchungsgegenstand konnte bereits in Ansätzen gezeigt werden, dass sich die theoretischen Konzepte gut auf das praktische Beispiel ,Heizenergiekonsum` übertragen lassen und Heizen als Anwendungsbeispiel womöglich auch gut geeignet ist, um die Theorie (sozialer Praktiken) insbesondere im Hinblick auf Fragen des Wandels und der Veränderbarkeit sozialer Praktiken weiterzuentwickeln.

Wandel stellt ein klassisches soziologisches Thema dar. In der Vergangenheit wurde allerdings häufiger die Kritik geäußert, dass der Fokus praxistheoretischer Zugänge zumeist auf Stabilität und Repetitivität liege und Wandlungsphänomenen bisher vergleichsweise wenig Beachtung finden, weshalb die praxistheoretische Perspektive auch eher ungeeignet sei, um Wandel zu untersuchen. Diese Kritik konnte in diesem Kapitel entkräftet werden. Vielmehr konnte gezeigt werden, dass speziell der Ansatz sozialer Praktiken ein sehr gutes theoretisches Gerüst bietet, um sich den zentralen Fragen nach Wandel und Veränderbarkeit von Praktiken angemessen zu widmen.

Im folgenden Kapitel soll es nun darum gehen, wie das Vorhaben einer detaillierten Erforschung praktischen Heizens in Privathaushalten methodisch adäquat umzusetzen ist. 


\section{Methodischer Zugang und Forschungspraxis}

Diese Arbeit hat zum Ziel, die impliziten, dem alltäglichen Heizgeschehen zugrundeliegenden und sich immer auch wieder verändernden Deutungsmuster aufzuzeigen, um dadurch das in Privathaushalten regelmäßig vollzogene Heizen sowie dessen Wandel besser verstehen und erklären zu können.

Wie eingangs beschrieben, liegt der besondere Fokus der vorliegenden Studie auf der Rekonstruktion von (typischen) Dynamiken und Wandlungsprozessen, wie sie sich aufgrund von spezifischen Kontexteinwirkungen (wie in diesem Forschungsprojekt der Umzug in ein Passivhaus und der Einbau einer intelligenten Heizungssteuerung) in den handlungsleitenden Sinnstrukturen ereignen und dementsprechend in der alltäglichen Heizpraxis sichtbar werden.

Bisher ist allgemein noch wenig über Heizen in Privathaushalten bekannt. Von daher ist es wichtig, zunächst zu einem besseren Verständnis von der grundlegenden Beschaffenheit des alltäglichen Heizgeschehens zu gelangen, da diese Erkenntnis wiederum die eigentliche Grundlage dafür darstellt, Veränderungsprozesse im Heizen überhaupt identifizieren und rekonstruieren zu können.

Daher lauten die für den Forschungsprozess leitenden Fragen:

- Wie gestaltet sich grundsätzlich das Heizen in Privathaushalten?

- Welche Aktivitäten vollziehen die Alltagshandelnden konkret, wenn sie sich ihrem Sinnverstehen nach zuhause heizend betätigen bzw. welche Tätigkeiten zählen sie alle zum Heizen dazu?

- Was geschieht mit den privaten Heizaktivitäten, wenn sich der gesamte Kontext oder etwas Wesentliches am Setting ändert?

- Und wie sehen die ,neuen', gewandelten Heizpraktiken dann tatsächlich aus?

Aus dem hier einleitend nochmals kurz geschilderten Erkenntnisinteresse und den daraus abgeleiteten Forschungsfragen (dazu ausführlicher, siehe Kapitel 1.8) sowie der gewählten praxistheoretischen Perspektive auf alltägliches Heizen (siehe Kapitel 2) ergeben sich bereits zentrale Implikationen, wie eine geeignete methodische Herangehensweise auszusehen hat.

In der empirischen Sozialforschung wird nach wie vor wesentlich zwischen quantitativen und qualitativen Methoden unterschieden (Kelle 2008). Der deutlichste Unterschied zwischen beiden Verfahren ist bereits 
an den Bezeichnungen abzulesen: Mittels quantitativer Forschungsmethoden werden Mengen, Häufigkeiten und statistische Zusammenhänge der erhobenen Daten ermittelt. Mittels qualitativer Methoden lassen sich hingegen Sinnstrukturen und Handlungsmuster in ihrer sprachlichen Vermitteltheit und Prozesshaftigkeit erfassen und analysieren. Qualitative Forschung zielt demnach auf Verstehen; bei quantitativer Forschung steht dagegen das Messen im Mittelpunkt (vgl. Helfferich 2004: 19).

Während quantitative Verfahren also vor allem darauf abzielen, ihre Forschungsgegenstände numerisch zu erfassen und sich daran anschließende Interpretationen sowie Verallgemeinerungen in der Regel auf die „Häufigkeit des Auftretens bestimmter sozialer Phänomene“ (Rosenthal 2011: 13) stützen, sind qualitative Methoden eher darauf ausgerichtet, interessante bzw. markante Einzelfälle zu identifizieren und die interessierenden Phänomene dann tiefgehend zu erheben, also detailliert zu beschreiben und zu interpretieren (vgl. ebd.: 22).

Beruht quantitative Forschung (und auch die Generalisierung ihrer Ergebnisse) grundsätzlich auf der Erhebung und Auswertung großer Datenmengen bzw. Fallzahlen, sind in der Logik qualitativer Verfahren bereits geringe Fallzahlen ausreichend, um zu validen Ergebnissen und verallgemeinerbaren Aussagen zu gelangen. Hier werden eher Einzelfälle eingehend beschrieben und interpretiert, das heißt Wirkungszusammenhänge und latente Sinngehalte werden am konkreten Einzelfall rekonstruiert. Diese Einzelfallbeschreibungen bilden dann häufig den Ausgangspunkt für exemplarische Verallgemeinerungen, womit gemeint ist, dass die ausführlich beschriebenen Einzelfälle als repräsentative Fälle betrachtet werden, wenn sie typische Ausprägungen einer Gruppe ähnlicher Verlaufsformen darstellen.

Ein qualitatives empirisches Vorgehen eignet sich vor allem auch dafür, bisher noch relativ unbekannte Phänomene oder wenig erkundete Lebensbereiche zu erforschen (ebd.: 18). Denn im Gegensatz zu quantitativen Verfahren, die immer bereits eine gewisse Kenntnis des interessierenden Phänomens voraussetzen, operiert qualitative Sozialforschung nach einer „Logik des Entdeckens“ (ebd.: 13). Damit ist gemeint, dass Hypothesen und gegenstandsbezogene Theorien erst im Laufe des Forschungsprozesses, vor allem in der Auseinandersetzung mit dem empirischen Material entwickelt werden. In der quantitativen Forschung geht es hingegen stets um die Prüfung bereits vorab bestehender Hypothesen. Und während sich die Güte quantitativer Forschung ausgerechnet an der Standardisierung der zum Einsatz kommenden methodischen Instrumente bemisst, deren Auswahl bzw. Entwicklung wohlgemerkt ebenfalls bereits vorhandene 
theoretische Konzepte zum interessierenden Phänomen und daraus abgeleitete Hypothesen erforderlich macht, besteht für ein dezidiert qualitatives Vorgehen vielmehr die „Forderung zur Offenheit“ (ebd.). Diese besteht in einem bewussten Verzicht auf eine vorherige Standardisierung der Instrumente zur Erhebung und Auswertung. Stattdessen sind die Instrumente sowie der Forschungsverlauf an den jeweiligen Relevanzsetzungen der zu beforschenden Personen bzw. an den jeweiligen Besonderheiten des Untersuchungsobjekts auszurichten. Wie in den folgenden Abschnitten 3.1 und 3.2 noch zu erläutern sein wird, bedeutet Offenheit jedoch nicht, dass man sich dem Forschungsgegenstand und Datenmaterial ganz ohne theoretisches Vorverständnis nähert und (gegenstandsbezogene) Hypothesen und Theorien ausschließlich aus dem empirischen Material generiert werden (sollten), wie dies etwa die Begründer“innen der ,Grounded Theory vorschlagen (vgl. Strauss und Corbin 1990: 24).

Qualitative Methoden wurden vor allem in den 1960er Jahren weiterentwickelt, häufig mit Bezug auf ethnomethodologische Ansätze. Sie stellten häufig einen Gegenentwurf zu quantitativen Ansätzen dar, die als mangelhaft bewertet wurden. Zwar wird in den Sozialwissenschaften bis heute eine kontroverse Debatte darüber geführt, ob empirische Forschung generell besser mittels quantitativer oder qualitativer Methoden durchzuführen ist. Dennoch stellt die Wahl der Methode heute keine solche Grundsatzentscheidung mehr dar, wie noch zu Hochzeiten des ,Methodenstreits' gegen Ende der 1960er Jahre. Heutzutage kommt die Wahl der Methode für das eigene Forschungsvorhaben jedenfalls nicht mehr einer vorläufig endgültigen Positionierung des bzw. der Sozialforscher*in im ,Paradigmenstreit' quantitativer versus qualitativer Verfahren gleich. Vielmehr koexistieren verschiedene methodische Ansätze mit jeweils eigener Begründung und unterschiedlichen Stärken; sie werden zudem seit Anfang der 1980er Jahre unter den Stichworten ,Mixed Methods Research', ,Methodenintegration', ,Methodenmix' und ,Triangulation' verstärkt gemeinsam zum Einsatz gebracht (Kelle 2008: 25ff).

Generell sollte sich das methodische Vorgehen stets an der Angemessenheit gegenüber dem Forschungsgegenstand orientieren und die vorhandenen Forschungsressourcen berücksichtigen. 


\subsection{Die Wabl eines qualitativen Ansatzes: Eine vom Erkenntnisinteresse geleitete Entscheidung}

Der in dieser Untersuchung interessierende Bereich der Alltagswelt, das alltägliche Heizgeschehen in Privathaushalten, ist aus soziologischer Perspektive bisher noch wenig empirisch erforscht worden. Bisher lag der Fokus soziologischer Studien zum Heizen meist einseitig auf der verwendeten Technik und dem Umgang mit dieser. Über die tatsächliche (Ausgestaltung der) alltäglichen Heizpraxis, die allgemeinen und detaillierten (Sinn-)Zusammenhänge in diesem Alltagsbereich sowie die Sinndeutungen der unterschiedlichen am privaten Heizgeschehen beteiligten Akteure ist dagegen noch kaum etwas bekannt. ${ }^{56}$ Insbesondere die für diese Studie gewählten Untersuchungsfälle - Heizen in Passivhäusern und in so genannten SmartHomes - sind bislang noch kaum aus konsumsoziologischer Perspektive untersucht worden (siehe aber Foulds et al. 2012; Nyborg und Røpke 2011). Damit verfügt diese Untersuchung über einen ausgeprägt explorativen Charakter. Heizen soll in seiner gesamten Komplexität erfasst und detailliert untersucht werden.

Beruht quantitative Forschung (und auch die Generalisierung ihrer Ergebnisse) grundsätzlich auf der Erhebung und Auswertung großer Datenmengen bzw. Fallzahlen, sind in der Logik qualitativer Verfahren bereits geringe Fallzahlen ausreichend, um zu validen Ergebnissen und verallgemeinerbaren Aussagen zu gelangen. Hier werden eher Einzelfälle eingehend beschrieben und interpretiert, das heißt Wirkungszusammenhänge und latente Sinngehalte werden am konkreten Einzelfall analysiert bzw. rekonstruiert (Flick et al. 2010: 23).

„Standardisierte Methoden benötigen für die Konzipierung ihrer Erhebungsinstrumente (z.B. ein Fragebogen) eine feste Vorstellung über den untersuchten Gegenstand, wogegen qualitative Forschung für das Neue im Untersuchten, das Unbekannte im scheinbar Bekannten offen sein kann.“ (ebd.: 17)

Ein qualitatives Vorgehen deckt sich daher mit dem hier vorliegenden Erkenntnissinteresse: Es geht darum, meist unbewusste Heizpraktiken zu erforschen und nachzuvollziehen, welche Sinn- und Bedeutungszuschreibungen hiermit verbunden sind. Die Bedeutungszuschreibungen und das

56 Eine Ausnahme bilden Sonnberger und Zwick (2016) mit ihrer Verbindung von problemzentrierten Leitfadeninterviews und technischen Daten am Beispiel ihrer Untersuchung des Energieverbrauchs in Privathaushalten. 
ihnen zugrundeliegende Wissen sind den handelnden Akteuren jedoch nicht unbedingt bewusst. Daher wird ein qualitatives Verfahren benötigt, das geeignet ist, diese größtenteils impliziten, aber das Heizen eben grundlegend orientierenden Sinnmuster aufzudecken und es dadurch für den sozialwissenschaftlichen Erkenntnisprozess zugänglich und fruchtbar zu machen. Qualitative Forschungsmethoden erlauben nicht nur den Nachvollzug subjektiver Sichtweisen, sondern sie ermöglichen auch die Rekonstruktion latenter Sinnstrukturen (vgl. Helfferich 2004: 19; Rosenthal 2011: 19), welche den zentralen Erkenntnisgegenstand dieser Untersuchung bilden.

Die Exploration von neuen Zusammenhängen ist eine der besonderen Stärken qualitativer Forschung (vgl. Rosenthal 2011: 18). Qualitative Verfahren zeichnet eine große Offenheit gegenüber dem Forschungsobjekt aus, die bei den verschiedenen Schritten im Forschungsprozess zum Tragen kommt: Fragen werden offen formuliert und dem Gesprächsverlauf angepasst, Hypothesen werden nicht schon vor der Datenerhebung aufgestellt, sondern erst aus dem Material heraus generiert.

Darüber hinaus besteht ein zentrales Anliegen dieser Arbeit darin, Dynamiken und Veränderungsprozesse im Heizen zu erfassen, die sich im Übergang zu neuen bzw. abgewandelten Wohnkontexten ereignen. „[W]ährend bei quantitativen Untersuchungen nur die Ergebnisse von Prozessen erfasst werden können“, wird es durch ein qualitatives Verfahren möglich, sowohl „die Prozesse der Entstehung von sozialen Phänomenen“ (ebd.: 22), als auch Umbrüche und Kontinuitäten, mithin den gesamten Verlauf von Handlungspraxen zu rekonstruieren.

Die Explikation der Methode und des Herangehens an die Daten ist in der qualitativen Sozialforschung ein wesentliches Instrument der Qualitätssicherung. Nur so können Reliabilität und Validität der Daten aufgezeigt und somit die Wissenschaftlichkeit belegt werden. Die so auf qualitativem Wege gewonnenen Erkenntnisse werden somit anschlussfähig für weitere wissenschaftliche Untersuchungen, wie am Ende der Arbeit ersichtlich werden wird.

Innerhalb der qualitativen Methoden bilden rekonstruktive Verfahren, insbesondere die dokumentarische Methode einen besonders interessanten Ansatz im Sinne des Untersuchungsgegenstandes und der für diese Arbeit gewählten theoretischen Perspektive. Dies wird im folgenden Abschnitt näher ausgeführt, um anschließend die gewählte Erhebungsmethode, das gewonnene und herangezogene Datenmaterial und den Datenumgang zu explizieren. 


\subsection{Dokumentarische Methode als methodologische (und methodische) Entsprechung zur gewählten theoretischen Perspektive}

Qualitative Forschungsansätze unterscheiden sich in ihren theoretischen Annahmen sowie in ihrem Gegenstandsverständnis und sie differieren gleichfalls in ihrem methodischen Fokus (Flick et al. 2010: 18). Vielfach geht es hierbei ausdrücklich um eine subjektivistische Herangehensweise, die oft als Spezifikum qualitativer Methoden betrachtet wird; demgegenüber werden objektivistische Zugänge typischerweise mit quantitativen Methoden assoziiert (vgl. Przyborski und Wohlrab-Sahr 2013: 280).

Um eine rein subjektive Sichtweise kann es in dieser Untersuchung allerdings nicht gehen. Vielmehr geht es um das zu übersubjektiven Heizpraktiken geronnene individuelle Handeln des Heizens. Diese habitualisierten Heizpraktiken lassen sich demnach weder einseitig der Handlungsnoch der Strukturebene zuordnen. Wie in Teilkapitel 2.1.1, Abschnitt 2.1.1.1 bereits ausgeführt, bilden sie eine Art dritte, mittlere oder, wie Reckwitz es ausdrückt, eine „emergente Ebene des Sozialen“ (Reckwitz 2003: 289). Sie werden also als zwischen Handeln und Strukturen vermittelnd konzipiert. Benötigt wird demnach ein methodischer Zugang, dem ähnliche theoretische Annahmen zugrunde liegen, der folglich von einem ähnlichen Gegenstandsverständnis wie der Ansatz sozialer Praktiken ausgeht. Hier hat die dokumentarische Methode ihre Stärke, die die erkenntnislogische Differenz ebenfalls nicht in den Kategorien ,subjektiv ${ }^{6}$ und ,objektiv' sieht, sondern eine qualitative Herangehensweise genau für diese vermittelnde Ebene darstellt:

„Sie unterscheidet vielmehr zwischen der im Erleben verankerten Herstellung von Wirklichkeit, dem handlungspraktischen Wissen einerseits, und kommunikativ generalisiertem Wissen, das in der Regel in begrifflich explizierter Form zur Verfügung steht, andererseits. Es geht also um das inkorporierte Erfahrungswissen, um habitualisierte Praktiken, [...], mithin um das Wie der Herstellung sozialer Realität.“ (Przyborski und Wohlrab-Sahr 2013: 281, Hervorh. im Original)

Dies passt in besonderer Weise zum Erkenntnissinteresse der hier vorliegenden Arbeit und auch zur gewählten theoretischen Perspektive (vgl. Kapitel 2): Die praxistheoretische Perspektive richtet ihren Fokus auf alltägliche Routinen und habituelles Handeln, also die Handlungspraxis des Alltags. Es geht dabei nicht um primär subjektive Bedeutungen und individuelle Sinnzuschreibungen, also nicht vorrangig um die Sicht des Subjekts, und auch nicht rein um die objektivierten Strukturen und Deutungsmus- 
ter, die in den sozialen Praktiken hergestellt werden. Die leitende Annahme ist vielmehr, dass Handeln und Strukturen sich wechselseitig bedingen. Genauso wie der Ansatz sozialer Praktiken konzipiert auch die dokumentarische Methode nach Ralf Bohnsack (2014 [1991]) Handeln und soziale Strukturen nicht als sich fix gegenüberstehende Phänomene, sondern vielmehr als sich ständig gegenseitig rekursiv bedingend:

„[S]ie verlagert Ursprung und Wirkung sozialer Struktur in das Handeln selbst. Das Wissen, das in Handlungs- und Wahrnehmungspraxen eingelassen ist, wird in dieser Perspektive als strukturbildend betrachtet." (Przyborski und Wohlrab-Sahr 2013: 281, Hervorh. im Original)

Es zeigen sich somit bemerkenswerte Übereinstimmungen, die eine Verbindung der Fundierung der Arbeit in der Theorie sozialer Praktiken mit der dokumentarischen Methode als sinnvoll und produktiv erscheinen lassen. Neben der beschriebenen Gemeinsamkeit im Erkenntnisinteresse ist dies ein ähnliches Verständnis, wie methodisch an die Wissensebene des impliziten "handlungspraktischen und handlungsleitenden [...] Erfahrungswissens, [...] welches von den Akteuren selbst nicht oder nur auf Umwegen zur Explikation gebracht wird“ (Bohnsack 2011b: 137) heranzukommen ist: Beide Ansätze gehen davon aus, dass sich dieses durch Erfahrung gespeiste, kollektive Wissen in dem Wie sozialer Praxis dokumentiert, also in Handlungen, Interaktionssituationen, Ritualen, Diskursen, usw. deutlich wird und somit jederzeit durch direkte Beobachtung eben dieser Handlungspraxis zugänglich ist (Bohnsack 2001: 333). Dieses Wissen lässt sich aber nicht nur durch direkte Beobachtung der Handlungspraxis erschließen, sondern ist auch „einer genetischen oder dokumentarischen Interpretation der seitens der Erforschten erbrachten Beschreibungen und Erzählungen dieser Szenarien und Diskurse“ (ebd.: 335) zugänglich. Dieser Punkt spielt für die Wahl der Methode zur Datenerhebung eine wichtige Rolle und wird deshalb in den folgenden Abschnitten zum methodischen Forschungsdesign und zu Interviews noch einmal aufgegriffen.

Hinzu kommt, dass beide Ansätze in der Konzeption des Forschungsgegenstands übereinstimmen: Demnach kommt dieses handlungspraktische und zugleich handlungsorientierende Wissen nicht nur in Handlungen und Aussagen zum Ausdruck, sondern sämtliche ,Kulturgebilde‘ oder ,Objektivationen“ (Mannheim 1980: 105f), also auch Dinge bzw. Alltagsgegenstände wie Geräte, Kleider und Fotos, und genauso geistige Gebilde wie Sprache, Konventionen und religiöse Vorstellungen tragen diesen sozialen Sinn in sich bzw. sind als Manifestationen oder Zeugnisse dieses implizi- 
ten Wissens zu verstehen. Das heißt, sie eignen sich alle gleichermaßen für eine dokumentarische Analyse.

Der Ansatz sozialer Praktiken in der Übersicht verschiedener Forschungszugänge und Erkenntnisebenen:

\begin{tabular}{|l|l|l|l|l|}
\hline Ebene & Theorietypus $^{57}$ & $\begin{array}{l}\text { Theorie/ } \\
\text { theoretische Posi- } \\
\text { tion }\end{array}$ & $\begin{array}{l}\text { Soziales Phänomen/ } \\
\text { Erkenntnis- und } \\
\text { Forschungs- } \\
\text { gegenstand }\end{array}$ & $\begin{array}{l}\text { Methodische } \\
\text { Zugänge }\end{array}$ \\
\hline $\begin{array}{l}\text { Makro- } \\
\text { ebene }\end{array}$ & $\begin{array}{l}\text { Gesellschafts } \\
\text { theorien }\end{array}$ & $\begin{array}{l}\text { Strukturtheoretische } \\
\text { Ansätze }\end{array}$ & $\begin{array}{l}\text { Uberindividuelle } \\
\text { soziale Strukturen }\end{array}$ & $\begin{array}{l}\text { Objektivistische } \\
\text { Zugänge (eher } \\
\text { quantitative } \\
\text { Methoden) }\end{array}$ \\
\hline $\begin{array}{l}\text { (Mesoebene) } \\
\text { bzw. emer- } \\
\text { gente Ebene } \\
\text { des Sozialen } \\
\text { oder vermit- } \\
\text { telnde Ebene }\end{array}$ & $\begin{array}{l}\text { Theorien } \\
\text { begrenzter } \\
\text { Reichweite }\end{array}$ & $\begin{array}{l}\text { z.B. Theorie sozialer } \\
\text { Praktiken }\end{array}$ & $\begin{array}{l}\text { z.B. Soziale Praktiken } \\
\text { und das ihnen zu- } \\
\text { grunde liegende } \\
\text { handlungspraktische } \\
\text { Wissen }\end{array}$ & $\begin{array}{l}\text { z. B. Dokumentari- } \\
\text { sche Methode } \\
\text { (= qualitative } \\
\text { Methode) }\end{array}$ \\
\hline $\begin{array}{l}\text { Mikroebene } \\
\text { Sozialtheorien }\end{array}$ & $\begin{array}{l}\text { Handlungs- } \\
\text { theoretische Ansätze }\end{array}$ & $\begin{array}{l}\text { Individuelle Hand- } \\
\text { lungen; subjektive } \\
\text { Sichtweisen }\end{array}$ & $\begin{array}{l}\text { Subjektivistische } \\
\text { Herangehenswei- } \\
\text { sen (eher qualita- } \\
\text { tive Methoden) }\end{array}$ \\
\hline
\end{tabular}

Selbst erstellte tabellarische Darstellung

Als Auswertungs- und Interpretationsverfahren wird für diese Untersuchung die dokumentarische Methode gewählt, wie sie Bohnsack (2014) auf Grundlage der Ethnomethodologie Harold Garfinkels (1967) und der Wissenssoziologie Karl Mannheims (1964, 1980) entwickelt hat. Die dokumentarische Methode ist ein forschungspraktisch ausgefeiltes Verfahren, das in der qualitativen Sozialforschung mittlerweile gut etabliert ist (Przyborski und Wohlrab-Sahr 2013).

Im Folgenden werden die zentralen theoretischen Annahmen und Konzepte beschrieben, auf denen das rekonstruktive Verfahren der dokumentarischen Methode fußt.

\section{Theoretische Grundlagen der dokumentarischen Methode}

Bei dem rekonstruktiv arbeitenden Auswertungsverfahren der dokumentarischen Methode handelt es sich um eine qualitative Herangehensweise für „methodisch kontrolliertes Fremdverstehen“ (Schütze et al. 1973).

57 Vgl. Lindemann 2008: 109. 
Eine zentrale Komponente ist hierbei die besondere Beobachter*innenhaltung, wie sie für die Sozialwissenschaften erstmals von Mannheim umfassend begründet wurde. Diese resultiert aus einer spezifischen Analyseeinstellung, die Mannheim als "genetische“ bzw. „soziogenetische Einstellung" (Mannheim 1980: 85) bezeichnet hat (vgl. Bohnsack 2001: 326). Anstatt wie in vermeintlich objektivistischer Herangehensweise danach zu fragen, was die betrachteten Phänomene sind, ob sie etwa wahr, richtig oder rechtens oder ob sie im Gegenteil falsch sind, wird mit einer genetischen Analyseeinstellung auf die sozialen Prozesse der Herstellung dessen fokussiert, was den Beforschten als soziale Realität gilt. Durch die Abwendung von der Frage nach faktischer Wahrheit oder normativer Richtigkeit bzw. durch die „Einklammerung des Geltungscharakters“ (Mannheim 1980: 88) sozialer Tatsachen, wie Mannheim dies genannt hat, kann sich die dokumentarische Methode der Interpretation nun ganz auf das Wie der Hervorbringung sozialer Wirklichkeit konzentrieren (vgl. Bohnsack 2001: 326).

Dementsprechend gibt es in dieser Perspektive nicht, eine objektive Wirklichkeit' oder, die eine soziale Wirklichkeit an sich', die es für den bzw. die Sozialwissenschaftler"in lediglich zu entdecken gilt, sondern es gibt in dieser Analyseeinstellung nur Perspektiven auf, Welt' und ,Wirklichkeit', die subjektiv unterschiedlich sind. Auch Wissenschaftler*innen stehen demnach nicht außerhalb der beobachteten sozialen Zusammenhänge, sondern sie nehmen ,Welt' und ,Wirklichkeit' ebenfalls lediglich von einem subjektiven Standpunkt aus in den Blick, der stets mit dem eigenen Sein verbunden, das heißt von persönlichen Erfahrungen geprägt ist. Die von Mannheim in seiner Wissenssoziologie erarbeitete grundlegende Beobachter*innenposition setzt bei der grundsätzlichen ,Standortgebundenheit' und ,Seinsverbundenheit' von Denken und Wissen an (Mannheim 1985). Daraus folgt, dass "die sozialwissenschaftliche Interpretation grundsätzlich keine höhere Rationalität dem Alltagsdenken gegenüber in Anspruch nehmen kann" (Bohnsack 2014: 59, Hervorh. im Original). Aus Sicht der dokumentarischen Methode gibt es also kein „Besserwissen der Wissenschaft gegenüber den Untersuchten aufgrund einer höher eingestuften Vernunft" (Przyborski und Wohlrab-Sahr 2013: 281).

Genau durch diesen Wechsel vom Was zum Wie in der grundlegenden Analyseeinstellung unterscheidet sich der Blickwinkel eines bzw. einer sozialwissenschaftlichen Beobachter*in von der Perspektive eines bzw. einer alltäglichen Beobachter*in auf (alltägliche) soziale Geschehnisse. Denn während „[d]ie Untersuchten ihre eigenen Beobachtungen (meist) nicht selbst - jedenfalls nicht systematisch - [beobachten]" (Przyborski und 
Wohlrab-Sahr 2013: 282), sondern (auch in den Schilderungen ihrer Handlungen) in der Regel ihren subjektiven Erfahrungen, also der eigenen Perspektive auf ,Welt' und ,Realität' verhaftet bleiben, ist die Beobachter*innenhaltung in der dokumentarischen Methode weitaus stärker formalisiert und systematisiert. Bei der Mannheimschen Wissenssoziologie, auf der die dokumentarische Methode wesentlich basiert, handelt es sich - in den Begrifflichkeiten Niklas Luhmanns - um ein „Beobachten von Beobachtungen“ (Luhmann 1990: 86), also um „Beobachtungen zweiter Ordnung“ (ebd., vgl. auch Bohnsack 2001: 328). Dieses Beobachten zweiter Ordnung bedeutet, dass die dokumentarische Interpretation konsequent auf die Rekonstruktion der sich in den Handlungen und Äußerungen dokumentierenden Erfahrungen und Orientierungen der Darstellenden abzielt, anstatt den subjektiv gemeinten Sinn nachzuvollziehen oder gar die Darstellungen auf ihren faktischen Wahrheitsgehalt und ihre normative Richtigkeit hin zu überprüfen (vgl. Bohnsack 2014: 65).

Hierbei bedient sich die dokumentarische Methode der Unterscheidung verschiedener Formen der Verständigung (Sozialität), verschiedener Wissensformen sowie verschiedener Sinnebenen, was im Folgenden näher ausgeführt wird.

Hinsichtlich der Verständigung (Sozialität) ist vor allem zwischen ,Verstehen' und ,Interpretieren' zu differenzieren (vgl. z.B. Bohnsack 2001, 2014). ,Verstehen' meint, dass sich die Mitglieder eines gemeinsam geteilten ,Erfahrungsraumes" intuitiv verständigen können, ohne dass dafür das der Erfahrung zugrundeliegende Wissen explizit in Worte gefasst werden muss. Die gleichen Akteure müssen jedoch im Kontakt mit anderen Personen, denen der entsprechende Erfahrungshintergrund bzw. ,Erlebniszusammenhang' fehlt, anders kommunizieren: Wenn sie die eigene (konjunktive) Erfahrung mitteilen bzw. zugänglich machen möchten, müssen sie sich bzw. ihr Handeln erklären und sich wechselseitig ,interpretieren'. Das heißt, sie müssen in eine kommunikative Beziehung eintreten. Dabei ermöglicht nur die Teilhabe bzw. „das Eindringen in einen konjunktiven Erfahrungsraum“, so Mannheim (1980: 272), echtes gegenseitiges Verstehen. Vom „schlichten Verstehen“, dem „vorreflexiven Erfassen“ (ebd.) von Gebilden grenzt Mannheim somit das „theoretisch-reflexive Erfassen von Gebilden“ (ebd.) ab. Letzteres definiert er als „Interpretation“, die „die stets auf diesen [vorreflexiven] Erfassungen beruhende, aber sie niemals erschöpfende theoretisch-reflexive Explikation des Verstandenen“ darstellt (ebd.).

Die dokumentarische Methode selbst stellt mit ihrer Systematisierung des Erschließens der Erfahrungsräume anderer eine wissenschaftliche 
Form der Interpretation dar. Sie zielt konsequent auf die Rekonstruktion der sich in den Handlungen und Äußerungen dokumentierenden Erfahrungen und Orientierungen ab. "Während wir im Alltag intuitiv auf die praktische Ebene zurückgreifen und [...] einfach vormachen" (Nohl 2017: 5), um einer außenstehenden, unwissenden oder fragenden Person eine Handlung bzw. Äußerung zu verdeutlichen oder zu vermitteln, „sind wir in der Wissenschaft darauf angewiesen, Wege zu finden, den Herstellungsprozess bzw. den Orientierungsrahmen von Texten und Handlungen verbal zu explizieren“ (ebd.).

Eine weitere zentrale Differenzierung innerhalb der dokumentarischen Methode ist die unterschiedlicher Wissensformen (Mannheim 1980: 73, vgl. auch Bohnsack et al. 1995: 11). Während ,theoretisch-explizites Wissen' häufig leicht zugänglich ist, geht in routinisierte Handlungsvollzüge vor allem unbewusstes „atheoretisches Wissen“ (Mannheim 1980: 73) ein. Dieses Wissen, das notwendig ist, um an den betreffenden Aktivitäten in angemessener Weise partizipieren und sie auch ,korrekt ausführen zu können, ist ,atheoretisch', weil es fest an die Handlungspraxis geknüpft ist, besser gesagt: Es ist grundlegend in diese eingelassen. Das atheoretische Wissen lässt sich in diesem Sinne auch als ein ,inkorporiertes' oder, verkörpertes Wissen' begreifen, das im konkreten Handeln wirksam und sichtbar wird. Intuitiv, aus ihrer persönlichen Erfahrung wissen die Akteure, wie man z.B. heizt, schreibt, schwimmt und Kaffee kocht. Jedoch ist dieses Wissen meist nicht kognitiv gewusst, sondern die Akteure haben es meist schon so stark verinnerlicht, es erscheint ihnen so selbstverständlich, dass sie es nur schwer sprachlich zum Ausdruck bringen können. ${ }^{58}$ Erst wenn wir in die Situation kommen, dass wir einer neuen (noch) nicht eingeweihten Person einen für uns längst gewohnten Ablauf oder eine Alltagsroutine erklären müssen, bemühen wir uns, „den Gegenstand des habituellen Handelns und damit unser atheoretisches Wissen in alltagstheoretische und allgemeinverständliche Begrifflichkeiten zu überführen“ (Nohl 2017: 6).

58 In anderen Theorietraditionen innerhalb der praxistheoretischen Strömung wird das ,atheoretische Wissen' als ,verkörpertes' bzw. ,Körperwissen' oder ,körperliches Können' (Hirschauer 2008: 977) bezeichnet; auch ,tacit knowledge‘ (,stillschweigendes Wissen') (Polanyi 1985) oder ,knowing how (,Kenntnis') (Ryle 1969) sind ähnliche Begriffe. Die Ethnomethodologie spricht von ,skills‘ (Garfinkel 1967), Michel Foucault von ,Disziplinen`(Foucault 1976), Pierre Bourdieu von ,Habitus' (Bourdieu 1976) oder ,praktischem Sinn' (Bourdieu 1993) und Giddens von ,praktischem Bewusstsein` (Giddens 1997 [1984]: 36). 
Bei dem atheoretischen bzw. handlungspraktischen Wissen handelt es sich um ein kollektiv geteiltes Wissen, das in „einer gleichartigen Handlungspraxis und Erfahrung" (ebd.: 7) begründet liegt. Mannheim spricht hier dementsprechend von einer „konjunktiven“ (Mannheim 1980: 225) also gemeinsamen - Erfahrung, die man mit anderen teilt. Menschen sind demnach durch bestimmte atheoretische Wissens- und Bedeutungsstrukturen/-inhalte miteinander verbunden. Sie gehören dadurch einem „konjunktiven Erfahrungsraum“ (ebd.) an.

Es ist eine besondere Stärke der dokumentarischen Methode, dieses inkorporierte, ,atheoretische Wissen' systematisch in die Analyse einzubeziehen.

Ein weiterer zentraler Ausgangspunkt der dokumentarischen Methode nach Mannheim, der bei dem Umgang mit den gewonnenen Forschungsdaten eine bedeutende Rolle spielt, ist die Unterscheidung zweier Sinnebenen. Mannheim unterscheidet grundlegend zwischen ,immanenten' und ,dokumentarischen Sinngehalten' (u.a. Mannheim 1980: 85ff). Ihm zufolge weist jede Handlung, jede Äußerung diese Doppelstruktur ihrer Bedeutung auf.

Der ,immanente' oder ,objektive Sinngehalt' bezieht sich auf das wahrnehmbare Resultat einer Handlung und bei Schilderungen auf das, was wörtlich und explizit mitgeteilt wird. Es geht demnach um den allgemein gültigen Bedeutungsgehalt einer Handlung oder einer Äußerung (vgl. Bohnsack 2014: 61f). Auf immanente Sinngehalte lässt sich unabhängig von ihrem Entstehungszusammenhang schließen. Hier versucht man ein soziales Phänomen, das jeweilige interessierende ,Dokument' gewissermaßen aus sich selbst heraus zu verstehen. Das heißt, man bleibt bei Interpretationen, die dem Handlungskontext oder dem systemischen Zusammenhang immanent sind (vgl. Przyborski und Wohlrab-Sahr 2013: 283f) - man bezieht sich also nur auf das, was tatsächlich sichtbar oder geäußert wird.

Neben der Ebene des immanenten Sinngehalts gibt es die zweite Sinnebene, den ,Dokumentsinn“ (Mannheim 1964). Der Dokumentsinn bezieht sich auf die Art und Weise, wie eine Handlung ausgeführt wird bzw. auf die Herstellungsweise eines Textes oder einer Schilderung - mit Bourdieu gesprochen geht es hierbei um die „generative Formel“, den „modus operandi“" (Bourdieu 1976 u. 1982, zitiert nach Bohnsack 2014: 61) des interessierenden Dokuments. Bei der Ermittlung bzw. Rekonstruktion des Dokumentsinns steht die Frage im Mittelpunkt, wie die unmittelbar beobachtete Handlung oder Interaktion bzw. die erlebnismäßige Darstellung, die Erzählung und Beschreibung einer Handlungspraxis entworfen und aufgebaut ist (vgl. ebd.: 62). Im Unterschied zur immanenten Sinninter- 
pretation „, $[$ nimmt $\mathrm{d}]$ er dokumentarische Sinngehalt bzw. Dokumentsinn den soziokulturellen Entstehungszusammenhang bzw. das, was sich davon [in dem interessierenden Dokument] manifestiert hat, in den Blick" (Przyborski und Wohlrab-Sahr 2013: 284).

Vom dokumentarischen und vom immanenten Sinngehalt ist noch eine dritte Sinnart zu unterscheiden, die Bohnsack mit Verweis auf Mannheim (1964: 104ff) als den ,intendierten Ausdruckssinn' bzw. ,subjektiven Sinn“ beschreibt (Bohnsack 2014: 62). Mit dem subjektiven Sinn sind die Intentionen und Motive des bzw. der Handelnden oder Erzählenden bezeichnet. Demnach ist der ,intendierte Ausdruckssinn' unlösbar mit dem handelnden bzw. erzählenden Subjekt und dessen innerer Erlebniswelt verknüpft und für eine"n außenstehende"n Beobachter"in nur mittelbar zugänglich. Der bzw. die Interpret*in muss sich hier mehr oder weniger auf die (Selbst-)Darstellung der bzw. des Handelnden oder Erzählenden verlassen.

Mit der Differenzierung verschiedener Sinngehalte, unterschiedlicher Wissensformen und Sozialitäten (Verständigungsformen) sowie der spezifischen Beobachtungseinstellung bietet die dokumentarische Methode ein fundiertes und mittlerweile praxiserprobtes Gerüst der qualitativen Erforschung komplexer sozialer Zusammenhänge.

Przyborski und Wohlrab-Sahr fassen dies in folgendem Zitat noch einmal prägnant zusammen:

„Die Unterscheidung zwischen immanentem und dokumentarischem Sinngehalt $[\ldots]$ hebt das mittels dieser Unterscheidung gewonnene Forschungswissen von anderen Wissensformen ab. Sie ist zudem Drehund Angelpunkt der methodologischen Grundbegriffe und -konzepte sowie folgerichtig auch das strukturierende Prinzip aller Auswertungsschritte." (Przyborski und Wohlrab-Sahr 2013: 283)

Diese methodologischen bzw. theoretischen Grundzüge geben wichtige Implikationen für das praktisch-methodische Vorgehen, was in den folgenden Teilkapiteln ersichtlich wird.

\subsection{Methodisches Forschungsdesign}

Im vorherigen Teilkapitel wurde gezeigt, dass die dokumentarische Methode eine geeignete methodologische Grundlage für einen adäquaten $\mathrm{Zu}$ gang zu den der Forscherin selbst teils fremden Sinndeutungen der Beforschten darstellt. Es soll nun verdeutlicht werden, mittels welcher Erhe- 
bungsmethode das handlungspraktische, aber den Beforschten meist nicht bewusste, und deshalb von ihnen nicht ohne weiteres in Worte zu fassende Heizwissen am besten zu ermitteln ist.

Die methodologische Position der dokumentarischen Methode ist hier, dass sich dieses gemeinsam geteilte handlungspraktische Wissen der sich im Alltag heizend betätigenden Akteure nicht nur deutlich in ihrem alltäglichen Heizhandeln niederschlägt, sondern untrennbar mit dieser alltäglichen Handlungspraxis verknüpft ist. Demnach ist dieses konjunktive Erfahrungswissen sehr gut direkter Beobachtung zugänglich. Unter Vertreter*innen des Ansatzes sozialer Praktiken gilt die (teilnehmende) Beobachtung häufig immer noch als der ,Königsweg` zur Erschließung der vorreflexiven bzw. atheoretischen Sinnzusammenhänge sozialer Praxis (vgl. Schatzki 2012: 25; Schmidt 2012: 44-50, insbesondere 49). Sie bietet eine unmittelbare Zugangsart zu den meist ,stummen' Praktiken (vgl. Hirschauer 2001).

Im vorliegenden Fall sprechen jedoch mehrere Gründe gegen teilnehmende Beobachtung als primäre Erhebungsmethode. Erstens ist das Feld des privaten Heizens bisher noch wenig erschlossen. Es war daher nicht möglich, vorab festzulegen, welche Aktivitäten und Handlungen die Beforschten im jeweiligen Kontext und in der jeweiligen Situation unter Heizen subsumieren. Diese Sinndeutungen und Relevanzsetzungen bilden genau das Forschungsinteresse. Sie erschließen sich demnach erst im Laufe des Forschungsprozesses. Teilnehmende Beobachtung bietet somit womöglich nicht die benötigte Offenheit gegenüber dem Forschungsgegenstand (vgl. Kapitel 2.2). Zweitens kommt hinzu, dass es extrem aufwendig gewesen wäre, längere teilnehmende Beobachtungen in zwei unterschiedlichen Settings von Heizformen und in mehreren Haushalten sowie zu verschiedenen Zeitpunkten durchzuführen. Drittens findet das in dieser Arbeit interessierende Heizgeschehen im nicht-öffentlichen und damit auch im nicht frei zugänglichen, sondern im persönlich-privaten Bereich statt. Der Feldzugang zu Privaträumen und damit auch zum Privatleben von fremden Menschen ist immer äußerst heikel und kompliziert. Demnach wäre die forschungspraktische Umsetzung von längeren, intensiven Beobachtungen nicht realistisch gewesen. Auch wäre zu erwarten gewesen, dass es aufgrund der ,unnatürlichen' (Beobachtungs-)Situation zu zahlreichen Beobachter*innen-Effekten gekommen wäre und dementsprechend auch keine wirklich validen Daten hätten ermittelt werden können. ${ }^{59}$

59 „Der Hawthorne-Effekt (auch als Beobachter-Effekt bezeichnet) ist eine Form von Reaktivität, bei der Individuen einen Aspekt ihres Verhaltens verändern oder 
Mit der Perspektive der dokumentarischen Methode lassen sich konjunktive Sinnzusammenhänge zwar gut, aber nicht ausschließlich auf dem Weg direkter Beobachtung erschließen. Bohnsack zufolge kann das die sozialen Praktiken untermauernde konjunktive Wissen genauso gut mittels „einer genetischen oder dokumentarischen Interpretation der seitens der Erforschten erbrachten Beschreibungen und Erzählungen dieser Szenerien“ (Bohnsack 2001: 335) und Aktivitäten erschlossen werden. Das bedeutet, dass unter anderem Interviews einen validen methodischen Zugang zur Ebene konjunktiver Sinngehalte eröffnen können (vgl. Hitchings 2012). Allerdings müssen sie dafür narrativ fundiert sein (vgl. Nohl 2017: 15-28; vgl. auch Teilkapitel 3.6 zur Interviewausgestaltung).

Bei Interviews hat man, wenn diese vollständig aufgezeichnet und dann wörtlich transkribiert werden, jene Art von Protokolltexten zur Analyse vorliegen, „die nicht bereits von vornherein durch die Sprache des Beobachters gefiltert ist und in die Interpretamente des Beobachters lediglich insoweit eingelassen sind, als die mit der Verschriftlichung (Transkription) notwendigerweise verbundene Selektivität dies erforderlich macht" (Bohnsack 2014: 213). Das heißt, dass man bei dieser Art von Protokolltexten die Erfahrungsberichte und Beschreibungen alltäglicher sozialer Praxis in den Originalworten der Beforschten sowohl elektromagnetisch als auch schriftlich fixiert und somit eine gute, valide Datengrundlage für die dann später folgenden (eigenen) sozialwissenschaftlichen Interpretationen hat.

„Mit der ,Protokollierung‘ auf der Basis wörtlicher Transkriptionen und der Möglichkeit der Kontrolle ihrer Selektivität ist bereits ein wesentlicher Beitrag zur Kontrolle der Interpretamente, also des Vorwissens der Beobachterin bzw. der Forscherin geleistet.“ (ebd.)

In dieser Arbeit steht der Wandel alltäglicher Heizpraktiken im Fokus. Von Interesse ist insbesondere die Heizpraxis der Beforschten vor ihrem Umzug in ein Passivhaus bzw. vor der Umrüstung auf neue smarte Heizungssteuerungstechnik, um festzustellen, welche Veränderungen sich bei ihrem alltäglichen Heizen im Übergang zum Passivhaus und SmartHome ereignet haben. Bereits vergangene Heizpraktiken können nicht mehr direkt beobachtet werden. Sie lassen sich aber über die Analyse von (gezielt) generierten Erzählungen und Beschreibungen rekonstruieren. Dadurch wird sehr gut nachvollziehbar, inwiefern durch den Wechsel des Wohn-

verbessern als Reaktion auf ihre Wahrnehmung, beobachtet zu werden“ (psylex.de/psychologie-lexikon/sozialpsychologie/hawthorne-effekt.html, zuletzt geprüft am 29.08.2018). 
kontextes bzw. durch Abwandlungen am Heizsetting Veränderungen im alltäglichen Heizen stattgefunden haben.

Allerdings gibt es auch Grenzen des Interviews als Erhebungsinstrument. Zwar können anhand von Interviews bzw. Interviewtranskripten vergangene erlebte Erfahrungen gut rekonstruiert werden, aber die damals und aktuell involvierte Materialität sowie die tatsächliche Körperlichkeit bereits vergangener und gegenwärtiger Heizpraxis lassen sich nur begrenzt nachvollziehen.

Die oben ausgeführten Argumente führten zu der Entscheidung, die für dieses Forschungsvorhaben relevanten Daten vorrangig über Interviews zu generieren. Sie bieten einen adäquaten Zugang zu dem bisher kaum sozialwissenschaftlich erschlossenen Feld der Heizpraktiken. Durch die geeignete Auswahl verschiedener Heizformen als Kontext sowie differenter Gruppen von Gesprächspartner*innen kann über Interviews die gewünschte Bandbreite der Handlungspraxen von Heizen erfasst werden. Der Einsatz eines Methodenmixes - z.B. durch eine Kombination aus Interviews, teilnehmender Beobachtung, ggf. Bildanalyse und physikalischer Messungen - hätte deutlich fokussierter erfolgen müssen, was nicht im Sinne der Arbeit gewesen wäre.

Die Festlegung auf Interviews schließt nicht aus, dass forschungsrelevante Daten da, wo es sich anbietet, auch auf anderem Wege gewonnen werden - so z.B., wenn die Interviews bei den befragten Bewohner*innen zuhause stattfinden und dabei interessante Beobachtungen gemacht werden, die das Sinnverstehen aus dem Feld heraus erleichtern.

„Practices are more ethereal than material entities. [...], practices must be uncovered. [...]. Language ${ }^{60}$ is an important clue as to which activities and practices exist. [...]. Lexicon is an important clue here. The use of words for activities and practices is built into practices." (Schatzki 2012: 24)

Es zeigte sich rasch, dass nicht nur die konkret heizenden Personen von Interesse für diese Arbeit sind. Darüber hinaus spielen auch andere Akteure eine maßgebliche Rolle in der Ausgestaltung der alltäglichen Heizpraktiken in Privathaushalten, etwa wenn es um die Festlegung geht, welche Heiztechnik zur Verfügung gestellt wird. In Teilkapitel 3.5 und 3.6 wird vertieft, welche Art von Interviews mit welchen Gruppen ausgewählter Interviewpartner*innen geführt wurden.

60 Mit ,language' meint Schatzki hier sowohl Sprache bzw. verbale Kommunikation als auch Körper-Sprache und körperlichen Ausdruck. 
$\mathrm{Da}$ in dieser Arbeit nicht die einzelnen, sich heizend betätigenden Akteure, sondern die von ihnen performten Heizpraktiken im Fokus des Interesses stehen und sich die Auswahl geeigneter Interviewpartner*innen sowie die geeignete Form der Interviewführung dementsprechend von den konkret gewählten Untersuchungsfällen ableiten, wird im folgenden Teilkapitel zunächst die Auswahl der zwei für diese Untersuchung gewählten Fallbeispiele - Heizen in Passivhäusern und in so genannten SmartHomes - dargelegt.

\subsection{Begründete Auswabl der beiden Fallbeispiele}

Bei der Auswahl der Fallbeispiele wurde ebenfalls dem Postulat zur Offenheit von qualitativer Sozialforschung gefolgt. Ein zentrales Ziel dieser Untersuchung ist, das Feld alltäglichen Heizens möglichst breit zu erfassen sowie tiefgehend zu erkunden. Gleichzeitig soll mit der vorliegenden Studie mehr über den (bereits ablaufenden) tatsächlichen Wandel von konventionellen, in der Regel sehr energieintensiven Heizformen zu modernen, meist deutlich energiesparenderen und damit potenziell zukunftstauglichen Heizansätzen in Erfahrung gebracht werden.

Diese Überlegungen haben dazu geführt, dass für diese Arbeit als interessante und geeignete Untersuchungsfälle Heizpraktiken in zwei neuartigen Wohnkontexten ausgewählt wurden. Um mehr über Beständigkeit und insbesondere Wandel von Heizpraktiken in Privathaushalten zu erfahren, wurden zwei unterschiedliche Heizformen zur Analyse ausgewählt: dies ist zum einen Heizen im Wohnkontext Passivhaus und zum anderen Heizen mittels des Settings des SmartHome. Die für dieses Forschungsprojekt gewählten Untersuchungsfälle sind bislang noch kaum aus konsumsoziologischer Perspektive untersucht worden (siehe aber Foulds et al. 2012; Foulds 2013; Nyborg und Røpke 2011; Hargreaves et al. 2015).

Im Wesentlichen sind es zwei Aspekte, die die ausgewählten Fälle zur Erforschung von Praktiken und ihrem Wandel besonders aufschlussreich erscheinen lassen: Erstens handelt es sich bei der Passivhaustechnik und der intelligenten Heizungssteuerung um Veränderungen von unterschiedlicher Reichweite. So kann man bei der Passivhaustechnologie von einer Basisinnovation sprechen, weil sie das Heizgeschehen grundlegend verändert - eine konventionelle Gebäudeheizung wird obsolet. Bei der intelligenten Heizungssteuerung - SmartHomes - handelt es sich, vereinfacht gesagt, um eine klassische Nachrüsttechnologie: der konventionelle Heizvorgang wird automatisiert - die Intervention ist damit deutlich weniger 
radikal. Dementsprechend sind auch die zu erwartenden Einsparpotenziale bei Heizenergie und CO2-Emissionen für beide Fälle sehr unterschiedlich. Zweitens stehen die beiden zur Untersuchung gewählten Fälle für unterschiedliche Stadien von Neuerungsprozessen. Während sich Passivhäuser in der Praxis schon länger erfolgreich bewährt haben und regelmäßig gebaut werden, befindet sich die SmartHome-Technologie noch in der Erprobung. So gibt es erste größere Pilotprojekte; jedoch ist die Technologie noch nicht ausgereift und hat über die Pilotprojekte hinaus noch wenig Verbreitung gefunden (vgl. Balta-Ozkan et al. 2013: 363). Demnach ist mit den zwei ausgewählten Fällen ein breites Feld von Heizen abgedeckt.

Darüber hinaus kann mit dem Untersuchungsdesign dieser Studie (indirekt) auch das Heizen im konventionellen Wohnkontext bzw. mittels konventioneller Heiztechnik miterfasst werden. Durch die gezielte Auswahl der einzelnen konkreten Untersuchungsfälle (Wohnprojekte, einzelne Haushalte) und die gezielte Auswahl konkreter Interviewpartner*innen werden persönliche Erfahrungen konventioneller Heizpraxis aufgegriffen, da alle zum Interview ausgewählten Bewohner*innen in der Vergangenheit in einem konventionellen Wohnkontext ausgestattet mit einem konventionellen Heizungssystem gelebt haben. Somit können alle interviewten Bewohner*innen einen Vergleich zwischen vergangener und gegenwärtiger Heizpraxis anstellen und einen Vorher-Nachher-Bericht abgeben.

Es gibt keine verlässlichen Zahlen, wie viele Passivhäuser derzeit in Deutschland bewohnt werden, da es keine Meldepflicht für Passivhäuser gibt. Es gibt lediglich Schätzungen. Diese bewegen sich zwischen 20.000 und 40.000, wobei nicht ganz klar ist, ob damit Häuser oder Wohneinheiten gemeint sind und ob Nichtwohngebäude hier mit einbegriffen werden. Das Statistische Bundesamt weist mit seiner langjährigen Zahlenreihe „Baugenehmigungen und Baufertigstellungen von Wohn- und Nichtwohngebäuden (Neubau) nach Art der Beheizung und Art der verwendeten Heizenergie“ (Destatis 2017) zum Beispiel für das Jahr 2010 aus, dass von insgesamt 94.602 genehmigten Wohngebäuden 493 Wohngebäude im Passivhausstandard genehmigt wurden (ebd.: 10). Zudem lassen die Tabellen erkennen, dass die Anzahl der fertiggestellten Passivhäuser seit 2013 wieder rückläufig ist. Es zeigt sich somit, dass Passivhäuser in Deutschland quantitativ nur schwach vertreten sind. Dennoch eignen sie sich als Fallbeispiel für diese Arbeit besonders gut, weil sie, wie oben beschrieben, einen radikalen Bruch im Heizen implizieren und somit eine besondere Form des zu untersuchenden Wandels von Heizpraktiken darstellen.

Die aktuellen Zahlen zu SmartHomes in Deutschland basieren fast allesamt auf Schätzungen. Laut Deloitte, einem internationalen Dienstleister 
in den Bereichen Wirtschaftsprüfung, Risk Advisory, Steuerberatung, Financial Advisory und Consulting für Unternehmen und Institutionen aus allen Wirtschaftszweigen, gab es im Jahr 2013 rund 315.000 SmartHomeHaushalte in Deutschland (vgl. Deloitte und Bitcom 2014: 10). Für die Jahre bis 2020 gibt es jeweils ein konservatives als auch ein progressives Szenario (vgl. ebd.: 11-12). Während im konservativen Szenario für das Jahr 2018720.000 SmartHome-Haushalte in Deutschland prognostiziert werden (ebd.: 11), liegt die prognostizierte Anzahl der SmartHome-Haushalte nach progressivem Szenario bereits bei 1.000 .000 (ebd.: 12). Deutlich wird, dass die Anzahl an Haushalten mit SmartHome-Anwendungen in Deutschland rasant ansteigt. Aufgrund der uneinheitlichen Definition, was unter einem SmartHome genau zu verstehen ist, sind diese Zahlen nicht sehr aussagekräftig. Es zeichnet sich jedoch ab, dass smarte Heiztechnik und weitere SmartHome-Anwendungen in Zukunft eine wichtige Rolle spielen werden. Die Politik hat bereits entsprechende Förderprogramme aufgelegt. Gerade die hohen Erwartungen an SmartHomes bei gleichzeitig vager Definition macht Heizen im Kontext von SmartHome zu einem interessanten Fallbeispiel im Hinblick auf Wandel von alltäglichen Heizpraktiken.

Es zeigt sich somit, dass die Fallbeispiele nicht danach ausgewählt wurden, Heizen größtmöglich zu erfassen, sondern vielmehr danach, verschiedene Wandlungsprozesse von Heizpraktiken aufzuzeigen und erforschen zu können.

\subsection{Auswabl der Interviewpartner"innen}

Die genaue Stichprobe stand vor Beginn der Feldforschung noch nicht fest, da auch für diesen Schritt des Forschungsprozesses die weitgehend offene, das heißt vorrangig auf die Besonderheiten des interessierenden Phänomens hin ausgerichtete Forschungspraxis beibehalten wurde (vgl. Rosenthal 2011: 83-86). Im Sinne des Untersuchungsgegenstands (alltägliches Heizen in Privathaushalten) und der zwei Fallbeispiele (Heizen im Wohnkontext Passivhaus und Heizen mittels intelligenter Heizungssteuerung) galt es, geeignete Interviewpartner*innen auszuwählen.

Es sollte auf jeden Fall mit Bewohner*innen sowohl von Passivhäusern als auch SmartHomes gesprochen werden. Das Interesse an der Bewohner*innenperspektive erscheint offenkundig und logisch, da es sich bei den Bewohner*innen um die Performer*innen bzw. genuinen Träger*innen der in dieser Arbeit primär interessierenden alltäglichen Heizprakti- 
ken handelt. Darüber hinaus wurde bei der Auswahl geeigneter Interviewpartner*innen darauf geachtet, dass sie nicht schon ihr ganzes Leben in einem Passivhaus oder SmartHome wohnen, sondern vorher schon einmal für längere Zeit mit einem konventionellen Heizungssystem gelebt haben. Ihre Erfahrungen des Heizens in einem konventionellen Wohnkontext bzw. mittels konventioneller Heizungstechnik sollen den Interviewpartner*innen als Referenzmaßstab dienen, um berichten zu können, wie sich aus ihrer Sicht Heizen im Passivhaus bzw. SmartHome von Heizen im konventionellen Wohnkontext unterscheidet und welche Veränderungen sie in ihrer persönlichen Heizpraxis beim Übergang zu neuen Heizformen haben feststellen können. Durch diese gezielte Auswahl ist ein Vergleich zwischen alten und neuen Heizansätzen nicht nur jederzeit möglich, sondern in den Erzählungen und Beschreibungen der Interviewten immer schon enthalten bzw. durch gezielte Nachfrage zu generieren.

Bei den ersten vor allem theoretischen Annäherungen an das Feld wurde eruiert, dass neben den Bewohner"innen auch noch andere Akteure eine maßgebliche Rolle in der Ausgestaltung der alltäglichen Heizpraktiken in Privathaushalten spielen. Expert"innen etwa, die aufgrund ihres Spezialwissens sowie ihrer korrespondierenden beruflichen Position eine zentrale Rolle im Bau- bzw. Umrüstungsprozess (hin zu) einer neuen Heizlösung spielen. Expert*innen sind häufig schon am Zustandekommen, immer aber an der konkreten Ausgestaltung einer bestimmten Heizlösung beteiligt. Sie können als ,Gatekeeper' bezeichnet werden - als Personen, die aufgrund von besonderen Fähigkeiten und Kenntnissen sowie ihrer beruflichen Position die Möglichkeit haben, die Entscheidung und Gestaltung der Heizlösung in den betreffenden Privathaushalten zu beeinflussen.

Generell sind sehr viele verschiedene Akteure am Planungs- und Bauprozess eines Hauses oder einer Wohnung als Passivhaus und dementsprechend an der Gestaltung des Energiestandards $s^{61}$ und der Heizlösung für den verbleibenden Heizwärmebedarf beteiligt: Architekt“innen, Bauinge-

61 Der Energiestandard eines Gebäudes legt fest, wie hoch der Bedarf an Energie pro Quadratmeter Energiebezugsfläche und Jahr sein darf. Für die Einordnung einer Immobilie ist demnach ihre energetische Qualität entscheidend. Sie wird mit den Referenzgrößen Primärenergiebedarf und Transmissionswärmeverlust gemessen. Die Energieeinsparverordnung (EnEV) definiert für diese beiden Größen Höchstwerte, die ein so genanntes vergleichbares Referenzgebäude einzuhalten hat. Ein Effizienzhaus 55 benötigt demnach nur 55 Prozent der Energie des Referenzgebäudes, oder anders ausgedrückt: es darf nur 55 Prozent der nach EnEV gültigen Höchstwerte hinsichtlich Jahres-Primärenergiebedarf und Transmissionswärmeverlust erreichen (siehe Burgdorf 2009*). 
nieur*innen, Statiker"innen, Energieberater"innen und Haustechniker*innen. Häufiger kommt es vor, dass mehrere dieser Aufgaben von einer Person in Personalunion übernommen und erledigt werden. Meist handelt es sich bei diesen Personen von ihrer professionellen Ausbildung her um ausgewiesene, diplomierte Architekt*innen. Sie sind häufig zentrale, Gatekeeper' im Wohnkontext eines Passivhauses, weshalb Interviews mit ihnen durchgeführt werden sollen. Darüber hinaus fließen Vorstellungen und Annahmen der Architekt"innen über die künftigen Bewohner*innen sowie zu deren Nutzungs- und Heizverhalten und dementsprechendem Energieverbrauch schon frühzeitig in das Haus- oder Wohnungsdesign sowie die Konzeption der Heizlösung mit ein (vgl. Shove et al. 2012: 148f).

Architekt"innen kommt eine tragende Rolle im Hinblick auf den Entwurf, die integrierte Planung und die Umsetzung von Passivhäusern zu und sie nehmen mit ihrer Tätigkeit Einfluss auf die Heizenergiekonsumpraktiken der späteren Bewohner*innen. ${ }^{62}$

Im Falle der intelligenten Heiztechnik stellen Vertreter"innen großer Energieversorgungsunternehmen wichtigste ,Gatekeeper' dar, insofern die betreffenden Personen in ihrem Unternehmen wichtige Ansprechpartner*innen für SmartHome-Anwendungen und -Produkte, wie etwa eine intelligente Heizungssteuerung sind. In diesem Fall werden zudem Vertreter"innen von Unternehmen als Expert"innen betrachtet, die sich mit ihrer Unternehmenstätigkeit auf intelligente Heizungsregelungstechnik, die entsprechenden technologischen Lösungen sowie die dafür geeigneten und darauf zugeschnittenen Anwendungen für Computer, Tablet-PC und Smartphone spezialisiert haben und ihre Produkte auf dem Markt anbieten, sowie Erbauer*innen und/oder ,Manager*innen' so genannter LivingLabs (Musterhäuser).

Dass sowohl die Perspektiven von Passivhaus- und SmartHome-Bewohner*innen als auch von (den) entsprechenden Expert"innen in diese Untersuchung miteinbezogen werden, ist tatsächlich innovativ: So wird nicht nur deutlich, welche Fragen neue Heizformen im praktischen Alltag aufwerfen, sondern auch wer am erfolgreichen Zustandekommen und der konkreten Ausgestaltung einer neuen Heizlösung beteiligt ist und wie diese Mitwirkung im Einzelnen aussieht.

In fast allen Gruppen von Interviewpartner*innen waren Männer wie Frauen vertreten. Die Geschlechterverteilung bei den Interviewpartner*in-

62 Zur besonderen Rolle von Architekt*innen für den Planungs- und Umsetzungsprozess eines Hauses oder einer Wohnung als Passivhaus siehe auch die Interviewgespräche Grund-Ludwig 18.04.2009 und Grotelüschen 2010. 
nen spiegelt vermutlich die allgemeine Geschlechterverteilung in den ausgewählten Gruppen wider. Da Geschlechterfragen im Weiteren nicht im Fokus stehen, kann dies jedoch vernachlässigt werden, sofern die Analyse keinen Geschlechterbias offenbart.

\subsection{Interviews}

Innerhalb der qualitativen Sozialforschung stellen Interviews eine häufig verwendete Form der Datengenerierung dar, die sich auch für diese Arbeit anbietet. Das Interview ist eine Form der mündlichen Befragung, die unterschiedlich stark strukturiert sein kann und für die verschiedene qualitative inhaltsanalytische Auswertungsverfahren vorhanden sind (vgl. Atteslander 2010: 110ff bzw. 195ff). Da im Mittelpunkt der hier vorliegenden Untersuchung ein eingegrenztes Thema - privates Heizen als Ausschnitt alläglicher Handlungspraxis - steht, ist es sinnvoll, sowohl die Interviewsituation mit den Bewohner*innen als auch diejenige mit den Expert*innen durch einen Leitfaden gezielt auszurichten. Gleichzeitig ist dem Umstand Rechnung zu tragen, dass die Untersuchung neues, bisher unbekanntes Wissen über die kollektiv geteilte Praxis alltäglichen Heizens in Privathaushalten hervorbringen soll. Das heißt, die Interviewsituation sollte Raum für generativ neue Erkenntnisse lassen, die sich womöglich erst in der Analyse des Datenmaterials als relevant erschließen. Die Leitfäden für die vier unterschiedlichen Gruppen ausgewählter Interviewpartner*innen und die dazugehörigen Interviewsituationen sind dementsprechend offen zu gestalten. Eine methodische Entsprechung kann das Forschungsanliegen in offenen Leitfadeninterviews - Expert*inneninterviews stellen hiervon eine spezifische Form dar - finden.

\subsubsection{Leitfadengestützte Interviews}

In dieser Untersuchung wird auf einen Leitfaden zur Gesprächsführung zurückgegriffen, weil sich auf diese Weise am besten sicherstellen lässt, dass sich die Befragten in jedem Fall zu den für das Forschungsinteresse relevanten Themen äußern. Das heißt, eine leitfadenorientierte Gesprächsführung wird dem thematisch eingegrenzten Interesse der Forscherin an den Beforschten, deren Erfahrungen und handlungspraktischem Wissen gerecht. Sollte der bzw. die Befragte im Laufe des Interviews thematisch zu stark abschweifen, kann der bzw. die Interviewer*in unter Zuhilfenahme 
des Leitfadens die befragte Person immer wieder zu den interessierenden Themen zurückleiten und das Interview wieder auf die für das Forschungsinteresse relevanten Themen fokussieren. Eine leitfadengestützte Interviewführung gewährleistet zudem eine gewisse „Vergleichbarkeit der Interviewtexte" (Meuser und Nagel 1991: 453, 2005: 269). Da sich für alle Interviews mit Personen einer Zielgruppe prinzipiell am selben Leitfaden orientiert wird, „sind die Interviews zumindest insofern vergleichbar, als sich alle befragten Personen [innerhalb einer Zielgruppe] zu denselben Themen äußern mussten“ (Nohl 2017: 17). Dies ist für die Auswertung der dieser Arbeit zugrundeliegenden Leitfadeninterviews von herausragender Bedeutung, da es sich bei der dokumentarischen Methode um ein von Anfang an konsequent vergleichendes Analyseverfahren handelt (vgl. Nohl 2013). Wie dieses durchweg vergleichende Vorgehen umzusetzen ist und was damit bezweckt wird, wird in Abschnitt 3.10 dieses Kapitels genauer erläutert.

Wird der Leitfaden darüber hinaus flexibel und unbürokratisch „im Sinne eines Themenkomplexes und nicht im Sinne eines standardisierten Ablaufschemas" (Meuser und Nagel 2005: 269) gehandhabt und laufend der Interviewsituation angepasst, beispielsweise indem der bzw. die Interviewer*in sich die tatsächliche Reihenfolge und Vertiefung der behandelten Themen erst im konkreten Gesprächsverlauf und durch eigene Relevanzsetzungen seitens des bzw. der Interviewten ergeben lässt, können auch mit den Fragen eines Leitfadens ausführliche Erzählungen zu den einzelnen Themengebieten generiert werden. Demnach ist der Leitfaden, wie Andreas Witzel es ausdrückt, in erster Linie als "Orientierungsrahmen“ bzw. flexible „Gedächtnisstütze“ (Witzel 1982: 90) für den bzw. die Interviewer*in zu verstehen:

„Zum einen ,hakt" [.] der Interviewer sozusagen im Gedächtnis die im Laufe des Interviews beantworteten Forschungsfragen ab, kontrolliert also durch die innere Vergegenwärtigung des Leitfadens die Breite und Tiefe seines Vorgehens. Zum anderen kann er sich aus den thematischen Feldern, etwa bei stockendem Gespräch bzw. bei unergiebiger Thematik, inhaltliche Anregungen holen, die dann ad hoc entsprechend der Situation formuliert werden. Damit lassen sich auch Themenfelder in Ergänzung zu der Logik des Erzählstranges seitens des Interviewten abtasten, in der Hoffnung, für die weitere Erzählung fruchtbare Themen zu finden bzw. deren Relevanz aus Sicht der Untersuchten festzustellen und durch Nachfragen zu überprüfen.“ (ebd.) 
Demzufolge steht der Leitfaden weder einem offenen Gesprächsverlauf noch der Erzählgenerierung entgegen; vielmehr kann er - bewusst von dem bzw. der Interviewer"in eingesetzt - sogar als hervorragende Unterstützung bzw. als „Instrument für die narrative Ausgestaltung von Interviews“ (Nohl 2017: 18) dienen. Dafür ist es wichtig, „dass die durch den Fragebogen thematisch oder sogar im Wortlaut vorgegebenen Fragen erzählgenerierend sind" (ebd.). Das heißt, dass die Fragen des Leitfadens möglichst offen formuliert sein sollten, so dass die Untersuchten jederzeit die Möglichkeit haben, auch noch eigene, von dem bzw. der Interviewer*in nicht angesprochene Themen einzubringen, unerwartete Themendimensionierungen vorzunehmen und einzelne angesprochene Themen nach eigenem Ermessen zu vertiefen. Die Untersuchten sollten im Interview stets die Gelegenheit erhalten, ihre eigenen Sinndeutungen und Relevanzsysteme in ihrer eigenen Sprache vorzubringen und ausführlich zu entfalten. Nicht nur bei den im Leitfaden vorgesehenen Fragen, sondern ebenfalls bei den meist etwas freier formulierten oder zum Teil sogar ad hoc gestellten immanenten Nachfragen sollte der bzw. die Interviewer*in stets darauf achten, dass diese narrativ fundiert sind, damit auch sie dazu beitragen (können), die Schilderungen der Befragten weiter zu vertiefen. Im Idealfall achtet der bzw. die Forscher*in während des gesamten Interviews auf eine narrative Gesprächsführung, damit die Interviewten „größtmöglichen Raum zur Selbstgestaltung der Präsentation ihrer Erfahrungen und bei der Entwicklung ihrer Perspektive auf das angesprochene Thema" (Rosenthal 2011: 151) haben. Das Ziel, möglichst viele Erzählungen zu generieren, resultiert aus der besonderen Bedeutung, die narrativen Passagen bei der Auswertung von Interviewtexten mittels der dokumentarischen Methode zukommt: Aus Sicht der dokumentarischen Methode liegen nur „Erzählungen der Erfahrung und erlebten Handlungspraxis [nahe]“ (Nohl 2017: 19); in Unterschied zu argumentativen Textstellen, in denen die Befragten in der Regel zur Explikation ihrer Motive und Handlungsintentionen sowie Begründung ihres Tuns gedrängt werden, was immer auf die aktuelle Situation und nicht auf die vergangenen erlebten Erfahrungen verweist (vgl. ebd.: 24), können damit auch nur narrative Passagen „der Artikulation ,atheoretischen Wissens" und ,konjunktiver Erfahrung" dienen“" (ebd.: 19) - dem Erkenntnisinteresse dieser Arbeit. 


\subsubsection{Expert*inneninterviews}

Des Weiteren soll in dieser Arbeit noch eine besondere Form des offenen leitfadenorientierten Interviews zur Anwendung kommen: das Expert"inneninterview. Das Verfahren des Expert"inneninterview haben Michael Meuser und Ulrike Nagel erstmals in einem Aufsatz Anfang der 1990er Jahre methodisch umfassend ausgearbeitet (vgl. Meuser und Nagel 1991). Das Besondere an Expert"inneninterviews - wodurch sie sich gleichzeitig auch deutlich von anderen Formen offen gestalteter Interviews unterscheiden - ist laut Meuser und Nagel, dass in ihnen ,nicht die Gesamtperson den Gegenstand der Analyse, d.h. die Person mit ihren Orientierungen und Einstellungen im Kontext des individuellen und kollektiven Lebenszusammenhangs [bildet]" (ebd.: 442, Hervorh. im Original). Vielmehr werden die wesentlich in Abhängigkeit vom jeweiligen Forschungsinteresse ausgewählten Expert*innen vor allem zu ihrer beruflichen Praxis, d.h. ihrem „organisatorische[n] oder institutionelle[m] Zusammenhang“ befragt, „der mit dem Lebenszusammenhang der darin agierenden Personen gerade nicht identisch ist und in dem sie nur einen ,Faktor" darstellen" (ebd.). Während die Passivhaus- und SmartHome-Bewohner*innen (in ihrer Rolle) als Privatpersonen, quasi als ,Expert*innen ihrer alltäglichen Heizpraxis` (vgl. Hörning 2001) angesprochen und zu ihrem handlungspraktischen Wissen im Hinblick auf ihr alltägliches Heizhandeln befragt werden, sind die im Rahmen dieser Forschungsarbeit als Expert"innen identifizierten Personen (Architekt"innen und professionelle Ansprechpartner*innen für smarte Heiztechnik) vorrangig als „FunktionsträgerInnen innerhalb eines organisatorischen oder institutionellen Kontextes" (Meuser und Nagel 1991: 444) von Interesse. Sie werden als Vertreter"innen ausgewählter Berufsgruppen angesprochen, als „RepräsentantInnen einer Organisation oder Institution, insofern sie die Problemlösungen und Entscheidungsstrukturen (re)präsentieren“ (ebd.). Die Gegenstände des Expert"inneninterviews sind demnach die mit ihrer beruflichen Funktion bzw. Stellung im Unternehmen „verknüpften Zuständigkeiten, Aufgaben, Tätigkeiten und die aus diesen gewonnenen exklusiven Erfahrungen und Wissensbestände“ (ebd.). Bei den Expert"innen ist primär nicht ihr alltagspraktisches Wissen in Bezug auf Heizen von Interesse, welches sie im Kontext ihres persönlichen Lebenszusammenhangs erworben haben, sondern bei ihnen geht es vorrangig um ihr handlungspraktisches Wissen, das sie sich über ihr berufliches Handlungsfeld und im Rahmen ihrer beruflichen Tätigkeit angeeignet haben. Im Fokus steht demnach das „Betriebswissen“ (ebd.: 446) der jeweiligen Expert"innen; das heißt, „die Interviews sind da- 
rauf angelegt, daß die ExpertInnen Auskunft über ihr eigenes Handlungsfeld geben“ (ebd.: 445); „der/die ExpertIn [wird] zum eigenen Handeln und dessen institutionellen Maximen und Regeln befragt" (Meuser und Nagel 2005: 264). Am Rande dienen die Interviews mit Expert*innen aber auch der Ermittlung des so genannten „Kontextwissen[s]“ (Meuser und Nagel 1991: 446); das heißt, der bzw. die Expert*in soll an manchen Stellen auch „Auskunft geben über die Kontextbedingungen des Handelns, über Zielgruppen [hier die Bewohner*innen, JM], Adressaten, Betroffene“ (Meuser und Nagel 2005: 264).

Meuser und Nagel fassen die Vorteile dieses Vorgehens in Bezug auf Expert"inneninterviews prägnant zusammen:

„In unseren Untersuchungen haben wir mit offenen Leitfäden gearbeitet, und dies scheint uns die technisch saubere Lösung der Frage nach dem Wie der Datenerhebung zu sein. Eine leitfadenorientierte Gesprächsführung wird beidem gerecht, dem thematisch begrenzten Interesse des Forschers an dem Experten wie auch dem Expertenstatus des Gegenübers. Die in die Entwicklung eines Leitfadens eingehende Arbeit schließt aus, daß sich der Forscher als inkompetenter Gesprächspartner darstellt. [...] Die Orientierung an einem Leitfaden schließt auch aus, daß das Gespräch sich in Themen verliert, die nichts zur Sache tun, und erlaubt zugleich dem Experten, seine Sache und Sicht der Dinge zu extemporieren.“ (Meuser und Nagel 1991: 448)

Im Hinblick auf die Durchführung der Expert*inneninterviews gelten somit die gleichen Prämissen wie für die sonstigen, im Rahmen dieses Forschungsvorhabens geplanten Interviews: Es wird sich an einem Leitfaden orientiert, der von der Interviewerin flexibel und situationsadäquat anzuwenden ist.

\subsection{Feldzugang}

Wie bereits in Teilkapitel 3.3 zum methodologischen Forschungsdesign beschrieben, erfolgt die tiefergehende Sinnerschließung alltäglicher Heizpraxis in Privathaushalten vorrangig über Interviews. Auf andere Zugänge, wie etwa teilnehmende Beobachtung, wurde nur in einzelnen Fällen, bei denen es sich situativ angeboten hat, ergänzend zurückgegriffen. In diesem Abschnitt wird geschildert, wie für das Thema dieser Arbeit geeignete Gesprächspartner*innen kontaktiert und zu einer Teilnahme am Interview bewegt wurden. 
Auch wenn es in beiden ausgewählten Untersuchungsfällen um das gleiche Forschungsphänomen - Heizen mittels moderner Heiztechnik - geht, so handelt es sich beim Passivhaus und SmartHome dennoch um zwei deutlich voneinander zu unterscheidende Bereiche innerhalb des einen übergeordneten Forschungsfeldes ,Heizen'. Das heißt, für dieses Forschungsvorhaben musste der Zugang zu zwei unterschiedlichen Bereichen erarbeitet werden. Bei der Felderschließung wurde nicht parallel, sondern mit nur kleinen Überschneidungen nacheinander vorgegangen: Zunächst wurde nach geeigneten Interviewpartner*innen für den Untersuchungsfall ,Passivhaus' gesucht und erst nachdem fast alle Interviews mit PassivhausArchitekt"innen und -Bewohner"innen absolviert waren, wurde mit der Akquise von kompetenten Gesprächspartner*innen für smarte Heiztechnik begonnen. Dieses eher sequenzielle Vorgehen von Fallbeispiel zu Fallbeispiel hat sich im Nachhinein als sinnvoll erwiesen, da beide Feldbereiche tatsächlich auch sehr unterschiedliche Erschließungsstrategien erfordert haben.

Die erste Ansprache und Rekrutierung von geeigneten Interviewpartner*innen zum Passivhaus-Fall erfolgte über öffentliche Veranstaltungen, wie z.B. die überregional organisierten „Tage der offenen Tür im Passivhaus“63 des Jahres 2012, die „10. Hamburger Wohnprojekte-Tage“64 und die „4. Norddeutsche Passivhauskonferenz “65 - die beiden letztgenannten Veranstaltungen fanden ebenfalls im Jahr 2012 statt. Auf diesem Wege lieBen sich rasch einige Passivhaus-Architekt"innen für ein Interview gewinnen. Die Akquise von Passivhaus-Bewohner*innen, also Privatpersonen, zur Teilnahme an einem Interview stellte sich als etwas schwieriger dar: Den ersten Kontakt zu Bewohner*innen vermittelten die interviewten Expert"innen. Auf diese Weise kamen zwei Interviews zustande. Ursprünglich konnte davon ausgegangen werden, dass sich aus den ersten erfolgreichen Bewohner*innengesprächen im "Schneeballverfahren“ (Schnell et al. 2011: 294) weitere geeignete Interviewkontakte ergeben. ${ }^{66}$ Dieses Vorgehen war allerdings erfolglos. Aus diesem Grund wurde ein einseitiges offi-

63 Vgl. www.ig-passivhaus.de/index.php?page_id=157\&, zuletzt geprüft am 09.10.2018.

64 Vgl. www.stattbau-hamburg.de/index.php/events-leser/wohnprojektetage.html, zuletzt geprüft am 09.10.2018.

65 Vgl. docplayer.org/18684504-4-norddeutsche-passivhauskonferenz.html (Programmflyer zur 4. Norddeutschen Passivhauskonferenz in Hamburg), zuletzt geprüft am 09.10.2018.

66 Beim Schneeball-Verfahren werden, ausgehend von einer Person, im Weiteren die von dieser Person benannten Personen befragt. Man geht also davon aus, dass 
zielles Einwurfschreiben mit einer Skizze des Forschungsvorhabens formuliert. Dieses direkt an Bewohner*innen von Passivhäusern gerichtete Schreiben wurde an die Briefkästen mehrerer verschiedener Passivhauswohnprojekte im Großraum Hamburg verteilt. Die Resonanz auf dieses Anschreiben fiel insgesamt recht gut aus, so dass binnen kurzer Zeit genügend Bewohner*innen als Interviewpartner*innen gewonnen werden konnten.

Im SmartHome-Fall gestaltete sich der Feldzugang insgesamt deutlich komplizierter. Dies dürfte vor allem damit zusammenhängen, dass das Thema ,SmartHome' zum damaligen Zeitpunkt (2013) in der Öffentlichkeit noch wenig bekannt war und die Technik in deutschen Privathaushalten bisher noch wenig genutzt wird. „Abfragen in der Community haben ergeben, dass Smart Homes deutlich unter 1\% der Neubauten in Deutschland ausmachen" (Strese et al. 2010: 12). ${ }^{67}$ Beim Konzept ,SmartHome handelt es sich also noch mehr um eine ,Zukunftsvision' als um eine tatsächlich praktizierte Alltagslösung (vgl. Strengers 2013). Dazu kommt, dass SmartHomes nicht so einfach - wie etwa die meisten Passivhäuser von außen als solche zu erkennen bzw. zu identifizieren sind. Dies liegt zum einen daran, dass es sich hierbei nicht um eine grundlegend andere oder besondere Hausbauweise handelt, sondern der größte Teil dieser neuen Technologie verbirgt sich in der Regel im Inneren des Hauses oder der betreffenden Wohnung (vgl. Stringer et al. 2006). Zum anderen lassen sich auch nur einzelne Komponenten dieser Technologie in Haushalte einbauen oder Komponenten für einzelne Bereiche um- oder nachrüsten, wie zum Beispiel die Heizungssteuerung (vgl. Strese et al. 2010: 8f). Es ist also durchaus möglich, dass ein älteres, dem äußeren Anschein nach wenig modernes Wohngebäude bereits mittels mordernster Haussteuerungstechnologie verwaltet und kontrolliert wird und daher von der Technikausstattung her als ein SmartHome eingestuft werden kann. Darüber hinaus gab es für SmartHomes zum Erhebungszeitpunkt (noch) keine regelmäßig stattfindenden überregionalen öffentlichkeitswirksamen Veranstaltungen für interessierte Privatpersonen. Jedoch gab es bereits einige (größere) SmartHome-Initiativen bzw. -Projekte in Deutschland. ${ }^{68}$ Noch handelt es

geeignete Interviewpartner*innen weitere geeignete Interviewpartner*innen kennen und dem bzw. der Interviewer*in den Kontakt zu diesen Freund"innen oder Bekannten vermitteln.

67 Im Jahr 2013 gab es in Deutschland gerade einmal 315.000 SmartHome-Haushalte (vgl. Deloitte und Bitcom 2014: 10).

68 Für eine ausführliche ,Übersicht zum Status Quo von SmartHome-Initiativen und -Projekten in Deutschland' im Jahre 2010, siehe Strese et al. 2010: 16-34. 
sich beim SmartHome um ein Nischensegment. Strese et al. schreiben in ihrer ,Untersuchung zu SmartHome im Kontext eines Begleitforschungsprojektes‘ im Auftrag des Bundesministeriums für Wirtschaft und Technologie (BMWi) zur Marktsituation Folgendes:

„Angebote am Markt für Smart Home-Anwendungen konnten trotz vielfacher Anläufe noch keine selbst tragende Nachfrage generieren. Der Markt ist weiterhin als Zukunftsmarkt zu charakterisieren. Dementsprechend und mangels eindeutiger, allgemein akzeptierter Definition gibt es auch kaum verlässliche Marktzahlen zu Smart Home.“ (Strese et al. 2010: 12)

Aus diesen Gründen wurde die Suche nach geeigneten Gesprächspartner*innen nicht auf Hamburg und die nähere Umgebung begrenzt, sondern von Anfang an auf ganz Deutschland ausgeweitet.

Durch ausführliche (Internet-)Recherche konnten für das Thema ,SmartHome' und insbesondere für smarte Heiztechnik interessante und relevante Expert*innen in ganz Deutschland ausfindig gemacht werden, von denen einige gezielt ausgewählt und dann per Mail oder telefonisch kontaktiert wurden. Auf diesem Wege ließen sich - genauso wie im Passivhaus-Fall - mitinsgesamt sechs Expert*innen zum Thema ,Heizen im SmartHome' Interviews generieren. Der Kontakt zu Bewohner*innen, die bereits mittels smarter Technik heizen, kam dann über einen der interviewten Expert"innen zustande. Im Interview mit einem Vertreter eines großen Energieversorgungsunternehmens erfuhr die Interviewerin, dass dieses Unternehmen noch für dasselbe Jahr (2013) den Start eines größeren, einjährigen Pilotprojekts zum intelligenten Heizen in einer Hamburger Liegenschaft geplant hatte. ${ }^{69}$ Es ergab sich die Möglichkeit, dieses Pilotprojekt, das aufgrund von größeren Verzögerungen während der Anlaufphase noch einmal um ein Jahr verlängert wurde und dadurch letztendlich fast zwei Jahre andauerte, wissenschaftlich zu begleiten. Ich habe regelmäßig an den in der Anlaufphase und während der winterlichen Heizperiode wöchentlich und dann später etwas seltener stattfindenden Baubesprechungen, den Informationsveranstaltungen für die Mieter*in-

69 Bei diesem Pilotprojekt handelte es sich um ein Kooperationsprojekt einer Wohnungsbaugenossenschaft mit einem Energieversorgungsunternehmen sowie einer Firma für Gebäudeautomatisierungstechnik, an dem sich auch die Stadt Hamburg in Form einer finanziellen Förderung beteiligt hat. Für diesen Pilotversuch wurde die Hälfte der Wohneinheiten, insgesamt circa 75 Mietwohnungen einer größeren Genossenschafts-Immobilie, für eine Testphase von einem Jahr mit intelligenter Heizungssteuerungstechnik ausgestattet. 
nen sowie den öffentlichen (Presse-)Veranstaltungen teilgenommen. Darüber hinaus konnten einige wenige der betroffenen Mieter*innen für ein Interviewgespräch gewonnen werden. Ein Grund für die eher verhaltene Resonanz auf meine Interviewanfragen ist in der grundsätzlichen Konzeption des Pilotprojekts zu suchen: die Teilnahme der Miethaushalte am Pilotprojekt beruhte nämlich nicht auf Freiwilligkeit, sondern die Entscheidung darüber wurde allein von der Genossenschaftsverwaltung getroffen; das heißt, die Teilnahme war für die ausgewählten Haushalte verpflichtend. Immer wieder wurde in den Kontakten mit Mieter"innen deutlich, dass die meisten von ihnen dem Projekt deshalb von Anfang an skeptisch bis ablehnend gegenüberstanden. Viele Mieter*innen übertrugen diese Verweigerungshaltung vermutlich auf die für diese Arbeit durchgeführte Untersuchung. Dementsprechend viele Absagen erfolgten auf die mehrmaligen Interviewanfragen. Auch waren mehrmals Mieter"innen zu bereits vereinbarten Interviewterminen nicht anzutreffen. Darüber hinaus ist zu erwähnen, dass es sich um eine sehr heterogene Mieter*innenschaft handelt. Etwa ein Drittel der von der Maßnahme betroffenen Mieter*innen verfügt über einen Migrationshintergrund. In einigen Haushalten, die im Rahmen des Pilotprojekts mit einer intelligenten Heizungssteuerung ausgestattet wurden, waren kaum deutsche Sprachkenntnisse vorhanden. Zudem handelt es sich um viele sozial schwache und bildungsferne Haushalte. Diese Faktoren haben den Zugang zu den Privathaushalten somit noch zusätzlich erschwert, so dass sich für den Untersuchungsfall ,SmartHome letztendlich nur eine kleine Anzahl (insgesamt sechs) an Bewohner*innengesprächen realisieren ließ.

\subsection{Entwicklung und Erprobung der Interviewleitfäden}

Die vorliegende Studie hat insgesamt vier verschiedene Zielgruppen: Zum einen die Expert"innen für Passivhäuser: die Passivhaus-Architekt*innen und die Gruppe der Passivhaus-Bewohner*innen; zum anderen die Expert"innen für die SmartHome-Technik und die Gruppe der SmartHomeBewohner*innen. Für diese vier verschiedenen Gruppen von Interviewpartner*innen wurden auch vier verschiedene Interviewleitfäden entwickelt.

Als Forscherin diente mir die Erarbeitung der Gesprächsleitfäden für die Expert"inneninterviews vor allem dazu, mich schon vorab mit den anzusprechenden Themen vertraut zu machen und damit eine Basis dafür zu schaffen, den jeweiligen Expert*innen im Interview als kompetente Ge- 
sprächspartnerin zu begegnen (vgl. Meuser und Nagel 1991: 448f). Dadurch soll grundsätzlich verhindert werden, dass das Interviewgespräch auf der Ebene der Darstellung allgemeiner technischer Sachverhalte verbleibt. Vielmehr soll der bzw. die Expert*in durch die vorbereiteten Fragen dazu angeregt werden, ausführlich über die eigene berufliche Praxis zu sprechen, darüber wie er bzw. sie Entscheidungen trifft und Probleme löst oder auch anhand von Beispielen das eigene Vorgehen in bestimmten Situationen zu erläutern (vgl. Meuser und Nagel 2011: 58).

Zur Erstellung der unterschiedlichen Leitfäden wurden zunächst Kernthemen eruiert. Zu diesen Kernthemen wurden dann jeweils mehrere Fragen entwickelt und diese entwickelten Fragen wurden in einem nächsten Schritt geclustert. Auf diese Weise konnten sieben größere thematische Blöcke erstellt werden, die jeweils mehrere Fragen zu einem Themenkomplex enthielten. Dabei wurde darauf geachtet, dass die Einleitungs- bzw. Eröffnungsfrage eines jeden Themenblocks möglichst offen und erzählgenerierend formuliert wurde. Die weiteren Fragen innerhalb eines Themenblocks knüpften entweder direkt an diese Einleitungsfrage an oder sie dienten der weiteren Vertiefung des angesprochenen Oberthemas. Neben Nachfragen enthielt jeder Themenblock auch einige so genannte Aufrechterhaltungsfragen, die dazu dienen sollten, das Gespräch am Laufen zu halten. Diese Fragen sollten den bzw. die Interviewpartner*in zum weiteren Erzählen anregen, falls er bzw. sie einmal ins Stocken gerät oder auch da$\mathrm{zu}$, begonnene Erzählungen und Beschreibungen fortzusetzen, weiter auszuführen und durch immer weitere Details zu ergänzen.

Auch wenn die entwickelten Gesprächsleitfäden sehr detailliert ausgearbeitet sind, wurden sie nie als starrer Gesprächsablaufplan verwendet, sondern stets sehr flexibel gehandhabt und immer individuell an die konkrete Interviewsituation, den bzw. die jeweilige Interviewpartner*in sowie den besonderen Gesprächsverlauf angepasst. Gerade die vorherige Erarbeitung der Gesprächsleitfäden hat mir als Interviewerin aber erst eine lockere und unbürokratische Interviewführung ermöglicht (vgl. Meuser und Nagel 1991: 449). Durch diese intensive Vorarbeit und thematische Einarbeitung war ich mit den Leitfäden vollkommen vertraut und wusste, welche Fragen im jeweiligen Interview bereits behandelt worden waren, zu welchen Themen sich mein Gegenüber noch nicht geäußert hatte oder welche Themen bisher noch gar nicht zur Sprache gekommen waren. Dadurch konnten gezielt Nachfragen gestellt und das Gespräch bewusst auf noch nicht behandelte Themen gelenkt werden.

Die Interviewleitfäden wurden im Sinne etablierter wissenschaftlicher Praxis und Qualitätskontrolle in Zusammenarbeit mit anderen Wissen- 
schaftler*innen vorbereitet. Und bevor mit den eigentlichen Interviews mit ausgewählten Gesprächspartner*innen begonnen wurde, wurden die Leitfäden mit anderen erprobt, um sie auf Verständlichkeit, Stimmigkeit und Adäquanz zu überprüfen.

Die allgemeinen Richtlinien zum Datenschutz in der sozialwissenschaftlichen Forschung wurden eingehalten. Die Interviewpartner*innen wurden am Anfang des Interviews von der Interviewerin darüber aufgeklärt, wie die Interviewaufnahmen verwendet werden und ihnen wurde Anonymität zugesichert. Die Anonymisierung der Interviews erfolgt durch Namensänderung und Weglassen von persönlichen Detailinformationen, wie Alter, Beruf, usw. Darüber hinaus wurden die meisten Ortsangaben (z.B. Wohn- und Standorte) sowie wichtige Kennzahlen und Größen geändert oder ganz weggelassen.

\subsection{Materialbilanzierung}

Über die verschiedenen Kontaktwege kamen in der Summe 27 Interviews mit insgesamt 33 Personen zustande, die im Zeitraum von Dezember 2012 bis März 2014 geführt wurden. Bis auf wenige Ausnahmen dauerten alle Interviews für den Untersuchungsfall ,Passivhaus' zwischen einer und zwei Stunden an. Die Interviews für den Untersuchungsfall ,SmartHome' fielen etwas kürzer aus; sie dauerten in der Regel zwischen 30 Minuten und einer Stunde an. Alle Interviews wurden aufgezeichnet und anschließend vollständig transkribiert - liegen somit als Textdokumente vor.

Von den 27 Interviews entfallen 17 Interviews mit insgesamt 21 Personen auf den Untersuchungsfall ,Passivhaus'. Die verbleibenden zehn Interviews mit insgesamt zwölf Personen sind dem Untersuchungsfall ,SmartHome' zuzurechnen.

Für den Untersuchungsfall ,Passivhaus “ wurden sechs Expert*innengespräche mit sechs verschiedenen Architekt*innen geführt und es fanden elf Leitfadeninterviews mit insgesamt 15 Bewohner*innen von Passivhäusern statt. Bei den Bewohner*innengesprächen handelt es sich um sieben Einzelinterviews, drei Tandem-Interviews (mit jeweils zwei Bewohner"innen aus unterschiedlichen Haushalten) und ein Paar-Interview.

Für den Untersuchungsfall ,SmartHome ${ }^{6}$ wurden vier Expert"inneninterviews mit insgesamt sechs Personen geführt. Davon sind drei Einzelinterviews und an einem Expert"inneninterview waren drei Mitarbeiter"innen eines städtischen Energieversorgers beteiligt. Zudem wurden sechs Leitfadeninterviews mit sechs SmartHome-Bewohner*innen durchgeführt. 
Darüber hinaus liegen für den Fall ,SmartHome‘ zahlreiche schriftliche Kurzprotokolle der Baubesprechungen vor, zudem die Ergebnisse aus einer quantitativen Befragung zur Nutzer*innenzufriedenheit, die die Genossenschaftsverwaltung durchgeführt hat sowie statistische Daten zu den durch die intelligente Heizungssteuerungstechnologie erzielten Energieund $\mathrm{CO}_{2}$-Einsparungen. ${ }^{70}$

Der Schwerpunkt der Auswertung liegt eindeutig auf den Interviews. Auf anderen Wegen gewonnene Informationen, wie z.B. durch Beobachtungen bei den Interviewpartner*innen zuhause, bei Hausbesichtigungen und Wohnungsrundgängen, bei öffentlichen Veranstaltungen, Besuchen in LivingLabs, usw., wurden zwar nicht systematisch dokumentiert, aber durchaus zur Kontextualisierung des Interviewmaterials herangezogen. Sie wurden bei der Interpretation ausgewählter Interviewpassagen ergänzend verwendet, etwa um Sinnzusammenhänge besser rekonstruieren zu können. Damit erleichterte das aus anderen Zugängen generierte Wissen das Sinnverstehen aus dem Feld heraus.

Die Erfassung soziodemografischer Daten war für die Auswertung der Interviewdaten nicht notwendig.

\subsection{Dokumentarische Methode - konkretes Auswertungsverfahren}

In diesem Teilkapitel werden die zentralen Arbeitsschritte für eine dokumentarische Interpretation von Textmaterial theoretisch vorgestellt, wie sie ursprünglich von Ralf Bohnsack (2014 [1991]: 136ff) erarbeitet und dann von Arnd-Michael Nohl (2017 [2006]) erstmals speziell für die Interpretation von Interviews weiterentwickelt wurden. Im darauffolgenden Teilkapitel gilt es dann zu zeigen, welche dieser Arbeitsschritte auf das eigens generierte Material angewendet wurden und wie sich dies im Einzelnen konkret gestaltete.

Bei der dokumentarischen Interpretation von Interviews handelt es sich um ein dreistufiges Verfahren, wobei jede der drei Stufen noch einmal jeweils zwei Zwischenstufen bzw. Teilschritte umfasst (vgl. tabellarische Übersicht in Nohl 2017: 30).

Wie im Teilkapitel 3.2 zu den theoretischen Grundlagen der dokumentarischen Methode bereits erläutert, ist für die dokumentarische Auswertung die von Mannheim (1980: 85ff) entwickelte "(Leit-)Differenz von kommunikativem bzw. immanentem Sinngehalt auf der einen und kon-

70 Siehe Fußnote 86. 
junktivem bzw. dokumentarischem Sinngehalt auf der anderen Seite“ (Bohnsack 2001: 337) konstitutiv. Diese Unterscheidung wird von Bohnsack in der Forschungspraxis aufgegriffen, indem er zwei Interpretationsschritte klar voneinander trennt: Als erstes erfolgt die thematisch zusammenfassende ,formulierende' Interpretation und im zweiten Schritt dann die ,reflektierende Interpretation ' des herausgearbeiteten Orientierungsrahmens. Besonderes Merkmal der dokumentarischen Methode ist hierbei, dass es sich um ein von Anfang an konsequent vergleichendes Analyseverfahren handelt.

\subsubsection{Die formulierende Interpretation}

Noch vor der Transkription der Interviews beginnt bereits deren formulierende Interpretation. Dafür wird das Tonmaterial von den Forschenden zunächst aufmerksam angehört und thematisch gegliedert. Für jedes Interview wird im ersten Schritt ein so genannter "thematischer Verlauf" (Bohnsack 2014: 137, Hervorh. im Original) erstellt. Dabei werden die markanten Ober- und Unterthemen in der gleichen Reihenfolge, wie sie im Interview auftauchen, in Form von Überschriften oder kurzen Zusammenfassungen schriftlich festgehalten. Diese thematischen Verläufe dienen dem bzw. der Forscher*in vor allem dazu, einen Überblick über die Inhalte und Struktur der Interviews zu erlangen. Darüber hinaus bilden sie die Grundlage für die Auswahl jener Textabschnitte, die tatsächlich transkribiert werden sollen - insbesondere, wenn keine Totaltranskription der Interviews angestrebt wird (vgl. Nohl 2017: 30) -, um die ausgewählten thematischen Abschnitte dann in einem nächsten Schritt im Sinne der formulierenden und reflektierenden Interpretation detailliert zu analysieren.

Beim Vorgehen nach der dokumentarischen Methode werden einzelne Interviews in der Regel nie in Gänze ausgewertet, sondern es werden vorrangig solche Textstellen im erhobenen Material gesucht und zur dokumentarischen Interpretation ausgewählt, in denen sich die subjektiven Relevanzsetzungen der Interviewten besonders deutlich zeigen. In der Regel heben sich solche Passagen auch formal deutlich vom Rest des Textes ab. Bei Gruppendiskussionen spricht Bohnsack in diesem Zusammenhang von „Fokussierungsmetaphern“ (Bohnsack 2011a: 67). Im Vergleich zu anderen Passagen derselben Diskussion bzw. desselben Dialogs zeichnen sich diese Stellen durch eine besondere interaktive und metaphorisch-erzählerische Dichte aus. Dies äußert sich zum Beispiel durch rasche Sprecher*innenwechsel oder gleichzeitiges Sprechen, durch die lange und ausführliche 
Behandlung eines Themas oder durch den Wechsel der bevorzugten Textsorte (z.B., wenn ein*e Sprecher*in vom Argumentieren immer mehr ins Erzählen kommt) (vgl. Przyborski und Wohlrab-Sahr 2013: 293). Auch in (Einzel-)Interviews sind solch fokussierte Stellen zu finden, die in der Regel ein Hinweis darauf sind, dass in ihnen ein übergreifender handlungsleitender ,Orientierungsrahmen' zum Ausdruck kommt (vgl. Loos und Schäffer 2001: 70f). Fokussierte Passagen in Interviews sind meist an detaillierten Erzählungen und Beschreibungen zu erkennen oder daran, dass sich die befragte Person besonders engagiert und metaphorisch zu einem Thema äußert.

Ein zweiter wichtiger Gesichtspunkt für die Auswahl von Textstellen zur detaillierten Auswertung ist die Forschungsfrage. So werden diejenigen Passagen zur dokumentarischen Interpretation ausgewählt, in denen die theoretisch interessierenden Aspekte und Themen behandelt werden Textstellen also, die für die forschungsleitenden Fragen inhaltlich von Bedeutung sind.

Darüber hinaus werden in der Regel noch weitere Interviewausschnitte zur Interpretation ausgewählt. Und zwar solche, die besonders geeignet für einen Vergleich mit Passagen aus anderen Interviews erscheinen, etwa, weil in ihnen Themen gleichermaßen behandelt werden, sich also in unterschiedlichen Fällen ein gleicher impliziter Orientierungsrahmen abzeichnet (vgl. Nohl 2017: 30).

Das heißt, dass bei der Interpretation von Interviews sich an thematischen Einheiten orientiert wird, an Textpassagen, die vom Inhalt her zusammengehören und die durchaus über die Texte verstreut sind. Auf die Sequenzialität von Äußerungen je Interview wird dabei nicht fokussiert, da diese stark durch die Reihenfolge der Fragen beeinflusst wird, die mit einem thematisch strukturierten Gesprächsleitfaden zu einem gewissen Grad vorgegeben ist.

Als nächstes werden die ausgewählten Passagen einer ausführlichen ,formulierenden Feininterpretation' unterzogen. Bei der formulierenden Interpretation ist noch auf der Ebene des immanenten Sinngehalts zu verbleiben. Das heißt, es geht hier zunächst einmal um eine Rekonstruktion der Sachebene. Die Aufgabe besteht vorerst darin, lediglich das zu reformulieren, was tatsächlich in den Interviews zur Sprache kam und von den Beforschten gesagt wurde. Die Paraphrasierung des Gesagten sollte in klar verständlicher Sprache erfolgen, auf sozialwissenschaftliche Begrifflichkeiten ist hier bewusst zu verzichten (vgl. ebd.: 61). Stattdessen sollte sich die Zusammenfassung des Gesagten an den sprachlichen Spezifika der Beforschten orientieren und bei hoher Indexikalität sollte deren Terminolo- 
gie in Form wörtlicher Zitate aufgegriffen werden. Das heißt, von den Beforschten verwendete besondere Ausdrücke oder eigens formulierte Wendungen sind zu übernehmen (- eigene Wortschöpfungen wie z. B. ,Heizungsgene', oder Begriffe wie ,Gewohnheitstier' als Ausdruck für ,routinemäßig handelnder Mensch' können in die formulierende Interpretation aufgenommen werden). Damit ist die formulierende Interpretation auf den in einer Passage kommunikativ explizierten (objektiven) Sinn gerichtet.

\subsubsection{Die reflektierende Interpretation}

Der darauffolgende Schritt der ,reflektierenden Interpretation' (vgl. Bohnsack 2014: 137-141) bildet das eigentliche Kernstück der dokumentarischen Methode, da er auf den dokumentarischen Sinngehalt bzw. Dokumentsinn zielt. Nun geht es nicht mehr um den thematischen Inhalt ausgewählter Passagen, sondern der (Orientierungs-)Rahmen, in dem ein Thema behandelt oder eine Problemstellung bearbeitet wird, ist nun zu rekonstruieren. Statt nach dem ,Was', wird jetzt nach dem ,Wie' des Gesagten gefragt. Im Fokus des Interesses steht nun die Art und Weise, in der ein*e Interviewpartner*in über ein konkretes Thema spricht. Im Rahmen der reflektierenden Interpretation sucht der bzw. die Forscher*in in der Regel folgende Fragen zu beantworten:

„Was zeigt sich hier über den Fall? Welche Bestrebungen und/oder welche Abgrenzungen sind in den Redezügen impliziert? Welches Prinzip, welcher Sinngehalt kann die Grundlage der konkreten Äußerung sein? Welches Prinzip kann mir verschiedene (thematisch) unterschiedliche Äußerungen als Ausdruck desselben ihnen zugrunde liegenden Sinnes verständlich machen?" (Przyborski und Wohlrab-Sahr 2013: 295)

Da die reflektierende Interpretation dem Wie eines Dokuments gewidmet ist, wird in diesem Interpretationsschritt den performatorischen Aspekten der Hervorbringung des Dokuments besondere Beachtung geschenkt. Dies bedeutet für die Analyse von Textdokumenten, dass nun ihre formale Konstruktion und ihre Semantik verstärkt in den Blick genommen werden:

„Die Frage nach der Art und Weise, in der ein Thema bearbeitet wird, verweist gleichermaßen auf den formalen wie auf den semantischen Aspekt von Interviews. Die Semantik des Textes ist von seiner formalen Konstruktion nicht zu trennen, geht es hier doch darum, wie eine 
Praxis oder eine praktische Erfahrung geschildert wird.“ (Nohl 2017: 31)

\section{Formale Interpretation mit Textsortentrennung}

Ursprünglich hat Bohnsack die dokumentarische Methode zur Analyse von Daten aus Gruppendiskussionsverfahren ausgearbeitet (vgl. hierzu Mangold und Bohnsack 1983, 1988, sowie Bohnsack 1989), weshalb sie sich vor allem zur Auswertung dieser Art von Daten eignet. So wird im Rahmen der formalen Interpretation (bei Textprotokollen) von Gruppendiskussionen auf den Diskursverlauf fokussiert - die „Rekonstruktion der Diskursorganisation“ (Bohnsack 2014: 140, Hervorh. im Original) steht hier im Mittelpunkt der formalen Analyse.

Immer häufiger werden nun auch Interviews (biografische, problemzentrierte ebenso wie leitfadengestützte Einzel- und Paar- oder Tandeminterviews) mittels dokumentarischer Methode ausgewertet. Durch eine entscheidende Ergänzung hat Arnd-Michael Nohl (2017 [2006]) das ursprüngliche, von Bohnsack (2014 [1991]: 33-58) entwickelte Auswertungsverfahren der dokumentarischen Methode speziell für die Analyse von Interviewdaten fruchtbar gemacht. Und zwar greift Nohl für die formale Textanalyse im Rahmen der reflektierenden Interpretation zusätzlich die von Fritz Schütze (1987) in der Narrationsstrukturanalyse entwickelte Textsortentrennung auf. Dabei wird zwischen Erzählungen, Beschreibungen sowie Argumentationen und Bewertungen unterschieden (Nohl 2017: 23-24). Erzählungen wird dabei eine besondere Bedeutung beigemessen, da über sie besonders gut - zumindest deutlich besser als über die anderen Textsorten - an die erlebten Erfahrungen des bzw. der Erzähler*in zu gelangen ist. Erzählungen vor allem in Form von kleineren Geschichten oder ausführlichen Situationsbeschreibungen eignen sich demnach besonders für eine Handlungs- und Erfahrungsanalyse. Hierbei ist unerheblich, ob im Interview nach der Biografie gefragt wird oder anhand eines Leitfadens verschiedene Themen behandelt werden, immer geht es vorrangig darum, den befragten Personen „Erzählungen zu deren persönlichen, in ihrer Handlungspraxis fundierten Erfahrungen hervorzulocken“ (ebd.: 16, Hervorh. im Original). Das Ziel narrativ fundierter Interviews besteht also darin, mithilfe von geeigneten Fragen möglichst viele Erzählungen zu generieren.

In ,Erzählungen' geht es in der Regel um konkrete, singuläre Ereignisse. Erzählungen sind daran zu erkennen, dass in ihnen Handlungs- und Geschehensabläufe geschildert werden, die einen Anfang und ein Ende aufweisen, deren Bestandteile in einer klaren zeitlichen Abfolge stehen und 
die Geschehnisse von den Informant"innen auch ihrem tatsächlichen temporalen Verlauf entsprechend dargestellt werden. Typische Formulierungen, die im Rahmen von Erzählungen zur Strukturierung des geschilderten Handlungsgeschehens verwendet werden, sind z.B. ,erst', ,und dann', ,daraufhin', usw. Von Erzählungen wird angenommen, dass sie den erlebten Erfahrungen am nächsten sind, weshalb der Fokus bei der dokumentarischen Interpretation auf Erzählungen gelegt wird (vgl. ebd.: 25f). Begründet wird dies mit den so genannten „Zugzwängen des Erzählens" (Kallmeyer und Schütze 1977). Gerade bei längeren Darstellungen kommt der bzw. die Interviewte nicht umhin, immer mal wieder „etwas zu erläutern, eine ungewöhnliche Handlung argumentativ zu rechtfertigen oder zu bewerten, Hintergründe eines Ereignisses zu schildern oder bestimmte $\mathrm{Zu}$ stände bzw. Räume zu beschreiben“ (Nohl 2017: 25). Das heißt, der bzw. die Erzähler" in ist immer wieder dazu gezwungen, seine bzw. ihre Schilderung zu detaillieren, zu kondensieren und zu komplettieren, also in ihrer Gestalt zu schließen. Aufgrund dieser Zwänge „verstrickt sich der Erzähler in den Rahmen seiner eigenen Erfahrungen und lässt damit in den Erzählungen einen tiefen Einblick in seine Erfahrungsaufschichtung zu" (ebd.).

In ,Beschreibungen“ werden in der Regel „immer wiederkehrende Handlungsabläufe, allgemeine bzw. feststehende Sachverhalte oder typische Ereignisse dargestellt (ebd.: 23). Beschreibungen sind also stärker abstrahierend. Zudem verfügen Beschreibungen über keine eindeutige temporale und kausale Struktur. Typische Worte, die auf Beschreibungen hinweisen, sind z.B. ,immer', ,dauernd', ,öfters', ,gelegentlich', usw. Die erwähnten Zugzwänge kommen auch bei längeren detaillierten Beschreibungen zum Tragen, allerdings in deutlich geringerem Maße als bei Erzählungen. Dennoch kann auch Beschreibungen eine gewisse Nähe zu erlebten Erfahrungen beigemessen werden, was bedeutet, dass ebenfalls Beschreibungen einen Zugang zu den praxisgenerierenden Schemata eröffnen.

Bei ,Argumentationen“ handelt es sich um „(alltags-)theoretische Zusammenfassungen und Stellungnahmen zu den Motiven, Gründen und Bedingungen für eigenes oder fremdes Handeln“ (ebd.: 24). Interviewpartner*innen äußern sich meistens dann argumentierend, wenn sie meinen, dem bzw. der Interviewer*in einen Sachverhalt oder Handlungshintergrund erklären oder sich rechtfertigen zu müssen. Im Zuge dessen erfolgt gelegentlich eine direkte Ansprache des bzw. der Zuhörer"in. Argumentationen orientieren sich an der Gegenwart, das heißt sie beziehen sich immer auf die aktuelle Kommunikationssituation des Interviews und nicht auf in der Vergangenheit Erlebtes. Daher weisen Argumentationen von allen ge- 
nannten Textsorten die geringste Nähe zu vergangenen erlebten Erfahrungen auf.

Bei ,Bewertungen“ handelt es sich um evaluative Stellungnahmen zum eigenen oder fremden Handeln, die oft in Form von Prädikaten oder als kurze Einschübe in Argumentationen eingelassen sind. Das heißt, die häufig in Argumentationen enthaltenen bewertenden Textteile sind demnach ebenfalls der aktuellen Interviewsituation verhaftet und lassen folglich auch keine verlässlichen Rückschlüsse auf vergangene Bewertungen einer erlebten Erfahrung bzw. vollzogenen Handlungspraxis zu (vgl. ebd.).

Wegen ihrer Ferne zum atheoretisch-impliziten Handlungswissen betrachtet die dokumentarische Methode die argumentativen Textsorten eher skeptisch. „Denn während Erzählungen nahe der Erfahrung und erlebten Handlungspraxis liegen - und damit der Artikulation ,atheoretischen Wissens" und ,konjunktiver Erfahrung' dienen -“ (Nohl 2017: 19, Hervorh. im Original), werden die Interviewpartner*innen in den argumentativen Passagen bewusst zur Explikation ihrer Motive, Handlungsgründe und Sicht auf bestimmte Probleme angeregt. Mit anderen Worten: In der Argumentation versucht der bzw. die Befragte sein bzw. ihr Handeln durch Nennung von Motiven und Gründen für Handlungs- und Geschehensabläufe dem bzw. der Interviewer"in gegenüber zu plausibilisieren. Dafür muss der bzw. die Beforschte sich zwangsläufig auf ein gemeinsam geteiltes Wissen beziehen. „Ein solches gesellschaftlich geteiltes Wissen ist notwendiger Weise abstrakt und damit von der Handlungspraxis abgehoben" (Nohl 2005: Kapitel 5.1). Insofern wird verständlich, dass das kommunikative Wissen vor allem mit der Textsorte der Argumentation korrespondiert bzw. argumentative Textstellen beziehen sich immer schon auf das theoretisch-explizite Wissen.

Nohl zufolge lässt sich die Unterscheidung zwischen Argumentationen oder Bewertungen einerseits und den Textsorten der Erzählung und Beschreibung andererseits im Rahmen der dokumentarischen Methode grundlagentheoretisch folgendermaßen fassen:

„Die Erfahrung unmittelbarer Handlungspraxis, wie sie in Erzählungen und Beschreibungen zu rekonstruieren ist, ist derart an diese Handlungspraxis, an das handlungspraktische Wissen und die Selbstverständlichkeiten der Informanten gebunden, dass sie von diesen nicht kommunikativ expliziert, sondern nur erzählt oder beschrieben werden kann. Ein solches praktisches oder ,konjunktives Wissen ${ }^{6}$ (Mannheim 1980) erschließt sich uns nur dann, wenn wir entweder direkt die Handlungspraxis beobachten, oder auf dem Wege von Erzählungen und Beschreibungen zu dieser Handlungspraxis gelangen [...]. 
Die Erzählungen und Beschreibungen im narrativen Interview dienen also dazu, das praktische oder ,konjunktive Wissen' der Interviewten zu erheben." (Nohl 2005: Kapitel 5.1)

Da sich qualitative Sozialforschung in der Regel nicht für das kommunikative, von allen ohnehin geteilte und gewusste Wissen, sondern gerade für das unbekannte konjunktive Wissen interessiert, liegt der Schwerpunkt bei der Interpretation eindeutig auf Erzählungen und Beschreibungen, in denen dieses atheoretische Wissen vorrangig artikuliert wird (Nohl 2017: 34). Nohl betont jedoch, dass dies nicht den Umkehrschluss zulässt, dass die theoretischen Textsorten für die Analyse gänzlich ungeeignet sind. Vielmehr betont er, dass sich auch Argumentationen und Bewertungen dokumentarisch interpretieren lassen und schreibt hierzu:

„Anstatt ihrem wörtlichen Sinngehalt zu folgen, kann man auch die Herstellungs- bzw. Konstruktionsweise der Argumentationen rekonstruieren und auf diese Weise herausarbeiten, wie jemand seine Handlungsweisen rechtfertigt bzw. bewertet. Auch dieser modus operandi des Theoretisierens kann Aufschluss über die Orientierungsrahmen geben, innerhalb derer eine Person ihre Themen und Problemstellungen bearbeitet." (ebd.: 34f, Hervorh. im Original)

Dominiert in Interviews die Textsorte der Argumentation, so kann es sinnvoll sein, den Gesprächscharakter dieser Interviews genauer in den Blick zu nehmen und bei der formalen Interpretation dieser Interviews „die Gesprächsanalyse der Dokumentarischen Methode [...] mitsamt ihren Kategorien für die Bezeichnung der Diskursorganisation (Proposition, Elaboration, Konklusion)“ (Nohl 2017: 35, Fn 5; vgl. hierzu auch Przyborski und Wohlrab-Sahr 2013: 298-302) anzuwenden.

\section{Semantische Interpretation mit komparativer Sequenzanalyse}

Der zweite wichtige Teilschritt innerhalb der reflektierenden Interpretation ist die systematische Analyse der semantischen Gehalte der einzelnen (ausgewählten) Erzählsequenzen sowie deren Vergleich mit Erzählsequenzen aus anderen Interviews, in denen zwar das gleiche Thema behandelt, dieses aber in einem kontrastierenden Orientierungsrahmen bearbeitet wird.

Die Sequenzanalyse ist kein besonderes Spezifikum der dokumentarischen Methode; vielmehr ,stellt [die Sequenzanalyse] für alle neueren qualitativen Methoden ein zentrales, bisweilen das zentrale methodische Prinzip dar“ (Bohnsack 2014: 170, Hervorh. im Original). Im Unterschied zu 
anderen Auswertungsverfahren wird in der dokumentarischen Methode die Sequenzanalyse jedoch konsequent vergleichend betrieben. Das heißt, dass bei der dokumentarischen Interpretation die einzelnen Orientierungsrahmen der Beforschten von Anfang an durch Vergleich mit weiteren empirischen Fällen herausgearbeitet werden. Durch ein ständiges Danebenhalten von anderen Interviewtexten, in denen zur Bearbeitung derselben Problemstellung bzw. desselben Themas andere Orientierungsrahmen zutage treten, wird die Interpretation bzw. die Herausarbeitung eines grundlegenden Orientierungsrahmens erleichtert. Dahinter steckt die Annahme, dass sich ein Orientierungsrahmen erst dann empirisch valide erfassen lässt, wenn er von anderen alternativen Orientierungsrahmen abgegrenzt werden kann (vgl. Nohl 2017: 8). Einerseits stellt solch ein konsequent vergleichendes Vorgehen sicher, dass man als Forscher*in nicht den subjektiven Sinnzuschreibungen der Beforschten aufsitzt. Andererseits dient der ständige Vergleich aber auch der Reflextion und methodischen Kontrolle der Forscher*innenperspektive. Wenn wir nur jedes Interview für sich analysieren würden, könnten und „würden wir [den einzelnen Interviewtext] ausschließlich vor dem Hintergrund unseres eigenen (impliziten und expliziten) Alltagswissens über das jeweilige Thema (unsere eigenen Erfahrungen beispielsweise mit [dem Beheizen von Wohnräumen, JM]) interpretieren. Die Interpretation wäre stark durch die ,Standortgebundenheit ${ }^{6}$ und ,Seinsverbundenheit' (Mannheim 1985) der Interpret(inn)en geprägt" (Nohl 2017: 9, Hervorh. im Original; und siehe auch Teilkapitel $3.2 \mathrm{zu}$ den theoretischen Grundlagen der dokumentarischen Methode). Durch das Danebenhalten von Ausschnitten anderer Interviews, in denen ähnliche oder auch ganz andere Erfahrungen mit derselben Thematik bzw. Problematik zum Ausdruck kommen, wird das Vorwissen des bzw. der Forscher*in zwar nicht komplett ausgeblendet, jedoch methodisch relativiert.

\subsubsection{Sinn- und soziogenetische Typenbildung}

In der dokumentarischen Methode dient die komparative Analyse allerdings nicht nur der methodischen Kontrolle der Interpretation, sondern sie stellt in der dokumentarischen Auswertung zugleich die Grundlage für die Generierung von Typen dar (vgl. Bohnsack 2013, 2014: 143-155). Bei der Typenbildung handelt es sich um die dritte und letzte Stufe der dokumentarischen Analyse. Auch dieser Arbeitsschritt umfasst wiederum zwei aufeinander aufbauende Teilschritte: die sinn- und die soziogenetische Typenbildung. Diese werden im Folgenden nur sehr knapp beschrieben, da 
sie in der vorliegenden Arbeit nur in Ansätzen umgesetzt wurden. Insgesamt geht es bei der Typenbildung der dokumentarischen Methode darum, immer stärker vom Einzelfall zu abstrahieren und elementare, gemeinsame geteilte Erfahrungsbestände sowie allgemeine Strukturen eines impliziten, konjunktiven Wissens zu entdecken, um auf diesem Wege auch zu verallgemeinerbareren Erkenntnissen über den interessierenden Gegenstand zu gelangen (vgl. Nentwig-Gesemann 2013: 295).

Bei der ,sinngenetischen Typenbildung' geht es darum, die wesentlichen Sinn- bzw. Orientierungsmuster (zunächst jeweils innerhalb der einzelnen Fälle) zu identifizieren, die den praktischen Handlungen als Erzeugungsprinzipien zugrunde liegen. Die Herausarbeitung der praxisgenerierenden Schemata ist daher auch als Habitusanalyse zu verstehen (vgl. Bohnsack 2014: 152). Konnte ein Orientierungsrahmen nicht nur in einem Fall (durch fallinternen Vergleich verschiedener Erzählsequenzen) spezifiziert, sondern durch fallexterne bzw. fallübergreifende komparative Analyse in mehreren Fällen identifiziert werden und konnte dieser spezifische Orientierungsrahmen zudem noch von kontrastierenden Orientierungsrahmen, das heißt von anderen handlungsgenerierenden Schemata zur Bearbeitung derselben Aufgaben- oder Problemstellung unterschieden werden, so lässt sich dieser Orientierungsrahmen abstrahieren und zum Typus ausarbeiten (vgl. Nohl 2017: 9). Während die sinngenetische Typenbildung demnach die Erarbeitung einer Basistypik zum Ziel hat, geht es bei der ,soziogenetischen Typik' bzw. Typenbildung darum, die Erfahrungsräume zu rekonstruieren, innerhalb derer bestimmte Orientierungen entstanden sind. In diesem letzten Schritt dokumentarischer Interpretation wird also die Entstehungsgeschichte (Soziogenese) der Orientierungsrahmen systematisch analysiert. Hierbei wird auch untersucht, ob und inwiefern unterschiedliche Typiken miteinander zusammenhängen, „, sodass unterschiedliche Typiken in ihrer Überlagerung, Verschränkung ineinander und wechselseitigen Modifikation sichtbar werden“ (Bohnsack 2014: 154).

Bei der, soziogenetischen Typik handelt es sich demnach um eine mehrdimensionale Typologie, die auf der sinngenetischen Typenbildung aufbaut. Im folgenden Zitat von Iris Nentwig-Gesemann ist noch einmal präzise zusammengefasst, wodurch sich die soziogenetische von der sinngenetischen Typik unterscheidet bzw. inwiefern sie auch noch einmal entscheidend über diese Basistypik hinausgeht:

„Nur durch den Zugang zu ineinander verschachtelten Erfahrungsdimensionen bzw. -räumen eines Falles und durch die komparative Analyse mit den erfahrungsraumgebundenen Orientierungsrahmen anderer Fälle ist es möglich, einzelne Fälle nicht vollständig in einem Ty- 
pus aufgehen zu lassen, sondern Typiken zu generieren, in denen eine Verbindung zwischen Orientierungsrahmen und ihrer Soziogenese transparent gemacht werden kann." (Nentwig-Gesemann 2013: 297, Hervorh. im Original)

Auf Grundlage dieser mehrdimensionalen Typenbildung „lassen sich dann Grenzen und Reichweite einzelner Typiken bestimmen und so generalisierungsfähigere Aussagen treffen" (Nohl 2017: 10).

\subsection{Auswertungsschritte am Material}

Bei der Auswertung des Interviewmaterials wurde sich an den oben dargestellten Arbeitsschritten für die dokumentarische Interpretation von Textmaterial, genauer Interviews orientiert. Bei der Auswertung wurde bewusst auf die Nutzung von Analyse-Software verzichtet, wobei die dokumentarische Methode ohnehin den Einsatz von Datenanalyse-Software nicht vorsieht.

\subsubsection{Zur formulierenden Interpretation}

Die geführten Leitfaden-Interviews wurden alle audiografisch aufgezeichnet und wörtlich transkribiert. Von allen Interviews wurden Totaltranskriptionen angefertigt. Auch Nebengespräche oder Unterbrechungen, z.B. durch Kolleg*innen der interviewten Expert"innen in Großraum- oder Gemeinschaftsbüros, und genauso spontane Gesprächsbeteiligungen von Familienangehörigen, wie z.B. von (Ehe-)Partner*innen oder Kindern, wurden transkribiert, um diese ,Nebengespräche“ und Einwürfe - falls aufschlussreich und für die Beantwortung der Forschungsfrage relevant - später auswerten zu können. Auf eine Feintranskription mit Intonation und genauer Angabe jeglicher Pausenlängen wurde jedoch verzichtet. Für die Transkriptionen wurden weitestgehend die „Richtlinien der Transkription von Texten: TiQ“ befolgt, wie sie in Bohnsack (2014: 253ff) angegeben sind.

Diejenigen Richtlinien bzw. Zeichen, die für das angemessene Verstehen der in Kapitel 4 zitierten Interviewausschnitte relevant sind, sind in der folgenden Übersicht(stabelle) aufgeführt und kurz erläutert: 
Richtlinien der Transkription: TiQ (nach Bohnsack 2014: 253f)

TiQ: Talk in Qualitative Research

\begin{tabular}{|l|l|}
\hline$L$ & Beginn einer Überlappung \\
\hline$\lrcorner$ & Ende einer Überlappung \\
\hline$()$. & Pause bis zu einer Sekunde \\
\hline$(3)$ & Anzahl der Sekunden, die eine Pause dauert \\
\hline$\underline{\text { doch }}$ & betont \\
\hline doch & $\begin{array}{l}\text { laut (in Relation zur üblichen Lautstärke des Sprechers } \\
\text { bzw. der Sprecherin) }\end{array}$ \\
\hline viellei- & Abbruch eines Wortes \\
\hline oh=nee & Wortverschleifung \\
\hline nei::n & $\begin{array}{l}\text { Dehnung, wobei die Häufigkeit vom : der Länge der Deh- } \\
\text { nung entspricht }\end{array}$ \\
\hline $\begin{array}{l}\text { (stöhnt), } \\
\text { (zeigt })\end{array}$ & $\begin{array}{l}\text { Kommentare bzw. Anmerkungen zu parasprachlichen, } \\
\text { nicht verbalen oder gesprächsexternen Ereignissen }\end{array}$ \\
\hline$@ j a @ ~$ & lachend gesprochen \\
\hline$@() @$. & kurzes Auflachen \\
\hline @(3)@ & drei Sekunden Lachen \\
\hline
\end{tabular}

Selbst erstellte tabellarische Übersicht

Im Sinne der qualitativen Sozialforschung und einem praxeologischen (Forschungs-)Verständnis folgend, das empirische Forschung und Theorieentwicklung nicht als separate, streng aufeinanderfolgende, sondern als permanent ineinandergreifende und wechselseitig verschränkte Prozesse ansieht (vgl. Kalthoff et al. 2008), habe ich bereits während der Feld-Erhebungsphase damit begonnen, die Transkripte erster vollständig transkribierter Interviews genau zu lesen und einer ersten Auswertung zu unterziehen.

Die Auswertung des Datenmaterials erfolgte weitestgehend orientiert an den Arbeitsschritten, wie sie von Bohnsack für die dokumentarische Interpretation von Textmaterial erarbeitet worden sind (vgl. Bohnsack 2014: 136ff).

Da für die Auswertung alle Interviews als Totaltranskriptionen vorlagen, wurden die thematischen Verläufe nicht in einem gesonderten Dokument, sondern direkt auf den Transkripten festgehalten. An den jeweiligen Stel- 
len direkt am Rand des Interviewtextes wurden sowohl die im Interview behandelten Themen und Unterthemen (wie z. B. Wohn- und Heizvergangenheit, Behaglichkeit, Kontrollverlust, usw.), als auch eigene Notizen zu ersten Auswertungsideen notiert. Anhand dieser Themenlisten und Notizen wählte ich später für die Forschungsfrage interessante und relevante Textpassagen aus, die im Weiteren einer detaillierten Interpretation unterzogen werden sollten.

Nachdem alle Interviewtranskripte aufmerksam durchgelesen und auf die oben beschriebene Weise ausführlich durchgegangen worden waren, habe ich im nächsten Schritt eine umfassende Tabelle angelegt, in der sukzessiv alle zur Beantwortung der Forschungsfrage interessant und relevant erscheinenden Themen und (Fokussierungs-)Metaphern aus den einzelnen Interviews gesammelt bzw. schriftlich festgehalten wurden. Dabei handelt es sich um Sinn- bzw. Sprachbilder oder Themen, die mir in einzelnen Interviews besonders häufig begegnet oder auch in verschiedenen Interviews (immer wieder) aufgefallen sind und sich deshalb zur detaillierten Analyse eignen (z.B. Metaphern wie ,Sonnenhaus', ,Raumschiff' oder ,Iglu' und Themen wie etwa Kontrolle, Mensch-Umwelt-Beziehung, Umgang mit (technischen) Neuerungen, Übernahme und Weitergabe von Heizpraktiken, Prägung durch die eigene Wohn- und Heizvergangenheit, Bedeutung von Materialität, Gewohnheits- und Routinebildung, usw.).

Diese Auswertungstabelle gliedert sich in drei Spalten, wobei in der mittleren Spalte die zentralen, beide Fallbeispiele bzw. auch die einzelnen Fälle übergreifenden Ober- und Unterthemen sowie wichtige thematische Inhalte, die aus dem gesamten Interviewmaterial herausgearbeitet wurden, festgehalten sind. Die linke Spalte der Tabelle bezieht sich auf den Untersuchungsfall ,Passivhaus' und die rechte Spalte dementsprechend auf den Untersuchungsfall ,SmartHome'. In diesen beiden äußeren Spalten zu den zwei Fallbespielen sind dann immer die im Material entdeckten Ausprägungen und Varianten zum jeweiligen, die Fälle übergreifenden Oberthema notiert - also passende Textstellen und/oder bereits vollständige Zitate sowie konkrete Inhalte aus den einzelnen Interviews entweder zum Heizen im Passivhaus oder im SmartHome.

Die thematischen Verläufe und vor allem die erstellte Thementabelle wurden herangezogen, um die im empirischen Material enthaltenen spannenden ,Fokussierungsmetaphern“ (Bohnsack 2011a) zu identifizieren und relevante Textpassagen für eine detaillierte Interpretation auszuwählen. Anhand der Tabelle wurden die (fünf) ergiebigsten Oberthemen ausgewählt, denen ganze Teilkapitel im empirischen Teil dieser Arbeit gewid- 
met sind bzw. häufig wurden in einem Kapitel auch mehrere Themen miteinander verknüpft (vgl. Kapitel 4).

Für die ausgewählten Interviewpassagen wurden zunächst jeweils eine formulierende und danach eine reflektierende Interpretation angefertigt.

\subsubsection{Zur reflektierenden Interpretation}

Hier wurde der Empfehlung Nohls gefolgt, der bezüglich der reflektierenden Interpretation von Interviews vorschlägt, zunächst die in der interessierenden Passage enthaltenen Textsorten zu bestimmen (vgl. Nohl 2017: 32-35). Hinter der ,Textsortentrennung' steckt die Idee, dass sich auf Basis der bestimmten Textsorten leichter beurteilen lässt, ob sich die in der betrachteten Passage enthaltenen Schilderungen und Äußerungen auf in der Vergangenheit tatsächlich erlebte Erfahrungen beziehen oder ob mit ihnen eher der aktuellen Kommunikationssituation und dem besonderen Gesprächscharakter des Interviews Rechnung getragen wird. Im ersten Fall bestünde die Passage überwiegend aus erzählerischen und beschreibenden Teilen, im zweiten Fall enthielte sie vor allem Argumentationen und Bewertungen. Obwohl bei der Konzeption der Interviewleitfäden bewusst auf erzählgenerierende Fragen geachtet wurde, dominiert in den Interviews eindeutig die Textsorte der Beschreibungen. Dies sehe ich allerdings als unproblematisch an. Vielmehr führe ich dieses Ergebnis auf den typischen Routinecharakter des Heizens zurück. Tätigkeiten, die allgemein unter ,Heizen' gefasst werden, werden im Alltag häufig und immer wieder auf ähnliche Weise vollzogen, wiederholen sich also regelmäßig und unterliegen daher starker Routinisierung. Somit lässt sich dieses Ergebnis als zusätzliche Bestätigung dafür werten, dass eine praxistheoretische Perspektive dem Forschungsgegenstand dieser Untersuchung angemessen ist.

Zur Erschließung des dokumentarischen Sinngehalts der protokollierten Praxis (ausgewählte transkribierte Interviewpassagen) wurde anschließend bei der Interpretation der semantischen Gehalte der einzelnen ausgewählten Passagen sequenzanalytisch vorgegangen. Dafür wurde das thematisch gegliederte Material Sequenz für Sequenz interpretiert und erst danach einer vergleichenden, fallübergreifenden Analyse unterzogen. Hier, ab diesem Stadium geht die Auswertung über die einzelne Texteinheit (Interviewtranskription) hinaus. Jetzt werden Textpassagen aus verschiedenen Interviews gebündelt, in denen das gleiche Thema aufgegriffen und verhandelt wird und die sich aufgrund dessen für einen Vergleich eignen (z.B. der Glaube bzw. ,Mythos‘, dass im Passivhaus die Fenster nicht geöffnet 
werden dürfen, vgl. Kapitel 4.2.4). Ziel hierbei ist die Herausarbeitung von Perspektiven sowie die Rekonstruktion von charakteristischen ,Orientierungen ' - Bohnsack hat dafür die Begriffe, Orientierungsmuster' und ,Orientierungsrahmen' geprägt (Bohnsack 1998) - der Beforschten. Auf diese Weise konnten die persönlichen Erfahrungen, aus denen diese Orientierungen letztlich hervorgegangen sind und die von den Beforschten in ihren Schilderungen meist nur implizit zum Ausdruck gebracht werden, gut herausgearbeitet werden.

Die Arbeit an der umfassenden (Auswertungs-)Tabelle beinhaltete bereits diesen zentralen, vorrangig zur reflektierenden Interpretation gehörenden Schritt des fallinternen wie fallexternen Vergleichs bzw. den Vergleich einzelner Erzählsequenzen aus unterschiedlichen Interviews, in denen dasselbe Thema entweder auf gleiche, ähnliche oder vollkommen unterschiedliche Weise behandelt wird. Dadurch können grundlegende Orientierungsrahmen identifiziert und voneinander abgegrenzt werden.

\subsubsection{Modifizierter Abschluss der dokumentarischen Interpretation}

Als nächsten Schritt der dokumentarischen Auswertung ist von Bohnsack eigentlich eine umfassende Beschreibung der einzelnen Fälle vorgesehen. Hierzu schreibt er:

„In der Fallbeschreibung wird die Gesamtgestalt des Falles zusammenfassend charakterisiert. Die Fallbeschreibung hat primär die Aufgabe der vermittelnden Darstellung, Zusammenfassung und Verdichtung der Ergebnisse im Zuge ihrer Veröffentlichung. Soweit es sich um die Analyse von Gruppendiskussionen handelt, ist [...] auch von ,Diskursbeschreibung' die Rede." (Bohnsack 2014: 141; und vgl. u.a. auch Bohnsack 1989)

Übertragen auf die für diese Untersuchung geführten Interviews bestünden die einzelnen Falldarstellungen - neben einer kurzen Vorstellung bzw. Einführung der jeweils interviewten Person anhand der gebräuchlichen sozio-demografischen Merkmale - demnach in einer ausführlichen chronologischen Darstellung der persönlichen „Heiz-Biografie“ der Beforschten. Auf diesen Zwischenschritt dokumentarischer Auswertung wurde in dieser Arbeit allerdings bewusst vollständig verzichtet. Das zentrale Argument hierfür ist, dass sich in dieser Arbeit für eine praxistheoretische Betrachtung der Alltagsaktivität ,Heizen' in Privathaushalten entschieden wurde. Der Fokus liegt demzufolge auf den tatsächlich in Vergangenheit 
und Gegenwart performten Heizpraktiken. In dieser Perspektive werden sich heizend betätigende Personen neben Gegenständen als Träger"innen bzw. Speichermedien von Heizpraktiken betrachtet. Das bedeutet, dass für die Auswertung in der Tat nicht sonderlich wichtig ist, wer im Einzelnen geheizt hat bzw. heizt. Von zentralem Interesse ist vielmehr die konkrete Heizpraxis, also wie geheizt wird und welche Erfahrungen die Befragten mit dem Heizen gemacht haben, die sich auch körperlich eingespeichert haben. Bei der Analyse des Datenmaterials wurde deshalb nicht vorrangig von den heizenden Personen ausgegangen, sondern ich habe mich in der Auswertung an den für jedwede Praktik zentralen Kategorien (Materialien - wozu auch die menschlichen Körper zählen, Kompetenzen/Wissen und Bedeutungen) sowie den dazugehörigen, aber konkret aus dem empirischen Material hervorgehenden spezifischen Aspekten und Themen orientiert. Von diesen für Heizen spezifischen Aspekten und konkret relevanten Themen - wie etwa der Heizkörper als zentrales materielles Artefakt oder Lüften als mit dem Heizen unmittelbar verknüpfte Aktivität oder das Kontrollerleben im Zusammenhang mit Heizen - ausgehend, wurde gesucht, bei welchen ,Fällen' das jeweilige Thema auf ähnliche oder ganz andere Art und Weise verarbeitet wird, um daraufhin zu entscheiden, welche (weiteren) ,Fälle` bzw. Passagen aus weiteren Interviews jeweils vertiefend analysiert werden sollen. Das heißt, für die Analyse waren die einzelnen Personen und ihre persönlichen Heiz-Geschichten nur insoweit von Interesse, als dass ihre individuellen Merkmale und Eigenschaften sowie ihre geschilderten persönlichen Lebensereignisse und Erfahrungen in offenkundigem Zusammenhang mit dem gerade im Fokus stehenden Aspekt ihrer Heizpraxis standen. Dieses Vorgehen sei an einem Beispiel verdeutlicht: Beim Thema ,Behaglichkeitserleben' ist es für das Verstehen der Fallgeschichte Frau Köhlers (vgl. Teilkapitel 4.3.1) interessant wie hilfreich, miteinzubeziehen, dass Frau Köhler mittlerweile komplett erblindet ist. Dies wirkt sich zum einen dahingehend auf Frau Köhlers Behaglichkeitserleben im Passivhaus aus, dass sie die Abschirmung aller Geräusche von außen besonders deutlich registriert, da sie, wie sie selbst sagt, „als Blinde sehr viel auf Geräusche orientiert [lebt]" (Bewohnerin PH, Interview 60: 9, 448-449). Diese für Frau Köhler wichtige Orientierungsquelle fällt im Passivhaus nun weg bzw. sie fällt deutlich anders aus, so dass vor diesem Hintergrund verständlich wird, dass Frau Köhler die Geräuscharmut im Passivhaus, vor allem aber das Fehlen natürlicher Außengeräusche (z.B. Vogelgezwitscher, Blätterrauschen, Lärm draußen spielender Kinder) eher nachteilig empfindet. Darüber hinaus hatte Frau Köhlers Wissen um ihre fortschreitende Erblindung zur Folge, dass die Heiztechnik für ihre Passiv- 
hauswohnung von Anfang an anders als in den sonstigen Wohnungen des Mehrfamilienhauses geplant wurde: Bei Frau Köhler wurden von Beginn an Heizkörper in allen Wohnräumen zum Dazuheizen eingebaut. Da Frau Köhler als Blinde weder Licht benötigt, noch Kerzen anzündet oder fernsieht, stand von vornherein fest, dass in ihrem Fall viele gängige und für die Wärmebilanz im Inneren des Passivhauses normalerweise wichtige passive Wärmequellen wegfallen. Somit wusste man schon vorab, dass sie dafür an kalten Wintertagen definitiv einen Ausgleich in Form zusätzlicher Wärmequellen, respektive Heizkörpern benötigen würde, weshalb man diese gleich von Anfang an installierte.

Wird bei der Analyse stringent nach der dokumentarischen Methode vorgegangen, so findet im Anschluss an die umfangreichen Falldarstellungen normalerweise - wie im vorherigen Teilkapitel 3.10 beschrieben - erst eine sinngenetische und darauffolgend eine soziogenetische Typenbildung statt. Da diese Arbeit jedoch nicht zum Ziel hat, eine Typik von Heizpraktiken in alten und neuen bzw. abgewandelten Wohnkontexten zu erstellen, wurde auch auf die vollständige Umsetzung dieses letzten Arbeitsschritts dokumentarischer Interpretation verzichtet.

In dieser Arbeit geht es zunächst einmal darum, ein möglichst breites Spektrum an Aspekten und Themen aufzuzeigen - es lässt sich hier auch von grundlegenden Dynamiken oder Wandlungstendenzen sprechen -, die beim Übergang von Heizen in konventionellen Wohnkontexten zu Heizen im Passivhaus und im SmartHome eine zentrale Rolle spielen. In einem zweiten Schritt sollen dann jeweils verschiedene Varianten eines Themas bzw. Varianten der Veränderung im Erleben und Handeln - im Sinne von unterschiedlichen Orientierungen - beim Übergang von konventionellen Wohnkontexten zum Passivhaus und SmartHome sichtbar gemacht werden. Diese unterschiedlichen Varianten eines Themas bzw. eines Veränderungsprozesses werden kontrastierend analysiert, um die unterschiedlichen Bearbeitungsweisen derselben Problemstellung möglichst präzise und umfassend herauszuarbeiten. Allerdings wurden diese Vergleiche themen- bzw. problemstellungsbezogen durchgeführt und nicht streng systematisch und erschöpfend umgesetzt. Darüber hinaus wurden die herausgearbeiteten Orientierungen hinsichtlich eines Themas oder einer Problemstellung aus den oben bereits aufgezählten Gründen nicht detailliert an die persönlichen Heiz-Biografien der Befragten rückgebunden. Dieses leicht verkürzte Vorgehen, insbesondere die nur oberflächliche Analyse und Miteinbeziehung der persönlichen Heiz-Geschichten hat unter anderem den Vorteil, dass eine deutlich größere Menge an Datenmaterial empirisch analysiert werden konnte, als bei Auswertungen mittels dokumenta- 
rischer Methode im Allgemeinen sonst üblich ist. Zudem unterstreicht dieses Vorgehen noch einmal die beabsichtigte Fokussierung auf die tatsächlich vollzogene bzw. erlebte Handlungspraxis und macht somit ebenfalls erneut deutlich, dass es in dieser Arbeit um das (bessere) Verstehen einer sozialen und damit vom Einzelfall losgelösten Praxis geht. 


\section{Wandlungsdynamiken im alltäglichen Heizen}

Ausgangspunkt dieser Arbeit ist die (aus der theoretischen Literatur zu sozialen Praktiken abgeleitete) Annahme, dass die Konfrontation und der Umgang mit neuer Heiztechnik zu mehr oder minder gravierenden Veränderungen in der alltäglichen Heizpraxis führen. Wie bereits in Teilkapitel 2.3.2.1 zu den Ausgangspunkten für Wandel beschrieben, zählen Kontextveränderungen, nicht nur radikale wie der Wechsel des gesamten Handlungssettings (Umzug), sondern auch kleinere Veränderungen und Interventionen wie das Aufkommen eines neuen Artefakts, zu den Hauptquellen, aus denen Wandel von Praktiken resultiert (vgl. Reckwitz 2003: 295).

Allerdings zieht, wie im Folgenden noch zu zeigen sein wird, eine radikale Abwandlung des Kontextes - der Umzug von einer unsanierten Altbauwohnung in ein neu gebautes Passivhaus stellt zweifelsohne solch eine fundamentale Veränderung dar - nicht zwangsläufig eine drastische Veränderung im alltäglichen Heizen nach sich. Vielmehr sind gerade in den Heizperformances der Bewohner*innen, die solch einen drastischen Wechsel vom (unsanierten) Altbau zum Passivhaus vollzogen haben, auch deutliche Kontinuitäten zu entdecken. Umgekehrt kann eine deutlich weniger invasive Veränderungsmaßnahme, wie die Einführung einer neuen smarten Heizungssteuerungstechnik, die bisherige Heizroutine gravierend stören und demzufolge deutliche Anpassungen oder Umstellungen in der alltäglichen Heizpraxis bewirken. Das heißt, Wandel und Kontinuität sind als zwei Seiten einer Medaille zu betrachten und gehören bei einer umfassenden Analyse des Heizens in abgewandelten Wohnkontexten somit beide gleichermaßen untersucht.

In diesem Kapitel geht es nun um die Rekonstruktion der zentralen sozialen Sinnmuster anhand derer alltägliches Heizen orientiert ist sowie deren Entwicklungen infolge der hier untersuchten Kontextabwandlungen (Wechsel in einen komplett neuer Wohn- und Heizkontext und Hereingabe neuer Heiztechnik in bestehenden Wohnkontext). Je nachdem, inwieweit die Kontextveränderungen die das alltägliche Heizen leitenden Orientierungen tangieren, hat dies unmittelbar Einfluss auf die alltäglich ausgeübte Heizpraxis der Bewohner*innen. Denn solche Veränderungen schlagen sich normalerweise als erstes erkennbar in den alltäglichen Praktikenperformances nieder. Wie bereits im theoretischen Teil dieser Arbeit aufgezeigt wurde, stehen die konkreten Performances einer Praktik und die ab- 
strakt-theoretische Vorstellung derselben Praktik, die Praktik-als-Einheit, in einem rekursiven Verhältnis (vgl. Teilkapitel 2.3.2). Das heißt, in der Regel sind Veränderungen zuerst in den Performances zu beobachten. Sind diese Modifikationen von Dauer und bleiben bestehen, so wirkt sich dies auch auf das grundlegende Bild und die allgemeine Definition der betreffenden Praktik aus. Auf diese Weise kommt es allmählich zu einem Wandel des grundsätzlichen Praktikverständnisses (z.B. des Heizens), was wiederum Auswirkungen auf die konkrete Handlungspraxis der sich regelmäßig heizend betätigenden Akteure hat usw.

Inwiefern die im Folgenden beschriebenen Änderungen in den Heizperformances tatsächlich alle nachhaltig (im Sinne von stabil und dauerhaft) sind und dazu beitragen, dass sich etwas Grundsätzliches am Heizen verändert, lässt sich an dieser Stelle noch nicht abschließend beurteilen. Dies wird sich erst im Laufe der Jahre zeigen und vor allem daran abzulesen sein, mit welchem Erfolg und in welcher Geschwindigkeit sich Passivhäuser und die intelligente Heizungssteuerungstechnik in nächster Zeit weiterverbreiten, in welchem Umfang diese zwei neuen Heizansätze also tatsächlich praktiziert werden.

Um ein möglichst umfassendes Bild vom Wandel alltäglicher Heizpraktiken zu erhalten, wird ihre Entwicklungsdynamik aus verschiedenen Blickwinkeln beleuchtet. Dabei geht es nicht darum, was aus Sicht der Akteure die gesellschaftliche oder ihre persönliche Realität ist, sondern es gilt aufzuzeigen, wie diese Realität in der Praxis von ihnen erzeugt wird. Und hier „ist sowohl die Praxis des Handelns wie diejenige des Sprechens, Darstellens und Argumentierens [gemeint]" (Bohnsack et al. 2013: 13). Ziel ist es, die wichtigsten empirisch vorgefundenen Dynamiken und Wandlungsprozesse, wie sie sich für die Beforschten im alltäglichen Heizen in den neuen bzw. abgewandelten Wohnkontexten ereignet haben, anschaulich und in all ihren Facetten darzustellen. Statt des üblichen Vorgehens in der Analyse primär von den beforschten Personen sowie ihren persönlichen Heizbiografien auszugehen und diese als einzelne Fälle umfassend zu analysieren und zu präsentieren, ist das hier gewählte Verfahren folgendes: Der Fokus der Analyse liegt auf den konkreten Heizpraktikenperformances, sowohl in ihrer elementhaften Zusammensetzung als auch sinnhaften Integration. Das heißt, es wurde vorrangig nach wichtigen Themen und relevanten Dynamiken beim Übergang von konventionellem Heizen zum Heizen im Passivhaus und SmartHome geforscht. Anhand der im Zusammenhang mit Heizen zentralen Themen wurden die passenden einzelnen Fälle bzw. Fallgeschichten ausgewählt, die letztendlich in den verschiedenen Teilkapiteln dieses gesamten Analyseteils detailliert präsentiert werden. 
Demnach erfolgte nicht nur die Auswertung des empirischen Materials anhand von Themen, sondern die aus dem Material herausgearbeiteten zentralen Themen dienten ebenfalls zur Gliederung des gesamten Auswertungskapitels - sie wurden also verwendet, um das zu präsentierende Material zu strukturieren (vgl. Teilkapitel 3.11.3) Zusammengefasst heißt das: Die zentralen Ergebnisse dieser Untersuchung werden nicht fallspezifisch, weder stringent getrennt nach Passivhaus und SmartHome, noch durchgängig sortiert nach erforschten Personen, sondern themenbezogen und damit überwiegend fallübergreifend dargestellt.

Im Folgenden sollen kleine und größere Wandlungs- und Stetigkeits-Geschichten von Heizaktivitäten aus den Perspektiven der unterschiedlichen, in privates Wohnraumheizen involvierten Akteure geschildert werden. Dafür wurde sich für die verschiedenen Einzelfalldarstellungen zu den zentralen Themen in einigen ausgewählten Punkten an den formalen Merkmalen der Textform ,Kurzgeschichte' orientiert: So erfolgt meistens ein recht unmittelbarer Einstieg ins Geschehen. Weder werden die handelnden Charaktere umfassend vorgestellt, noch wird ausführlich auf ihre aktuelle Lebenssituation eingegangen. In der Regel erfährt der bzw. die Leser“in nur sehr wenig über die handelnden Personen; vielmehr erhält die Leserschaft jeweils nur die kontext- und personenbezogenen Informationen, die notwendig sind, um die dargestellten Geschehnisse sowie die daran anschließenden Interpretationen gut nachvollziehen zu können. Bei den in diesem Kapitel geschilderten Ereignissen oder Situationen handelt es sich um Ausschnitte aus dem Alltagsleben der Erforschten. Die beschriebenen Umstände sind demnach nicht ungewöhnlich, sondern dem alltäglichen (Privatoder Berufs-)Leben der Interviewpartner“innen entnommen. Zudem werden die thematisch relevanten Ereignisse meist in äußerst komprimierter Form dargestellt und in jeder Fallgeschichte steht in der Regel immer nur ein, dafür aber ein sehr zentraler Aspekt oder Sachverhalt (des Heizens) oder nur ein besonderes Ereignis, das mit moderner Heiztechnik in $\mathrm{Zu}$ sammenhang steht, im Mittelpunkt der jeweiligen (Fall-)Geschichte. In den einzelnen kurzen Fallgeschichten oder dargestellten Alltagsausschnitten geht es nie nur um die konkrete Person oder die Personen, über die gerade geschrieben wird bzw. von denen die jeweilige Geschichte gerade handelt, sondern es geht immer um die Lebensumstände und das Handeln der Menschen im Allgemeinen. Damit wird dem Ziel qualitativer Sozialforschung, vom Einzelfall zu abstrahieren und zu verallgemeinerbaren Ergebnissen zu gelangen, Rechnung getragen. Diese Art der Darstellung kurze Fallgeschichten bzw. -episoden - wurde gewählt, um die Ergebnispräsentation für die Leserschaft ansprechend zu gestalten und dennoch über- 
schaubar zu halten. Zudem lässt sich mit dem Darstellungsformat der Kurzgeschichte der typische Prozesscharakter von Kontinuitäten und Veränderungsdynamiken im Heizen besonders gut einfangen und abbilden.

Die beiden Untersuchungsfälle Heizen im Passivhaus und Heizen mittels smarter Heizungssteuerungstechnik werden nicht separat analysiert, um dann am Ende die Ergebnisse aus beiden Fällen systematisch miteinander zu vergleichen, trotzdem findet aber ein Fallvergleich statt. Dieser wurde direkt von Anfang an in die Analyse miteinbezogen. Dem Postulat der dokumentarischen Methode folgend, dass bei der reflektierenden Interpretation konsequent vergleichend zu verfahren ist, um auf diesem Wege die Spezifika des Einzelfalles besonders pointiert herauszuarbeiten, wurden einzelne handlungsleitende Orientierungen in Abgrenzung zu anderen kontrastierenden Orientierungsrahmen, die der Behandlung desselben Themas dienen, rekonstruiert (vgl. Teilkapitel 3.10). Hierbei war unerheblich, ob die jeweiligen Beispiele dem Passivhaus- oder dem SmartHomeFall entnommen sind, ob sich die Akteure in ihrem Handeln also auf den Wohnkontext Passivhaus oder SmartHome beziehen. Vielmehr wurde primär nach interessanten und für das jeweilige Thema relevanten, das heißt tatsächlich handlungsleitenden Orientierungen gesucht. Wurden dabei geeignete Textpassagen sowohl in den Erfahrungsberichten der Passivhausals auch in denen der SmartHome-Bewohner*innen entdeckt, so wurde dies als Beleg dafür gewertet, dass diese Themen und Problemstellungen in Bezug auf Heizen generell eine zentrale Rolle spielen, unabhängig davon, $\mathrm{ob}$ in einem Passivhaus oder in einem SmartHome geheizt wird. Das heißt, wenn interessante Passagen zu einem Thema in Interviewtexten zu beiden Fallbeispielen auffindbar waren, dann wurde der Fallvergleich gleich automatisch in die Analyse mitaufgenommen. Je nachdem in welcher Reihenfolge die einzelnen kurzen Fallgeschichten zu den übergeordneten Themen präsentiert werden, sind die fallübergreifenden komparativen Analysen zum Teil bereits direkt in die Falldarstellungen mit eingeflossen. Dies hat zur Folge, dass schon in den Kurzbeschreibungen der Fälle, besser gesagt in den kurzen Beschreibungen der Alltagsausschnitte und Situationen, Gemeinsamkeiten und Unterschiede aufgezeigt werden (können), womit wiederum bereits von fall- und personenspezifischen Orientierungen abstrahiert wird (vgl. Bohnsack 2013: 251).

Das Heizen besteht wie jede Praktik immer aus mehreren verschiedenen Elementen, die sich den drei übergeordneten Kategorien Materialien/ Dinge, Kompetenzen/Wissen und Bedeutungen zuordnen lassen (vgl. Kapitel 2.1.5). Bei der Analyse einzelner Heizperformances wurde diese praxistheoretische Grundannahme stets beachtet. Die Elemente wurden im- 
mer zusammen, in ihrer jeweiligen Zusammensetzung und spezifischen Verknüpfung betrachtet, es wurde keine künstliche Trennung vorgenommen.

Für den Aufbau und die Strukturierung der einzelnen Kapitel wurde aus analysepragmatischen Gründen jedoch entschieden, einzelne Kategorien oder sogar nur einzelne Elemente aus den drei Kategorien in den Mittelpunkt der Analyse zu stellen. Dabei wurden vor allem diejenigen Themen und Details tiefergehend erforscht, die sich für die Interviewpartner*innen als elementar wichtig im Zusammenhang mit ihrer alltäglichen Heizpraxis erwiesen haben.

Zur Verdeutlichung dieses Vorgehens wird dem bzw. der Leser"in an dieser Stelle ein kurzer Überblick gegeben, welche Themen und Inhalte ihn bzw. sie in den folgenden fünf Teilkapiteln erwarten: Für das erste Teilkapitel wurde als Aufhänger der Heizkörper gewählt. In fast allen Interviews wurde deutlich, dass die allermeisten Interviewpartner*innen den materiellen Gegenstand ,Heizkörper ${ }^{`}$ als Inbegriff (Versinnbildlichung) des Heizens verstehen. Insgesamt werden im Rahmen dieses Teilkapitels acht (Fall-)Geschichten von unterschiedlicher Länge geschildert, die sich alle um den Heizkörper drehen und auf unterschiedliche Weise die prägende Kraft vergangener Heizerfahrungen für die gegenwärtige Heizpraxis verdeutlichen. Anhand der unterschiedlichen Entwicklungen des Heizkörpers im Übergang des Heizens in konventionellen Wohnkontexten zum Heizen im Passivhaus und SmartHome wird zudem die tiefe Einbettung alltäglichen Heizens in ein Netz sozialer Praktiken erkennbar und es wird deutlich, wie viele Lebensbereiche von der Entscheidung über eine neue Heizlösung und die Nutzung neuer Heiztechnik tatsächlich berührt sind.

Im zweiten Teilkapitel geht es um die (neuerdings wieder enger gewordene) Beziehung von Heizen und Lüften. Während Heizen und Lüften in konventionellen Wohnkontexten noch als zwei relativ eigenständige Aktivitäten aufgefasst werden können, sind sie im Passivhaus so eng miteinander verknüpft, dass sie einen hybriden Vorgang darstellen. Demnach hat sich für die interviewten Passivhausbewohner*innen mit ihrem Einzug ins Passivhaus nicht nur das Heizen verändert, sondern auch die alltägliche Lüftungspraxis ist von diesem Wechsel wesentlich betroffen. Die hier vorgestellten Fälle zeigen, dass es für die Analyse von diesbezüglichen Veränderungsprozessen hilfreich ist, grundsätzlich zwischen Routine- und Gewohnheitsbildung zu differenzieren, da, wie in Teilkapitel 2.1.4.1 dargelegt, die beiden repetitiven Handlungsmuster auf unterschiedlichen Arten von Wissen basieren und infolgedessen auch auf unterschiedlichem Wege zustande kommen. Zwar nicht im selben Ausmaß wie beim Passivhaus, 
aber auch nicht unbeträchtlich, wird im Fall des SmartHomes der Lüftungsvorgang von der neuen Heizungssteuerungstechnik tangiert. Der hierzu präsentierte Fall zeigt darüber hinaus, mit welchen anderen Aktivitäten das Lüften (und damit indirekt auch das Heizen) noch verknüpft sein können.

Das dritte Teilkapitel widmet sich den Veränderungen im Behaglichkeits- und Komforterleben, die sich beim Übergang von konventionellen Wohnkontexten zum Passivhaus und SmartHome ereignen. Während die hier zur Darstellung ausgewählten Fälle bzw. kurzen Fallgeschichten verdeutlichen, dass für den Passivhaus-Fall fast ausschließlich eine Orientierung an Behaglichkeit erfolgt und dabei von den Bewohner*innen vorrangig die Frage diskutiert wird, was sie im Zusammenhang mit Heizen persönlich als behaglich empfinden, spielen im Fall des SmartHomes die Themen ,Behaglichkeit' und ,Komfort' insgesamt eine deutlich geringere Rolle. Wenn überhaupt, geht es für die SmartHome-Bewohner"innen eher um Komfort als um Behaglichkeit, wobei sie auch ,Komfort' nicht vorrangig mit dem thermischen Raumklima assoziieren, sondern allgemein, eher im Sinne von ,Bequemlichkeit' verstehen.

Das vierte Teilkapitel handelt von Veränderungen im Kontrollerleben im Übergang von konventionellen Wohnkontexten zum Passivhaus und SmartHome. Bei den Themen ,Kontrolle und ,Kontrollverlust ${ }^{\natural}$ wird eine große Diskrepanz zwischen den interviewten Personengruppen deutlich: Während das Thema ,Kontrollverlust ' in den Interviews mit Expert"innen praktisch kaum eine Rolle spielte und die neuen Heiztechnologien hier relativ einseitig, nämlich nur positiv dargestellt wurden, brachten die Bewohner*innen in den Interviews überwiegend ihre Ängste vor einer zunehmenden Technikabhängigkeit sowie ihre negativen Gefühle von bereits erfahrenen Kontrollverlusten durch die Einführung weitgehend autonomer Technik zum Ausdruck. Im Passivhaus beziehen sich die Ängste und Kontrollverlustgefühle der Bewohner*innen vorrangig auf die (eingeschränkten bzw. zeitverzögerten) Regulierungsmöglichkeiten der Raumtemperaturen und für die SmartHome-Bewohner*innen steht vor allem die Frage, wie der Technikanbieter mit ihren persönlichen Heiz-Daten umgeht, im Vordergrund.

Im fünften Teilkapitel werden die wichtigsten Wege beschrieben, wie die Praktiken des passiven und des smarten Heizens erfolgreich neue Anhänger*innen für sich gewinnen. Hierfür wird ein Perspektivwechsel vorgenommen, der helfen soll, festgefahrene Verstehensgewohnheiten aufzubrechen. Statt aus Sicht der handelnden Akteure, wird das alltägliche Heizgeschehen diesmal aus der Perspektive der Praktiken analysiert. Anhand 
von acht Fallgeschichten werden unterschiedliche Wege beschrieben, wie es den zwei neuartigen Heizansätzen bisher gelungen ist und weiterhin gelingen kann, sich erfolgreich zu verbreiten.

\subsection{Die prägende Kraft der Vergangenheit - am Beispiel von Entwicklungen rund um den Heizkörper}

Dieses Kapitel handelt von Gewöhnungsprozessen, die sich beim Wohnraumheizen in Passivhäusern und SmartHomes ereignen. In diesem Kapitel werden unterschiedliche Arten und Weisen einer fortschreitenden Anpassung an die veränderten Wohnkontexte aufgezeigt. Die zentrale These ist, dass aktuelle Heizpraktiken entscheidend durch die zum Teil sehr verschiedenartigen Wohn- und Heizvergangenheiten der Praktizierenden geprägt sind. Es wird gezeigt, dass sich die Wohnsituation der Praktizierenden vor Einzug ins Passivhaus bzw. vor Einbau der intelligenten Regelungstechnik und die in diesen vorherigen Kontexten meist über viele Jahre gesammelten Erfahrungen im Heizen erkennbar auf die neue, noch ungewohnte Heizpraxis auswirken. Der Einfluss der Heizvergangenheit auf die gegenwärtige Praxis wird vor allem daran deutlich, dass nach dem Wechsel zum Passivhaus bzw. intelligenten Heizen zunächst häufig an alten, gewohnten Handlungs- und Deutungsweisen festgehalten wird. Indem altbekannte Wissens- und Praxiselemente unverändert auf bzw. in den neuen Kontext übertragen werden, setzen sich bestimmte Routinen im Heizen fort. So soll mit den in diesem Kapitel präsentierten Fallgeschichten verdeutlicht werden, dass die einzelnen Heizpraktikenperformances Teil eines schon lange andauernden kontinuierlichen Aktivitätenstroms sind und sequenziell aufeinanderfolgen. Das heißt, die Heizperformances entfalten sich nicht vollkommen losgelöst, sondern sie knüpfen an vergangene Vollzüge an, enthalten immer auch alte Komponenten und aktualisieren dadurch die in sie eingegangene Geschichte. Zugleich wird dadurch zukünftiges Heizen präformiert. Mit der Zeit, durch zunehmende Kenntnis und Einübung des Heizens im gewandelten Handlungsumfeld, findet eine sukzessive Gewöhnung statt und dementsprechend wandelt sich die alltägliche Heizpraxis.

Wie in Teilkapitel 2.1.4.4 zur besonderen Bedeutung von ,Materialität ${ }^{6}$ dargelegt, gelten aus praxistheoretischer Perspektive nicht nur Subjekte als körperlich-mentale Speicher von praktischem (Heiz-)Wissen - in Form des Habitus' tragen die Beforschten einen großen Erfahrungsschatz in sich, haben sie Heizgeschichte gewissermaßen inkorporiert -, sondern auch mate- 
rielle Artefakte stellen wichtige Wissensträger dar. Heizpraktiken werden genauso stark durch die in sie involvierten Technologien und Gegenstände geprägt, wie durch die sich jeweils heizend engagierenden Subjekte. Bei materiellen Artefakten handelt es sich nicht um neutrale, für sich stehende Dinge, die in Praktiken lediglich angewendet werden; vielmehr enthalten die Gegenstände oftmals eigene ,Drehbücher', die in die Vollzüge miteingehen und dadurch die Praktiken entschieden mitgestalten:

„Technologies are 'scripted' in that they embody a certain way of knowledge and moral judgement, which leads to new reciprocal dispositions between people and things, and indeed 'new forms of knowledge about the world'." (Akrich 1992: 207, zitiert nach Sahakian und Wilhite 2014: 29)

Im Laufe dieses Kapitels werden verschiedene Varianten des Übergangs von konventionellem Heizen zum Heizen im Passivhaus und SmartHome beschrieben. Dabei wird in der Darstellung auf den Gegenstand des Heizkörpers fokussiert. Das heißt, es werden in erster Linie solche Gewöhnungsverläufe im Heizgeschehen geschildert, die wesentlich mit dem Heizkörper in Zusammenhang stehen. In den Gesprächen mit Passivhausund SmartHome-Bewohner*innen wurde deutlich, dass der Heizkörper als Inbegriff des Wohnraumheizens gesehen wird. Dies ist nicht verwunderlich, bleibt doch der größte Teil der Heiztechnik dem täglichen Anblick der Bewohner"innen verborgen: In den meisten Haushalten stehen der Heizkessel sowie der Öl- oder Gastank in einem gesonderten Kellerraum und befinden sich die Heizungsrohre zur wassergeführten Wärmeverteilung größtenteils versteckt hinter den Zimmerwänden. Lediglich die in den einzelnen Wohnräumen aufgestellten Heizkörper sind für die Bewohner*innen ständig sichtbar. Als einziges im Alltag deutlich wahrnehmbares materielles Artefakt steht der Heizkörper daher stellvertretend für das ganze Heizungssystem, verkörpert er Heizen in den Augen der Bewohner*innen wie nichts anderes. Dementsprechend kreisen die meisten Erzählungen und Berichte vom alltäglichen Heizen um diese offensichtliche Wärmequelle. Um Veränderungen im Heizen nachzuvollziehen, erscheint es daher aufschlussreich, sich eingehend mit demjenigen Artefakt zu beschäftigen, das von vielen interviewten Bewohner*innen mit Heizen in Verbindung gebracht und dementsprechend früh im Interview thematisiert wird. Daher werden in diesem Kapitel vorrangig solche Gewöhnungsprozesse dargestellt, die sich wesentlich um den Heizkörper drehen. Welche Änderungen nehmen hier ihren Ausgang? Und wie wandelt sich Heizen, wenn sich etwas am Heizkörper verändert oder er sogar ganz, verschwindet'? 
Folgende Punkte haben sich hierbei als relevant herausgestellt:

1. Die Bedeutung der persönlichen Wohn- und Heizvergangenheit für die gegenwärtige Heizpraxis

2. Die unterschiedliche Bedeutungszuschreibung für Heizkörper: a) als Absicherung, b) als direkte und dadurch besonders angenehme Wärmequellen, c) als flexibel aufstellbare Gegenstände der Raummöblierung oder d) als wichtiges oder als verzichtbares zusätzliches ,Komfortmerkmal

3. Die Abhängigkeit der Bewertung neuer Heizlösungen vom vorherigen Informations- und Wissensstand und der (davon abgeleiteten) vorab ausgebildeten Erwartungshaltung bei (Neu-)Bewohner*innen

4. Das Praxislernen bzw. das Lernen durch Erfahrung auf Expert*innenseite beim Passivhausbau mit neuer Heiztechnik und die Auswirkungen dessen auf die Interaktion mit Hausbauherr*innen und/oder Neubewohner*innen

\begin{tabular}{|l|c|c|c|c|c|c|l|l|}
\hline & $\begin{array}{l}\text { Frau } \\
\text { Rosental }\end{array}$ & $\begin{array}{l}\text { Frau } \\
\text { Schulze }\end{array}$ & $\begin{array}{l}\text { Frau } \\
\text { Köhler }\end{array}$ & $\begin{array}{l}\text { Frau } \\
\text { Kirsch }\end{array}$ & $\begin{array}{l}\text { Herr } \\
\text { Frings }\end{array}$ & $\begin{array}{l}\text { Herr } \\
\text { Thomsen }\end{array}$ & $\begin{array}{l}\text { Lerr } \\
\text { Leh- } \\
\text { mann u. } \\
\text { Herr } \\
\text { Meier }\end{array}$ & $\begin{array}{l}\text { Frau } \\
\text { Huber }\end{array}$ \\
\hline $\begin{array}{l}\text { 1. Heizvergan- } \\
\text { genheit }\end{array}$ & $\mathrm{X}$ & $\mathrm{X}$ & $\mathrm{X}$ & $\mathrm{X}$ & $\mathrm{X}$ & $\mathrm{X}$ & & $\mathrm{X}$ \\
\hline $\begin{array}{l}\text { 2. Bedeutung } \\
\text { Heizkörper }\end{array}$ & (a) & (a) & (b) & (b) & (c) & (c) & (d) & (d) \\
\hline $\begin{array}{l}\text { 3. Informati- } \\
\text { ons- u. Erwar- } \\
\text { tungsabhän- } \\
\text { gigkeit }\end{array}$ & & & & & $\mathrm{X}$ & $\mathrm{X}$ & & $\mathrm{X}$ \\
\hline 4. Praxislernen & $\mathrm{X}$ & & & & $\mathrm{X}$ & & $\mathrm{X}$ & \\
\hline
\end{tabular}

Das Kapitel ist wie folgt gegliedert: Im ersten Teil werden exemplarisch einige ausgewählte Umstellungsprozesse beim Wechsel vom konventionellen Heizen zum Heizen im Passivhaus dargestellt (Teilkapitel 4.1.1). Innerhalb der Passivhaus-Fälle wird noch einmal differenziert zwischen Passivhäusern der ersten Generation (1990er bis Mitte der 2000er Jahre), in denen es (außer im Badezimmer) in der Regel keine Heizkörper gibt, da sie lediglich mittels Nacherwärmung der Zuluft beheizt werden, und Passivhäusern der zweiten Generation (ab den späten 2000er Jahren), die meist mit einer konventionellen Zusatzheizung ausgestattet sind. Dieser Unterschied hat sich als relevant für die Auffassung der Bedeutung des Heizkörpers herausgestellt. Im zweiten Teil des Kapitels wird dann von Anpas- 
sungsprozessen rund um den Heizkörper nach dem Einbau der intelligenten Heizungssteuerungstechnik berichtet (Teilkapitel 4.1.2).

\subsubsection{Heizen im Passivhaus}

Wie bereits in der Einleitung, in Abschnitt 1.10.1 zum Passivhausstandard erläutert wurde, ist im Passivhaus eine herkömmliche aktive Gebäudeheizung mit Wärmeverteilung über Heizkörper nicht erforderlich und das klassische Passivhauskonzept sieht auch keine solche Zusatzheizung vor. Der sich gerade auf den Bau von Passivhäusern spezialisierende Architekt Herr Meier beschreibt dies im Interview folgendermaßen:

„das klassische Passivhauskonzept ist eben äh der entscheidende Punkt dass Sie keine Heizkörper mehr haben fühlbar im Grunde keine Heizung." (Architekt PH, Interview 48: 18, 819-821) 71

Die ,Heizung، des Passivhauses übernimmt stattdessen eine Lüftungsanlage mit effizienter Wärmerückgewinnung - (nach-)geheizt wird über die Zuluft. Das heißt, das zentrale materielle Element, welches für die meisten Bewohner*innen sinnbildlich für Heizen steht, ist im Passivhaus entbehrlich und kann dementsprechend wegfallen. Laut Herrn Meier besteht genau darin die Besonderheit der Passivhauskonstruktion: „der Kniff am Passivhaus ist im Grunde braucht keine Heizung mehr- das ist so der der der verkürzte Slogan“ (ebd., 838-839).

Auch Herr Lehmann, ein erfahrener Passivhausarchitekt, erklärt im Interview mit folgenden Worten, weshalb eine konventionelle Heizung im Passivhaus abkömmlich ist:

„also Passivhaus is' ja ähm so berechnet von Herrn Feist der hat das ja so konzipiert dass ich auf 'ne Heizung im Prinzip verzichten kann [...]

71 Aus den vollständigen Interviewtranskripten wird in dieser Arbeit wie folgt zitiert: Es werden die Funktion, aufgrund derer die Person interviewt wurde, die Interviewnummer, die Seitenzahl(en) sowie die Zeilennummer(n) angegeben. Zur Erklärung: Insgesamt gibt es vier Gruppen von Interviewten: Bewohner*innen Passivhaus, Bewohner*innen SmartHome, Architekt*innen Passivhaus, Expert*innen SmartHome. Die Zuordnung zum Fall des Passivhauses wird mit PH und die zum Fall des SmartHomes entsprechend mit SH abgekürzt (für eine vollständige Übersicht der im Rahmen dieser Arbeit geführten Interviews, siehe Anhang $\mathrm{B}$ ).

In seltenen Fällen wurden die Zitate aus Gründen der besseren Lesbarkeit sprachlich leicht geglättet. 
Sein Konzept beruht ja dadrauf ich brauch' keine Heizung mehr ich habe (.) an meiner Lüftungszentrale hab' ich sozusagen einen Nacherwärmer in welcher Form auch immer. Und dann wird dann meine Luft die: ja ähm über den Wärmetauscher kommt und was weiß ich von 22 Grad auf:: dann noch 18 oder 20 Grad herausgeholt werden und ab 1718 Grad wird dann das letzte wieder angehoben und wird dann so in die Wohnung geschickt. Das hat sich- das ist sozusagen das Konzept eigentlich des- beim Passivhaus dass ich auf die Heizung verzichte bis auf dass ich dann Mehrkosten durch die Lüftung habe (.) spare ich mir ein dass ich keine Heizungsverbohrung und keine Heizkörper und irgendwie Pi Pa Po brauche." (Architekt PH, Interview 52: $9,448-463)^{72}$

Gleich im Anschluss räumt Herr Lehmann allerdings ein, dass in Norddeutschland die gängige Praxis inzwischen anders aussieht: das klassische Passivhausprinzip mit reiner Zuluftheizung werde hier meist nicht mehr umgesetzt, da die reine Zuluftheizung von den Nutzer*innen bisher nicht angenommen werde. Stattdessen werde, so habe er beobachtet, mittlerweile häufig eine Zusatzheizung mit konventionellem Wärmeverteilnetz installiert:

„das habe ich auch bei- jetzt auch wieder auf den Passivhaus-Tagen da letztes Jahr im November auch gesehen. Fast alle- die haben- bauen überall mittlerweile kleine Heizkörper irgendwo ein." (ebd.: 10, 491494)

Für die Untersuchung wurde sowohl mit Bewohner*innen gesprochen, die ihr Passivhaus lediglich über eine in die Lüftungsanlage integrierte Zuluftheizung beheizen, als auch mit solchen, die über eine Zusatzheizung mit Heizkörpern in den einzelnen Räumen verfügen. Dabei wurde festgestellt, dass - übereinstimmend mit den Aussagen des Architekten Herr Lehmann - vor allem die älteren Häuser und Wohnungen in Mehrfamilienhäu$\operatorname{sern}^{73}$, also die erste Generation Passivhäuser ohne aktive Zusatzheizung konzipiert wurden. Hingegen sind die neueren Passivhäuser der zweiten

72 Wolfgang Feist ist ein deutscher Physiker und Bauphysiker. Er gilt als Vorreiter des Passivhaus-Energiestandards für Gebäude. 1996 gründete Feist das Passivhaus Institut in Darmstadt, das er aktuell noch leitet.

73 Es wird von den Einzelfällen abstrahiert und aus Gründen der Lesbarkeit wird im Folgenden einmal von Häusern und ein anderes Mal von Wohnungen gesprochen. Wo künftig ausschließlich von Häusern oder nur von Wohnungen die Rede ist, sind immer beide Wohnformen (Häuser und Wohnungen) gemeint. 
Generation meist mit einer konventionellen Zusatzheizung und Heizkörpern in allen Räumen ausgestattet. Während der Analyse hat sich gezeigt, dass dieser Unterschied relevant ist, weil sich das Verständnis der Bedeutung des Heizkörpers bei den Bewohner*innen dieser beiden PassivhausVersionen unterscheidet. An dieser Stelle sollen nun Unterschiede zwischen den beiden Passivhaus-Ausführungen herausgearbeitet werden.

\section{Passivhäuser der ersten Generation - vom Heizen mit Heizkörpern zum Heizen obne Heizkörper}

Am gesammelten Interviewmaterial ist auffällig, dass viele Interviewpartner*innen bereits früh im Interview erwähnen, ob sie zusätzliche Heizkörper eingebaut haben oder nicht. Ebenfalls wird von den Interviewpartner*innen, die in Passivhäusern der ersten Generation wohnen immer wieder thematisiert, in welcher Art von Wohnung sie zuvor gewohnt haben.

So schildern einige Bewohner"innen von Passivhäusern der ersten Generation, dass sie es anfangs, vor Bezug ihres Passivhauses nicht für möglich gehalten haben, dass ein Haus ohne konventionelle Heizung an kalten Tagen ausreichend warm wird. Obwohl sich einige Bewohner"innen sogar vorher bereits fertiggestellte Passivhäuser angeschaut hatten, konnten sie sich vor ihrem Einzug nicht vorstellen, dass sie bei entsprechend niedrigen Außentemperaturen im Passivhaus nicht frieren würden.

In diesem Zusammenhang ist interessant, wie Frau Köhler zum Passivhaus kam. Zum Zeitpunkt des Interviews wohnt Frau Köhler bereits seit über zwölf Jahren in ihrer Wohnung in einem Mehrfamilien-Passivhaus, welches von ihr zusammen mit anderen als Wohnungsbaugenossenschaftsprojekt realisiert wurde. ${ }^{74}$ Das Mehrparteienwohnhaus wurde in den frühen 2000er Jahren fertiggestellt und umfasst knapp 20 unterschiedlich große Wohnungen. Frau Köhler gehört dem ursprünglichen Gründungszirkel des gemeinschaftlichen Wohnprojekts an:

„also ich gehör zu der Kernzelle sozusagen. Wir ham uns vor- ja das sind zwanzig Jahre jetzt gut her da haben wir fünf Leute uns zusammengetan und gesacht wir wollen im Alter anders leben als dass es uns

74 Frau Rosental, ebenfalls eine der anfänglichen Mitbegründerinnen des Wohnprojekts B, erinnert sich, dass die Entscheidung für ein Passivhaus von der Baugemeinschaft ausging. Diese hätte ihren Wunsch an die Architektin herangetragen, die sich daraufhin bereit erklärt habe, das gemeinschaftliche Bauvorhaben als Passivhaus umzusetzen. 
irgendwann so weit geht dass wir halt jetzt irgendwo in 'nen Altenheim müssen." (Bewohnerin PH, Interview 60: 6, 299-303)

Frau Köhler beschreibt, dass die Befürchtungen, im Passivhaus unter Kälte leiden zu müssen, bei einigen der ursprünglich am Wohnprojekt Interessierten sogar so groß waren, dass diese sich noch während des Planungsprozesses aus dem Bauprojekt zurückgezogen haben: „da sind einige von unseren Interessentinnen sind abgesprungen als sie merkten dass wir uns dafür entschieden (.) weil sie sagten also frieren wollten sie nich" (ebd.: 8, 410-413).

Dass die Frage nach zusätzlicher Heizung auch unter den im Bauprojekt verbliebenen Wohnparteien eine zentrale Rolle gespielt hat, macht der Fall Frau Rosentals deutlich.

\subsubsection{1 „[I]ch hab zusätzlich[e Heizkörper] ja. Die benutz ich jetzt nich ähm aber $[\ldots]$ wenn's richtig kalt ist $[\ldots]^{]}$- Frau Rosental}

Frau Rosental, eine weitere Mitbegründerin und aktuelle Bewohnerin desselben Wohnprojekts, reagierte trotz ähnlicher Bedenken anders. Sie verlangte den Einbau zusätzlicher konventioneller Heizkörper in ihren Wohnräumen, um für den Notfall eine Möglichkeit zum Dazuheizen zu haben. Auf die Frage, ob sie Vorbehalte gegenüber dem Passivhaus oder grundlegende Befürchtungen hatte, antwortet sie:

„Ja ich hatte das da- der da geplant hat ähm der hat gesagt äh man braucht kein Heizung. Im Bad aber sonst nich. Und das war- fand ich 'n- äh (.) dann- da hab ich also das glaub ich nich wenn ich lang sitze äh am Schreibtisch dann we- wär mir das- und und das war dann auch nich irgend 'n Problem. Die anderen haben dann irgendwie mehr auf ihn gehorcht und haben dann die Heizkörper sich gar nich anmontieren lassen die er geplant hat. [...] Ja. Und ich hab zusätzlich ja. Die benutz ich jetzt nich ähm aber äh (.) ja also wenn's wenn's richtig kalt ist jetzt nicht um äh ich könnte das Ganze ja wärmer stellen [...].“ (Bewohnerin PH, Interview 59: 5f, 268-280)

Anhand dieser Passage wird erkennbar, dass Frau Rosental der Einschätzung des Fachmanns nicht recht Glauben schenken konnte und sie sich deshalb nicht auf seinen Rat verlassen wollte. Frau Rosentals Befürchtungen zu frieren, beziehen sich offenbar auf längere Arbeitsphasen, die sie stillsitzend am Schreibtisch verbringt. Hierbei scheint sie in der Vergangenheit bereits die Erfahrung gemacht zu haben, dass ihr kalt wird, wenn 
sie über längere Zeit kaum körperlich aktiv ist. Die Vermutung liegt nahe, dass Kälte und Frieren in der eigenen Wohnung für Frau Rosental ein unangenehmes Szenario darstellen und ihr die Vorstellung, es könnte ihr in den eigenen Räumlichkeiten zu kalt sein, Sorge bereitet. Damit hängt offenbar zusammen, dass sie sich damals Heizen und eine ausreichende Wärmeversorgung ohne Heizkörper (noch) nicht vorstellen konnte.

Ihr Zweifeln und ihre Sorge, ohne Zusatzheizung in den eigenen Räumlichkeiten an kalten Wintertagen womöglich zu frieren, haben Frau Rosental - offenbar im Unterschied zu den meisten anderen Hausbewohner*innen - dazu bewogen, dass sie sich Heizkörper in allen ihren Wohnräumen installieren ließ. Für sie ging es anscheinend in erster Linie darum, sich abzusichern und für einen möglichen ,Kälte-Ernstfall technisch ausgestattet zu sein.

Frau Rosental kontrastiert ihr eigenes Entscheidungshandeln gegenüber dem technischen Experten mit dem der meisten anderen Hausbewohner*innen in Bezug auf den Einbau zusätzlicher Heizkörper: Während die anderen Bewohner*innen dem Expertenurteil, im Passivhaus seien zusätzliche Heizkörper unnötig, offenbar mehrheitlich vertraut und dem auch Folge geleistet haben, hat sich Frau Rosental davon offensichtlich nicht beeinflussen lassen; vielmehr hat sie sich in ihrer Entscheidung primär an ihrem persönlichen Empfinden und bisherigen Erleben orientiert.

Darüber hinaus vollzieht Frau Rosental in dieser Passage gegen Ende einen entscheidenden Perspektivwechsel: Während sie sich zunächst an die Planungs- und Bauphase des Passivhausprojekts B zurückerinnert - erkennbar an der von ihr verwendeten Vergangenheitsform -, nimmt sie mit ihren letzten Schilderungen Bezug auf die gegenwärtige Situation. Hier stellt sie zunächst ihre aktuelle Ausgangslage dar, indem sie betont, dass die zusätzlich installierten Heizkörper in ihrer Wohnung immer noch vorhanden sind. Frau Rosental wohnt zum Zeitpunkt des Interviews bereits seit etwa 13 Jahren in ihrer Passivhauswohnung, sie hat mittlerweile also Erfahrung mit dem Heizen im Passivhaus gesammelt. Aus heutiger Perspektive hat sich herausgestellt, dass sich ihre damalige Besorgnis als unbegründet erwiesen hat und sie die zusätzlich anmontierten Heizkörper tatsächlich nicht gebraucht. Offenbar ist es nie so kalt, dass sie die zusätzlichen Heizkörper anstellen muss, um ihre Wohnung ausreichend zu erwärmen. ${ }^{75}$

75 An dieser Stelle ist wichtig zu erwähnen, dass Frau Rosental mit „das Ganze“ (Bewohnerin PH, Interview 59: 6, 280) nicht ihre Zusatzheizung, sondern die zentrale Lüftung (mit Wärmerückgewinnung) des Passivhausprojekts B meint. Dieser 
Insgesamt macht die Passage deutlich, dass Frau Rosental ihre damalige Entscheidung nicht abwegig findet oder gar bereut; vielmehr erscheint sie ihr aus damaliger Sicht nach wie vor plausibel. Zur damaligen Zeit, während der Planungsphase des Mehrfamilien-Passivhauses B, stand für sie die Sorge im Vordergrund, ohne zusätzliche Heizkörper könnte sie bei sehr niedrigen Außentemperaturen in den eigenen Räumlichkeiten womöglich frieren. Offenbar ging es für Frau Rosental damals vorrangig darum, dieses Risiko zu vermeiden.

Ein möglicher Hintergrund für diese Deutung wird in einer anderen Passage deutlich, in der Frau Rosental explizit auf negative Erfahrungen aus ihrer Wohn- und Heizvergangenheit rekurriert. Als es um die Frage geht, wie sie vor dem Einzug in das Passivhaus gewohnt hat, erzählt sie von ihrer letzten zugigen Altbauwohnung. In dieser habe sie häufig gefroren und in den Räumen sei es für sie gefühlt nie richtig warm geworden, weil Fenster und Wände nicht ausreichend wärmeisoliert und die Heizkörper auch nicht entsprechend dimensioniert gewesen seien:

„Und da war- also das war schon äh das war jetzt nich- das waren dicke Mauern (.) und isolierverglaste Fenster. Aber wenn ich die die Wände angefasst habe dann waren die kühl und dann- und und und ich wollte ' $n$ zweiten Heizkörper aufstellen und dann hat der Heiz- der- dass das nix bringt der Heizungsmann hat gesagt das bringt nix. Die Wände sind kühl und dann selbst wenn jetzt die Temperatur dann das anzeigt $21 \mathrm{Grad}$ is das trotzdem dass man fröstelt weil von den von den Wänden oder vom vom Fenster ähm einfach 'ne kühle Luft ausstrahlt. [...] also vor zweifach verglast könntest du dich nich so davor setzen. Und das finde ich is schon das is schon äh also das gibt ja auch mehr Raum wenn ich da den den Raum vor vorm Fenster auch nutzen kann (.) und keine kalte Luft also so." (Bewohnerin PH, Interview 59: 19f, 1019-1035)

Diese Schilderung zeigt, dass sich Frau Rosental auch heute noch lebhaft an die schon länger zurückliegenden Erfahrungen von Kälte abstrahlenden Wänden und Fenstern erinnert. Es erscheint plausibel, dass ihr diese Erinnerungen zum damaligen Zeitpunkt des Planens ihres künftigen Passivhauses und dazugehöriger Heizlösung gleichermaßen präsent waren und in ihre damalige Entscheidung eingeflossen sind. Es liegt nahe, dass sie

Punkt wird in Teilkapitel 4.1.1.7 noch einmal von Bedeutung sein, wenn es um das Lernen der Architekt*innen im Prozess des Passivhausbaus mit entsprechender Lüftungs- und Heizungstechnik geht. 
eine Wiederholung dieses negativen Erlebens vermeiden wollte und sich um dem vorzubeugen - deshalb ihre Passivhauswohnung trotz standardmäßiger sehr guter Wärmedämmung und Dreifach-Isolierverglasung mit zusätzlichen Heizkörpern ausrüsten ließ.

Zudem lässt sich der Passage entnehmen, dass Frau Rosental über den zusätzlich gewonnenen (Wohn-)Raum im Passivhaus erfreut ist. Demnach lässt sich aufgrund der hocheffektiven Wärmedämmung und der DreifachIsolierverglasung der Raum im Passivhaus auch bei niedrigen Außentemperaturen in vollem Umfang (aus-)nutzen. Im Kontrast zum konventionellen (unsanierten) Altbau, wo man sich, um nicht zu frieren, im Aufenthalt offenbar ständig nach der vorhandenen Wärmequelle im Raum orientieren muss, sind die Bewohner*innen im Passivhaus flexibel, was die Raumnutzung angeht. Dieser Punkt, Platzgewinn und mehr (Einrichtungs-)Freiheit im Passivhaus' wird an späterer Stelle noch einmal aufgegriffen, wenn beispielhafte Entwicklungen rund um den Heizkörper in Passivhäusern der zweiten Generation dargestellt werden (siehe Teilkapitel 4.1.1.5).

4.1.1.2 „Äh also es war so klapperkalt es war so schrecklich im Winter dass ich mir das [ohne zusätzliche Heizkörper] nicht vorstellen konnte“ - Frau Schulze

Von ähnlichen Erfahrungen aus ihrer Wohn- und Heizvergangenheit in einem Altbau erzählt im Interview auch eine andere Passivhaus-Bewohnerin. ${ }^{76}$ Mit Frau Schulze fand das Gespräch (vorrangig) aufgrund ihrer beruflichen Tätigkeit als Passivhausarchitektin statt. Während des Interviews stellt sich dann heraus, dass Frau Schulze selbst in einem gut gedämmten Niedrigenergiehaus wohnt. Sie berichtet, hier wichtige Wohn- und Heizerfahrungen gesammelt zu haben, die sie nun in ihre Arbeit als Passivhausarchitektin miteinbeziehe. Auch sie habe sich damals, nachdem sie gravierende Kälteeinbrüche in ihrer vorherigen Altbauwohnung erlebt habe,

76 Genau genommen handelt es sich hierbei nicht um ein Passivhaus, sondern um ein Mehrfamilienhaus, das noch nach Vorgabe der alten, 1995 novellierten Wärmeschutzverordnung errichtet wurde. Der Bewohnerin zufolge verfügt das Wohnhaus über einen „ganz gute[n] Dämmstanda::rd insgesamt“ (Architektin PH, Interview 51: 19, 931) und liegt „auch mit dem Energieverbrauch [...] auf Niedrigenergiehaus-Standard“ (ebd., 932-933). Da dieser Standard dem Passivhaus recht nahe kommt, wird er in die Untersuchung mit hineingenommen und formal der ersten Generation Passivhaus zugerechnet. 
ebenfalls zusätzliche Heizkörper in einigen Räumen ihrer aktuellen Wohnung einbauen lassen:

„Ich habe vor- ja das ist 'n ganz entscheidender Faktor finde ich wo man in welchem Gebäude man vorher gewohnt hat. Ich habe in 'nem Altbau gewohnt da ist mir 'n paar Mal die Toilette eingefroren (.) Ich habe auf 'm Flur bei solchen Minusgraden ähm hatte ich auf dem Flur 7 Gr:ad ich habe wirklich Thermometer ausgelegt. Äh also es war so klapperkalt es war so schrecklich im Winter dass ich mir das [ohne zusätzliche Heizkörper, JM] nicht vorstellen konnte. Der Haustechniker hat das gesagt vermutlich braucht Ihr im Flur und (.) dann braucht Ihr gar keine Heizungen und gerade im Flur wenn man da bei 7 Grad irgendwie morgens aus dem Bett durchhuscht um irgendwie ins Badezimmer zu kommen ich äh habe gedacht nee da möchte ich jetzt- das will ich nich'.“ (Architektin PH, Interview 51: 947-958)

In dieser Passage liefert Frau Schulze sich selbst die Erklärung für die Installation der Extra-Heizkörper in ihrer Wohnung. Und zwar äußert sie eine Alltagstheorie über die Motive, die hinter dem Einbau der zusätzlichen Heizkörper stehen, wobei sie die Bedeutung vergangener Wohn- und Heizerfahrungen in den Vordergrund stellt. Sie bringt ihre eigenen gegenwärtigen Heizgewohnheiten mit früheren Heizerlebnissen in Verbindung und folgert daraus, dass ihre aktuelle Heizpraxis wesentlich durch ihr langes Wohnen im schlecht gedämmten Altbau geprägt worden sei. Zudem wird deutlich, dass sie den Haustechniker, der die Anlage geplant hat, als unsicher in seiner Empfehlung erlebt hat, ob auf eine Zusatzheizung vollständig verzichtet werden kann. Somit passten für Frau Schulze zum damaligen Zeitpunkt zwei Dinge zusammen: erstens ihre eigenen negativen Erfahrungen mit heftiger Kälte und zweitens die Unsicherheit des Experten. Diese Kombination hat dazu geführt, dass sie sich daraufhin für den Einbau zusätzlicher Heizkörper entschieden hat, um sicherzugehen, in ihrer Wohnung zukünftig nicht (wieder) frieren zu müssen.

Diesen (an sich selbst beobachteten) prägenden Einfluss von Wohn- und Heizgeschichte auf gegenwärtiges Handeln verallgemeinert Frau Schulze:

„das ist sehr entscheidend (.) wie man vorher gewohnt hat weil irgendwie trägt man das (.) das prägt ja wenn man lange in 'ner schlecht geheizten Wohnung oder in 'nem schlecht geheizten Haus gewohnt hat." (Architektin PH, Interview 51: 19, 962-965)

Diese Geschichte, die jeder in sich trage, lasse sich demnach nicht einfach abschütteln oder durch einen Umzug vergessen. Vielmehr habe sie bei sich 
selbst festgestellt, dass ihre Heizvollzüge, mit denen neue Tatsachen geschaffen wurden, nach dem Umzug ins Passivhaus unmittelbar an vergangenes Erleben und Handeln anknüpften. Um ihre Theorie zu untermauern, liefert Frau Schulze eine Analogie aus ihrer Arbeit als Architektin:

Frau Schulze: [...] und jetzt auch in der [bestimmtes Passivhauswohnprojekt] die kamen (räuspern) vielfach aus 'nem schlecht geheizten Altbau mit unheimlich kleinen Bädern (lacht).

Interviewerin JM: So richtig klein?

Frau Schulze: Richtig klein. Äh und jetzt im Neubau sind manche Bäder au::ch ganz schön klein geraten.

Interviewerin JM: Vermuten Sie dass da 'n Zusammenhang is'?

Frau Schulze: Ja auf jeden Fall besteht da ein Zusammenhang das trägt man im Kopf.

Interviewerin JM: Mhm. Also wie sich so 'n so 'n so 'n Gedächtnis bildet und so so Gewohnheit.

Frau Schulze: Äh ja! [...] und äh also das ich meine das habe ich sogar gehört dass äh Familien dachten ,Oh Gott was stelle ich denn überhaupt jetzt so in die Wohnung rein das ist ja so riesig.' Und dann (.) sind sie eingezogen und dann dauert das nicht lange dann hat man sich da ganz gut dran gewöhnt. Aber erst mal so auf 'm Papier das is' schon- das ist schon prägend. "77

(Architektin PH, Interview 51: 19f, 962-995)

Laut Frau Schulze enthalten die neu gebauten Wohnungen nicht nur konkrete Hinweise auf die persönliche Wohnvorgeschichte ihrer Bewohner*innen; vielmehr seien die Wohnungskonzeptionen in einigen wesentlichen Aspekten das direkte Produkt der von den Passivhaus-Neubewohner*innen in der Vergangenheit in konventionellen Wohnkontexten, vor allem in schlecht isolierten Altbau-Wohnungen, gesammelten Erfahrungen. Anhand der auf Geheiß der einzelnen Wohnparteien angefertigten konkreten Wohnungsbaupläne und -zeichnungen, die Frau Schulze als erstes vorlagen, sei deutlich geworden, wie prägend vor allem die zuvor erlebten materiellen Arrangements für Vorstellungen von künftigem Wohnen sind. Weil ihre Wahrnehmungsweisen sowie Denk- und Deutungsmuster

77 Bei zitierten Interviewsequenzen mit Sprecher*innenwechsel stehen die Anführungszeichen nur am Ende, um kenntlich zu machen, dass es sich bei den Redebeiträgen der unterschiedlichen Sprecher*innen um wörtliche Zitate handelt, jedoch der Sprecher*innenwechsel, also die konkreten Sprecher*innennamen und -bezeichnungen im Gespräch selbstverständlich nicht verbalisiert wurden. 
wesentlich durch vergangenes Erleben geformt seien, hätten sich die Bewohner*innen im Vorhinein kein konkretes Bild vom Wohnen im Passivhaus machen können. Stattdessen seien sie in ihren Entwürfen den Wohnund Heizvorstellungen verhaftet geblieben, die sie von ihren früheren Wohnkontexten her kannten. Frau Schulze drückt hier auch aus, dass sobald sich die Bewohner*innen mit dem Einzug ins Passivhaus mit veränderten Tatsachen konfrontiert sehen und es damit - gewissermaßen von heute auf morgen - zu einem neuen Erleben komme, die Umstellung bzw. Anpassung an den neuen Wohnkontext und den gestiegenen Komfort in der Regel dann gleichfalls binnen kurzem erfolge.

Damit stützt diese Deutung der Expertin die sozialwissenschaftliche Deutung der Interviewerin, dass sich die individuelle Wohn- und Heizgeschichte nachhaltig auf die gegenwärtige Heizpraxis auswirkt. Demnach schaffen vergangene Vollzüge die Grundlage für darauffolgendes Heizen und sie stellen meist einen wichtigen Referenzpunkt für deutlich späteres Heizen dar. ${ }^{78}$

Während Frau Rosental die in ihrer Wohnung zusätzlich installierten Heizkörper - obwohl sie sie nach eigenen Angaben nicht benutzt - bis heute alle behalten hat und offenbar zur Absicherung auch weiterhin an diesen festhält, wird im Fall Frau Schulzes eine deutlich andere Entwicklung hinsichtlich der Bewertung und des daraus resultierenden tatsächlichen Umgangs mit den zusätzlichen Heizkörpern deutlich: Frau Schulze hat nach einigen Heizperioden gemerkt, dass sie die Zusatzheizung, die sie in einigen Räumen hat installieren lassen, tatsächlich nicht benötigt. Daraufhin hat sie die entsprechenden Heizkörper kurzerhand selbst entfernt:

Frau Schulze: [...]. Also ich finde auch dass wir nich' besonders viel viele Heizkörper irgendwie aufdrehen müssen. Ich hab' im Flur und im äh ich habe so 'n separates WC da habe ich die Heizkörper ähm demontiert weil ich die nie angemacht hab'. Die hab' ich abgebaut.

Interviewerin JM: Um einfach mehr Platz zu haben auch?

Frau Schulze: (Ausatmen) Joa die waren mir dann irgendwie 'n bisschen im Wege genau und hab' gedacht ah nun brauche ich die da auch nich'. Ich habe sie auch noch nicht wirklich äh vermisst.“

(Architektin PH, Interview 51, 19: 934-943)

78 Die prägende Wirkung, die die persönliche Wohn- und Heizgeschichte auf gegenwärtiges Heizen ausübt, wird auch von anderen Expert*innen im Interview thematisiert. 
Diese Sequenz zeigt, dass Frau Schulze nach ihrem Einzug die konkrete Erfahrung gemacht hat, dass in ihrem Haushalt die zusätzlich verbauten Heizkörper überflüssig sind. Dadurch hat sich auch ihre Wahrnehmung dieser erkennbar verändert: Mit der Zeit hat sie die Heizkörper als störend empfunden, was sie schließlich dazu bewegt hat, die Heizkörper selbständig abzumontieren. Auch rückblickend bestätigt sich für Frau Schulze, dass sie mit dem Ausbau die richtige Entscheidung getroffen hat. Durch die sachliche Schilderung der Geschehnisse wird der Eindruck erweckt, als sehe Frau Schulze die gesamte Entwicklung eher unproblematisch und dass sie nicht noch über ihre damalige Entscheidung, zusätzliche Heizkörper installieren zu lassen, nachsinniert. Vielmehr scheint sie die ganze Angelegenheit eher pragmatisch zu sehen: So haben sich ihre anfänglichen Befürchtungen, ohne zusätzliche Heizkörper frieren zu müssen, in der alltäglichen Praxis als unbegründet erwiesen und daraus hat sie die praktischen Konsequenzen gezogen.

Bei den Bewohner*innen der ersten Generation Passivhaus wurden noch andere interessante Varianten von der Auffassung der Rolle des Heizkörpers entdeckt. So haben sich einige Bewohner“innen von Passivhäusern der ersten Generation zwar direkt auf „das Andersartige eines Passivhauses" (Architekt PH, Interview 52: 20, 1058-1059) eingelassen und trotz eventueller Bedenken auf zusätzliche Heizkörper verzichtet. Diese bemerken aber nach langer Zeit immer wieder, dass sie zu denen gehören, „die es wirklich brauchen [...] irgend so 'n Gegenstand an den [man sich, JM] kuscheln kann der dann ganz warm ist" (Bewohnerin PH, Interview 56: 2691-2692).

4.1.1.3 „Also manchmal hab ich mich gesehnt wenn's draußen kalt war und ich kam hierher dass ich irgendwo meine kalten Füße an 'n Heizkörper halten kann“ - Frau Köhler

Im Gespräch mit Frau Köhler, die zum Zeitpunkt des Interviews schon seit mehr als einem Jahrzehnt in ihrer Passivhaus-Wohnung lebt, wird deutlich, welch elementare Rolle der Heizkörper für die subjektive Behaglichkeit spielt. Sie berichtet, dass für sie der Verzicht auf eine direkte Wärmequelle eine große Umstellung bedeutete und dass sie nach wie vor in einigen Situationen einen Heizkörper vermisst:

„Und sonst was- wo musste ich mich umstellen? (überlegt länger) Joa. Ja dass man keine (.) Wärmequelle mehr hat. Also manchmal hab ich mich gesehnt wenn's draußen kalt war und ich kam hierher dass ich 
irgendwo meine kalten Füße an 'n Heizkörper halten kann. Oder dass man mal irgendwas Kleines auswäscht und es an- im Winter an denim Sommer kann mer's raus hängen aber im Winter an 'nen Heizkörper hängt. Das also so 'ne direkte Wärmequelle die- das war so vom Gefühl her musste ich mich da sehr umstellen." (Bewohnerin PH, Interview 60: 18, 948-955)

Frau Köhler äußert, dass sie sich inzwischen an diese veränderte Heizpraxis gewöhnt habe, diese Anpassung aber eher allmählich erfolgt sei. Hieraus lässt sich schlussfolgern, dass Veränderungen Zeit brauchen. Je mehr Abstand zum Altbekannten gewonnen wird und je länger das Neue erlebt wird, je länger die Erinnerungen an die altbekannte Verfahrensweise zurückliegen und damit eventuell auch verblassen, desto eher kann sich offenbar für das einst Neue ein Gefühl von Gewohnheit und Normalität einstellen. Frau Köhler fasst diesen bei ihr sehr langsam verlaufenen Gewöhnungsprozess distanziert und nüchtern mit folgenden Worten zusammen:

„Inzwischen (.) ja hat- nach zehn Jahren hat man sich da drauf eingelassen und eingestellt ja. [...] Also der Mensch is schon auch in vielem wenn er bereit is anpassungsfähig.“ (ebd., 956-962)

In dem Zitat kommt keinerlei Begeisterung zum Ausdruck, sondern Frau Köhlers Wortwahl unterstreicht vielmehr die nüchterne Funktionalität der Passivhaus-Heizung. Ihre distanziert-sachliche Formulierung deutet darauf hin, dass Frau Köhler über etwas spricht, dass sie nicht wirklich gerne macht bzw. gemacht hat.

4.1.1.4 „Also wenn ich bei meinen Kindern bin [...] die haben 'nen Ofen das finde ich dann immer herrlich" - Frau Kirsch

Ähnlich(es) berichtet Frau Kirsch, die dem gleichen Passivhaus-Wohnprojekt wie Frau Köhler und Frau Rosental angehört. Auch sie hatte anfangs keine konkrete Vorstellung davon, wie das Wohnen im Passivhaus sein würde. Sie hat sich dann aber informiert und war danach mehr und mehr vom Konzept des Passivhauses überzeugt. In dem gemeinschaftlichen Wohnprojekt gehört Frau Kirsch demnach zu denjenigen, die sich auf das ursprüngliche Passivhauskonzept verlassen haben: Sie hat keine zusätzlichen Heizkörper in den einzelnen Wohnräumen. Sie sagt, sie habe sogar ganz bewusst auf eine Zusatzheizung verzichtet, weil sie von den im Passivhaus garantiert erreichten Temperaturen her davon ausgegangen sei, keine zu brauchen: ,ich hab sie extra nich' genommen weil ich es wurde 
gesagt zwanzig Grad und- erreiche ich immer und hab gesagt na ja das reicht für mich" (Bewohnerin PH, Interview 64: 17, 899-901).

Im Rückblick äußert sich Frau Kirsch einerseits erfreut darüber, dass im Passivhaus die Wände nicht auskühlen und dementsprechend auch keine Kälte in die Wohnräume ausstrahlen, sondern dass im Passivhaus in allen Räumen die gleiche Wärme vorherrscht. Andererseits vermisst sie eine direkte Wärmequelle, wie beispielsweise einen Ofen bzw. Kamin oder Heizkörper in den einzelnen Wohnräumen.

Später im Gespräch, auf die Frage der Interviewerin, was für sie zu einem angenehmen Wohnraumklima und zu Behaglichkeit alles dazugehöre, führt Frau Kirsch im Dialog mit ihrer Nachbarin Frau Greiner den Punkt des Wärmeerlebens deutlicher aus:

Frau Kirsch: Also wenn ich bei meinen Kindern bin dann finde ich zum Beispiel immer- die haben 'nen Ofen das finde ich dann immer herrlich.

Frau Greiner: Wenn man weiß wo die Wärm- Wärme herkommt $L_{\text {so- }}$ Ja.

Frau Kirsch: Herkommt $\lrcorner$ und man kann sich näher setzen man kann sich weiter weg setzen und irgendwie hat das 'ne andere Gemütlichkeit ja. Aber ich schätze auch sehr dieses diese gleichmäßig verteilte Wärme-“

(Bewohnerinnen PH, Interview 64: 22, 1164-1173)

In dieser Passage wird deutlich, dass es Frau Kirsch einerseits um eine klare Verortung der Wärme geht. Für sie gehört zu Behaglichkeit, dass es sich nicht nur um eine diffuse Wärme handelt, sondern dass die Wärme einen eindeutigen Ursprung hat, dass sie spürt, von welcher Quelle die Wärme ausgeht. Damit verbindet sich für Frau Kirsch die Vorstellung, dass wenn die Wärme einen festen Ausgangsort hat bzw. einem materiellen Gegenstand eindeutig zugeordnet werden kann, sie dann auch ihren persönlichen Bedarf an Wärme - der je nach Situation und Verfassung variiert selbst regulieren kann, indem sie sich in gewähltem Abstand zur Wärmequelle platziert. Dies ist Frau Kirsch in ihrer jetzigen Passivhauswohnung nicht möglich, da hier die Luft und mit ihr die Wärme zwischen allen Räumen frei zirkuliert.

Obwohl an mehreren Stellen im Interview eine positive Bewertung der gleichmäßigen Wärme erfolgt, wird andererseits deutlich, dass Frau Kirsch etwas an der zirkulierenden Einheitswärme im Vergleich mit der direkten Wärme eines Ofens oder eines Heizkörpers fehlt. Dass sie ambivalent in ihrem Urteil ist, zeigt sich unter anderem daran, dass sie ihre Wertschät- 
zung für die einheitliche und recht konstante Innenraumtemperatur im Passivhaus an mehreren Stellen im Interview in einem relativierenden Wortlaut und einem eher förmlich-distanziert klingenden Stil zum Ausdruck bringt. Hingegen wählt sie für die direkte Wärme eines Ofens sehr eindeutige und positiv emotional aufgeladene Worte wie z.B. ,herrlich'. Auffällig ist zudem, dass sie nur im Zusammenhang mit der Ofenwärme von ,Gemütlichkeit' spricht. Daran wird deutlich, dass sie zwischen der Raumwärme, die ein Ofen verbreitet und der gleichmäßig über die Lüftung verteilten Wärme des Passivhauses unterscheidet: Während sie die Ofenwärme mit ,Gemütlichkeit' verbindet, scheint sie die ,gleichmäßige Wärme' des Passivhauses eher mit funktionalem Wärmekomfort zu assoziieren. Die Deutung, dass es sich bei der gleichmäßig konstanten Wärme des Passivhauses um einen objektiv-funktionalen Wärmekomfort handelt, der wenig mit ihrem subjektiven Wärme- und Behaglichkeitsempfinden zu tun hat, wird durch eine weitere Passage gestützt, in der Frau Kirsch ihre Unzufriedenheit mit der Wärmeversorgung in ihrer Passivhauswohnung deutlich artikuliert:

„ich finde oft dass die gefühlte Wärme anders ist als die gemessene Wärme. Also es kann zwanzig einundzwanzig Grad sein und ich fröstel' dass ich das Bedürfnis hab ich will irgendwas Wärmeres anziehen

(.) Und eigentlich sind genug Grad-“ (Bewohnerin PH, Interview 64: $17,911-915)$

Hier zeigt sich, dass sich Frau Kirsch in ihrer Passivhauswohnung wärmemäßig oft nicht behaglich fühlt. So schildert sie, in ihrer Passivhauswohnung häufig auch bei Raumtemperaturen um die $20^{\circ} \mathrm{C}$, die sie als ausreichend bzw. angemessen bewertet und an anderer Stelle im Interview sogar als ihre ,persönliche Wohlfühltemperatur' angibt, noch ein Kältegefühl zu haben, ja regelrecht zu frieren. Die gleichmäßige Wärme des Passivhauses kann ihr offenbar nicht solch ein wohlig-angenehmes Gefühl vermitteln, wie es beispielsweise die Wärme eines Ofens bei ihr erzeugt. Auf die Nachfrage der Interviewerin, worauf sie dieses unterschiedliche Wärmeempfinden zurückzuführen glaubt, antwortet Frau Kirsch:

„Ja ich denke an dieser anderen Art der- der Lüftung und der Umwandelung der Wärme auch der Wärmeströme. Das muss irgendwie-“ (ebd.: 18, 921-923)

Diese Aussage verdeutlicht noch einmal, dass Frau Kirsch die Besonderheiten des Passivhauses im Hinblick auf die Wärmeversorgung und Belüftung für ihr oft nicht ausreichendes Wärmegefühl im Passivhaus verantwortlich 
macht. Zwar sei mit dem Passivhausprinzip die unangenehme Strahlungskälte der Wände abgeschafft, stattdessen sei es überall in der Wohnung gleichmäßig warm und es könne auf Heizkörper verzichtet werden. Allerdings seien dies genau die drei Punkte, die - positiv gedeutet - in Frau Kirschs Augen nun ausgerechnet für Wärmebehaglichkeit und Gemütlichkeit sorgten und wofür ihrer Ansicht nach ein Ofen bzw. Heizkörper stehe: Dies sind die spürbare Strahlungswärme, die von einer direkten Wärmequelle ausgeht und infolgedessen wahrnehmbare Temperaturunterschiede innerhalb eines Raumes sowie zwischen verschiedenen Wohnräumen. Diese Merkmale werden von Frau Kirsch an der Passivhauswärmeversorgung vermisst und bemängelt.

Im internen Dialog mit Frau Greiner während des gemeinsamen Interviews bringt Frau Kirsch deutlich zum Ausdruck, dass ihr die Wärmeversorgung in ihrer Passivhauswohnung während der Wintermonate häufig nicht ausreicht. Als Frau Greiner sie daraufhin fragt, ob in ihrer Wohnung denn ein Anschluss für eine konventionelle (Gas-)Heizung vorhanden sei, antwortet Frau Kirsch:

„Ja ja. Ja. Aber ich werde mir zum nächsten Winter so 'ne Heizung rein(?) - ja.“ (ebd.: 17, 909)

Frau Kirschs Antwort lässt sich entnehmen, dass ihre Wohnung bereits über einen Anschluss für eine zusätzliche aktive Heizung verfügt, wodurch prinzipiell die Möglichkeit zur einfachen Nachrüstung gegeben ist. Ganz offensichtlich strebt Frau Kirsch zum kommenden Winter eine dahingehende Veränderung an und will sich um eine zusätzliche Wärmequelle in ihrer Wohnung kümmern. Allerdings geht aus ihrer Antwort nicht eindeutig hervor, ob sie tatsächlich plant, sich zusätzliche Heizkörper in allen ihren Wohnräumen dauerhaft installieren zu lassen, oder - was ebenfalls möglich und deutlich einfacher zu realisieren wäre - ob sie gedenkt, sich lediglich flexibel aufstellbare Heizgeräte (z.B. kleine elektrische Heizöfen) anzuschaffen, die sie dann je nach Bedarf zur zusätzlichen Erwärmung ihrer Wohnräume während der Wintermonate nutzen könnte.

\section{Passivhäuser der zweiten Generation - vom Heizen mit Heizkörper zum Passivhaus mit Heizkörpern}

Geht es in den Interviews um die Frage des Vorhandenseins einer Zusatzheizung inklusive Heizkörpern in allen Räumen, wird von den Interviewpartner"innen, die Passivhäuser der zweiten Generation bewohnen, häufig angesprochen, wie ihre anfänglichen Vorstellungen vom Passivhaus aussahen, welche ursprünglichen Erwartungen sie an das Heizen im Passivhaus 
hatten und wie sich die reale Wohnpraxis im Passivhaus davon unterscheidet.

Während den meisten Bewohner*innen der ersten Generation Passivhaus das theoretische Konzept des Passivhauses noch relativ unbekannt war und sie daher Heizkörper vermissten, erging es vielen Bewohner*innen von Passivhäusern der zweiten Generation, deren Wohnprojekte meist erst in den letzten sieben bis zehn Jahren realisiert wurden, genau umgekehrt: Viele von ihnen hatten bereits vom Passivhausprinzip gehört oder sich vorab darüber informiert, so dass sie vor dem Planungs- und Bauprozess die klare Erwartung hatten, dass in ihren künftigen Passivhauswohnungen keine konventionelle Heizung vonnöten sei und dementsprechend auf den Einbau zusätzlicher Heizkörper verzichtet werde.

In diesem Zusammenhang ist interessant, wie Herr Frings auf die Ausstattung seiner Wohnung mit zusätzlichen Heizkörpern reagiert hat.

\subsubsection{5 „Und na was ich super attraktiv fand tatsächlich [...] war dass sie gesagt haben dass es so was (klopft gegen den Heizkörper) nich mehr gibt" - Herr Frings}

Herr Frings bewohnt mit seiner Familie eine Eigentumswohnung in einem mehrgeschossigen Mehrparteienhaus, das insgesamt zwischen 15 und 20 Wohneinheiten umfasst. Das als Passivhaus realisierte Mehrgenerationenhaus wurde für eine Baugemeinschaft aus jungen Familien, Senior*innen, Paaren und Singles erstellt, der auch Herr Frings und seine Familie angehören. Das Wohnhaus ist nach Plänen eines Architekturbüros entstanden, die von Anfang an ein Passivhaus vorsahen. Bereits vor dem endgültigen Zusammenschluss der Baugemeinschaft hatte das Architekturbüro mit dem Konzept eines Mehrgenerationen-Passivhauses einen Wettbewerb gewonnen und damit die Genehmigung sowie ein passendes Grundstück für den Bau des privaten Wohnhauses erhalten. Für die Bewohner*innen dieses Wohnprojekts war somit von Beginn an klar, dass sie in ein Passivhaus einziehen. Hingegen stand die Entscheidung darüber, wie die Restwärmeversorgung in diesem Passivhaus erfolgen soll, nicht vorab fest, sondern dies war die Angelegenheit der Baugruppe. Über die endgültige Heizlösung konnten die Mitglieder der Baugemeinschaft demzufolge mitentscheiden.

So scheint Herr Frings dennoch enttäuscht über die Entscheidung zu sein, dass seine Wohnung mit einer Zusatzheizung versehen wurde. Der komplette Verzicht auf eine aktive Heizung und damit verbunden die Vor- 
stellung, keine Heizkörper mehr in den Wohnräumen zu haben, genau das war es, was ihm am ursprünglichen Passivhausprinzip besonders gefallen hatte.

Herr Frings erzählt, dass es zu Beginn der Planungen hieß, dass eine zusätzliche Heizung bzw. Heizkörper nicht notwendig seien, anfangs sei lediglich von einer standardmäßigen Zuluftheizung, wie es das ursprüngliche Passivhauskonzept vorsieht, die Rede gewesen:

„Und dann hieß es genau am Anfang hieß es ja es gibt so eine Lösung da soll irgendwie über die Tür (.) also (.) oder [...] (.) so was (zeigt) über die Türen und so und das würde reichen weil diese Lüftungenund die und und einige Male hieß es nee es würden doch Heizkörper benötigt.“ (Bewohner PH, Interview 66: 3, 113-117)

Diese Passage verdeutlicht das Hin und Her des Planungsprozesses: Offenbar ist die Baugemeinschaft in ihren Überlegungen und Diskussionen bezüglich der Heizlösung zwischen den verschiedenen Optionen hin und her geschwankt. Herrn Frings zufolge ging es dabei wesentlich um die Entscheidung zwischen zwei grundsätzlich verschiedenen Lösungen: $\mathrm{Zu}-$ nächst habe es die Idee gegeben, dem klassischen Passivhausprinzip zu folgen und die Zimmer lediglich über die Zuluft zu beheizen. Dafür wären lediglich kleine elektrische Nacherwärmer vor den Zuluftschächten über den Zimmertüren anzubringen gewesen. Dann, so beschreibt es Herr Frings, sei innerhalb der Bauprojektgruppe diskutiert worden, ob nicht doch ein konventionelles Heizungssystem mit Heizkörpern in allen Räumen für besondere Kälteperioden notwendig sei. Offenbar lebte diese Debatte um die Heizlösung noch einige Zeit fort. Herr Frings gibt auf jeden Fall an, von der endgültigen Entscheidung für ein zusätzliches Heizungssystem erst aus den finalen Bauplänen erfahren zu haben. Der Entschluss für ihn scheinbar bis heute nicht nachzuvollziehen, wann und wie dieser zustande gekommen ist - muss demnach noch im Planungsprozess erfolgt sein:

„Und da waren wir einmal bei dieses- musste man halt jede [Wohnpartei, JM] so zu einem Büro gehen und dann hab ich die Zeichnungen gesehen und ich hab gesagt,Nee das kann doch nich@wahr sein@‘. Aber gut (.) es is notwendig anscheinend und dann da kann man-“ (ebd.: 3, 118-122)

Herr Frings’ spontaner Ausspruch „Nee das kann doch nich@wahr sein@“ (ebd., 120-121) zeigt, dass er bis zuletzt mit der Entscheidung für eine so umfassende Zusatzheizung nicht gerechnet hat. Allerdings wird in dieser 
Passage auch deutlich, dass er sich diesem Entschluss gefügt und die grundsätzliche Entscheidung über die Heizlösung offenbar als nicht mehr verhandelbar hingenommen hat.

Die Entscheidung für die Zusatzheizung scheint bei Herrn Frings jedoch negativ nachgewirkt zu haben. So beschreibt er, dass bei ihm dadurch neue grundsätzliche Zweifel an der (Tauglichkeit der) Passivhaustechnologie aufgekommen sind. In der Vorstellung von Herrn Frings erfordert das Passivhaus im Prinzip keine Zusatzheizung. Das Hin und Her bezüglich der Heizlösung und dass die Expert*innen entgegen der Theorie behaupteten, die Bewohner*innen des Passivhauses D würden nun doch eine zusätzliche Heizung benötigen, hat Herrn Frings offenbar verunsichert und skeptisch gegenüber der Funktionsweise der Passivhaustechnologie werden lassen.

Gleichzeitig scheint es so, dass Herr Frings seine Erwartungshaltung schnell an diese Entscheidung angepasst hat bzw. dass bei ihm schon vorher weitergehende Erwartungen bezüglich der Heizlösung ,Passivhaus mit Zusatzheizung' vorhanden gewesen sind: An anderer Stelle im Interview wird deutlich, dass Herr Frings bereits für den Fall, dass im Passivhausprojekt D zur Restwärmedeckung tatsächlich eine zusätzliche Heizung installiert würde, genaue Vorstellungen hatte. So hatte er die Erwartung, dass wenn schon zusätzliche Heizung - nicht unbedingt alle Wohnräume mit Heizkörpern versehen werden (müssen) und diese notwendig einzubauenden Heizkörper entsprechend klein dimensioniert sein würden:

„Heizung. Äh beziehungsweise wenn überhaupt nur ganz klein irgendwo so nur irgendwo eine Zelle und so. Und das fand ich super weil das hab ich gehasst äh dass immer eine Wand so (.) kaputt is." (ebd.: 2, 80-82)

Hier kommt erneut zum Ausdruck, dass sich Herr Frings auf den Wegfall einer Zusatzheizung bereits eingestellt hatte. Er hatte sich von der Einsparung zusätzlicher Heizkörper erhofft, mehr freie Wandfläche zur Verfügung zu haben. Deutlich wird, dass Herr Frings die feste (und vorab festgelegte) Installation von Heizkörpern in Wohnräumen als Eingriff in die Freiheit sieht, die Wohnräume gemäß seinen Vorstellungen einzurichten und zu gestalten. Denn damit die von ihnen ausgehende Wärme in den Raum ausstrahlen kann, müssen Heizkörper frei stehen. Das heißt, vor die Wand, an der ein Heizkörper anmontiert ist, können in der Regel keine Möbel mehr gestellt werden - ein Teil an freier Stellfläche fällt damit weg. Mit der Platzierung eines Heizkörpers an einer Zimmerwand ist ein Wohnraum in seinem materiellen Arrangement immer schon zu einem 
gewissen Grad festgelegt, dadurch bleiben den Bewohner*innen nur begrenzte Möglichkeiten, die Wohnräume flexibel bzw. den eigenen Wünschen entsprechend einzurichten.

Dieses Muster, Enttäuschung über die Installation eines zusätzlichen konventionellen aktiven Raumheizungssystems, weil man die Vorab-Erwartung hatte, durch den Wegfall der dafür erforderlichen Heizkörper, zusätzliche freie Stellfläche in den Wohnräumen zu gewinnen, wird auch im Fall von Frau Hartwig deutlich. Frau Hartwig bewohnt ein Passivhaus, welches Teil einer größeren Reihenhaussiedlung ist. ${ }^{79}$ Auch Frau Hartwig erzählt, dass sie anfangs regelrecht enttäuscht gewesen sei, als sie davon gehört habe, dass die Architektin fest plane, das Passivhausprojekt C zusätzlich mit einer konventionellen Heizung auszustatten. Denn genauso wie Herr Frings hatte sich Frau Hartwig bereits auf flexibel einzurichtende Zimmer bzw. den dazugewonnenen Stellplatz eingestellt, der sich durch den Verzicht auf einzelne Heizkörper in allen Wohnräumen ergeben hätte.

Bisher ist der Eindruck entstanden, dass Herr Frings die grundsätzliche Vereinbarung der Baugemeinschaft, Zusatzheizungen in den einzelnen Wohnungen zu installieren, ohne große Widerrede akzeptiert hat. Ein etwas anderes Bild entsteht, als Herr Frings ausführlicher von der konkreten Ausgestaltung der Heizlösung in seiner Wohnung erzählt: So erklärt er, dass er zunächst weiterhin versucht hat, den Einbau von Heizkörpern in allen Zimmern seiner Wohnung zu verhindern, räumt aber ein, dass er damit gescheitert sei. Und auch über die Lage bzw. die genaue Platzierung der Heizkörper im Raum, gibt Herr Frings an, habe er mit dem Ingenieur verhandelt. Dieser wollte die Heizkörper möglichst nah an den Türen platzieren, um lange Rohrleitungen zu sparen. Herr Frings hat sich dann aber dafür eingesetzt, dass - wo dies möglich war - die Heizkörper in üblicher Weise unter den Fenstern installiert werden, damit ihm durch die Monta-

79 Die Wohnhaussiedlung besteht aus insgesamt 45 Wohneinheiten, wovon sich 34 Wohneinheiten in Niedrigenergiehäusern und 11 Wohneinheiten in Passivhäusern befinden. Die Siedlung wurde als Genossenschaftsprojekt realisiert. Für die Errichtung dieses Mehrparteienwohnprojekts haben sich Familien, Lebens- und Wohngemeinschaften, Paare und Alleinstehende in einer Bau- und Wohnungsgenossenschaft zusammengeschlossen. Frau Hartwigs Geschichte stellt insofern einen Sonderfall dar, als das Passivhausprojekt, dem ihr Haus angehört, eindeutig der ersten Generation Passivhäuser zuzurechnen ist. Demnach taucht die Übergangsvariante von konventionellem Heizen zum Heizen im Passivhaus mit zusätzlichen Heizkörpern vereinzelt auch schon bei Passivhäusern erster Generation auf (siehe Anhang A - Es handelt sich hier um das Passivhausprojekt C). 
ge der Heizkörper nicht noch weitere kostbare freie Wandstellflächen verloren gehen. Hinsichtlich der Größe der Heizkörper ist er wiederum enttäuscht worden, alle verbauten Heizkörper seien ,normal groß`. Dies ärgert Herrn Frings umso mehr, da sich im Verlauf der letzten zwei Jahre und damit während zwei Heizperioden gezeigt hat, dass die zusätzliche Heizung von seiner Familie wie von Gästen tatsächlich kaum gebraucht wird.

Im weiteren Verlauf des Interviews wird deutlich, dass Herr Frings, obwohl er zugibt, dass die zusätzlichen Heizmöglichkeiten gelegentlich schon gebraucht werden, er dennoch gerne auf die fest installierten Heizkörper verzichtet hätte. Es lässt sich hier spekulieren, ob Herr Frings für die seltenen Situationen, in denen eine zusätzliche Wärmequelle in seiner Passivhauswohnung benötigt wird, beispielsweise die Aufstellung mobiler Heizgeräte in den einzelnen Wohnräumen gegenüber den dauerhaft fest an der Wand installierten Heizkörpern favorisiert hätte, um - wie oben bereits erwähnt - insgesamt mehr freie Wandstellfläche zur Verfügung zu haben.

Später beim gemeinsamen Rundgang durch die Wohnung fällt auf, dass der große Heizkörper für Flur und Wohnzimmer offenbar bereits zu einer Art Magnetpinnwand mit Ablagefläche umfunktioniert wurde. An diesem hängen zahlreiche Zeichnungen und gemalte Bilder der Kinder und oben auf dem Heizkörper stehen Telefon und ein Stiftständer, liegen ein Zettelblock sowie ein Paar Handschuhe. Daraufhin fragt die Interviewerin noch einmal direkt nach, ob dieser Heizkörper in Benutzung ist, woraufhin Herr Frings erklärt, dass sie diesen Heizkörper seines Wissens tatsächlich noch „nie angemacht“ (Bewohner PH, Interview 66: 13, 662) hätten.

Die Umnutzung des Heizkörpers während der Heizperiode verdeutlicht, dass dieser für gewöhnlich von der Familie nicht angestellt wird. Die Umnutzung für andere Zwecke - hier konkret als Ablage und Pinnwand sorgt dafür, dass sich Herr Frings nicht ständig an den in seinen Augen ,nutzlosen' Heizkörper und den durch ihn verschwendeten kostbaren Stellplatz erinnert fühlt. Der Heizkörper erscheint hier wie ein ,Überbleib-

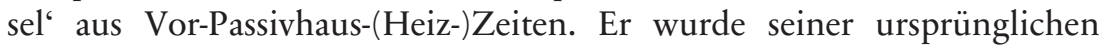
Funktion enthoben und stellt in diesem Haushalt gewissermaßen ein (technisches) Relikt längst vergangener Heizpraxis dar.

Shove und Pantzar (2006) vergleichen diese Entwicklung mit Prozessen, die in der Paläontologie als Versteinerung (,Fossilisation') bezeichnet werden; sie wenden ,Versteinerungsmetaphern' (ebd.: 59) zur Analyse des Soziallebens an, um Prozesse des Wandels und ,(Aus-)Sterbens' von Praktiken zu beschreiben, die ihrer Ansicht nach - vor allem im Vergleich zu sozialen Innovationen - bislang noch sehr wenig erforscht worden sind (vgl. 
ebd.). Auf Praktiken angewandt, bedeutet der Prozess der ,Versteinerung', wie in Teilkapitel 2.3.2.2 bereits dargelegt, im Wesentlichen das Aufbrechen bestehender Kombinationen und Verknüpfungen von bzw. zwischen bereits existenten Elementen. Demnach handelt es sich bei ,sozialen Fossilien' (ebd.) um Materialien, Bedeutungen oder Kompetenzen, die einst Bestandteil(e) einer integrierten sozialen Praktik waren, nun aber (heraus-)getrennt wurden und vor sich hindümpeln.

Möglich ist, dass die Vergangenheit bzw. vergangene Praxis in gewisser Hinsicht in der Gegenwart weiter fortlebt, etwa in Form ,lebendiger Fossilien' (ebd.: 60). Normalerweise bzw. zu erwarten wäre, dass funktionsbzw. nutzlos gewordene Elemente irgendwann ,verschwinden'. In manchen Fällen bleiben sie aber auch über lange Zeit praktisch unverändert bestehen und werden dann manchmal nach langer Inaktivität wieder ,zu neuem Leben erweckt' (vgl. ebd.: 60ff). Die Metapher des ,lebenden Fossils` lässt sich auf den Heizkörper im Passivhaus anwenden.

Mobile Gegenstände, die nicht mehr gebraucht werden (z.B. Brotbackautomat oder Küchenmaschine), werden häufig in den Keller oder auf den Dachboden verfrachtet und dort aufbewahrt. Beim Heizkörper handelt es sich allerdings um ein fest installiertes Objekt, deshalb stellt sich seine Beseitigung als schwieriger dar.

Frau Schulze hat sich die Mühe gemacht und die nicht benötigten Heizkörper irgendwann selbständig demontiert. Diesem Schritt ging eine lange Phase voran, in der die Heizkörper ungenutzt an der Wand hingen. Dies dürfte bei unbrauchbar gewordenen, aber fest installierten Artefakten meistens der Fall sein, dass sie als ,Rudimente' vorheriger Praktiken erhalten bleiben. Entweder ruhen sie dann bzw. existieren als, lebendes Fossil ${ }^{\circ}$ fort oder sie werden - wie etwa im Fall des Haushaltes Frings - zweckentfremdet und sinnvoll umfunktioniert.

\subsubsection{6 „Aber wir haben die [Heizkörper] überall und konnten die auch nicht wegdiskutieren" - Herr Thomsen}

Herr Thomsen, ein Mitglied aus dem gleichen Mehrparteien-Passivhauswohnprojekt, in dem Herr Frings wohnt, erzählt im Interview ebenfalls von den Diskussionen rund um die Heizkörper. Auch er hat sich darüber gewundert, dass in allen Wohnräumen zusätzliche Heizkörper eingebaut wurden, noch mehr war er über die enorme Größe der Heizkörper verwundert. Genauso wie sein direkter Nachbar Herr Frings war er fest davon ausgegangen, dass im Passivhaus - wenn überhaupt - nur sehr kleine Heiz- 
körper zum Dazuheizen erforderlich sind. Auf die Frage, ob bei ihm in der Wohnung in jedem Raum Heizkörper eingebaut sind, erklärt Herr Thomsen:

„Mhm (.) Das war uns so vorgeschrieben. Das hat uns auch 'n bisschen erstaunt weil die auch riesig groß sind. Ähm (.) Aber wir haben die überall und konnten die auch nicht wegdiskutieren. Das hat uns auch 'n bisschen erstaunt weil ich tatsächlich auch dachte sowas braucht man im Passivhaus nicht. Da hängen eher so kleine kleine Dinger rum. Aber irgendwie hat uns unser Haustechniker ausgerechnet wie groß die sein müssen und hat uns die reinge-(.)dotzt. Ich hätte mir die kleiner vorge- also das hätte ich mir tatsächlich kleiner vorgestellt.“ (Bewohner PH, Interview 69: 8, 397-405)

In diesem Zitat klingt bereits an, dass auch Herr Thomsen die Entscheidung über die Zusatzheizung und die Dimensionierung der einzelnen Heizkörper nicht widerspruchslos hingenommen, sondern in seinem Sinne zu beeinflussen versucht hat. Allerdings scheinen seine Versuche ohne großen Erfolg geblieben zu sein.

Der Passage lässt sich entnehmen, dass der Haustechniker keine ,Verhandlungen' zugelassen hat, sondern offenbar streng professionell vorgegangen ist, um die erforderliche Größe der Heizkörper zu ermitteln: er hat „ausgerechnet wie groß die [Heizkörper, JM] sein müssen“" (ebd., 402403). Der Ausdruck „unser Haustechniker [...] hat uns die reinge-(.)dotzt“ (ebd.) lässt darauf schließen, dass der Technik-Experte nicht nur bei der Entscheidung über die Größe, sondern auch beim Einbau der Heizkörper relativ rücksichtslos vorgegangen und weder auf Fragen noch Einwände oder individuelle Wünsche der Bewohner*innen eingegangen ist.

Genauso wie Herr Frings fühlt sich Herr Thomsen offenbar vor den Kopf gestoßen. Auch für ihn ist nicht ganz verständlich, weshalb im Planungsprozess die Interessen der künftigen Bewohner*innen weitestgehend übergangen wurden. Zwar hätten sie sich für ihre Interessen eingesetzt und nicht nur untereinander, sondern auch mit den Expert*innen diskutiert, so erzählt Herr Thomsen, aber viel erreicht hätten sie nicht:

„Da haben wir drüber diskutiert über die Heizkörper ja. Aber da ging irgendwie nix. Also an der Größe ging gar nichts. Am Platz konnte man irgendwie 'n bisschen was schieben. Aber (.) die sind jetzt ja auch nicht so breit insgesamt aber die- Also der (zeigt auf den Heizkörper im großen offenen Wohnzimmer) nervt total.“ (ebd.: 8, 409-412) 
In den Schilderungen von Herrn Thomsen wird bereits etwas darüber deutlich, wie die Interaktion zwischen der Baugemeinschaft und den Passivhaus- bzw. Technik-Expert"innen verlaufen ist. Offenbar sind die in die Diskussion involvierten Personen der beiden Gruppen bei der Planung und Auswahl einer geeigneten Heizlösung für das Passivhausprojekt D von unterschiedlichen bzw. konkurrierenden Zielgrößen ausgegangen: Während sich die Technik-Expert*innen für ihre Planungen offenbar ausschließlich an dem (objektiven) Wärmebedarf der späteren Nutzer*innen (bei vorgegebener Raumgröße usw.) orientiert haben, spielten für die künftigen Bewohner*innen für die Entscheidung und konkrete Ausgestaltung der Heizlösung ganz andere Faktoren eine (vorrangige) Rolle. Wie den Darstellungen des Herrn Frings und Herrn Thomsen zu entnehmen ist, stand für die Bewohner*innen des Passivhauses D bei der Diskussion über den Einbau einer zusätzlichen aktiven Gebäudeheizung vor allem im Vordergrund, wie viele zusätzliche Heizkörper in ihren Wohnungen fest installiert werden, wie groß diese jeweils sind bzw. sein müssen und wo, das heißt an welcher Wand die Heizkörper in den einzelnen Räumen jeweils montiert werden (können). Demnach scheinen die Bewohner*innen von Anfang an eher mit Fragen der Raumnutzung und danach, wieviel freier (Stell-)Platz ihnen letztendlich in ihren Wohnungen zur Verfügung steht, beschäftigt gewesen zu sein, als dass sie sich von sich aus Gedanken um eine (nicht) ausreichende Wärmeversorgung im Passivhaus gemacht hätten.

\subsubsection{Einfluss und Lernen der Expert*innen im Prozess des Passivhausbaus (mit neuer Heizlösung) - Herr Frings, Frau Rosental, Herr Lehmann und Herr Meier}

Sowohl die Schilderungen des Herrn Frings als auch die des Herrn Thomsen vermitteln den Eindruck, dass die Entscheidung über die letztendlich zustande gekommene Heizlösung im Passivhausprojekt D nicht primär von den künftigen Bewohner"innen ausging, obwohl sie als Baugemeinschaft gleichzeitig Bauherr*innen des Passivhauses waren. Die Berichte der beiden Bewohner verdeutlichen außerdem, dass die Anliegen und Interessen der Baugemeinschaftsmitglieder und gleichzeitigen Bauherr"innen im Verhandlungsprozess sogar vergleichsweise wenig Beachtung gefunden haben. Vielmehr deutet sich in ihren Erzählungen an, dass mehr oder weniger über die Köpfe der künftigen Bewohner*innen hinweg entschieden wurde und sie sich letztendlich mit vollendeten Tatsachen bzw. mit bereits 
fertigen Bauplänen konfrontiert sahen. Es scheint, dass der Entschluss, eine Zusatzheizung mit Heizkörpern zur Wärmeverteilung in allen Räumen zu installieren, bei diesem Wohnprojekt wesentlich von der verantwortlichen Architektin in Kooperation mit dem verantwortlichen Haustechniker forciert und durchgesetzt wurde. Diese Annahme bestätigt sich, als die Interviewerin im Gespräch mit Herrn Frings noch einmal dezidiert nachfragt, wie es (aus seiner Sicht) letztendlich zur Entscheidung über die realisierte Heizlösung gekommen ist:

„Also ich glaube dass (1) das war so eine technische Entscheidung (.) und die wurde überwiegend (.) so ff- ich erinner so als fast alternativlos vorgestellt also (2). Alles an- also wenn ich es richtig verstanden habe damals und ich mich richtig erinnere hätte es die Möglichkeit gegeben eine andere Art von Aufwärmen der Luft de=de- ich glaube so durch diese Lüftungsanlage tatsächlich. Aber (2) ging es technisch nich hundertprozentig weil die Schächte nich groß genug waren oder war kostenmäßig viel mehr als das hier so dass es den Rahmen übersprang und (.) in viele technische Sachen na- Obwohl in der Gruppe sich auch Leute immer sehr gut informiert haben und so was aber (.) waren wir auch auf das Rat von der Architektin und von den Ingenieuren angewiesen und wenn sie gesagt haben nee eigentlich gibt es (.) wirklich keine richtige Alternative da saß man da und sagt na gut dann is es halt so. Kann man nich (3) nich ändern." (Bewohner PH, Interview 66: $10,472-485)$

Offensichtlich wurden den Baugruppenmitgliedern niemals ernsthaft verschiedene Heizlösungen zur freien Auswahl gestellt. Zwar wurde ihnen von den Expert"innen neben der Option einer aktiven Zusatzheizung auch die grundsätzliche Möglichkeit vorgestellt, das Passivhaus über eine reine Zuluftheizung zu beheizen, aber als eine wirklich wählbare Alternative wurde den künftigen Bewohner*innen die letztgenannte Heizlösung offenbar nicht präsentiert. Die Beschreibung des Herrn Frings macht deutlich, dass die verantwortliche Architektin und auch die involvierten Ingenieure in den Diskussionen mit den Baugruppenmitgliedern um eine geeignete Heizlösung für das Passivmehrfamilienhaus D von Anfang an sowohl triftige technische Gründe als auch finanzielle Restriktionen angeführt haben, die die Entscheidung über die Heizlösung für die künftigen Bewohner*innen praktisch ,alternativlos' erscheinen ließ. Die Schilderung des Herrn Frings verweist somit auf die zentrale Rolle, die Architekt*innen und Bauingenieur*innen im Planungs- und Bauprozess eines Passivhauses sowie für die damit einhergehende neue Heizlösung zukommt. 
Gleichzeitig wird anhand der Darstellung von Herrn Frings deutlich, welches Verständnis er vom Verhältnis der beiden zentral am Hausbau beteiligten Gruppen hat. Herr Frings geht offenbar von der klassischen Differenzierung zwischen erfahrenen Expert"innen auf der einen Seite und weitgehend ahnungslosen Lai"innen auf der anderen Seite aus: Als Expert"innen mit viel praktischer Erfahrung stehen Architekt"innen und Bauingenieur"innen diesem Verständnis nach den technisch meist unbewanderten künftigen Bewohner*innen und (manchmal) gleichzeitigen Bauherr*innen, die sich im besten Fall vorab in Eigeninitiative zumindest „sehr gut informiert haben“ (ebd.: 10, 481) gegenüber. Mit dieser Vorstellung ist verbunden, dass es sich bei dem von den Bewohner"innen angeeigneten Wissen lediglich um ein rein theoretisches, häufig nur oberflächlich angelesenes Wissen handelt, wohingegen die Architekt"innen, Bauingenieur*innen und Haustechniker*innen neben der besonderen Fachkenntnis zusätzlich über praktische Erfahrung verfügen. Aus diesem Wissensgefälle leiten sich für Herrn Frings die Überlegenheit der Expert*innenmeinung sowie die Angewiesenheit der Bewohner*innen auf den Expert"innenrat ab.

An dieser Stelle soll noch einmal an die in Teilkapitel 4.1.1.1 präsentierte Fallgeschichte Frau Rosentals angeknüpft werden. Interessant ist, was Frau Rosental - mehr oder weniger nebenbei - von der Kommunikation ihrer Baugruppe mit der für das Passivhausprojekt B verantwortlichen Architektin hinsichtlich der in diesem Mehrparteien-Passivhaus realisierten Heizlösung berichtet, als sie mit der Erzählung zu ihren zusätzlichen Heizkörpern fortfährt.

Zur Erinnerung: Bei dem Passivhausprojekt B, in dem Frau Rosental eine Wohnung bewohnt, handelt es sich um ein Passivhaus der ersten Generation mit der klassischen, wie im ursprünglichen Passivhauskonzept vorgesehenen Heizlösung (vgl. Feist et al. 2005): Das Mehrparteien-Passivhaus B wird über die kontrolliert eingeschleuste Zuluft erwärmt, verfügt also über eine so genannte Luftheizung - das heißt, die Heizung ist hier an die Lüftung gekoppelt. Wie bereits in Teilkapitel 4.1.1.1 dargelegt, hat sich Frau Rosental im Unterschied zu den meisten anderen Hausmitbewohner*innen auf expliziten Wunsch zusätzliche Heizkörper in allen ihren Wohnräumen einbauen lassen, um jederzeit eine Möglichkeit zum Dazuheizen zu haben. Allerdings nutzt sie diese Zusatzheizung praktisch nicht. In diesem Zusammenhang ist interessant, wie Frau Rosental an dieser Stelle weiter argumentiert, warum sie die zusätzlichen Heizkörper offenbar dennoch sinnvoll findet und diese (als alternative Option) auch weiterhin behalten will: Die Fortsetzung ihrer Argumentation lässt nämlich erken- 
nen, dass Frau Rosental die zusätzlichen Heizkörper tatsächlich als Absicherung für ,richtig kalte' Tage ansieht, die es aber offenbar während ihrer bisherigen Zeit im Passivhaus nahezu nicht gab. Darüber hinaus erwähnt Frau Rosental, dass ihr dadurch grundsätzlich immer auch die Möglichkeit offensteht, die Zuluftheizung höher zu stellen. Den anderen Hausbewohner*innen, die keine Zusatzheizung installiert haben, steht demgegenüber nur diese Option zur Verfügung. Allerdings stellt diese Option, die Wärmezufuhr über die Lüftung zu erhöhen, aus Frau Rosentals Sicht keine wirklich attraktive Alternative dar. Das lässt darauf schließen, dass die Wärme(zufuhr) über die Lüftung in Frau Rosentals Wohnung nur zentral zu regeln ist und wie es das ursprüngliche Passivhauskonzept vorsieht, dass sie mittels der Luftheizung also keine unterschiedlichen Temperaturen für die einzelnen Räume einstellen, sondern nur eine Temperatur für die gesamte Wohnung festlegen kann. Offenkundig hängt Frau Rosentals Festhalten an den zusätzlichen Heizkörpern also vorrangig mit ihrer Unzufriedenheit mit der Konstruktion der grundsätzlichen Wärmeversorgung im Passivhausprojekt B zusammen. Anstatt die Gesamttemperatur höher einzustellen, hat sie somit jederzeit die Möglichkeit, ihre zusätzlichen Heizkörper anzustellen. Diese Deutung bestätigt sich im Anschluss, als sich Frau Lutz, ebenfalls eine Bewohnerin des Passivhauses B, die eine Etage über Frau Rosental wohnt, in das gemeinsame Interviewgespräch einbringt:

Frau Lutz: Es lassen sich nich die Zimmer einzeln regulieren. In unserem nich. Ich glaube [die Architektin] Lhat inzwischen

Frau Rosental: Genau $\lrcorner$

Frau Lutz: gemerkt dass das 'n Defizit is und (.) dass man das anders Lbauen muss.

Frau Rosental: Ja die hat also $\lrcorner$ Lüftungen abgekoppelt und hat die

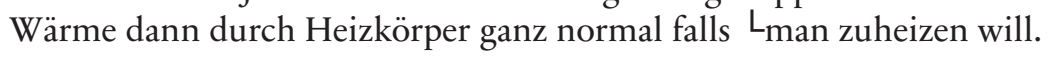
Ja und dass

Interviewerin JM: Dass man dazu regulieren kann $\lrcorner$

Frau Rosental: das nich mit der Lüftung gekoppelt is. Und das is bei uns nich.“

(Bewohnerinnen PH, Interview 59: 6, 292-305)

Der Dialogausschnitt verdeutlicht einen weiteren wichtigen Punkt, der für den hier angestrebten Fallvergleich mit Herrn Frings eine zentrale Rolle spielt: So beschreiben die beiden Bewohnerinnen indirekt mit, wie die Realisierung ihres Passivhauses zu einem wichtigen Lernprozess für die verantwortliche Architektin geworden ist. Anscheinend hat die Architek- 
tin bei diesem Bauprojekt erste wichtige Erfahrungen mit der Passivhausbauweise, vor allem aber in Bezug auf die Konzeption von Lüftung und Wärmeversorgung des Passivhauses gesammelt, die sie bei darauffolgenden Passivhausbauprojekten offenbar bereits erfolgreich umgesetzt hat. Hier liegt die Deutung nahe, dass die Architektin zu Beginn des Bauprojekts B über nur geringe oder keinerlei praktische Kenntnisse hinsichtlich der Passivhausbauweise verfügte und sich ihr praktisches Wissen zum Passivhaus erst allmählich mit der Umsetzung konkreter Bauprojekte angeeignet hat. Diese Deutung wird durch eine andere Passage aus dem gemeinsamen Interview mit Frau Rosental und Frau Lutz gestützt. Auf die Frage der Interviewerin, wie die Architektin in den Entscheidungsprozess für das Passivhaus involviert gewesen sei, erklärt Frau Rosental, dass die Architektin mit der Konzeption und Umsetzung des Passivhausprojekts B sich etwas Neues erarbeitet habe. Aus diesem Grund sei die Architektin damals mit ihnen gemeinsam nach Kassel gefahren, um die dort errichteten Passivhäuser zu besichtigen und von diesen Pionierprojekten zu lernen. ${ }^{80}$

Dieser Punkt, dass viele der Architekt*innen von Passivhäusern der ersten Generation mit wenig Vorkenntnis ihre ersten Bauprojekte begonnen und wichtiges praktisches Know-how zum Passivhaus erst über die Jahre mit zunehmender Praxis gewonnen haben, ist wesentlich mitbestimmend für den Umschwung hinsichtlich der Heizlösung von Mehrfamilien-Passivhäusern der ersten zu jenen Passivhäusern der zweiten Generation. Mit den ersten größeren Passivhausbauprojekten wurde gewissermaßen ,Pionierarbeit' geleistet. Die hierbei gemachten Erfahrungen haben die Architekt"innen der ersten Generation Passivhäuser in ihre neuen Projekte hineingetragen bzw. dieses akkumulierte Praxiswissen wurde von nachfolgenden Architekt*innen übernommen, die es in ihre Arbeit einfließen ließen und es wiederum mit ihren Erfahrungen immer weiter anreicherten und noch weiterhin anreichern.

Während also die für diese Arbeit interviewten Bewohner*innen der zweiten Generation (Mehrfamilien-)Passivhäuser inzwischen besser über das Passivhausprinzip informiert gewesen sind und sich ihre Vorstellungen und Erwartungen teilweise dahingehend geändert hatten, dass sie nicht mit einer zusätzlichen Heizung im Passivhaus rechneten, haben die Passivhaus-Architekt*innen und Bauingenieur*innen offenbar gleichzeitig die

80 In Kassel befindet sich eines der ersten in Deutschland erbauten (Mehrfamilien-)Mietwohnungshäuser, die im Passivhausstandard realisiert wurden und deren Betrieb im Rahmen des EU-geförderten Projekts ,Cost Efficient Passive Houses as European Standards‘ (CEPHEUS) evaluiert wurde (vgl. Feist et al. 2005: 1189). 
gegenteilige Wendung vollzogen. Auf Expert"innenseite ist man (zumindest in hiesigen Breitengraden) mittlerweile dazu übergegangen, Passivhäuser mit mehreren Wohneinheiten standardmäßig mit einer konventionellen Zusatzheizung und einzeln regelbaren Heizkörpern in allen Wohnräumen auszustatten. Dabei begründen die Architekt*innen ihre Entscheidung genauso wie einst die Bewohner*innen der ersten Generation Passivhäuser, die sich nicht vorstellen konnten, auf Heizkörper in den einzelnen Wohnräumen zu verzichten, ihre damalige Forderung nach einer Zusatzheizung begründeten: mit ihrem Erfahrungswissen. Bei den Expert*innen verhält es sich ähnlich wie bei den Bewohner*innen. Auch sie verfügten anfangs über keine großen Erfahrungen mit der Passivhausbauweise, sondern mussten sich damals vor allem auf die Theorie und ihr technisches Fachwissen verlassen. Inzwischen haben Architekt*innen und Ingenieur*innen etwa zweieinhalb Jahrzehnte lang Erfahrungen mit der Passivhausbau- und -funktionsweise sammeln können und versuchen nun das hierbei Gelernte umzusetzen.

Fast alle interviewten Passivhaus-Architekt*innen erklären, in der praktischen Umsetzung überwiegend die Erfahrung gemacht zu haben, dass die meisten Bewohner*innen mit nur einer einheitlichen Temperatur in der ganzen Wohnung bzw. in allen Wohnräumen nicht zufrieden seien und sich damit nicht wohlfühlten, sondern dass sie zum Teil sehr unterschiedliche Temperaturen in den einzelnen Räumen bevorzugen. Zudem hat sich herausgestellt, so berichten mehrere Architekt*innen in den Interviews, dass die Bewohner*innen großen Wert darauf legten, die Temperatureinstellungen für die eigene Wohnung individuell handhaben zu können. Dies beides sei technisch deutlich einfacher mit einer konventionellen $\mathrm{Zu}$ satzheizung mit dezentraler Wärmeverteilung über Heizkörper in jedem Zimmer zu erreichen als mit einer reinen Zuluftheizung. Das Hauptargument vieler Architekt*innen ist hier, dass sich durch diese Maßnahmen nicht nur die Zufriedenheit der Nutzer*innen, sondern auch die Akzeptanz von Passivhäusern deutlich steigern lässt. Das folgende längere Zitat des erfahrenen Passivhausarchitekten Herrn Lehmann illustriert diesen Punkt anschaulich:

„eine Luftheizung in den einzelnen Räumen unterschiedlich zu temperieren ist extrem aufwendig und schwierig. Ähm die Leute wollen auch in den Räumen unterschiedliche Temperatur haben also äh im Badezimmer will man gerne $24\left[{ }^{\circ} \mathrm{C}\right]$ haben im Wohnzimmer was weiß ich 20 bis 22 und in den Schlafräumen will man irgendwie aber vielleicht nur 16 ja haben. Und das is' dann immer so für 'ne Luftheizung relativ schwierig. Wenn ich generell meine Luft mit was weiß ich 16 
17 Grad einblase und dann die Räume nur dementsprechend nachtemperiere mit kleinen Heizkörpern ist die Akzeptanz viel- viel größer da. Dann haben die Leute das Gefühl sie können selber- es lässt sich auch wirklich einfach händeln. Ich kann den Heizkörper eher regeln als hochkompliziert irgendwo die äh Belüftung irgendwo in den Temperaturen zu regeln. Das geht zentral schon schwierig auch wenn ich's dezentral mache für die Wohnung auch da ist es dann relativ schwierig sie so dass in den einzelnen Räumen unterschiedliche Temperaturen rein kommen. [...] Zwei sechs [2006] oder zwei sieben [2007] hatte ich [...] eine Untersuchung der hier [.] gebauten Passivhäuser gemacht. Und da kam also raus dass ähm wir hatten- also ich hatte acht Mehrfamilienhäuser äh untersucht und da waren bei vier mit Heizungen und vier ohne. Und die Akzeptanz bei denen mit Heizung war ein wesentlich größeres als in den anderen. Und= äh das hat sich mittlerweile [...]. Weil es einfach glaube ich einfacher durchsetzbar is und regelbarer einfach is.“ (Architekt PH, Interview 52: 9f, 466-495)

Diese längere Passage verdeutlicht, dass die Expert*innen durch konkrete Praxis zwar viel gelernt haben, beispielsweise was die technische Realisierbarkeit und (bestmögliche) Umsetzung des Passivhausstandards anbelangt, dass sie dabei aber dem vorherrschenden Akzeptanz-Rahmen verhaftet geblieben sind. Demnach war es vor allem die größere Nutzer*innenakzeptanz, die sie dazu bewogen hat, in Passivhaus-Mehrfamilienhäusern - anstelle einer Zuluftheizung in Form eines der Lüftung vorgeschalteten elektrischen Nachheizregisters - häufig (wieder) ein konventionelles aktives Heizungssystem bzw. Wärmeverteilnetz mit regelbaren Heizkörpern in allen Räumen zu installieren, obwohl dies für eine ausreichende Wärmeversorgung in der Regel nicht erforderlich ist. Laut dem Architekten Herrn Meier stellt die Zusatzheizung in den meisten Fällen vielmehr ein zusätzliches „Komfortmerkmal“ (Architekt PH, Interview 48: 7, 292) dar, mit dem man den gängigen Erwartungen und Komfortansprüchen von Bauherr*innen (Geldgeber*innen) und potenziellen künftigen Nutzer*innen des Passivhauses gerecht zu werden versucht. Hier liegt die Vermutung nahe, dass die Expert*innen offenbar nicht gelernt haben, bisher nicht willens waren oder es sich womöglich auch nicht zutrauten, derartige Themen und Fragen mit den jeweiligen Bauherr*innen und/oder künftigen Bewohner*innen offen auszuhandeln. Diese Deutung, dass von Expert"innenseite die Diskussionen um die im Einzelfall am besten geeignete Heizlösung für ein Passivmehrfamilienhaus zum Teil eher gemieden werden, wird durch die folgende Schilderung von Herrn Meier gestützt: 
„die Frage der: ähm (1) Art der Wärmeverteilung ähm ist eigentlich so [...] der ganze Witz des Passivhauses ist (.) dass es eben keine Wärmeverteilung mehr braucht - also wir wir planen unsere Passivhäuser so dass wir ähm nur 'ne Zuluftheizung brauchen was eben dazu führt dass wir diese ganzen Heizkörper sparen können und [...] das ist eben auch der der Punkt ähm wo Sie- dadurch dass Sie das Wärmeverteilnetz weitestgehend einsparen (1) können Sie sich im Grunde die Mehrkosten für die Lüftungsanlage leisten und dadurch wird's wieder günstiger- und wir haben ähm äh- Kollege von mir der (räuspern) plant (räuspern) für [ein kommunales Wohnungsunternehmen] [...] wo dann in der Verwaltung irgendwelche Leute auf der Etappe sitzen die sich das nicht trauen ohne Heizkörper weil die meinen das: verstehen die Mieter nicht oder das kennen wir nicht oder funktioniert [nicht] oder wie auch immer - die bauen dann doch die Heizkörper ein. So. Nur zur Sicherheit. Funktioniert technisch natürlich genauso ist dann aber am Ende teurer möglicherweise sogar überreguliert [...] und (1) das ist dann eben auch so 'n Punkt wo: man dann nachher feststellt dass [kommunales Wohnungsunternehmen] dann erst gegen: (.) den Rat der Fachkreise eben so aus Nummer Sicherheit [...] und hinterher sagt ,Nee Passivhaus ist ja gar nicht günstiger im Neubau'، (Archtiekt PH, Interview 48: 6, 252-281)

Die Passage verdeutlicht, dass Herr Meier und Kolleg*innen diesbezüglich offenbar bei einem aktuellen Projekt, bei dem der Bauherr ein kommunales Wohnungsunternehmen ist, schlechte Erfahrungen gemacht haben: Hier hat Herr Meier (erneut) den Eindruck gewonnen, dass unter den Entscheidungsträger*innen im kommunalen Wohnungsbau offensichtlich große Skepsis gegenüber dem Passivhaus(prinzip) vorherrscht und die Verwaltung des kommunalen Wohnungsunternehmens seinem bzw. dem fachmännischen Rat seiner Kolleg*innen nicht traut, dass im Passivhaus auf eine zusätzliche aktive Heizung mit Wärmeverteilsystem verzichtet werden kann.

Herr Meier spekuliert hier über die diesbezüglichen Gründe der zuständigen Entscheidungsträger*innen in der Verwaltung des kommunalen Wohnungsunternehmens, weshalb von diesen so beharrlich am Altbekannten festgehalten wird: So hält Herr Meier es für möglich, dass die Entscheidungsträger*innen im kommunalen, wie häufig auch im sozialen Wohnungsbau (noch) von einem äußerst negativen, klischeehaften Mieter*innenbild ausgehen, wonach die für diese Art von Wohnraum in Frage kommende Klientel mit anspruchsvoller Gebäudetechnik wie der Passivhauslüftung mehrheitlich intellektuell überfordert sei. Liegt er mit dieser 
Vermutung richtig, dann wird sich sehr wahrscheinlich von Gebäudeverwaltungsseite deshalb nicht getraut, vom konventionellen Heizansatz abzuweichen, weil man ansonsten die kritische Auseinandersetzung mit (technisch überforderten) Mieter*innen befürchtet. Oder, so könne sich Herr Meier auch gut vorstellen, die entsprechenden Entscheidungsträger*innen in diesem Bereich haben selbst noch keinerlei Kenntnis von bzw. Erfahrung mit dem Passivhaus-Energiestandard - tragen also die gleichen Bedenken und Zweifel wie unerfahrene Passivhaus-Neubewohner*innen in sich - und begegnen dem Expert*innenvorschlag, auf zusätzliche Heizkörper zu verzichten, deshalb entsprechend skeptisch bis ablehnend.

Was der Passage in jedem Fall zu entnehmen ist, ist, dass offenbar häufiger, wenn es um größere kommunale Bauvorhaben geht, die Bauherr*innen - in diesem Fall ein kommunales Wohnungsunternehmen - unabhängig vom Rat der Expert"innen und z.T. auch ungeachtet finanzieller Aspekte bestimmen. Und der bzw. die für dieses Bauvorhaben angefragte Architekt"in wird das Bauprojekt vermutlich gemäß den Wünschen und Forderungen des bzw. der Bauherr*in umsetzen, um den Zuschlag für den Bauauftrag zu erhalten, auch wenn er bzw. sie fachlich und womöglich auch persönlich von der besseren Eignung einer anderen ,sparsameren Heizlösung für das entsprechende Bauprojekt überzeugt ist.

Von ähnlichen negativen Erfahrungen zu dem oben erwähnten kommunalen Wohnungsunternehmen wird auch in anderen Expert"inneninterviews berichtet. Zum Teil fällt hier die Kritik an dem kommunalen Wohnungsunternehmen jedoch deutlich drastischer aus: Der Architekt Herr Voigt und auch der Architekt Herr Beckert berichten davon, dass das Passivhausprojekt, das dieses kommunale Wohnungsunternehmen vor einigen Jahren testweise gebaut hat, sowohl technisch fehlerhaft geplant und umgesetzt als auch nicht korrekt wissenschaftlich evaluiert worden sei. Beide Architekten kommen im Interview unabhängig voneinander zu dem Schluss, dass die verantwortlichen Entscheidungsträger*innen bei dem kommunalen Wohnungsunternehmen damit „eigentlich nur nachweisen [wollten] dass Passivhaus nicht geht" (Architekt PH, Interview 53: 13, 633), und das deshalb, weil „die das [Passivhaustechnologie im sozialen Wohnungsbau, JM] am liebsten gar nicht machen möchten" (Architekt $\mathrm{PH}$, Interview 49: 6, 295). Es scheint so, als hätten die Expert"innen zumindest bezüglich dieses Bauherren, besagtes kommunales Wohnungsunternehmen, vorerst den Versuch aufgegeben, die dort für Neubauvorhaben verantwortlichen Entscheidungsträger"innen vom Passivhaus mit ,sparsamer` Heizlösung zu überzeugen. 
Im zweiten Teil dieses Kapitels werden Anpassungsprozesse rund um den Heizkörper nach dem Einbau der intelligenten Heizungssteuerungstechnik beleuchtet. Anhand einer ausgewählten Fallgeschichte, die etwas umfassender präsentiert wird, soll nun der prägende Einfluss der vergangenen Heizpraxis auf gegenwärtiges Heizen im SmartHome aufgezeigt werden. Zuvor erfolgt jedoch - ähnlich wie für die zuletzt dargestellten Passivhaus-Fälle - noch eine einführende Beschreibung der Ausgestaltung des technischen Heizsettings in den untersuchten SmartHome-Miethaushalten.

\subsubsection{Heizen im SmartHome - vom (konventionellen) Heizen mit Heizkörper mit mechanischem Thermostat zum intelligenten Heizen mit Heizkörper mit Funk-Stellantrieb}

In diesem Teil werden Gewöhnungs- und Umstellungsprozesse rund um den Heizkörper beschrieben, die sich nach dem Einbau intelligenter Heizungssteuerungstechnik ereignet haben. Im SmartHome beziehen sich die Anpassungsprozesse beim Heizen noch sehr viel stärker als im Passivhaus auf den Gegenstand des Heizkörpers. Dafür gibt es zwei Gründe: Erstens bleiben die Heizkörper im SmartHome grundsätzlich erhalten und sie verbleiben auch - nahezu unverändert - an ihrem bisherigen Platz. Lediglich die alten mechanischen Thermostate an den einzelnen Heizkörpern werden durch neue, digitale und per Funk steuerbare Geräte ausgetauscht. Dem Heizkörper kommt im SmartHome also auch weiterhin die Rolle des zentralen gegenständlichen und für die Bewohner*innen sichtbaren Elements des Heizens zu. Zweitens setzt die intelligente Heizungsregelungstechnik in den einzelnen Haushalten hauptsächlich am Heizkörper an: So besteht im SmartHome bezogen auf das Heizen die wesentliche Veränderung darin, dass der gesamte Heizvorgang weitestgehend automatisiert wird. Dafür werden die einzelnen, für das Wohnraumheizen wichtigen Apparaturen und technischen Geräte - in Wohnungen mit Zentralheizung sind dies im Wesentlichen die Heizkörper - intelligent miteinander vernetzt. Dadurch kann der gesamte Heizungsanlagenbetrieb eines Gebäudes bzw. die Heizung einer Wohnung zentral und weitestgehend automatisch kontrolliert werden. ${ }^{81}$ Die automatische Einzelraumtemperaturregelung, also der Zugriff auf die Ventilstellantriebe zur Steuerung der Wärme-

81 Während Mieter*innen in der Regel kaum Einfluss auf die Steuerung der zentralen Heizungsanlage im Hauskeller nehmen können, erhalten sie mit der intelli- 
abgabe der einzelnen Heizkörper, kann über ein Webportal mittels PC oder Tablet oder auch aus der Ferne via Smartphone erfolgen. Das heißt, an der grundlegenden ,Architektur ' des Heizens und der grundsätzlichen ,Aufgabenverteilung' zwischen den Heizgeräten ändert sich beim Übergang vom konventionellen zum vernetzten, intelligenten Heizen insgesamt nur wenig. Was für die Bewohner*innen an materiellen Gegenständen in ihren Wohnungen sichtbar neu hinzukommt, sind im Wesentlichen die intelligenten Heizkörperstellantriebe und kleine Raumtemperatursensoren in allen Räumen sowie ein Tabletcomputer, auf dem die Anwendungs- bzw. Bedienungssoftware installiert ist und von dem aus die zentrale Steuerung hauptsächlich erfolgen soll.

Die intelligente Heizungssteuerungstechnik ist damit weniger invasiv als die Passivhaustechnologie. So wurde bei allen befragten Bewohner*innen die intelligente Heizungsregelungstechnik in ihren aktuellen Wohnungen eingebaut, niemand ist umgezogen oder musste dafür gar temporär aus der eigenen Wohnung ausziehen. Die für diese Untersuchung interviewten Bewohner*innen stammen alle aus demselben Mehrparteien-Wohnhaus. Die mehrgeschossige Wohnimmobilie befindet sich in der Hand einer großen Hamburger Wohnungsbaugenossenschaft, alle Bewohner*innen wohnen dort zur Miete. Das in diesem Wohngebäude durchgeführte Pilotprojekt zum intelligenten Heizen hat die Baugenossenschaft gemeinsam mit einem großen Energieversorger initiiert. Dafür wurde die Hälfte der insgesamt etwa 150 Wohneinheiten umfassenden Liegenschaft mit intelligenter Heizungssteuerungstechnik ausgestattet. Die Teilnahme an dem Pilotprojekt war für die Mieter*innen verpflichtend; das heißt, die betroffenen Bewohner*innen hatten nicht die Option, sich gegen den Einbau zu entscheiden. Mit dem Pilotprojekt zielt die Genossenschaft darauf ab, durch eine automatische Steuerung des Wärmeverbrauchs in ihren Wohnimmobilien aktiv und effektiv Heizenergie und dadurch bedingte $\mathrm{CO}_{2}$-Emissionen einzusparen bzw. die Wärmeeffizienz in ihren Gebäuden zu steigern. Für die Mieter"innen verspricht man sich von dieser Maßnahme, dass sich durch die automatisierte Steuerung der Heizung der (Wärme-)Komfort in den Wohnungen erhöht und sie durch Reduzierung des Energieverbrauchs merklich an Heizkosten sparen. Darüber hinaus wurden für das Pilotprojekt bewusst denkmalgeschützte Häuser (mit Backsteinfassade, so genannter ,Rotklinker ${ }^{\mathrm{c}}$ ) ausgewählt, da die Baugenossenschaft Alternativen zur

genten Heizungssteuerungstechnik nun die Möglichkeit, zumindest die Heizung bzw. die Wärmeversorgung in ihrer Wohnung eigenständig zu steuern. 
Dämmung der Außenwände entwickeln möchte (vgl. HANSA Baugenossenschaft eG 2013: 6).82

\section{Dingliche Ausgestaltung der intelligenten Heizungsteuerung ${ }^{83}$}

Aus welchen materiellen Elementen setzt sich die neue Heizlösung zusammen? Wie sieht das technische Arrangement der intelligenten Heizungssteuerung in den einzelnen Wohnungen konkret aus? Im Folgenden wird kurz erklärt, wie die intelligente Heizungssteuerung auf der Ebene der einzelnen Wohnungen und auf Gebäudeebene in dem für diese Arbeit wissenschaftlich begleiteten Pilotprojekt ausgestaltet ist.

Auf der Wohnungsebene wurden zunächst alle mechanischen Thermostate an den einzelnen Heizkörpern durch neue digitale Geräte, so genannte (batteriebetriebene) Funk-Stellantriebe ersetzt. Die neuen Heizkörperstellantriebe sind nicht mehr manuell regelbar, sondern werden elektronisch per Funk über das lokale WLAN gesteuert, der Zugriff erfolgt über Internettechnologien. Das heißt, dass die einzelnen Heizkörper nur noch zentral, von einem fest neben der Wohnungstür installierten Tabletcomputer, dem so genannten ,Wohnungsmanager', aus angesteuert und bedient werden können. Der Wohnungsmanager ist über ein so genanntes ,Raumbussystem‘ mit den weiteren Komponenten der Einzelraumtempe-

82 Im Gebäudebereich stellt die Wärmedämmung der Außenwände im Allgemeinen die effektivste Maßnahme zur Energieeinsparung dar, weshalb dieser Schritt von Hausbesitzer*innen auch am ehesten getätigt wird. Dafür wird auf der bestehenden Fassade ein spezielles Wärmedämm-Verbundsystem fixiert und im Anschluss verputzt. Das heißt, die ursprüngliche Fassade wird überklebt und ihr Anblick verschwindet. Da Hamburgs rote Backsteinfassaden (,Rotklinker') aber als prägend für das ortstypische Stadtbild erachtet werden und als architektonischhistorisch wertvolles Erbe gelten, wurden sie unter Denkmalschutz gestellt. Dies bedeutet zugleich, dass für Rotklinker-Bauten die klassische Wärmedämmung als Maßnahme zur Energieeinsparung nicht in Frage kommt, sondern dass hier nach anderen Lösungen gesucht bzw. an anderer Stelle angesetzt werden muss. Genau dies wird mit der intelligenten Heizungssteuerung angestrebt, indem man mittels Automatisierungstechnik den Anlagenbetrieb zu optimieren versucht.

83 Die Ausführungen zur Ausgestaltung und Funktionsweise der smarten Heizungssteuerungstechnik basieren auf den Produktbeschreibungen des Technikanbieters. Diese Textdokumente (Broschüren, Flyer, Bedienungsanleitungen, usw.) können allerdings nicht präzise als herangezogene Informationsquelle angegeben werden, da sie eindeutige Rückschlüsse auf die in das Pilotprojekt involvierte Technikfirma zulassen. 
raturregelung informationstechnisch verbunden. ${ }^{84}$ Zur Einzelraumregelung gehören neben dem Wohnungsmanager auch die Raumtemperatursensoren, welche die jeweiligen Ist-Temperaturen der Wohnräume erfassen, und die Ventilstellantriebe, die die Wärmeabgabe der Heizkörper steuern. In diesem Fall findet eine funkbasierte Kommunikation zwischen dem Wohnungsmanager und den Temperatursensoren und Stellanrieben der Heizkörperventile in den einzelnen Räumen statt. Der Wohnungsmanager übernimmt die Verarbeitung der von den einzelnen Raumkomponenten erfassten Temperaturen und zeigt u.a. die Verbräuche für Heizung an. Der Wohnungsmanager stellt das zentrale Bedien- und Anzeigegerät der intelligenten Heizungssteuerung dar, über ihn kontrolliert der bzw. die Bewohner*in die Wärmeversorgung in seiner bzw. ihrer Wohnung. Das heißt, die Bewohner*innen regulieren die Heizkörper demnach nur noch zentral über den Wohnungsmanager. Dieser verfügt über ein spezielles Touchdisplay, die Bedienung erfolgt über diesen Touch-Bildschirm und zwei Sensortasten.

Der Wohnungsmanager besitzt eine Werkeinstellung, nach der alle Räume von sechs bis neun Uhr und von 18 bis 22 Uhr auf eine Temperatur von $21 \mathrm{Grad}$ Celsius geregelt werden. Werden keine individuellen Raumnutzungsprofile eingerichtet, so läuft die Heizung entsprechend dieser Standardeinstellung. Die Standardprofile, die auf jedem Wohnungsmanager anfangs verfügbar sind, sind mit ,Normal' und ,Abwesend' bezeichnet. Darüber hinaus können die Bewohner"innen weitere, eigene Nutzungsprofile erstellen.

Insgesamt ermöglicht der Wohnungsmanager die zeitprogrammierbare Temperaturregelung von bis zu 15 Räumen. Das heißt, die Bewohner*innen können für jeden ihrer Räume ein individuelles Zeit-Temperaturprogramm einstellen. Dafür geben die Bewohner*innen über das Touchdisplay ihre individuellen Nutzungszeiten und gewünschten Raumtemperaturen (Sollwerttemperaturen) für jeden Wohnraum und Wochentag ein.

84 Mit ,Bus' ist hier ein System zur Datenübertragung gemeint. Dabei sind mehrere ,Teilnehmer' (Geräte) über einen gemeinsamen Übertragungsweg miteinander verbunden, so dass sie auf diesem Wege Informationen austauschen können. Im Fall der Hausautomation verbindet ein solches System sämtliche Teilnehmer (Computer und Computerbestandteile) eines vernetzten Gebäudes logisch und auch physikalisch miteinander und stellt somit einen Datenverbindungsweg dar, über den die unterschiedlichen, Teilnehmer' Informationen austauschen bzw. miteinander ,kommunizieren' können (vgl. de.wikipedia.org, Artikel zum Thema ,Gebäudeautomation', zuletzt aktualisiert am 30.09.2018, zuletzt geprüft am 11.10.2018). 
Die Mindesttemperatur wird von dem bzw. der Gebäudeeigentümer*in vorgeschrieben und deshalb über den übergeordneten Gebäudemanager reguliert. Die Eingabe der Nutzungszeiten und die Einstellung der Wunschtemperaturen während der Raumnutzung sowie der Spartemperatur während der Abwesenheit erfolgt raumweise und jeweils für den Zeitraum von einer Woche. Das heißt, die Zeitprogramme lassen sich für jeden Tag einer Woche vorprogrammieren. Die Bewohner*innen können ihre individuellen Zeit- und Temperatureingaben abspeichern, so dass diese für die weitere Verwendung zur Verfügung stehen, indem sie den gemachten Einträgen ein Nutzungsprofil zuordnen bzw. indem sie bereits vorab auswählen, in welchem Nutzungsprofil sie ihre Einträge tätigen. Bei den Nutzungsprofilen handelt es sich um voreingestellte Heizzeiten für jeden Raum und Wochentag. Über die Kalenderfunktion lassen sich die unterschiedlichen Nutzungsprofile den einzelnen Tagen zuweisen. Das zugeordnete Profil gilt dann immer für alle Räume der Wohnung. Die Umschaltung der Nutzungsprofile erfolgt automatisch.

Die Sensortasten am unteren Ende des Wohnungsmanagers sind mit zwei Symbolen versehen: ein Haus für ,Ankommen' und ein gehendes Männchen für ,Weggehen'. Über diese Funktionstasten werden An- und Abwesenheit den Nutzungsprofilen entsprechend automatisch geregelt. So schaltet das Heizungssystem bei Abwesenheit auf das Sparprogramm um und wechselt bei Ankommen wieder in den eingestellten Normalbetrieb. Das heißt, dass durch die Betätigung dieser Tasten gelegentliche Abweichungen von der eingestellten Nutzungszeit, wie etwa das temporäre Verlassen der Wohnung für Besorgungen oder die frühere Rückkehr in die Wohnung, mitberücksichtigt werden können.

Die Software der intelligenten Heizungssteuerung beinhaltet einen selbstlernenden Algorithmus, der die verschiedenen individuellen Nutzer*ineinstellungen sowie die aus den einzelnen Räumen ständig eingehenden Daten verarbeitet und die $\mathrm{Zu}$ - und Abschaltung der Wärmeströme zum einzelnen Heizkörper automatisch ermittelt (vgl. Cook 2012: 1579f). Das heißt, dass der Algorithmus allmählich die Aufheizzeiten und Absenkzeitpunkte optimiert. Durch die ständige Auswertung der Raumzustände über das Bussystem ,lernt ' die Heizungssteuerung die Vorheizphase für jeden einzelnen Raum zeitlich immer genauer anzupassen. Bereits nach kurzer Zeit hat die Software ermittelt, wann die Heizung zu heizen beginnen muss, damit die gewünschte Raumtemperatur im jeweiligen Raum zum eingestellten Nutzungsbeginn erreicht ist und hält die Temperatur danach konstant. Dadurch wird erreicht, dass der Heizbetrieb bei Nichtnutzung so lange wie möglich unterbrochen bleibt und stets nur die tatsächlich benö- 
tigte Menge an Heizenergie eingesetzt wird, was zur Wärmeeffizienz beiträgt. Das bedeutet, dass Überlegungen wie die Planung erforderlicher Vorheizzeiten dem bzw. der Nutzer*in von der Elektronik abgenommen werden. Dieses Lernen der Technik ersetzt jedoch nicht die Programmierung der Nutzungsprofile. ${ }^{85}$

Während programmierter Abwesenheitszeiten werden die Temperaturen aller Räume ohne Veränderung der festgelegten Zeitprogramme und Solltemperaturen automatisch auf Sparbetrieb bzw. einen Minimalwert abgesenkt. Eine weitere Energieeinsparfunktion stellt die Erkennung eines geöffneten Fensters dar: Bei längerer Fensteröffnung - die sich in der Regel durch einen schnellen Temperaturabfall bemerkbar macht und vom System anhand der Auswertung der Temperaturgradienten im Raum erkannt wird - wird die Wärmeversorgung des jeweiligen Raumes automatisch abgeschaltet, was bedeutet, dass die jeweiligen Heizkörperthermostatventile automatisch geschlossen werden. Der Heizkörper bleibt sodann bis zum Erreichen der Mindesttemperatur ausgeschaltet. Wird das Fenster wieder geschlossen, erkennt das System dieses als Raumtemperaturerhöhung und gibt die Heizungsregelung wieder frei.

Insgesamt soll durch die intelligente Heizungsregelung Heizenergie nur dann eingesetzt werden, wenn sie erforderlich ist.

Auf der Ebene des Gesamtgebäudes gibt es einen zentralen, übergeordneten Leitrechner, den so genannten, Gebäudemanager'. Dieser befindet sich im Heizungskeller und ist über eine Datenleitung mit allen Wohnungsmanagern verbunden. In Fall des untersuchten Gebäudes ,kommuniziert' der Gebäudemanager über einen so genannten seriellen, Gebäudebus' mit den Wohnungsmanagern. Die Gebäudezentrale erfasst automatisch alle Verbrauchsdaten, wertet diese in der Zusammenschau aus und regelt dementsprechend die Wärmeleistung des gesamten Gebäudes.

Der Gebäudemanager analysiert das Regelungsverhalten aller angeschlossen Heizkörper und ermittelt über Sensoren die Außentemperatur, was der Regelung der Vorlauftemperatur des Gebäudes dient. Um die Räume eines Gebäudes auch bei unterschiedlichen Außentemperaturen auf ein beständiges Temperaturniveau zu erwärmen, benötigen die von Heizwasser durchströmten Heizflächen jeweils eine bestimmte Vorlauftemperatur. Sinkt die Außentemperatur ab, so steigt die Vorlauftemperatur. Wie eine bestimmte Außentemperatur und eine für einen bestimmten Heiz-

85 In dieser Logik werden die Endnutzer*innen als Programmier*innen gesehen, die Kontrolle an technische Geräte delegieren, z.B. indem sie individuelle Nutzungsprofile erstellen (vgl. Strengers 2013, sowie auch Hargreaves et al. 2016: 3f). 
kreis zugehörige Vorlauftemperatur genau zusammenhängen, beschreibt die so genannte ,Heizkurve“ oder ,Heizkennlinie' (vgl. Paschotta 2012*). Die Heizkurve sorgt demnach dafür, dass die Vorlauftemperatur ,ideal ${ }^{\star}$ an den Wärmebedarf angepasst wird. Diese ständige adaptive Regelung der zentralen Wärmeversorgung und der Vorlauftemperatur führt der Gebäudemanager voll automatisch aus. Dadurch wird eine fortlaufende Optimierung der Heizkurve aller Wohneinheiten als Gesamtsystem erreicht. Das heißt, dass eine richtig eingestellte Heizkurve Wärmeverluste vermindert, Raumtemperaturen besser regelt und dadurch Energie spart.

Gleichzeitig dient der Gebäudemanager als Vermittlungsgerät für die Fernwartung. Störmeldungen werden von der Gebäudezentrale automatisch entweder über Funknetze oder über das Telefonnetz an die externe Service-Firma weitergeleitet. So kann auf die Gebäude- und Prozessdaten zugegriffen werden, ohne dass die einzelnen Wohnungen bzw. das Wohngebäude betreten werden müssen.

\section{Intelligente Heizungssteuerungstechnik in der Anwendung}

Insgesamt wurde beobachtet, dass der überwiegende Anteil der Bewohner*innen, in deren Wohnungen die intelligente Heizungssteuerungstechnik verbaut wurde, dem Projekt von Anfang an eher skeptisch bis ablehnend gegenüberstand. So kamen beispielsweise nur sehr wenige betroffene Bewohner*innen - insgesamt waren etwa nur acht bis zehn Mietparteien vertreten - zu einer vorab von der Genossenschaft organisierten abendlichen Informationsveranstaltung. Im Rahmen dieses Informationsabends erläuterten Vertreter"innen der Wohnungsbaugenossenschaft gemeinsam mit Vertreter*innen des involvierten Energieversorgungsunternehmens und der ausführenden Technikfirma den Mieter*innen die Gründe sowie die konkreten Maßnahmen des Pilotprojekts. Im Anschluss durften Fragen gestellt werden, auf die die Expert"innen zu antworten versuchten.

Im Folgenden wird exemplarisch eine Variante des Übergangs zum intelligenten Heizen ausführlich dargestellt. Die Fallgeschichte Frau Hubers wurde ausgewählt, da sich an ihr zeigen lässt, dass hier ähnliche Themen wie beim Wechsel zum Passivhaus verhandelt werden: So thematisiert die SmartHome-Bewohnerin Frau Huber, als es um ihre Haltung zum neuen Heizungssteuerungssystem geht, wie sie in ihrer vorherigen Wohnung geheizt hat.

In diesem Fall zeigt sich die Prägung durch die frühere Heizpraxis, die subjektive Bedeutung bekannter Heizformen und die starke Gewöhnung an zentrale Gegenstände des Heizens, hier konkret an manuell regelbare Heizkörperthermostate. Darüber hinaus wird anhand der exemplarisch 
dargestellten Fallgeschichte erkennbar, dass eine Automatisierung bestimmter Vorgänge und Handgriffe von den Bewohner*innen nicht unbedingt als Erleichterung empfunden wird, wenn der vorherige Zustand bereits als zufriedenstellend aufgefasst wurde - wenn also die Bewohner*innen selbst keinen Bedarf an der neuen Technik gehabt haben, die neue Heizlösung aber dennoch bei ihnen implementiert wurde. Hieran wird deutlich, dass durch technische Neuerungen womöglich mehr Energieeffizienz erreicht werden kann, diese aber auch ihren Preis hat - in diesem Fall wurde sie durch eine geringere Zufriedenheit der Nutzer*innen erkauft (vgl. Krödel 2013). ${ }^{86}$

Mit Frau Huber wird nun ein Fall vorgestellt, bei dem Flexibilität, Spontaneität und Variabilität zentrale Themen sind.

\subsubsection{1 [D]ass sich mir auch jetzt wo ich das nutze immer weniger erschließt warum es einfacher sein soll“ - Frau Huber}

Frau Huber ist Mitte Vierzig, wohnt alleine und arbeitet ganztags. Das Interview findet bei Frau Huber zu Hause in ihrer Küche statt. Zunächst ist interessant, wie Frau Huber auf die Entscheidung der Genossenschaft reagiert hat, das einjährige Pilotprojekt zur automatisierten Steuerung des Wärmeverbrauchs unter anderem in ihrer Wohnung durchzuführen. Sie ist eine jener wenigen Mieter*innen, die an der Informationsveranstaltung teilgenommen haben. Sie berichtet, die Entscheidung „[m]it gemischten Gefühlen“ (Bewohnerin SH, Interview 75: 1, 30) aufgenommen zu haben, zwar offen, aber „nicht wirklich begeistert“ (ebd., 34) gewesen zu sein. Sie findet nicht in Ordnung, dass sie als direkt betroffene Mieterin lediglich

86 Die abschließende Projektauswertung und Evaluation der Verbrauchsdaten durch den Technikanbieter haben ergeben, dass mittels der technischen Heizungsoptimierung in den beteiligten Mietwohnungen der jahresdurchschnittliche Raumheizwärmeverbrauch im Jahr 2014 klimabereinigt im Vergleich zum Mittelwert der Verbrauchswerte der Jahre 2011-2012 um 19 Prozent gesunken ist. Verglichen mit den Referenz-Objekten (Wohnungen im selben Gebäude ohne intelligente Heizungssteuerungstechnik) fiel in den mit smarter Heizungstechnik ausgestatteten Miethaushalten der Raumheizwärmeverbrauch im Jahr 2015 klimabereinigt ebenfalls um 19 Prozent geringer aus. Diese konkreten Zahlen zu erzielten Einsparungen gehen aus den Daten des Technikanbieters hervor, die der Forscherin im Rahmen der Baubesprechungen zugänglich gemacht wurden. Da es sich um vertrauliche Informationen nur für den internen Gebrauch handelt, kann an dieser Stelle für die betreffenden Angaben keine öffentlich einsehbare Quelle angegeben werden. 
über das geplante Vorhaben in Kenntnis gesetzt, nicht aber ihre Einwilligung für die Maßnahme eingeholt wurde:

„zunächst war ich nicht wirklich begeistert davon weil das über meinen Kopf hinweg sozusagen einfach entschieden worden ist wir machen das jetzt mal wir machen jetzt mal dieses Projekt. Und äh ich bin einfach aufgrund der Tatsache dass ich in dieser Straße wohne und nicht woanders das fand ich 'n bisschen-“ (Bewohnerin SH, Interview 75: 1, 34-39)

Anhand dieser Passage wird deutlich, dass sich Frau Huber in einer für sie weitreichenden Entscheidung von ihrer Genossenschaft als Vermieterin übergangen fühlt. Auch sieht sie sich als Betroffene einer Eingriffsmaßnahme, die aufgrund willkürlicher Kriterien zustande gekommen ist. Frau Huber kritisiert vornehmlich, wie die Entscheidung für das Projekt entstanden ist: sie moniert, dass ihr als betroffene Mieterin kein Mitspracherecht eingeräumt wurde.

Dass sie nicht nur die Vorgehensweise bedenklich findet, sondern auch ihre Haltung gegenüber der neuen Heizungssteuerungstechnik kritisch ausfällt, wird im weiteren Verlauf des Interviewgesprächs klar, als die Interviewerin Frau Huber fragt, ob sie selbst schon einmal über Energiesparmaßnahmen bezüglich des Heizens nachgedacht habe. Daraufhin gibt sie preis, mit der bisherigen Heizlösung zufrieden gewesen zu sein und sich keine weitere Veränderung gewünscht zu haben. Dabei thematisiert sie zuallererst ihre Wohn- und Heizsituation vor ihrem Einzug in ihre aktuelle Wohnung. Die Beurteilung der neuen Heizlösung wird vor dem Hintergrund ihrer Erfahrungen mit Nachtspeicherheizungen deutlich: ${ }^{87}$

87 Bei der Nachtspeicherheizung handelt es sich um eine elektrisch betriebene Heizung, bei der ein Wärmespeicher während so genannter Schwachlastzeiten durch elektrischen Strom aufgeheizt wird. Da die Stromanbieter den elektrischen Strom in Schwachlastphasen in der Nacht und am Nachmittag im Vergleich zum Normaltarif günstiger anbieten, nutzt man diesen Tarif, der auch als Nachtstrom bezeichnet wird, indem man den Speicher während dieser Zeiten aufheizt. Da die Aufladung des Wärmespeichers in der Regel über Nacht erfolgt, ist die für den nächsten Tag bereitzustellende Wärmemenge deshalb stets einen Tag im Voraus zu ermitteln. Dies geschieht, indem mittels eines Außentemperaturfühlers die Außentemperatur gemessen und auf Basis dieser Messung die erforderliche Wärmemenge für den folgenden Tag abgeschätzt wird. Die Aufladesteuerung übernehmen so genannte Aufladeregler, die sich an den Speicherheizgeräten befinden. Diese Regler schalten die Aufladung dann ab, wenn die für den kommenden Tag erforderliche Wärmemenge durch das Gerät gespeichert wurde. Plötzli- 
"weil ich vorher in 'ner Wohnung gewohnt hab die mit Nachtspeichern beheizt worden ist Jahrzehn- ja- Jahrzehnte @lang@ eigentlich. Und von daher als ich hier vor zwei Jahren eingezogen bin nur ganz froh war dass ich 'ne Heizung hatte die ich aufdrehen kann und abdrehen wenn's zu warm ist und nicht schon Tage im Voraus planen muss wie wird das Wetter morgen weil das ist bei Nachtspeichern eben einfach so dass man da wirklich- Gerad' in der Übergangszeit ist es die Katastrophe. Und auch wenn es richtig kalt ist dann sitzt man in so 'ner Wohnung- morgens wenn man aus 'm Haus geht ist die Wohnung warm. Und wenn man abends nach Hause kommt und zur Ruhe kommen will braucht man doch 'ne Wolldecke weil's dann @wieder kalt ist@.“ (Bewohnerin SH, Interview 75: 2, 59-70)

„Ähm insofern hab ich mir da einfach noch gar keine weiteren Gedanken drum gemacht sondern war ganz glücklich dass ich hier jetzt kleine flache Heizkörper an der Wand hab die ich nach Bedarf anstellen kann.“ (ebd., 80-83)

Diese beiden Passagen machen deutlich, dass Frau Huber ihre Heizerfahrungen mit Nachtspeichereizungen als Referenzpunkt dienen, um anhand dieser Art des Heizens ,ex negativo ' aufzuzeigen, worauf es ihr bei der Wärmeversorgung ankommt. Sie kontrastiert Heizen mit Nachtspeicheröfen mit dem Heizen mittels einer konventionellen Warmwasser-Zentralheizung. Während sie das Nachtspeichersystem wesentlich mit der Notwendigkeit verbindet, den eigenen Wärmebedarf immer für einige Tage vorausplanen zu müssen, beschreibt sie die moderne Zentralheizung als ein System, das keiner Vorplanung bedarf, sondern mit dem sich die Wärmeversorgung einfach und unmittelbar dem situativen Bedarf anpassen lässt. Zudem kommen in den beiden Interviewpassagen deutlich Frau Hubers Erleichterung und Freude darüber zum Ausdruck, vor etwa zwei Jahren in eine Wohnung mit moderner Zentralheizung gezogen und mit diesem Umzug von allen Unannehmlichkeiten des Nachtspeicherheizens auf einen Schlag befreit worden zu sein. Durch die Formulierung „nur ganz froh“ (ebd., 62) über diese Veränderung gewesen zu sein, wird erkennbar, dass sie den Wechsel von einer mit Nachtspeichern beheizten Wohnung zu einer Wohnung mit konventionellem Heizungssystem als erfreuliche Komfortsteigerung erlebt hat. Durch den Wechsel war sie u.a. von der Notwendigkeit des Vorausplanens befreit worden und verfügte nun über

che Kälteeinbrüche werden mit solch einer einfachen Steuerung nicht berücksichtigt. 
ein Heizungssystem, mit dem sie die Raumtemperatur ihrem persönlichen Bedarf entsprechend, ganz spontan durch einfaches Drehen am jeweiligen Heizkörperthermostat, einstellen konnte. In diesen Ausschnitten wird somit eine Orientierung an Situativität und Flexibilität deutlich. Den Formulierungen lässt sich entnehmen, dass Frau Huber es besonders schätzte, dass sich mit dem konventionellen Heizungssystem die Wärmezufuhr direkt für die jeweilige Situation einstellen ließ und damit die Möglichkeit gegeben war, auch auf kurzfristige Veränderungen reagieren zu können. Schließlich verdeutlichen die Zitate, dass Frau Huber die Erfahrung gemacht hat, dass es trotz gründlicher Vorausplanung oft nicht möglich war, die Nachtspeicherheizung den individuellen Wünschen entsprechend regeln zu können. So ist ihrer Beschreibung zu entnehmen, dass es mit Nachtspeicherheizungen immer wieder zu Gegebenheiten kommt, in denen die Planung versagt, etwa weil sich manche zukünftige Entwicklungen der sicheren Planung entziehen und dass es genauso immer wieder Situationen gibt, in denen die Wärmeversorgung trotz Planung nicht wunschgemäß funktioniert. Daraus lässt sich schließen, dass sie mit ihrer konventionellen Heizung ohne neue Steuerungstechnik zufrieden war. In ihren Augen funktionierte das bisherige Heizungssystem gut, weshalb sie für sich auch keinen Anlass gesehen hatte, hier über Veränderungen nachzudenken und auch keine Umgestaltung der Heizung wünschte. Insgesamt wird an den Passagen deutlich, dass ein Heizungssystem wie die Nachtspeicherheizung so viel Vorüberlegungen und Kalkül erfordert, dass es situativen Bedürfnissen nicht mehr gerecht werden kann. ${ }^{88}$ Hingegen scheint ein Heizungssystem mit jederzeit regelbaren Heizkörperthermostaten eher individuellen Wünschen und Vorstellungen von adäquater Wärmeversorgung zu entsprechen.

Vor diesem Hintergrund wird nun verständlich, dass Frau Huber vor allem von ihrer Unzufriedenheit und ihren Problemen mit der neuen Heizungssteuerungstechnik erzählt, als die Interviewerin sie nach ihren ersten Erfahrungen mit dem neuen System fragt:

88 An anderer Stelle im Interview findet sich ein weiterer Beleg für diese Deutung: Hier berichtet Frau Huber davon, dass sie zu Nachtspeicherheizungszeiten jeden Abend die Wettervorhersage für den Folgetag habe hören müssen, insbesondere in den Übergangsjahreszeiten Frühling und Herbst, wenn z.T. drastische Temperaturumbrüche eintreten können, um rechtzeitig zu wissen, ob sie die Heizung ausgeschaltet lassen kann oder eben anschalten muss, damit diese sich über Nacht aufheizen bzw. aufladen kann. Diese Überlegungen und Vorausplanungen habe sie immer als sehr lästig empfunden. 
„Also ich fühle mich eigentlich in meinen ursprünglichen Vorbehalten so 'n bisschen bestätigt dass sich mir auch jetzt wo ich das nutze immer weniger erschließt warum es einfacher sein soll zu diesem Tablet an der Wand zu laufen und dort kompliziert rumzusuchen welches Zimmer ich jetzt ansteuer' als einfach zur Heizung zu gehen. Also ich meine wir sitzen jetzt hier in der Küche. Da sitzen wir gut. Wir sitzen an der Heizung. Es ist warm. Wenn ich die Küche jetzt nachher verlasse muss ich erst mal eigentlich wieder am Tablet sagen ,Ich brauche die Küche jetzt erst heute Abend wieder' und muss da runter schalten. Und sonst bräuchte ich jetzt einfach hier nur ausdrehen [...] und drehe nachher wieder auf wenn ich zurückkomme." (Bewohnerin SH, Interview 75: 4, 201-212)

In dieser Passage kommt nun deutlich zum Ausdruck, dass Frau Huber vom angeblichen Nutzen der neuen Heizungssteuerung nicht überzeugt ist. Offenbar gab es ein Versprechen - des Technikanbieters oder der Wohnungsbaugesellschaft - das neue System nehme ihr Arbeit ab und mache das Heizen bequemer. Für Frau Huber hat sich diese Ankündigung in der Praxis allerdings als leere Versprechung erwiesen. Die Passage verdeutlicht, dass sie die automatisierte Steuerung der Wärmeversorgung nicht als Vereinfachung wahrnimmt. Im Gegenteil, im Vergleich mit der direkten Steuerung durch Heizkörperthermostate erlebt sie die zentrale Steuerung der Heizung über den Wohnungsmanager als Verkomplizierung. Erstens bedeutet die neue zentrale Steuerung für sie zusätzliche Wege, da sich die Heizeinstellungen für die einzelnen Wohnräume nur noch am Tablet ausführen lassen und es keine manuell bedienbaren Thermostate mehr an den einzelnen Heizkörpern gibt. Dadurch ist ein schnelles Herübergreifen und Drehen am Heizkörperthermostat nun nicht mehr möglich. Zweitens erhöht sich für Frau Huber mit dem neuen System der Arbeitsaufwand: Anstatt die Heizung weiterhin intuitiv aus der jeweiligen Situation heraus und direkt vor Ort an den einzelnen Heizkörpern einstellen zu können, muss sie nun am Wohnungsmanager durch die verschiedenen Einstellungen und Raumprogramme navigieren, um die hier voreingestellten Heizzeiten zu ändern oder um neue Heizeinstellungen für die betreffenden Räume vorzunehmen. Heizen wird für sie damit wieder stärker zu einer Sache rationaler Überlegung und Vorplanung, wie sie es noch von ihrer Nachtspeicherheizung her kennt.

Insgesamt verdeutlicht dieser Interviewabschnitt, dass Frau Huber ihr bisheriges Heizungssystem ohne intelligente Steuerung als einfach und bequem zu bedienen empfunden hat, was daran erkennbar wird, dass sie zweimal den Ausdruck ,einfach` im Zusammenhang mit ihrer vorherigen 
Heizung verwendet. Das bisherige Heizungssystem steht für Einfachheit, Spontaneität und Flexibilität und wird daher auch mit Komfort verbunden. Die neue Heizungssteuerung ermöglicht diese Spontaneität nicht mehr, was sich auch in folgendem Zitat bestätigt:

„Ähm ich meine wenn ich jetzt die Heizung für's Schlafzimmer aboder- egal welchen Raum für 'ne bestimmte Uhrzeit programmiert

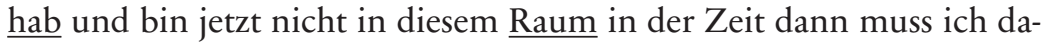
ran denken dass ich dort die Heizung abstell'. Also ich muss immer wieder davor stehen und überlegen ja wie ist es denn heute? Wann komme ich denn heute nach Hause? Klar da gibt es jetzt so 'ne Sparfunktion. Und man kann das alles auf ,spar' stellen. [Interviewerin JM: Mhm. Aber Ihnen fehlt so 'n bisschen dieses Spontane?]. Mir fehlt das Spontane. Ich bin sehr festgelegt. Ich muss mich sehr festlegen auf bestimmte Zeiten in denen die Räume genutzt werden." (Bewohnerin SH, Interview 75: 6, 285-299)

Anhand dieser Passage wird noch einmal sehr gut deutlich, dass die Programmierung, also die Voreinstellung der Heizzeiten voraussetzungsvoll und aufwendig ist, und zwar in dem Sinne, dass sie vor allem viel Denkarbeit erfordert. Die Programmierung der Heizzeiten bedarf des Blickes in die Zukunft. Im Grunde genommen wird von den Nutzer"innen erwartet, dass sie ihre Bedürfnisse bereits im Vorhinein kennen bzw. dass sie sich zumindest im Voraus festlegen, um überhaupt entsprechende Nutzungsprofile eingeben zu können. Weicht die tatsächliche Praxis allerdings von dieser Planung ab - wobei unbedeutend ist, ob die Änderung unbeabsichtigt oder bewusst vorgenommen erfolgt -, so ist erneut Nachdenken und (Hand-)Arbeit nötig, um die Programmierung den geänderten Plänen oder spontan eingetretenen Ereignissen anzupassen. Hieran zeigt sich, dass die neue automatisierte Steuerung in vielen alltäglichen Situationen im Prinzip sogar eine Verdoppelung der Arbeit impliziert.

In dieser Passage räumt Frau Huber ein, dass sich mit dem neuen System zwar auf manche sporadischen Abweichungen von den eingestellten Nutzungszeiten reagieren lässt, dass damit aber längst nicht alle spontanen Ereignisse und persönlichen Änderungswünsche abgedeckt sind. Damit wird noch einmal klar, dass die Heizungsautomatisierung nicht dafür geeignet ist, die Wärmeversorgung spontan und flexibel zu regeln.

In welchen Situationen sich die Wärmeversorgung mit der neuen automatisierten Steuerung gut regeln lässt und in welchen alltäglichen Lebenslagen sie sich dagegen als ungeeignet erweist, dafür gibt folgendes Zitat einen Hinweis: 
"Also wenn ich jetzt 'nen geregelten Arbeitstag hab und morgens die Wohnung- Ich stehe um sechs auf ich verlasse die Wohnung um halb acht ähm dann kann ich die Zeit genau anwählen. Super dann ist die Wohnung ist das- ist die Küche und das Bad auch warm wenn ich aufstehe. Das ist schon irgendwie ganz kuschelig in ein warmes Bad zu kommen und nicht erst aufdrehen zu müssen. Aber jetzt wo ich krank zu Hause gesessen hab [...] hab ich eigentlich ständig dieses- dieses Tablet im Blick haben müssen weil ja- Schlafe ich nun heute bis um elf oder- oder schlafe ich um neun nur und stehe dann auf oder wie brauche ich meine Wärme jetzt das war ja jetzt die letzten zwei Wochen wirklich bitter kalt dass man die auch nicht komplett vergessen konnte." (Bewohnerin SH, Interview 75: 5, 220-232)

Hier kommt zum Ausdruck, dass erfolgreiche Programmierung an bestimmte Bedingungen geknüpft ist: Die Vorabplanung, die sich in einzelne Raumheizprofile übertragen lässt, gelingt nur, wenn der Alltag in sehr geregelten Bahnen verläuft. Bei der automatisierten Heizungssteuerung handelt es sich demnach um eine für Regelmäßigkeit und Routine ausgelegte Technik, die folglich als sinnvolle Unterstützung und (Arbeits-)Erleichterung wahrgenommen werden kann, wenn der Alltag sehr gleichförmig bzw. nach Plan verläuft.

Die Interviewpassage macht aber auch deutlich, wie schnell eine einseitig an Gleichförmigkeit und Regelmäßigkeit orientierte Automatisierungstechnik an ihre Grenzen geraten kann. Frau Huber nimmt hier erneut eine Kontrastierung vor: der normalen Routine stellt sie mit Kranksein ein typisches Störereignis alltäglicher Routine gegenüber. Während dieser Phase haben sich die von ihr für den geregelten Alltag voreingestellten Raumheizzeiten als nicht passend erwiesen. Hier wird nun deutlich, dass im Falle einer Abweichung vom geregelten Alltag mit der neuen digitalen Steuerungstechnik auf einmal (wieder) sehr viel Denk- und Programmierarbeit hinsichtlich der Wärmeversorgung notwendig ist - deutlich mehr als vor dem Einbau neuer Technik erforderlich war. Das zeigt noch einmal, dass die zentrale Heizungssteuerungstechnik bei flexibler Tagesgestaltung bzw. abwechslungsreicher Lebensführung keine Hilfe, sondern eher eine zusätzliche Erschwernis dargestellt. Hieraus lässt sich schließen, dass durch das neuerliche Planungserfordernis der Steuerungstechnik das Heizen von einer Hintergrundaktivität plötzlich wieder zu einer Hauptsache geworden ist: Eigentlich handelte es sich beim Heizen bereits um einen routinisierten Ablauf, der praktisch keiner bewussten Reflextion mehr bedurfte. Diese wohl erprobte Routine war gut zu vollziehen, weil die Heizung erwartungsgemäß funktionierte. Das Heizen warf keine Probleme auf, bis es zur 
Unterbrechung der Routine kam. Am Kranksein wird deutlich, wie der eigentlich selbstverständliche und deshalb kaum mehr beachtete Vorgang des Heizens wieder in den Fokus gerät und wie lästig sich dieses erweist.

Dass Heizen ständig Thema ist, kennt Frau Huber noch von früher, von ihrer alten Nachtspeicherheizung, aber von ihrem vorherigen Heizungssystem ohne intelligente Steuerung war sie mittlerweile anderes gewohnt: nämlich ohne großes Vorüberlegen ihre gewünschten Raumtemperaturen spontan und flexibel direkt an den einzelnen Heizkörpern einstellen zu können. Dementsprechend resümiert sie:

„Ich find's unpraktisch. Ich finde es einfach unpraktisch weil's für

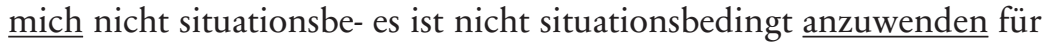
mich sondern es bedarf immer einer Vorplanung. Und das heißt die Intelligenz die Intelligenzleistung die mir das Gerät eigentlich abnehmen muss die muss ich ihm ja erst zufüttern. Und wenn mein Leben variabel ist dann muss ich diese Variablen immer wieder reinfüttern. [...]. Das ist eigentlich nur ein zusätzliches Gerät das äh gepflegt werden muss und gewartet werden muss. Und Zeit bindet dadurch dann wieder.“ (Bewohnerin SH, Interview 75: 10, 492-505)

Und weiter:

„mir macht das einfach Stress darüber nachzudenken. Ich würde tatsächlich- ich hätte ganz gerne meine Regler an der Heizung wieder (lacht) würde die gerne aufdrehen." (ebd.: 11, 563-565)

Hier wird noch einmal deutlich, dass Frau Huber die Implementierung der neuen Heizungssteuerungstechnik als einen Schritt von situativer und intuitiver Regelung zurück zu Planung und Einstellung der Heizung im Voraus empfindet. Vor dem Hintergrund, dass sie mit ihrer konventionellen Zentralheizung zufrieden war, stellt das neue System also wieder eine Minderung ihres erst gerade gewonnenen Komforts dar. In Anbetracht dessen wird verständlich, dass sich Frau Huber die Wiederherstellung des vorherigen, für sie optimalen Zustands wünscht: sie möchte wieder manuell regelbare Thermostate an jedem einzelnen Heizkörper haben.

Die neue Steuerung kann den Nutzer"innen zwar das einfache An- und Abschalten der Heizung abnehmen, nicht aber die eigentliche Arbeit: die Vorausplanung und die ständigen Überlegungen „ja wie ist es denn heute? Wann komme ich denn heute nach Hause?“ (ebd.: 6, 289-290) und „wie warm will ich's eigentlich in der Wohnung haben“ (ebd.: 11, 559-560). Dies verdeutlicht noch einmal, dass sich bei flexibler Lebensgestaltung der Planungsaufwand und damit die Beschäftigung mit Heizen durch das 
neue System eher erhöhen. Aus diesem Grund hat sich für Frau Huber die neue Heizungssteuerungstechnik als unpassend bzw. wenig alltagstauglich erwiesen, da sie an ihrer konkreten Lebenswirklichkeit vorbeigeht.

Aus Nutzer*innensicht besteht daher die Gefahr, dass die Heizungsautomatisierung damit nicht nur ihren eigentlichen Zweck verfehlt - soll sie doch eigentlich den Arbeitsaufwand für das Heizen minimieren und die Wärmeversorgung insgesamt komfortabler gestalten -, sondern dass sie sich sogar als kontraproduktiv erweisen kann, wenn sich das Heizen dadurch von einer einfachen, schnell nebenbei auszuführenden Hintergrundaktivität zu einer komplizierten und zeitaufwendigen Tätigkeit wandelt, die viel Aufmerksamkeit und regelmäßige Auseinandersetzung fordert.

Der Fall von Frau Huber macht somit deutlich, dass Heizen nicht (wieder) zu einer Angelegenheit rationaler Planung werden, sondern eine Hintergrundtätigkeit bleiben soll(te), die sich flexibel in einen abwechslungsreichen Alltag integrieren lässt. Heiztechnik, so lässt sich zusammenfassen, muss sich spontan und unkompliziert an die Bedürfnisse und konkrete Lebenswirklichkeit der Nutzer"innen anpassen lassen.

\subsubsection{Vergleichendes Kapitelfazit}

Im Rahmen dieses Kapitels wurden verschiedene Varianten der Umstellung und Anpassung an neue Heiztechnik beim Wechsel von konventionellem Heizen zum Heizen im Passivhaus und SmartHome dargestellt. Ausgangspunkt der hier präsentierten Fallgeschichten war stets der Heizkörper, da er von den interviewten Bewohner*innen als der zentrale Gegenstand beim Heizen betrachtet wird. Dementsprechend kreisen viele ihrer Erzählungen und Beschreibungen um Entwicklungen rund um den Heizkörper. In allen Fallgeschichten wurde der prägende Einfluss vergangener Wohn- und Heizerfahrungen auf die gegenwärtige Heizpraxis bzw. auf den (anfänglichen) Umgang mit neuer Heiztechnik deutlich erkennbar. Darüber hinaus hat die Analyse der unterschiedlichen Fallgeschichten verdeutlicht, wie viele Lebensbereiche durch die Entscheidung für bzw. über eine neue Heizlösung berührt sind. Es konnte aufgezeigt werden, dass es beim Wohnraumheizen eigentlich nie nur um das reine Heizen, also das Erwärmen der Wohnräume auf ,X' Grad Celsius geht, sondern das Thema Heizen bzw. die Frage, wie und mithilfe welcher Technik geheizt wird, vieles mehr betrifft: So wird etwa eine bestimmte Heiztechnik zur Absicherung gewählt, es werden unterschiedliche Heiztechniken mit un- 
terschiedlichen Arten von Wärmekomfort assoziiert, die zum Einsatz kommende Heizungstechnik hat Auswirkungen auf die Inneneinrichtung und die Raumnutzungsmöglichkeiten und sie beeinflusst die Gestaltungsfreiheit und Kontrollmöglichkeiten der Nutzer*innen bezüglich der Wärmeversorgung.

Im Folgenden wird auf die zentralen Ergebnisse dieses Kapitels näher eingegangen. Dabei werden die Aspekte ,Behaglichkeits- und Komforterleben' sowie ,Kontrolle und Kontrollverlust ${ }^{`}$ allerdings ausgespart, da sie sich als so bedeutend im Zusammenhang mit dem Heizen erwiesen haben, dass ihnen im Rahmen der empirischen Analyse jeweils ein eigenes Kapitel gewidmet ist (siehe Kapitel 4.3 und 4.4).

\section{Die häufige Fortschreibung der Vergangenheit in die Gegenwart}

Die Untersuchung hat gezeigt, dass sich vornehmlich diejenigen Passivhausbewohner*innen weiterhin an ihre alte Heizpraxis halten, bei denen sich der neue Heizansatz stark von ihrer vorher praktizierten Heizroutine unterscheidet. Diesen Bewohner*innen fällt es aufgrund fehlender Erfahrung des Lebens im Passivhaus offensichtlich schwer, dieses zukünftige und neuartige Heizen im Passivhaus im Vorhinein zu antizipieren. Vergleicht man die in diesem Kapitel dargestellten Passivhaus-Fallgeschichten, so wird deutlich, dass vor allem diejenigen Bewohner*innen den Wechsel von einem konventionellen Wohngebäude in ein Passivhaus als außergewöhnlich große Veränderung wahrnehmen und beschreiben, die direkt vorher in einem klassischen (unsanierten) Altbau gewohnt haben. Außerdem wurde deutlich, dass es vornehmlich unangenehme Kälteerfahrungen, wie Kälte abstrahlende Außenwände oder ständige Zugluft sind, die bei diesen Bewohner*innen anfänglich Bedenken und Zweifel gegenüber der Passivhaustechnologie hervorgerufen haben. Daraus lässt sich schlussfolgern, dass den bisherigen Altbau-Bewohner"innen die Erfahrung einer guten Isolierung bzw. Wärmedämmung fehlt - das unterscheidet sie von den Passivhaus-Neubewohner*innen, die zwar ebenfalls aus einem konventionellen Wohnkontext kommen, jedoch vor ihrem Einzug ins Passivhaus bereits in einem Neubau bzw. relativ modernen Wohngebäude gelebt haben.

\section{Der Heizkörper als, Brücke(ntechnologie)' bzw. als, Vermittlungsinstanz' zwischen älteren und neuartigen Heizformen}

Im Hinblick auf die Heizpraxis der bisherigen Altbau-Bewohner*innen von Passivhäusern der ersten Generation stellen die zusätzlich installierten 
Heizkörper gewissermaßen eine Art ,Brückentechnologie‘ dar; sie fungieren als Bindeglied zwischen konventionellem Heizen und dem neuartigen Heizen im Passivhaus. Durch sie wird für die bisherigen Altbau-Bewohner*innen der große Abstand zwischen dem alten und dem neuen HeizAnsatz gewissermaßen, überbrückt‘.

In der Biologie wurde für solch ein Verbindungs- bzw. Zwischenstück der Begriff des „missing link“ (Osche 1974: 24) geprägt. Dabei handelt es sich um eine (ursprünglich noch fehlende) fossile Übergangsform zwischen entwicklungsgeschichtlichen Vorgänger*innen und ihren Nachfolger*innen. Ein solch verbindendes Element verfügt über Mosaikformcharakter, das heißt das Fossil weist sowohl Merkmale der älteren als auch der jüngeren Form auf (vgl. ebd.: 21f). Da inzwischen viele solcher fossilen Verbindungsformen entdeckt worden sind, wird für diese mittlerweile die Bezeichnung, connecting link' bevorzugt.

In diesem Sinne erscheint der Heizkörper als ein solches Verbindungselement zwischen der bisher gewohnten aktiven Gebäudeheizung und der anfangs noch unbekannten (Luft-)Heizung im Passivhaus. Die Heizkörper repräsentieren zwar vor allem die vergangene Heizpraxis, gleichzeitig lebt durch sie dieses Altbekannte im Neuen weiter fort, so dass für die Praktizierenden weiterhin erkennbar bleibt, an welche bisherige Praxis mit der neuen Praktik des passiven Heizens angeknüpft wird. Indem die Bewohner*innen mit dem Heizkörper einen Teil ihrer bisherigen Heizpraxis in die Gegenwart ,tragen', haben sie sich einen Ankerpunkt geschaffen, an den sie zum Heizen im Notfall jederzeit sicher anknüpfen können. Denn im Gegenteil zur Bedienung der neuen, ungewohnten, für das Heizen im Passivhaus aber entscheidenden Kompaktlüftung, sind sie die Handhabung eines aktiven Gebäudeheizungssystems gewohnt.

\section{Der Heizkörper als Gegenstand der Inneneinrichtung und entscheidendes Element im Hinblick auf die Raumnutzung(smöglichkeiten)}

Insbesondere die Fallgeschichten Frau Rosentals, Herr Frings ${ }^{\varsigma}$ und die Herr Thomsens haben veranschaulicht, dass in den Wohnräumen aufgestellte Heizkörper ein wichtiges Element sowohl der Inneneinrichtung als auch im Hinblick auf die Raumnutzungsmöglichkeiten sind. Während fest an den Wänden angebrachte Heizkörper einerseits die Wohnraumgestaltung zu einem gewissen Grad vorgeben und die Flexibilität bzw. die Möglichkeiten der Bewohner*innen für eine freie, den individuellen Wünschen entsprechende Inneneinrichtung mehr oder minder stark einschränken (können), kommt ihnen andererseits als (einzige oder hauptsächliche) Wärmequelle eine ermöglichende Funktion zu: Je nachdem wo im Raum, 
genauer an welcher Wand ein Heizkörper platziert ist, verteilt sich die von ihm abgehende Wärme besser oder schlechter im Raum bzw. gelingt es gut oder weniger gut, einen Raum ausreichend und gleichmäßig zu erwärmen. Das beeinflusst, wie ausschöpfend ein Wohnraum von den Bewohner*innen genutzt werden kann.

Durch die luft- und winddichte, wärmebrückenfreie und extrem wärmegedämmte Gebäudehülle des Passivhauses ist dafür gesorgt, dass die warme Innenluft im Gebäude gehalten und die kalte Außenluft vom Eindringen in die Wohnräume abgehalten wird. Wie mit den hier präsentierten Fallgeschichten eindrücklich aufgezeigt wurde, werden zusätzliche Wärmequellen wie Heizkörper oder ein Kaminofen im Passivhaus dadurch nicht nur überflüssig, sondern vielmehr ergeben sich durch den besonderen Wärmekomfort des Passivhauses ganz neue Raumnutzungsmöglichkeiten für die Bewohner*innen - der auch während der Heizperiode nutzbare Wohnraum erweitert sich.

Eine direkte Wärmequelle (z.B. ein Heizkörper) hat sich nur dann als besonders wichtig erwiesen bzw. ist nur dann unabkömmlich, wenn es in den Wohnräumen insgesamt (zu) kalt ist - und dies gilt ebenso für das Passivhaus.

Wohnraumheizen und die Schaffung von Wärmebehaglichkeit sind also nicht nur abhängig von dem Vorhandensein bzw. Fehlen von Heizkörpern, sondern immer ist hierfür ein breites technisches Arrangement relevant. Und dieses mehr oder minder umfangreiche technische Heizsetting hat somit stets Einfluss auf die Einrichtungs- und Raumnutzungspotenziale der Bewohner*innen.

Dass es beim Wohnraumheizen und der Schaffung von Wärmebehaglichkeit immer auch um Nichttechnisches und Immaterielles geht, wird in den Kapiteln 4.3 und 4.4 aufgezeigt.

\section{Das Wechselspiel von antizipierten Erwartungen und Erfabrungen}

Die Analyse des Datenmaterials hat deutlich gemacht, dass das (Erfahrungs-)Wissen der Expert*innen für die Entscheidung über die Restwärmeversorgung im Passivhaus eine zentrale Rolle spielt. Verfügte der oder die beauftragte Architekt*in zu Beginn des Bauprozesses selbst noch über keinerlei oder nur sehr wenig praktische Erfahrung mit dem Passivhausstandard, so war er bzw. sie meist dazu geneigt, die theoretisch-wissenschaftlichen Vorgaben zum Passivhaus-Baukonzept ohne Abweichungen, also relativ streng umzusetzen. Darüber hinaus konnte gezeigt werden, dass nicht nur die Neubewohner*innen der ersten Generation Passivhäuser erst allmählich mit der Passivhausfunktionsweise vertraut wurden, sich eingelebt 
und die neuen Heiz- und Lüftungsabläufe erlernt haben, sondern auch, dass die ersten Passivhausbauprojekte in den 1990er Jahren für die Berufsgruppe der Architekt*innen ein wichtiger Lernprozess waren. Die hierbei gemachten Erfahrungen haben dazu geführt, dass mittlerweile viele auf Niedrigenergie- und Passivhäuser spezialisierte Architekt*innen hinsichtlich der Restwärmeversorgung im Passivhaus vom ursprünglichen Prinzip einer in die Kompaktlüftung integrierten Zuluftheizung Abstand nehmen und stattdessen neben der notwendigen Wohnraumlüftung noch ein klassisches Heizsystem einbauen. Und dies, obwohl sie wissen, dass das Heizen mittels Lüftung bzw. über die Zuluft funktioniert, ausreichend ist und eine besonders günstige Heizvariante darstellt, weshalb auch viele Architekt"innen diese Heizlösung nach wie vor für die Geeignetste für Passivmehrfamilienhäuser halten. Vielmehr waren es, so konnte aus dem Datenmaterial herausgearbeitet werden, typische Akzeptanzüberlegungen, im Sinne von ,Was akzeptieren potenzielle Nutzer*innen am ehesten? Mit welcher Heizlösung sind sie am einfachsten schnell fürs Passivhaus zu begeistern?‘, die mehrheitlich zu dieser Veränderung in der gängigen Handlungspraxis der Expert*innen geführt haben.

\section{Die Reaktivierung von (rubenden) Elementen einer eigentlich bereits als überholt geltenden Heizpraxis}

Bei dem in diesem Kapitel präsentierten Fall zum smarten Heizen kommt die Fortschreibung der Vergangenheit in die Gegenwart auf etwas andere Weise zum Ausdruck. Hier hat gewissermaßen eine ,Reaktivierung' von zentralen Elementen einer alten, bereits vorvergangenen Heizpraxis stattgefunden. Mit dem ausführlich dargestellten Fall Frau Hubers konnte gezeigt werden, dass die neue smarte Heiztechnik durch das Erfordernis zu ständiger Vorausplanung in gewisser Hinsicht stark an die ursprünglich bereits schon mal als, veraltet' und überholt geltende Heizform der Nachspeicherheizung(spraxis) erinnert. Die neue smarte Heizungssteuerung lässt demnach Flexibilität, Spontaneität und Variabilität in der Anpassung der Wärmeversorgung an individuelle, situative Wärmebedarfe vermissen. Im Hinblick auf die Bewertung der neuen Heizungssteuerungstechnik bedeutet das, dass die mit ihr u. a. ursprünglich verbundene Intention, das Heizen für die Bewohner*innen einfacher und komfortabler zu gestalten, aus Sicht einiger SmartHome-Bewohner*innen offenbar verfehlt wurde. Frau Huber wie auch anderen SmartHome-Bewohner*innen erscheint Heizen durch die Zwischenschaltung smarter Technik nun sogar stark verkompliziert (vgl. z.B. der Fall des Herrn Martens, ausführlich präsentiert in Teilkapitel 4.4.1.3). 
Zudem hat der Fall Frau Hubers verdeutlicht, dass die Bewertung des neuartigen Heizansatzes stark von der Wahrnehmung der bisherigen Heizlösung abhängt. Demnach fallen die Bereitschaft, sich beim Heizen auf eine neue Technik einzulassen und diese in die eigene Heizpraxis zu integrieren, sowie die Zufriedenheit mit dem neuen System deutlich geringer aus, wenn der vorherige Zustand von den Bewohner*innen bereits als optimal bzw. zufriedenstellend aufgefasst wurde - sie also keinen Grund zur Veränderung gesehen haben und von ihnen selbst kein Anstoß zur Veränderung ausgegangen wäre (vgl. Krödel 2013).

Im nächsten Kapitel wird es um Gewöhnungsprozesse beim Lüften gehen.

\subsection{Gewöhnungsprozesse beim Wohnraumlüften}

In diesem Kapitel werden nun Gewöhnungsprozesse beim Wohnraumlüften im Übergang von konventionellen Wohnkontexten zum Passivhaus und SmartHome dargestellt. Wie die Geschichte des Heizens gezeigt hat, sind Praktiken des Wohnraumheizens und -lüftens seit langer Zeit miteinander verknüpft (vgl. Teilkapitel 2.2.4.1). Das Belüften der Wohnräume dient der Verbesserung der Luftqualität und dem Abführen von Luftfeuchtigkeit sowie der Regulierung der Raumtemperatur. ,Richtiges' Lüften ist vor allem während der Heizperiode, wenn die Temperaturunterschiede zwischen drinnen und draußen besonders groß sind, sehr wichtig, um etwa Schimmelbildung und Feuchtigkeitsschäden zu vermeiden. Wie gelüftet wird, entscheidet wesentlich mit darüber, wieviel Heizenergie verbraucht wird. In Deutschland arbeiteten im Jahr 2015 immer noch drei Viertel $(75,8 \%)$ aller in Wohngebäuden installierten Heizungen mit den fossilen Energieträgern Erdgas oder Öl, bei deren Verbrennung erhebliche Mengen an $\mathrm{CO}_{2}$ freigesetzt werden (vgl. BDEW 2015). Hier trägt ,richtiges (Fenster-)Lüften entscheidend dazu bei, dass Heizenergie nicht ungenutzt verbraucht wird und entsprechend weniger heizungsbedingte $\mathrm{CO}_{2}$-Emissionen anfallen. Insbesondere „in energetisch optimierten Gebäuden, in denen aus baulich-technischer Sicht bereits größtmögliche Energieeinsparpotenziale gehoben wurden“ (Hacke 2009b: 8) erhält das Lüftungsverhalten - neben der Heizpraxis - einen maßgeblichen, wenn nicht sogar den wichtigsten Stellenwert (vgl. ebd.: 23).

Beide in dieser Arbeit betrachteten Technologien beziehen den Vorgang des Lüftens in ihre Funktionsweise mit ein, dies aber in unterschiedlichem Ausmaß und mit unterschiedlichen Konsequenzen. 
Das Passivhausprinzip stellt die alte Verschränkung des Heizens und Lüftens in gewisser Hinsicht in Frage bzw. verändert das Verhältnis der beiden Tätigkeiten zueinander grundlegend. Im Passivhaus übernimmt die Lüftungsanlage mit Wärmerückgewinnung das Be- und Entlüften der Wohnräume während der Heizperiode komplett, so dass die klassische Fensterlüftung entfällt. Das heißt, der nach wie vor für das Heizen wichtige Lüftungsvorgang wird durch die kompakte Passivhauslüftungsanlage vollständig automatisiert und den Praktizierenden als zusätzlich durchzuführende Aktivität somit ,abgenommen'. Heizen erfolgt größtenteils ebenfalls über die Lüftungsanlage. Die ganze Technik des Passivhauses ist also in einer Anlage zusammengefasst, wodurch sowohl Heiz- als auch Lüftungsaktivitäten entscheidend reorganisiert werden. Durch die Technik wird die Trennung zwischen den beiden Tätigkeiten somit aufgehoben: Heizen und Lüften sind nun keine separaten eigenständigen Aktivitäten mehr, sondern zu einem mehr oder weniger hybriden Vorgang verschmolzen.

Im SmartHome gibt die intelligente Heizungssteuerungstechnik ebenfalls eine technische Antwort auf den Vorgang des Lüftens. Um ,falsches ${ }^{6}$ Lüften zu vermeiden und dadurch Energie einzusparen, erkennt die Technik ein geöffnetes Fenster anhand eines schnellen Temperaturabfalls und schaltet daraufhin automatisch die Heizkörper in dem jeweiligen Raum ab. Das Schließen der Fenster erfasst das System wiederum als Raumtemperaturerhöhung und gibt die Heizungsregelung wieder frei.

In den Interviews mit Passivhausbewohner*innen waren das Lüftungssystem und Lüften zentrale Themen. In der Fachliteratur zum Passivhaus wird die Lüftungsanlage häufig als „Kernstück eines Passivhauses“ (z.B. Balkowski 2006: 43) bezeichnet, da über sie das Haus sowohl beheizt als auch belüftet wird. Eingeplant war, die Bewohner*innen im Interview explizit nach ihren Erfahrungen mit der Lüftungsanlage zu fragen. Dies hat sich als überflüssig erwiesen, da alle Gesprächspartner*innen von sich aus sehr frühzeitig im Interview auf das Thema zu sprechen kamen. Auf die Frage nach vorab bestehenden Befürchtungen oder Vorbehalten gegenüber dem Passivhaus äußerten viele Bewohner*innen, dass sie vor ihrem Einzug vor allem Bedenken in Bezug auf die Lüftung hatten. Einige berichten, vorher davon gehört zu haben, dass man im Passivhaus die Fenster nicht öffnen dürfe. Die meisten der heutigen Passivhausbewohner"innen kannten zu diesem Zeitpunkt nur die klassische Fensterlüftung, von kontrollierter Be- und Entlüftung hatten sie bis dahin noch nicht gehört. Dass Innenräume ausreichend gelüftet sind, ohne dass dafür die Fenster geöffnet werden (müssen), erschien vielen Passivhausbewohner*innen vor 
ihrem Einzug kaum vorstellbar. Sie erzählen, dementsprechend verunsichert und fragend, sowie neugierig und interessiert in ihre Wohnungen eingezogen zu sein. Interessant ist, wie diese Bewohner*innen den Veränderungen begegnet sind und zu welchen Entwicklungen es hier gekommen ist.

In den Gesprächen mit Mieter*innen, die eine intelligente Heizungssteuerung erhalten haben, kam das Thema Lüften eher am Rande auf. Lediglich eine Mieterin thematisierte die Umstellungen im Lüften aufgrund der Heizungsautomatik explizit. Ihr Fall wird im Rahmen dieses Kapitels dargestellt.

Im Folgenden werden verschiedene Varianten des Übergangs von Lüften im konventionellen Wohnkontext zur Lüftung im Passivhaus und SmartHome beschrieben. Dafür wurden exemplarisch einige Umstellungsprozesse rund um den Vorgang des Lüftens rekonstruiert.

Folgende Punkte haben sich hierbei als relevant herausgestellt:

1. Die unterschiedliche Aneignung von neuem Wissen und die Unterscheidung zwischen Routinen und Gewohnheiten

2. Die Ver- und Entflechtung von Praktiken sowie

3. Der Umgang mit Regeln zum ,richtigen` Lüften

\begin{tabular}{|l|c|c|c|c|c|c|}
\hline & Frau Möller & Frau Rosental & Frau Fischer & Herr Frings & Frau Greiner & $\begin{array}{c}\text { Herr } \\
\text { Lehmann }\end{array}$ \\
\hline $\begin{array}{l}\text { 1. Routine } \\
\text { oder } \\
\text { Gewohnheit }\end{array}$ & $\mathrm{X}$ & $\mathrm{X}$ & & & & $\mathrm{X}$ \\
\hline $\begin{array}{l}\text { 2. Ver- u. } \\
\text { Entflechtung }\end{array}$ & & $\mathrm{x}$ & $\mathrm{x}$ & & & \\
\hline 3. Regeln & & & $\mathrm{x}$ & $\mathrm{x}$ & $\mathrm{x}$ & \\
\hline
\end{tabular}

\subsubsection{Die Befreiung von der „Last des Lüftens“ - Frau Möller}

Frau Möller bewohnt mit ihrer Familie eine Reihenhauseinheit im Passivhausprojekt C (siehe Anhang A). Im Interview mit Frau Möller wird frühzeitig deutlich, dass sie sich im Vorhinein viele Gedanken um den Lüftungsvorgang im Passivhaus gemacht hat. Als Frau Möller nach anfänglichen Vorbehalten gegenüber dem Passivhaus gefragt wird, antwortet sie:

„Ja wir hatten schon äh (.) (seufzt) also wir hatten- wussten nicht ob das funktioniert so richtig also mit der Lüftung. Wir haben gesagt na ja so:o, wie ist das in 'nem Haus zu wohnen wo man praktisch eigentlich im Winter nicht lüften soll? Funktioniert das da wirklich mit dem 
Luftaustausch? Ist das la:ut mit der Lüftungsanlage?` (2) Ähm hmm war schon 'n kleines Abenteuer so damals." (Bewohnerin PH, Interview 62: 4, 172-177)

Deutlich wird hier, dass Frau Möller die Lüftung vorab als Unsicherheitsfaktor wahrgenommen hat und deshalb das Passivhausprojekt für sie zu Beginn ein gewisses Wagnis darstellte. Im weiteren Verlauf des Interviews zeigt sich, dass ihre ersten Zweifel am Lüftungsprinzip sehr schnell nach dem Einzug verschwunden sind, mehr noch, dass ihre anfängliche Ungläubigkeit und Zurückhaltung gegenüber der Lüftung in regelrechte Begeisterung für das Passivhauskonzept umgeschlagen sind. Im Zuge der neuen Erfahrung kam es somit zu einer Neubewertung der früheren Lüftungspraxis, die in folgender Passage zum Ausdruck kommt:

„Die Luft ist viel besser. [...] das ist ja so dass man (1) sich das gar nicht vorstellen kann dass man im Winter nicht lüften muss das ist etwas was man sich vorher nicht vorstellen kann dass einen das wirklich erleichtert wenn man nicht lüften muss. Ich hab- ich hab immer gerne gelüftet. Ich bin so 'n- eigentlich so 'n @Frischluftfanatiker@ sowas und als dann- wir haben dann so 'ne Einführungsveranstaltung bekommen von den Leuten die das hier gebaut- die- die halt da das eingebaut haben. Und da haben die gesagt@am Anfang@,Ihnen wird die Last des Lüftens genommen‘. Und da hab ich gedacht der@spinnt@. [...]. Ja da hab ich gedacht wovon redet der? Ich hab keine Last des Lüftens und hab aber festgestellt dass es wirklich einfacher ist. Also ich muss jetzt nicht mehr gucken- also mein Sohn wohnt ganz oben äh der ist jugendlich ich muss nich' gucken ob da oben gelüftet ist ja oder ich muss nicht im Schlafzimmer ständig noch mal lüften und dann ist es kalt im Schlafzimmer. [...]. Also wir waren eigentlich von Anfang an begeistert wie leicht es ist und dass einem doch eher- dass es wirklich leichter ist mit dem- als vorher. [...] äh mit dem Lüften dass das gar kein Thema mehr ist. Muss ich im Winter lüften? Wann muss ich lüften? Das ist eher leicht. Also es ist immer gelüftet. Punkt.“ (Bewohnerin $\mathrm{PH}$, Interview 62: 12f, 638-689)

Die Passage lässt erkennen, dass Frau Möller die damalige Situation retrospektiv mit Bezug auf den Vergleichshorizont ihrer heutigen Perspektive betrachtet. Der Beschreibung lässt sich entnehmen, dass sie die frühere Lüftungspraxis vor ihrem Einzug ins Passivhaus noch sehr positiv bewertet hat. Ihre Schilderung verdeutlicht, dass sie das regelmäßige Lüften aus damaliger Sicht nicht als große Anstrengung, geschweige denn als Belastung empfunden hat. 
Erst der Einzug ins Passivhaus und die dadurch bedingte Veränderung des Lüftungsvorgangs haben dazu geführt, dass Frau Möller das Lüften als Tätigkeit wieder bewusst wahrgenommen hat. Ihre Beschreibung verdeutlicht, dass das neue Erleben im Passivhaus auch ihre Perspektive auf die damalige Situation verändert hat. Erst die neue Erfahrung, selbst nicht mehr aktiv lüften zu müssen, lieferte ihr einen Vergleichshorizont, der ihr eine kritische Reflextion ihrer bis dahin selbstverständlich erscheinenden Routinepraxis ermöglicht. Die Erfahrung, dass ohne ihr Zutun bereits „immer gelüftet [ist]“ (ebd., 688-689), hat Frau Möller dazu veranlasst, die damalige Situation heute neu zu bewerten: So spricht sie in dieser Passage wiederholt von ,müssen', woran erkennbar wird, dass sie das damalige Lüften aus heutiger Perspektive als eine zu erfüllende Pflicht bzw. Notwendigkeit betrachtet. Offenbar ist ihr erst im Nachhinein klar geworden, in welchem Ausmaß sie früher mit Lüften beschäftigt war und welche Überlegungen und Aufgaben das Lüften damals alle umfasste. In ihrer Darstellung erscheint die damalige Art des Lüftens nun als eine anspruchsvolle und umfangreiche Tätigkeit, die Zeit und vor allem Nachdenken erfordert und die es mit anderen Praktiken zu koordinieren gilt. Diese Neubewertung bestätigt sich an anderer Stelle, an der Frau Möller äußert, dass mit dem Wohnen im Passivhaus „viel Stress weg[fällt]“ (ebd.: 18, 925).

Ihre Beschreibung bringt weiterhin zum Ausdruck, dass nicht Expert"innenmeinungen bzw. theoretisches Wissen zu einer Neubeurteilung ihrer früheren Lüftungspraxis geführt haben, sondern dass sich ihre Wahrnehmung der damaligen Situation erst aufgrund eigener Erfahrung gewandelt hat.

Insgesamt macht die Passage deutlich, wie schnell und unproblematisch im Fall Frau Möllers der Gewöhnungsprozess an das Wohnen im Passivhaus und den Wegfall des aktiven Lüftens verlaufen ist. Vor dem Hintergrund der Neubewertung wird sichtbar, dass die alte Lüftungsroutine vor dem Umzug als ,normal' und selbstverständlich wahrgenommen wurde und die Ausübung kein bewusstes Nachdenken mehr erforderte. Verallgemeinernd lässt sich aus dieser Passage schließen, dass Routinen und gewohnheitsmäßige Abläufe erst durch den Bruch mit dem Altbekannten sichtbar werden.

\subsection{2 (Fenster-)Lüftung als „Wissenschaft“ - Frau Rosental}

Ein ähnliches Muster in der Bewertung der alten Lüftungsroutine wird im Fall Frau Rosentals deutlich. Auch für Frau Rosental stellt das damalige 
Lüften eine anspruchsvolle Aufgabe dar. Im Unterschied zu Frau Möller ist Frau Rosental dies aber nicht erst durch ihr Leben im Passivhaus klar geworden, sondern sie war sich dessen offenbar schon früher bewusst. Im Interview bringt die Frage nach Unterschieden im Heizen zwischen Passivhaus und konventionellem Wohngebäude Frau Rosental dazu, ihre damalige Lüftungspraxis vor dem Hintergrund ihrer heutigen Situation kritisch zu reflektieren:

"Ja ich muss mich zum Beispiel nich mehr mit Heizen und Lüften also ich weiß dass (.) da hat mein Sohn noch bei mir gewohnt dass das 'ne Wissenschaft war die ihn unheimlich genervt hat mit dem Lüften (.) also dann wurde in dem Zimmer gelüftet und in dem weil man nun in der Küche frühstückte. Aus'm Frühstück bin ich dann hin hab die Türen zugemacht damit dann bis wir fertig waren mit Frühstücken dass dann wieder also im Winter etwas angewärmt war. Das war- das is schon mit mit so was beschäftige ich mich hier überhaupt nich. Ich stehe auf mach mich fertig und dann geh ich und dann is die Sache erledigt. (.) Und und wenn es wärmer is dann hab ich die Tür offen fertig. Also äh das finde ich is schon äh @also@ de- also da ka-weiweil da ma- war ich natürlich auch immer ne- dass mein Sohn dann immer genervt war dass ich aufgestanden bin. Aber ich konnte ja nu nich irgendwie 'ne Viertelstunde oder zwanzig Minuten bei zwanzig Grad minus oder zehn Grad minus die Tür offen lassen. Und das war dann schon immer so dass man dann da lüften musste wenn man den Raum nich nutzte und so und damit beschäftigt man sich hier gar nich.“ (Bewohnerin PH, Interview 59: 30, 1576-1593)

In dieser Passage beschreibt Frau Rosental für sie spürbare Unterschiede im Heizen und Lüften zwischen Passivhaus und konventionellem Wohngebäude. Ihre Beschreibung springt die ganze Zeit zwischen ihrer heutigen Wohnsituation im Passivhaus und ihrem früheren Wohnen in einer konventionellen Wohnung hin und her, was zeigt, dass sie ihre Erfahrungen in Beziehung setzt und miteinander vergleicht. Sie beginnt ihre Darstellung mit ihrem aktuellen Erleben im Passivhaus und spricht hier wie selbstverständlich vom Heizen und Lüften als einem Vorgang. Auffallend ist, dass die Interviewerin nur nach dem Heizen gefragt hatte, Frau Rosental in ihrer Antwort aber vor allem das Lüften thematisiert. Daraus lässt sich schließen, dass für sie Heizen und Lüften nicht voneinander zu trennen sind. Zwar beendet sie ihren Satz nicht, aber an zwei anderen Stellen in dieser Passage wird deutlich, dass sie hier anscheinend aussagen möchte, dass für sie mit dem Passivhaus Heizen und Lüften als Aktivitäten im her- 
kömmlichen Sinne so gut wie ganz wegfallen sind und sie hierfür fast nichts mehr machen muss. Statt ihren Satz zu beenden, wechselt sie in ihrer Beschreibung unmittelbar zu ihren früheren Lüftungsgewohnheiten in einer konventionellen Wohnung.

An den nun folgenden argumentativen Einwürfen wird deutlich, dass ihr das damalige Lüften als eine zu erledigende Notwendigkeit in Erinnerung geblieben ist. Der Beschreibung lässt sich entnehmen, dass Frau Rosental das Lüften als eine besonders anspruchsvolle und komplizierte Tätigkeit wahrgenommen hat, die einer ,Wissenschaft' gleichkam. Mit Wissenschaft werden in der Regel Tätigkeitsbereiche bezeichnet, für die ein theoriebegründetes, geordnetes und für gesichert erachtetes Wissen vorliegt und die eigentlich Expert"innen vorbehalten sind. Die Charakterisierung von Lüften als Wissenschaft impliziert demnach ein informiertes und regelgeleitetes Handeln. Frau Rosentals Schilderung ihrer früheren alltäglichen Lüftungsroutine lässt das systematische Vorgehen mit den erforderlichen Arbeitsschritten für richtiges Lüften deutlich erkennen. Zudem wird in diesem systematischen Vorgehen deutlich, welchen Regeln sie beim Lüften folgt: gemäß ihrer Beschreibung geht es darum, die Wohnräume während der Heizperiode jeweils nur für einige Minuten stoßzulüften.

Frau Rosentals Wissenschaftsvergleich entspricht dem typischen Lai“innenverständnis von wissenschaftlicher Praxis, wonach alles dem Bereich Wissenschaft Zugeordnete im Allgemeinen als anspruchsvoll und kompliziert gilt. Insofern beschränkt sich der Vergleich im Wesentlichen auf die für sie komplizierte Durchführung des damaligen Lüftens.

Ihre Schilderung macht deutlich, dass Frau Rosental das Lüften früher sehr ernst genommen hat. Die Beschreibung lässt deutliche Parallelen zu Regeln zum ,richtigen' Lüften erkennen, wie sie in zahlreichen Anleitungen beschrieben sind. ${ }^{89}$ So wird etwa immer wieder von Expert"innen empfohlen, die Wohnung während der kalten Jahreszeit mehrmals am Tag für einige Minuten stoßzulüften, wogegen eine dauerhafte Kippstellung von Fenstern vermieden werden soll. In der Passage wird nun deutlich, dass Frau Rosental Vorstellungen darüber verinnerlicht hat, wann gelüftet werden soll und wie lange gelüftet werden soll. Die häufige Verwendung des Ausdrucks ,man', als auch die Formulierungen „ich konnte ja nu nich“

89 Vgl. exemplarisch die Info-Broschüre herausgegeben von der Deutschen EnergieAgentur (dena) „Gesund Wohnen durch richtiges Lüften und Heizen“ (Deutsche Energie-Agentur GmbH (dena) o.J.*) sowie die Info-Broschüre der Verbraucherzentrale „Gesundes Raumklima. Heizen, Lüften, Feuchtigkeit und Schimmel“ (Verbraucherzentrale Bundesverband e.V. (VZBV) 2017*). 
(ebd., 1589) und „dass man da lüften musste“ (ebd., 1591) lassen schließen, dass sie diese Regeln nicht mehr bewusst in Frage stellt, sondern als selbstverständlich annimmt. Offenbar sind hier früher einmal bewusst gelernte Regeln am Werk. Weiterhin stellt sich die Frage, was über den Charakter der Regelbefolgung sichtbar wird. Frau Rosental äußert hier nicht explizit, warum sie die Tür bei Minusgraden nicht für 15 Minuten oder gar länger offenstehen lassen konnte. Naheliegend erscheint es, dass sie befürchtet, die Räume würden sonst auskühlen. Ist diese Vermutung richtig, so wird hier eine Orientierung am rationalen Gehalt der Regel zum kurzen Stoßlüften deutlich. Der rationale Gehalt der vor langer Zeit gelernten Regel besteht darin, dass ein starkes Auskühlen der Wohnräume infolge langen Lüftens während der Heizperiode vermieden werden soll. Denn je stärker die Räume sowie die Wände in Fensternähe auskühlen, desto mehr Energie ist anschließend erforderlich, um die Raumtemperaturen wieder auf ein behagliches Niveau zu bringen, so dass der Raum wieder genutzt werden kann. Demnach wirkt kurzes Stoßlüften der Verschwendung von Heizenergie entgegen. Gleichzeitig lassen Frau Rosentals Formulierungen erkennen, dass es hier auch um die Befolgung einer sozialen Norm geht. Sowohl die häufige Verwendung des Ausdrucks ,man', als auch die Formulierungen „ich konnte ja nu nich“ (ebd., 1589) und „dass man da lüften musste" (ebd., 1591) deuten darauf hin. Offenbar hat Frau Rosental hier eine Normalitätsvorstellung von richtigem Lüften so tief verinnerlicht, dass sie sich von diesem Wissen kaum mehr lösen und somit auch keinen anderen Ablauf mehr vorstellen konnte. Es scheint so, als würden hier die rationalen Gehalte der Regel mit den sozialen Vorstellungen über ,richtiges` Lüften zusammenfallen. Wie notwendig ihr dieses Vorgehen damals erschien, zeigt sich auch daran, dass sie nicht von ihrer Handlungsweise für richtiges Lüften abgewichen ist, obwohl ihr offensichtlich bewusst war, dass sie mit ihrem Handeln regelmäßig Hektik und Unruhe beim gemeinsamen Frühstück verbreitet, womit sie ihren Sohn offensichtlich genervt hat. Dies verdeutlicht ihren unbewussten Anspruch, den früher einmal in Form von Regeln vermittelten bzw. gedachten gesellschaftlichen Anforderungen an ,richtiges' Lüften gerecht zu werden.

Dieser früheren Lüftungspraxis stellt sie ihr heutiges Lüftungshandeln im Passivhaus gegenüber: Es wird deutlich, dass sie nun kaum noch selbst aktiv werden muss, damit ihre Wohnräume gut gelüftet sind. Alle Aufgaben rund ums Lüften, mit denen Frau Rosental vorher täglich konfrontiert war, sind durch die Lüftungsanlage auf einen Schlag erledigt.

Frau Rosental bricht ihre angefangenen Sätze häufig in der Mitte oder kurz vor Beendigung ab. Auch ihre bewertenden Einwürfe führt sie leider 
nicht zu Ende. Dem Kontext ist aber zu entnehmen, dass sie die Delegation des Lüftungsvorgangs an die Technik als angenehme Entlastung empfindet. Dies wird daran deutlich, dass sie die frühere Praxis - mit einer abwertenden Konnotation - als, Wissenschaft' bezeichnet.

Ein interessanter Aspekt, der in dieser Passage sichtbar wird, ist: die Verflechtung des Heizens und Lüftens mit anderen alltäglichen Praktiken. Im Fall Frau Rosentals überschneidet sich das Lüften zeitlich mit dem Frühstück und musste damit koordiniert werden. Im Passivhaus fällt dieser Aufwand nun weg. Durch die Technik kommt es hier zu einer Entflechtung ehemals miteinander verflochtener Tätigkeiten.

\subsection{3 „E]ntweder ich geh' auf die Straße zum Rauchen oder ich leb' mit dem Gestank jetzt“ - Frau Fischer}

Auch mit anderen Tätigkeiten kann das Lüften im Alltag verflochten sein, wie der Fall von Frau Fischer zeigt. Frau Fischer ist Mitte 30 und lebt mit zwei Hunden in einer 3-Zimmer-Mietwohnung, die mit einer intelligenten Heizungsautomatik ausgestattet wurde. Im folgenden Zitat beschreibt Frau Fischer, wie sich aufgrund der neuen Heizungssteuerungstechnik ihr Lüftungsverhalten und infolgedessen auch ihre Rauchgewohnheiten verändert haben:

„Ich hab' beispielsweise im Schlafzimmer eigentlich generell das Fenster offen es sei denn es sind echt massiv Minustemperaturen. Das mache ich jetzt nich' mehr. Ähm weil ja diese diese Heizautomatik auf das Lüften zwar reagiert aber maximal 'ne Stunde ähm und dann geht die Heizung irgendwann wieder an ähm das heißt wenn es jetzt ganz ganz dolle kalt wird also unter denen- die Werte sinkt die ich eingestellt hab' also unter 18 Grad sind in dem Raum- geht die Heizung an und das will ich natürlich nich'. Das heißt ich lüfte weniger im im Schlafzimmer als ich's vorher gemacht hab'. Das is' 'n bisschen ungewohnt weil- das hängt einfach damit zusammen dass ich in der Wohnung rauche weil wir hier keinen Balkon haben und ich das hasse wenn ich nach Hause komme und die Bude stinkt so massiv nach kaltem Rauch darum habe ich eigentlich immer ein Fenster offen ähm (2) entweder ich geh' auf die Straße zum Rauchen oder ich leb' mit dem Gestank jetzt. Aber das is'- is' dann halt so (lacht). “ (Bewohnerin SH, Interview 72: 11, 545-562) 
Vor Einbau der Heizungsautomatik hat Frau Fischer in der Wohnung geraucht und dauerhaft ein Fenster geöffnet, um die Rauchgerüche abziehen zu lassen. Die automatische Heizungssteuerung verändert nun die Rahmenbedingungen dieser Praxis. Wie bereits in Teilkapitel 4.1.2 beschrieben, beinhaltet das neue System eine Energiesparfunktion, die eigens der Erkennung eines geöffneten Fensters dient: Bei einem schnellen Temperaturabfall werden die Heizkörperthermostatventile im jeweiligen Raum automatisch geschlossen. Eine Verschwendung von Heizenergie soll vermieden werden, wenn in einem Raum gleichzeitig die Heizung angeschaltet und ein Fenster geöffnet ist. Die Verschließung des Fensters registriert das System wiederum als Raumtemperaturerhöhung und gibt daraufhin die Heizungsregelung wieder frei. Das System wurde vom Hersteller so programmiert, dass der jeweilige Heizkörper höchstens bis zum Erreichen der von dem bzw. der Nutzer\%in für den jeweiligen Wohnraum eingestellten Mindesttemperatur ausgeschaltet bleibt. In diesem Fall hat der Technikhersteller die maximale Dauer der Abschaltung auf eine Stunde begrenzt. Die Bewohner*innen sollen durch die zeitliche Begrenzung angehalten werden, eine längere Kippstellung zu vermeiden, was auch das Auskühlen der Räume verhindern soll.

Diese Programmierung führt nun allerdings paradoxerweise dazu, dass bei längerer Fensteröffnung als vorgesehen, die aufsteigende Warmluft des Heizkörpers ungenutzt nach draußen strömt und buchstäblich ,zum Fenster heraus geheizt' wird. Hier zeigt sich, dass die Technik allein nicht die Dauer der Fensteröffnung regulieren kann. Die Technik gibt hier Anreize zu bestimmten Handlungsweisen, die letztliche Ausführung liegt jedoch weiterhin bei den Bewohner*innen. Um diesen Effekt der wiederanspringenden Heizung zu vermeiden, ist Frau Fischer nun dazu übergegangen, das Fenster nicht mehr dauerhaft geöffnet zu lassen. Offenbar gibt es keine bzw. zumindest keine ihr bekannte technische Lösung, die ihr die Deaktivierung dieser automatischen Funktion ermöglicht. Weil die Technik sich offenkundig nicht ihren Bedürfnissen entsprechend einstellen lässt, hat sich Frau Fischer dazu gezwungen gesehen, ihre Lüftungspraxis an das neue System anzupassen. Diese Verhaltensänderung hat für sie allerdings zu dem neuen Problem geführt, dass sie den Zigarettenrauch nun nicht mehr wie gewohnt aus ihren Wohnräumen abziehen lassen kann.

Allem Anschein nach ist hier eine Regel, die das ,richtige' Heizen üblicherweise anleitet - nämlich, dass man langes Kipplüften vermeiden soll -, in die Programmierung der digitalen Steuerungstechnik eingeflossen. Damit bringt die neue Technik Frau Fischer in eine Dilemma-Situation, denn die bisher von ihr praktizierte Handlungsweise wird von der neuen Tech- 
nik ausgeschlossen. Wenn sie ein Fenster dauerhaft offenstehen lässt, muss sie in Kauf nehmen, dass die Heizung dagegen an heizt. Unerwünschte Konsequenz kann hier sein, dass es zu einem so genannten ,Rebound'wenn nicht gar ,Backfire-Effekt kommt. ${ }^{90}$ Oder aber sie verzichtet auf das Dauerlüften. Dann muss sie sich jedoch mit dem Geruch des Zigarettenqualms in ihrer Wohnung abfinden. Eine weitere, für Frau Fischer ebenfalls wenig attraktive Option besteht darin, die hauptsächlich durch die neue Technik entstandene Lüftungsproblematik zu umgehen, indem sie zum Rauchen ihre Wohnung verlässt. In jedem Fall bedeutet das neue Steuerungssystem somit eine Reduzierung der Handlungsoptionen. Der Handlungsspielraum wird mit Einführung des Systems deutlich einschränkt.

Wie schon bei Frau Rosental wird deutlich, dass Heizen und Lüften im Alltag oft mit ganz anderen Praktiken zusammenhängen, an die Technikhersteller vielleicht zunächst gar nicht denken. Frau Fischers Lüftungspraxis war bisher auf ihr Rauchverhalten abgestimmt. Die neue Technik stört nun ein gewohntes und wohl erprobtes Praktikenarrangement. Der Einbau einer Technik, die eigentlich nur das Heizen verändern sollte, hat hier gleich die Umstellung mehrerer Praktiken bzw. die Neuordnung eines kleinen Praktikengefüges erforderlich gemacht.

4.2.4 Zum Umgang mit Regeln, die das Lüften im Passivhaus betreffen Herr Frings und Frau Greiner

Im Vergleich zum Fall von Frau Fischer zeigt sich bei Herrn Frings und Frau Greiner noch ein anderes Muster zwischen von Expert"innen geäußerten Regeln und dem Umgang der Bewohner"innen damit.

An mehreren Stellen im Interview mit Herrn Frings wird deutlich, dass die Expert"innen, die den Bewohner"innen des Passivhausprojekts D zu Beginn die Handhabung der Lüftungsanlage erklärt haben, den Bewohner*innen bei dieser Gelegenheit auch Regeln zum Fensterlüften im Passivhaus mit auf den Weg gegeben haben. Für das Passivhaus gelten beim

90 In der Energieökonomie wird die Bezeichnung, Rebound' für mehrere Effekte verwendet, die alle dazu führen, dass das Einsparpotenzial von Effizienzsteigerungen entweder gar nicht oder nur teilweise realisiert wird. Hat eine Effizienzsteigerung sogar einen erhöhten Verbrauch zur Folge, das heißt einen Rebound-Effekt von über 100 Prozent, so spricht man von ,Backfire` (vgl. Frondel 2012; Santarius 2012). 
Fensterlüften die gleichen Regeln wie für konventionelle Wohngebäude: mehrmaliges kurzes Stoßlüften, statt dauerhaftes Kipplüften und Fensterlüften nur bei abgedrehten Heizkörperthermostaten. Herrn Frings zufolge wurden den Mitgliedern der Hausgemeinschaft diese „einfache[n] Regeln“ (Bewohner PH, Interview 66: 15, 730-731) beim Einzug mündlich mitgeteilt: ${ }^{91}$

Nach eigenen Angaben haben sich die Frings' anfangs sehr genau an diese Vorgaben gehalten. Mit der Zeit und zunehmender Erfahrung des Lebens im Passivhaus ist ihr Umgang mit den Regeln zur Fensterlüftung aber offenbar etwas lockerer geworden. Herr Frings meint diese Veränderung, die Loslösung von den einstigen Vorgaben der Expert"innen zur korrekten Fensterlüftung, auch bei einigen benachbarten Wohnparteien zu beobachten:

„Und dieses Jahr- (.) Aber ich glaube bei anderen Nachbarn das sieht man auch dass is irgendwie alle gehen ein bisschen lockerer damit um und (.) man macht schon (.) häufiger mal das Fenster auf und so. (1) Und Lüften also wir lüften nich jeden Morgen alle ff- alle Räume einmal fünfzehn Minuten oder so $L_{\text {das }}$ machen- [...] brauchen wir nich nee.“ (Bewohner PH, Interview 66: 16, 789-797)

In dieser Passage wird deutlich, wie sich das Verhältnis von Expert“innenwissen und -autorität einerseits und erlebter Erfahrung der Bewohner*innen andererseits allmählich gewandelt hat. Anfangs, als die Bewohner*innen noch keine Erfahrung mit dem Wohnen im Passivhaus hatten, waren sie offenbar sehr bemüht darum, die von den Expert*innen geäußerten Regeln zum Fensterlüften zu befolgen. Dagegen orientieren sie sich mittlerweile nicht mehr vorrangig an dem Wissen der Expert"innen, sondern verlassen sich mehr auf ihre eigene Erfahrung. Der Schilderung lässt sich entnehmen, dass die erlebte Erfahrung die Regeln entkräftet.

Ein ähnliches Muster zwischen von Expert*innen geäußerten Regeln und dem Umgang der Bewohner*innen damit zeigt sich auch bei Frau Greiner. Frau Greiner gehört dem Passivhausprojekt B an. Frau Greiner ist sehr frühzeitig in das Projekt eingestiegen und war dadurch an der Ent-

91 Da im Passivhaus die Lüftungsanlage das Be- und Entlüften der Wohnräume erledigt, ist das Lüften durch ein geöffnetes Fenster im Prinzip gar nicht mehr erforderlich. Zwar können die Fenster im Passivhaus geöffnet werden, aber in der Heizperiode sollte dies möglichst nicht geschehen, um die Effektivität der Wärmerückgewinnung nicht zu umgehen. Offenbar gehen die Expert*innen aber davon aus, dass auch Passivhausbewohner*innen während der kalten Jahreszeit zum Lüften öfters einmal ein Fenster öffnen. 
scheidung zum Passivhaus beteiligt. Auch in diesem Fall haben die Bewohner*innen zu Anfang sehr klare Anweisungen zum Fensterlüften im Passivhaus erhalten. Im Unterschied zum Fall des Herrn Frings waren die anfänglichen Regeln zur Fensterlüftung im Fall Frau Greiners bzw. des Passivhausprojekts B etwas strikter. Hier wurde den Bewohner*innen zu Anfang gesagt, dass sie in der Heizperiode die Lüftung durch geöffnete Fenster gänzlich vermeiden sollten, wie die beiden folgenden Zitate von Frau Lutz, einer Hausmitbewohnerin Frau Greiners, deutlich machen:

„Na ja stoß- stoßlüften aber nich jetzt also über Nacht Fenster offen lassen.“ (Bewohnerinnen PH, Interview 59: 7, 340-341)

„Ja also ich hatte das eher auch so verstanden dass so lange es draußen kälter is als drinnen sollte man eigentlich die Fenster geschlossen halten." (ebd.: 18, 974-975)

Frau Greiner berichtet, dass eine Frau noch während des Planungsprozesses aus dem Projekt ausgestiegen ist, weil sie sich nicht mit diesen strengen Vorgaben arrangieren konnte: ${ }^{92}$

„Und im Planungsprozess entwickelte es sich dass es ein Passivhaus wurde. [...]. Eine Frau ist ausgestiegen daraufhin. [...] Die- die die wollte nicht die wollte nicht diese Reglementierung mit Lüften oder nicht wobei wir das auch nicht so streng handhaben. Da ist irgendwas noch mal umgestellt worden. Also wir dürfen durchaus lüften ohne dass das ganze System zusammenbricht. Aber so hieß es zunächst." (Bewohnerin PH, Interview 64: 3, 113-132)

Hier zeigt sich, dass die von den Expert*innen geäußerten Regeln zum Fensterlüften abschreckend wirken können, bis zu einem Ausmaß, in dem sich Interessent"innen wieder vom Passivhaus abwenden.

Wie im Fall des Herrn Frings lässt sich auch der Beschreibung Frau Greiners entnehmen, dass sich die Bewohner*innen in der Praxis nicht streng an die ursprünglichen Vorgaben der Expert*innen halten, sondern durchaus zum Lüften die Fenster öffnen. Anzunehmen ist, dass die Bewohner*innen keine für sie negativen Konsequenzen beim Fensterlüften bemerkt haben, die sie von dieser Praktik abgebracht haben. Zudem deutet der Hinweis Frau Greiners, dass „[d]a irgendwas noch mal umgestellt worden [ist]“ (ebd., 130-131), darauf hin, dass die Lüftungsanlage im Pas-

92 Auch Frau Rosental, eine weitere Hausmitbewohnerin Frau Greiners, erwähnt im Interview den Fall der Frau, die das Passivhausprojekt aufgrund des strengen Reglements zur Fensteröffnung sehr frühzeitig wieder verlassen hat. 
sivhausprojekt B im Nachhinein noch einmal neu eingestellt wurde. Zwar äußert sich Frau Greiner hierzu nicht explizit, aber es ist naheliegend, dass die Nachjustierung der Lüftungsanlage mit dazu geführt hat, dass die Expert"innen die Regeln zum Fensterlüften etwas gelockert bzw. ihr anfängliches Fensterlüftungsverbot korrigiert und den Bewohner*innen zumindest das Stoßlüften zugestanden haben. ${ }^{93}$

Die Passage lässt erkennen, dass die Expert"innen den Bewohner*innen dringend davon abgeraten haben, in der Heizperiode durch das geöffnete Fenster zu lüften. An Frau Greiners Ausführung wird deutlich, dass die Expert*innen ihr damals (Mitte der 1990er Jahre) vermittelt haben, dass durch Fensterlüftung das gesamte Be- und Entlüftungssystem in seiner Funktionsweise grundlegend gefährdet sei oder zumindest empfindlich gestört werde.

Der Fall lässt sich als Hinweis darauf lesen, wie der Mythos, dass im Passivhaus die Fenster nicht geöffnet werden dürfen, entstanden sein könnte. Auch macht er klar, dass Expert"innen mit ihrem Wissen wesentlich an der Entstehung dieses Mythos' beteiligt waren. Den Ausführungen Frau Greiners lässt sich entnehmen, dass Expert"innen in den 1990er Jahren offenbar sehr deutlich kommuniziert haben, dass Fensterlüftung im Passivhaus nicht nur nicht mehr erforderlich sei, sondern dass auf das Fensteröffnen in der Heizperiode möglichst ganz verzichtet werden sollte, um die Effektivität der Wärmerückgewinnung nicht zu umgehen. Es liegt nahe, dass diese oft kommunizierte ,Regel' bzw. Handlungsanweisung einen wichtigen Nährboden für den weit verbreiteten Mythos von den nicht zu öffnenden Fenstern im Passivhaus bildete. Dieser Mythos hält sich nun schon ziemlich lange. Die Expert*innen, die mittlerweile dazu übergegangen sind, weniger strenge Vorgaben zum Fensterlüften zu machen, sehen sich in ihrer beruflichen Praxis immer noch häufig mit diesem Mythos konfrontiert und haben die Erfahrung gemacht, dass er für die Akzeptanz des Passivhauses abträglich ist.

Die Schilderung Frau Greiner zeigte bereits, dass derartige ,Regeln` einige Interessent*innen abschrecken können, was in der Folge die weitere Durchsetzung des Passivhauses erschweren kann.

93 Aus dem gemeinsamen Interview mit Frau Rosental und Frau Lutz geht hervor, dass die anfänglich von den Expert*innen mitgeteilten Regeln zum Fensterlüften zusätzlich von anderen Bewohner*innen des Passivhausprojekts B sogar als mehr oder weniger generelles Verbot zur Fensteröffnung verstanden worden sind. 
4.2.5 Von Fensterlüftung zu kontrollierter Be- und Entlüftung - ein „schleichender Gewöhnungsprozess“ - Herr Lehmann

Der Mythos, dass man im Passivhaus die Fenster nicht öffnen dürfe, zeigt sich zudem in den Interviews mit Passivhaus-Architekt*innen. Es wird deutlich, dass sich anfängliche Bedenken neuer Bewohner*innen meist auf die neue Art des Lüftens im Passivhaus beziehen und viele künftige Bewohner"innen anfangs davon ausgehen, dass im Passivhaus generell kein Fenster mehr geöffnet werden darf. Von diesen Bedenken berichtet z.B. der Architekt Herr Meier im Interview:

„das hieß ja immer äh äh (.) ,Kann ich denn die Fenster noch öffnen? Oder werden denn die Fenster abgeschlossen im Passivhaus?“" (Architekt PH, Interview 48: 18, 851-853)

Die interviewten Architekt*innen berichten unabhängig voneinander einhellig, dass sie festgestellt haben, dass in der allgemeinen Bevölkerung generell noch große Vorbehalte gegenüber kontrollierter Be- und Entlüftung im Wohnbereich bestehen. In Bezug auf die Akzeptanz des Passivhauses in der Bevölkerung gehe es dementsprechend nach wie vor hauptsächlich um die Lüftung, wie etwa im Interview mit dem Architekten Herr Beckert deutlich wird:

„Also die äh: Hauptfragestellung ist nach wie vor Lüften und die Sauerstofffrage.“ (Architekt PH, Interview 53: 19, 966-967)

In diesem Zusammenhang ist insbesondere das Interview mit dem langjährig erfahrenen Passivhaus-Architekten Herrn Lehmann aufschlussreich. Herr Lehmann berichtet vor etwa zehn Jahren für eine städtische Behörde selbst eine Studie zur Nutzer*innenzufriedenheit mit Passivhäusern durchgeführt zu haben. Bei dieser Untersuchung sei als ein zentrales Ergebnis herausgekommen, dass viele der befragten Bewohner*innen anfangs vor allem mit der neuen Art des Lüftens Probleme hatten und dass von einigen das automatisierte Lüften aus verschiedenen Gründen nach wie vor kritisch gesehen wird. Herr Lehmann findet dieses Ergebnis jedoch weder beunruhigend noch erstaunlich. Er erklärt sich die meist nur anfänglich bestehende kritische Haltung der Bewohner*innen gegenüber der Lüftung damit, dass die allermeisten Bewohner*innen vor ihrem Bau oder Einzug ins Passivhaus weder von automatischer Wohnungsbe- und -entlüftung gehört haben, noch über Erfahrungen mit Wohnungslüftungssystemen verfügen. Herr Lehmann erklärt, dass im Wohnungsbau Lüftungsanlagen erst mit Erfindung des Passivhauses eingeführt wurden. Folglich handele es 
sich um eine noch relativ junge Entwicklung. Hingegen seien Heizungssysteme schon lange etabliert, weshalb Änderungen hier meist kleiner ausfielen und von den Bewohner*innen auch weniger wahrgenommen würden. Dementsprechend geht er davon aus, dass sich die Bewohner*innen auch an diese Neuerung erst einmal gewöhnen müssten.

Wie Herr Lehmann den Verlauf der Gewöhnung an die Passivhauslüftung genau sieht, führt er erst an späterer Stelle, gegen Ende der Unterhaltung über die verschiedenen Faktoren für ein behagliches Innenraumklima, im Interview aus. ${ }^{94}$ Aus seinem beruflichen Alltag weiß er zu berichten, dass die Behaglichkeitsvorstellungen und diesbezüglichen Bedürfnisse der Bewohner*innen teilweise weit auseinanderlägen und sich mit zunehmender Wohnerfahrung im Passivhaus oft wandelten. Bereits hieraus lässt sich schließen, dass Herr Lehmann davon ausgeht, dass beim Übergang von konventionellen Wohnsituationen zum Passivhaus Gewöhnungsprozesse ablaufen.

So schildert Herr Lehmann, dass er die Erfahrung gemacht habe, dass es erstens generell eine gewisse Zeit brauche, bis Neubewohner*innen tatsächlich verstanden hätten, was die Unterschiede beim Heizen und Lüften im Vergleich zwischen Passivhaus und konventionellem Wohngebäude seien. Zweitens sei es aber auch individuell sehr unterschiedlich, wie lange diese Gewöhnung „an das Andersartige eines Passivhauses“ (Architekt PH, Interview 52: 20, 1058-1059) dauere. Hier ist seine generelle Beobachtung, dass die Dauer des Gewöhnungsprozesses in hohem Maße mit den vorherigen Wohnerfahrungen der Bewohner*innen korreliert ist: Je geringer die Unterschiede im Wärmedämmstandard sowie bei der Heizungs- und Lüftungstechnik zwischen vorheriger Wohnung und dem Passivhaus sind, desto schneller verläuft in der Regel der Gewöhnungsprozess.

Herr Lehmann beschreibt, dass die neuen Bewohner*innen zum Anfang zwar häufig so etwas wie einen „Aha-Effekt“ (ebd.: 21, 1063) erleben würden, womit er meint, dass sie die neue (Wohn-)Situation im Passivhaus umgehend als Komfortsteigerung erfahren, dass es aber eine gewisse Zeit dauert, bis es infolge der neuen Erfahrung auch zu einer dauerhaften Än-

94 Während Herr Lehmann in dieser Unterhaltung anfangs nur technische Parameter wie den objektiven Standard für thermische Behaglichkeit und dementsprechende Normwerte für angemessene Raumtemperaturen, Luftfeuchtigkeit und Luftgeschwindigkeit beschreibt, von denen er in seinen Planungen ausgeht, thematisiert er erst auf Nachfrage soziale Faktoren, wie diesbezügliche Vorstellungen und Bedürfnisse der Nutzer*innen, die seiner Ansicht nach für die Wahrnehmung und Beurteilung von Behaglichkeit bzw. eines behaglichen Wohnraumklimas eine ebenso bedeutende Rolle spielen. 
derung des Lüftungsverhaltens kommt. In einer aufschlussreichen Passage erörtert er ein typisches Muster derartiger Anpassungsprozesse:

„Nee ich weiß nich' wie lange die Leute brauchen. Ich kann das nur (1) an so einem kleinen etwas anderen Beispiel festmachen. Ähm ich wohne ja selber jetzt in 'nem nur in Anführungsstrichen nur Niederenergiehaus [...]. (1) Und ähm wir haben das eben auch damals schon mit 'ner Lüftungsanlage auch ausgestattet wo es auch ganz viel Widerstand früher noch gab wegen Lüftung und sonstiges wo auch ganz viele Leute gesagt haben ,Nee also ich kann nich' mit geschlossenem Fenster schlafen. Das muss- muss immer offen bleiben'. Und ähm wir wohnen da jetzt seit 13 Jahren (.) und wenn ich am Anfang so im Winter mal geguckt hatte wie viele Fenster da nachts dann noch gekippt waren und wenn man heute mal guckt wie viele noch gekippt sind (.) is' das verschwindend gering. Und das liegt aber nicht daran dass die Leute bewusster unbedingt geworden sind (1) sondern mehr daran dass ähm die Leute es gar nicht mehr merken sondern die kommen rein die merken ihre Luftqualität is' gut ja und denken gar nich' mehr dran dass 'n Fenster aufgemacht werden muss so dann auch. Und das is' einfach so 'n- so 'n schleichender Gewöhnungsprozess der irgendwo auch stattfindet." (Architekt PH, Interview 52: 21, 10911110)

Aus diesem Beispiel geht hervor, dass sich die anfängliche Ablehnung und Kritik und eine nur allmähliche Gewöhnung an eine kontrollierte Be- und Entlüftung für Herrn Lehmann als Experte als normaler Anpassungsprozess an eine technische Neuerung darstellt.

Die Passage zeigt, dass Herr Lehmann bei dem Gemeinschaftswohnprojekt die Beobachtung gemacht hat, dass einige Bewohner*innen ihre gewohnte Lüftungspraxis des Fenster-Kippens zunächst noch für einige Jahre beibehalten haben, dass dieses Verhalten mit der Zeit aber immer seltener geworden und bis heute nahezu verschwunden ist. Herr Lehmann stellt hierzu die These auf, dass diese Verhaltensänderung von den Bewohner*innen nicht bewusst vollzogen wurde, sondern sich weitestgehend unbewusst ereignet hat, dass die Bewohner*innen irgendwann intuitiv dazu übergegangen sind, das Fenster im Winter nachts geschlossen zu lassen.

Wie schon vorher an verschiedenen Stellen im Interview deutlich wurde, nimmt er an, dass die Dauer der Gewöhnung vor allem von den bisherigen Wohn- und Heizerfahrungen der Bewohner*innen abhängt. In dieser Passage spekuliert er nun über den konkreten Verlauf der Gewöhnung. Seiner Darstellung lässt sich entnehmen, dass es Jahre dauern kann, bis die 
neuen Sinneseindrücke auch mental verarbeitet und so weit verinnerlicht sind, dass sich die neue Praxis des automatisierten Be- und Entlüftens in einem geänderten Handeln niederschlägt und die Bewohner"innen die Fenster während der Heizperiode nachts nicht mehr öffnen. Herr Lehmann geht, wie aufgezeigt, davon aus, dass sich diese Entwicklung größtenteils unbewusst abspielt und es sich hierbei um einen mehr oder weniger passiven Prozess handelt. Das würde bedeuten, dass Gewöhnungsprozesse auch komplett unbewusst ablaufen können.

Direkt im Anschluss fährt Herr Lehmann fort:

„wenn ich das denen kopfmäßig äh sagen würde und so dann ,Nein!‘. Und wenn ich sage ,Doch.' ,Stimmt. Ich mache mein Fenster tatsächlich kaum noch auf.' Aber das kopfmäßig is'- is' es so dass es- es is' halt dass viele die Leute die wollen ja frische Luft haben es geht ja nicht um die kalte Luft es geht ja um frische Luft. Und äh bei- bei was weiß ich bei minus $10 \mathrm{Grad}$ mit gekipptem Fenster schlafen ist ja nicht gesund also in dem Sinne. Äh aber ist mir auch- in 'nem normalen Haus wenn ich was weiß ich 'nen 10 Quadratmeter Schlafraum habe da schlafen vielleicht auch noch zwei Personen dann drin dann ist nach 'n paar Stunden ist der $\mathrm{CO}_{2}$-Gehalt dermaßen gestiegen (lacht) dass man äh aufwacht und kriegt keine Luft mehr und reißt das Fenster auf. Das is' doch dann ganz normal irgendwo auch. Und äh das wird einfach frische Luft und kalte Luft wird einfach miteinander vermengt immer so.“ (Architekt PH, Interview 52: 21, 1111-1125)

In dieser Passage versucht Herr Lehmann seine These vom langsamen unbewussten Gewöhnungsverlauf anhand eines fiktiven Dialogs zu untermauern, in dem er die Bewohner*innen auf rationaler Ebene mit ihrer neuen Lüftungspraxis konfrontiert. Aus dieser Äußerung geht hervor, dass den Bewohner*innen ihr geändertes Verhalten selbst gar nicht bewusst sei, sondern sie die Änderung höchstwahrscheinlich erst registrieren würden, wenn man sie darauf anspräche. Selbst dann, so vermutet er, würden sie ihm im ersten Moment noch widersprechen, woraus Herr Lehmann schließt, dass sie bisher noch nicht über ihr verändertes Handeln nachgedacht hätten. Herr Lehmanns These ist also, dass die Bewohner"innen erst bei Konfrontation über ihr geändertes Verhalten nachdenken und schließlich zu der Einsicht gelangen, dass sie mittlerweile dazu übergegangen sind, die Fenster in der Heizperiode nachts geschlossen zu lassen. Stimmt diese These, so lässt sich daraus ableiten, dass die Bewohner*innen den genauen Ablauf des Zustandekommens der Verhaltensänderung nicht mehr rekonstruieren könnten. 
Es liegt nahe, die von Herrn Lehmann beschriebene weiterhin praktizierte Fensterlüftung als eine auf tief verankerten Dispositionen beruhende Handlungsroutine zu beschreiben, die dem vorherigen Wohnkontext der Bewohner*innen entstammt und für den sie auch gepasst hat. Diese alte Lüftungspraxis haben die Bewohner*innen offenbar unverändert auf den neuen Wohnkontext übertragen.

Weiterhin unterstellt Herr Lehmann, dass viele Bewohner*innen die Assoziation haben, dass frische Luft mit kühler Luft gleichzusetzen ist. Deutlich wird, dass er als Experte die Meinung vertritt, dass hier eine klare Trennung bzw. Klärung vorzunehmen ist, was von den Bewohner*innen mit der Fensterlüftung bezweckt wird. Darüber hinaus lässt sich seiner Beschreibung entnehmen, dass dieser Zusammenhang für den konventionellen Wohnkontext ohne automatischen Luftaustausch in der Regel auch gegeben ist. Seine Darstellung verdeutlicht, dass ihm als Experte damit bewusst ist, dass die meisten Bewohner*innen vor ihrem Einzug ins Passivhaus noch nicht die Erfahrung gemacht haben, dass warme Luft unverbraucht sein kann und er es deshalb begreiflich findet, dass die Bewohner*innen im Passivhaus zunächst auf die Weise reagieren, wie sie es für einen anderen Kontext gelernt haben. Offenbar hat Herr Lehmann also durchaus Verständnis dafür, dass sich über viele Jahre eingeübte Denkund Handlungsmuster nicht von heute auf morgen ändern, sondern dass dieser Wandlungsprozess einige Zeit dauert.

Die gesamte Passage macht deutlich, dass es für eine Veränderung von Routinen nicht unbedingt notwendig ist, dass die entsprechenden Handlungen erst bewusst reflektiert werden. Vielmehr scheint vor allem entscheidend zu sein, welche Erfahrungen von den Praktizierenden tagtäglich gemacht werden. Werden im Alltag neue Erfahrungen gemacht, die nicht mehr mit der bisherigen Handlungspraxis übereinstimmen, so kann sich offenbar automatisch über kurz oder lang ein anderes Verhalten einstellen, das zu den neuen Erfahrungen passt.

Die Passage vermittelt den Eindruck, dass Herr Lehmann aufgrund seiner Erfahrungen selbst davon überzeugt ist, dass das Passivhaus spätestens in der Praxis überzeugt. Aus diesem Grund kann er gelassen damit umgehen, wenn die Bewohner"innen im Passivhaus anfangs noch ,falsch' lüften, weil er darauf vertraut, dass sie in absehbarer Zeit zu einer der neuen Wohnsituation angemessenen Lüftungspraxis wechseln werden.

Insgesamt macht diese Passage deutlich, wie eine alte Routine von einer neuen Gewohnheit abgelöst wird.

Zum näheren Verständnis der Ausführungen Herrn Lehmanns ist die von Bongaerts vorgeschlagene theoretische Unterscheidung zwischen Rou- 
tine und Gewohnheit hilfreich (vgl. Teilkapitel 2.1.4.1). In der Praxis sind Routinen und Gewohnheiten meist nicht voneinander zu unterscheiden, stellen sie doch beide ständig wiederkehrende und sich gleichförmig wiederholende Tätigkeitsvollzüge dar, die beide auf einem impliziten Wissen basieren, über das die Akteure aufgrund ihrer auch körperlichen Sozialisation verfügen (vgl. Bongaerts 2007: 249). Das Entscheidende, worin sich Routinen und Gewohnheiten jedoch voneinander unterscheiden, ist der Aneignungsmodus des dem Handeln jeweils zugrundeliegenden impliziten Wissens. Gemäß Bongaerts wurde ein als Routine bezeichnetes Handeln anfänglich bewusst eingeübt, bevor es dann irgendwann aufgrund häufiger Wiederholung selbstverständlich ist. Hingegen zeichneten sich Gewohnheiten gerade dadurch aus, dass über die entsprechenden Verhaltensweisen nie bewusst reflektiert werden musste; gewohnheitsmäßiges Handeln entspricht demnach eher einem unreflektiert erlernten Tun (vgl. ebd.: 256).

Möchte man also feststellen, ob es sich bei einem sich wiederholenden Handlungsmuster um eine Routine oder eine Gewohnheit handelt, so gilt es, wie in Teilkapitel 2.1.4.1 dargelegt, den konkreten Aneignungsmodus des dem Handeln zugrundeliegenden impliziten Wissens zu rekonstruieren.

Wendet man die von Bongaerts vorgeschlagene Unterscheidung auf den von Herrn Lehmann geschilderten Ablauf an, so wird deutlich, wie eine alte Routine von einer neuen Gewohnheit abgelöst wird: Im von Herrn Lehmann referierten Beispiel bestand die alte Lüftungsroutine darin, dass die Bewohner"innen im Winter nachts immer ein Fenster geöffnet hatten, um auch während des Schlafens mit ausreichend frischer, sauerstoffreicher Luft versorgt zu werden und ihrer Erfahrung nach war die hineinströmende Luft immer kühl. Dieses Handlungsmuster, das bei längerem Raumaufenthalt ein Fenster für den Luftwechsel zu öffnen ist, wurde von ihnen irgendwann rational gelernt und ergab im konventionellen Wohngebäude ohne automatische Lüftung Sinn. Diese alte Fensterlüftungspraxis wird von vielen Bewohner*innen zunächst noch im Passivhaus für längere Zeit beibehalten. Offenbar findet keine bewusste Neuprüfung der Angemessenheit der Lüftungsroutine statt, nachdem sich die Rahmenbedingungen verändert haben - die Routine wird dem neuen Kontext zunächst nicht angepasst. Irgendwann entfällt die vorherige Lüftungshandlung dann, ohne dass die Bewohner*innen dafür über die veränderte Situation oder ihr Verhalten bewusst nachgedacht haben (müssen). Damit ist eine neue Gewohnheit entstanden. Die neue Lüftungsgewohnheit im Passivhaus gestaltet sich so, dass während der Heizperiode nachts nicht mehr das Fenster 
geöffnet wird, sondern dass man den Luftaustausch zwischen drinnen und draußen nun der Lüftungsanlage überlässt.

\subsubsection{Vergleichendes Kapitelfazit}

Die Analyse des Datenmaterials hat deutlich gemacht, dass die Untersuchung des Heizens in Passivhäusern und SmartHomes automatisch die Thematisierung der Lüftung bzw. Lüftungsaktivitäten mit sich bringt. Aufgrund der neu eingeführten Technik sind sowohl im Passivhaus als auch im SmartHome der Heizungs- und der Lüftungsvorgang untrennbar miteinander verknüpft.

\section{Verzicht auf Fensterlüftung wird zur Gewohnheit}

Die analysierten Passivhaus-Fälle zum Thema Wohnraumlüften haben alle gezeigt, dass im Übergang von konventionellen Wohnkontexten zum Passivhaus eine lang eingeübte und wohl erprobte Routine durch eine neue Gewohnheit ersetzt wurde (vgl. Teilkapitel 2.1.4.1). Während in konventionellen Wohnkontexten ein spezielles Wissen für, richtiges' Lüften erforderlich ist, welches von den Bewohner"innen früher einmal bewusst erlernt und eingeübt wurde, bevor sie es routinisiert vollzogen haben, ist im Passivhaus für ausreichende Lüftung praktisch kein menschliches Handeln mehr erforderlich, sondern hier wird die Be- und Entlüftung der Wohnräume automatisch durch die Technik erledigt. Mit ihrem Einzug in ein Passivhaus mussten die Neubewohner*innen also kein neues Wissen zum ,korrekten' Lüften erlernen; vielmehr ging es darum, dass sie sich von ihrer alten (Fenster-)Lüftungsroutine lösen, sie aufgeben und sich stattdessen an die selbständig funktionierende Passivhauslüftungsanlage gewöhnen. ${ }^{95}$

Im Rahmen dieses Kapitels wurden verschiedene Varianten von Gewöhnungsprozessen aufgezeigt. Dabei wurde deutlich, dass es sehr unterschiedlich sein kann, in welcher Geschwindigkeit die Gewöhnung an die neue Art der Lüftung im Passivhaus verläuft: Frau Möller und Frau Rosental, die das Lüften vorher im konventionellen Wohnkontext beide sehr ernst genommen und dementsprechend gewissenhaft praktiziert haben und von denen zumindest Frau Rosental auch über eine elaborierte Lüftungsrouti-

$95 \mathrm{Vgl}$. hierzu auch die zusammengefassten Ergebnisse aus mehreren verschiedenen empirischen Untersuchungen zur ,Nutzer*innenzufriedenheit im Passivhaus' in Hacke 2009a. 
ne verfügte, haben sich offenbar sehr schnell und problemlos an die kontrollierte Be- und Entlüftung im Passivhaus gewöhnt. Beide Bewohnerinnen haben die Delegation des Lüftungsgeschehens an die Passivhaustechnologie sofort als enorme Entlastung empfunden, so dass ihnen der Umstellungsprozess, also der Verzicht auf das alltägliche (aufwendige und komplizierte) Lüftungshandeln nicht schwergefallen ist. Hingegen machen die Schilderungen Herrn Lehmanns deutlich, dass es bei vielen Neubewohner*innen durchaus eine gewisse Zeit dauert, manchmal sogar mehrere Jahre, bis sie sich vollständig an die Passivhauslüftung gewöhnt haben und gänzlich von ihrer alten Fensterlüftungspraxis ablassen. Da die alte Lüftungspraxis im Passivhaus eben nicht durch eine neue menschliche Aktivität ersetzt werden muss - somit eine bewusste Reflextion des bisherigen Handelns nicht zwingend erforderlich ist - und die alte Routine durch in der Regel jahrzehntelange Erfahrung fest von den Bewohner*innen verinnerlicht ist, stellt sich ein neues, den neuen Erfahrungen angepasstes Verhalten oft erst allmählich ein.

Darüber hinaus wurde an mehreren Stellen deutlich, dass Fensteröffnung ganz offensichtlich nicht nur dem Lüften dient, sondern auch andere Bedeutungen und Funktionen hat. Dies veranschaulichen insbesondere die Erzählungen Frau Greiners und Frau Rosentals, die von einer ursprünglichen Wohnprojektteilnehmerin berichten, die offenbar aufgrund der (strengen) Reglementierungen zur Fensteröffnung gänzlich vom Wohnen in einem Passivhaus abgeschreckt wurde und deshalb aus dem Wohnprojekt ausschied. Und auch Frau Lutz berichtet von bis heute andauernden eher negativen bis ablehnenden Reaktionen in ihrem Freundeskreis auf ihr Wohnen in einem Passivhaus, mit der Begründung, dass ein Leben mit überwiegend geschlossenen Fenstern für sie (die Freund*innen) nicht vorstellbar ist und deshalb niemals in Frage käme. Insbesondere das Schlafen bei gekipptem Fenster scheint für einige Menschen offenbar weit mehr als eine unbewusste Gewohnheit zu sein.

\section{Die Ver- und Entflechtung von Praktiken}

Sowohl die Fallgeschichte Frau Rosentals als auch die Frau Fischers haben illustriert, dass Praktiken im Alltag niemals isoliert und vollkommen losgelöst von anderen Tätigkeiten auftreten, sondern dass sie stets mit anderen Praktiken mehr oder weniger eng verflochten und mit diesen in Ablauf sowie Durchführung koordiniert sind. Demnach wirken sich Veränderungen im Heizen bzw. Interventionen, die intentional nur das Heizen adressieren, mit hoher Wahrscheinlichkeit auf andere angrenzende und/ oder mit dem Heizen jeweils direkt zusammenhängende Praktiken aus. 
Im Fall Frau Rosentals ist es durch den Wegfall des Erfordernisses zu aktiver manueller Fensterlüftung im Passivhaus zu einer Entflechtung ehemals miteinander verschränkter Tätigkeiten gekommen - die Koordination des Heizens und Lüftens während des Frühstücks hat sich erübrigt. Im Fall Frau Fischers macht die neu eingeführte smarte Heizungssteuerungstechnik hingegen gleich die Umstellung mehrerer Praktiken erforderlich. War Frau Fischers Lüftungspraxis bisher auf ihr Rauchverhalten abgestimmt, wird dieses Verflechtungsverhältnis durch die neue Technik praktisch umgekehrt: nun muss Frau Fischer sich in ihrem Rauchverhalten nach den fest einprogrammierten (Heiz- und Lüftungs-)Vorgaben der Technik richten. In ihrem Fall gilt es nun, ein neues, dem veränderten Heizsetting angepasstes Arrangement für das Praktikengefüge bestehend aus Heizen, Lüften und Rauchen zu finden.

\section{Unterschiedliche Arten und Weisen der Regelvermittlung und des Um- gangs mit Regeln}

Die Analyse hat gezeigt, dass die Regeln bzw. Vorgaben zum ,richtigen“ Lüften auf unterschiedliche Weise an die Passivhaus- und SmartHome-Bewohner*innen herangetragen wurden und sich der Umgang der Bewohner*innen mit diesen Regeln sehr unterschiedlich gestaltet. So hat der Fall der Frau Fischer verdeutlicht, dass den SmartHome-Bewohner*innen eine bestimmte, vom Technikanbieter als ,korrekt" erachtete (Fenster-)Lüftungspraxis quasi durch die Technik aufoktroyiert wird. Den Nutzer*innen bietet sich keine Möglichkeit, diese Vorgaben zu umgehen oder außer Kraft zu setzen, sondern ihnen bleibt nur die Option, sich den in die Technik eingeschriebenen Regeln zur Fensteröffnung zu fügen und ihre davon tangierten Praktiken - bei Frau Fischer ist es das Rauchen - anzupassen, so dass sie mit den technischen Vorgaben kompatibel sind. Im Kontrast dazu wurden den Passivhaus-Bewohner"innen Regeln zum ,richtigen' (Fenster-)Lüften von den entsprechenden Expert"innen - meist waren dies die projektverantwortlichen Architekt"innen - bereits frühzeitig im Planungsund Bauprozess bzw. bei Einzug mündlich mitgeteilt. Sowohl der Fall des Herrn Frings als auch die Schilderungen Frau Greiners lassen erkennen, dass sich die Neubewohner*innen anfangs meist sehr genau an die von den Expert"innen vorgegebenen Regeln gehalten haben - offenbar, weil ihnen hier die eigene Erfahrung fehlte. Mit zunehmender Erfahrung des Lebens im Passivhaus sind die Bewohner*innen aber immer mehr dazu übergegangen, die Fenster (wieder) eigenmächtig zu öffnen. Das zeigt, dass die eigens erlebte Erfahrung vorrangig handlungsleitend ist und dadurch das Potenzial besitzt, die Regeln zu entkräften. 
Darüber hinaus hat die Analyse erbracht, dass Expert*innen in den ersten Jahren nach Entwicklung der Passivhaustechnologie den Bewohner*innen noch deutlich strengere Vorgaben zur Fensteröffnung im Passivhaus gemacht haben als sie sie heute propagieren und vertreten. Der anscheinend aus diesen anfänglich sehr strikten Handlungsanweisungen entstandene Mythos der nicht zu öffnenden Fenster bzw. des Verbots der Fensteröffnung im Passivhaus hält sich hartnäckig und wirkt sich noch heute hinderlich auf die Akzeptanz des Passivhauses aus.

Im folgenden Kapitel stehen die Aspekte ,Behaglichkeit' und ,Komfort ${ }^{`}$ im Zusammenhang mit dem Heizen und der Wahrnehmung des Innenraumklimas im Kontext neuer Heizsettings im Mittelpunkt. Es wird gezeigt, dass neue Heiztechnik deutliche, z.T. auch überraschende Auswirkungen auf das Behaglichkeits- und Komforterleben im eigenen Zuhause haben kann.

\subsection{Veränderungen im Behaglichkeits- und Komforterleben}

In diesem Kapitel werden Veränderungen im Behaglichkeits- und Komforterleben im Übergang von konventionellen Wohnkontexten zum Passivhaus und SmartHome dargestellt.

Wohlfühlen, Behaglichkeit und Wohnkomfort haben sich als wichtige Themen im Zusammenhang mit dem Heizen und der Wahrnehmung des Innenraumklimas erwiesen.

Wenn es um die Beschreibung und Beurteilung des Raumklimas und der Wohnatmosphäre geht, werden in der Fachliteratur ,Behaglichkeit ${ }^{\star}$ und ,Komfort' als zentrale Begriffe gehandelt (Rybczynski 1991), bzw. ,comfort ${ }^{\star}$ in englischsprachigen Publikationen (z.B. Crowley 1999, 2001; Brager und Dear 2003; Chappells und Shove 2005; Shove et al. 2008).

,Behaglichkeit' bezeichnet einen körperlichen und seelischen Zustand subjektiven Wohlbefindens. Behaglichkeit ist demnach ein individuelles Empfinden. Im heutigen Sprachgebrauch wird Behaglichkeit häufig synonym zu ,Gemütlichkeit' und ,Wohlfühlen', seltener auch zu ,Annehmlichkeit' bzw. ,Bequemlichkeit' oder ,Komfort' verwendet. Wenn im Folgenden von Behaglichkeit die Rede ist, so ist stets die Behaglichkeit innerhalb von Wohnräumen gemeint.

Das subjektive Wohlbefinden einer Person in einem Raum hängt von zahlreichen verschiedenen Faktoren und Einflüssen ab. Neben dem Alter und Geschlecht, dem Gesundheitszustand, der körperlichen Konstitution und dem allgemeinen Befinden der Person, gehören auch die Intensität 
der ausgeübten Tätigkeit, die Bekleidung, die Aufenthaltsdauer sowie die Anzahl der anwesenden Personen im Raum dazu. Aber auch (äußere) Einflüsse aus der jeweiligen Umgebung bzw. dem Wohnumfeld wie etwa die Temperaturen, die Luftqualität, Gerüche, die Lichtverhältnisse bzw. die natürliche und künstliche Beleuchtung, Geräusche, die Akustik sowie die verwendeten Materialien und die Farbgebung spielen für das subjektive Empfinden von Wohnbehaglichkeit eine wichtige Rolle. ${ }^{96}$

In dieser Untersuchung geht es jedoch nicht allgemein um Wohnbehaglichkeit, sondern speziell um die Aspekte des Behaglichkeitsempfindens, die mit dem Heizen oder den Heizungs- bzw. Lüftungstechniken zusammenhängen. Es geht primär um das menschliche Wohlbefinden in Abhängigkeit vom thermisch-hygrischen Zustand des Raumklimas, das heißt von den Raumtemperatur- und Raumluftfeuchteverhältnissen. In der Heizungs- und Klimatechnik wird für die Beurteilung des thermischen Raumklimas der Begriff der ,thermischen Behaglichkeit bzw. des ,thermischen Komforts' (im Englischen ,thermal comfort') verwendet (vgl. Dentel und Dietrich o. J.; Lipp 2006). Nach DIN EN ISO 7730 ist die „thermische Behaglichkeit" definiert als „das Gefühl, das Zufriedenheit mit dem Umgebungsklima ausdrückt". In der wissenschaftlichen Literatur zur Raumklimatechnik wird das thermische Raumklima im Wesentlichen durch vier Parameter bestimmt, die den Wärmehaushalt des Menschen beeinflussen. Dies sind (1.) die Raumlufttemperatur, (2.) die Temperaturen der raumumschließenden Oberflächen (Decken, Böden, Wände, Fenster), die man auch in der mittleren Strahlungstemperatur zusammenfassen kann, sowie (3.) die Luftbewegung und (4.) die relative Luftfeuchte im Raum (vgl. Dentel und Dietrich o. J.: 4).

Wie sich diese Raumklimaparameter auf das Behaglichkeitsempfinden des Einzelnen auswirken, lässt sich allerdings nicht präzise vorhersagen, da Personen unterschiedlich auf äußere Einflüsse reagieren.

Die heizungs- und klimatechnische Seite thermischer Behaglichkeit gilt mittlerweile als gut erforscht. Ein wichtiger Anteil der heute vorliegenden Erkenntnisse geht auf die bereits in den 1960er und 1970er Jahren durchgeführten Untersuchungen zur thermischen Behaglichkeit des dänischen Ingenieurs Povl Ole Fanger zurück (Fanger 1970). Seine Arbeiten und Erkenntnisse aus den 1970er Jahren sind nach wie vor Grundlage und Maßstab moderner Raumklimatechnik (vgl. z.B. Richter 2003: 16ff).

96 Für einen Überblick über sowie eine Einordnung und (kritische) Besprechung vorhandener konzeptioneller Ansätze zum Thema ,Wohlbefinden in Gebäuden“, siehe Hanc et al. 2018. 
Von diesem raumklimatechnischen Verständnis von ,thermischer Behaglichkeit' bzw. ,thermischem Komfort' wurde bei der Forschung im Rahmen der vorliegenden Arbeit zunächst ausgegangen. In den Interviews wurde überwiegend der Begriff der ,Behaglichkeit', etwas seltener der des ,Komforts' verwendet. Dabei wurden die beiden Ausdrücke synonym zueinander benutzt. So wurden beispielsweise die Passivhaus- und die SmartHome-Bewohner*innen zunächst danach gefragt, was für sie ,Behaglichkeit' im Zusammenhang mit Wohnen und Heizen bedeutet und wodurch sich für sie persönlich ein ,behagliches Wohnraumklima' auszeichnet. Gegen Ende des Interviews wurden die Bewohner*innen noch einmal gefragt, ob und wie sich ihre diesbezüglichen Komfortvorstellungen durch ihre Erfahrung des Lebens im Passivhaus bzw. SmartHome und durch den Umgang mit der neuen Heizungssteuerungstechnik spürbar verändert haben.

In der Empirie haben sich deutliche Unterschiede hinsichtlich des Sinngehalts und der Relevanz der beiden Begriffe herausgestellt. Hier hat sich gezeigt, dass viele der interviewten Bewohner*innen die Begriffe ,Behaglichkeit" und ,Komfort' nicht als bedeutungsgleiche Ausdrücke interpretieren und verwenden, sondern die Begriffe differenziert auslegen und unterschiedlich gebrauchen. Während es in den Gesprächen mit Passivhausbewohner*innen fast ausschließlich um Aspekte thermischer Behaglichkeit ging und viel vom ,Wärmekomfort ${ }^{`}$ des Passivhauses die Rede war, spielte ,Behaglichkeit' in der Diskussion um die intelligente Heizungssteuerungstechnik praktisch keine Rolle. Hier war dagegen „Komfort' eher ein Thema, wobei es nicht um den thermischen Komfort ging, sondern um ,Komfort ${ }^{6}$ im Sinne von ,Bequemlichkeit', welche dadurch entsteht, dass die Technik den Bewohner*innen körperliche Arbeit abnimmt.

Auf die unterschiedliche Rolle der beiden Begrifflichkeiten in Bezug auf die beiden untersuchten Technologien wird im Kapitelfazit noch einmal genauer eingegangen. Hier soll nun zunächst vorgestellt werden, welche Begriffsverständnisse im Feld empirisch vorgefunden wurden. Dies ist relevant, weil es einen erheblichen Einfluss auf den Energieverbrauch in Wohngebäuden hat, von welchem Standard für thermische Behaglichkeit im Alltag ausgegangen und wie dieser sichergestellt wird. So ist zum Beispiel zu beobachten, dass in vielen Passivhäusern die Raumtemperaturen im Winter im Durchschnitt etwa zwei bis drei Grad höher liegen, als von den verantwortlichen Architekt"innen ursprünglich erwartet und eingeplant. Offenbar hat sich durch die Erfahrung des Lebens im Passivhaus das Behaglichkeitsempfinden vieler Passivhausbewohner*innen dahingehend verändert, dass sie nun während der kalten Jahreszeit deutlich höhere 
Raumtemperaturen bevorzugen als noch vor ihrem Einzug. Aus den gestiegenen Erwartungen an den Wärmekomfort resultiert, dass der Einsparungseffekt bei der Energie für Raumwärme geringer ausfällt als erwartet hierbei handelt es sich um einen typischen direkten Reboundeffekt (Santarius 2012: 11).

Beide in dieser Arbeit betrachteten Technologien sind mit dem Ziel entwickelt worden, dass sich der Energieverbrauch für Raumwärme und die heizungsbedingten $\mathrm{CO}_{2}$-Emissionen deutlich reduzieren lassen und die Behaglichkeit bzw. der allgemeine Wohnkomfort gleichzeitig spürbar verbessert wird.

Mit dem Passivhaus wandelt sich der gesamte Heizvorgang. Im Passivhaus übernimmt zum größten Teil die Lüftungsanlage mit hocheffizienter Wärmerückgewinnung das Beheizen der Innenräume. Diese grundlegende Veränderung wirkt sich offenbar nicht nur entscheidend auf das thermische Behaglichkeitsempfinden, sondern auch auf das generelle Wohlbefinden der Bewohner"innen im Passivhaus aus.

Hingegen erfolgt im SmartHome lediglich eine Delegation von einigen Handgriffen an die Heizungssteuerungstechnik, die Heiztechnik bleibt in diesem Fall jedoch die Gleiche. Dementsprechend hat die neue Automatisierungstechnik praktisch keine Auswirkungen auf die thermische Behaglichkeit. Hier spielt demnach weniger der (allgemeine) Behaglichkeitsbegriff, sondern eher der ,weite' bzw. allgemeine Komfortbegriff eine Rolle. In diesem Fall geht es eher um ,Behaglichkeit' im Sinne von ,Bequemlichkeit': Der Wohnkomfort soll hier dadurch gesteigert werden, dass die intelligente Heizungssteuerung den Bewohner*innen die körperliche Anstrengung (in Form) des regelmäßigen manuellen Bedienens der Heizkörperthermostate abnimmt.

Im Folgenden werden verschiedene Varianten der Veränderung von thermischer Behaglichkeit im konventionellen Wohnkontext zum thermischen und allgemeinen Komforterleben im Passivhaus und im SmartHome beschrieben. Dafür wurden exemplarisch einige Wandlungsprozesse in der subjektiven Erfahrung von Behaglichkeit rekonstruiert. 
Folgende Punkte haben sich hierbei als relevant herausgestellt:

1. Die unterschiedliche Verwendung und Auslegung der Begriffe ,Behaglichkeit' und ,Komfort ${ }^{6}$

2. Nicht intendierte Nebeneffekte von erfolgreicher Wärmedämmung, die sich entscheidend auf das Wohlbefinden der Bewohner*innen im Passivhaus auswirken

3. Gestiegene Erwartungen an den thermischen Komfort

\subsubsection{Im Winter komme ich mir oft vor „wie in 'nem Iglu“ - Frau Köhler}

Zum Zeitpunkt des Interviews bewohnt Frau Köhler bereits seit mehr als zwölf Jahren eine Wohnung im Passivhausprojekt B (siehe Anhang A). Sie gehört der Gründungsgruppe dieses gemeinschaftlichen Wohnprojekts an, die die Realisierung eines Passivhauses initiiert und entschieden hat. Im Interview mit Frau Köhler wird frühzeitig erkennbar, dass sie sich von der gesamten Wohnatmosphäre und den Temperaturverhältnissen her im Passivhaus nicht besonders wohl fühlt. Um ihr Wohngefühl im Passivhaus zu verdeutlichen, beschreibt Frau Köhler zunächst ihre vorherige Wohnsituation und vergleicht diese mit ihrem aktuellen Wohnen im Passivhaus:

„Ich hab vorher in 'ner allerdings Vierzimmerwohnung und da hab ich auch noch beruflich da gearbeitet. Ähm das hatte ne- (.) war auch sehr hoch das war [...] so 'ne Altbauwohnung. Und da hatte ich so 'ne Gasetagenheizung. Das hatte auch insofern was Praktisches das war schnell wurd's warm es wurde allerdings auch relativ schnell wieder kühl.“ (Bewohnerin PH, Interview 60: 9, 437-442)

Frau Köhler berichtet hier zunächst von ihrer früheren Altbauwohnung, die offenbar sehr hohe Decken hatte. Der Beschreibung lässt sich entnehmen, dass die Heizung dort sehr leistungsstark war: mit dieser ließ sich die Wohnung schnell erwärmen. Zwar thematisiert Frau Köhler mit keinem Wort die Isolierung, aber aus ihrem Gesagten lässt sich schließen, dass das Wohngebäude, in dem sich die Wohnung befand, kaum isoliert war, so dass die Heizwärme nie lange in den Wohnräumen verblieb. Ihre Bewertung des früheren Settings fällt recht moderat aus. Frau Köhler konnte dem Setting im Altbau durchaus etwas Positives abgewinnen, was daran deutlich wird, dass sie das schnelle Warmwerden ihrer Altbauwohnung, wenn sie die Heizung aufgedreht hat, als ,praktisch' bewertet. 
Nach einer kurzen Pause springt Frau Köhler thematisch und spricht nun über das veränderte Wohngefühl im Passivhaus:

„(1) Und ich äh merkte schon dass da 'n Unterschied is dann hier dass die Fenster so viel mehr isoliert sind. Übrigens das hab ich zunächst nich so bedacht das is mir dann erst weil Sie vorhin fragten wie äh wusste ich was wusste ich und was wusste ich nich. Ich wusste nich dass das so sehr die Geräusche abschirmt nach draußen dass ich mir im Winter oft wie in 'nem Iglu vorkomme. Denn ich lebe natürlich als Blinde sehr viel auf Geräusche orientiert.“ (ebd., 442-449)

Ihrer Beschreibung lässt sich entnehmen, dass sie einen deutlichen Unterschied in der Fensterisolierung zwischen Passivhaus und Altbau wahrnimmt. Die Formulierung „so viel mehr“ (ebd., 443) deutet darauf hin, dass Frau Köhler mit dem Ausmaß des Unterschieds zwischen den beiden Wohnformen nicht gerechnet hatte. Zwar spricht Frau Köhler nicht explizit über die Fensterisolierung in ihrer früheren Altbauwohnung, ihre Formulierung, dass sie „hier“ (ebd., 443) einen Unterschied bemerkt hat, lässt aber darauf schließen, dass die Fenster in der Altbauwohnung im Vergleich zu denen im Passivhaus kaum isoliert waren.

Im weiteren Verlauf setzt Frau Köhler zu einer Erklärung an, wann ihr der diesbezügliche Unterschied zwischen Passivhaus und Altbau erstmals aufgefallen ist, bricht ihren Satz dann aber ab. Es lässt sich hier spekulieren, dass ihr der Unterschied erst später, nach ihrem Einzug in das Passivhaus bewusst geworden ist. Der darauffolgende argumentative Einwurf verweist auf eine vorhergehende Frage im Interview, bei der es um den Informationsstand der Bewohner*innen bezüglich des Passivhauses vor ihrem Einzug ging. Danach fährt Frau Köhler fort, über die geräuschliche Abschirmung im Passivhaus zu sprechen. Der Ausdruck „so sehr“ (ebd., 446) lässt wiederum eine Überraschung erkennen, diesmal in Bezug auf die Abschirmung von Geräuschen. Frau Köhler erklärt ihre verstärkte Orientierung an akustischen Reizen und Signalen mit ihrer Blindheit. Zu vermuten ist, dass ihr das Fehlen jeglicher Außengeräusche im Passivhaus deshalb besonders deutlich auffällt.

An der gesamten Passage werden somit zwei Kontraste zwischen Passivhaus und Altbau sichtbar, von denen Frau Köhler jeweils nur eine Seite anspricht und ausführt. Im ersten Teil beschreibt sie explizit, dass sich die Raumtemperaturen in der Altbauwohnung immer schnell geändert haben. Hier bleibt implizit, dass im Passivhaus die Temperatur im Vergleich dazu recht konstant bleibt. Im zweiten Teil der Passage äußert sich Frau Köhler explizit zum Wohngefühl im Passivhaus. Hier schildert sie, dass im Passiv- 
haus bei geschlossenen Türen und Fenstern praktisch keine Außengeräusche mehr zu vernehmen sind. Diesmal bleibt der Kontrast implizit, dass man in der Altbauwohnung auch bei geschlossenen Türen und Fenstern noch Geräusche von draußen hört.

Frau Köhler vergleicht ihr Wohngefühl im Passivhaus während der kalten Jahreszeit mit dem Leben in einem „Iglu“ (ebd., 448). In der Metapher des Iglus verdichten sich die beiden zentralen Unterscheidungen zwischen Passivhaus und Altbau. Es lohnt sich, diese Fokussierungsmetapher etwas genauer zu betrachten: Die Metapher des Iglus weist eine Parallele mit dem Passivhaus auf, da sowohl die dicke Gebäudehülle und die Dreischeiben-Wärmeschutz-Fensterverglasung als auch der Schnee als guter Wärmeisolator wirken. ${ }^{97}$ Die Temperaturen im Inneren eines Iglus können sich von den Außentemperaturen durchaus um 50 Grad unterscheiden, was noch einmal verdeutlicht, wie effektiv die äußere Hülle als Barriere gegen äußere Einflüsse wirken kann und welch starke Metapher Frau Köhler gewählt hat. Dies bedeutet gleichzeitig, dass die Innenraumzustände kaum mehr einen Bezug zu den umgebenden Verhältnissen aufweisen. Durch die dicke Isolierung können kaum natürliche Einflüsse von draußen zu den Bewohner*innen im Inneren vordringen. Aus der Bauweise von Passivhäusern ergibt sich somit als Nebenfolge, dass die Bewohner"innen von allen Geräuschen von draußen weitestgehend abgeschirmt werden, was Frau Köhler tendenziell als Nachteil ansieht.

Auf die Metapher des Iglus wird im Kapitelfazit 4.3.8 noch einmal eingegangen. Dort wird sie im Vergleich mit einer weiteren Metapher für das Passivhaus ausführlich diskutiert.

\subsection{2 „Also dieses ganz Konstante [...] es ist nicht mein Ding“ - Frau Köhler}

Nachdem sich Frau Köhler im Interview lange und ausführlich zu den aus der Passivhaus-Wärmedämmung resultierenden Problemen und Konsequenzen geäußert hat, kommt sie von sich aus auf das Raumklima zu sprechen. Hier äußert sie gleich zu Beginn, dass sie das Raumklima im Passivhaus „nich so sehr angenehm“ (Bewohnerin PH, Interview 60: 13, 657) empfindet. Nach den Gründen für ihre Unzufriedenheit mit dem Raumklima gefragt, holt Frau Köhler etwas weiter aus. Allerdings wird schnell

97 Schnee ist dafür bekannt, dass er sehr gut vor Kälte schützt und gleichzeitig keine Geräusche durchlässt. 
deutlich, dass sie neben der trockenen Raumluft vor allem die in der gesamten Wohnung ständig relativ gleichmäßige Temperatur als unangenehm wahrnimmt:

„Also dieses ganz Konstante. Also ich bin nun vielleicht ' $n$ Mensch der sehr mit der Natur und auch dem Wechsel in der Natur von Kindheit an ich hab früher auf dem Land gelebt äh gelebt hat und ich find das is was Menschliches was Natürliches. Und äh (.) das Konstante (1) ja mir sagte- da sprach ich dann in den Ferien in der Schweiz mit einem so genannten Passivenergiepapst in der Schweiz [...] ähm der sagte mir ,Na ja also jetzt da sagen Sie sich einfach Sie wohnen irgendwo im Mittelmeerbereich wo Sie auch viel ausgeglichenere Temperaturen haben. Sie müssen sich einfach da drauf einstellen und ihr Organismus wird sich da drauf einstellen.' Das mag zum gewissen Grad stimmen dass ich mich langsam notdürftig halt aus der Not raus angepasst hab. Aber es is nicht mein Ding würde ich mal sagen." (Bewohnerin PH, Interview 60: 14, 700-713)

Bezieht man den Kontext des Interviews mit ein, wird deutlich, dass Frau Köhler eingangs mit ihrem Halbsatz auf das zuletzt von der Interviewerin angesprochene Thema zurückkommt: die konstanten Raumtemperaturverhältnisse im Passivhaus. An der darauffolgenden argumentativen Sequenz wird deutlich, dass Frau Köhler das Raumklima im Passivhaus kritisch bewertet. Sie beginnt ihre Argumentation mit einer Relativierung, mit der sie deutlich macht, dass sie nur ihre persönliche Meinung äußert. Dem lässt sich entnehmen, dass sie eine bescheidene Person ist, die sich nicht anmaßt, von sich auf andere zu schließen bzw. für andere mitzusprechen. In der Fortsetzung des Satzes wird eine Kontrastierung erkennbar: Während sie „das Konstante“ (ebd., 704) im Passivhaus als ,unnatürlich“ ansieht, beschreibt sie den Wechsel als ,natürlich'. Dass Frau Köhler in dieser Passage zweimal im Zusammenhang mit dem Passivhaus generalisierend von ,dem Konstanten' spricht, macht deutlich, dass sie die Temperaturverhältnisse im Passivhaus als konträr zu den von ihr skizzierten grundsätzlich unbeständigen natürlichen Gegebenheiten betrachtet. Das Konstante steht demnach für das Unnatürliche und Artifizielle. In Bezug auf das Passivhaus ist hiermit die annährend gleichbleibende Raumtemperatur gemeint, die also ,künstlich' mittels Technik ständig auf einem komfortablen Niveau gehalten wird. An der Wahl einer derart starken Metapher wird eine negative Bewertung des Passivhauses deutlich. Zudem wird der Kontrast durch einen Verweis auf die eigene Biografie unterfüttert, womit zum 
Ausdruck gebracht wird, dass sie an den Wechsel gewöhnt ist und ihr dieser normal erscheint.

Interessant ist, dass Frau Köhler den „Wechsel in der Natur“ (ebd., 702) zudem als ,menschlich' bezeichnet. Es lässt sich spekulieren, dass sie damit sagen möchte, dass sich nicht nur die natürliche Umwelt fortwährend wandelt, sondern dass sich auch das menschliche Leben ,im Fluss' befindet und sich somit kontinuierlich verändert. Auch könnte es sein, dass sie mit dieser Formulierung zum Ausdruck bringen möchte, dass für sie zum Menschsein der Wechsel gehört und der Mensch für den Wechsel gemacht ist.

Nach kurzem Innehalten fährt Frau Köhler damit fort, von einer Unterhaltung mit einem Energieexperten zu berichten, wobei der genaue Zeitpunkt des Gesprächs unklar bleibt. Es lässt sich somit nicht sicher sagen, ob das Gespräch noch vor Frau Köhlers Einzug stattgefunden hat oder erst als sie bereits im Passivhaus wohnte.

Der Schilderung lässt sich entnehmen, dass der Experte in diesem Gespräch mit Nachdruck versucht hat, Frau Köhler ein angenehmes Bild vom Wohngefühl im Passivhaus zu vermitteln. Der Experte vermittelt hier den Eindruck, dass die Akzeptanz des Passivhauses vor allem eine Frage der (inneren) Einstellung sei. Die Formulierung des Experten suggeriert Wahlfreiheit: man kann diese Haltung einnehmen, wenn man nur will. Daran wird deutlich, dass er Frau Köhler in ihren eigenen Bedenken nicht ganz ernst nimmt. In seiner Anpreisung zeichnet er ein Bild vom Leben im Passivhaus, das den Bewohner*innen quasi einen ,ewigen Urlaub' an einem Sehnsuchtsort der Deutschen verspricht. Sinngemäß werden die Passivhausbewohner*innen entwurzelt und von ihrer Heimat Norddeutschland an das Mittemeer versetzt. Ihnen wird suggeriert, dass sie im Passivhaus dauerhaft in solch angenehmen klimatischen Verhältnissen wohnen können, die andere nur im Urlaub erleben. Der zweite Satz des Experten macht deutlich, dass er die Akzeptanz des Passivhauses in erster Linie als eine Frage der richtigen Einstellung ansieht, an der man aktiv arbeiten kann und auch sollte. Vor dem Hintergrund der Wahlfreiheit über die Einstellung zum Passivhaus wirkt die Aussage des Experten wie ein Vorwurf: Implizit wird die Meinung des Experten deutlich, Frau Köhler solle sich nicht so anstellen, mit ihrer skeptischen Haltung mache sie es sich nur selbst schwer. Dagegen begreift der Experte die körperliche Anpassung an das Raumklima im Passivhaus als weitgehend intuitiven und passiven Prozess, der sich über kurz oder lang von selbst ereignet.

Frau Köhler stimmt dem Experten in der Hinsicht zu, dass sie sich über die Jahre mehr oder weniger mit den Raumklimaverhältnissen im Passiv- 
haus arrangiert hat. Aus ihrer Argumentation geht allerdings deutlich hervor, dass dieser Anpassungsprozess nur widerwillig erfolgt ist und entsprechend lange gedauert hat. Für Frau Köhler verlief die Gewöhnung keineswegs unbemerkt und wie von selbst. Dass sie die Anpassung als aktiven Prozess beschreibt, deutet vielmehr darauf hin, dass sie sich bewusst um einen angemessenen Umgang mit den Klimaverhältnissen im Passivhaus hat bemühen müssen, was ihr offenbar nicht leichtgefallen ist. Zudem lässt sich dem Interviewkontext entnehmen, dass Frau Köhler sich diese Mühe nur gemacht hat, weil ihr kaum eine Alternative blieb. Ein Ausstieg aus dem Wohnprojekt kam für sie zum damaligen Zeitpunkt offenbar nicht mehr in Frage. Immerhin handelt es sich bei ihrer Passivhauswohnung auch um ihr eigenes Bauprojekt. Wie in Teilkapitel 4.4.1 bereits dargestellt, gehört Frau Köhler der Initiativgruppe des Wohnprojekts B an, die sich damals ganz bewusst für den Bau eines Passivhauses entschieden hat. ${ }^{98}$

Ihre abschließende Bewertung zeigt jedoch, dass sich an ihrer ablehnenden Haltung gegenüber den konstanten Temperaturverhältnissen bis heute nichts geändert hat. Nach wie vor empfindet sie die technisch erzeugte, ständig gleichmäßige und in allen Räumen gleiche Wärme des Passivhauses nicht als behaglich. Erneut lässt Frau Köhlers Formulierung „nicht mein Ding“ (ebd., 713) erkennen, dass sie zurückhaltend ist. Damit macht sie deutlich, dass sie nur ihre Meinung kundtut, dass sie nur für sich spricht und sich nicht herausnimmt, für andere zu sprechen. Der Experte maßt sich hingegen an, zu verallgemeinern.

Nahezu der gleiche Orientierungsrahmen wird auch bei Frau Lutz sichtbar, die ebenfalls zur Initialgruppe des Passivhausprojekts B gehört. Wie schon bei Frau Köhler wird bei Frau Lutz eine Kontrastierung zwischen einer natürlichen und einer unnatürlichen Lebensweise erkennbar. Genauso wie bei Frau Köhler steht auch bei Frau Lutz das Passivhaus für ein ,unnatürliches Leben'. Auch sie beurteilt die Abschirmung von äußeren Einflüssen, vor allem von natürlichen Geräuschen als negativ und führt dies wie Frau Köhler auf die dicke Isolierung des Passivhauses zurück:

98 Als es damals für Frau Köhler um die Frage ging, wie sie im Alter leben möchte, hat sie sich mit einigen anderen älteren Frauen, die ihre Vorstellungen von gemeinschaftlichem und ökologischem Wohnen teilten, zu einer Baugruppe zusammengetan. Gemeinsam haben sie sich damals bewusst für den Bau eines Passivhauses entschieden. 
„Dieses dreifache Isolierte das isoliert einen wirklich von der Welt drau-“ (Bewohnerin PH, Interview 59: 19, 980-981)

„Äh dies Isoliertsein von der Außenwelt [...] (.) ich find es es is ein (1) äh es is 'n unnatürliches Leben für mich. Man is abgeschnitten von der Natur und dem was normal zirkuliert und also ich würd's nich nochmal machen." (Bewohnerin PH, Interview 59: 19, 990-994)

Zwar schildert Frau Lutz den gleichen Kontrast zwischen der Wohnatmosphäre im Passivhaus und einer natürlichen Lebensweise wie er bereits von Frau Köhler beschrieben wurde. Im Fallvergleich wird allerdings deutlich, dass Frau Lutz diesen Kontrast deutlich drastischer bewertet als Frau Köhler. Während Frau Köhler lediglich deutlich zum Ausdruck bringt, dass die Wohnatmosphäre im Passivhaus nicht ihren Vorstellungen von behaglichem Wohnen entspricht, zieht Frau Lutz aus ihrer negativen Bewertung einen deutlich schwerwiegenderen Schluss. Für sie wiegen die Nachteile des Passivhauses so schwer, dass - hätte sie erneut die Wahl - sie sich nicht noch einmal für (den Einzug in) ein Passivhaus entscheiden würde: „ich würde nich noch mal in 'n Passivhaus ziehen [...]. Nee (.) nee ich würd's nich noch mal tun" (ebd.: 19, 981-985).99

\subsubsection{Von „Leben mit den Jahreszeiten“ zu „’n bisschen raumschiffmäßig“ - Herr Thomsen}

Ein anderes Muster in der Bewertung der Raumtemperaturverhältnisse und der Wohnatmosphäre im Passivhaus wird im Fall Herrn Thomsens deutlich. Die Familie Thomsen hat vor dem Bezug ihrer Eigentumswohnung im Passivhausprojekt D, genauso wie Frau Köhler, in einer klassischen Altbauwohnung gewohnt, die sich in einem kaum isolierten Wohngebäude befand. Während die Altbauwohnung Frau Köhlers jedoch bereits mit einer leistungsstarken Heizung ausgestattet war, verfügte die Altbauwohnung der Thomsens offenbar nur über eine alte und somit eher

99 Bezieht man den Passagenkontext ihrer Aussage „es is 'n unnatürliches Leben für mich" (Bewohnerin PH, Interview 59: 19, 992) mit ein, so wird deutlich, dass insgesamt drei Aspekte in ihrem Urteil „unnatürliches Leben“ (ebd.) zusammenlaufen. Neben dem Abgeschnittensein von der Außenwelt bzw. der Natur kritisiert Frau Lutz auch die Technikabhängigkeit („meine Atemluft nich davon abhängig machen was irgendwelche digitalen Geräte mir zuschreiben“, ebd., 989-990) und „die Trockenheit der Luft“ (ebd., 991) im Passivhaus. Alle drei Kritikpunkte finden sich ebenso im Interview mit Frau Köhler. 
leistungsschwache Heizung. Dementsprechend drastisch fällt Herr Thomsens Bewertung der Raumklimaverhältnisse in der damaligen Altbauwohnung aus. Gleichwohl zeigt er sich deutlich weniger überrascht als Frau Köhler über die Unterschiede hinsichtlich der Raumtemperaturverhältnisse zwischen unsaniertem Altbau und Passivhaus bzw. modernem Neubau. Im Interview bringt die Frage nach Unterschieden im Heizen zwischen Passivhaus und konventionellem Wohngebäude Herrn Thomsen dazu, seine damalige Wohnsituation und Heizpraxis vor dem Hintergrund seiner heutigen Situation kritisch zu reflektieren:

„Also wir haben ja wie gesagt vorher eben in [einem anderen Stadtteil] gewohnt in- in 'ner Wohnung wo es eher so Leben mit den Jahreszeiten war. Also da war halt im Winter (1) Die waren auch wirklich beide sehr kalt die wir da gewohnt haben. Ähm. Da war- musste man halt tatsächlich- (1) Da haben wir noch die Heizung nachts immer so 'n bisschen runter gedreht. Aber da waren die Fenster morgens oft eingefroren. Und wir haben dann mit- morgens früh mit sechzehn Grad in der Wohnung gestartet. So. Und dann hm hat man alle Heizungen aufgerissen und gehofft dass es warm wird. [...]. Ähm. Aber da war's einfach- da gab's überhaupt jetzt sozusagen nicht 'n Heizverhalten sondern irgendwie wenn's kalt war hat man versucht die Wohnung irgendwie warm zu halten. (.) Ist im Winter auch nicht über zwanzig Grad gekommen braucht man ja auch nicht." (Bewohner PH, Interview 69: 13, 649-669)

Herr Thomsen beschreibt die damalige Wohnsituation in einer Dachaltbauwohnung als „Leben mit den Jahreszeiten“ (ebd., 651), wodurch zum Ausdruck kommt, dass die Raumklimaverhältnisse in der alten Wohnung immer deutlich wahrnehmbar mit den äußeren Witterungsbedingungen korrespondierten. Die Beschreibung macht deutlich, dass es in der Altbauwohnung allgemein schwierig war, im Winter die Raumtemperatur auf einem relativ konstanten, angenehmen Niveau zu halten.

Der Schilderung lässt sich entnehmen, dass sich die Heizung in der alten Wohnung bei Kälte ,nach unten' ganz anders verhalten hat als ,nach oben': Während sich ein nur geringes Herunterregeln der Heizung bereits deutlich spürbar auf die Raumtemperaturen ausgewirkt hat, war selbst ein maximales Aufdrehen der Heizung noch keine Garantie dafür, dass die Wohnräume der Thomsens ausreichend warm wurden. Die Thomsens kämpften in der Altbauwohnung während der kalten Jahreszeit mehr oder weniger ständig gegen die Kälte an. 
Deutlich wird, dass den Thomsens in der damaligen Situation gar nicht die Möglichkeit offenstand, die Wohnräume ihren Bedürfnissen entsprechend zu heizen. Damals gab es gar keinen Spielraum, die Raumtemperaturen situativ oder gemäß dem Tagesablauf anzupassen, da diese sich in der Heizperiode ohnehin schon ständig an der Grenze zum Unbehaglichen bis Unangenehmen bewegten. Denn die alte Heizungstechnik ermöglichte es offensichtlich kaum, Raumtemperaturen über 20 Grad Celsius zu erreichen.

Im Gegensatz zu Frau Köhler, die das das Auf und Ab der Temperaturen in der Altbauwohnung recht neutral und nüchtern beschreibt, schildert und bewertet Herr Thomsen das Setting und die Temperaturverhältnisse im Altbau als defizitär. Während Frau Köhler am Setting im Altbau das schnelle Erwärmen ihrer Altbauwohnung schätzte, wenn sie die Heizung aufgedreht hat, erscheint in Herr Thomsens Beschreibung Heizen in der Altbauwohnung während der kalten Jahreszeit als permanentes - mehr oder weniger vergebliches - ,Ankämpfen' gegen die Kälte.

Direkt im Anschluss fährt Herr Thomsen fort. Er vergleicht die damalige Situation mit der heutigen Situation im Passivhaus:

„So. Ähm und das ist hier äh dreht man die natürlich nicht voll auf. Aber ich weiß jetzt gar nicht ob das nicht in allen Neubauhäusern irgendwie so ist dass die Heizung einfach 'n bisschen zivilisierter funktioniert als in so 'nem nicht renovierten Dachaltbau unter'm Dach. So. Von daher würde ich sagen es ist so wie ich-d-die funktioniert wie ich mir 'ne Heizung vorstelle dass sie funktioniert 'ne neu installierte." (Bewohner PH, Interview 69: 13, 669-675)

Hier wird deutlich, dass er im Passivhaus eine ausreichende Reserve sieht, bzw. es hier Spielraum für Anpassungen der Raumtemperaturen an unterschiedliche Situationen und den Tagesablauf gibt. Die von Herrn Thomsen anschaulich geschilderten, deutlichen Unterschiede im Komfortniveau zwischen den Wohnformen lassen nun eine besonders positive Bewertung des Passivhauses vermuten. Dies ist jedoch nicht der Fall. Aus der Darstellung geht hervor, dass Herrn Thomsen den Komfortstandard des Passivhauses nicht als außergewöhnlich wahrnimmt. In einem konventionellen Neubau wäre dies auch seine Erwartung gewesen, dass das Heizungssystem bei entsprechend niedrigen Außentemperaturen ohne Schwierigkeiten ausreichend Wärme bereitstellt. In diesem Sinne stellt das Passivhaus für ihn einfach ein ,normales' modernes Wohngebäude dar, ausgestattet mit entsprechend neuer Heiztechnik, die gemäß seinen Erwartungen an moderne Technik funktioniert. 
Die gesamte Passage macht deutlich, wie selbstverständlich und unproblematisch im Fall Herrn Thomsens die Gewöhnung an den Komfortstandard des Passivhauses und das nur in geringem Maß erforderliche aktive Dazuheizen erfolgt ist. Da die vorherige Altbauwohnung und die aktuelle Passivhauswohnung der Thomsens hinsichtlich des Wärmekomforts denkbar weit auseinanderliegen, erscheint die Vermutung naheliegend, dass sich Herr Thomsen besonders begeistert von der Behaglichkeit im Passivhaus zeigt. Seine Schilderung lässt allerdings erkennen, dass ihn der Komfortstandard des Passivhauses nicht sonderlich beeindruckt, sondern dieser vollkommen im Rahmen seiner Erwartungen liegt, die er an den Standard eines modernen Neubaus hat. Um mehr über Herrn Thomsens Erwartungen und Vorstellungen von Wohnbehaglichkeit im Zusammenhang mit Heizen zu erfahren, wird ihm daraufhin von der Interviewerin die Frage gestellt, was für ihn ein behagliches Wohnraumklima charakterisiert. Seine erste Antwortreaktion macht deutlich, dass er keine konkrete Antwort auf die Frage parat hat und bisher offenbar noch nicht bewusst über dieses Thema nachgedacht hat:

„Ich ffff--- wa- weiß ich ga- ich find das ist in Ordnung hier. Also es ist schon irgendwie so 'n bisschen mittelmäßiger insgesamt. Also [in der alten Wohnung] haben wir so gesagt wir leben da mit den Jahreszeiten. Im Sommer waren's da halt- Dachstuhl waren's dreißig Grad (.) da oben. Und ging auch nicht raus die Wärme so. Und im Winter ging halt die Kälte nicht raus. Das war eher so- und jetzt ist es schon irgendwie die ganze Zeit- ist irgendwie die ganze Zeit (.) neunzehn Grad. Im Sommer wird's=n bisschen wärmer im Winter kann's auch mal 'n bisschen kälter werden. Aber es ist eher so ausgeglichen insgesamt. [...]. Es ist ein bisschen mittelmäßiger und eigentlich finde ich das ganz gut. Manchmal ist mir das aber auch fast 'n bisschen zu:u (1) zu (.) balanciert irgendwie. So.“ (Bewohner PH, Interview 69: 14, 715-728)

In dieser Passage bewertet Herr Thomsen das Raumklima im Passivhaus vor dem Hintergrund seiner Erfahrungen in der vorherigen unsanierten Altbauwohnung. Seine verzögerte Antwortreaktion lässt darauf schließen, dass sich Herr Thomsen bisher noch nicht bewusst damit beschäftigt hat, was seiner Ansicht nach relevante Aspekte eines behaglichen Wohnraumklimas sind.

In seiner Argumentation äußert sich Herr Thomsen grundsätzlich positiv über das Raumklima im Passivhaus. Im Kontrast zum Fall Frau Möllers, der später noch vorgestellt wird, wird deutlich, dass die ganzjährig relativ konstanten Klimaverhältnisse bei ihm jedoch keine Begeisterung aus- 
lösen. Er bleibt in seiner Reaktion eher verhalten, was noch einmal zeigt, dass er das Passivhaus nicht außergewöhnlich findet, sondern dass es in der Funktionsweise seinen Vorstellungen von moderner Technik gemäß heutigem Standard entspricht.

Beim Vergleich mit seinen Erfahrungen im unsanierten Altbau verwendet Herr Thomsen zweimal den Begriff ,mittelmäßig', um das Raumklima im Passivhaus zu charakterisieren. Dies deutet darauf hin, dass ihm die gleichmäßigen Raumtemperaturverhältnisse nicht mehr nur ausgeglichen, sondern beinahe schon langweilig monoton erscheinen und er sich gar nicht mehr sicher ist, ob er diesen gemäßigten Dauerzustand wirklich angenehm findet.

Da immer noch nicht viel mehr darüber in Erfahrung gebracht werden konnte, welches Herr Thomsens Vorstellungen von Behaglichkeit im Hinblick auf Wohnen und Heizen sind, welche Einflüsse und Faktoren seiner Ansicht nach hierbei eine wichtige Rolle spielen, wird ihm von der Interviewerin die Frage noch einmal gestellt, wodurch sich für ihn persönlich ein behagliches Wohnraumklima auszeichnet. Aber auch im zweiten Anlauf gibt Herr Thomsen keine genaue Antwort darauf, wodurch für ihn Wohnbehaglichkeit entsteht. Stattdessen äußert er sich erneut darüber, wie er die Behaglichkeit und die Wohnatmosphäre im Passivhaus empfindet:

„Ich find' das schon behaglich. Ich finde das ist so 'n bisschen also ich $\mathrm{f}$ - hab da noch nie so drüber nachgedacht aber wissen Sie das is 'n- nÄhm dass es ein bisschen komisch ist dass man sozusagen so 'n bisschen abgekoppelt lebt von dem wie es draußen so ist. [...] Es hat halt immer so 'ne relativ gleichmäßige Temperatur relativ gleichmäßige Lärmschwelle. Man kriegt- also man könnte hier die ganze- das ganze Jahr irgendwie relativ ähnlich leben unabhängig davon was eigentlich für 'n Wetter draußen ist. Und das ist natürlich auf 'ne Art angenehm. Auf 'ne andere Art finde ich's aber auch 'n bisschen irritierend ähm (1) weil ich viele Jahre meines Lebens eher relativ unmittelbar $k$ - äh s- gewohnt habe wie's halt draußen so das Wetter ist. So von daher finde ich- will jetzt nicht so weit gehen dass mir das manchmal fehlt aber is 'n bisschen abgekoppelt 'n bisschen raumschiffmäßig." (Bewohner $\mathrm{PH}$, Interview 69: 14, 733-747)

Angeregt durch die Wiederholung der Frage reflektiert Herr Thomsen in dieser Passage noch einmal über das Raumklima im Passivhaus. Hier spricht er nun selbst an, dass er sich bisher noch keine Gedanken darüber gemacht habe, was er für ein behagliches Raumklima als wichtig erachtet. 
Hieraus lässt sich schließen, dass dieser Reflexionsprozess erst durch das Interviewgespräch angestoßen wurde. Offenbar wird Herrn Thomsen erst im Prozess des Nachdenkens bewusst, dass im Passivhaus praktisch das ganze Jahr über ein gleichbleibendes und von äußeren Witterungsverhältnissen vollkommen unabhängiges Innenraumklima vorhanden ist.

Durch die kritische Reflexion gelangt Herr Thomsen zu einer durchaus ambivalenten Einschätzung der Wohnverhältnisse im Passivhaus. Im Vergleich zum Wohnen im Altbau erscheint ihm die Lebenssituation im Passivhaus verhältnismäßig abgekapselt und weltabgewandt. Die Wahrnehmung des von der Außenwelt ,abgeschirmt Seins' teilt Herr Thomsen zwar mit Frau Köhler, jedoch ist seine Bewertung differenziert. Im Kontrast zu Frau Köhler ist seine Wertung deutlich moderater, was daran zu erkennen ist, dass er in dieser Passage praktisch vor jede seiner Bewertungen den abschwächenden Ausdruck, ein bisschen' setzt.

Um das Lebensgefühl im Passivhaus zu beschreiben, verwendet Herr Thomsen die Metapher des ,Raumschiffs'. Bei einem Raumschiff handelt es sich um einen hermetisch abgeschlossenen Raum, in den von außen nichts unkontrolliert eindringen darf und in dessen Innerem technisch streng kontrollierte Bedingungen herrschen. Deutlich wird, dass Herr Thomsen Parallelen zwischen einem Raumschiff und dem Passivhaus sieht. Auch das Passivhaus lässt sich als eine Art Raum- bzw. Klimakapsel betrachten, in der mittels moderner Technik künstlich ein beständig behagliches Raumklima hergestellt wird, das in seinen Bedingungen kaum mehr eine Anbindung zu seiner Umgebung aufweist. Gleichzeitig steht das Raumschiff für Modernität und technischen Fortschritt, gilt es als ein Sinnbild für den Triumph der Technikwissenschaft über die Natur. Dem entspricht, dass das Passivhaus als eine sehr fortschrittlich-moderne Art des ökologischen und energieeffizienten Bauens gilt, bei der negative äußere Umwelteinflüsse durch die Bauweise und die verwendeten Materialien herausgehalten werden und im Inneren mit Hilfe von moderner Technik und einem vergleichsweise sehr geringen Energieeinsatz ein beständig komfortables Raumklima erzeugt wird. Darüber hinaus machen die Metapher des Raumschiffs sowie die Fragilität des künstlich erschaffenen Innenraumklimas deutlich: Wenn im Inneren alles technisch sehr fein kontrolliert wird, können bereits kleine technische Probleme zu spürbaren Veränderungen in den Raumklimaverhältnissen führen, wodurch bei den Bewohner*innen ein Gefühl der Ohnmacht und des Ausgeliefertseins gegenüber einer weitestgehend eigenständig funktionierenden Technik entstehen kann - wie der Fall Frau Lutz' deutlich macht. 
Die Raumschiff-Metapher wird im Kapitelfazit 4.3.8 noch einmal aufgegriffen. Dort erfolgt dann der Vergleich mit der Metapher des Iglus.

\subsection{4 „So 'ne Wärme [...] dass man [sich] im gesamten Haus wohl fühlt [...] das ist so 'n Gefühl das hat so 'ne Gleichmäßigkeit im ganzen Haus. Das gibt so 'n Freiheitsgefühl“ - Frau Möller}

In den Falldarstellungen zu Frau Köhler und zu Herrn Thomsen ging es vorrangig um die Effekte von effizienter Wärmedämmung auf das allgemeine Wohlbefinden im Passivhaus. In beiden Fällen spielten auch Aspekte des thermischen Raumklimas für das Behaglichkeitsempfinden der Bewohner*innen eine zentrale Rolle. Mit Frau Möller wird nun ein Fall vorgestellt, bei dem es spezifisch um die Wahrnehmung von thermischer Behaglichkeit im Passivhaus geht. Der Fall Frau Möllers macht deutlich, dass von ihr die konstante Grundwärme im Passivhaus als deutliche Steigerung im Wärmekomforterleben erfahren wird.

Nachdem sich Frau Möller im Interview bereits begeistert über den Wegfall des aktiven Lüftens im Passivhaus geäußert hat (vgl. Teilkapitel 4.2.1), kommt sie in diesem Zusammenhang auch auf den Wärmekomfort des Passivhauses zu sprechen:

„Wir wollen nicht mehr in 'nem anderen Haus wohnen. Das schränktdas schränkt wirklich dann äh das so ein wo man dann noch hinziehen will ja. Also wenn man jetzt- wenn ich mir jetzt vorstelle ich müsste- ich möchte nicht mehr in einem alten Haus wohnen wo's immer kalt ist. Also das ist eher so dass man wenn man woanders zu Besuch ist dass man verwöhnt ist@(.)@ Also wirklich temperaturmäßig." (Bewohnerin PH, Interview 62: 13f, 697-703)

In dieser Passage geht es darum, wie sich Frau Möllers subjektive Erfahrung von thermischer Behaglichkeit durch die Erfahrung des Wohnens im Passivhaus verändert hat.

Frau Möller äußert hier die Präferenz, in keinem anderen Haus mehr wohnen zu wollen. Dem ist zu entnehmen, dass die Möllers vollständig an den Komfort des Passivhauses gewöhnt sind. An der Formulierung „Das schränkt [...] ein“ (ebd.: 13, 698) wird ein Bewusstsein darüber erkennbar, dass der Familie mit diesem Kriterium im Falle eines Umzugsvorhabens nicht viele Wohnorte und Wohnobjekte zur Auswahl stünden.

An mehreren Stellen im Interview mit Frau Möller finden sich Hinweise darauf, dass die Möllers aktuell ernsthaft einen Umzug erwägen. Von 
der Interviewerin konkret darauf angesprochen, erklärt Frau Möller, dass sie in den letzten Jahren überlegt hätten, ein Haus zu kaufen. Allerdings seien sie immer wieder davon abgekommen, da sie bisher kein passendes Objekt gefunden hätten, das hinsichtlich des Wohnkomforts an das Passivhaus herankommt. Bevor sie in ein Haus mit einem deutlich geringeren Standard als Passivhaus zögen, sagt Frau Möller, würden sie wohl eher selbst, und wenn ein Passivhaus, neu bauen.

Frau Möller fährt fort, indem sie zunächst einen verallgemeinernden Satz beginnt, den sie nicht zu Ende spricht. Dann fängt sie einen Satz mit fiktionalem Gehalt an, der sich in der Aussage nur auf sie bezieht, aber auch diesen beendet sie nicht. Im dritten Anlauf formuliert sie dann eine Präferenz-Aussage, nämlich, dass sie im eigenen Zuhause niemals wieder frieren müssen möchte. Frau Möller nimmt hier von Anlauf zu Anlauf eine immer stärkere Konkretisierung ihrer Aussage vor. Ihre Selbstkorrekturen machen deutlich, dass Frau Möller eine klare Präferenz für das Passivhaus gebildet hat - ihr graust es regelrecht vor der Vorstellung, in einem Haus mit deutlich geringerem energetischen Standard zu wohnen. Dies bestätigt sich an mehreren Stellen im Interview.

Im Vergleich mit anderen Wohnkontexten, in denen es nicht so warm wie im Passivhaus ist, werden der besondere Wärmekomfort desselben sowie die eigene Gewöhnung daran aufgezeigt. Frau Möllers Verweis, in Bezug auf die Raumtemperatur „verwöhnt“ (ebd., 702) zu sein, sowie das kurze Lachen zwischendurch („@(.)@“, ebd., 702) zeigen, dass Frau Möller ihre Gewöhnung an den hohen Wärmekomfort des Passivhauses bewusst ist.

Später im Interview mit Frau Möller spricht die Interviewerin das Thema Behaglichkeit im Zusammenhang mit Wohnen und Heizen noch einmal ausführlicher an. Zunächst fragt die Interviewerin Frau Möller danach, was für sie ein behagliches Wohnraumklima ausmacht und welche Faktoren hierbei für sie eine zentrale Rolle spielen. Neben vielen anderen Faktoren thematisiert Frau Möller hier bereits ausführlich die konstante Grundwärme im Passivhaus und hebt heraus, dass ihr in den letzten Jahren bewusst geworden sei, was für einen ,Luxus' diese darstelle. An späterer Stelle wird Frau Möller dazu befragt, ob sich ihre Komforterwartungen und -vorstellungen hinsichtlich Wohnen und Wärme in den letzten Jahren stark verändert haben. Frau Möller bejaht dies vor allem für ihr Wärmeempfinden. Erneut kommt sie auf die Grundwärme im Passivhaus zu sprechen. Sie bezeichnet diese als einen Lebensstandard, auf den sie nicht mehr verzichten möchte. Immer wieder - so auch an dieser Stelle - wird deutlich, wie stark Frau Möller an das Passivhaus gewöhnt ist. 
Auch die folgende Passage bezieht sich auf die vorangegangene Frage nach merklichen Veränderungen ihrer Komforterwartungen. Die gesamte Passage macht deutlich, dass Frau Möller seit ihrer Erfahrung des Lebens im Passivhaus gestiegene Erwartungen an den Wärmekomfort ihres $\mathrm{Zu}$ hauses hat:

„Hmm. Also ich würd sagen dass ich irgendwie mehr wahrnehme wenn ich irgendwo reinkomme dass 'n Raum überhitzt ist dass er dass die Luft schlecht ist dass das [...] irgendwie so nach äh Heizungsluft stinkt ich mag das irgendwie nich' [...] es hat sich so verändert dass es so 'n- so 'ne Wärme ist die man vielleicht gar nicht so bemerkt aber die einfach angenehm ist also wenn man das Gefühl hat dass- so ich fühl mich wohl ohne dass ich jetzt irgendwie direkt vor der Heizung kleben müsste oder dass man da mit so 'nem Gefühl ich kann mich einfach bewegen und ähm im Haus [...] ich glaub was sich auch noch so verändert hat dass man im gesamten Haus sich wohl fühlt ja dass man nicht einen Raum nur der so ganz heiß ist und dann ist der nächste so kalt sondern das ist so 'n Gefühl das hat so 'ne Gleichmäßigkeit im ganzen Haus. Das gibt so 'n Freiheitsgefühl [...] Aber so also im Haus mache ich mir ja keine Gedanken mehr darüber ob das irgendwie warm ist oder nicht warm sondern es ist einfach warm und Punkt [...]. Das ist- hat sich vielleicht- es hat- gibt so 'ne Selbstverständlichkeit dadrin dass Wärme einfach so 'n- so 'n Grundrecht ist oder sowas nicht mehr was wo man so- so äh kämpfen muss oder sowas." (Bewohnerin PH, Interview 62: 21, 1102-1128)

In ihrer Argumentation legt Frau Müller eine Reihe von Gründen dar, warum sie die Wärme des Passivhauses schätzt. Der Argumentation lässt sich entnehmen, dass Frau Möller durch das Leben im Passivhaus eine Sensibilisierung für Raumwärme und Luftqualität erfahren hat.

In der gesamten Passage nimmt Frau Möller drei Kontrastierungen zwischen Passivhaus und konventionellen Wohngebäuden vor, von denen sie jeweils immer nur eine Seite explizit ausführt. Im ersten Teil der Passage stehen die Folgen und Nebeneffekte von Raum- bzw. Heizungswärme im Vordergrund. Hier beschreibt Frau Möller, dass sie mittlerweile deutlich wahrnimmt, wenn konventionell, also mittels Heizung erwärmte Wohnräume fehltemperiert sind und wenn die Luft stickig und verbraucht ist.

Im weiteren Verlauf der Passage geht es um die Verteilung der Wärme im Raum und im gesamten Haus. Diesmal führt Frau Möller nur die Seite des Passivhauses aus und die Seite konventioneller Wohngebäude bleibt weitestgehend implizit. Hier beschreibt sie, dass im Passivhaus die Wärme 
im ganzen Haus gleichmäßig verteilt ist. Ihre Schilderung macht deutlich, dass es im Passivhaus weder innerhalb der einzelnen Räume noch zwischen den verschiedenen Räumen deutliche Temperaturunterschiede gibt, sondern dass es im gesamten Haus die gleiche Grundwärme gibt. Im Gegensatz zum Passivhaus entsteht in konventionell erwärmten Gebäuden häufig ein deutlich spürbares Temperaturgefälle, und zwar sowohl innerhalb eines Raumes - hier ist es in direkter Nähe zum Heizkörper warm und in weiterer Entfernung zum Heizkörper deutlich kühler - als auch zwischen beheizten und unbeheizten Räumen.

Auffällig ist, dass Frau Möller die Wärmeverteilung im Passivhaus durchweg positiv beschreibt und bewertet. Komplementär dazu entsteht ein negatives Bild von der Wärmeverteilung in konventionellen Wohngebäuden.

Der dritte Kontrast bezieht sich auf Frau Möllers Wärmeerleben. Hier geht es darum, was die Wärmeverteilung im Passivhaus (und in anderen Gebäuden) für sie bedeutet. Wieder führt Frau Möller nur eine Seite aus; sie äußert sich nur zu ihrem Wärmeerleben im Passivhaus explizit. Die Argumentation lässt erkennen, dass durch die Grundwärme im Passivhaus alle Räume stets nutzbar sind und man deshalb jederzeit spontan von Raum zu Raum wechseln kann.

Es wird deutlich, dass für Frau Möller das Heizen als Aktivität im herkömmlichen Sinne im Passivhaus so gut wie ganz wegfallen ist und sie fast nichts mehr selbst aktiv machen muss, damit ihre Wohnräume angenehm warm sind. Diese Erfahrung, sich im Passivhaus um ausreichende Wärme nicht mehr aktiv bemühen zu müssen, hat offenbar einen Beitrag dazu geleistet, dass sich Frau Möllers Vorstellung von thermischer Behaglichkeit gewandelt hat.

„Freiheit" (ebd., 1116), „Grundrecht“ (ebd., 1127), „Selbstverständlichkeit“ (ebd., 1126), „nicht mehr [...] kämpfen“ (ebd., 1127-1128) - Frau Möller hat starke Metaphern gewählt, um ihr Wärmeempfinden im Passivhaus zu beschreiben. An allen Metaphern zusammen wird deutlich, dass gleichmäßige Wärme hier als eine große Errungenschaft gesehen wird. Ihrer Aussage, „dass Wärme [...] 'n Grundrecht ist“ (ebd., 1126-1127) lässt sich entnehmen, dass Grundwärme kein Luxus sein sollte, sondern ein Standard, der grundsätzlich jedem zusteht und der demnach auch jedem zuteilwerden sollte; ein Standard, unter den man - einmal erreicht - nicht wieder sinken sollte.

An der gesamten Passage wird ein ,Quantensprung' im Komforterleben deutlich, ein solches Wärmeempfinden schien Frau Möller vorher nicht vorstellbar. Darüber hinaus ist zu erkennen, was zu dieser ,Komfortrevolu- 
tion' geführt hat. Drei Punkte sind hier zu nennen: 1. die gleichmäßige Wärmeverteilung, 2. frische Luft bei gleichzeitiger Wärme und 3. ohne dafür etwas aktiv machen zu müssen.

Die Argumentation zeigt, dass Frau Möller mittlerweile an die Grundwärme des Passivhauses gewöhnt ist. In Referenz zur Wärme im Passivhaus empfindet sie die Wärme in anderen Gebäuden in vielerlei Hinsicht als mangelhaft.

\subsection{5 „Es is [...] 'ne andere Wärme also 'ne gleichmäßigere“ - Frau Rosental}

Ein ähnliches ,Drei-(Argumentations-)Punkte-Muster' wie bei Frau Möller wird im Interview mit Frau Rosental deutlich. Frau Rosental wohnt wie Frau Köhler und Frau Lutz seit über zwölf Jahren im Passivmehrfamilienhaus B (siehe Anhang A). Auch sie ist ein Mitglied der Gründerinnengruppe. Danach gefragt, ob sie festgestellt habe, dass sich ihre Vorstellungen von Komfort und Behaglichkeit, was Heizen und Wärme anbelangt, durch ihre Erfahrung des Lebens im Passivhaus verändert haben, geht Frau Rosental auf drei zentrale Punkte ein, in denen sich ihrem Empfinden nach der Wärmekomfort zwischen Passivhaus und konventionellen Wohnkontexten besonders deutlich unterscheidet:

„Also ich merk das schon wenn ich bei Freundinnen@zu Besuch@bin dass ich mir schon mal überlege was hast du jetzt an is es da auch warm genug. (.) Und dass wenn die Freundinnen hierher kommen äh sie immer sagen hoch is hier schön warm. Also das is äh offensichtlich schon die- ne- es is wohl auch 'ne andere Wärme also 'ne gleichmäßigere. Also ich denk von meinem- wenn ein Heizkörper warm is dann dann ge- je weiter man vom Heizkörper weg is desto kühler is es ja auch und wir haben hier ja egal ob ich da oder da hinten sitze is eüberall die gleiche Temperatur. (.) und das is in in in Wohnungen die durch 'n Heizkörper- schon da da überlegt man sich schon wo man 'n Sessel hinstellt. (.) Wenn man wenn ich das- die die Wohnung einrichte und das is hier völlig egal wo ich das jetzt hinstelle." (Bewohnerin PH, Interview 59: 34f, 1820-1831)

Ebenso wie Frau Möller bezieht sich Frau Rosental in ihrer Beschreibung und Bewertung der Wärme im Passivhaus auf den Vergleich mit anderen Wohnkontexten. Sie nimmt in dieser Passage eine Kontrastierung zwischen der Wärme im Passivhaus und der in konventionellen Wohngebäu- 
den vor. Im Gegensatz zu Frau Möller führt Frau Rosental aber immer beide Seiten dieser Kontrastierung aus. Als erstes thematisiert sie das unterschiedliche Wärmeniveau. Hier wird deutlich, dass es, anders als in konventionellen Wohngebäuden, im Passivhaus stets angenehm warm ist. Wie Frau Möller spricht sie in einem zweiten Schritt über die Verteilung der Wärme im Raum. Der Beschreibung lässt sich entnehmen, dass im Passivhaus die Wärme im ganzen Raum gleichmäßig verteilt ist, wohingegen in konventionellen Gebäuden typischerweise ein deutlich spürbares Temperaturgefälle in den einzelnen Räumen besteht. Im letzten Schritt schildert Frau Rosental, welche Konsequenzen sich für sie aus den beiden unterschiedlichen Wärmeerleben jeweils ergeben. Hier betont sie ähnlich wie Frau Möller, dass durch die konstante und gleichmäßig verteilte Wärme in der gesamten Passivhauswohnung die Wohnräume deutlich flexibler zu nutzen und einzurichten sind als in einer konventionellen, ,nur ${ }^{6}$ mittels Heizung erwärmten Wohnung. All dies zusammen lässt erkennen, dass Frau Rosental - genauso wie Frau Möller - den thermischen Komfort im Passivhaus als gesteigert erlebt.

Dieses Muster findet sich auch noch bei anderen Passivhausbewohner*innen. So erzählt Frau Greiner, dass sie bei ihren Besuchen bei einem Freund selbst bei voll aufgedrehter Heizung noch friere. Genauso wie Frau Möller spricht Frau Greiner davon, vom Wärmekomfort des Passivhauses verwöhnt zu sein. Sowohl ihr Fall als auch der Frau Möllers und der Frau Rosentals machen deutlich, dass sich manche Bewohner*innen, seitdem sie den Wärmekomfort des Passivhauses gewohnt sind, sich kaum noch bei anderen Raumtemperaturverhältnissen wohlfühlen. Daraus lässt sich schließen, dass alle drei Bewohnerinnen seit ihrer Erfahrung des Lebens im Passivhaus gestiegene Erwartungen an den Wärmekomfort ihres $\mathrm{Zu}$ hauses haben.

Im Folgenden wird es um das Erleben der Raumluftverhältnisse im Passivhaus gehen, da sich herausgestellt hat, dass es sich hierbei um einen weiteren wichtigen Aspekt für (das Wahrnehmen von), Wohnbehaglichkeit handelt.

\subsubsection{Trockene Raumluft im Passivhaus}

Ein weiteres Thema, das in den Interviews mit Passivhausbewohner*innen im Zusammenhang mit Wohnbehaglichkeit häufig angesprochen wird, ist, dass im Passivhaus trockene Luft herrsche (vgl. hierzu auch Hacke 2009a: 11). 
Viele der interviewten Passivhausbewohner*innen äußern, dass sie die Luft im Passivhaus insbesondere während der Wintermonate als unangenehm trocken wahrnehmen. So berichten auffällig viele Bewohner*innen aus verschiedenen Passivhausprojekten von gesundheitlichen Problemen wie trockene oder gereizte Schleimhäute in Nase oder Rachen, trockene, brennende Augen, anhaltender Husten, ständig wiederkehrende Erkältungen und Atemwegserkrankungen infolge der Lufttrockenheit bzw. einer zu geringen Luftfeuchte im Passivhaus. Andere Bewohner*innen wiederum haben bei sich einen verstärkten Durst bemerkt oder stellen an einem verstimmten Klavier fest, dass die Raumluft in der kalten Jahreszeit sehr trocken ist. Mehrere Bewohner*innen berichten, dass sie die Luftfeuchte regelmäßig mittels Hygrometer kontrollieren, um bei einem zu niedrigen Feuchtigkeitsgehalt der Raumluft geeignete Gegenmaßnahmen ergreifen zu können.

Hierzu ein paar Zitate:

„Die [Luft] is sehr trocken. Also ich hab Schwierigkeiten mit meinen Augen in diesem Winter (.) äh die also ständig jucken von der Trockenheit und mir haben zwei Augenärzte gesacht das is Trockenheit.“ (Bewohnerin PH, Interview 59: 12, 602-604)

„Ja einfach trockene Nase und also so (.) alles austrocknet. Also fällt mir grad nur so auf aber [...] das is im Winter dann schon Thema." (Bewohnerin PH, Interview 61: 22, 1147-1149)

„Also was- was uns aufgefallen is'- und da hat uns der Klavierbauer und -stimmer drauf gebracht (.) ähm (1) die- die Luft ist hier- (1) [...]. Aber ich finde das schon dass man das merkt so an der Nase oder so dass die Luft hier trocken is' im Winter." (Bewohner PH, Interview 55: 21, 1083-1089)

„die L- Luft hier is enorm trocken ich merk's an meinem Klavier dass also der Hygrometer der meldet auch immer dass es viel zu trocken is und der Klavierstimmer sagt auch immer das tut ihrem Klavier aber gar nich gut." (Bewohnerin PH, Interview 60: 10, 504-507)

Inwiefern die Aspekte ,Behaglichkeit‘ und ,(Wärme-)Komfort' im Hinblick auf das alltägliche Heizen für die Bewohner*innen von SmartHome-Haushalten eine Rolle spielen, ist Inhalt des nächsten Teilkapitels. 


\subsubsection{Veränderungen im Behaglichkeits- und Komforterleben im Fall der} SmartHomes

In den Gesprächen mit Mieter*innen, bei denen eine intelligente Heizungssteuerung eingebaut wurde, spielen die Themen ,Behaglichkeit' und „Komfort' sowie die Veränderung von Komfortvorstellungen im Vergleich zum Passivhaus eine deutlich geringere Rolle. Dies hängt vermutlich damit zusammen, dass es sich bei der intelligenten Heizungssteuerung um eine einfache Nachrüsttechnologie handelt, deren Einbau keinen großen Eingriff in das vorhandene Setting darstellt. Für die Mieter*innen hat sich im hier untersuchten Fall vergleichsweise wenig am technischen Setting ihrer Heizung verändert, lediglich die Heizungssteuerung ist neu.

Die Einschätzung, dass die neue Steuerungstechnik weder den Heizvorgang noch das persönliche Komforterleben stark verändert hat, wird in folgendem Zitat deutlich:

„Ich ich find' das wirklich sehr angenehm also is' jetzt nichts wo ich vorher gesacht hätte muss ich unbedingt haben weil das fehlt mir zum zum bequemen Leben ähm man bricht sich auch keinen Zacken aus der Krone die Heizung aufzudrehen aber es is' halt nett das zu haben." (Bewohnerin SH, Interview 72: 13, 654-658)

Darüber hinaus hat die Auswertung der Interviews zum intelligenten Heizen ergeben, dass die SmartHome-Bewohner*innen anders als viele Passivhausbewohner*innen ,Komfort ${ }^{`}$ nicht vorrangig mit dem thermischen Raumklima assoziieren. Dementsprechend thematisieren und diskutieren sie unter dem Stichwort ,Komfort' auch nicht primär ihre Vorstellungen von thermischer Behaglichkeit, sondern an entsprechenden Interviewstellen wird deutlich, dass sie ,Komfort ${ }^{\star}$ allgemein verstehen. Beispielsweise beschreiben mehrere SmartHome-Bewohner*innen die neue Situation mit automatischer Heizungssteuerung als ,komfortabel', da die neue Technik ihnen Arbeit abnimmt - sie müssen die Temperatur nun nicht mehr per Hand an den einzelnen Heizkörperthermostaten einstellen - und sie dadurch weniger Aufstehen müssen. In diesem Zusammenhang hat ,Komfort' also eher die Bedeutung von auf technischen Einrichtungen beruhende ,Bequemlichkeit'. Dieses eher allgemeine bzw. auf eine bestimmte gegenständlich-technische Ausstattung bezogene Komfortverständnis wird durch folgendes Zitat illustriert:

„Also ich $\mathrm{mhm}$ (1) das [mit den Komforterwartungen, JM] hat sich jetzt glaub' ich nich' so viel verändert wobei ich auch sagen muss wenn wir jetzt hier noch mal ausziehen werden also- das werden wir 
spätestens in einem Jahr wenn das zweite Kind da is'- [...] jetzt glaube ich schon erstmal wieder 'ne Umstellung sein manuell die Heizung einstellen zu müssen also es is' schon jetzt wo sich das alles eingespielt hat schon irgendwie gemütlicher und ähm einfacher geworden und ähm das wird dann schon wieder so 'n Rückschritt sein so 'n System nich' zu haben." (Bewohnerin SH, Interview 73: 15, 787-800)

\subsubsection{Vergleichendes Kapitelfazit}

\section{Die unterschiedliche Verwendung und Auslegung der Begriffe, Behaglich- keit' und, Komfort'}

Die Analyse des Datenmaterials hat gezeigt, dass den beiden von der Interviewerin in den Interviews synonym verwendeten Begriffen ,Behaglichkeit $^{\star}$ und ,Komfort ${ }^{`}$ in den Diskussionen der beiden Fälle eine unterschiedliche Relevanz zukommt. Die Passivhausbewohner*innen knüpfen in ihren Schilderungen zur Wohnatmosphäre und zum Raumklima primär am Begriff der ,Behaglichkeit ${ }^{\varsigma}$ an und diskutieren - wie ursprünglich von der Interviewerin erwartet - unter diesem überwiegend zentrale Aspekte thermischer Behaglichkeit, wie etwa den Wärmekomfort des Passivhauses und den Feuchtigkeitsgehalt der Raumluft. Hingegen war Behaglichkeit in der Diskussion um die intelligente Heizungssteuerungstechnik praktisch kein Thema. Dafür hat sich hier der Ausdruck ,Komfort' als anschlussfähig erwiesen, wobei deutlich wurde, dass die SmartHome-Bewohner*innen diesen eher allgemein verstehen. Hier ist von ,Komfort ${ }^{6}$ die Rede, wenn es um auf der neuen Heizungssteuerung beruhende Bequemlichkeiten geht.

Auch in der sozial- und kulturwissenschaftlichen Literatur zum Thema ,Behaglichkeit' wird die zunehmende Bedeutung des Komfortbegriffs betont. Laut dem englisch-kanadischen Architekten und Kulturhistoriker Witold Rybczynski spielt in der heutigen Zeit vor allem der Ausdruck ,Komfort ${ }^{`}$ eine zentrale Rolle, wenn es um die Beurteilung von Wohnatmosphäre bzw. das Wohlbefinden des Einzelnen in seinem Wohnumfeld geht (Rybczynski 1991). In manchen Bereichen scheint er den der Behaglichkeit bereits abgelöst oder ersetzt zu haben. Der Ausdruck Komfort ist auf das lateinische Wort ,confortare` zurückzuführen, das soviel wie stärken', ,fördern' oder auch ,trösten' bedeutet. In seiner heutigen Verwendung überschneidet sich sein Bedeutungsgehalt mit dem von Ausdrücken wie ,Behaglichkeit', ,Bequemlichkeit', ,Wohnlichkeit' und ,Gemütlichkeit ${ }^{\star}$ (ebd.: 17). Ganz sinngleich sind die Begriffe allerdings nicht, wie es sich auch in der Empirie erwiesen hat; vielmehr verfügen sie alle über spezifi- 
sche Nuancierungen, durch die sie sich voneinander unterscheiden. Laut Rybczynski liegt die spezifische Nuance des Begriffs, Komfort' in seiner Beziehung zur Moderne. Denn er verweist auf jene Art von Behaglichkeit oder „Bequemlichkeit, wie wir sie durch die Ausstattung unserer Wohnumwelt mit technischen Geräten erreichen, die uns körperliche Anstrengungen aller Art abnehmen“ (ebd.). Rybczynskis These ist, dass für die Schaffung einer behaglichen Wohnatmosphäre Technisierung und Funktionalisierung eine immer größere Rolle spielen. Damit werde eine Wohnatmosphäre, in der sich Menschen wohlfühlen, so Lipp, in immer stärkerem Maße von technischen Entwicklungen abhängig, „die mehr und mehr zur Voraussetzung für die vom Zeitgeist beeinflusste Lebensqualität werden“ (Lipp 2006: 6).

Offenbar wird der Ausdruck ,Komfort ${ }^{\varsigma}$ von den SmartHome-Bewohner"innen in seinem modernen Verständnis gebraucht. Er bezeichnet demnach die Art von ,Bequemlichkeit' oder ,Behaglichkeit', die auf dem Vorhandensein von bestimmten Gegenständen oder technischen Anlagen beruht, die dem Menschen Arbeit verringern. Die neue Heizungssteuerung führt nun das Öffnen und Verschließen der Heizkörperthermostatventile automatisch aus, wodurch den Bewohner*innen der Gang zu den einzelnen Heizkörpern sowie deren manuelle Bedienung erspart bleiben.

\section{Nicht intendierte Nebeneffekte von erfolgreicher Wärmedämmung mit deutlichen Auswirkungen auf das Woblbefinden der Bewobner"innen im Passivbaus}

Ein weiteres interessantes Ergebnis ist, dass einige Passivhausbewohner*innen in ihren Beschreibungen ihres Behaglichkeitserlebens im Passivhaus nicht ausschließlich Aspekte thermischer Behaglichkeit thematisieren. Offenbar werden nicht alle von der neuen Heiztechnik verursachten und sich entscheidend auf das Wohlbefinden der Bewohner*innen in ihren Wohnräumen auswirkenden Effekte mit dem Konzept thermischer Behaglichkeit erfasst. So hat sich zum Beispiel herausgestellt, dass einige Passivhausbewohner*innen die Wahrnehmung haben, durch die dicke, luftdichte Gebäudehülle sowie die Dreischeiben-Wärmeschutz-Fensterverglasung von der natürlichen Umwelt isoliert und von jeglichen Außengeräuschen abgeschirmt zu sein. In diesem Punkt reicht der Begriff der thermischen Behaglichkeit für die Argumentation nicht aus, sondern hier geht es um akustische Aspekte von Wohnbehaglichkeit bzw. um vielfältige Auswirkungen dicker Isolierung auf das subjektive Behaglichkeitsempfinden in Innenräumen. Dieser Punkt wurde in den Falldarstellungen zu Frau Köhler und Herrn Thomsen herausgearbeitet. 
Im Fallvergleich wird deutlich, dass Frau Köhler und Herr Thomsen zwar den gleichen Kontrast im Hinblick auf die Isolierung zwischen Passivhaus und Altbau schildern, diesen aber unterschiedlich bewerten. Während Frau Köhler den Kontrast als sehr drastisch wahrnimmt und beschreibt und ihre Bewertung eindeutig negativ ausfällt, erscheinen Herr Thomsens Schilderung und Beurteilung viel weniger drastisch. Er sieht stärker die Vorteile einer sehr guten Isolierung.

Die Unterschiede in der Bewertung zwischen Herr Thomsen und Frau Köhler werden besonders deutlich, wenn man die von ihnen verwendeten Metaphern, die des Raumschiffs mit der des Iglus vergleicht. Zwar bringen beide Bilder das Gefühl des Abgetrenntseins von der umgebenden Welt und natürlichen Einflüssen zum Ausdruck, aber mit unterschiedlicher Konnotation.

Das Raumschiff steht für Modernität, den Glauben an technischen Fortschritt und die Beherrschbarkeit der Natur. Fortschritt wird allgemein als positiv gesehen und so sieht Herr Thomsen auch das Passivhaus. Er ist im Prinzip ein ,Fortschrittsdenker'. Das Abgekoppeltsein im Passivhaus betrachtet er als unerwünschte, aber nicht weiter bedenkliche Konsequenz der Bauweise von Passivhäusern. Herr Thomsen vermutet sogar, dass dieses Phänomen kein Spezifikum des Passivhauses darstellt, sondern dass es im Prinzip für jeden modernen, energieeffizienten Neubau zutrifft. Zwar bekomme man im Hausinneren nicht mehr viel von den äußeren Witterungsbedingungen und natürlichen Geräuschen mit, dafür sei man durch die Isolierung beständig vor unangenehmer Kälte und Feuchtigkeit, vor Zugluft sowie Lärm geschützt. Für die Vorteile eines modernen Wohnund Wärmekomforts nimmt Herr Thomsen diese Abstriche bereitwillig in Kauf.

Hingegen stellt ein Iglu keine moderne oder zukunftsweisende Wohnform dar. Im Gegenteil, bei einem Iglu handelt es sich um eine archaische, einfach-primitive Behausung, die heutzutage selbst von den Inuit nicht mehr als dauerhafte Wohnung genutzt wird. Es erscheint plausibel, dass Frau Köhler die Metapher des Iglus deshalb gewählt hat, um ihre Kritik an der massiven Bauweise von Passivhäusern und den sich daraus ergebenden Konsequenzen deutlich zu machen. So wie die dicken Schneeblöcke eines Iglus sehr effektiv äußere Einflüsse wie extreme Kälte und eisigen Wind vor dem Eindringen in das Schneehausinnere abhalten, schirmen die sehr dicken Wände, die Dreifachisolierverglasung und eine komplett luftdichte Gebäudehülle die Passivhausbewohner*innen von unangenehmen Witterungseinflüssen, aber eben auch von angenehmen Geräuschen von draußen wie Vogelgezwitscher, Stimmen und Wind vollkommen ab. Die mas- 
sive Bauweise von Passivhäusern lässt offenbar keine Unterscheidung zu, sondern es wird pauschal alles von draußen abgehalten. Frau Köhler empfindet diese totale Abschirmung als großes Manko der Passivhausbauweise und bewertet diesen Zustand negativ. Durch die kompakte, luftdichte Gebäudehülle und die Isolierung fühlt sie sich im Passivhaus wie ,eingesperrt ${ }^{6}$ und von der Außenwelt ,abgetrennt'. Anzunehmen ist, dass sie diese Entwicklung nicht als Fortschritt, sondern eher als einen Rückschritt betrachtet und sie deshalb die Metapher vom traditionellen Haus der Inuit zum Vergleich gewählt hat.

Ob der Vergleich noch weiter trägt und Frau Köhler die Metapher des Iglus auch deshalb gewählt hat, weil sie die durchschnittlichen Raumtemperaturen im Passivhaus generell als niedrig wahrnimmt oder ob sie die Wohnatmosphäre im Passivhaus als kalt bzw. unterkühlt empfindet und dies sie an ein Schneehaus denken lässt oder auch ob keine dieser Deutungen zutrifft, lässt sich nicht sagen. Im Interview finden sich keine eindeutigen Hinweise darauf, dass sich eine dieser Thesen erhärten lässt.

Lediglich an einer Stelle im Interview gibt es einen eher indirekten Hinweis darauf, dass es Frau Köhler im Passivhaus manchmal etwas zu kalt ist. Als sich Frau Köhler explizit über die im Passivhausprojekt B eingebaute Lüftungsanlage äußert, berichtet sie über die ständigen Diskussionen, die es offenbar in den ersten Jahren nach Fertigstellung des Hauses zwischen den Bewohner*innen und dem Ingenieur gab, der die Lüftungsanlage konzipiert hat. In diesen Diskussionen haben die Bewohner*innen ihm offenbar wiederholt gesagt, dass die Anlage für ihr Empfinden nicht gut eingestellt sei. Hier lautete die zentrale Kritik, dass es in den Wohnungen entweder zu warm oder zu kalt sei. Allerdings geht aus dieser Stelle nicht eindeutig hervor, ob sich Frau Köhler dieser Kritik vollständig anschließt. An anderen Stellen im Interview wird wiederum deutlich, dass sie es im Passivhaus gelegentlich zu warm findet. So wünscht sie sich beispielsweise im Schlafzimmer generell etwas kühlere Temperaturen als in der restlichen Wohnung. Insgesamt wird im Interview deutlich, dass sie das Raumklima im Passivhaus als eher unangenehm empfindet. Frau Köhler stört vor allem die Gleichförmigkeit, sie wünscht sich mehr spürbare Wechsel zwischen warm und kalt über den Tag und das Jahr. Zudem stört sie, dass es praktisch nur eine Temperatur für die gesamte Wohnung gibt und sich die einzelnen Räume kaum bzw. nur sehr schwer und mithilfe von kleinen ,Tricks' unterschiedlich temperieren lassen. Insofern passt hier der Ver- 
gleich mit dem Iglu nicht mehr, da es in einem Iglu keine Unterteilung in unterschiedliche Räume gibt. ${ }^{100}$

An einer weiteren Stelle im Interview relativiert Frau Köhler ihre negative Bewertung des Passivhauses mit dem Hinweis, dass diese nicht für Passivhäuser im Allgemeinen gelte, sondern sich nur auf das eigene Passivhausprojekt B ihrer Baugruppe beziehe. Sie ist sich dessen bewusst, dass viele Probleme und Anfangsschwierigkeiten in der Ausführung der Lüftungstechnik bei ihrem Passivhaus aus der Tatsache resultieren, dass es sich um eines der ersten Passivhäuser im Geschosswohnungsbau handelt und dass die Architektin, der verantwortliche Lüftungsingenieur sowie die ausführenden Handwerker*innen damals noch über keinerlei praktische Erfahrung im Konzipieren und Bauen von Passivhäusern verfügten, sondern mit dem Hausprojekt B Neuland betreten haben.

Die Ambivalenz hinsichtlich des Wohngefühls im Passivhaus, die insbesondere in Herr Thomsens Beschreibungen an mehreren Stellen zum Ausdruck kommt, versinnbildlicht auch der Begriff ,Isolierung', die zentrales Merkmal moderner energieeffizienter Gebäude wie dem Passivhaus ist.

Der Begriff ,Isolierung' hat einerseits eine technisch-funktionale Bedeutung, andererseits gibt es für ihn eine eher negativ konnotierte soziale Sinndeutung. Im Bereich der Bau- bzw. Gebäudetechnik bezeichnet ,Isolierung` Baumaßnahmen zur Energieeffizienz. Durch ,Isolierung' - im deutschen Sprachraum wird eher der Begriff, (Wärme-)Dämmung verwendet - soll der Durchgang von Wärmeenergie durch eine Gebäudehülle reduziert werden, um die Innenräume im Winter vor Auskühlung und im Sommer vor zu starker Erwärmung zu schützen. Die ,Isolierung trennt demnach die unterschiedlichen Temperaturniveaus von innen und außen.

Im Sozialen verbindet sich mit dem Begriff eine andere Sinndeutung. Mit ,Isolierung' oder ,Isolation' lässt sich auch die Lebenssituation von Menschen beschreiben, die nur wenig soziale Kontakte zu anderen Menschen haben, oder allgemeiner: die durch physische, materielle oder immaterielle Barrieren von der Außenwelt, ihrer sozialen und/oder natürlichen Umwelt stark abgeschirmt bzw. weitestgehend abgeschnitten sind. In diesem Verständnis geht es also um die Trennung zwischen Menschen bzw. zwischen Mensch und Natur.

Im Gegensatz zu Frau Köhler, die explizit von „so viel mehr isoliert“ (Bewohnerin H, Interview 60: 9, 443) spricht, verwendet Herr Thomsen den Begriff ,Isolierung` zwar selbst an keiner Stelle, seine Beschreibung des

100 Allerdings zirkuliert im Passivhaus die Luft relativ frei durch alle Räume, so dass die Grundwärme bzw. die Temperatur in allen Räumen die gleiche ist. 
Lebens im Passivhaus illustriert jedoch die beiden unterschiedlichen Begriffsvorstellungen sehr anschaulich und bringt sie darüber hinaus in einen kausalen Zusammenhang: So macht seine Schilderung deutlich, dass dieses Lebens- bzw. Wohngefühl im Passivhaus, ,abgekoppelt‘ von der Außenwelt zu sein, offenbar Resultat einer sehr guten Wärmeisolierung der gesamten Gebäudehülle ist.

Sein Vergleich der beiden sehr unterschiedlichen Wohnsituationen im Hinblick auf das Wohnklima macht deutlich, dass Herr Thomsen mit dem Übergang von unsanierter Altbauwohnung zum Passivhaus gewissermaßen von einem Extrem zu einem anderen Extrem gewechselt ist: Während man in der nicht isolierten Altbauwohnung den jahreszeitlichen Temperaturschwankungen relativ unmittelbar ausgesetzt ist und den natürlichen Wechsel quasi mitvollziehen muss, entsteht im Passivhaus ein von äußeren Witterungsverhältnissen unabhängiges Raumklima. Werden die Türen und Fenster konsequent geschlossen gehalten, wie es für ein ordnungsgemäßes Funktionieren der Passivhaustechnik erforderlich ist, bekommen die Bewohner*innen im Inneren des Passivhauses so gut wie nichts mehr von der Außenwelt mit. Durch die Dämmung wird demnach nicht nur Unerwünschtes herausgehalten, sondern auch erwünschte Einflüsse.

Ein wichtiges Ziel bei der Entwicklung des Passivhauses war es, durch optimale Dämmung effektiv Energie einzusparen - im Winter für Heizung und im Sommer für Kühlung. Dass sich einige Passivhausbewohner*innen dadurch wie in (Raumklima-)Kapseln eingesperrt fühlen, scheint offenbar ein nicht intendierter Nebeneffekt erfolgreicher Dämmung zu sein.

\section{Gestiegene Erwartungen an den thermischen Komfort}

Während bei Frau Möller die Gewöhnung an das Passivhaus mit seiner gleichmäßigen Grundwärme vollkommen linear, sehr schnell und unproblematisch verlaufen ist, haben sich Frau Köhler und Frau Lutz bis heute nicht gänzlich an das Passivhaus und den besonderen Wärmekomfort gewöhnt. Noch immer erfordert es bei Frau Köhler regelmäßiges aktives Bemühen, sich auf die Raumklimaverhältnisse im Passivhaus einzustellen. Dabei ist ihr bewusst, dass es nur die Möglichkeit gibt, dass sie sich anpasst, da es die im Passivhausprojekt B eingebaute Heiz- und Lüftungstechnik der ersten Generation nicht hergibt, sie optimal auf die individuell unterschiedlichen Bedürfnisse der Bewohner"innen einzustellen.

Entgegen der unter Expert"innen weit verbreiteten Überzeugung, dass das Passivhaus „nur Vorteile“ (Architekt PH, Interview 53: 17, 834) bringe und die Behaglichkeit beim Übergang vom konventionellen Wohnkontext zum Passivhaus grundsätzlich gesteigert werde, zeigt der Fall von Frau 
Köhler, dass das Passivhaus nicht für jeden gleichermaßen einen Gewinn darstellt und einen Zuwachs an Wohlbefinden bedeutet.

Im Gegensatz dazu lobt Frau Möller das Passivhaus regelrecht in den höchsten Tönen. Frau Möller empfindet im Passivhaus optimale thermische Behaglichkeit. Im Vergleich mit konventionellen Wohnkontexten erlebt sie das Leben im Passivhaus hinsichtlich des Heizens und Lüftens als einfach und sehr komfortabel, weil sie für beständig frische Luft bei gleichzeitiger angenehmer Wärme nicht mehr aktiv handeln muss.

Nicht nur der Fall Frau Möllers, sondern auch die Fälle Frau Greiners und Frau Rosentals verdeutlichen, dass bei diesen drei Bewohnerinnen bereits eine vollständige Gewöhnung an den Wärmekomfort im Passivhaus stattgefunden hat. Dieses neue Komforterleben hat dazu geführt, dass sich ihre diesbezüglichen Erwartungen und Vorstellungen deutlich verändert haben. So berichten alle drei Bewohnerinnen, dass sie sich in anderen Wohnkontexten mit abweichenden Raumtemperaturverhältnissen nicht mehr wohlfühlen. Offenbar sind die Erwartungen der drei Bewohnerinnen an den Wärmekomfort in ihrem Zuhause seit ihrer Erfahrung des Lebens im Passivhaus merklich gestiegen. Diese Entwicklung entspricht am ehesten dem zweiten der vier von Gebäudeexpert*innen für möglich gehaltenen Zukunftsszenarien, in welche Richtung sich die Komfortvorstellungen bzw. die Erwartungen an ein behagliches Wohnraumklima und die entsprechenden materiellen Realitäten wandeln können (vgl. Chappells und Shove 2005: 38). Die vier unterschiedlichen Szenarien wurden in Teilkapitel 2.3.2.1 zu den Ausgangspunkten für Wandel bereits kurz umrissen. Das zweite Szenario beschreibt eine weitere Eskalation der Komfortansprüche, die an ein behagliches Wohnraumklima gestellt werden, woraus im Winter ein erhöhter Energiebedarf für Raumwärme resultiert. Zwar ist das Passivhaus bereits ein sehr effizientes Gebäude, mit dem auch weiterhin noch erheblich Heizenergie eingespart wird, wenn die Bewohner"innen ihre Wohnräume statt auf durchschnittlich 20 jetzt auf 23 bis 24 Grad Celsius während der kalten Jahreszeit erwärmen - selbst dann ist der Heizenergieverbrauch im Vergleich zum Altbau oder einem anderen konventionellen Gebäude noch äußerst gering. Dennoch kommt es durch diese Entwicklung zu einem, wenn auch kleinen Rebound-Effekt: ein Teil der Effizienzsteigerungen kann durch einen erhöhten Verbrauch - hier für höhere Raumtemperaturen während der Wintermonate - nicht realisiert werden. Diese Entwicklung wurde von den Expert*innen (Archtiekt*innen und Ge- 
bäudetechniker*innen) offenbar nicht vorausgesehen und dementsprechend nicht eingeplant. ${ }^{101}$

Darüber hinaus wird im Fallvergleich deutlich, dass einige Bewohner*innen, die bereits seit vielen Jahren im Passivhaus wohnen, den Wechsel „zwischen das ist mal kühler und das ist mal wärmer“ (Bewohnerin PH, Interview 64: 29, 1521) nicht mehr gewohnt sind, weil es im Passivhaus immer konstant warm ist. Während Frau Köhler das Fehlen dieses Wechsels explizit beklagt, äußern sich Frau Möller und Frau Greiner regelrecht erleichtert, dass sie sich in ihrem Zuhause (im Passivhaus) nun nicht mehr auf große Unterschiede bei den Raumtemperaturen einstellen müssen; sie empfinden es bereits als Zumutung, dass sie meist frieren (müssen) bzw. sich von den Raumtemperaturverhältnissen her absolut nicht behaglich fühlen, wenn sie sich für eine gewisse Zeit für Besuche bei Freund"innen und Bekannten wieder in konventionell beheizten Wohnkontexten aufhalten.

Geht man davon aus, dass sich die gesellschaftlichen Komfortansprüche im Bereich ,Bauen und Wohnen' in den letzten Jahrzehnten deutlich erhöht haben und sich die Menschen im Allgemeinen sehr schnell an einen gestiegenen Komfort gewöhnen, so wäre wünschenswert, dass dies in den theoretischen Planungen und Berechnungen von (Neubau-)Gebäuden und Gebäudeheizungssystemen stärker berücksichtigt wird. Expert"innen sollten ihren Erfahrungsschatz und ihr in der Praxis erworbenes Wissen (noch mehr) in ihre Planungsarbeit einfließen lassen und mehr mit künftigen Bewohner*innen in einen Dialog treten, um eine realistischere Sichtweise dessen zu erlangen, wie Menschen in neuen (technischen) Gebäude- und Heiz-Settings alltäglich wohnen und heizen und wieviel Energie dabei tatsächlich verbraucht wird.

Im nächsten Kapitel werden Veränderungen im Kontrollerleben behandelt, die sich typischerweise im Übergang von konventionellen Wohnkontexten zum Passivhaus und SmartHome ergeben können.

101 Diese Problematik ist bereits seit Längerem bekannt und wird in der diesbezüglichen Forschungsliteratur seit einigen Jahren prominent unter dem Stichwort ,(energy) performance gap' diskutiert (vgl. z.B. Bordass et al. 2001; SunikkaBlank und Galvin 2012; Majcen et al. 2013; Gram-Hanssen et al. 2017, Brom et al. 2018, sowie das gleichnamige Special Issue ,Energy Performance Gaps: Promises, People, Practices' der Zeitschrift ,Building Research \& Information“ (2018), Vol. 46(1), herausgegeben von den Gast-Herausgeber*innen: Kirsten Gram-Hanssen und Susse Georg (Gram-Hanssen und Georg 2018). 


\subsection{Das Gefühl von Kontrolle und Kontrollverlust}

In diesem Kapitel werden Veränderungen im Kontrollerleben im Übergang von konventionellen Wohnkontexten zum Passivhaus und SmartHome dargestellt.

Möglichkeiten der Einflussnahme, Gefühle von ,Beherrschung', ,Fremdbestimmung' und ,Kontrollverlust' haben sich in den Interviews als wichtige Themen im Zusammenhang mit dem Heizen und dem Umgang mit neuer Heiztechnologie erwiesen.

Hier zeigt sich die größte Diskrepanz zwischen Expert*innen und gewöhnlichen Nutzer*innen: Während das Thema ,Kontrollverlust ${ }^{6}$ in den Expert*inneninterviews praktisch kaum eine Rolle spielte, sondern hier wenn überhaupt - nur indirekt und dann eher positiv verstanden als ,Arbeitsabnahme' für die Bewohner*innen vorkam, thematisierten Bewohner*innen in den Interviews sehr häufig ihre Ängste vor einer zunehmenden Abhängigkeit von Technik und ihre negativen Gefühle von bereits erlebtem Kontrollverlust durch die Einführung weitgehend autonomer Technik.

In der Empirie haben sich deutliche Unterschiede in den (Be-)Deutungen der Passivhaus- und der SmartHome-Technologie zwischen Expert"innen bzw. Urheber*innen und den Nutzer*innen der Technologien gezeigt. Die Gestalter*innen und Vertreiber*innen der neuen Heiztechniken haben meist schon vorab konkrete Vorstellungen davon, zu welchen Resultaten der Einsatz der neuen Techniken jeweils führen wird bzw. soll: So gehen Passivhaus-Expert*innen in der Regel davon aus, dass sich mit einem Passivhaus erhebliche Mengen an Wärmeenergie einsparen lassen und für die Bewohner*innen die Behaglichkeit gleichzeitig erhöht wird. Genauso erwarten die Urheber*innen bzw. Gestalter*innen der ,smarten“ Technik, dass eine intelligente Heizungssteuerung die Wärmeeffizienz deutlich steigert und parallel der Komfort für die Bewohner*innen erhöht wird. Nachteile, Risiken oder ernsthafte Gefahren, die für die Bewohner*innen durch den Einsatz und Gebrauch der neuen Technik möglicherweise entstehen könnten, sehen die Expert*innen nicht. So stellt für den Architekten Herrn Beckert das Passivhaus „eigentlich nur 'n Gewinn“ (Architekt PH, Interview 53: 17, 831) dar und insbesondere in der kontrollierten Be- und Entlüftung sieht er „nur Vorteile“ (ebd., 834). Und auch der SmartHomeExperte und LivingLab-(Mit-)Urheber Herr Kurt sieht in einer intelligenten Steuerung des Heizvorgangs großes Potenzial. Er betont, „um Geld zu sparen [...] und um $\mathrm{CO}_{2}$ zu sparen“ (Experte SH, Interview 70: 25, 12931294), sei eine Heizungsautomatisierung „das größte Feld überhaupt“ 
(ebd., 1294) bei den SmartHome-Anwendungen. Um dies zu belegen, beruft er sich auf Zahlen einer wissenschaftlichen Untersuchung, die von der Technischen Universität Wildau durchgeführt wurde und die ergeben habe, dass ,zwischen 20 und 40 Prozent in der Regel aber 30 äh sich an Heizkosten einsparen [lässt] (.) alleine durch diese Maßnahme“" (ebd.: 2, 86-87). Und bezüglich der Datenschutzthematik ist er der Überzeugung, dass „alles was an Argumenten dafür gebracht worden is' sich alles aushebeln [lässt]“" (ebd.: 6, 267-268). Die Branchen der Passivhausgebäudetechnik sowie der Raumautomation suggerieren, dass das Heizen mit Hilfe der von ihnen vertriebenen Technik effizienter, komfortabler und angenehmer wird und preisen die Komponenten und Funktionen ihrer Technik jeweils vollmundig an.

Für die Bewohner*innen hängt hingegen ein erheblicher Teil der Bedeutung des Heizens mit ,Kontrolle' zusammen. In den Interviews wurden von ihnen so verschiedene Aspekte wie die Reaktionsgeschwindigkeit der Heizung, ihre Funktionsfähig- und Störanfälligkeit nach Einbau der neuen Technologie, die zunehmende Abhängigkeit von elektrischer Energie sowie die Sicherheit der neuen technischen Anwendung, etwa im Hinblick auf die von ihr ermittelten Heiz-Daten, zuallererst mit dem Thema ,Kontrolle bzw. ,Kontrollverlust' assoziiert.

Beide in dieser Arbeit betrachteten Technologien funktionieren weitgehend automatisch. Das heißt, dass der Vorgang des Heizens größtenteils durch die Technik ausgeführt wird.

Wie bereits in Kapitel 4.2 erklärt, sind im Passivhaus Heizen und Lüften keine separaten eigenständigen Aktivitäten mehr, sondern zu einem mehr oder weniger hybriden Vorgang zusammengefasst. Hier übernimmt die Lüftungsanlage mit Wärmerückgewinnung das Be- und Entlüften der Wohnräume während der Heizperiode komplett. Das Heizen erfolgt größtenteils ebenfalls über die Lüftungsanlage. Die Passivhauslüftung sorgt also nicht nur für den notwendigen Luftaustausch im Gebäude, sondern deckt große Teile des Heizbedarfs gleich mit ab. Durch die kompakte Passivhauslüftungsanlage gibt es nun einen hybriden Vorgang des ,Lüftungsheizens', der praktisch komplett automatisiert ist, wodurch den Praktizierenden das Lüften vollständig und das Heizen in weiten Teilen ,abgenommen' wird. Die Passivhausbewohner*innen können bzw. müssen an der Passivhauslüftungsanlage lediglich die Luftwechselgeschwindigkeit über eine Stufenschaltung regulieren. Heizen im herkömmlichen Sinne findet im Passivhaus somit nicht mehr statt; es sei denn, das Passivhaus verfügt über eine aktive ,Zusatzheizung'. Diese ist zwar nicht zwingend erforderlich, wird als zusätzliches „Komfortmerkmal“ (Architekt PH, Interview 48: 7, 292) 
mittlerweile aber häufig wieder miteingebaut, so dass für die Bewohner*innen dadurch weiterhin die Möglichkeit zur individuellen Handhabung der Wärmeversorgung vorhanden ist.

Im SmartHome wurde der Heizvorgang ebenfalls weitgehend automatisiert. Das zentrale Steuerungsgerät, der Wohnungsmanager, mit welchem alle Sensoren und Aktoren über Funk kommunizieren, ist mit dem Internet verbunden, so dass die Heizung auch aus der Ferne gesteuert werden kann. Die Bewohner*innen können bzw. müssen lediglich am Wohnungsmanager ihre Nutzungszeiten und gewünschten Raumtemperaturen eingeben. Das An- und Abschalten der Heizung sowie das rechtzeitige Vorheizen, damit bei Ankunft der Bewohner*innen die gewünschte Solltemperatur erreicht ist, wird vollständig von der Technik übernommen.

Beide Technologien sind für ihren Betrieb auf eine verlässliche Stromversorgung angewiesen. Die SmartHome-Technologie ist für die Steuerung und Wartung der Heizung aus der Ferne zusätzlich auf eine stabile und schnelle Internetverbindung angewiesen.

In den Gesprächen mit Passivhausbewohner*innen waren ,Kontrolle‘, ,Kontrollverlust' und ,Abhängigkeit von Technik' wichtige Themen. Hierbei hat sich herausgestellt, dass von einigen Bewohner*innen das weitgehend selbständige Lüften und gleichzeitige (passive) Heizen durch die Lüftungsanlage nicht vorrangig als Arbeitsabnahme und Entlastung wahrgenommen wird. Vielmehr fühlen sich einige durch diese Art des Lüftens und Heizens eher von der Technik bevormundet und fremdbestimmt. So haben diese Bewohner*innen das Gefühl, dass sie die Wärmezufuhr in ihren Wohnräumen mit der Passivhausluftheizung nicht mehr spontan und ihrem individuellen Bedarf entsprechend einstellen können, sondern dass sie sich in ihrem Wärmebedarf vielmehr den technischen Möglichkeiten des neuen Systems anpassen müssen. Dies kann bedeuten, dass sie gegebenenfalls auch einmal ein bis zwei Tage auf ausreichende, behagliche Wärme warten müssen. Insgesamt erleben sich viele Passivhausbewohner*innen nun als verstärkt abhängig von moderner, komplizierter Technik. Interessant ist, wie diese Bewohner*innen auf die Veränderungen reagiert haben und zu welchen Entwicklungen es hier gekommen ist.

In den Gesprächen mit Mieter*innen, die eine intelligente Heizungssteuerung erhalten haben, spielten die Themen ,Kontrolle', ,Einfluss' und „Mitbestimmung' eine ganz entscheidende Rolle. Hier thematisierten tatsächlich alle interviewten Bewohner*innen Gefühle und Erfahrungen des Kontrollverlustes, die sich sowohl auf die Technik selbst als auch auf die Einführung der Technik beziehen. Immer wieder wurde in den Gesprächen mit den Mieter*innen deutlich, dass die Art und Weise, wie das Pilot- 
projekt zum intelligenten Heizen grundsätzlich angelegt war und durchgeführt wurde, zu ihrer skeptischen bis ablehnenden Haltung gegenüber der Maßnahme in erheblichem Maße beigetragen hat.

Im Folgenden werden verschiedene Varianten der Veränderung von Kontrolle und Kontrollausübung im konventionellen Wohnkontext zu Kontrolle und Kontrollverlust im Passivhaus und SmartHome beschrieben. Dafür wurden exemplarisch sowohl bisher nur vorgestellte Risiken als auch bereits reelle Kontrollverlusterfahrungen und der subjektive Umgang der Beforschten mit diesen rekonstruiert.

Folgende Punkte haben sich hierbei als relevant herausgestellt:

1. Das Gefühl des Kontrollverlustes und gesteigerter Technikabhängigkeit bezieht sich auf ganz verschiedene Aspekte, wie z.B. die individuelle Regelbarkeit der Heizung, die Störanfälligkeit der Technik oder der Umgang mit persönlichen Daten

2. Der Umgang mit Kontrollverlusterfahrungen weist ein breites Spektrum auf: dieses reicht von Sich-still-Fügen, über Sich-Einbringen und/ oder moderate Kritik üben, bis hin zu Rebellion, Widerstand leisten oder Resignation

3. Auffallend unterschiedliche Deutungen neuer Technik und ihrer Einführung von Expert*innen bzw. Urheber*innen und ,gewöhnlichen“ Nutzer*innen

Im Folgenden werden die unter Punkt eins aufgezählten verschiedenen Aspekte, die für die Bewohner"innen im weitesten Sinne alle mit Kontrollverlust und gesteigerter Technikabhängigkeit im Zusammenhang stehen, zur inhaltlichen Gliederung des Kapitels verwendet.

\subsubsection{Eingeschränkte bzw. fehlende Regelbarkeit der Heizung}

Sowohl Passivhaus- als auch SmartHome-Bewohner"innen beklagen die zum Teil erheblich verzögerte Reaktionsweise ihrer Heizungen und das dadurch bedingte, nur langsame Aufheizen ihrer Wohnräume.

4.4.1.1 „Bis die [Heizung] auf das reagiert was ich gerne möchte bis dahin weiß ich schon nich mehr was ich gestern eigentlich wollte“ - Frau Lutz

Im gemeinsamen Interview mit Frau Rosental und Frau Lutz wurden die beiden alleinlebenden Rentnerinnen von der Interviewerin zunächst da- 
nach gefragt, wie sich ihrer Ansicht nach das Heizen in einem Passivhaus vom Heizen in einem konventionellen Wohngebäude unterscheidet. Während Frau Rosental auf diese Frage sofort mit dem Beschreiben von für sie spürbaren Unterschieden beginnt, äußert sich Frau Lutz hierzu zunächst nicht. Erst als die Interviewerin gezielt bei Frau Lutz nachfragt, wie sie vor dem Bezug ihrer Passivhauswohnung gewohnt und geheizt habe, erwähnt sie nur knapp, dass sie vorher in einer "normalen Etagenwohnung“ (Bewohnerin PH, Interview 59: 30, 1600) gewohnt habe. Nach einem erneuten Redebeitrag Frau Rosentals kommt auch Frau Lutz ins Erzählen. In der folgenden Passage knüpft Frau Lutz an Frau Rosentals Schilderungen an und beschreibt, wo sie deutliche Unterschiede hinsichtlich des Heizens zwischen Passivhaus und konventionellem Wohngebäude wahrnimmt:

„Und jetzt wo wir drüber sprechen merk ich natürlich es is ' $n$ Thermostat an der Heizung gewesen und den konnte man rauf- und runterstellen und dann hat die Heizung entsprechend reagiert. Und ich konnte wenn ich gelüftet hab dann hab ich die Heizung abgedreht und wenn ich wieder zugemacht hab dann hab ich sie wieder angedreht und dann war's in in nullkommanix wieder warm. Hier reagiert die Heizung ja erst am nächsten Tach@(.)@ wenn wenn ich sie höher oder weniger stelle. Und (.) da läuft das ja so nich mehr also da hab ich 'ne gleichmäßige Temperatur und alles andere kann man vergessen. Bis die auf das reagiert was ich gerne möchte bis dahin hab- weiß ich schon nich mehr was ich gestern eigentlich wollte [...] Also@(.)@ insofern das da- äh es is 'n ganz anderes (.) Gefühl. Aber gut ich kümmer' mich jetzt gar nich mehr drum und es is $21 \mathrm{Grad}$ und so is es dann." (Bewohnerin PH, Interview 59: 31, 1626-1642)

Frau Lutz betrachtet die damalige Situation in der Etagenwohnung retrospektiv mit Bezug auf den Vergleichshorizont ihrer heutigen Perspektive. In der gesamten Passage nimmt sie zwei Kontrastierungen zwischen Passivhaus und konventionellen Wohngebäuden vor, von denen sie jeweils beide Seiten ausführt. Der erste Kontrast bezieht sich auf das Reaktionsverhalten der Heizung auf von ihr getätigte Einstellungen und der zweite Kontrast betrifft die sich daraus ergebenden Raumtemperaturverhältnisse im konventionellen Wohnkontext und im Passivhaus.

Frau Lutz beginnt ihre Darstellung mit ihrem damaligen Erleben im konventionellen Wohnkontext. Aus ihrer Beschreibung geht hervor, dass sie die Raumtemperatur in ihrer früheren Etagenwohnung durch entsprechendes Drehen am jeweiligen Heizkörperthermostat raumweise regulieren konnte und die Heizung unmittelbar auf die von ihr vorgenommenen 
Einstellungen reagiert hat. Ihre Schilderung macht deutlich, dass sich ihre frühere Wohnung mit der konventionellen Heizung immer schnell erwärmen ließ.

Dem früheren Setting stellt Frau Lutz die heutige Situation im Passivhaus gegenüber. Ihrer Beschreibung lässt sich entnehmen, dass die ,Heizung' (Luftheizung) im Passivhaus mit erheblicher Verzögerung auf von ihr getätigte Einstellungen reagiert. Das Heizen im Passivhaus funktioniert demzufolge deutlich anders als Frau Lutz es gewohnt war. Offenbar lässt sich im Passivhaus die Temperatur nicht so einfach und schnell verändern wie in ihrer früheren Etagenwohnung mit konventionellen Heizkörpern und verstellbaren Thermostaten. Stattdessen gibt es nur noch eine „gleichmäßige Temperatur“ (ebd., 1634) für ihre gesamte Passivhauswohnung. Frau Lutz kann in ihrer Passivhauswohnung weder wie früher die einzelnen Räume unterschiedlich temperieren, noch lässt sich mit der Passivhaus-Luftheizung die Temperatur spontan und dem individuellen Bedarf entsprechend regulieren. Dies lässt die Schlussfolgerung zu, dass Frau Lutz die Raumtemperaturverhältnisse in ihrer aktuellen Passivhauswohnung insgesamt nur wenig aktiv beeinflussen kann, vor allem nicht kurzfristig und gemäß ihrem situativen Bedarf. Die Schilderung verdeutlicht, dass Frau Lutz das sehr träge Reagieren der Passivhaus-(Zu-)Luftheizung auf von ihr vorgenommene Einstellungen als gravierendsten Kontrast zur Funktionsweise ihrer früheren Heizung wahrnimmt und sie sich in diesem Punkt offenbar spürbar umstellen musste. Ihre abschließende Bilanzierung zeigt aber, dass sie sich mit dem Heizsetting und den Temperaturverhältnissen im Passivhaus mittlerweile abgefunden hat und gar nicht mehr versucht, die Raumtemperatur irgendwie in ihrem Sinne zu beeinflussen. Stattdessen nimmt sie es inzwischen offenbar stoisch hin, dass es in ihrer gesamten Wohnung konstant 21 Grad Celsius sind und diese Raumtemperatur im Bereich des Behaglichen liegt.

Etwas später im Interview noch einmal auf die träge Reaktionsweise der Passivhaus-(Luft-)Heizung angesprochen, wiederholt Frau Lutz, dass sie mittlerweile dazu übergegangen ist, es bei der Grundeinstellung der Luftheizung im Passivhaus zu belassen:

„also dieses äh langsame Reagieren auf was was man an der Heizung einstellt (.) äh aber äh inzwischen verstell ich da auch nix mehr dran ich lass es einfach so wie es is und dann- ich hab keine Lust mich also ständig mit so was zu beschäftigen. [...]. Und (.) hier würde es mich nerven wenn ich dann versuche es irgendwie wärmer oder kälter zu machen und das reagiert gar nich da drauf beziehungsweise (.) äh so 
langsam dass es mich dann schon gar nich mehr interessiert." (Bewohnerin PH, Interview 59: 31, 1647-1654)

Erneut macht ihre Erklärung deutlich, dass sie sich inzwischen damit abgefunden hat, die Temperatur für ihre Passivhauswohnung nicht selbst aktiv regeln zu können. Frau Lutz hat es mittlerweile offenbar aufgegeben, die Passivhaus-Luftheizung zu bedienen, da es sie „nerven“ (ebd., 1652) würde, ständig wieder die Erfahrung zu machen, dass ihr Handeln hier ohne Wirkung bliebe oder die von ihr gewünschte Wirkung immer erst mit großer Verzögerung und damit für sie viel zu spät eintreten würde.

Als es später im Interview ausführlich um das Wohngefühl im Passivhaus geht und die Interviewerin explizit bei Frau Lutz nachfragt, was neben den bereits zuvor von ihr genannten Aspekten ,Wohlfühltemperatur und ,frische Luft' für sie noch ,Behaglichkeit' im Zusammenhang mit Wohnen und Heizen bedeutet, thematisiert sie erneut die fehlende Möglichkeit zur Temperaturregelung in ihrer Passivhauswohnung. Aus der Antwort von Frau Lutz entspinnt sich eine regelrechte Diskussion zwischen ihr und Frau Rosental über das Für und Wider des Einbaus zusätzlicher Heizkörper im Passivhaus:

Frau Lutz: [...] also äh im Prinzip würde für mich eigentlich auch dazugehören äh die Temperatur äh selber regeln zu können und ich hab das Gefühl das kann ich hier nich. So. Ich $\mathrm{mm}$ mm die Temperatur regelt mich@(.)@. So. Äh und äh wenn ich das wollte dann wär das offenbar auf ne- weiß ich nich müsste ich irgendwie (.) wie ihr also irgendwie Heizkörper einbauen oder irgend so was und- $L_{d a}$ hab ich auch keine Lust zu.

Frau Rosental: Aber du hast hast du hast $\mathrm{du}\lrcorner$ keinen dir einbauen lassen? Aber die sind doch vorgesehen (.) bei dir?

Frau Lutz: Die die Rohre sind $\mathrm{L}_{\text {vorgesehen. }}$

Frau Rosental: Ja dann lass $\lrcorner$ dir doch einen anbauen.

Frau Lutz: Ja will will ich ja gar nich.

Frau Rosental: Ja aber sind- du ka- du hast dann eher 'ne 'ne LGestaltungsmöglichkeit.

Frau Lutz: Ja ja $\lrcorner$

Frau Rosental: Also du bist dann nich so abhängig von dem- also daalso ich empfinde dafür mache ich dann wirklich hier die Tür zu. Äh und das heißt schon was wo ich irgendwie- also da dass ich dann regulieren kann dass in einem Raum das kühler is."

(Bewohnerinnen PH, Interview 59: 32f, 1716-1740) 
In dieser Sequenz wird nun deutlich, dass Frau Lutz es als Manko empfindet, die Temperatur für ihre Passivhauswohnung nicht selbst bestimmen und nach Bedarf einstellen zu können. Zu erkennen ist, dass sie sich im Hinblick auf die Temperaturverhältnisse eher als Reagierende denn als Agierende erlebt. Sie nimmt es offenbar so wahr, dass ihr von der Technik die Temperatur für ihre Wohnung weitestgehend vorgegeben wird und sie sich diesen technisch regulierten Temperaturverhältnissen dann anpassen bzw. notgedrungen fügen muss. Frau Lutz lässt an dieser Stelle offen, inwiefern sie sich von der automatisch regulierten Temperatur als beherrscht erfährt. Es lässt sich hier spekulieren, dass sie sich zum Beispiel bewusst mit ihrer Bekleidung und Schlafdecke an die Temperaturverhältnisse in ihrer Passivhauswohnung anpasst. Dass Frau Lutz nach ihrer Aussage, die Temperatur regele sie, kurz lacht und mit ihrem „So“ (ebd., 1719) noch eine Art verbales Ausrufungszeichen hinter ihre Aussage setzt, lässt darauf schließen, dass ihr durchaus bewusst ist, dass hier etwas offenbar nicht ganz richtig läuft und die Anpassung eigentlich in umgekehrter Richtung verlaufen müsste: Eigentlich wäre zu erwarten, dass sich die Temperatur entsprechend den Wünschen und Bedarfen der Bewohner*innen einstellen ließe, damit diese sich in ihrem Zuhause möglichst behaglich fühlen.

In der Argumentation skizziert Frau Lutz bereits einen Vorschlag, wie sich der Zustand dahingehend verändern ließe, dass sie die Temperatur wieder wie in ihrer früheren Wohnung für jeden ihrer Wohnräume einzeln bestimmen kann: sie müsste sich zusätzliche konventionelle Heizkörper einbauen lassen. Das zeigt, ihr ist bewusst, dass sie den von ihr als nicht ganz komfortabel empfundenen Zustand nicht zwingend ertragen muss. An dem „wie ihr“ (ebd., 1721) ist zu erkennen, dass andere Bewohner*innen des Passivhausprojekts B, einschließlich Frau Rosental, bereits über zusätzliche Heizkörper zum Dazuheizen in allen Räumen verfügen. Frau Lutz steht also eine realistische Alternative zur Verfügung. Allerdings macht ihre Schlussbemerkung wiederum deutlich, dass sie diese ,Nachrüstlösung' für sich bzw. ihre Wohnung nicht ernsthaft in Erwägung zieht. Die fehlende Option zur Temperaturregelung stellt für Frau Lutz offenbar kein dringliches oder ernsthaftes Problem dar. Zumindest scheint es sie nicht so stark zu stören, dass bei ihr der akute Wunsch vorhanden ist oder sie sich sogar gezwungen sieht, hier verändernd tätig zu werden. Diese stoische, schon leicht desinteressiert wirkende Haltung wird im weiteren Dialog mit Frau Rosental deutlich: Nachdem Frau Lutz die Möglichkeit des Einbaus zusätzlicher Heizkörper erwähnt hat, fällt ihr Frau Rosental ins Wort. Die Intonation sowie die Frage selbst machen deutlich, dass es Frau Rosental erstaunt, zu hören, dass sich Frau Lutz nicht gleich zu An- 
fang die für ihre Wohnung offenbar vorgesehenen zusätzlichen Heizkörper hat anmontieren lassen. Dem weiteren Gesprächsverlauf lässt sich entnehmen, dass Frau Lutz um diese Option weiß, sie aber offenbar nicht realisiert haben möchte. Der schnelle Wortwechsel sowie die Tatsache, dass sich Frau Rosental und Frau Lutz gegenseitig immer wieder dazwischenreden, verdeutlichen, dass die beiden Frauen in der ,Heizkörperfrage' unterschiedliche Positionen vertreten. Während Frau Lutz offenbar gut damit zurechtkommt, keine zusätzlichen Heizkörper zu haben, mit denen sie ihre Räume ergänzend heizen und unterschiedlich temperieren kann und hier offenbar für sich auch keinen Handlungsbedarf sieht, daran etwas zu ändern, scheint für Frau Rosental diese Position vollkommen unverständlich. Sie versucht Frau Lutz gegen deren Willen davon zu überzeugen, sich wenigstens jetzt noch zusätzliche Heizkörper einbauen zu lassen. Ihre stockende Redeweise lässt erkennen, dass Frau Rosental Frau Lutz' stoische Haltung in dieser Sache nicht nur nicht nachvollziehen kann, sondern offenbar auch nicht ganz ernst nimmt. Frau Rosental vermittelt hier den Eindruck, dass der freiwillige Verzicht auf zusätzliche Heizkörper eine nicht hinnehmbare und in ihren Augen unvernünftige, weil unnötige Komforteinbuße darstellt. Darüber hinaus macht Frau Rosentals Argumentation deutlich, dass sie in dem nachträglichen Einbau von Heizkörpern die adäquate und naheliegende ,Antwortreaktion' auf Frau Lutz' Beanstandungen an der Passivhaus-Heizlösung sieht.

Auffällig ist, dass Frau Rosental gar nicht auf den Einwand von Frau Lutz, keine zusätzlichen Heizkörper zu wollen, eingeht. Stattdessen fährt Frau Rosental unbeirrt fort in ihrer Argumentation. Sie redet nun mehr oder weniger an Frau Lutz vorbei und versucht diese mit Argumenten zu überzeugen, die diese offenbar gar nicht hören will. Frau Lutz hatte ihre Kritik an der Passivhaus-Heizung nie als Problem formuliert, für das sie eine Lösung wünscht oder sucht. Im Gegenteil, bereits an mehreren vorangegangenen Stellen im Interview wird deutlich, dass Frau Lutz ihre Position in der Heizkörperfrage bereits gefunden hat. So hat sie zweimal zuvor deutlich zum Ausdruck gebracht, dass sie sich inzwischen mit dem Heizsetting und den Temperaturverhältnissen im Passivhaus arrangiert habe. Für Frau Lutz ist dieses Thema mittlerweile abgeschlossen und sie möchte ganz offensichtlich nicht mehr weiter darüber diskutieren. Zwar lässt sie Frau Rosental weiterreden, erwidert auf ihre Worte aber nichts, sondern lässt das Gespräch auf diese Weise enden. Der Ablauf der Diskussion lässt vermuten, dass die beiden Frauen diese oder ähnliche Diskussionen mit ähnlicher oder gleicher Positionsverteilung schon häufiger geführt und dabei festgestellt haben, dass sie in manchen Fragen divergierender Meinung 
sind und jede an ihrer Position festhält, so dass sie hier keine Einigung finden.

\title{
4.4.1.2 „[E]s macht's die Technik es macht's jetzt der Computer“ - Frau Köhler
}

Eine ganz ähnliche Kritik am Heizsetting des Passivhauses, wie von Frau Lutz vorgebracht, zeigt sich im Interview mit Frau Köhler:

\begin{abstract}
„Also (.) wenn ich so eben denke an früher wo ich sonst gewohnt hab wo also eher noch andere Heizformen waren (.) da hatte ich mehr Einfluss dadrauf und das fand ich eher positiv. Und (.) jetzt is mir das so abgenommen. Aber gut ich kann natürlich auch sagen es is bequemer. Nur (.) ich hab dann auch weniger Einfluss drauf. Das- (.) äh weil es macht's die Technik es macht's jetzt der Computer. Und (.) äh (.) den aber- den hab ich nich im Blick und kann ihn nich im Blick haben sondern den hat nur der der von dem Computer da oben im Technikraum was versteht.“ (Bewohnerin PH, Interview 60: 19, 989-997)
\end{abstract}

Auch Frau Köhler vergleicht das Heizsetting aus ihren früheren Wohnungen mit dem Heizsetting in ihrer aktuellen Passivhauswohnung hinsichtlich der Möglichkeit, Einfluss auf den Heizvorgang zu nehmen. Und genauso wie Frau Lutz kommt sie zu dem Schluss, dass sie im Passivhaus nun deutlich weniger Kontrolle über den Heizvorgang hat. Dass Frau Köhler die früheren Settings als „eher positiv“ (ebd., 991) bewertet, lässt darauf schließen, dass sie die Entwicklung zum Heizsetting im Passivhaus als Verschlechterung empfindet. Im Gegensatz zu früher braucht Frau Köhler im Passivhaus nichts mehr selbst aktiv machen, damit ihre Wohnräume ausreichend beheizt werden.

Zwar suggeriert ihre Formulierung „ich kann natürlich auch sagen es is bequemer" (ebd., 992-993), dass sich zum neuen Heizsetting im Passivhaus theoretisch auch einfach eine andere, nicht kritische, sondern positive Haltung einnehmen lässt, nämlich, dass die digitale Lüftungsanlage den Bewohner*innen die mit Heizen verbundene Arbeit abnimmt und die Bewohner"innen somit entlastet sind. Insgesamt wird an der Passage aber deutlich, dass Frau Köhler von dieser Sichtweise selbst nicht überzeugt ist, sondern sie geht offenbar davon aus, den gestiegenen Komfort in Form von Arbeitsabnahme mit „weniger Einfluss“ (ebd., 993) auf den Heizvorgang ,bezahlt ${ }^{\star} \mathrm{zu}$ haben. Ihrer Argumentation lässt sich entnehmen, dass das Heizen in ihrer Passivhauswohnung weitestgehend automatisch, also 
über die zentrale Lüftungsanlage erfolgt, die sich in einem gesonderten Technikraum im Obergeschoss des Passivhausprojekts B befindet. Frau Köhlers Argumentation macht deutlich, dass es sich bei der Passivhaustechnologie um anspruchsvolle Technik handelt, die nicht mehr ohne weiteres von Lai"innen bedient werden kann. Wirkliche Kontrolle über den Heizvorgang (in Frau Köhlers Wohnung) hat demnach nur noch diejenige Person, die über die entsprechende Expertise verfügt, solch eine größere Passivhauslüftungsanlage zu bedienen. Das zeigt, dass in diesem Fall die Verantwortung, aber auch das entsprechende Know-how und die Kompetenz für ,richtiges' Heizen und Lüften nun nicht mehr hauptsächlich bei den Bewohner*innen liegen, sondern in Expert*innenhand übergegangen sind. Naheliegend ist, dass sich die Bewohner"innen des Passivhausprojekts B dadurch in einem wichtigen Alltagsbereich, von der ihr Wohlfühlen in ihrem Zuhause zentral abhängt, teilweise entmündigt fühlen und sie die weitgehende Automatisierung des Heiz- und Lüftungsvorgangs deshalb persönlich gar nicht als Komfortgewinn, sondern vielmehr primär als Kompetenz- und Kontrollverlust erleben. Frau Köhlers Äußerung, dass ihr das ,jetzt [...] so abgenommen“ (ebd., 991-992) sei, deutet zumindest in diese Richtung.

Im Interview mit Frau Köhlers Hausmitbewohnerinnen Frau Rosental und Frau Lutz wird deutlich, dass auch sie sich hinsichtlich der Bedingung der zentralen Lüftungsanlage über die ihre Wohnungen größtenteils beheizt sowie be- und entlüftet werden, als angewiesen auf eine"n professionelle"n Lüftungstechniker*in erleben. Mehreren Interviewstellen ist $\mathrm{zu}$ entnehmen, dass die Bewohner*innen des Passivhausprojekts B schon einmal für längere Zeit ohne professionelle Betreuung und Wartung der Lüftungsanlage auskommen mussten und derweil, wie das folgende Zitat von Frau Lutz verdeutlicht, beinahe an der Technik verzweifelt sind:

„Und ich weiß dass ich irgendwann gesacht hab ich würde nie wieder in ein Haus ziehen wo meine Atemluft abhängig is (räuspert sich) von irgend 'ner digitalen Technik. Und so war das ja. Wir hatten ja diese Kästen dann haben wir immer äh justiert immer gemessen wie viel Zuluft wie viel Abluft welche Temperatur und so das wurde- haben wir selber dann immer noch wieder nachgeguckt und so. Und äh nutzte mit unserem äh Techniker der [...] hat ja nachher überhaupt nix mehr das Haus war fertig und dann interessierte ihn das nich mehr und wenn wir unseren [Rainer] nich hätten (.) dann säßen wir ganz schön auf'm Trockenen.“ (Bewohnerin PH, Interview 59: 8, 394-407) 
Die Passage macht deutlich, dass Frau Lutz im Passivhaus den Einfluss und damit die Abhängigkeit von moderner digitaler Technik bereits als zu weitreichend empfindet. Für sie haben sich durch die Passivhaustechnik die ursprünglich relativ einfachen Vorgänge des Heizens und Lüftens unnötig und übertrieben verkompliziert. Vorher verliefen diese Vorgänge relativ unvermittelt, konnte sie direkt und ihrem Bedarf entsprechend heizen und lüften. Nun hängt der Lüftungsvorgang von zahlreichen komplizierten Messungen und feinsten Einstellungen ab und wird weitestgehend automatisch gesteuert. Als Lai"in - in diesem Fall die Passivhausbewohner*innen - scheint man mit der Betreuung der Lüftungsanlage vollkommen überfordert zu sein und für eine adäquate Bedienung und Wartung der Anlage befarf es offenbar einer Fachkraft, also eines bzw. einer erfahrenen Lüftungstechniker*in. Aus Frau Lutz' Schilderung geht hervor, dass der ursprünglich für die Lüftungsanlage verantwortliche Techniker die Baugruppe direkt nach der Fertigstellung des Passivhauses (Anfang der 2000er Jahre) im Stich gelassen hat. Nach dem notgedrungenen Versuch, den Betrieb und die Kontrolle der Anlage vorübergehend selbst zu übernehmen, sind die Bewohner"innen des Passivhausprojekts B nun erleichtert, in Rainer, einem nachträglich in das Wohnprojekt eingezogenen Energietechniker, nun wieder einen kompetenten Ansprechpartner für die Lüftungsanlage gefunden zu haben. Allerdings wird ebenso deutlich, dass die Bewohner*innen nun wiederum abhängig von einer Person, einem Experten sind und nicht mehr wie früher im konventionellen Wohnkontext das alltägliche Heizen und Lüften mehr oder weniger selbst in der Hand haben.

Ganz ähnliche Erfahrungen mit einer träge reagierenden Heizung und des Kontrollverlustes über den Heizvorgang an die Technik, machen auch die SmartHome-Bewohner*innen, wie unter anderem der Fall des Herrn Martens zeigt.

\subsubsection{3 „Also ich sag ja mit dem Scheiß bin ich absolut unzufrieden“- Herr Martens}

Im Interview mit Herrn Martens wird eine weitere Variante der Verkomplizierung des Heizens und dadurch empfundenem Kontrollverlust deutlich: Für Herrn Martens war das Heizen bisher eine selbstverständliche und unscheinbare Aktivität, die keine Probleme aufwarf und deshalb auch kein Interesse erregte. Durch die neue zentrale Steuerungstechnik ist für ihn das Heizen zum Problem geworden. 
Herr Martens ist über 60 Jahre alt und bereits verrentet. Er ist gesundheitlich stark angeschlagen, ist ledig und lebt alleine. Das Interview findet bei Herrn Martens im Wohnzimmer statt.

Wie Frau Huber, deren Fall in Kapitel 4.1.2.1 ausführlich dargestellt wurde, hat auch Herr Martens wenig begeistert auf die Entscheidung der Wohnungsbaugenossenschaft reagiert, seine Wohnung mit einer intelligenten Heizungssteuerung auszustatten. Für Herrn Martens kam die Umgestaltungsmaßnahme zu einem schlechten Zeitpunkt: Herr Martens ist seit längerer Zeit gesundheitlich stark angeschlagen und als die Informationsveranstaltung zum Pilotprojekt stattfand, war er kurz zuvor von seiner Rehabilitationskur zurückgekehrt. Er erzählt, sich von den Baumaßnahmen regelrecht überrumpelt gefühlt zu haben.

Vor der Maßnahme hat Herr Martens für sich keinen Bedarf gesehen, an der Heizungstechnik etwas zu verändern. Er erzählt, bereits vorher auf einen sparsamen Betrieb der Heizung geachtet zu haben, weshalb er hier für sich kein weiteres Optimierungs- bzw. Einsparpotenzial mehr sah. Darüber hinaus hielt er das vorherige Heizungssystem mit manuell regelbaren Thermostaten an jedem Heizkörper für einfach zu handhaben und gut zu kontrollieren, wie an folgenden zwei Aussagen deutlich wird:

„Und vorher habe ich den einfach aufgedreht. Und innerhalb von zehn Minuten Viertelstunde war das Zimmer warm." (Bewohner SH, Interview 76: 7, 345-346)

„[...] vorher habe ich ausgedreht. Und dann wusste ich das ist aus.“ (ebd: 16, 834-835)

Herr Martens hatte bisher keine Probleme mit der Heizung. Er berichtet, seine vorherige unsanierte und schlecht wärmegedämmte Wohnung zu akzeptablen Heizkosten immer ausreichend beheizt zu haben, was er als Begründung anführt, bislang nicht groß über das Heizen nachgedacht zu haben.

Vor diesem Hintergrund fällt die Beurteilung der neuen Heizlösung bei Herrn Martens ähnlich kritisch aus wie bei Frau Huber (vgl. Kapitel 4.1.2.1).

Herr Martens ist unzufrieden mit der neuen Steuerungstechnik. Er stört sich vor allem an der optischen Ausgestaltung der neuen Heizlösung, und er bemängelt die Funktionsweise der neuen Technik. Inwiefern beides miteinander zusammenhängt und wie Herr Martens im Kleinen aktiv Widerstand gegen die Maßnahmen in seiner Wohnung leistet, wird in den folgenden drei längeren Interviewausschnitten deutlich. Die erste Passage 
bezieht sich auf das verzögerte Reagieren seiner Heizung nach Einbau der neuen Steuerungstechnik:

Interviewerin JM: Ähm sind Sie denn zufrieden mit dieser Art von Steuerung oder?

Herr Martens: Nee insgesamt nicht weil äh das zeitverzögert teilweise kommt.

Interviewerin JM: Mhm. Können Sie mir das mal erklären was das heißt zeitverzögert- also-?

Herr Martens: Dann sitze ich hier schon mal zwanzig Minuten fass' die Heizung an obwohl ich da [am Wohnungsmanager, JM] angeschaltet hab. Und die ist immer noch kalt. [...]. Und vorher habe ich den einfach aufgedreht. Und innerhalb von zehn Minuten Viertelstunde war das Zimmer warm. Und hier sitze ich erst mal zwanzig Minuten rum und es passiert nichts. ${ }^{. "}$

(Bewohner SH, Interview 76: 7, 329-347)

Diese Sequenz macht deutlich, dass Herr Martens die neue Heizungssteuerung insgesamt als hinderlich und als Verkomplizierung des Heizens wahrnimmt.

Herr Martens kontrastiert die neue Zentralsteuerung mit der Regelung seiner Heizung vor dem Einbau der neuen Technik: Während das alte Heizungssystem in der Regel sehr schnell auf Einstellungen reagiert und dementsprechend geheizt hat, hat er mit dem neuen System die Erfahrung gemacht, dass die Heizung zum Anlaufen deutlich länger als früher braucht und die Heizkörper erst deutlich später oder gar nicht warm werden.

Deutlich wird hier eine bei Herrn Martens vorhandene Erwartungshaltung: die Erwartung besteht darin, dass das Aufdrehen der Heizkörperthermostatventile zeitnah zum Erwärmen des Zimmers führt. Diese Erwartung überträgt Herr Martens auf das neue System, bei dem er allerdings enttäuscht wird. Hier hat er nun die Erfahrung gemacht, dass die Heizung auch nach längerem Warten nicht erwartungsgemäß funktioniert. Mittels haptischer Heizkörperüberprüfung hat er festgestellt, dass beim neuen System die Heizung offenbar nicht mehr auf seine Handlung reagiert.

An dieser Passage wird deutlich, dass Heizen durch die neue Technik, besser gesagt, aufgrund des nicht adäquaten Funktionierens der neuen Technik, für Herrn Martens zum offensichtlichen Problem geworden ist. Ohne die Steuerungstechnik lief das Heizen bequem und ganz ohne Schwierigkeiten ab, so dass Herr Martens dieses nicht bewusst wahrgenommen hat. Erst seitdem bei ihm die Wärmeversorgung bisweilen fehl- 
schlägt, ist er auf den Vorgang des Heizens verstärkt aufmerksam geworden und befasst sich zwangsläufig damit.

Im weiteren Verlauf des Interviews wird deutlich, dass Herr Martens sich bereits mehrmals bei der zuständigen Servicestelle des Technikanbieters wegen des nicht adäquaten Reagierens seiner Heizung beschwert und die Technikfirma schon mehrfach an dem (Steuerungs-) Problem gearbeitet hat. Vorher habe die Verzögerung in der Reaktionszeit noch viel größere Ausmaße gehabt, so erklärt er, durch die Bearbeitung sei die zeitliche Lücke bereits kleiner geworden. Allerdings ist Herr Martens nach wie vor unzufrieden. In seinen Augen funktioniert die neue Heizungssteuerungstechnik nicht vernünftig.

Dass das nicht ordentliche Funktionieren der neuen Technik sowie Herr Martens' Unzufriedenheit nicht nur mit der Technik selbst zusammenhängen, sondern dass er sich vor allem auch über die Einführung der Technik sowie die Art und Weise ärgert, wie sich die ausführenden Techniker ${ }^{102}$ dabei ihm gegenüber verhalten haben, wird bei Betrachtung des gesamten Interviews erkennbar.

Bereits direkt zu Beginn des Interviews bringt Herr Martens deutlich zum Ausdruck, dass er von Anfang an äußerst skeptisch gegenüber der Umrüstung auf die neue Heizungsautomatik eingestellt war. Laut Herrn Martens' eigener Darstellung hat er sich in der Folge jedoch von den Erklärungen der Technikinstallateure bezüglich der geplanten Arbeiten überzeugen lassen und in seine Teilnahme am Pilotprojekt und damit auch in die Umbaumaßnahmen in seiner Wohnung eingewilligt. Das folgende zweite Zitat verdeutlicht, wie dieser erste Kontakt mit den Technikern aus Herr Martens' Sicht abgelaufen ist:

„Die waren hier bei mir in der Wohnung äh bevor das losging haben mich gefragt. An und für sich bin ich für sowas offen okay äh Kabel sollten im Kabelschacht hochgelegt werden und das Display dann flach und alles wunderbar. Ja und wenn ich mir das jetzt anguck' diesen großen rotschwarzen Scheißkasten da und unter Putz (lacht). Jetzt haben wir durch 's ganze Treppenhaus 'nen Kabelkanal mit obendrauf

102 Die ausführenden Technikinstallateure waren männlich. Überwiegend war es nur ein hauptverantwortlicher Techniker von der am Pilotprojekt beteiligten Technikfirma; hinzu kamen während der Einbauzeit unterstützend tätige Personen, die ebenfalls ausschließlich männlich waren. Somit verwenden die beforschten Mieter*innen nicht zufällig ausschließlich die männliche Form, weshalb im Folgenden immer die männliche Form gebraucht wird, wenn von den bzw. von dem (haupt-)ausführenden Technikinstallateur(en) die Rede ist. 
solchen Riesenkästen laufen. Und das Treppenhaus war clean vorher.

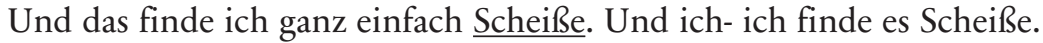
Und dadurch sehe @ich’s auch@ jeden Tag.“ (Bewohner SH, Interview 76: $1,32-41$ )

Die Passage macht deutlich, dass sich Herr Martens von der Technikfirma hinsichtlich der Umsetzung der neuen Heizlösung getäuscht sieht und die realisierte Heizlösung für ihn eine große Enttäuschung darstellt.

Der Beschreibung lässt sich entnehmen, dass die Techniker vor Beginn der Umbaumaßnahmen das persönliche Gespräch mit Herrn Martens gesucht haben. In diesem Gespräch haben sie Herrn Martens erklärt, welche Umbaumaßnahmen im Treppenhaus und in seiner Wohnung für die Installation der neuen Steuerung erforderlich sind und wie die neue Heizlösung am Ende aussehen soll. Die Schilderung macht deutlich, dass Herr Martens grundsätzlich bereit ist, sich an Maßnahmen zur Energieeinsparung zu beteiligen. Mit der von den Technikern angekündigten Lösung war Herr Martens offenbar einverstanden und er hat seine Zustimmung zu den Maßnahmen gegeben. Allerdings ist seiner Beschreibung auch zu entnehmen, dass die endgültig realisierte Heizlösung deutlich anders aussieht als er nach den von den Technikern ursprünglich gemachten Ankündigungen erwartet hatte. Die tatsächlich realisierte Heizlösung scheint praktisch das Gegenteil von dem zu sein, was die Techniker ihm gegenüber ursprünglich angekündigt haben: Statt unter Putz verlaufen die Kabel im Treppenhaus jetzt in einem großen, direkt auf der Wand angebrachten Kabelschacht, der ständig sichtbar ist, und der Wohnungsmanager hat sich offenbar ebenfalls als klobiger und insgesamt deutlich auffälliger erwiesen als Herr Martens aufgrund der Beschreibungen der Techniker eigentlich erwartet hatte. An der Kontrastierung von dem, was die Techniker ihm vorher gesagt haben und dem, was letztendlich herausgekommen ist, sowie an seinem ironischen Lachen zwischendurch, wird deutlich, dass Herr Martens das tatsächliche Resultat, die gestalterische Umsetzung des neuen Systems, als einen Wortbruch durch die Techniker wahrnimmt. Herr Martens ist verärgert über die seinem Empfinden nach unansehnliche Ausführung der Bauarbeiten und die nun bei ihm eingebaute Technik, die er als optische Verunstaltung seiner ursprünglich ordentlichen Wohnung ansieht.

An anderer Stelle im Interview erklärt Herr Martens, dass er seine Einwilligung zum Einbau in seiner Wohnung nicht gegeben hätte, wenn er im Vorhinein gewusst hätte, wie die Techniker die Installation der neuen Heizungssteuerung in der Praxis wirklich umsetzen. Stattdessen hätte er sich der Maßnahme verweigert - so wie es sein eine Etage unter ihm woh- 
nender Wohnungsnachbar und guter Bekannter als einziger im gesamten Wohnprojekt getan hat. Insgesamt wird an seinen Schilderungen deutlich, dass Herr Martens in der gesamten Umsetzung der neuen Heizlösung durch die Technikfirma im Nachhinein eine komplette Bestätigung für seine anfänglich eher skeptisch-verhaltene Haltung gegenüber dem Pilotprojekt sieht.

Seine Wortwahl und Intonation machen deutlich, dass ihn die Angelegenheit aufregt und er die gestalterische Umsetzung der Heizlösung als regelrechte optische Verschandelung wahrnimmt, die er nun ertragen muss und an die er zudem, da nicht zu übersehen, ständig erinnert wird. Auch im weiteren Verlauf des Interviews kommt Herr Martens immer wieder auf das seinem Empfinden nach unpassende und schlechte Aussehen des Wohnungsmanagers zu sprechen. Daraus lässt sich schließen, dass für Herrn Martens das Aussehen der neuen Technik von zentraler Bedeutung ist. Seine Zufrieden- bzw. Unzufriedenheit mit der ,Optik ' der neuen Steuerungstechnik sowie die Tatsache, dass er darüber keine Kontrolle hatte, beeinflussen wesentlich seine Beurteilung der gesamten Heizlösung.

Vor diesem Hintergrund ist verständlich, dass Herr Martens während des Interviewgesprächs immer wieder auf das Thema der optischen Ausgestaltung der neuen Heizlösung zu sprechen kommt, so auch, als es noch einmal um das verzögerte Reagieren seiner Heizung im Wohnzimmer und die möglichen Gründe dafür geht.

Auf die konkrete Nachfrage, woran es liegen könnte, dass seine Heizung manchmal nicht oder mit einer gewissen Verzögerung auf seine Einstellungen reagiere und ob der Technikanbieter ihm dazu eine Erklärung geliefert habe, entspinnt sich ein längerer Dialog zwischen Herr Martens und der Interviewerin. In der folgenden dritten Passage berichtet Herr Martens von der ganzen Problematik rund um die Platzierung der Raumtemperaturfühler in seinen Wohnräumen und den Verhandlungen, die er diesbezüglich mit den Technikinstallateuren geführt hat:

Interviewerin JM: Und wissen Sie woran das liegt? Hat der [Techniker, $\mathrm{JM}]$ irgendwas gesagt also?

Herr Martens: Ich nehme an das liegt an den Fühlern bis die die Befehle geben äh da haben die ja auch noch dran rumgedoktert. Ich meine bei mir sitzt das Ding hier hinter der Tür. Die haben das da erst direkt über- über 'm äh Lichtschalter angebracht. Das fand ich $\underline{\text { Scheiße. }}$ Interviewerin JM: Sie wollen das nicht alles so sichtbar haben? Herr Martens: Eben. Und da habe ich gesagt: ,Wo kann man das denn sonst anbringen?' ,Ja hinter der Tür'. Dann haben die die Wand noch gestrichen weil der Kleber der hat- war da dran- äh 
Interviewerin JM: Ah das haben Sie aber gemacht dass sie Ihnen @das wieder hergestellt@ haben?

Herr Martens: Ja ja das-

Interviewerin JM: Haben Sie auch drauf@bestanden@?

Herr Martens: Ja.

Interviewerin JM: Ja das kann ich verstehen.

Herr Martens: [...] Äh im $\underline{\text { Bad }}$ ist der auch nicht da wo er war. Der hängt jetzt hinten an der Seite unter so 'nem kleinen Schrank. Das ist alles okay. In der Küche ging 's nicht anders. Da hängt das Ding noch dadrüber. Ich weiß nicht wie man das Ding da oben anbringen kann. Ich finde das scheiße von der Optik her.

Interviewerin JM: Ja vor allen Dingen wenn-wenn Sie das schon nicht so schön finden so wie das aussieht. Und dann kommen jetzt immer mehr Sachen die dann dazu gehören dann-

Herr Martens: Eben was kommt denn als Nächstes? Und nee.

Interviewerin JM: Hat er denn gesagt dass das damit zusammenhängt dass das hinter der Tür ist?

Herr Martens: Äh wahrscheinlich ja weil dahinter ein Wärmestau ist eigentlich. Und dann- weil die bleibt eigentlich immer auf. Dann muss ich die ein bisschen hin und her bewegen und das geht. Aber dann müssen sie (.) vernünftiges Material besorgen was dann auch so funktioniert finde ich."

(Bewohner SH, Interview 76: 7f, 360-405)

Diese längere Gesprächssequenz macht deutlich, dass Herr Martens die Funktionsweise der einzelnen Komponenten des neuen Heizungssteuerungssystems verstanden hat und er deswegen auch weiß, dass es weder am verwendeten technischen Material noch an dem geänderten Sitz des Raumtemperaturfühlers liegt, dass seine Heizung verspätet auf von ihm vorgenommene Einstellungen reagiert. Ihm ist durchaus bewusst, dass das langsame Reagieren seiner Heizung im Wohnzimmer vor allem mit seiner präferierten Praxis, die Zimmertür permanent geöffnet zu haben, zu tun hat. Dennoch kritisiert Herr Martens das Vorgehen der Techniker und moniert die schlechte Qualität des technischen Materials.

In der Passage kommt zum Ausdruck, dass Herr Martens es nicht toleriert hat, dass die Techniker bei der Platzierung der Sensoren, die die Raumtemperatur erfassen und an den Wohnungsmanager übermitteln, nach eigenem Ermessen verfahren. Hier hat er sich diesmal dem geplanten Vorgehen der Techniker widersetzt. Anstatt die hier für alle Wohnungen gleichermaßen vorgesehene Standardlösung zu akzeptieren, die darin besteht, dass der Raumtemperaturfühler immer direkt über dem Lichtschal- 
ter neben der Tür platziert wird, hat Herr Martens sich dafür eingesetzt, dass in seinen Räumen die Sensoren - da, wo möglich - nicht ganz so offen sichtbar installiert werden. Deutlich wird, dass er mit seinem Ansinnen teilweise erfolgreich war. Demnach sieht die Ausgestaltung der Heizlösung bei ihm anders aus als vom Technikanbieter ursprünglich geplant: statt über dem Lichtschalter ist bei ihm der Temperatursensor im Wohnzimmer an der (der Heizung gegenüberliegenden) Wand, im Bereich hinter der nach innen zu öffnenden Tür angebracht. Das heißt, wenn die Zimmertür offen steht, wird der Sensor von der Tür verdeckt.

Der abschließende Teil der Passage macht deutlich, dass Herr Martens die Wohnzimmertür in der Regel permanent weit geöffnet stehen hat. Die offenstehende Tür aber verhindert, dass die Luft im gesamten Raum frei zirkulieren kann. Stattdessen wirkt die Tür wie eine Barriere, was dazu führt, dass sich ein Teil der Luft hinter der Tür ansammelt, wodurch hier ein Wärmestau entsteht. Das heißt, der hinter der geöffneten Tür befindliche Sensor erfasst nicht mehr die tatsächliche Raumtemperatur, sondern ermittelt nur die Temperatur für den Bereich hinter der Tür, die tendenziell etwas höher liegt als die Temperatur der restlichen Raumluft und übermittelt diesen ,falschen' Wert dann an den Wohnungsmanager. Dementsprechend geht auch der Wohnungsmanager von einer höheren als der eigentlich im Gesamtraum vorhandenen Temperatur aus und reguliert folglich die Heizung etwas herunter. Weil die Software für den Raum hinter der Tür eine geringere Differenz zwischen Soll- und Ist-Temperatur feststellt, wird die Heizung dementsprechend langsamer hochgefahren oder gegebenenfalls sogar gar nicht angeschaltet.

Der Passage lässt sich entnehmen, dass Herr Martens dennoch die Technikmonteure für das nicht korrekte Funktionieren der Sensoren verantwortlich macht. Die Formulierung „dran rumgedoktert“ (ebd.:7, 364) macht deutlich, dass er das Vorgehen der Techniker abschätzig beurteilt. Erkennbar wird hier, dass er den Technikern, die Experten für das neue System sein sollten, vorwirft, in Wirklichkeit gar keine Ahnung zu haben, wie sie dieses Problem ernsthaft bewerkstelligen können und nur vorgeben, nach einer Lösung zu suchen, aber eigentlich nur planlos irgendetwas ausprobieren würden. Seinen Anteil am Zustandekommen der nun nicht richtig funktionierenden Heizlösung sieht er lediglich darin, seinen Unmut über die offene Sichtbarkeit des Sensors kundgetan und deshalb eine Änderung gewünscht zu haben. Die Schilderung des Gesprächsverlaufs macht deutlich, dass der Alternativvorschlag offenbar vom ausführenden Techniker kam: Herr Martens gibt an, auf seine Frage, wo der Sensor gegebenenfalls noch fixiert werden könne, die Antwort „Ja hinter der Tür““ 
(ebd., 372) erhalten zu haben. Das zeigt, dass die Techniker ihm den Platz hinter der Tür als realistische Option präsentiert haben. Herr Martens erwähnt hier nicht, dass die Techniker auf mögliche Nachteile der Umgestaltung hingewiesen haben, was darauf schließen lässt, dass die Techniker zu diesem Zeitpunkt darin keine Beeinträchtigungen für das einwandfreie Operieren des Systems gesehen oder vermutet haben. Herr Martens hat diese Möglichkeit vor allem deshalb gewählt, weil der neue Vorschlag seinem expliziten Wunsch, die einzelnen technischen Bauteile der Heizungssteuerung nicht so auffällig und direkt sichtbar installiert zu haben, eher entspricht.

Hier zeigt sich erneut eine Orientierung an ,Raumoptik ${ }^{6}$ und ,Raumgestaltung' sowie ,Ordentlichkeit'. Die Beanstandung der Sichtbarkeit des kleinen Sensors, die Veranlassung seiner Umsetzung und das anschließende Bestehen auf Ausbesserung des Wandanstrichs - all das macht deutlich, dass Herr Martens bei der optischen Gestaltung seiner Wohnräume viel Wert auf akkurates Aussehen legt und er deshalb auf jedes kleine Detail achtet.

Das anscheinend unproblematische Umsetzen des Sensors wie auch die Beseitigung des optischen Schadens, der offenbar beim Ablösen des Sensors durch den hartnäckigen Kleber am Wandanstrich entstanden ist, dokumentieren das Bemühen des Technikdienstleisters, den Bedürfnissen der Bewohner"innen möglichst gerecht zu werden und ordentliche Arbeit zu leisten.

Deutlich wird, dass für den ordentlichen Betrieb des Steuerungssystems erforderlich ist, dass die Sensoren in den Räumen möglichst offen hängen, damit sie die Raumtemperatur korrekt erfassen können. Der Wunsch des Nutzers besteht hingegen darin, dass die Technik möglichst nicht sichtbar ist. Beides in optimaler Weise gleichzeitig zu erreichen, ist praktisch unmöglich. Daraus lässt sich ableiten, dass die Erfordernisse des Systems nicht bzw. nur begrenzt kompatibel mit den Wünschen des Nutzers sind und beides - in diesem Fall - nicht in Einklang zu bringen ist.

Aus der Passage geht hervor, dass die Technikmonteure bei der Umsetzung der Heizlösung bereits auf Herrn Martens eingegangen sind, und dort, wo es möglich war, wurde seinem Wunsch, die Sensoren eher versteckt anzubringen, entsprochen: Auch im Badezimmer wurde durch die Techniker der Sensor umgesetzt. Lediglich in der Küche musste der Sensor über dem Lichtschalter hängen bleiben, weil es hier offenbar keine Alternative gab. Offenbar wurde aber keine technische Lösung dafür gefunden, wie die Sensoren die Raumtemperatur auch dann korrekt ermitteln (können), wenn sie nicht permanent offen empfänglich, sondern zeitweise et- 
wa von der Zimmertür verdeckt sind. Wenn Herr Martens weiterhin auf die dauerhaft geöffnete Tür besteht, muss er sich dafür bis zu einem gewissen Grad den Erfordernissen des Systems beugen und sich stattdessen hinsichtlich des Heizens der neuen Technik anpassen: So hat er die Wahl, entweder darauf zu achten, dass er die Wohnzimmertür geschlossen hält, damit die Luft im Raum frei zirkulieren kann und der Sensor die korrekte Raumtemperatur erfasst. Oder er bedient sich einer Behelfsmaßnahme, indem er immer mal wieder die Tür hin und her bewegt und auf diesem Wege dafür sorgt, dass sich die hinter der Tür gestaute Warmluft wieder mit der restlichen Raumluft vermengt, woraufhin der Sensor wieder die tatsächliche Raumtemperatur, und nicht nur die meist höher liegende Temperatur hinter der Tür, ermitteln kann.

Die Beschreibung zeigt, dass dieser Trick bzw. diese ,Notlösung' zwar funktioniert und das System dann offenbar korrekt arbeitet. Gleichzeitig kommt hier klar zum Ausdruck, dass Herr Martens es eigentlich nicht akzeptabel findet, dass er nun durch sein Verhalten ausgleichen soll, was die Technik nicht zu leisten vermag.

$\mathrm{Da}$ es sich bei der fehlerhaften Messung der Sensoren und der dadurch verzögerten Antwort seiner Heizung eindeutig um Probleme handelt, die erst mit dem Einsatz der neuen Steuerungstechnik aufgetaucht sind, hier also ganz offensichtlich ein Zusammenhang besteht, und Herr Martens diese neue Technik nicht gewünscht hat, fühlt er sich auch nicht verpflichtet, zum Gelingen des neuen Heizansatzes beizutragen, etwa indem er sich zu kleinen Verhaltensanpassungen bereit zeigt. Die vorangegangenen Passagen haben verdeutlicht, dass Herr Martens der festen Überzeugung ist, dass ihm die neue Technik , angedreht' wurde, wobei seitens der Techniker falsche Angaben gemacht wurden. Daher scheint er weder gewillt noch bereit zu sein, sich kompromissbereit oder kooperativ zu zeigen. Im Gegenteil, aus der letzten Passage geht deutlich hervor, wie unkooperativ er sich den Technikern gegenüber in den Verhandlungen um die Platzierung der Raumsensoren verhalten hat. Mit all ihren Bemühungen, die Heizlösung so weit wie möglich seinen Wünschen entsprechend auszugestalten, hat Herr Martens die Techniker mehr oder weniger , auflaufen lassen'. Hieran zeigt sich noch einmal, dass er die Bringschuld und Verantwortung eindeutig beim Technikanbieter sieht. Dessen Aufgabe sei es, für den störungsfreien Betrieb der von ihm verbauten Geräte zu sorgen und bei Anwendungsproblemen oder besonderen Nutzer*innenwünschen gegebenenfalls nach einer neuen technischen Lösung zu suchen. Kurz gesagt: Nicht der bzw. die Nutzer"in soll sich umstellen oder in seinem bzw. ihrem Verhalten anpassen (müssen), sondern die Technik bzw. der gesam- 
te neue Heizansatz sind an die Nutzer*innenpräferenzen zu adaptieren insbesondere, wenn der Wunsch nach Neuerung bzw. Veränderung nicht primär von den Nutzer"innen ausgeht. Offenbar begreift Herr Martens die Verhandlungen mit den Technikern um die Implementierung der neuen Heizlösung in seiner Wohnung auch als eine Art ,Machtkampf', bei dem es darum geht, wer sich letztendlich durchsetzt, die ,Spielregeln' bestimmt und damit den ,Spielverlauf kontrolliert.

Darüber hinaus macht die letzte längere Sequenz insgesamt deutlich, dass Herr Martens die neue Steuerungstechnik nicht nur als massiven Eingriff in seine raumgestalterische Freiheit erlebt, sondern dass er sie als regelrechte Zumutung begreift. Die neue Technik stellt für Herrn Martens insofern eine Zumutung dar, als sie ihm abverlangt, dass er sich beim Heizen bzw. seiner sonstigen Praxis (Wohnzimmertür dauerhaft geöffnet lassen) auf sie einstellt. Es geht Herrn Martens offenbar darum, sich dieser Kontrolle, die er als übergriffige Fremdbestimmung wahrnimmt, zu widersetzen. Dass sich sein Widerstand dabei vorrangig in der Interaktion mit den Technikinstallateuren entlädt, hängt damit zusammen, dass die Techniker im Pilotprojekt diejenigen gewesen sind, die - zumindest in der Startphase - den engsten Kontakt zu den Mieter*innen gehabt haben. Vor allem während der Anlaufzeit des Projekts waren die Techniker ständig vor Ort, zunächst, um die neue Heizungsautomatik in allen Haushalten zu installieren und das ganze System erstmalig einzustellen, später dann, um erste Probleme zu beheben, Reparaturen und Korrekturen vorzunehmen und das System regelmäßig zu warten. Zudem war der Technikanbieter während der gesamten Projektlaufzeit bei Beschwerden und Problemen mit der neuen Heizungssteuerung der erste Ansprechpartner für die Mieter"innen. $\mathrm{Zu}$ diesem Zweck wurde vom Anbieter eine 24-Stunden-Servicehotline eingerichtet.

Für den Fall, dass die Komplikationen beim Heizen mit der neuen Steuerung weiter anhalten und Herr Martens nicht weiter bereit ist, dies zu dulden, hat er für sich eine alternative Lösung ersonnen. Er plant, das System dann eigenmächtig rückzubauen, so dass er seine Heizung danach wieder wie früher manuell über ein verstellbares Thermostat direkt an den Heizkörpern regulieren kann:

„Ich hab nämlich (2) zwei Regler die habe ich mir gekauft genau die die hier dran waren. Und dann schraube ich die da wieder dran. Dann kann das Andere da dran bleiben und das auch weil die benutze ich sowieso nicht. Und dann regele ich das wieder ganz normal. Das das geht mir auf den Sack.“ (Bewohner SH, Interview 76: 9, 455-460) 
4.4.2 Erlebte Störfälle und das daraus resultierende Gefühl zunehmender Technikabhängigkeit

Auch bei anderen SmartHome-Bewohner*innen sind bereits größere Probleme mit dem neuen Heizungssteuerungssystem aufgetreten, die sie nun eine sehr weitreichende Abhängigkeit von Technik beim Heizen haben spüren lassen. Hier ist der Fall Frau Fiedlers interessant, der verdeutlicht, wie hilf- und machtlos Nutzer"innen einer weitgehend automatisch funktionierenden Technik insbesondere bei gravierenden Störfällen gegenüberstehen.

\subsubsection{1 „[M]an ist halt jetzt auch so von dieser Technik so abhängig“ - Frau Fiedler}

Frau Fiedler ist Mitte 30, verheiratet und hat zwei Kinder. Der Sohn der Fiedlers ist knapp vier Jahre und die Tochter ist erst wenige Monate alt. Frau Fiedler ist zum Zeitpunkt des Interviews nicht erwerbstätig, sondern befindet sich in Elternzeit. Die Familie Fiedler lebt in einer Dreizimmerwohnung; das Interview mit Frau Fiedler findet im Wohnzimmer statt.

Für Frau Fiedler hat sich mit Verwendung der neuen automatischen Heizungssteuerung nicht nur der Komfort, sondern auch die Abhängigkeit von dieser Technik erhöht. Frau Fiedler bewertet die neue Technik „im Großen und Ganzen [...] schon positiv" (Bewohnerin SH, Interview 73: 1, 52). Sie findet es ,praktisch“ (ebd.: 1, 53), dass nun die Technik die Regulierung der Heizung übernimmt und sie selbst kaum mehr aktiv etwas dafür tun muss, damit ihre Wohnräume angenehm beheizt werden. Als Kehrseite dieser Veränderung sieht sie allerdings, dass sie jetzt deutlich weniger Einfluss als vorher auf den Heizvorgang in den einzelnen Wohnräumen nehmen kann, da die Heizung nun nicht mehr direkt manuell über die einzelnen Heizkörperthermostate zu regulieren ist. Mit dem neuen System lässt sich die Heizung bzw. lassen sich die einzelnen Heizkörper nur noch vom zentralen Wohnungsmanager aus ansteuern und einstellen. Die Adaptation der Heizkurve erledigt das System voll automatisch. Das heißt, die selbstlernende und selbstoptimierende Regelungstechnik ist in der Lage zu bestimmen, wann mit der Beheizung der Wohnräume begonnen werden muss, um zur eingestellten Uhrzeit die gewünschte Raumtemperatur zu erreichen. Die Nutzer“innen müssen dafür lediglich ihre Nutzungszeiten und Wunschtemperaturen eingeben, alles Weitere erledigt die Technik von selbst. 
Allerdings habe sich bereits gezeigt, so berichtet Frau Fiedler, dass das neue Steuerungssystem bei großen und raschen Temperaturumschwüngen immer „so 'n bisschen nachhäng[t] " (ebd.: 2, 58f) und die selbstlernende Technik es hier nicht schaffe, die Beheizung den veränderten Temperaturverhältnissen unverzüglich optimal anzupassen. Hingegen habe sie, so Frau Fiedler weiter, mit der vorherigen manuellen Heizungsregelung auf plötzliche große Temperaturschwankungen immer sofort reagieren können, indem sie die Heizung durch einfaches Drehen am jeweiligen Heizkörperthermostat situativ und ihrem individuellen Bedarf entsprechend höher oder niedriger gestellt habe.

Im weiteren Verlauf des Interviews erzählt Frau Fiedler von einem sich kürzlich ereigneten besonderen Vorfall, bei dem ihr Sohn beim Spielen unabsichtlich die Steuerungsautomatik eines Heizkörpers beschädigt habe. Dieser kleine ,Unfall' hat ihr offenbar bewusst gemacht, dass für sie die Technisierung bzw. Automatisierung des Heizvorgangs nicht nur Vorteile bedeutet. Die folgende Passage macht deutlich, dass für Frau Fiedler mit dem Zugewinn an Komfort, den sie in Form von Arbeitsabnahme durch die neue Steuerungstechnik erlebt, gleichzeitig auch ein deutlicher Verlust an individueller, unmittelbarer Kontrollmöglichkeit einhergeht:

„[...] das haben wir schon gemerkt dass es so 'n bisschen (1) man ist halt jetzt auch so von dieser Technik so abhängig. Also uns ist unser Sohn ist gegen einen (.) einen dieser Thermostate mal gegen gelaufen und das ist sofort abgebrochen also die sind super sensibel (1) und dann bollert die Heizung einfach die (.) die pumpt einfach nur heißes Wasser also das- man kann es dann überhaupt nicht mehr regulieren dann sind wir nachts noch zum- also abends spät abends noch zum Baumarkt gefahren und haben so 'n einfaches Thermostat erstmal gekauft um die Heizung auszumachen aber man ist dann halt sehr von der Technik abhängig so." (Bewohnerin SH, Interview 73: 2, 77-88)

Der Beschreibung lässt sich entnehmen, dass sich der kleine ,Unfall' offenbar beim normalen kindlichen Bewegen bzw. Spiel in der Wohnung ereignet hat. Frau Fiedlers Schilderung macht deutlich, dass sich die Wärmeabgabe der einzelnen Heizkörper ohne den mit dem Wohnungsmanager per Funk verbundenen Thermostatkopf nicht mehr regulieren lässt. Demzufolge war das Thermostatventil nach dem Abbrechen des Thermostatkopfes wie ,verhakt': hier offenbar in der Einstellung, voll geöffnet', also maximales Heizen. Beim neuen zentralen Steuerungssystem gibt es nun nicht mehr die Möglichkeit, die Heizung manuell herunterzuregeln. Hieran ist zu erkennen, dass die Fiedlers in dem Moment, als einer der neuen Funk- 
stellantriebe defekt war, die Heizung nicht mehr regulieren konnten und somit der neuen Regelungstechnik hilflos ausgeliefert waren.

An anderer Stelle im Interview wird deutlich, dass sich dieser Vorfall am Abend ereignet hat. Frau Fiedler berichtet, dass zu diesem Zeitpunkt das Hausmeisterbüro schon nicht mehr besetzt und auch von der Genossenschaft niemand mehr zu erreichen gewesen sei. Weiter erzählt sie, dass vom Technikanbieter für solche Fälle eine 24-Stunden-Notfallhotline eingerichtet wurde, dieser Telefonanschluss an dem betreffenden Abend aber nicht zu erreichen gewesen sei. Das zeigt, dass die Fiedlers bereits damals wussten, was in einer solchen Problemsituation konkret zu tun ist bzw. an wen sie sich bei technischen Problemen mit der neuen Heizungssteuerung wenden können. Zunächst haben sich die Fiedlers um professionelle Hilfe bemüht, was jedoch erfolglos blieb. Somit standen die Fiedlers mit ihrem akuten technischen Problem vollkommen alleine da. Hier liegt die Vermutung nahe, dass sie sich in dem Moment sowohl von ihrer Genossenschaft als auch vom Technikanbieter im Stich gelassen fühlten.

Die Passage verdeutlicht, dass die Fiedlers - offenbar aus dieser Not heraus - noch am selben Abend selbst aktiv eine Notlösung gefunden haben. Deutlich wird, dass diese Handlung der Fiedlers aufwendig und umständlich war. In dieser Situation hat ihnen die Technik, die das Heizen eigentlich erleichtern bzw. komfortabler machen soll, einen deutlichen zusätzlichen Arbeitsaufwand beschert. Eine andere, einfachere Lösung für ihr Problem scheint es in der damaligen Situation nicht gegeben zu haben.

Etwas später im Gesprächsverlauf, als die Interviewerin bei Frau Fiedler explizit nach bereits aufgetretenen Schwierigkeiten mit dem neuen System fragt, kommt sie noch einmal auf den Vorfall mit dem abgebrochenen Thermostat zu sprechen. Hier erzählt sie nun, wie es nach ihrer selbstorganisierten ,Behelfslösung' mit der defekten Heizungssteuerungstechnik weitergegangen ist:

„[...] und dann is halt der Hausmeister gekommen und musste (.) dann von der [Technikfirma] so 'n neues Thermostat anbringen und das einpr-programmieren und dieses Programmieren hat ewig gedauert weil das System irgendwie diesen einzelnen Thermostat- äh -regler dann nich erkannt hat und der (.) Hausmeister hat auch 'rumgeflucht und hat wie wild auf diesem Touchpad rumgehauen@(.)@ also irgendwie: ähm schien er schon öfters mal Probleme gehabt zu haben." (Bewohnerin SH, Interview 73: 8, 420-429)

Frau Fiedlers Darstellung der weiteren Ereignisse lässt erkennen, dass der Technikanbieter sich zwar darum gekümmert hat, dass die Fiedlers zügig 
ein neues funktionsfähiges Heizkörperthermostat erhalten. Allerdings musste die Montage und Neueinrichtung des Thermostats offenbar der vor Ort für die Wohnanlage zuständige Hausmeister erledigen, der jedoch kein Experte für die neue Heizungssteuerungstechnik ist. Ihrer Schilderung lässt sich entnehmen, dass die Neueinrichtung und Programmierung des ausgewechselten Thermostats keineswegs problemlos verlief, sondern den Hausmeister erhebliche Mühe und Zeit gekostet hat. Frau Fiedlers Beschreibung seines Verhaltens macht deutlich, dass sich der Hausmeister in der Situation stark aufgeregt und über die neue Technik geärgert hat, weil diese offenbar nicht so funktionierte, wie sie eigentlich funktionieren sollte. Das Nicht-Funktionieren der Technik hat den Hausmeister offenbar so sehr in Rage gebracht, dass er gegenüber dem Wohnungsmanager aggressiv geworden ist. Aus dem Verhalten des Hausmeisters lässt sich ableiten, dass er in diesem Moment relativ rat- und auch machtlos vor der Technik stand. Dem Anschein nach hat er sich an diesem Punkt der intelligenten Technik in gewisser Hinsicht ausgeliefert gefühlt.

Dadurch, dass auch der Hausmeister große Schwierigkeiten damit hatte, das scheinbar kleine Problem des nicht mehr steuerungsfähigen Heizungsstellantriebs zu beheben, sieht sich Frau Fiedler offenbar in ihrer Wahrnehmung bestätigt, dass das neue System insbesondere für Lai"innen nicht so einfach und problemlos wie noch die frühere manuelle Regelung zu handhaben und kontrollieren ist. Deutlich wird, dass es nun vorrangig die Programmierung der elektronischen Bauteile ist, die das neue Steuerungssystem kompliziert und anfällig für Komplikationen macht.

Das von Frau Fiedler geschilderte Geschehen macht deutlich: je mehr und je umfassender einfache Vorgänge und Handgriffe automatisiert und damit an Technik delegiert werden, desto weitreichender sind die Nutzer*innen auf das weitgehend störungsfreie Funktionieren dieser Technologien angewiesen. Kommt es bei anspruchsvoller, komplexer Technik zu Problemen, so stehen für diese oftmals keine einfachen Lösungen zur Verfügung. Wie der Fall der Fiedlers verdeutlicht, gestaltet sich die Lösung des technischen Problems dann als aufwendig und kompliziert, so dass die Nutzer*innen - meist technische Lai"innen - im Schadens- oder Problemfall in der Regel kaum selbst etwas ausrichten können. Stattdessen sind sie bei jeder Schwierigkeit, und ist sie noch so klein, auf die Unterstützung eines bzw. einer fachkundigen Expert"in angewiesen. Dies kann zu der paradoxen Entwicklung führen, dass Abläufe und Vorgänge, die durch Technisierung und Automatisierung eigentlich vereinfacht werden sollen, sich aus Nutzer*innensicht hingegen verkomplizieren. Denn Nutzer*innen geben bei einer weitgehenden Automatisierung eben nicht nur Arbeit an die 
Technik ab, sondern sie verlieren damit auch einen Teil oder sogar gänzlich die Kontrolle über die betreffenden Vorgänge. Dadurch, dass die Technik Tätigkeiten wie das Heizen übernimmt, kümmern sich Nutzer*innen immer weniger selbst um diese Aktivitäten und meist versuchen sie auch gar nicht (mehr) die technischen Vorgänge, die hinter der Automatisierung stecken, zu durchdringen. Das heißt, ein ehemals vertrauter und selbstverständlicher Vorgang wie das Heizen wird den technischen Lai"innen durch den Einsatz weitgehend autonom funktionierender Technik immer weniger verständlich und immer weniger zugänglich und ist damit immer schwieriger zu handhaben. Mit dem Einsatz einer neuen automatischen Technik werden die Dinge also nicht zwangsläufig einfacher und leichter, sondern meist kommen mit der neuen Technik auch neue Herausforderungen hinzu und ergeben sich andersartige Schwierigkeiten, mit denen zuvor niemand gerechnet hat.

\subsubsection{2 „Hab ich 'n bisschen-bisschen doller gedrückt. Und dann sagte es ,Knack“" - Herr Martens}

Ein ganz ähnliches Muster in der Behandlung des Wohnungsmanagers wird im Fall des Herrn Martens deutlich. Auch Herr Martens hat schon mit mehr Kraft auf den Touchscreen des Wohnungsmanagers eingewirkt als zur Bedienung des Geräts eigentlich erforderlich und vorgesehen wäre. Im Unterschied zum relativ harm- und folgenlosen ,wilden drauf Herumgehaue' des Hausmeisters auf dem Touchpad, hat das „bisschen doller[e]" (Bewohner SH, Interview 76: 2, 61) Drücken des Herrn Martens allerdings direkt zum Zerbrechen des Displays geführt. Im Interview bringt die Nachfrage nach Schwierigkeiten bei der Installation des neuen Systems Herr Martens dazu, der Interviewerin vom Vorfall des gebrochenen Displays zu berichten:

Interviewerin JM: Also Sie sagten ja auch dass es in Ihrer Wohnung irgendwie- also dass es da Schwierigkeiten gab dass es Sie auch ein bisschen-

Herr Martens: Ja die hatten das dann noch auf- auf den Schrank verlegt den Kabelkanal also nicht nur oben durch die Wand siehst das ganz oben an der Ecke da kommt das. (1) Dann hatten die das bis zur Mitte und dann di- direkt in der Mitte vom Schrank runter gelegt. Da hab ich gesagt da-das will ich so nicht. Dann ist das erste Display gleich im Arsch gewesen. Interviewerin JM: Ja okay. 
Herr Martens: Da hab ich drauf gedrückt. Passierte nichts. Interviewerin JM: Funktionierte gar nicht?

Herr Martens: Hab ich 'n bisschen-bisschen doller gedrückt. Und dann sagte es ,Knack'. Ist das gebrochen. Also ich sag ja mit dem Scheiß bin ich absolut unzufrieden."

(Bewohner SH, Interview 76: 1f, 43-63)

Die Passage macht deutlich, dass Herr Martens das schnelle Zerbrechen des Displays bei einem seiner ersten Versuche, den Wohnungsmanager zu bedienen, als eine weitere Bestätigung seiner von Anfang an skeptisch bis ablehnenden Haltung gegenüber der Maßnahme und seiner großen Unzufriedenheit mit der neuen Technik ansieht.

Der Passage lässt sich entnehmen, dass die Technikinstallateure offenbar kurz vor dem Ereignis mit dem Display die für den Anschluss des Wohnungsmanagers notwendigen Kabel in Herrn Martens' Wohnungsflur verlegt haben. Deutlich wird, dass Herr Martens mit dieser ersten Ausführung der Kabelführung nicht einverstanden war und dies den Technikern auch deutlich mitgeteilt hat. Herr Martens sagt hier nicht, ob die Techniker auf seinen Einspruch eingegangen sind und seine Wünsche und Vorstellungen beachtet und den Kabelkanal entsprechend anders verlegt haben. Stattdessen berichtet er von dem Kaputtgehen des Displays. Es lässt sich hier spekulieren, dass es einen Zusammenhang zwischen dem Verhalten der Techniker bei den in Herr Martens' Wohnungsflur durchgeführten Kabelarbeiten und seinem Umgang mit der Technik gibt. Herr Martens' Schilderung lässt sich hier nur entnehmen, dass die Displayanzeige des Wohnungsmanagers auf sein erstes ,normales' Drücken auf den Touchscreen nicht reagiert hat und er sich dadurch veranlasst sah, mit ein wenig mehr Kraftaufwand auf den Bildschirm zu drücken. Durch dieses „bisschen doller[e]“ (ebd.: 2, 61) Drücken sei das Display gleich zerbrochen. Offenbar nimmt Herr Martens es so wahr, dass die Technik nicht so funktioniert, wie sie eigentlich funktionieren sollte, sondern von Anfang an versagt hat. Dass die neue Technik von ein „bisschen doller“ (ebd.) Drücken kaputtgeht, zeigt aus Herrn Martens' Sicht nur, wovon er ohnehin schon überzeugt ist, nämlich, dass die neue Technik nicht taugt.

Noch mehrmals im Interview kommt Herr Martens auf den Vorfall des zerbrochenen Displays zu sprechen. Dabei wird immer wieder deutlich, dass er den Grund für das Kaputtgehen des Touchscreens nicht in einer zu starken Druckausübung seinerseits sieht. Er lastet den Defekt alleine dem Material an bzw. er macht hier wieder - wie schon bei den nicht ordentlich arbeitenden Raumtemperaturfühlern - die für die Installation der Steuerungsanalage verantwortliche Technikfirma für seine Probleme mit 
der neuen Heizungssteuerung verantwortlich. Diese habe, so Herr Martens' Eindruck, für die neue Heizlösung im Pilotprojekt insgesamt kein vernünftiges, robustes Material verwendet, sondern ihm und den anderen Mieter"innen vielmehr minderwertige Ausschussware eingebaut. Herr Martens sieht sich durch die anfänglich gehäuft aufgetretenen technischen Probleme wie etwa mit den „Reglern“ (ebd.: 13, 673) in dieser Meinung bestätigt. Mit ,Reglern' meint er die neuen Funkstellantriebe an den einzelnen Heizkörpern, die aufgrund eines Materialfehlers in allen Wohnungen relativ zu Beginn des Projekts noch einmal ausgetauscht werden mussten. Hier zwei kurze Äußerungen von Herrn Martens, die belegen, dass er diese Deutung von minderwertigem technischen Material hat:

„Und das ist auch bei dem Ding [dem Touchpad, JM] jetzt wieder. Die Scheibe können Sie rein drücken was eigentlich meiner Meinung nach nicht sein sollte. Aber ich weiß jetzt ja ich darf da nicht so doll drücken." (Bewohner SH, Interview 76: 21, 1120-1122)

„Und (.) die mussten das ja erst mal alles wieder rausreißen was die an Reglern mir eingebaut hatten weil die schrott waren. [...]. Und also (.) ich hab das Gefühl gehabt das ist weit weg von [Hauptsitz der Technikfirma], Denen bauen wir erst mal den ganzen Schrott da rein'so hatte ich das Gefühl.“ (ebd.: 13, 677-679)

Dieses Deutungsmuster, dass die Technikfirma in jeglicher Hinsicht - bezüglich des verwendeten Materials, der technischen Ausführung sowie der Betreuung, des Umgangs und der Kommunikation mit den von der Maßnahme betroffenen Mieter*innen - in dem Pilotprojekt keine zufriedenstellende Arbeit abgeliefert hat, zieht sich wie ein roter Faden durch das gesamte Interview mit Herrn Martens.

\subsubsection{3 „Und da hab ich gedacht wir sind komplett abhängig“- Herr Frings}

Von deutlich größeren, zum Teil bereits erlebten Störfällen im Zusammenhang mit moderner Heizungs- und Lüftungstechnik und einer dadurch neuerdings verstärkt empfundenen Technikabhängigkeit berichtet Herr Frings, ein Bewohner des Passivhausprojekts D.

Zum Zeitpunkt des Interviews wohnt die fünfköpfige Familie Frings bereits seit ungefähr zweieinhalb Jahren in ihrer Passivhaus-Eigentumswohnung. Vorher haben die Frings' in einer klassischen Altbauwohnung gewohnt. 
Als es im Interview um Unterschiede beim Heizen zwischen Passivhaus und konventionellem Wohngebäude geht, kommt Herr Frings nach und nach auf die umfangreiche moderne Technik zu sprechen, die in dem Passivhausprojekt D verbaut wurde. Hierbei wird deutlich, dass er sich im Vergleich zu früher im Altbau, in seinem heutigen Passivhausneubau stark abhängig von moderner, komplexer Technik fühlt.

Herr Frings thematisiert als erstes die Lüftung und erklärt, dass sich im Übergang zum Passivhaus die deutlichsten Veränderungen bei seiner Lüftungspraxis ergeben hätten. Früher habe er im Sommer fast durchgehend die Fenster offen stehen gehabt; das mache er im Passivhaus jetzt viel weniger, eigentlich kaum mehr. Anfangs habe er deshalb das Gefühl gehabt, „wie in ein[em] Käfig zu wohnen“" (Bewohner PH, Interview 66: 21, 1070), mittlerweile habe er sich aber an die automatisch kontrollierte Be- und Entlüftung der Wohnräume über eine Lüftungsanlage gewöhnt und empfinde die reglementierte Fensteröffnung(spraxis) als keine große Einschränkung mehr.

Als die Interviewerin bei Herrn Frings nachfragt, ob es für ihn darüber hinaus noch weitere Dinge gebe, die im Passivhaus spürbar anders verlaufen als in konventionellen Wohnkontexten, erklärt er:

Herr Frings: (2) Ja also es läuft schon anders (.) Ich meine dass wir- was wir auch so manchmal mit den andern Nachbarn so besprochen haben (.) also nich nur wegen Passivhaus wir haben auch unten haben Sie auch schon gesehen diese Heizkraftwerk- oder (.) so was woInterviewerin JM: Das kleine äh Zuhause-Kraftwerk? Herr Frings: Genau. [...].“

(Bewohner PH, Interview 66: 22, 1103-1110)

Der Passage lässt sich entnehmen, dass Herr Frings bei Unterschieden zwischen Passivhaus und konventionellem Wohngebäude nicht nur an die typischen Spezifika des Passivhauses, wie zum Beispiel die Lüftung denkt. Seine Argumentation verdeutlicht, dass er in seinen Überlegungen ganz konkret von dem eigenen Mehrparteien-Wohnprojekt ausgeht. So macht Herr Frings im Folgenden Aussagen darüber, wodurch sich für ihn das eigene Projekt von konventionellen Wohngebäuden unterscheidet. Deutlich wird, dass Herr Frings das kleine Blockheizkraftwerk, das im Keller des Passivhausprojekts D steht und der Strom- und Wärmeversorgung des gesamten Hauses dient, als eine Besonderheit seines Passivhauses begreift.

Das Passivhausprojekt D verfügt über ein eigenes kleines erdgasbetriebenes Blockheizkraftwerk, ein so genanntes ,Zuhause-Kraftwerk', das den ge- 
samten Gebäudekomplex mit elektrischer Energie und Wärme versorgt. ${ }^{103}$ Das Zuhause-Kraftwerk arbeitet nach dem so genannten ,Schwarmstromkonzept $^{6}$. Bei diesem entsteht ein virtuelles Großkraftwerk dadurch, dass viele kleine Kraftwerke zu einem großen Kraftwerk vernetzt werden. Die einzelnen Einheiten, also die kleinen Zuhause-Kraftwerke werden dabei zentral vom Energieversorger per Mobilfunk gesteuert und produzieren sowohl Strom als auch Wärme. Die Wärme wird vor Ort gespeichert und eingesetzt. Der Strom wird, sofern er nicht lokal genutzt wird, in das öffentliche Stromnetz eingespeist. Ist der Wärmespeicher für Heizung und Warmwasser einer Einheit voll, so ruft die Zentrale von dieser Einheit erst dann wieder Strom ab, wenn weitere Wärme verbraucht worden ist und somit wieder Kapazitäten vorhanden sind, sodass neue Energie gespeichert werden kann. ${ }^{104}$

Gleich im Anschluss fährt Herr Frings argumentierend fort und zählt weitere Dinge auf, die in dem Passivhausneubau spürbar anders verlaufen als er es von vorherigen konventionellen Wohnkontexten her gewohnt ist:

„Oder diese Anlage in dem (.) Parkplatz. (.) Das sind schon einige Sachen die sehr technisch sind. Und natürlich hat man schon- (.) So wie gestern Abend ich fand ja hier is das Licht komplett ausgefallen im ganzen Viertel. Da hab ich auch gedacht also jetzt kommt man mit dem Auto nich raus (.) Äh diese ganze Lüftung funktionier- [Interviewerin JM: Strom komplett?] Ja es gab kein Strom. Also ich hab auch gekuckt nirgendswo im Treppenhaus nix das war nich nur unsere Wohnung sondern überall. Und da hab ich gedacht wir sind komplett abhängig (.) oder viel mehr abhängig als so im Passivhaus [meint Altbau, JM] gut da ha- hatte man die Heizung die die war durch Gas und das fällt nich so schnell aus. (1) Und hier hat man schon de- oder als diese paar Tage diese Anlage ausfiel da hat man auch schon gemerkt okay da is was (.) wenn es kaputt geht muss man sofort reagieren also weil da: is (1) is es schon: (1) das Gefühl dass man in- mit viel mehr Technik lebt.“" (Bewohner PH, Interview 66: 22, 1110-1126)

103 Die Umsetzung der Idee des Zuhause-Kraftwerks geht u. a. auf ein Energieversorgungsunternehmen zurück. Dieses hat das Zuhause-Kraftwerk für den Betrieb bei der Liegenschaft installiert, wobei das Kraftwerk aber im Besitz des Unternehmens blieb.

104 Vgl. de.wikipedia.org, Artikel zum Thema ,Zuhause-Kraftwerk', zuletzt aktualisiert am 17.05.2018, zuletzt geprüft am 10.08.2018. 
In dieser Passage geht es nun um Unterschiede im Grad der Technisierung und Automatisierung zwischen modernem Neubau (hier Passivhaus) und klassischem Altbau und darum, wie eine zunehmende Technisierung des Alltags gleichzeitig auch zu einer immer größeren Angewiesenheit der Menschen auf diese assistierende Technik für die Bewältigung ihres Alltags führt.

Herr Frings vergleicht die allgemeine technische Ausstattung und speziell das Heiz-Setting seiner heutigen modernen Passivhauswohnung mit dem technischen Heiz-Setting seiner früheren Altbauwohnung. Seine Beschreibung verdeutlicht, dass er den Alltag im modernen Passivhaus als stark von Technik bestimmt erlebt. Deutlich wird, dass sich Herr Frings heute im modernen Passivhaus als stark abhängig von moderner elektronischer Technik erlebt, was gleichzeitig bedeutet, ständig auf eine stabile Energieversorgung angewiesen zu sein.

Neben dem Zuhause-Kraftwerk und der im Interview bereits mehrfach von ihm erwähnten Lüftungsanlage dient Herr Frings die zum Passivhausprojekt D gehörige Parkplatzanlage ${ }^{105}$ als ein weiteres Beispiel dafür, von wieviel moderner, anspruchsvoller Technik er sich aktuell in seinem Passivhaus umgeben sieht. Seiner Beschreibung lässt sich entnehmen, dass es sich bei der erwähnten Parkplatzanlage ebenfalls um ein technisch hochmodernes System handelt, das für seinen Betrieb genauso wie die Lüftungsanlage des Passivhauses auf eine gesicherte Versorgung mit elektrischer Energie (Strom) angewiesen ist.

Darüber hinaus berichtet Herr Frings in dieser Passage von einem Stromausfall, der sich offenbar am Vorabend des Interviewgesprächs in der gesamten Wohngegend ereignet hat. Offenbar hat sich Herr Frings durch diesen ,Störfall' noch einmal wieder daran erinnert gesehen, von wieviel elektronisch betriebener Technik sie als Bewohner*innen des Passivhausprojekts $\mathrm{D}$ gegenwärtig in ihrem Alltag umgeben und damit abhängig sind. Dadurch, dass im modernen Neubau mittlerweile so viele Aktivitäten automatisch gesteuert und ausgeführt werden, hat bereits solch ein kurzer Stromausfall, wie die Bewohner*innen ihn am Vorabend erlebt haben, deutliche Auswirkungen auf die normale Alltagsbewältigung. Herrn Frings hat dieser kleine Stromausfall deutlich die eigene Vulnerabilität gerade im modernen Neubau vor Augen geführt.

105 Bei der Parkanlage im Kellergeschoss des Passivhauses handelt sich um ein automatisches Parksystem, bei dem auf elektrischen Hebeflächen, ähnlich einem Fahrstuhl, jeweils zwei Autos übereinander geparkt werden können. 
Sein spontaner erster Eindruck, in seinem heutigen modernen Passivhaus „komplett abhängig“ (ebd., 1120) von Technik zu sein, relativiert sich für ihn wieder ein wenig dadurch, dass er sich bewusst macht, dass er und dies bringt Herrn Frings auch sprachlich zum Ausdruck - die heutige Situation im Passivhaus-Neubau vor dem Hintergrund seiner früheren Erfahrungen in der klassischen Altbauwohnung bewertet. Hieran ist zu erkennen, dass Herr Frings zwei Extreme miteinander vergleicht: den modernen, voll komfortabel ausgestatteten Neubau mit dem einfachen, unsanierten und damit wenig komfortablen Altbau. Seiner Beschreibung lässt sich entnehmen, dass es in seiner früheren Altbauwohnung bereits moderne Heiztechnik gab: die Wohnung war mit einer modernen Gaszentralheizung ausgestattet. Allerdings wird an seinem Gesagten auch deutlich, dass er eine gasbetriebene Heizungsanlage für eher wenig störanfällig hält. Herr Frings führt hier nur eine Seite des Kontrasts zwischen Neubau bzw. Passivhaus und Altbau aus, nämlich die des Altbaus. Hier bleibt implizit, dass im Passivhaus die unbedingt erforderliche und als primäre ,Heizung fungierende Lüftungsanlage mit Wärmerückgewinnung im Vergleich zu einer konventionellen Heizung für ihren Betrieb auf die Versorgung mit Strom angewiesen ist. Diese Abhängigkeit von elektrischem Strom lässt die Passivhaus-Lüftungsanlage in Herrn Frings' Augen deutlich störanfälliger als eine konventionelle, stromunabhängige Heizungsanlage erscheinen.

Nach einer kurzen Pause springt Herr Frings thematisch und spricht nun wieder über die Abhängigkeit von moderner, meist elektrischer Technik im Passivhaus. Hier erwähnt er nun, dass es im Passivhausprojekt D schon einmal einen länger andauernden Ausfall der Lüftungsanlage gab. Dieser Ausfall liegt offenbar schon länger zurück. Im Gespräch über die Heizungs- und Lüftungstechnik sowie über den sich gerade erst am Vortag des Interviews ereigneten Stromausfall erinnert sich Herr Frings nun an dieses besondere ,Krisen-Erlebnis` zurück. Seiner Argumentation lässt sich entnehmen, dass die Lüftungsanlage damals nicht nur kurz, sondern gleich für mehrere Tage ausgefallen war, was für die Bewohner*innen eine unangenehme Erfahrung bedeutete. Es lässt sich hier spekulieren, dass Herr Frings bei dem größeren Stromausfall am Vorabend kurzzeitig die Sorge befallen hat, dass sich der, Worst Case', ein längerer Totalausfall des Lüftungssystems, noch einmal wiederholen könnte.

Herr Frings führt seine Begründung, weshalb sofort zu handeln ist, wenn die Lüftungsanlage im Passivhaus aufgrund eines Defekts ausfällt, nicht zu Ende aus. Allerdings ist klar, dass sich in einem normalerweise vollständig automatisch be- und entlüfteten Wohngebäude die Luftqualität in den Wohnräumen rapide verschlechtert, wenn die Lüftungsanlage 
über einen längeren Zeitraum ausfällt. Darüber hinaus handelt es sich bei dem Passivhausprojekt D um ein Mehrfamilienhaus mit knapp 20 Wohneinheiten. Das heißt, die zentrale Lüftungsanlage regelt den Luftaustausch für den gesamten Gebäudekomplex. Solch ein technisch anspruchsvolles und hocheffizientes System ist in seiner Leistung demnach nicht durch manuelle Fensterlüftung ersetzbar.

Deutlich wird, dass Herrn Frings bereits mit diesem ersten Ausfall der Lüftungsanlage bewusst geworden ist, wieviel Technik im Vergleich zu einem konventionellen (unsanierten) Altbau in einem modernen Neubau wie dem Passivhaus steckt. Damit geht einher, dass die Bewohner*innen eines Neubaus im Gegensatz zu den Bewohner*innen eines Altbaus in ihrem normalen Alltag gleichwohl sehr viel mehr von solch modernen technischen Systemen und deren einwandfreiem Funktionieren abhängen.

Da Herr Frings in dieser Passage alle bewertenden Einwürfe abbricht und sich auch im restlichen Interview keine aussagekräftigen Stellen finden, die belegen, wie er die Zunahme in der Technikabhängigkeit von Altzu Neubau bewertet, muss offen bleiben, ob er zu dieser Entwicklung überhaupt eine eindeutige Haltung einnimmt. Seine recht moderate Beschreibung der Unterschiede zwischen Alt- und Neubau hinsichtlich der Technikabhängigkeit deutet eher darauf hin, dass er diese Entwicklung als ,normal' und nicht ungewöhnlich ansieht. Offenbar geht er davon aus, dass der zunehmende Einsatz von Technik immer sowohl Vor- als auch Nachteile bedeutet.

\subsubsection{4 „Wir sind halt so 'n bisschen Versuchstiere und müssen mal gucken wie wir damit klarkommen" - Frau Fiedler}

Dass sich einige der SmartHome-Bewohner*innen von Anfang an darüber bewusst waren, dass insbesondere die erste reale Erprobung einer neuen Technologie im Feld meistens nicht problemlos verläuft, sondern mit einer gewissen potenziellen Unsicherheit und Misserfolgswahrscheinlichkeit verbunden ist und dies für die in den Pilotversuch involvierten Nutzer*innen dann wiederum bedeuten kann, in dem Technikeinsatzbereich plötzlich mit ganz neuen, zuvor niemals erlebten Problemen konfrontiert zu sein, macht der Fall Frau Fiedlers deutlich. Trotz Begeisterung, als Testhaushalt am Pilotprojekt zum intelligenten Heizen beteiligt zu sein, hat Frau Fiedler offenbar sofort auch an die möglichen Nachteile einer Teilnahme an solch einem ersten Testlauf gedacht. Dass sie dem Projekt bzw. der Teilnahme ihres Haushalts am Pilotprojekt ambivalent gegenüber- 
steht, ist an ihrer Antwort auf die Frage zu erkennen, wie sie das Zustandekommen der Entscheidung über ihre Teilnahme an dem Pilotprojekt zum intelligenten Heizen bewertet:

„Also eig- einerseits hey cool dass es uns getroffen hat wir dürfen sowas Neues ähm mitkriegen. Andererseits dann halt so- so Pilotprojekte sind halt auch immer Erprobungen man weiß immer nich' was schief läuft und was gut läuft und sind halt- $[\ldots]$ Wir sind halt so 'n bisschen Versuchstiere und müssen mal gucken wie wir damit klarkommen so.“ (Bewohnerin SH, Interview 73: 11, 577-583)

Frau Fiedlers Antwort lässt sich entnehmen, dass sie auf der einen Seite zwar erfreut darüber ist, dass ausgerechnet ihr Haushalt zur Teilnahme ausgewählt wurde und dadurch die Möglichkeit erhält, an der Erprobung einer neuen, möglicherweise zukunftsweisenden Technologie beteiligt zu sein. Auf der anderen Seite ist sich Frau Fiedler aber auch des besonderen Charakters solcher Großversuche bzw. Demonstrationsprojekte bewusst, nämlich, dass diese ersten größeren Testläufe immer auch gewisse Risiken bergen, wie zum Beispiel, dass adressierte Probleme nicht gelöst, sondern eher noch weiter verschärft werden oder dass der Versuch in Gänze scheitert, da sein Verlauf und Ausgang vorher nicht genau vorherzusehen sind. Um die Rolle der am Pilotprojekt beteiligten Miethaushalte zu beschreiben, verwendet Frau Fiedler hier die Metapher der „Versuchstiere“ (ebd., 582). ${ }^{106}$ Deutlich wird, dass Frau Fiedler Parallelen zwischen Versuchstieren und den am Pilotprojekt beteiligten Miethaushalten sieht. So wurde sowohl die Entscheidung, ein Pilotprojekt zum intelligenten Heizen durchzuführen, als auch die Entscheidung darüber, welche Miethaushalte in das Projekt einbezogen werden sollen, alleine von der Projektleitung (der Genossenschaft in Kooperation mit der Technikfirma sowie dem Energieversorger) und ohne Beteiligung der betroffenen Miethaushalte getroffen. Ähnlich wie Tiere für wissenschaftliche Experimente (Tierversuche) wurden auch die Haushalte nach bestimmten Kriterien, also aufgrund ihrer besonderen Eignung für die Teilnahme am Pilotprojekt von der Projektleitung ausgewählt. Und obwohl die Mieter*innen - vergleichbar den Tieren in Tierversuchen - die Hauptbetroffenen und im Fall ernster Schwierigkeiten auch die Hauptleidtragenden der Veränderungsmaßnahme sind, wurden sie in den Planungs- und Entscheidungsprozess nicht

106 Vor allem in der medizinischen, der Arzneimittel- und der Kosmetikforschung werden wissenschaftliche Experimente an bzw. mit lebenden Tieren durchgeführt. 
miteinbezogen. Die betroffenen Miethaushalte hatten hier keinerlei Mitsprache- oder Mitbestimmungsrecht, konnten die Teilnahme aber auch nicht verweigern, sondern es wurde über sie bestimmt und sie mussten sich der Entscheidung ihrer Genossenschaft als Vermieterin fügen. Die betroffenen Miethaushalte sind von den Projektleiter*innen erst nach Beschluss des Projekts, einige Wochen vor Beginn der Einbaumaßnahmen darüber informiert worden, was sie mit der Teilnahme an dem Pilotversuch genau erwartet.

Versuchstiere werden typischerweise nicht wie fühlende und denkende Lebewesen mit eigener Würde, sondern mehr wie nützliche Objekte behandelt. Die verwendeten Tiere werden von den Versuchsleiter"innen gewissermaßen als Mittel zum Zweck betrachtet. Mit ihnen wird experimentiert bzw. an ihnen wird etwas getestet, von dem man nicht sicher weiß, ob und wie es den Tieren letztendlich bekommt bzw. wie sie auf die Maßnahmen reagieren.

Auch über die für das Pilotprojekt ausgewählten Mithaushalte wurde von den Projektverantwortlichen in gewisser Hinsicht verfügt. Allerdings hat man in diesem Fall unterstellt, dass die Interventionsmaßnahme den Mieter*innen selbst zugutekommt. Für das Projekt wurden die ausgewählten Miethaushalte kurz vor Beginn der Heizperiode mit einer neuen intelligenten Heizungssteuerungstechnik ausgestattet, die Entwickler"innen und Fachleute zwar schon für technisch weit ausgereift halten, von der man aber noch nicht genau weiß, ob und wie praxistauglich und benutzer*innenfreundlich sie tatsächlich ist. Um derlei Fragen zu klären, werden im Allgemeinen solche Feldexperimente durchgeführt. Für die Betroffenen bedeutet das allerdings, dass während dieses Testlaufs viel Unerwartetes passieren kann, dass sie sich auf einmal vor neue Herausforderungen gestellt oder sich plötzlich mit unangenehmen oder problematischen Entwicklungen konfrontiert sehen und „dann gucken [müssen] wie [sie] damit klarkommen“ (ebd., 582-583). Denn anders als ,klassische' Tierversuche, die in der Regel im Forschungslabor unter streng kontrollierten Bedingungen durchgeführt werden, findet ein Feldexperiment nicht in einem speziellen Untersuchungsraum bzw. Labor statt, sondern im natürlichen Umfeld. Demensprechend lassen sich die Rahmenbedingungen und der Ablauf eines Feldversuchs auch nicht vollends kontrollieren. Insbesondere die beteiligten Versuchsobjekte bzw. -personen können das Feldexperiment in erheblicher und unerwarteter Weise beeinflussen, da ihr Handeln und Reagieren in der Regel schwer zu antizipieren ist. Das Handeln und Reagieren der Versuchspersonen stellt in den meisten Fällen das Forschungs- und Erkenntnisinteresse der Versuchsleitung dar. So geht es auch 
im Pilotprojekt zum intelligenten Heizen wesentlich darum, wie die neue Technik von den Nutzer*innen aufgenommen wird und wie sie im Alltag mit ihr praktisch zurechtkommen.

An welche möglichen größeren Probleme und Schwierigkeiten Frau Fiedler bei der nun aktuell an ihnen erprobten intelligenten Heizungssteuerungstechnik denkt, wird deutlich, als die Interviewerin sie konkret auf ihre Bedenken bezüglich des neuen Systems anspricht. Danach gefragt, ob sie die Befürchtung habe, dass mit der neuen Heizungsautomatik während der winterlichen Testphase etwas schiefgehen könnte, erzählt Frau Fiedler, dass sie tatsächlich schon an solch ein absolutes ,Worst-Case'-Szenario wie den Totalausfall des zentralen Gebäudesteuerungssystems gedacht und sie den Techniker bei der Installation auch direkt darauf angesprochen habe, was in diesem Fall mit ihrer Wärmeversorgung passieren würde:

"Also ich hab auch den Installateur damals gefragt was is eigentlich wenn mal das Internet ausfällt oder dieses ganze System und es gibt da wohl so 'ne Sicherheitsabregelung dass ähm (1) die Temperatur nicht unter $18 \mathrm{Grad}$ oder so fallen darf aber also die haben- ich ich vertrau schon dadrauf dass die von der [Technikfirma] oder auch von der [Genossenschaft] da ähm jetzt nich im kalten Sitzen lassen aber das is schon so 'n bisschen naja man muss halt doch der Technik sehr vertrauen is schon so 'n bisschen komisch." (Bewohnerin SH, Interview 73: 11f, 591-601)

In dieser Passage berichtet Frau Fiedler davon, welche Erklärung sie vom Technikinstallateur auf ihre Frage nach einem möglichen Totalausfall des Systems erhalten hat, wobei deutlich wird, dass sie diese Erklärung der technischen Absicherung in ihren Befürchtungen nicht ganz beruhigt hat.

Der Passage ist zu entnehmen, dass Frau Fiedler vor allem in der Internetbasierung des neuen Systems ein erhöhtes Störanfälligkeitsrisiko sieht. Sie macht sich grundsätzlich Gedanken darüber, ob die Wärmeversorgung sichergestellt ist, wenn es zu größeren Störungen im Betrieb der neuen Heizungsautomatik kommt und die Kontrolle über den Heizvorgang dann nicht mehr vorrangig bei den Bewohner*innen, sondern bei dem neuen computergesteuerten System und dessen Administrator*innen liegt.

Aus ihrer Darstellung geht hervor, dass das neue Heizungssteuerungssystem offenbar durch eine spezielle Regelung bzw. Programmierung des Technikherstellers gegen solche Krisen- und Worst-Case-Fälle wie einen Abbruch der Internetverbindung oder einen Totalabsturz des Systems abgesichert ist. Für solche Fälle hat der Technikhersteller als Mindesttempe- 
ratur eine Raumtemperatur von 18 Grad Celsius festgelegt. Auf diesem Wege soll ein zu starkes Auskühlen der Räume (etwa durch einen Ausfall der zentralen Heizungssteuerung auf Ebene des Gesamtgebäudes) vermieden werden. Allerdings liegt eine durchschnittliche Raumtemperatur von 18 Grad bezogen auf Wohnräume schon nicht mehr im Bereich des Behaglichen. Dementsprechend ist diese Information, dass die Raumtemperatur im Winter nicht unter $18 \mathrm{Grad}$ fallen kann, wenig geeignet für Mieter*innen, die sich ernsthaft sorgen, mit dem neuen System ihre Wohnräume im Winter nicht ausreichend erwärmen zu können, da deren Befürchtungen von mangelnder Behaglichkeit damit nicht widerlegt oder als gänzlich unbegründet ausgeräumt werden können.

Frau Fiedlers anschließende, leicht stockend vorgetragene Äußerung „ich ich vertrau schon dadrauf [...]“ (ebd.: 12, 595-596) wirkt wie eine Art Formel zur Selbstberuhigung, was deutlich macht, dass sie die Erklärung der für den Notfall einprogrammierten „Sicherheitsabregelung“ (ebd., 593) des Technikinstallateurs nicht beruhigt hat. Hieraus lässt sich ableiten, dass Frau Fiedler für sich einfach beschlossen hat, sich mit diesen Fragen zu Absicherung und Sicherheit nicht mehr weiter zu beschäftigen, sondern diese Fragen und Themen den Expert*innen zu überlassen. Offenbar geht sie davon aus, beim neuen System selbst kaum noch etwas ausrichten bzw. kontrollieren zu können. Ihre Argumentation zeigt, dass sie deshalb die Hauptverantwortung für die neue Technik und deren störungsfreien Betrieb insbesondere bei der Technikfirma und der Wohnungsgenossenschaft sieht, also bei denjenigen, die das Projekt initiiert, umgesetzt und damit auch zu verantworten haben. Frau Fiedler suggeriert sich offenbar selbst, dass die Projektverantwortlichen und die für die Technik kompetenten Programmierer*innen bereits eine Vorstellung davon haben, welche technischen Schwierigkeiten während des Testlaufs auftreten können und was bei möglichen technischen Problemen zu tun ist. Zumindest aber, möchte sie davon ausgehen (können), dass diese die Mieter"innen in einer ,Notsituation' bezüglich des Heizens nicht alleine ihrem Schicksal überlassen. An ihrer abschließenden Bewertung „aber das is [...] is schon so 'n bisschen komisch" (ebd.: 12, 599-601) ist allerdings zu erkennen, dass Frau Fiedler weiterhin skeptisch ist. Offensichtlich fällt ihr die Gewöhnung an den Gedanken schwer, dass nun nicht mehr primär sie als Bewohnerin die Heizung kontrollieren kann, sondern der Heizvorgang jetzt hauptsächlich von der Technik geregelt wird, was zur Folge hat, dass die Bewohner*innen beim Heizen jetzt von der Technik und deren störungsfreiem Funktionieren abhängig sind. 
Insgesamt verdeutlicht diese Passage, dass mit der Digitalisierung sowie der zunehmenden Automatisierung von immer mehr Alltagstätigkeiten und -vorgängen auch die Abhängigkeit der Nutzer*innen von neuen Technologien steigt. Denn die neu eingeführten digitalen Technologien nehmen den Nutzer*innen eben nicht nur Arbeit ab, sondern in der Regel geht mit der Einführung bestimmter Technologien, geht mit der Automatisierung auch ein Großteil der Kontrolle über die entsprechenden Tätigkeiten und Vorgänge auf die Technik über. Treten dann Schwierigkeiten bei der Bedienung bzw. im Umgang mit der neuen Technik auf, so können die Nutzer*innen häufig selbst kaum etwas ausrichten, da sie meist nicht über die notwendigen Kompetenzen verfügen, die neue und aus ihrer Sicht komplexe Technik zu steuern oder zu administrieren. Die Nutzer*innen sind dann bei Problemen auf die Hilfe von kompetenten Fachkräften, meist IT-Spezialist"innen angewiesen, was bei den Betroffenen die ohnehin bereits vorhandenen Gefühle von Kontrollverlust, Ausgeliefertsein und zunehmender Fremdbestimmung oft noch verstärkt.

Darüber hinaus deutet sich in dieser Passage schon in Ansätzen ein typisches und recht weit verbreitetes Muster in der Interaktion zwischen Expert"innen und Lai"innen an, das im dritten Teil dieses Kapitels zum Thema ,Datensicherheit" eine zentrale Rolle spielen wird (siehe Teilkapitel 4.4.3).

Diese kurze Passage aus dem Interview mit Frau Fiedler macht bereits deutlich, wie vollkommen unterschiedlich der Techniker als, idealtypischer' Experte und Frau Fiedler als klassische Technik-Laiin die neue Heizungssteuerungstechnik und die mit ihr verbundenen Risiken sehen und einschätzen. Während der Techniker offenbar davon ausgeht, Frau Fiedler auf ihre besorgte und leicht kritische Nachfrage zur Verlässlichkeit und Absicherung des Systems eine passende Antwort geliefert und ihre Bedenken damit ausgeräumt zu haben, verweist ihre Art der Darstellung vielmehr darauf, dass seine Erklärung ihre Bedenken bezüglich der neuen ITTechnik nicht wirklich entkräften konnte. Hieran wird erkennbar, dass der Techniker und Frau Fiedler ganz unterschiedliche Sichtweisen auf die neue smarte' Technik haben und dementsprechend alle Fragen und Themen rund um die neue Technik vollkommen unterschiedlich deuten. Der Techniker und Frau Fiedler kommen gewissermaßen aus zwei vollkommen unterschiedlichen Welten, in denen unterschiedliche ,Sprachen' gesprochen werden, in denen ganz unterschiedliche Dinge ein Problem oder Risiko darstellen und in denen mit diesen unterschiedlichen Problemen und Risiken dann wiederum ganz unterschiedlich umgegangen wird. Aufgrund dieser unterschiedlichen Anschauungs- und Handhabungsweisen 
kommt es deshalb häufig zu keiner Verständigung bzw. entstehen so häufig Missverständnisse in der Kommunikation zwischen Expert*innen und Lai*innen.

So kommt es häufig vor, dass sich die Bewohner*innen in ihren (persönlichen) Ängsten und Sorgen von den Technik-Expert*innen nicht verstanden und nicht ernst genommen fühlen, wohingegen die Expert"innen die Bedenken der Bewohner*innen eher als sachlich-technische Probleme oder rationale Einwände verstehen und auf diese Weise adressieren. Dementsprechend suchen und/oder liefern sie für die Probleme der Bewohner*innen meist handfeste technische ,Lösungen' oder sie versuchen, die Bedenken der Bewohner*innen technisch-argumentativ aufzulösen.

Diese unterschiedlichen Verstehens- und Umgangsweisen sowie die Missverständnisse und Konflikte, die sich ergeben, wenn Technik-Expert"innen bzw. -Urheber*innen und ,gewöhnliche' Nutzer*innen aufeinandertreffen, können für den Fall SmartHome sehr gut am Thema, Datenschutz' veranschaulicht und diskutiert werden, welches im Mittelpunkt des folgenden Teilkapitels steht.

\subsubsection{Sicherheitsbedenken bezüglich des Datenschutzes}

Hier werden noch einmal die Fälle Frau Fiedlers und Herrn Martens' aufgegriffen, da sich an ihnen gut aufzeigen lässt, welche unterschiedlichen Deutungen der neuen intelligenten Technik sowie ihrer Einführung Expert"innen und ,gewöhnliche“ Nutzer*innen haben, die sie in die verschiedenen Situationen und Interaktionen einbringen und welch unterschiedliche Anschauungen dabei aufeinanderprallen. Zudem machen beide Fälle deutlich, dass es Expert"innen und Nutzer*innen aufgrund ihrer unterschiedlichen Deutungen auch bei regem Austausch oftmals nicht gelingt, sich ,wirklich` zu verständigen, sondern dass sie - häufig unbewusst - die meiste Zeit aneinander vorbei kommunizieren.

4.4.3.1 „, [A]lle von der Firma [haben] Einsicht [...] das sind ja nur 20, 30 Mitarbeiter'. Da habe ich schon so gedacht, Oh das reicht mir eigentlich schon““ - Frau Fiedler

Frau Fiedler kommt auf das Thema ,Datensicherheit' zu sprechen und äußert sich ausführlich zum Umgang des Technikanbieters mit den vom System gespeicherten und übermittelten persönlichen Heiz-Daten der Bewoh- 
ner*innen, als die Interviewerin sie nach Vorbehalten und Befürchtungen gegenüber der neuen intelligenten Heizungssteuerung fragt.

Die folgende Passage macht deutlich, dass sich die Fiedlers nicht nur Gedanken darüber machen, ob firmenintern angemessen diskret und vertrauenswürdig mit ihren persönlichen Heiz-Daten, also den eingespeicherten und an den Technikanbieter übermittelten Heizprofilen umgegangen wird, sondern offenbar halten sie auch einen "Hackerangriff ${ }^{\star}$ von außen auf das System für eine realistische Gefahr, bei dem die sensiblen Daten von Kriminellen entwendet werden und auf diese Weise in falsche Hände geraten:

„Also das Einzige wo wir immer noch so ' $\mathrm{n}$ bisschen kritisch sind ähm es is ja so dass dieses Heizsystem- du kannst ja ähm speichern ok wir sind jetzt bis 16 Uhr oder so nich da oder auch wenn man im Urlaub ist ok wir sind die nächsten Wochen nicht da und diese Daten werden ja an die [Technikfirma] geschickt und alle Mitarbeiter der Firma haben Einsicht darein sprich alle wissen genau wann ist Familie Fiedler nicht da und wann kommen die wieder und ich finde das ist irgendwie so 'ne Sicherheitslücke die (.) äh nicht optimal ist weil ähm (1) man schon Vertrauen in die Firma haben muss dass die Daten irgendwie nich irgendwie missbrauchen oder weitergeben weil- [...] so ist halt irgendwie für jeden ersichtlich ob man da is oder nich. Das finde ich ist irgendwie- und es gibt bestimmt also wenn dieses System ausgeweitet wird da wird's bestimmt irgendwelche Leute geben die sich in dieses das is so 'ne Art W-LAN-System die sich da irgendwie 'reinhacken und dann die Daten 'rauslesen können also das finde ich so 'n bisschen- (1) schwierig." (Bewohnerin SH, Interview 73: 3, 123-145)

Die Passage macht deutlich, dass Frau Fiedler eine missbräuchliche Verwendung der vom neuen System digital gespeicherten und elektronisch via Internetverbindung an den Technikanbieter übermittelten Heiz-Daten der Bewohner*innen befürchtet. Vor allem sieht sie eine Gefahr darin, dass die einprogrammierten Heizprofile die persönlichen Heizgewohnheiten der Mieter"innen offenlegen und von diesen dann auch leicht auf die individuellen An- und Abwesenheitszeiten geschlossen werden kann, bzw. zum großen Teil sind An- und Abwesenheit der Bewohner*innen sogar direkt aus den Daten ersichtlich. Zwar thematisiert Frau Fiedler die Gefahr von Wohnungseinbrüchen mit keinem Wort, aber bei dem von ihr Gesagten ist naheliegend, dass sie beim Datenmissbrauch vor allem auch an mögliche Wohnungseinbrüche denkt. 
Der Passage lässt sich entnehmen, dass Frau Fiedler in erster Linie eine missbräuchliche Nutzung ihrer Daten durch Kriminelle befürchtet. An anderer Stelle im Interview wird deutlich, dass Frau Fiedler auch eine eventuell ,legale' (Weiter-)Verwendung der Heiz-Daten bereits bedenklich findet, etwa durch Vermieter*innen, die ihren Mieter*innen damit ,falsches ${ }^{6}$ Heizoder Lüftungsverhalten versuchen nachzuweisen, dass sie diese Art der Datenverwendung allerdings für durchaus realistisch hält. Frau Fiedler zufolge sind die Daten demnach nicht nur für Kriminelle interessant, sondern sie könnten auch bei anderen Personengruppen wie zum Beispiel bei Vermieter*innen (im Fall von Miet-Streitigkeiten) neue Begehrlichkeiten wecken.

An ihrer Bewertung wird deutlich, dass Frau Fiedler es bereits bedenklich findet, dass alle Mitarbeiter*innen der Technikfirma, die ja praktisch alle schon Fremde für die Bewohner*innen sind, freien Zugang und vollständige Einsicht in die eingespeicherten persönlichen Heizprofile aller am Pilotprojekt teilnehmenden Bewohner*innen haben und dementsprechend genau darüber informiert sind, wer von den Bewohner*innen wann und für wie lange zuhause bzw. abwesend ist. In Frau Fiedlers Argumentation klingt an, dass sie es bereits als ein großes und nicht unproblematisches Zugeständnis ihrerseits bzw. der betroffenen Nutzer*innen ansieht, hier pauschal dem Unternehmen als Ganzes, stellvertretend für alle seine Mitarbeiter*innen zu vertrauen. Und offenbar sieht sie in der eventuell fehlenden Integrität der Mitarbeiter“innen im Umgang mit den Daten noch das kleinere Sicherheitsrisiko. Am Ende der Passage benennt Frau Fiedler eine Gefahr von weit größerem Ausmaß. Hier mutmaßt sie, dass sich in Zukunft verstärkt auch nicht autorisierte Personen relativ einfach über das Internet Zugriff auf die Heizungsnutzungsdaten verschaffen könnten.

An der gesamten Passage wird deutlich, dass für Frau Fiedler die Informations- und Datensicherheit in dem Pilotprojekt (noch) nicht zufriedenstellend gewährleistet ist. Sowohl ihre einleitende als auch ihre abschließende Bewertung lassen erkennen, dass ihr die aktuelle Handhabung, vor allem von Seiten des Technikanbieters, nicht behagt.

Als die Interviewerin daraufhin bei Frau Fiedler nachfragt, ob sie wegen ihrer Bedenken bezüglich der Datensicherheit schon einmal mit einem Verantwortlichen der Technikfirma gesprochen und gefragt habe, wie man dort mit derlei Fragen umgehe, bejaht sie dies und erzählt kurz von ihrer Unterhaltung mit dem hauptverantwortlichen Techniker der Technikfirma, der regelmäßig vor Ort war und die Heizungssteuerung bei den Mieter*innen eingebaut hat: 
"Ja ich hab- also ich hab nur damals den ähm Techniker der das hier eingebaut hat ähm mal angesprochen und ähm der sachte dann nur ,Ja ja wir haben hier alle wir haben ja nur alle von der Firma Einsicht sonst ja niemand die Firma is ja nich so groß das sind ja nur 20, 30 Mitarbeiter'. Da habe ich schon so gedacht, Oh das reicht mir eigentlich schon'. Also eigentlich müsste das müssten diese Daten sensibler geschützt werden meiner Meinung nach (1) ja genau." (Bewohnerin $\mathrm{SH}$, Interview 73: 3, 152-159)

Aus der Passage geht hervor, dass Frau Fiedler mit ihrer anfänglich geäuBerten Vermutung, dass alle Mitarbeiter*innen der Technikfirma Einsicht in die Heiz-Daten der Mieter*innen haben, Recht hat. Von Frau Fiedler direkt darauf angesprochen, bestätigt ihr der Techniker dies. Die Antwort des Technikers macht deutlich, dass er offenbar überhaupt kein Problem darin sieht. Im Gegenteil, der Techniker vermittelt hier den Eindruck, als gehe er fest davon aus, dass er mit seiner offenen und ehrlichen Antwort und dem zusätzlichen Hinweis „,die Firma is ja nich so groß das sind ja nur 20, 30 Mitarbeiter“" (ebd., 155-156) Frau Fiedler in ihren Bedenken beruhigen und ihr damit einen Teil ihrer Sorge nehmen könne.

An Frau Fiedlers der Interviewerin gegenüber verbal zum Ausdruck gebrachten ,Reaktion' auf die Worte des Technikers wird deutlich, dass sein ehrliches Eingeständnis sie keineswegs beruhigt hat. Vielmehr scheint sie sich dadurch in ihren anfänglichen Bedenken noch zusätzlich bestätigt zu fühlen, nämlich, dass die Technikfirma den Schutz der persönlichen HeizDaten der Mieter"innen nicht ausreichend ernst nimmt. Ihr gedanklicher Kommentar „Oh das reicht mir eigentlich schon“ (ebd., 157) deutet darauf hin, dass ihrem Empfinden nach die „,20, 30 Mitarbeiter““ (ebd., 156) schon eine große Personengruppe darstellen, die firmenintern bereits schwerlich komplett zu überblicken ist und der sie nun mehr oder weniger ,blind' vertrauen soll. Da sicherheitstechnisch brisante Informationen wie die An- und Abwesenheitszeiten der einzelnen Mietparteien aus den gespeicherten Heizprofilen ablesbar sind, würde Frau Fiedler sich offenbar wünschen, dass diese persönlichen Daten vom Technikanbieter besser gesichert und geschützt werden.

Insgesamt verdeutlicht diese Passage, dass sich Frau Fiedler und der Technik-Experte in unterschiedlichen Welten bewegen und ihre Wahrnehmungen und Deutungen derselben Sachverhalte dementsprechend weit auseinander liegen. Während für den Technik-Experten der ständige Umgang mit persönlichen Informationen, beispielsweise zum Heizen, von ihm nicht persönlich bekannten Mieter*innen ,normales Alltagsgeschäft ${ }^{\star}$ ist und er daran offenkundig nichts (mehr) außergewöhnlich, spannend 
oder gar kritisch findet, nimmt Frau Fiedler es durchaus so wahr, dass sie mit ihren Heizprofil-Daten sehr viel von sich persönlich bzw. ihren alltäglichen Gewohnheiten preisgibt, die ihrer Ansicht nach aber eigentlich nur sie selbst etwas angehen. Im Gegensatz zum Techniker hält Frau Fiedler die vom Heizungssteuerungssystem ermittelten und gespeicherten Daten für brisant.

Zwar hat der Techniker Frau Fiedler in dem Gespräch offenbar zugesichert, dass seine Firma die vom System ermittelten Daten nicht an Dritte weitergibt, was zeigt, dass er sie in ihren Bedenken ernst nimmt. Allerdings konnte er ihre grundsätzlichen Sicherheitsbedenken mit seinen Erklärungen nicht ausräumen.

Durch den Einsatz der neuen Heizungssteuerungstechnologie haben nun nicht mehr die Mieter*innen selbst die alleinige und vorrangige Kontrolle über ihre persönlichen Heiz-Daten, sondern diese liegt nun hauptsächlich beim Technikanbieter. Die Mieter*innen sind somit darauf angewiesen, dass die Technikfirma sorgsam mit ihren Daten umgeht und diese ausreichend schützt. Im Kontrast zum Techniker, dem offensichtlich der Gedanke nicht gekommen ist, dass auch er selbst bzw. seine Kolleg*innen ein Sicherheitsrisiko bedeuten (könnten), empfindet Frau Fiedler eine Anzahl von 20 oder mehr Mitarbeiter*innen bereits als einen recht großen Unsicherheitsfaktor. Hieran wird deutlich, dass der Techniker und Frau Fiedler deutlich unterschiedliche Einschätzungen davon haben, welche Möglichkeiten und auch Risiken sich aus dem Einsatz und der Verbreitung neuer intelligenter Heizungssteuerungssysteme ergeben. Während der Techniker das Risiko von Angriffen auf die intelligente Heizungsautomatik und eines unbefugten Auslesens bzw. Diebstahls von persönlichen Nutzer*innendaten als gering einschätzt, sieht Frau Fiedler hierin ernsthafte Gefahren und bewertet das neue System entsprechend kritisch. Die Antwortreaktion des Technikers auf Frau Fiedlers geäußerte Befürchtungen hat deutlich gemacht, dass dem Techniker solche Bedenken vollkommen fernliegen, er diese offenbar nicht nachvollziehen kann und es ihm deshalb auch nicht gelingt, im Gespräch mit Frau Fiedler angemessen auf ihre Bedenken einzugehen. Diese große Diskrepanz in der Wahrnehmung und Einschätzung des Sachverhalts dürfte auch der Grund dafür sein, dass die Erklärungen des Technikers auf Frau Fiedler keine beruhigende Wirkung, sondern sie eher noch mehr alarmiert haben. 
4.4.3.2 „Äh wieso kann jetzt irgendwo in irgendeiner Zentrale die ich überhaupt nicht kenne [...] jemand [...] meine Heizungsnutzung [...] ablesen? Wozu? Mit welcher Berechtigung? Finde ich Scheiße“ - Herr Martens

Ähnlich empört über die Handhabung des Datenschutzes durch den Technikanbieter ist Herr Martens. Sein Fall macht deutlich, wie weitreichend die Dateneinblick- und Zugriffsmöglichkeiten des Technikanbieters tatsächlich sind und dass ihm die Technik-Experten aufgrund ihres Auftretens und ihrer Handhabung dieser Thematik erneut wenig vertrauenswürdig erscheinen.

Als die Interviewerin Herrn Martens im Verlauf des Interviews auf das Thema Datenschutz im Zusammenhang mit Gebäudeautomation und der nun bei ihm eingebauten intelligenten Heizungssteuerung anspricht und ihn daraufhin fragt, wie er über dieses Thema denkt, wird an seiner ersten, sehr knappen und pauschalen Antwort "Ja das finde ich- das finde ich auch Scheiße“" (Bewohner SH, Interview 76: 12, 639) sofort deutlich, dass der Datenschutz für ihn ein ähnliches Reizthema darstellt wie schon die Umsetzung und optische Ausgestaltung der neuen Heizlösung. Wie an vielen Stellen im Interview wird auch beim Thema ,Datenschutz erkennbar, dass Herr Martens dem Pilotprojekt und den dafür verantwortlichen Akteuren insgesamt ablehnend gegenübersteht.

Noch einmal bei Herrn Martens nachgehakt, woran er sich denn dabei genau störe, antwortet er nun etwas ausführlicher:

„Der kann in den Z- in der Zentrale abgucken was ich hier eingeschaltet hab das weiß ich. Der hatte nämlich angerufen als er das Display getauscht hat. ,Und kriegst- ist das jetzt alles drin und eingegeben und so?" ,Jo. 'Äh wieso kann jetzt irgendwo in irgendeiner Zentrale die ich überhaupt nicht kenne kann jemand mein Heizungsempfinden also mein Heizungs- $[\ldots]$ meine Heizungsnutzung die kann der da ablesen. Wozu? Mit welcher Berechtigung? Finde ich Scheiße.“ (Bewohner SH, Interview 76: 12f, 644-654)

Die Passage macht deutlich, dass Herr Martens es nicht in Ordnung findet, dass auch die Mitarbeiter*innen in der Firmenzentrale des Technikanbieters in einer anderen deutschen Großstadt kompletten Einblick in die persönlichen Heiz-Daten der Mieter*innen haben, also jederzeit aus der Ferne auf sein persönliches Heizprofil zugegriffen werden kann.

Der Argumentation lässt sich entnehmen, dass Herr Martens nicht von Anfang an davon wusste, dass die Einzelsteuerungen kommunikations- 
technologisch derart eng mit der Zentrale verbunden sind, dass die individuellen Heizprofile der Mieter*innen per Fernzugriff kontrolliert werden können und der Anbieter von dieser Funktion, z. B. bei der Behebung von Störungen, auch Gebrauch macht. Seine Schilderung lässt erkennen, dass ihm dies erst durch ein Telefonat des Technikinstallateurs mit der Firmenzentrale bewusst geworden ist, welches Herr Martens mitbekommen hat, als der Techniker bei ihm in der Wohnung war, um das beschädigte Display auszutauschen.

Genauso wie Frau Fiedler findet Herr Martens es unangemessen, dass ihm vollkommen unbekannte Personen detaillierten Einblick in die Daten seines Heizungsnutzungsverhaltens haben. Im Gegensatz zu Frau Fiedler empört sich Herr Martens aber über die Handhabung des Datenschutzes durch die Technikfirma. Nicht nur stellt er das Erfordernis des Fernzugriffs auf die Heizungsprofile der Mieter*innen für den Technikanbieter infrage. Offenbar erkennt er dafür keine dringende Notwendigkeit. Er fragt sich vor allem auch, wer dem Technikanbieter diese Praxis überhaupt erlaubt habe. Hieraus lässt sich ableiten, dass Herr Martens bis dahin offenbar nicht über diese Praxis des Technikanbieters informiert gewesen ist. Herr Martens scheint zumindest nicht bewusst in die Verwendung seiner Heiz-Daten durch den Technikanbieter eingewilligt zu haben bzw. dieser scheint sich offenbar nicht das explizite Einverständnis von Herrn Martens zur Erfassung und Verwendung seiner persönlichen Heizungsnutzungsdaten eingeholt zu haben. Für Herrn Martens stellt sich die Praxis der Datenerfassung und -verwendung des Technikanbieters somit als eine unbegründete, vor allem aber als eine unerlaubte Vorgehensweise dar.

Gleichzeitig scheint die tatsächliche Datenpraxis des Technikanbieters für Herrn Martens aber gut ins Bild zu passen und seinen bisherigen Eindruck vom Agieren der Technik-Experten noch einmal zu bestätigen, nämlich, dass sie bei der Installation der neuen Steuerungsanlage scheinbar mit ziemlicher Willkür vorgehen und dass dabei praktisch keine Rücksicht auf die Belange der Mieter*innen genommen wird.

An mehreren Stellen im Interview wird deutlich, dass Herr Martens es so wahrnimmt, dass von Seiten des Technikanbieters mit ihm von Anfang an nicht offen und ehrlich kommuniziert wurde. Offenbar sieht er Parallelen zwischen dem Vorgehen der Techniker vor Beginn der Installation, als sie zu ihm kamen, um ihn über die geplanten Umbaumaßnahmen in seiner Wohnung und im Treppenhaus zu informieren und dazu seine Einwilligung einholten, und dem, wie sie in der täglichen Praxis die Verwendung und den Schutz seiner persönlichen Heiz-Daten handhaben: In beiden Fällen hat sich für Herrn Martens im Nachhinein herausgestellt, dass 
er von den Technikern anfangs nur unzureichend über ihr konkretes Vorgehen informiert worden ist, oder sich die ersten Informationen im Nachhinein als falsch erwiesen haben. Zum Zeitpunkt als Herr Martens dies bemerken konnte, waren bereits Tatsachen geschaffen, die sich kaum mehr rückgängig machen ließen.

Dass die Techniker Herr Martens' Vertrauen, welches er ihnen, trotz seiner anfänglich großen Skepsis, mit seiner Einwilligung zum Einbau der Heizungssteuerung doch noch entgegengebrachte, durch ihr Agieren mittlerweile verspielt haben, wird am Fortgang des Dialogs mit ihm über den Datenschutz deutlich. Auf die Frage der Interviewerin, ob er seine Bedenken bezüglich des Datenschutzes schon einmal gegenüber einem der im Projekt für die Technik Verantwortlichen angebracht habe, antwortet er:

„Äh ich sag ja ich war auf keiner weiteren Besprechung. Die waren damals hier (.) es ist ganz anders geworden wie die gesagt hatten eigentlich. Das ist- sagte ich ja schon das ist Scheiße. Und danach habe ich mit eigentlich keinem mehr richtig gesprochen." (Bewohner SH, Interview 76: 13, 663-666)

Die Passage verdeutlicht noch einmal, dass Herr Martens' erstes Kontakterlebnis mit den Technikern, als diese ihn vor Baubeginn für ein persönliches Gespräch über die anstehenden Maßnahmen in seiner Wohnung aufgesucht haben, seine gesamte Einstellung zum Projekt und seinen Umgang mit den involvierten Technikern entscheidend geprägt hat. Deutlich wird, dass Herr Martens hier offensichtlich die Erfahrung gemacht hat, von den Technikern getäuscht worden zu sein. Aus seiner Sicht haben sie ihn damals mit ,falschen' Ankündigungen und Versprechen zur Einwilligung in das Projekt überredet, was für ihn allerdings erst später anhand der konkreten tatsächlichen Umsetzung der neuen Heizlösung erkennbar wurde. Dieser von Herrn Martens empfundene Wortbruch der verantwortlichen Technikinstallateure hat offenbar dazu geführt, dass er den Projektverantwortlichen, insbesondere aber den ausführenden Technikern vor Ort nicht mehr vertraut. Der Passage lässt sich entnehmen, dass Herr Martens seither die Kommunikation mit der Projektführung und den ausführenden Technikern weitestgehend vermieden hat. Hat Herr Martens schon vorher an keinem der offiziellen Termine, wie zum Beispiel der Informationsveranstaltung zum Pilotprojekt für die Mieterinnen teilgenommen, scheint er nun sogar nicht mehr daran interessiert zu sein, mit jemandem von der Projektleitung zu sprechen.

Insgesamt lassen Herr Martens' Schilderungen erkennen, dass er mittlerweile eine andere Form der Kommunikation als das direkte, offene und 
ehrliche Gespräch nutzt, um seinen ,Unmut' über das anfängliche Handeln der Technikinstallateure und die optische Ausgestaltung der neuen Heizlösung Ausdruck zu verleihen. Anstatt den Projektverantwortlichen oder den Technikern vor Ort seine Verärgerung über die Geschehnisse direkt mitzuteilen, verhält sich Herr Martens jetzt zunehmend unkooperativ im Umgang mit denselben. Dies lässt die Schlussfolgerung zu, dass er nunmehr verdeckten Widerstand gegen die Umsetzung des Projekts und die Arbeit der Techniker leistet, beispielsweise indem er ständig etwas an der neuen Heizungssteuerungstechnik beanstandet und laufend deren nicht ordentliches Funktionieren aufzeigt, woraufhin immer wieder ein Techniker in der Wohnung von Herrn Martens etwas an der Technik reparieren oder neu justieren muss. Dass ihm auf Seiten der Projektleitung und bei den ausführenden Technikern dafür mittlerweile der Ruf eines ,ewigen Querulanten' begleitet, scheint Herr Martens durchaus bewusst zu sein. Vielmehr vermittelt er im Interview mit seinen Schilderungen den Eindruck, dass er sich in dieser Rolle recht wohlfühlt. Zumindest scheint es ihn zu amüsieren, dass er die Techniker mit seinem an den Tag gelegten Verhalten genauso behelligen und ärgern kann, wie sie es mit ihrem Vorgehen anfänglich bei ihm gemacht haben. Dass diese Deutung wahrscheinlich zutrifft, wird noch einmal gegen Ende des Interviews deutlich. Auf die abschließende Frage, ob es von seiner Seite noch etwas zu besprechen gebe, was bisher im Interview noch nicht oder nicht ausreichend zur Sprache gekommen sei, kommt Herr Martens erneut auf die Datenschutzthematik zu sprechen. Er rekurriert hier noch einmal auf die Situation, bei der er mehr oder weniger zufällig erfahren hat, in welche persönlichen Details zum Heizungsnutzungsverhalten der Mieter*innen die Mitarbeiter*innen beim Technikanbieter aus der Ferne Einblick haben und was sie aus diesen Informationen herauslesen können:

Herr Martens: [...] und wie gesagt also dass die das hier äh mit dem Datenschutz das hat auch keiner vorher gesagt dass die das da komplett ablesen können dass da jetzt hier-

Interviewerin JM: Wie sind Sie da denn drauf gekommen weil Sie irgendwann mal gefragt haben $[\ldots]$ ?

Herr Martens: Nee der hat- ich hatte doch das Display kaputt. [...] Und dann $\underline{\mathrm{kam}}$ der ja und hat das getauscht. Und dann hat er per Telefon gefragt ob das jetzt alles ab- hinhaut mit einem da in der Zentrale. Und der hat ihm dann angesagt was er eingestellt hat.

Interviewerin JM: Und da waren Sie dabei und dann wussten Sie einfach okay der kann da die ganze Zeit von Ferne drauf zugreifen und gucken? 
Herr Martens: Eben und kann auch gucken wer das ist weil weil die haben irgendwie 'ne Nummer drin. Und dann weiß er auch genau welche Nummer wo was eingebaut ist.

Interviewerin JM: Haben Sie ihn direkt damit konfrontiert?

Herr Martens: Äh nö den Typen nicht. Der war eh genervt genug von $\operatorname{mir}$ (lacht).“

(Bewohner SH, Interview 76: 21f, 1107-1139)

In dieser Passage entrüstet sich Herr Martens noch einmal über die Datennutzungspraxis des Technikanbieters. Er macht den Projektverantwortlichen den Vorwurf, ihn in diesem Punkt, wie auch bezüglich anderer, relevanter Aspekte, vorab nicht ausreichend informiert zu haben.

Herr Martens' Schilderung lässt sich entnehmen, dass die Mitarbeiter*innen beim Technikanbieter per Fernzugriff nicht nur die individuellen Heizprofile der Mieter*innen vollständig einsehen können, sondern dass sie die einzelnen Heizprofile auch eindeutig den einzelnen Haushalten zuordnen können. Dies ist offenbar möglich, da jeder Wohnungsmanager über eine Gerätenummer verfügt, die mit der konkreten Wohnung verknüpft ist. Somit lässt sich hinterher jederzeit anhand der Gerätenummer ermitteln, um welchen Haushalt es sich beispielsweise bei einer Störungsmeldung handelt. Auch diese Information hat Herr Martens ,zufällig`während des Telefonats des Technikers mit einem bzw. einer Kolleg*in in der Zentrale mitbekommen. Aber auch mit diesem brisanten Faktum hat er den Techniker nicht gleich konfrontiert. Offenbar wollte er ihn in dem Moment nicht noch mit weiteren Beanstandungen behelligen. Durch sein Lachen vermittelt Herr Martens hier den Eindruck, als sei er amüsiert darüber, den Techniker durch seine mehrfachen vorangegangenen Beanstandungen bereits ziemlich geärgert und herausgefordert zu haben.

\subsubsection{Vergleichendes Kapitelfazit}

Die Bandbreite der in diesem Kapitel präsentierten Fälle zu den drei verschiedenen Aspekten (1.) fehlende individuelle Regelbarkeit der Heizung, (2.) Störanfälligkeit der Technik und zunehmende Technikabhängigkeit sowie (3.) Sicherheitsbedenken bezüglich des Datenschutzes zeigt, dass für ,gewöhnliche' Nutzer“innen das Gefühl des Kontrollverlustes ein zentrales Erleben im Umgang mit neuer Heiztechnik darstellt. 


\section{Vom Umgang mit Kontrollverlusterfahrungen}

Die Analyse des Datenmaterials hat deutlich gemacht, dass es hinsichtlich der Aspekte, auf die sich das Gefühl des Kontrollverlustes bezieht, noch recht große Überschneidungen zwischen Passivhaus- und SmartHome-Bewohner*innen gibt. Sowohl Passivhaus- als auch SmartHome-Bewohner"innen nehmen es so wahr, dass sie ihre Heizung mit der neuen Technik nur noch begrenzt spontan oder zeitnah ihren subjektiven Bedürfnissen und Wünschen entsprechend regulieren können. Im Fallvergleich wird allerdings deutlich, dass das Passivhaussystem insgesamt noch einmal deutlich träger als die intelligente Heizungsautomatik reagiert. Bei größeren Temperaturumschwüngen ist eine zeitliche Verzögerung in der Anpassung des Passivhauslüftungssystems von ein bis zwei Tagen vollkommen normal. Hingegen ,lernt' die intelligente Steuerungstechnik recht schnell, in der Regel binnen eines Tages, auf größere Temperaturveränderungen zu reagieren. Aber auch bei kleineren, von Nutzer"innen vorgenommenen Veränderungen in den Temperatureinstellungen reagiert die PassivhausLuftheizung mit einer deutlichen Verzögerung. Demgegenüber soll das automatische Heizungssteuerungssystem nach einer anfänglichen kurzen Lernphase unmittelbar auf von Nutzer*innen getätigte Einstellungen reagieren. Wie die Analyse des Datenmaterials auch gezeigt hat, muss die zeitverzögerte Reaktion der Heizung nicht vorrangig mit der Technik zusammenhängen, sondern kann auch durch widerständiges Verhalten der Nutzer*innen bedingt sein, welches im analysierten Fall wiederum größtenteils aus der Art und Weise der Einführung der Technik durch die Projektverantwortlichen resultiert.

Dass im Fall des Pilotprojekts zum intelligenten Heizen der Umgang gewöhnlicher Nutzer*innen mit ihren erlebten Kontrollverlusterfahrungen neben der Technik wesentlich von der Art und Weise der Technikeinführung beeinflusst ist, wird besonders gut deutlich, wenn man die Umgangsweise mit einer ähnlichen Problematik zwischen Passivhaus- und SmartHome-Bewohner*innen miteinander vergleicht. Hier zeigen sich deutliche Unterschiede zwischen den zwei Bewohner*innengruppen, sowohl darin, wie stark und weitreichend der Kontrollverlust durch den Einsatz neuer Technik von ihnen erlebt, als auch wie dieses Erleben bewertet und verarbeitet, wie also damit umgegangen wird.

Bei den Passivhausbewohner*innen sind generell eher moderate Reaktionen auf Kontrollverlusterfahrungen zu beobachten. Sie vermitteln im Großen und Ganzen eher den Eindruck, als würde es sie nicht (mehr) allzu sehr aufregen bzw. als hätten sie sich mittlerweile mit diesen Schwächen der Technik abgefunden oder arrangiert. Zumindest unternimmt 
von ihnen keiner etwas aktiv dagegen, sondern sie stellen mehr oder weniger alle nur fest, dass sie im Passivhaus sehr stark abhängig von moderner Technik sind. Hingegen fallen die Reaktionen der SmartHome-TechnikNutzer*innen auf zum Teil deutlich kleinere technische Probleme erkennbar drastischer aus.

In den Interviews lässt sich nachzeichnen, dass die Diskrepanz in der emotionalen, vor allem aber in der tatsächlich gezeigten Reaktion auf ein vergleichbares Erleben offenbar vor allem daraus resultiert, dass sich das Gefühl des Kontrollverlustes bei den SmartHome-Bewohner"innen nicht nur auf die Technologie selbst, sondern zusätzlich noch auf die Einführung der Technik durch die Projektinitiator*innen bezieht: Während sich die interviewten Passivhausbewohner*innen alle freiwillig und bewusst für den Bau und/oder das Wohnen in einem Passivhaus entschieden haben, sie selbst also verantwortliche Urheber"innen der nun bei ihnen vorzufindenden technischen Heizlösung sind, wurden die mit einer intelligenten Heizungssteuerung ausgestatteten Miethaushalte von der Projektführung nach bestimmten Kriterien ausgewählt und von der Wohnungsgenossenschaft zur Teilnahme an dem Pilotprojekt zum intelligenten Heizen verpflichtet. Die Mieter*innen, in deren Wohnungen eine intelligente Heizungssteuerung eingebaut wurde, waren nicht an der Entscheidung beteiligt, sondern sie haben die Projektteilnahme und damit auch die intelligente Technik von ihrer Genossenschaft als Vermieterin aufoktroyiert bekommen und mussten sich dieser Entscheidung fügen. Dieser besondere Umstand und die sich daraus ergebende Entscheidungs- und Machtkonstellation zwischen Projektplaner*innen und -teilnehmer*innen wirken sich in den meisten Fällen deutlich darauf aus, mit welcher Haltung die Mieter*innen der neuen, weitgehend autonom funktionierenden Technik sowie den für den Einsatz der Technik Verantwortlichen von Anfang an begegneten und wie sie das Pilotprojekt insgesamt bewerten. So war für die Interviewerin in zahlreichen persönlichen, aber informellen Gesprächen mit betroffenen Mieter*innen - etwa während der Öffentlichkeitsveranstaltung zum offiziellen Startschuss des Pilotprojekts - zu erfahren, dass für viele von ihnen diese ersten Erfahrungen von ,Nicht-ernsthaft-Miteinbezogen-Werden', von Einflusslosigkeit und weitgehender Fremdbestimmung so grundlegend und enttäuschend waren, dass sie resignierten. Die meisten dieser enttäuschten Mieter*innen sind allen freiwilligen (Informations-)Veranstaltungen zum Pilotprojekt ferngeblieben. Sie haben den Kontakt und die offene Konfrontation mit den Projektinitiator*innen vermieden und sich so weit wie möglich ins Private zurückgezogen. Dem entspricht auch, dass nur sehr wenige Bewohner*innen aus den insgesamt rund 75 von der Maß- 
nahme betroffenen Miethaushalten zu einem Interview zu ihren Erfahrungen mit der neuen Heiztechnik bereit waren, in dem sie auch ihre Unzufriedenheit und ihren Frust zur Sprache hätten bringen können.

\section{Von Aggression bis bin zu Resignation}

Vertieft man sich in die Literatur zum Umgang, gewöhnlicher' Nutzer*innen mit neuer (smarter) Technik, so fällt auf, dass häufig von Frustrationserfahrungen die Rede ist, die gelegentlich in aggressives oder sogar handgreifliches Handeln gegenüber der Technik münden (vgl. z.B. Norman 2004, 2011, 2013: hier insbesondere Chapter 1 und 2 sowie 213-214; Stringer et al. 2006; Balta-Ozkan et al. 2013; Hargreaves et al. 2015; Hargreaves et al. 2016; Wilson et al. 2017).

Das hitzig-aggressive Verhalten des Hausmeisters gegenüber der Technik, welches in der Falldarstellung zu Frau Fiedler deutlich wurde, scheint demnach nicht ungewöhnlich, sondern eher eine typische und häufiger zu beobachtende Reaktion auf (vermeintlich) besonders autonome technische Geräte zu sein, die ihre Aufgabe in der Regel weitgehend ohne menschliches Zutun erledigen und sich dementsprechend nur melden, wenn ein Problem auftritt. Laut Forschung kommt es häufiger zu verbalen oder handgreiflichen Attacken auf moderne technische Geräte, wenn Menschen mit betreffender Maschine oder betreffendem Gerät nicht zurechtkommen, oder wenn sie die Wahrnehmung haben, dass nicht sie das technische Gerät bedienen, kontrollieren oder steuern, sondern es sich ihrem Empfinden nach eher umgekehrt verhält, nämlich dass die Technik relativ autonom zu agieren scheint und den Nutzer"innen ihre eigene Logik und ihr eigenes Programm aufzwingt (vgl. Randall 2003; Herrmann 2014). Bei den Nutzer*innen entstehen dadurch dann offenbar Gefühle von ,Ausgeliefertsein', ,Kontrollverlust ${ }^{`}$ und ,Fremdbestimmung', was wiederum Empfindungen wie Ohnmacht, Unvermögen oder sogar Wut auslösen kann (vgl. Lewis 2011). Und diese Gefühle resultieren in ungnädigen Bewertungen oder führen zu aggressivem oder gar zerstörerischem Verhalten, zum Beispiel gegenüber der betreffenden Technik - hier konkret dem Wohnungsmanager-Gerät.

Das deutet darauf hin, dass Technik weniger nach ihrer Funktionalität als vielmehr nach persönlichem Erleben und Empfinden bewertet wird. Offenbar sind es vor allem Emotionen - meist ausgelöst durch eher nebensächliche Faktoren wie Ästhetik oder Design -, die die Zufriedenheit von Konsument*innen und ihr Urteil zur Nutzer"innenfreundlichkeit des entsprechenden Gerätes prägen. Deutlich wurde, wenn Technik so geschaffen ist, dass sie den Nutzer*innen kaum noch Kontrolle lässt und ihnen damit 
das Gefühl vermittelt, nicht mehr Handelnde*r, sondern primär nur noch Reagierende*r zu sein, kann sie den Nutzer*innen noch so viel Arbeit abnehmen, die Reaktionen auf die Technik werden sehr wahrscheinlich negativ ausfallen - und allem Anschein nach sogar umso negativer, je selbständiger die Technik funktioniert (vgl. Norman 1994: 69; Lewis 2011: 292ff). 107

Gefühle der Einflusslosigkeit, des Versagens bzw. Scheiterns und NichtZurechtkommens mit der Technik können auch genau ins Gegenteil von Tätigwerden oder Sich-zur-Wehr-setzen führen, also in Resignation umschlagen. Allerdings konnte resignierendes Verhalten, das vor allem eine häufige Reaktion auf die Einführung der smarten Heiztechnik darstellte, praktisch nur zufällig beobachtet und indirekt dokumentiert werden, da sich auf diese Weise reagierende Mieter*innen in der Regel erst gar nicht für ein Interview bereit erklärten. Jedoch konnte in den kurzen unverbindlichen Gesprächen mit zahlreichen Mieter*innen - z.B. während der offiziellen Einweihungsveranstaltung des Pilotprojekts oder an den Haustüren, bei den zahlreichen Kontaktaufnahme- und Interviewpartner*innen-Akquise-Versuchen - ein immer wiederkehrendes Deutungsmuster identifiziert werden. Dies war das Bild vom „kleine[n] Mann“ (Bewohnerin SH, Interview 71: 14, 657), der nicht nur der neuen smarten Technik, sondern noch viel mehr den Projektinitiator*innen und damit dem ganzen Pilotprojekt relativ hilf-, macht- und damit einflusslos gegenübersteht.

In den Interviewgesprächen sowie in den nur kurzen, flüchtigen Gesprächen wurde immer wieder deutlich, dass viele der von der Maßnahme betroffenen Mieter*innen die Machkonstellation im Pilotprojekt wie das bekannte Duell ,David gegen Goliath' deuten: der bzw. die kleine, schwache und einflusslose Nutzer“in bzw. Verbraucher*in gegen die Entscheidungsträger*innen großer, übermächtiger Institutionen und Unternehmen, die einfach über die Interessen der kleinen Leute hinweg entscheiden und handeln (können). Hierin äußert sich ein Gefühl des Ausgeliefertseins, das

107 Psycholog*innen haben diese Wirkung bereits in ähnlichen Zusammenhängen beobachtet und mit „IKEA-Effekt" benannt (Norton et al. 2012). Demnach schätzen die Konsument*innen die Möbel des schwedischen Einrichtungshauses im Vergleich zu fertig gekauften Möbelstücken so besonders, gerade weil sie diese selbst aufbauen müssen, am Ende also eigene Arbeitsleistung in ihnen steckt und sie in den Produktherstellungsprozess miteinbezogen waren. Dies kann damit begründet werden, dass der bzw. die Konsument*in während des Prozesses der Produktzusammenstellung offenbar gleichzeitig eine emotionale Bindung zu diesem Produkt aufbaut. Infolgedessen schätzten die Prosument"innen den Wert des selbst miterzeugten Gutes offenbar höher. 
auch in dem bildlichen Vergleich zwischen Mieter*innen und „Versuchstiere[n]" (Bewohnerin SH, Interview 73: 11, 582) mitschwingt, den Frau Fiedler verwendet, um den Involviertheitsstatus der am Pilotprojekt beteiligten Miethaushalte zu beschreiben. Demnach werden die eigentlichen Hauptakteure des Pilotprojekts, die von der Maßnahme betroffenen Miethaushalte, zu willenlosen Objekten degradiert und von der Projektführungsriege für deren eigene Zwecke ,missbraucht'.

Durch dieses häufiger aufgetauchte Deutungsmuster entsteht der Eindruck, dass das Verhalten der Projektführung hinsichtlich der Einführung der Technik bei vielen Mieter*innen ein ohnehin bereits vorhandenes Gefühl noch einmal bestärkt bzw. eine von ihnen offenbar schon häufiger gemachte Erfahrung erneut bestätigt hat: das Erleben nämlich, dass die Meinung von ,einfachen' Bürger*innen bzw. ,normalen' Verbraucher*innen, (die Machthabenden) nicht interessiert. Demnach zählt die Stimme des ,kleinen Mannes' bzw. der ,kleinen Frau' nicht viel und für ihn bzw. sie besteht praktisch kaum eine Möglichkeit, die Dinge in seinem bzw. ihrem Sinne zu beeinflussen.

Offenbar nehmen diese Mieter*innen die soziale Welt als grundsätzlich zweigeteilt wahr: In allen gesellschaftlichen Bereichen gibt es demnach immer eine kleine Gruppe von Herrschenden, die ,oben' stehen und die, die Macht haben, alles alleine zu entscheiden. Dieser Führungsschicht steht eine durch konkurrierende Partikularinteressen geteilte und kaum organisierte, sondern eher diffuse Menschenmenge gegenüber: die kleinen, einfachen Leute, die von allen wichtigen Entscheidungsprozessen ausgeschlossen und stattdessen den Interessen und der Willkür der Machtelite mehr oder weniger schutzlos ausgeliefert sind. Demnach kann sich „der kleine Mann“ (Bewohnerin SH, Interview 71: 14, 674) gegen diese Machenschaften im Grunde genommen nur zur Wehr setzen, indem er sich entscheidet, dieses ,Spiel' nicht mehr mitzuspielen und sich komplett daraus zurückzieht. Diese (Handlungs-)Strategie kommt offensichtlich in dem oberflächlich fügsam erscheinenden, tatsächlich aber wohl eher resignierenden Verhalten der allermeisten Mieter*innen zum Ausdruck, die in das Pilotprojekt involviert sind.

Darüber hinaus hat der Fall des Herrn Martens verdeutlicht, dass eine kritische bis ablehnende Haltung gegenüber dieser Art von technischer Intervention auch von Leuten vertreten wird, die prinzipiell für Energiesparmaßnahmen und neue Technik offen sind. Das zeigt, dass die Bewertung derartiger Maßnahmen sowie das sichtbare Gebaren der von solchen Maßnahmen betroffenen Personen nicht nur mit ihren Einstellungen zusammenhängt. Die tatsächliche Praxis erweist sich als deutlich komplexer. Die 
Analyse des Datenmaterials hat ergeben, dass die sich tatsächlich ereignende Interaktion und Kommunikation, also der praktische zwischenmenschliche Umgang primär entscheidend für den Verlauf und Ausgang eines solchen Pilotprojekts sind. Ebenso lässt sich aus der Analyse des Datenmaterials ableiten, dass eine offene und ehrlich-direkte Kommunikation der Projektleitung gegenüber den von der Maßnahme betroffenen Mieter*innen, beispielsweise im Hinblick auf die verpflichtende Teilnahme am Projekt, eher zielführend gewesen wäre, weil sich die Betroffenen dadurch wahrscheinlich eher respektvoll behandelt und weniger getäuscht und fremdbestimmt gefühlt hätten.

\section{Die gesteigerte Abhängigkeit von elektrischer Energie (Strom)}

Die in diesem Kapitel präsentierten Fallanalysen haben verdeutlicht, dass die permanente Angewiesenheit beider hier untersuchten Technologien auf eine stabile Stromversorgung bei einigen Bewohner*innen das Empfinden einer zunehmenden Technikabhängigkeit und dadurch bedingten Vulnerabilität entstehen lässt, oder bereits vorhandene derartige Gefühle noch verstärkt.

Die große Abhängigkeit von elektrischer Energie wird im Alltag jedoch kaum mehr bewusst wahrgenommen. Meist wird sie den Menschen erst (wieder) bewusst, wenn es zu Problemen kommt: wenn die Technik beispielsweise wegen eines größeren und/oder länger andauernden Stromausfalls nicht mehr funktioniert und dadurch das normale Alltagsgeschäft zum Erliegen kommt, dann wird diese große Abhängigkeit (wieder) sichtund spürbar, wie anhand der Fallgeschichte des Herrn Frings eindringlich deutlich wurde. Das zeigt, wie stabil und sicher die Stromversorgung in Deutschland normalerweise ist. Nur äußerst selten kommt es hier zu gravierenden Störfällen oder größeren Lücken in der Versorgung. Durch den immer weiter zunehmenden Einsatz von weitgehend selbständig funktionierenden, dafür aber meist elektrisch betriebenen Technologien wird sich die allgemeine Stromabhängigkeit noch weiter vergrößern. ${ }^{108}$ Welche (noch ungeahnten) Folgen diese Entwicklung haben wird und welche

108 Im Falle der SmartHome-Automatisierungstechnik, deren Verwendung u.a. zu einem effizienteren bzw. sparsameren Energieeinsatz, beispielsweise für Heizung, beitragen soll, kann deren zunehmende Verbreitung und Nutzung unter Umständen den zusätzlichen unerwünschten (Neben-)Effekt haben, dass der Betrieb dieser neuen Steuerungs- und Kontrollsysteme (für ein verbessertes Energiemanagement im Privathaushalt) deutlich mehr (elektrische) Energie erfordert als ursprünglich angenommen. Dies hätte zur Folge, dass das Einsparpoten- 
(neuen) Risiken sie mit sich bringt, lässt sich heute allerdings noch nicht einschätzen.

Während also sowohl die Passivhauslüftungsanlage als auch die intelligente Heizungsautomatik für ihren Betrieb auf eine verlässliche Stromversorgung angewiesen sind, was vielen Bewohner*innen bereits ein Gefühl von starker Technikabhängigkeit vermittelt und von einigen auch als ein gewisses Sicherheitsrisiko angesehen wird, gibt SmartHome-Bewohner*innen zudem die Internetabhängigkeit ihrer neuen intelligenten Heizungssteuerung zu denken. Hier ist für sie der Umgang des Technikanbieters mit ihren persönlichen (Heiz-)Daten dominierendes Thema.

\section{Unterschiedliche Deutungen der Expert"innen und ,gewöhnlichen' Nut- zer"innen}

Das Thema, das sich im Zusammenhang mit der intelligenten Heizungssteuerung als besonders wichtig herausgestellt und dementsprechend in den Interviews mit SmartHome-Bewohner*innen eine zentrale Rolle gespielt hat, ist die Kontrolle über die persönlichen Daten, die mit Anwendung der neuen Heiztechnologie anfallen und gespeichert werden. Hierbei wurde deutlich, wie weit die Deutungen neuer smarter (Heiz-)Technik von Expert*innen und gewöhnlichen Nutzer*innen auseinanderliegen - etwa im Hinblick darauf, welcher Nutzen und welche Vorteile, aber auch welche potenziellen neuen Gefahren und Risiken mit ihrem Einsatz einhergehen. In diesem Bereich haben Nutzer*innen besonders stark das Gefühl des Kontrollverlustes (vgl. Cook 2012: 1580; Balta-Ozkan et al. 2013: 369; Wilson et al. 2017: 76).

Einige Bewohner*innen haben nicht nur das Empfinden, die Kontrolle über ihre persönlichen Heiz-Daten an die Technik bzw. den Technikbe-

zial dieser Technik als Effizienzmaßnahme deutlich geringer ausfällt als erwartet, was einen klassischen Rebound-Effekt darstellt (vgl. Louis et al. 2015). Aufgrund der Energieintensität (einzelner Komponenten) von SmartHome-Energiemanagementsystemen (für den Privatbereich) kommen Louis et al. zu dem Schluss, dass bei einer beabsichtigten Verwendung von SmartHome-Automatisierungstechnologien stets deren Nutzen bzw. Vorteile und (nachteilige) Auswirkungen auf die Umwelt (z.B. energiebedingte $\mathrm{CO}_{2}$-Emissionen) mit Bedacht gegeneinander abzuwägen sind: „we need to find the balance between what we actually need to control and the resulting energy consumption of the control system“ (Louis et al. 2015: 885). In jedem Fall sollte, so argumentieren Louis et al. weiter, die Frage des Strombedarfs smarter Steuerungs- und Kontrollgeräte in Zukunft in der Diskussion um ,Heimautomatisierung ${ }^{6}$ bzw. SmartHome-Gebäudetechnik deutlich stärker thematisiert werden (vgl. ebd.). 
treiber verloren zu haben, sondern sie nehmen es auch so wahr, dass der Technikbetreiber den Datenschutz sowie die damit einhergehende Verantwortung, den betroffenen Nutzer*innen einen behutsamen und sachgemäßen Umgang mit personenbezogenen Daten zu gewährleisten, nicht ganz ernst nimmt. In den Analysen zum Fall des SmartHomes konnte herausgearbeitet werden, dass die Technik- bzw. IT-Experten den Datenschutz in der Praxis deutlich laxer handhaben als sich die Nutzer*innen eigentlich vorstellten und wünschen würden. Diese Diskrepanz, sowohl im abstrakten Verständnis als auch in der Praxis, zwischen Expert*innen und Nutzer*innen ist in Frau Fiedlers und Herr Martens' Schilderungen ihrer Interaktion und Kommunikation mit den Technikinstallateuren deutlich erkennbar. Während der Techniker den lockeren und wenig diskreten Umgang seiner Firma mit den personenbezogenen Heiz-Daten der Mieter“innen vollkommen unproblematisch empfindet, sind Frau Fiedler und Herr Martens überrascht über den ihnen allzu offenen und sorglosen Umgang mit ihren Daten. Hieran wird deutlich, wie unterschiedlich die Orientierungsrahmen dieser zwei Personengruppen sind, was zur Folge hat, dass ein und dieselbe Thematik bzw. Problematik auf vollkommen unterschiedliche Art und Weise interpretiert und verarbeitet wird. Es prallen hier also, Welten' aufeinander.

Im nächsten Kapitel soll einmal die Perspektive gewechselt werden: Das heißt, die zentralen Prozesse des Rekrutierens neuer Teilnehmer*innen und erfolgreichen Haltens von bereits aktiv Praktizierenden werden diesmal vom Standpunkt der Praktiken aus beleuchtet und beschrieben.

\subsection{Wege, auf denen neue Heizpraktiken Verbreitung finden}

In diesem Kapitel werden die wichtigsten Wege beschrieben, wie die Praktiken des passiven und des smarten Heizens erfolgreich neue Anhänger*innen für sich gewinnen. Es soll aufgezeigt werden, wie es den zwei in dieser Arbeit analysierten neuartigen Heizansätzen bisher gelungen ist und weiterhin gelingen kann, sich erfolgreich zu verbreiten.

Alle Interviewpartner*innen, die sich erstmals für ein Passivhaus entschieden haben oder die neuerdings eine intelligente Heizungssteuerung verwenden, haben vor ihrem Übergang zum Passivhaus bzw. SmartHome in konventionellen Wohnkontexten mit entsprechender Heizungstechnik gewohnt. Das heißt, bei ihrem Eintritt ins Passivhaus bzw. SmartHome haben sich die meisten Bewohner"innen zuvor bereits lange Zeit in einer eingeübten und von daher verinnerlichten Heizroutinepraxis betätigt. Diese 
individuelle „Heiz-Vorgeschichte ${ }^{6}$ bzw. die Erfahrung potenzieller neuer Anhänger"innen und den typischen Routinecharakter des Heizens gilt es zu beachten, wenn es um den Prozess geht, dass von alten Heizroutinen abgelassen wird und diese durch neue energiesparendere Verhaltensweisen ersetzt werden. Die hier gängige Herangehensweise besteht darin, diese alten Routinen und gewohnheitsmäßigen Abläufe als ein Wandlungshindernis zu betrachten und sie als einen voll automatisierten, häufig vorkommenden Verhaltenstyp zu verstehen, welcher in der Regel in einem stabilen Kontext stattfindet. In diesen Analysen stellen Gewohnheiten und Routinen Verhaltensweisen dar, die Menschen aufnehmen, haben und nur gelegentlich wieder aufgeben (vgl. Shove 2012).

In diesem Kapitel soll die Perspektive - wie Shove es in ihrem Aufsatz „Habits and Their Creatures" (Shove 2012) vorgemacht hat - einmal umgedreht und die Verbreitung neuer Heizpraktiken statt aus Sicht der handelnden Akteure aus Perspektive der betreffenden Praktiken analysiert werden. Eignet man sich die Sichtweise der Praktiken an und geht davon aus, dass nicht so sehr Menschen Praktiken übernehmen, sondern sie vielmehr von Praktiken erfasst, ja regelrecht, erobert' werden, so müssen auch die zentralen Fragen anders formuliert und zum Teil neue Fragen gestellt werden. Dann geht es nicht mehr vorrangig darum zu klären, was Menschen dazu motiviert bzw. sie daran hindert, von einem konventionellen Wohnkontext in ein Passivhaus zu ziehen oder sich eine intelligente Heizungssteuerung einbauen zu lassen. Aus Praktikenperspektive ist stattdessen zu fragen: Wie machen die neuen Heizansätze geeignete Träger*innen ausfindig? Wie gelingt es den neuartigen Heizpraktiken für potenzielle Anhänger*innen hinreichend attraktiv zu sein, so dass diese ihre begrenzten zeitlichen und sonstigen Ressourcen von ihren bisherigen Heizaktivitäten abziehen und in die neuen Heiztätigkeiten investieren? Wie schaffen es diese routinisierten Verhaltensweisen, betrachtet als Praktiken, die für ihr Fortbestehen auf regelmäßige, einigermaßen gleichbleibende Reproduktion angewiesen sind, ihre einmal gewonnen Träger*innen dauerhaft an sich zu binden? Und können politische Entscheidungsträger*innen oder andere, für das betreffende Themenfeld zuständige und wichtige einflussreiche Akteure, nachhaltige Heizpraktiken möglicherweise in ihrem Bestreben unterstützen, weite Teile der Bevölkerung zu erfassen und dabei gleichzeitig andere, zum Beispiel besonders energieintensive Praktiken zu verdrängen? Die beiden zentralen Fragen an dieser Stelle lauten somit: Auf welchen Wegen haben die beiden hier analysierten neuen Heizansätze bisher bereits erfolgreich neue Anhänger*innen geworben und tatsächlich erfasst? Wie sind die Praktiken des passiven und des smarten Heizens für die 
Praktizierenden zu attraktiven Alternativen gegenüber konventionellen Heizansätzen geworden? Dieser Perspektivwechsel wird vorgenommen, da er dabei hilft, festgefahrene Verstehensgewohnheiten aufzubrechen. Auch lässt sich die Entwicklung genereller sozialer Konsummuster dadurch womöglich eher verfolgen und verstehen. Im Folgenden sollen die im Fall des passiven und des smarten Heizens bereits erfolgreich zum Tragen gekommenen Wege zur Rekrutierung von Teilnehmer*innen aus dem empirischen Material herausgearbeitet werden.

$\mathrm{Ob}$ und wie schnell sich moderne, nachhaltige und energieeffiziente Heizformen wie das Passivhauskonzept oder das intelligente Heizen gegen konventionelle, noch deutlich energieintensivere Heizansätze, die zudem häufig auf fossilen Energieträgern basieren, durchsetzen, ist mitentscheidend dafür, wie rasch und effektiv der Ausstoß an heizungsbedingten $\mathrm{CO}_{2-}^{-}$ Emissionen gesenkt werden kann.

Beide in dieser Arbeit untersuchten Heizansätze haben spezifische Eigenschaften, die sie in den Augen potenzieller neuer Anhänger*innen für eine Übernahme attraktiv erscheinen lassen. Zum Teil verbreiten sich beide Heizansätze auf sehr unterschiedlichen Wegen, teilweise werden neue Träger*innen aber auch auf gleiche Weise in den Bann der Praktiken gezogen.

Allerdings war die Ausgangslage für die beiden in dieser Arbeit analysierten Heizansätze bei ihrer Rekrutierung der interviewten Nutzer*innen höchst unterschiedlich. Anders ausgedrückt: Die grundlegende Herangehensweise, die am Anfang des ,Eroberungsprozesses' der Praktik des passiven Heizens bei den für diese Arbeit interviewten neuen Passivhausbewohner*innen stand, ist eine gänzlich andere gewesen, als die Basisstrategie, die anfangs bei den interviewten, neu rekrutierten Nutzer*innen einer intelligenten Heizungsteuerung wirksam wurde. Während alle Passivhausbewohner*innen, mit denen gesprochen wurde, freiwillig und bewusst willentlich in ein Passivhaus gezogen sind - auch diejenigen, bei denen das Passivhaus nicht das Haupt- oder sogar überhaupt kein relevantes Entscheidungskriterium war -, wurde den interviewten Mieter*innen die intelligente Heizungsteuerung auf Geheiß ihrer Vermieterin (der Wohnungsbaugenossenschaft) eingebaut. Das heißt, diese Mieter"innen nehmen jetzt alle mehr oder weniger unfreiwillig bzw. gezwungenermaßen an der neuen Praktik des smarten Heizens teil.

Neben der Ausgangslage unterscheiden sich auch die beiden in dieser Arbeit betrachteten Technologien selbst sehr stark voneinander. Aus diesem Grund erfolgt die Darstellung der Rekrutierungs- und Werbungsverläufe in diesem Kapitel ausnahmsweise nicht fallübergreifend, sondern ge- 
trennt, also fallweise, wobei mit der Beschreibung von Entscheidungsprozessen für ein Passivhaus begonnen und sich dann im Anschluss den Anwerbungs- und Rekrutierungsprozessen neuer Teilnehmer*innen für smartes Heizen gewidmet wird.

In den Gesprächen mit Passivhausbewohner*innen sind verschiedene Wege und Muster von Akteurskonstellationen erkennbar, die es der Praktik des passiven Heizens damals ermöglichten, diese Anwender*innen für sich zu gewinnen. Aus den unterschiedlichen Verläufen der Passivhausbau- und -wohnprojekte lassen sich somit mehrere Möglichkeiten und Wege ableiten, wie das Heizen im Passivhaus bisher erfolgreich bei der Rekrutierung von Teilnehmer*innen war und möglicherweise auch in Zukunft erfolgreich neue Träger"innen für sich einnehmen kann.

Die fünf zentralen Pfade, die im Interviewmaterial identifiziert werden konnten, auf denen die Praktik des passiven Heizens bei ihrer Teilnehmer*innenrekrutierung offensichtlich besonders erfolgreich war, sind folgende:

- Kopplung bzw. das ,Sich-koppeln' an andere, den potenziellen Anwender*innen vorrangig wichtige Belange, wie z.B. das Wohnen in Gemeinschaft, eine attraktive Wohnlage, bezahlbarer Wohnraum oder allgemein Kostenersparnis

- Demonstration, also die anschauliche und anregende (Eigen-)Präsentation im alltäglichen, lebensweltlichen Kontext, inklusive der Möglichkeit für die Adressat"innen, eigene Erfahrungen zu machen (vgl. Wilhite 2012: 96)

- Das Suchen nach Meinungsführer*innen, die der Praktik bereits mit Begeisterung anhängen und die anderen Noch-Nicht-Engagierten deshalb als Vorbild dienen können. Gemeint sind aktive, enthusiastische Praktizierende, die ihre Begeisterung und positive Erfahrung gerne mitteilen und an andere weitergeben möchten, kurzum: Praktizierende, die das (Leben im) Passivhaus aus persönlicher Überzeugung weiterempfehlen (würden)

- Die Nutzung so genannter ,Gelegenheitsfenster und ,teachable moments` (vgl. Schäfer und Bamberg 2008; Jaeger-Erben 2010; Schäfer et al. 2012). Damit ist gemeint, dass der zeitlich-situative Kontext des ,InBerührung-kommens' mit einer Praktik von zentraler Bedeutung dafür ist, ob potenzielle neue Teilnehmer"innen sich in der neu aufgekommenen oder neu entdeckten Handhabung engagieren oder nicht (vgl. Wilhite 2012: 96f).

- Die Rolle von ,Gatekeepern` im Entscheidungsfindungsprozess für eine neue Wohn- oder Heizform 
In den meisten der analysierten Fälle eines neuen Engagements im passiven Heizen handelt es sich - und das dürfte typisch sein - um äußerst facettenreiche Verläufe. Das heißt, bei der Rekrutierung neuer Teilnehmer*innen kam häufig mehr als nur einer der oben aufgezählten Werbungsvorgänge zum Tragen, so dass sich im Nachhinein nicht immer eindeutig feststellen lässt, was letztendlich den Ausschlag für das Engagement des bzw. der jeweiligen, neuen Anhänger*in gegeben hat.

Anders stellt es sich hingegen bei den untersuchten Fällen zum intelligenten Heizen dar. Hier hat sich die Praktik des smarten Heizens selbst nicht um diese größere Teilnehmer*innenschar bemühen müssen, sondern ihr wurde bei der Rekrutierung zugearbeitet - die Praktik wurde gewissermaßen von engagierten Promotor*innen unterstützt. Aus Perspektive der Praktik wird deutlich, dass sie im Wesentlichen andere für sich hat werben lassen. Aus Sicht der von der Maßnahme betroffenen Bewohner"innen kann hier allerdings nicht wirklich von einem direkten und erfolgreichen Eroberungsprozess durch die Praktik gesprochen werden, sondern aus Sicht der zwangsrekrutierten Bewohner*innen lässt sich dieses Vorgehen eher als eine Art ,Zwangsbeglückung' beschreiben.

Aus Praktikenperspektive besteht der erfolgreiche Rekrutierungsweg darin, dass sich die Praktik des smarten Heizens starke und einflussreiche Promotor*innen gesucht hat, die aktiv für sie geworben und ihr auf diesem Wege geholfen haben, sich zu verbreiten. Im Fall smarten Heizens ist also zu beobachten, dass einige, der bereits von diesem Heizansatz Eingenommenen nun als ,Botschafter"innen' der Praktik tätig sind und dadurch unterstützend wirken, neue Teilnehmer*innen für smartes Heizen zu gewinnen. Hieraus lässt sich eine weitere, offenbar sehr effektive Vorgehensweise ableiten, die Praktiken dazu verhilft, möglichst schnell eine große Zahl neuer Anhänger*innen zu gewinnen:

- Das Suchen und Einspannen von professionellen, einflussreichen und besonders engagierten Promotor*innen, die auch aus Eigeninteresse intensiv für eine bestimmte Praktik werben

Im Fall der intelligenten Heizungssteuerung treten vor allem große und mittelgroße Energieversorgungsunternehmen als engagierte Promotoren auf. Mit ihrem Agieren verhelfen sie der Praktik des smarten Heizens aber keineswegs uneigennützig bei ihrer Weiterverbreitung, sondern der primäre Nutzen besteht für diese Unternehmen in nichts Geringerem als der Sicherung des eigenen Fortbestehens und dem Erhalt der eigenen Existenzgrundlage. Darüber hinaus dient das Unternehmensengagement im Bereich ,SmartHome' den betreffenden Unternehmen klassisch als Strategie der Gewinnoptimierung. Für die Analyse dieses Falls waren deshalb die In- 
terviews mit den SmartHome-Expert*innen, die alle bei einem großen oder mittelgroßen Energieversorgungsunternehmen arbeiten, von besonderer Bedeutung. So gibt es aus Sicht der SmartHome-Expert*innen klare ökonomische Eigeninteressen, warum sich die von ihnen vertretenen Unternehmen intensiv darum bemühen und stark dafür einsetzen, dass das smarte Heizen weitere Verbreitung findet. ${ }^{109}$ In den Gesprächen mit SmartHome-Expert*innen wird deutlich, dass die Unternehmen bei ihrer Kund"innenwerbung für SmartHome-Produkte und -Anwendungen zum Teil auf die gleichen Strategien zurückgreifen, die indirekt auch im Fall des Passivhaus-Ansatzes eine Rolle spielen. So setzen die Unternehmen beispielsweise ebenfalls auf Kopplung, Demonstration sowie die Nutzung von ,Gelegenheitsfenstern' und ,teachable moments'. Darüber hinaus nutzen sie zwei weitere Verkaufs- bzw. Werbungsstrategien, die sich besonders stark an den SmartHome-Technik-Anwender*innen und deren Bedürfnissen orientieren. Dies ist zum einen das Eingehen auf Anliegen und Wünsche von bestehenden Kund"innen sowie potenziellen neuen Anwender*innen. Zum anderen versuchen die Unternehmen für die Neu- und Weiterentwicklung von SmartHome-Produkten und -Anwendungen auch gezielt von fortschrittlichen Nutzer*innen, so genannte ,Lead-User', zu lernen.

Im Folgenden werden die unterschiedlichen Pfade, die die Praktiken des passiven und des smarten Heizens bei ihrer Rekrutierung neuer Teilnehmer*innen bisher hauptsächlich beschritten haben, beschrieben. Dafür wurden für den Fall des Passivhauses exemplarisch einige Entscheidungsfindungs- und Implementierungsprozesse, wie einzelne Bewohner*innen und ganze Baugruppen jeweils zu ihrem Passivhaus gekommen sind, rekonstruiert (Teilkapitel 4.5.1). Und für den Fall smarter Heizungssteuerungstechnik wurden exemplarisch einige der von professionellen Promotor"innen bereits erfolgreich angewendeten Verfahren und Methoden zur Neukund"innenwerbung sowie zur Bindung bereits bestehender SmartHome-Produkte-Nutzer*innen nachvollzogen (Teilkapitel 4.5.2).

109 Wie die Energieversorgungsunternehmen hier genau vorgehen, welche Instrumente und Methoden hierbei im Einzelnen angewendet werden, um dem SmartHome-Ansatz in Deutschland zum Erfolg zu verhelfen, ist Inhalt des zweiten Teils dieses Kapitels zu den Wegen zu einer intelligenten Heizungssteuerung (vgl. Teilkapitel 4.5.2). 


\subsubsection{Wege zum Passivhaus}

Die Untersuchung hat gezeigt, dass es offenbar viele unterschiedliche Wege gibt, auf denen Menschen zum Passivhaus gelangen bzw. geführt werden können.

\subsubsection{1 „[D]ass das nun 'n Passivhaus wurde war nun gerade Zufall“ - Herr Werner (und seine zwei Töchter)}

Der Fall Herrn Werners und seiner beiden Töchter macht deutlich, welche entscheidende Rolle Zufall, Glück sowie günstige Momente und Gelegenheitsstrukturen für die erfolgreiche Rekrutierung neuer Praktizierender spielen.

Herr Werner ist Mitte 60, erwerbstätig und verheiratet. Er und seine Frau haben zusammen drei Kinder, zwei Töchter und einen Sohn, die alle bereits im Erwachsenenalter sind. Die Eigentumswohnung im Passivhausprojekt D, die das Ehepaar Werner seit 2011 bewohnt, haben sich die Werners gekauft, als die Kinder alle bereits von Zuhause ausgezogen waren. Vorher hat Familie Werner in einem Reihenhaus in einem Stadtteil in Randlage gewohnt. Das Ehepaar Werner wollte nach dem Auszug der Kinder und auch perspektivisch im Alter unbedingt wieder zentral, am liebsten "mitten in der Stadt wohnen“ (Bewohner PH, Interview 67: 18, 952), um „alles mit 'm Fahrrad machen [zu] können oder äh mit der Bahn“ (ebd.: 19, 972-973) sowie um das kulturelle Angebot in der Stadt wieder besser und mehr nutzen zu können. Nachdem die Kinder alle „aus 'm Haus" (ebd.: 1, 28) waren, haben die Werners dann begonnen, aktiv nach einer Wohngelegenheit in der Stadt zu suchen und sind dabei auf die Baugruppe des Passivhausprojekts D gestoßen. Als die Werners in die Baugemeinschaft aufgenommen wurden, berichtet Herr Werner, „stand schon alles [Wesentliche zum geplanten Gemeinschaftsbau, JM] fest“" (ebd.: 1, 39), unter anderem, dass das Mehrparteienhaus definitiv ein Passivhaus wird. Dass ihr neues Zuhause nun gerade ein Passivhaus geworden ist, bezeichnet Herr Werner als „Zufall“ (ebd., 37). Für seine Entscheidung und die seiner Frau, sich der Baugruppe anzuschließen, sei vielmehr ausschlaggebend gewesen, dass das geplante Haus mitten in der Stadt errichtet werden sollte und dass dem Ehepaar Werner auch die sozialen Rahmenbedingungen der Baugemeinschaft sehr zusagten. Die Tatsache, dass das Bauprojekt von Anfang an als Passivhaus konzipiert war, war für die Werners „in dem Fall erstmal nebensächlich“ (ebd., 45-46) bzw. zu dem Zeitpunkt, als 
sie tatsächlich begannen, sich aktiv um die Aufnahme in die Baugemeinschaft D zu bemühen, war es ihnen, Herr Werner zufolge, sogar „völlig egal“ (ebd.: 2, 74-75). In ihrem Fall war der Aspekt ,Passivhaus' zufällig mit einem anderen Kriterium verbunden, das bei der Wahl ihres neuen Wohnstandorts für die Werners absolut entscheidend war: die Werners wollten zentral wohnen, was für sie „wirklich Komfort, also Lebensqualität“" (ebd.: 19, 976-977) bedeutet.

Herr Werner gibt an, sich erst etwas mehr über Passivhäuser informiert zu haben, als feststand, dass sie in die Baugemeinschaft aufgenommen werden. Und noch intensiver habe er sich mit dieser Art des Wohnens beschäftigt, „als es darum ging überhaupt sich für 'ne Heizung zu entscheiden“ (ebd.: 2, 82-83). Bei der Entscheidung für ein Heizungssystem zur Restwärmeversorgung war Herr Werner anfangs sogar vollkommen gegen das im Passivhausprojekt D letztendlich realisierte, Zuhause-Kraftwerk ${ }^{6}$. Er hätte gerne eine klassische Fernwärmeheizung gehabt. Herr Werner ist damals bei dieser Frage überstimmt worden, sagt nun aber, dass er „letztendlich [...] voll jetzt auch damit zufrieden [ist], dass das eben diese Konzeption wurde" (ebd., 96-98). Das zeigt noch einmal, dass Herr Werner nicht durch eigene Absicht und Wunsch zum Passivhaus mit entsprechender Heizlösung gekommen ist, sondern vielmehr, auf Umwegen', dass ihn das endgültige Resultat nun aber doch überzeugt hat.

Dass die neuen und positiven Erfahrungen der Werners mit dem Passivhaus und ihrer besonderen Heizlösung für die Restwärmeversorgung auch auf ihre Kinder gewirkt haben, verdeutlichen die Wohngeschichten der beiden Töchter: Während die eine Tochter aktuell in einer Wohnung mit alter Nachtspeicherheizung lebt und offenbar höchst unzufrieden mit der Wärmeversorgung in ihrer Wohnung ist, hat die andere Tochter mit ihrer kleinen Familie aktiv die Möglichkeit wahrgenommen, selbst eine (Genossenschafts-)Wohnung in einem Mehrfamilien-Passivhaus zu beziehen.

Auf die Frage, ob er seinen Kindern die Funktionsweise des Passivhauses bzw. die der Lüftungsanlage und die der Heizung nähergebracht habe, äuBert Herr Werner, dass sich seine Kinder von sich aus an dieser Art des Wohnens und Heizens interessiert gezeigt hätten und berichtet daraufhin ausführlicher von den momentanen Wohnsituationen seiner beiden Töchter. Der folgende Interviewausschnitt macht deutlich, dass das elterliche Passivhausprojekt den Kindern als positives Beispiel dient, das die eine Tochter offenbar bereits zur Nachahmung motiviert hat. Vor allem aber verdeutlicht die Interviewpassage, wie sehr Herr Werner selbst mittlerweile den Wärmekomfort seiner Passivhauswohnung schätzt: 
Herr Werner: Ja die haben sich schon so 'n bisschen auch dafür interessiert weil meine eine äh- ich hab eine Tochter die ist- [...]. die wohnt ähm da und hat ähm 'ne Zweieinhalb-Zimmer-Wohnung und mit Nachtspeicherheizung. Das ist natürlich ech- äh ätzend weil wir äh letztens dann noch mal- weil d- d- weil sie sagt natürlich auch wenn sie abends nach Hause kommt dann würde sie am liebsten gut- 'ne gut geheizte Wohnung vorfinden. Und dann ist also das eigentlich schon wieder so abgekühlt dass es erst am nächsten Morgen wieder warm wird wenn sie's nicht braucht weil sie dann wieder zur Arbeit geht. Also das ist schon sehr hm bescheuert. $\mathrm{Na}$ ja und meine andere Tochter die äh ist jetzt vor einer Woche in- [...]. Und da ist sie in eine Genossenschaftswohnung eingezogen. Und die ist auch im Passivhaus. [...] und da und da werden ganz viele Wohnungen gebaut. Das sind auch Baugemeinschaften und so. Und äh sie hat über ihre ehemalige ähm Wohnungsbaugesellschaft wo sie äh 'ne Wohnung hatte davon dann gehört und dann hat sie sich dann relativ schnell beworben. Und dann hat sie dann glücklicherweise denn da äh 'ne Wohnung bekommen 'ne Vier-Zimmer w- weil sie mittlerweile verheiratet ist und 'n Kind hat. Und das- das passt natürlich schon gut.

Interviewerin JM: Und jetzt wohnt sie da auch im Passivhaus $L$ in ihrer Wohnung?

Herr Werner: Ja ja die wohnt im Pa- Passivhaus. $\lrcorner$

Interviewerin JM: Und ist- wurde sie sozusagen von dem- von Ihrem Wohnen hier inspiriert oder kam sie dadrauf-?

Herr Werner: Das hier- äh ich meine [in dieser Stadt] äh da kann man sich eigentlich nichts aussuchen.@(.)@ [...] Man ist ja froh wenn man 'ne Wohnung findet. Und und äh das ist natürlich on top. Das nimmt man natürlich gerne mit. Aber man hätt' ja j- jede andere Wohnung auch genommen."

(Bewohner PH, Interview 67: 11f, 542-612)

Der Passage lässt sich entnehmen, dass die Tochter, die zurzeit in einer Wohnung mit Nachtspeicherheizung wohnt, äußerst unzufrieden mit der Funktionsweise derselben ist und dass es ihr in der eigenen Wohnung regelmäßig nicht warm genug ist. Herr Werners Schilderung ist zu entnehmen, dass die Nachtspeicherheizung genau antizyklisch zu den typischen Anwesenheitszeiten der Tochter arbeitet und dadurch Raumwärme überwiegend nur zu für die Tochter ungünstigen Zeiten bereitstellt: Wenn die Tochter abends nach der Arbeit nach Hause kommt, ist der über Nacht gespeicherte Wärmevorrat meist längst wieder aufgebraucht, so dass die Wohnung schon auszukühlen begonnen hat. Das heißt, dann, wenn die 
Tochter Wärme haben möchte und benötigt, ist keine Wärme (mehr) vorhanden.

Durch die Wohn- und Heizsituation seiner Tochter erlebt Herr Werner gerade im direkten, nahen Umfeld, wie groß die Komfortunterschiede zwischen Passivhaus und konventionellen Wohnkontexten mit entsprechend alten Heizlösungen sind. Dieser direkte Vergleich hat ihm bewusst gemacht, wie behaglich er es jetzt in seiner Passivhauswohnung hat und wie entsprechend komfortabel die Wärmeversorgung in einem Passivhaus geregelt ist. Dass Herrn Werner die Beheizung der Wohnung der Tochter vor dem Hintergrund seiner eigenen aktuellen Wohnsituation im Passivhaus betrachtet und beurteilt, wird auch an seinen deutlich negativen Bewertungen der Heizsituation seiner Tochter deutlich.

Weiterhin ist der Passage zu entnehmen, dass die andere Tochter der Werners mit ihrer kleinen Familie gerade erst selbst in eine Genossenschafts-Mitwohnung im Passivhausstandard gezogen ist. Deutlich wird, dass das Passivhaus in ihrem Fall ein ,Mitnahmeeffekt" war. Ihr hat sich zufällig die Gelegenheit geboten, es ihren Eltern nachzumachen und in eine für sie und ihre kleine Familie passende Mitwohnung im Passivhausstandard zu ziehen. Der Beschreibung des Herrn Werner ist zu entnehmen, dass die junge Familie ohnehin in eine größere Wohnung ziehen wollte und aktiv auf der Suche war. Die Tochter hat über ihre ehemalige Wohnungsbaugesellschaft, bei der sie offenbar früher einmal eine Wohnung gemietet hatte, von der neu gebauten Passivhaussiedlung erfahren und sich daraufhin „relativ schnell“ (ebd.: 12, 592-593) für eine Wohnung dort beworben und ganz offensichtlich Erfolg gehabt.

Zwar sagt Herr Werner, dass seine Tochter aufgrund des angespannten Wohnungsmarktes [in der Großstadt] ,jede andere Wohnung auch genommen“ (ebd.: 12, 612) hätte, die für die junge Familie in Frage gekommen wäre. Dass er aber von ,Glück spricht (vgl. ebd., 593), dass seine Tochter nun ausgerechnet eine ausreichend große Wohnung in einer neu errichteten Passivhaus-Wohnsiedlung bekommen hat und er das Merkmal ,Passivhaus‘ als Bonus bzw. zusätzlichen Vorteil bezeichnet, den „man natürlich gerne mit[nimmt]“ (ebd., 611), verdeutlicht, wie groß seine eigene Begeisterung und Überzeugung vom Wohnkomfort des Passivhausstandards mittlerweile ist. Aus diesem Grund freut sich Herr Werner für seine Tochter, dass sie mit ihrer kleinen Familie nun auch das Glück hat, in den besonderen Genuss des Passivhauswohnkomforts zu kommen.

Insgesamt verdeutlicht der Fall Herrn Werners die besondere Bedeutung von anfänglichem Zufall gepaart mit eigener, leiblicher Erfahrung. Zu Anfang war Herr Werner noch eher gleichgültig bis skeptisch gegenüber dem 
Passivhausstandard. Mittlerweile, nach etwa zwei Jahren eigener Erfahrung des Lebens im Passivhaus, ist er äußerst zufrieden mit seiner neuen Wohnsituation und weiß den besonderen Wärmekomfort sehr zu schätzen. Herr Werner wurde von der Passivhauspraxis regelrecht, erfasst'.

Darüber hinaus macht die Fallgeschichte Herrn Werners und seiner Töchter deutlich, dass für eine erfolgreiche Rekrutierung neuer PraktikenAnhänger*innen offenbar entscheidend ist, dass es eine günstige Gelegenheit gibt, bei der potenzielle Praktizierende mit der neuen, ihnen bis dahin eventuell noch vollkommen unbekannten Praktik selbst direkt in Berührung kommen. Der Fall Herrn Werners und seiner Töchter zeigt hier zwei mögliche Wege auf: Entweder potenzielle Anhänger"innen werden - wie damals die Eheleute Werner - mehr oder weniger zufällig mit der neuen Praktik konfrontiert, etwa indem die neue Praktik an andere, den potenziellen Anhänger*innen besonders wichtige Belange und Themen gekoppelt ist; und die potenziellen neuen Teilnehmer*innen zeigen sich dann offen, sich auf etwas Unbekanntes einzulassen und Neues auszuprobieren. Dadurch können die Vor- und/oder auch Nachteile eines neuen Ansatzes direkt selbst, sozusagen am eigenen Leib erlebt werden. Oder - wie im Fall der Kinder der Werners - potenzielle neue Teilnehmer*innen kommen durch ihr nahes und vertrautes soziales Umfeld mit einer neuen Praktik in Kontakt. Sie bekommen diese durch Verwandte, Bekannte oder Freunde, usw. präsentiert und haben dadurch die Möglichkeit, die Praktik erst einmal bei anderen mitzuerleben und auf diese Weise aus sicherer Distanz kennenzulernen. Dieses Vorgehen hat den Vorteil, dass künftige Praktizierende zusätzlich von den Erfahrungen der bereits in der Praktik Engagierten profitieren können.

Im Fall Herrn Werners und seiner Töchter besaß das elterliche Passivhauswohnprojekt genau solch einen Demonstrationscharakter für die Kinder der Werners. So konnten die erwachsenen Kinder das Wohnen und Heizen im Passivhaus bei ihren Eltern von Anfang an miterleben, ohne dabei selbst das Risiko des Scheiterns oder des Enttäuscht-werdens einzugehen oder tragen zu müssen. Sie konnten selbst entscheiden, ob sie die neue Wohnform der Eltern für so gut befinden, dass es für sie erstrebenswert erscheint, diese elterliche Praxis bei passender Gelegenheit nachzuahmen. Dass eine Tochter der Werners die Gelegenheit, an eine Mitwohnung im Passivhausstandard zu gelangen, genutzt hat, als diese sich ihr bot, zeigt, dass die bei den Eltern beobachtete Praxis offenbar nicht abschreckend, sondern vielmehr motivierend gewirkt hat, ebenfalls das Wohnen in einem Passivhaus anzustreben. 


\subsubsection{2 „Also das [Passivhaus] erlebe ich als dermaßenen Sprung in der} Lebensqualität bezogen jetzt auf so 'n Altbau - Herr Barth

Mit Herr Barth kommt noch ein Fall hinzu, bei dem eine besonders große Wandlung stattgefunden hat: Stand Herr Barth dem Passivhaus anfangs noch äußerst skeptisch bis ablehnend gegenüber, ist er mittlerweile ein „große[r] Fan von dieser Art des Bauens und dieser Art des Lebens auch geworden“ (Bewohner PH, Interview 68: 17, 903-905). Ähnlich wie Herr Werner ist auch Herr Barth eher auf Umwegen zum Passivhaus gekommen. Und genauso wie Herr Werner ist Herr Barth nun ein begeisterter Anhänger des Passivhauses. Der Fall Herrn Barths verdeutlicht, wie ein gelungener Praktiken-Vereinnahmungsprozess aussehen und im Detail verlaufen kann.

Herr Barth ist Anfang 40, verheiratet und hat zwei Kinder. Er ist als Selbstständiger in der Kreativwirtschaft tätig und arbeitet im Bereich Webdesign. Die Eigentumswohnung der Familie Barth befindet sich im Passivhausprojekt D. Das Interview mit Herrn Barth findet am Esstisch im offenen Wohnzimmer statt.

Genauso wie Herr Werner erzählt mir Herr Barth, sei es „eher dem Zufall geschuldet“ (ebd.: 1, 19) gewesen, dass sie sich am Bau des Passivhausprojekts D beteiligt haben und nun eine Eigentumswohnung im Passivhausstandard besitzen und bewohnen. Die Familie Barth ist als letzte Partei der Baugruppe beigetreten. Herr Barth erzählt, dass Freunde, die ebenfalls im Passivhausprojekt D wohnen, sie damals angesprochen hätten, ob sie sich nicht auf die letzte freie Wohnung bewerben wollten. Da die Barths zu diesem Zeitpunkt ohnehin auf Wohnungssuche waren und sich das Bauprojekt zudem noch in ihrem präferierten Stadtteil befand, sind sie nach längerem Überlegen schlussendlich dem Vorschlag der Freunde gefolgt. Sie haben sich beworben und sind gleich in die Baugemeinschaft aufgenommen worden. Interessant ist, dass Herr Barth in diesem Zusammenhang erzählt, dass sie bereits drei Jahre vorher von der Baugemeinschaft gehört hätten, jedoch das Bau- und Wohnprojekt ihnen damals für sich selbst nicht attraktiv erschienen sei. Herr Barth begründet an dieser Stelle nicht, weshalb das Projekt zum damaligen, früheren Zeitpunkt für sie „noch nicht“ (ebd., 28) in Frage kam. Die Erwähnung seiner anfänglich ablehnenden Haltung gegenüber dem Passivhausprojekt deckt sich aber mit der hier präsentierten Deutung der Fallgeschichte Herrn Barths, nämlich, dass sich eine radikale Veränderung sowohl in Herrn Barths Handeln als auch in seinem Denken bezüglich des Passivhauses von damals bis heute vollzogen hat. 
Zwar hätten sie von Anfang gewusst, dass das Hausprojekt als Passivhaus konzipiert war, erklärt Herr Barth weiter, dem hätten sie aber „zunächst mal jetzt nicht zu große Bedeutung beigemessen“ (ebd.: 1, 32). Wie Herr Werner hat sich auch Herr Barth erst näher über Passivhäuser informiert, als klar war, dass er bald selbst eines mit anderen gemeinsam bauen und bewohnen würde.

Die Barths haben zuvor lange im klassischen Altbau gewohnt, weshalb sie zunächst etwas gezögert und überlegt haben, ob sie tatsächlich in solch einen modernen Neubau wie ein Passivhaus ziehen möchten, wo der Heizund Lüftungsvorgang praktisch nur noch durch die Technik kontrolliert wird. Hingegen habe sein beratendes soziales Umfeld, so berichtet Herr Barth, ihnen gegenüber eher Bedenken wegen des Bauens in Gemeinschaft geäußert. Hier hatten die Barths wiederum wenig Bedenken. Aus dem folgenden Interviewausschnitt geht vielmehr hervor, dass die Baugruppe bzw. die konkret am Projekt beteiligten Mitglieder genau eine der mit ausschlaggebenden Variablen dafür waren, dass sich die Barths letztlich für den Einstieg in das Passivhausbauprojekt D entschieden haben. Darüber hinaus macht die Passage deutlich, dass Herr Barth persönlich eher Probleme damit hatte, in ein Passivhaus zu ziehen und damit, dass die Entscheidung für das Bauprojekt gleichzeitig bedeutete, dass er Haus- bzw. Wohnungseigentümer werden würde, was für ihn offenbar eine höchst unangenehme Vorstellung war:

„Ja also [...] ich hab mich auch schwer getan überhaupt in in so 'n Ding da zu ziehen ja? Das war jetzt nicht äh ein ein Schritt der irgendwie logisch war oder sonst irgendwas. Und ich hab mich auch lange gesperrt äh überhaupt Eigentum zu erwerben ja. Und äh hier haben halt einfach die Umgebungsvariablen gepasst. Die Leute haben gepasst. Das Projekt hat gepasst. Äh die Ansprüche die das Projekt hatte haben gepasst und (1) äh unser Bedarf ist gedeckt worden ja den wir hatten. Und in [zentral gelegener und bei jungen Familien besonders beliebter Stadtteil] mit zwei Kindern äh 'ne größere Wohnung zu finden äh ja das wollen viele ja also [...] da brauchst du eigentlich nur in die Kita zu gehen (.) und dann weiß man da gibt's noch zwanzig andere allein in meiner Kita die auch gerne sowas hätten ja." (Bewohner $\mathrm{PH}$, Interview 68: 14f, 741-757)

Der Beschreibung lässt sich entnehmen, dass Herr Barth mit der Teilnahme am Bau- und Wohnprojekt D seine persönlichen Hemmnisse überwunden hat und diese Entscheidung im Nachhinein nicht bereut. Dass er diese Entscheidung überhaupt nicht bereut, sondern im Gegenteil, mittler- 
weile überzeugt ist, damals die richtige Entscheidung getroffen zu haben, wird an anderer Stelle im Interview deutlich: Hier bezeichnet Herr Barth die Entscheidung für das Passivhausprojekt D retrospektiv als „die beste Entscheidung die wir [er und seine Frau, JM] in den letzten fünf Jahren getroffen haben seit die Kinder da sind" (ebd.: 2, 82-83).

Zudem geht aus der Passage hervor, dass für Herrn Barths positive Entscheidung für das Passivhausprojekt damals noch zahlreiche andere Faktoren eine Rolle gespielt haben, die nicht direkt mit dem (Gebäudetyp) Passivhaus zusammenhängen. Deutlich wird, dass den Barths von Anfang an die Mitglieder der Baugemeinschaft sympathisch waren, die Projektstruktur ihnen zugesagt hat, die geplante Wohnungsgröße ihrem Bedarf und ihren Vorstellungen entsprach und ihnen insbesondere die Wohnlage sehr attraktiv erschien. Hieraus lässt sich ableiten, dass alles zusammen, gewissermaßen das ,Gesamtpaket', die Barths im zweiten Anlauf davon überzeugt hat, sich dem Bau- und Wohnprojekt anzuschließen. Dass sich Herr Barths anfängliche Skepsis, die bei ihm vor allem auch gegenüber der Passivhaustechnologie bestand, inzwischen in reinste Euphorie gewandelt hat, hängt offenbar entscheidend mit den in dieser Passage beschriebenen „Umgebungsvariablen“ (ebd.: 14, 746) des Hausprojekts zusammen, die „einfach [alle] gepasst [haben]" (ebd., 745-746).

Während Herr Barth im Vorfelde noch ernsthafte Bedenken insbesondere bezüglich der Funktionsweise der Passivhauslüftungstechnologie hatte, ist er nun ausgerechnet von diesem Lüftungssystem (und dem dazugehörigen alternativen Heizansatz) vollkommen begeistert, wie folgendes Zitat verdeutlicht:

„Also dadurch dass wir das Umluftsystem haben ähm is halt auch relativ- also es sind ja jetzt schon zwei Jahre Erfahrung mit den- äh mit den Wintern. Und das funktioniert perfekt also- (1) dass es eigentlich in allen Räumen kontinuierlich in allen Räumen 'ne Temperatur hat. Also das erlebe ich als dermaßenen Sprung in der Lebensqualität bezogen jetzt auf so 'n Altbau wo es überall zieht und äh immer- immer je nach Situation im Zimmer irgendwie in Kältezonen steht oder sitzt und-“ (Bewohner PH, Interview 68: 5, 258-265)

Der Passage lässt sich entnehmen, dass die Lüftung in der Wohnung der Familie Barth so funktioniert, wie es sich Herr Barth vorstellt, wie solch ein modernes Lüftungssystem funktionieren sollte, nämlich, dass die kontrollierte Be- und Entlüftung mit Wärmerückgewinnung kontinuierlich für eine angenehme Grundwärme in allen Räumen sorgt. Herr Barth vergleicht das Wärmeerleben im Passivhaus mit dem Raumwärmegefühl im 
Altbau. Deutlich wird, dass er hier einen sehr großen Unterschied wahrnimmt: Während Herr Barth im Altbau in der gesamten Wohnung ständig einen Luftzug verspürte und es immer ein deutlich wahrnehmbares Temperaturgefälle innerhalb der einzelnen Räume gab, ist es im Passivhaus stets in allen Räumen gleichmäßig warm, was er als sehr angenehm empfindet. Die Schilderung zeigt, dass Herr Barth regelrecht hingerissen vom Wärmeerleben im Passivhaus ist und er die Veränderung hinsichtlich des Wärmekomforts von Altbau zu Passivhaus als enorme Verbesserung erlebt. Seine Formulierung „das erlebe ich als dermaßenen Sprung in der Lebensqualität“ (ebd.: 5, 262-263) lässt darauf schließen, dass sich Herr Barth einen solch großen Unterschied vorab nicht vorgestellt hat und er nun einmal kennengelernt - nicht mehr auf diesen Wärmekomfort verzichten und nicht mehr unter diesen (Energie-)Standard sinken möchte.

In dieser Passage deutet sich bereits an, was im Fall Herrn Barths den Sinneswandel in Bezug auf das Passivhaus und die damit verbundene Technik bewirkt hat. Für Herrn Barth war offensichtlich die positive eigene Erfahrung, also die tatsächliche Praxis entscheidend.

Dass es aber nicht nur das persönliche Erleben war, das Herrn Barth vom Passivhaus überzeugt hat bzw. wodurch er für die Praxis des Passivhauses eingenommen wurde, sondern dass noch weitere Faktoren eine zentrale Rolle dabei gespielt haben, dass er sich vom Skeptiker zum begeisterten Anhänger „dieser Art des Bauens und [...] des Lebens“ (ebd.: 17, 904-905) entwickelt hat, geht aus seiner bilanzierenden Äußerung am Ende des Interviews hervor:

„Also ich k- kann also wenn- wenn mich heute jemand fragen würde wie das ist mit dem Passivhaus dann äh kann ich da sozusagen einfach sagen dass äh durch Information und Aufklärung äh und realer Erfahrung ich zu 'nem großen Fan von dieser Art des Bauens und äh dieser Art äh des- des Lebens auch geworden bin ja dass äh meine Skepsis sich in äh- ja die in- in Überzeugung einfach verändert hat ja das äh denke ich dass- also die Me- Also ich glaube es sind so- $[\ldots]$ ich=schätz mal so zwanzig Prozent Mehrkosten die so 'n Projekt hat. Äh u- u- und ich denke aber wenn ma- die Möglichkeit hat dann sollte man versuchen die zu nutzen.“ (Bewohner PH, Interview 68: 17, 900-910)

Der Passage lässt sich entnehmen, dass auch vermitteltes Wissen in Form von „Information und Aufklärung“ (ebd., 902-903) dazu beigetragen haben, dass sich Herr Barth zur Teilnahme am Passivhausprojekt D motivieren ließ und er nach wie vor von dieser Entscheidung überzeugt ist. An mehreren Stellen im Interview bringt Herrn Barth deutlich zu Ausdruck, 
dass für ihn hierzu vor allem die verantwortliche Architektin einen entscheidenden Beitrag geleistet habe. Diese sei immer mit der Baugruppe im Gespräch gewesen, habe „immer versucht, auf [die] Wünsche [der künftigen Bewohner*innen] einzugehen" (ebd.: 2, 95-96) und bei Differenzen „dann immer auch zu vermitteln [versucht]" (ebd., 96-97). Letztendlich habe die Architektin „den ganzen Laden zusammengehalten“ (ebd., 91) und „sehr strukturiert“ (ebd., 92-93), manchmal zwar „nicht so richtig verständlich aber sehr beruhigend [...] unaufgeregt die ganze Sache das ganze Projekt auch vorangetrieben" (ebd., 93-95). All diese Formulierungen sowie die folgende Aussage Herrn Barths: „also das hätte ich jetzt auch der Architektin nicht zugetraut dass sie ein Haus baut [...] von dem sie selber nicht überzeugt ist dass man da hinterher gut wohnen drin kann“ (ebd.: 3, 149-151), verdeutlichen, dass Herr Barth von Beginn an großes Vertrauen in die Architektin und ihre Arbeit hatte.

Darüber hinaus haben Herrn Barth auch logische Argumente und Überlegungen davon überzeugt, dass es lohnenswert und sinnvoll ist, die anfänglichen Mehrkosten, die der Bau eines Passivhaues bedeutet, zu investieren. So argumentiert er, dass diese Mehrkosten letztendlich „ja eher auch 'n Vorteil" (ebd.: 3, 143) gewesen seien, „,weil [die Baugruppenmitglieder, JM] ja wussten dass- das Haus teurer [wird] dadurch dass es 'n Passivhaus ist" (ebd., 143-144) und den Mitgliedern der Baugruppe damit auch von Anfang an klar war, dass das Bauprojekt dadurch „, [g]leichzeitig in 'ne [finanzielle] Förder- äh Möglichkeit rein[rutscht]", die wieder[rum] allen [Mitgliedern der Baugruppe, JM] zugutekommt" (ebd., 144-146). Auch habe er sich überlegt, so argumentiert Herr Barth weiter, dass „aus [s]einer Sicht es jetzt auch keinen Sinn gemacht [hätte] so 'ne Struktur so 'n Passivhaus zu fördern wenn da irgendwie die danach folgende Wohnqualität nicht äh entsprechend gut gewesen wär“ (ebd., 146-149). Das lässt die Schlussfolgerung zu, dass Herr Barth auch in staatliche Strukturen vertraut bzw. an die Effektivität von Politik glaubt.

Dass das Passivhaus für Herrn Barth mittlerweile die bevorzugte Wahl darstellt und er - wenn möglich - nie wieder umziehen und in einem Haus oder einer Wohnung mit geringerem Energieeffizienz- und Komfortstandard wohnen möchte, macht auch die folgende Aussage Herrn Barths noch einmal eindringlich deutlich:

„also natürlich würde ich auch wieder in 'n Altbau ziehen ja wenn äh die Umstände es notwendig machen. Aber wenn ich jetzt die Wahl hätte dann äh phhh würde es mir reichen wenn ich am Ende hier (.) raus getragen werde.“ (Bewohner $\mathrm{PH}$, Interview 68: 15, 772-775) 
Dieses Statement, dass er für den Rest seines Lebens in seiner Passivhauswohnung leben möchte, lässt erkennen, dass Herr Barth regelrecht ,absorbiert' bzw. ,ergriffen' von der Passivhauspraxis ist. Damit dient der Fall Herrn Barths als ein Beispiel für einen überaus erfolgreichen Rekrutierungsverlauf eines neuen Teilnehmers aus der Perspektive sozialer Praktiken. An diesem Beispiel ist gut zu erkennen, wie es neuen Praktiken gelingen kann, potenzielle Teilnehmer*innen von alten, noch wenig nachhaltigen Praktiken abzuwerben, die potenziellen Teilnehmer*innen also dazu zu bewegen, ihre knappen Ressourcen wie Zeit, Arbeitskraft, Leidenschaft/ Engagement und Geld von veralteten Praktiken ,abzuziehen' und stattdessen in neue, deutlich umwelt- und klimaschonendere Praktiken zu investieren.

Als die Interviewerin Herrn Barth gegen Ende des Interviews noch fragt, ob sich ihm die Möglichkeit biete, seine gesammelten Erfahrungen auch weiterzugeben, gibt er nach kurzem Überlegen zur Antwort:

„(2) Also jetzt 'ne unmittelbare Möglichkeit äh nicht äh jetzt über persönliche Kontakte hinaus ja. Irgendwie jetzt da- äh mal im Job äh drüber zu sprechen oder eben wenn wir Besuch bekommen irgendwo äh in äh in- ja in- in Smalltalk auf Partys oder so. Ja:a also das ist eigentlich das was- Jo.“ (ebd.: 18, 937-945)

Offenbar nutzt Herr Barth bereits einige Gelegenheiten, um über seine persönlichen, äußerst positiven Erfahrungen mit dem Passivhaus zu sprechen. Hieran wird erkennbar, dass überzeugte und zufriedene Praktikenanhänger*innen durchaus im Sinne der betreffenden Praktik agieren, diese aktiv promoten (können) und der Praktik auf diese Art und Weise zu ihrer weiteren Verbreitung verhelfen können. Man könnte sagen, dass begeisterte Praktikenteilnehmer*innen damit häufig klassisches Empfehlungsmarketing in Form von Mundpropaganda im ,warmen Markt betreiben. ${ }^{110}$

110 Dem so genannten,warmen Markt ${ }^{\star}$ gehören all die Menschen an, die der bzw. die betreffende Praktizierende persönlich kennt bzw. zu denen bereits irgendeine Art von (persönlicher) Beziehung oder lockerer Verbindung besteht. 
4.5.1.3 „Ja also ich würde wahrscheinlich jetzt nich in einen Altbau einziehen [...] würde ich jetzt nich mehr machen. Wenn ich es mir leisten könnte“ - Herr Frings

In diesem Zusammenhang ist der Fall des Herrn Frings interessant. Genauso wie Herr Barth ist Herr Frings vom klassischen Altbau in das Passivhausprojekt D eingezogen. Doch im Gegensatz zur Familie Barth, die sich im Vorhinein weder auf Alt- noch auf Neubau festgelegt hatte, haben die Frings' damals, als sie umziehen wollten, zunächst gezielt nach einem Altbau gesucht, weil sie den Charme und Stil dieser Häuser bevorzugen. Allerdings ist ihnen bei ihrer Suche nach einer geeigneten Altbauwohnung für eine fünfköpfige Familie schnell klar geworden, dass sie sich den Kauf einer Altbauwohnung direkt in der Innenstadt wahrscheinlich nicht leisten können - erst recht nicht, wenn sie von Anfang an noch eine gewisse Geldsumme für etwaige, notwendige Sanierungsmaßnahmen miteinkalkuliert hätten, die laut Herrn Frings bei den Objekten, die sie sich angesehen haben, auf jeden Fall noch angefallen wäre.

Offenbar genau in dieser Phase, als sich die Familie Frings - offensichtlich von ihren Erfahrungen auf dem Wohnungsmarkt desillusioniert - allmählich von ihrem Wunschtraum verabschiedete, eine attraktive und bezahlbare Altbauwohnung mitten in der Stadt zu finden, erfuhren sie von dem Passivhausbauprojekt D. Herr Frings beschreibt es folgendermaßen:

„Und dann kam auf einmal dieses Angebot und dann haben wir gesagt gut das is schon (.) passt alles zusammen Nachbarn und Lage und dazu is neu und so. Und is bezahlbar." (Bewohner PH, Interview 66: 27, 1348-1351)

Das Angebot erreichte die Frings` zu einem (günstigen) Zeitpunkt, zu dem sie sich mittlerweile scheinbar vorstellen konnten, in einen Neubau zu ziehen. Darüber hinaus lässt sich der Beschreibung entnehmen, dass es gleich mehrere Argumente gab, die aus der Perspektive der Frings' damals sofort für das Projekt sprachen: So fanden sie die Mitglieder aus der Baugemeinschaft sympathisch, dann erschien ihnen die Wohnlage attraktiv und das Projekt lag ganz offensichtlich im Rahmen ihrer finanziellen Möglichkeiten.

Dass für die Frings' bei ihrer Entscheidung bezüglich einer Beteiligung am Passivhauswohnprojekt D Kostenüberlegungen und das Nachdenken über Finanzierungsmöglichkeiten eine besondere Rolle gespielt haben, wird gegen Ende des Interviews deutlich. Auf die offene standardmäßige Abschlussfrage, ob es noch etwas gebe, das im Interview bisher noch nicht 
zur Sprache gekommen sei, was man aber noch gerne anbringen würde, thematisiert Herr Frings erneut die finanzielle Förderung des Bauprojekts durch die Stadt:

"Gut vielleicht nur ich fand es ganz positiv dass das auch von von der Stadt gefördert war. Also dass man da ein bisschen finanzielle Hilfe dafür gekricht hat. (1) Also das hat uns auch (.) geholfen in der Entscheidung das zu machen. (.) Weil wir am Anfang dachten nee das kriegen wir finanziell nich hin aber als dann klar wurde nee es gibt auch diese Hilfen und so. (.) Das fand ich ganz (1) ganz positiv." (Bewohner PH, Interview 66: 29f, 1501-1507)

Auf die Nachfrage der Interviewerin, welche unterschiedlichen finanziellen ,Hilfen“ es denn gegeben habe, die die Familie Frings letztendlich zur Finanzierung ihrer Passivhaus-Eigentumswohnung in Anspruch genommen habe, beschreibt Herr Frings unter anderem das besondere Kreditmodell zur Restfinanzierung seiner und der meisten anderen Eigentumswohnungen im Projekt, um das sie sich als Baugemeinschaft in Kooperation bemüht haben:

„Also wir haben einerseits die- (.) Gut die Förderung is individuell. Teilweise geht zum Beispiel nach Anzahl der Kinder und so. Dann gibt es die eine Förderung die (.) mit dem Haus zusammenhängt. (1) Und was wir gemacht haben is die Kredite- wir haben versucht- (.) [...]. Also der Rest- Also ein Teil is von diese Wohnungsbaukreditanstalt da äh kriegt man ein bisschen (2) zu sehr günstige Konditionen. Aber die meisten brauchten noch viel mehr Geld um das- Und da haben wir sozusagen in der private Bankwirtschaft versucht (.) etwas Gemeinsames zu machen. (.) Und dann (1) tatsächlich hat es geklappt. Ich glaube alle haben bei der gleiche Bank das gemacht am Ende. (2) Und auch ganz nett eine anscheinend ethisch vertretbare @Bank@ (.).“ (ebd.: 30, 1513-1528)

Herr Frings äußert sich in den beiden letzten Passagen deutlich positiv über die verschiedenen erhaltenen Förderleistungen und das kooperative Restfinanzierungsmodell. Offenbar ist es der Familie Frings nur aufgrund dieses ,Gesamtpakets' günstiger Finanzierungsmaßnahmen möglich gewesen, sich am Passivhausprojekt D zu beteiligen. Aus dem Gesagten lässt sich ableiten, dass Herr Frings nach wie vor zufrieden mit seiner Entscheidung für einen modernen Neubau ist und nicht mehr damit hadert, sich nicht doch wieder für einen Altbau entschieden zu haben. Im Gegenteil, an anderer Stelle im Interview wird deutlich, dass sich Herr Frings ${ }^{6}$ Hal- 
tung durch seine nunmehr etwa zwei Jahre lange Erfahrung des Wohnens im Neubau komplett gewandelt hat: Wollte er vorher am liebsten für immer im Altbau wohnen bleiben, kann er sich heute kaum mehr vorstellen, jemals nochmal wieder freiwillig in einen Altbau zu ziehen. Diese Veränderung, die typische Anpassung und Steigerung genereller Komfortansprüche infolge eines real erlebten Komfortanstiegs, kommt in folgendem $\mathrm{Zi}$ tat von Herrn Frings deutlich zum Ausdruck:

„Also zum Beispiel die (3) ich frag mich heute wie wir da in der Altebau hatten wir die Kabel teilweise so (zeigt) hier an der [Wand, JM] selber angebracht und solche Sachen die man eigentlich nich machen darf. Aber- (3) und hier is alles ganz anders also hier is einfach auch neu und funktioniert (.) überwiegend alles so wie man sich das vorstellt. (4) Ja also ich würde wahrscheinlich jetzt nich in einen Altbau einziehen ohne es vorher zu sanieren. [...]. Äh das @glaub ich@würde ich jetzt nich mehr machen. Wenn ich es mir leisten könnte@(.)@.“ (ebd.: 26, 1327-1338)

Das Zitat macht deutlich, dass für Herrn Frings mittlerweile der technischmaterielle Ausstattungszustand einer Wohnung von zentraler Bedeutung ist, also beispielsweise eine sachgemäße Verkabelung, eine ordentlich funktionierende Elektrik und Heizung. Dementsprechend schließt Herr Frings mit hoher Wahrscheinlichkeit aus, dass er jemals wieder in einen unsanierten Altbau ziehen würde. Das zeigt, wie das Passivhaus bzw. der moderne Neubau Herrn Frings mittlerweile überzeugt und für sich eingenommen hat. Wie schon bei Herrn Barth war es auch bei Herrn Frings ein ganzes Bündel an Faktoren und Rahmenbedingungen, das für einen Umschwung im Denken und Handeln gesorgt hat. Im Fall Herrn Frings' erscheint es, als seien es hauptsächlich das eigene aktive und mutige Handeln sowie die dabei gemachten positiven Erfahrungen gewesen, die erst im Nachhinein eine deutliche Veränderung in den Deutungen bewirkt haben. Daran wird deutlich, dass nicht unbedingt die grundlegenden Einstellungen entscheidend sind, sondern dass es vielmehr auf die Praxis und das eigene tatsächliche Erleben ankommt, soll sich das alltägliche Entscheiden und Handeln etwa in Richtung Nachhaltigkeit und Umweltgerechtigkeit wandeln. Daraus lässt sich ableiten, dass offensichtlich die Möglichkeit konkreter, eigener Erfahrung von zentraler Bedeutung ist, wenn es um das Anstoßen grundlegender Veränderungsprozesse geht.

$\mathrm{Zu}$ beobachten ist, dass im Bereich des Umwelt- und des Klimaschutzes bisher überwiegend - häufig sogar ausschließlich - bei den Einstellungen der Konsument*innen angesetzt wird, um ihr Handeln in Richtung Nach- 
haltigkeit zu lenken. Das heißt, man versucht durch verschiedentliche Beeinflussung, zum Beispiel durch die Bereitstellung von Informationen, durch direktes Feedback zu spezifischen Handlungen, usw., zunächst einen Wandel in den persönlichen Einstellungen und grundlegenden Orientierungen der Menschen zu bewirken, von dem man sich erhofft, dass er sich auf die Praxis überträgt, das heißt, sich im Handeln niederschlägt. Allerdings ist man mit dieser Strategie bislang nicht sonderlich erfolgreich gewesen. Grunwald schreibt hierzu:

„Daraus, dass viele Menschen heute einiges über Umwelt und Nachhaltigkeit wissen, auch darüber, wie man nachhaltiger konsumieren kann, folgt nicht unbedingt eine Änderung des Verhaltens. Die viel beklagte Lücke zwischen Wissen und Handeln bleibt bestehen." (Grunwald 2013: 11; vgl. auch Reisch und Hagen 2011)

Die bisher in diesem Kapitel präsentierten Fälle deuten darauf hin, dass offenbar der genau umgekehrte Weg äußerst erfolgreich sein kann: Sowohl im Fall Herrn Werners, als auch in den Fällen Herrn Barths und zuletzt Herrn Frings‘ erfolgte zunächst eine Veränderung des praktischen Handelns. Mit der Zeit folgten die Einstellungen und grundlegenden Orientierungen nach und glichen sich aufgrund positiver Erfahrungen mehr und mehr der neuen Handlungsroutine an.

Statt an den Einstellungen herumzulaborieren, scheint es aussichtsreicher direkt am praktischen Tun anzusetzen. Bei diesem Vorgehen geht es darum, dass die potenziellen Praktikenanhänger*innen möglichst schnell in die konkrete Erfahrung des Neuen gebracht werden, dass sie die Veränderung, die neue Praxis selbst erleben, damit sich bei ihnen ein Urteil über die betreffende Praxis erst auf Basis des neuen, praktisch erfahrenen Wissens ausbildet. Die Chancen stehen dann gut, dass - auch bei vorheriger Skepsis oder Ablehnung - dieses Urteil anders bzw. eher zugunsten der neuen Praktik ausfällt, eben, weil die reale Praxis bereits überzeugen konnte. Wird die neue Praktik als positiv und als eine Verbesserung zur vorherigen Routine erfahren, so kann sie neu gewonnene Teilnehmer*innen in der Regel ohne Probleme länger an sich binden; das heißt, die einst neue Praktik besteht fort und prosperiert möglicherweise immer weiter. Meist erfordert diese Entwicklung jedoch eine gewisse Zeit der Gewöhnung bzw. Umstellung auf Seiten der Praktizierenden, die aufgrund ihrer persönlichen Vorgeschichte und Erfahrung unterschiedlich offen und geneigt sind, sich von neuen Wohn- und Heizansätzen einnehmen zu lassen. 
4.5.1.4,„Und@ für meine Tochterwar das ganz @witzig@. [...] Also die musste sich viel stärker umstellen“ - Frau Greiners Tochter

Im Interview mit Frau Greiner wird eine weitere Variante des Aneignens bzw. Erlernens einer neuen Heiz- und Lüftungspraxis deutlich. Fokussiert man im Interview mit Frau Greiner ebenfalls nicht vorrangig auf die handelnden Personen, sondern folgt stattdessen den betreffenden Heiztätigkeiten, so zeigt sich hier eine weitere Variante erfolgreicher Teilnehmerinnenrekrutierung. Die Geschichte, die Frau Greiner vom Einzug ihrer Tochter in das Passivhaus erzählt, macht deutlich, dass es sich hierbei um eine gelungene, weil sehr frühzeitig ansetzende Vereinnahmung durch eine neue Heiz- und Lüftungspraxis handelt. Der Fall der mittlerweile erwachsenen Tochter Frau Greiners verdeutlicht somit zweierlei: Erstens, dass es insgesamt entscheidend ist, zu welchem Zeitpunkt potenzielle Teilnehmer*innen mit einer Praktik in Berührung kommen. Die Praktiken müssen zur Gewinnung neuer Anhänger*innen gewissermaßen eine günstige Gelegenheit abpassen, um in das Leben dieser potenziellen Teilnehmer*innen einzutreten. Ein Umzug gilt als solch ein besonderes „Lebensereignis“ (vgl. z.B. Jaeger-Erben 2010) bzw. als ein typisches ,Gelegenheitsfenster' für die Umstellung auf eine neue Praxis. Und zweitens zeigt der Fall der Tochter Frau Greiners, dass Praktiken es leichter mit der Rekrutierung neuer Anhänger"innen haben, wenn diese noch eher jung sind bzw. wenn bei ihnen für die betreffende Tätigkeit bisher noch keine Gewohnheits- oder Routinebildung stattgefunden hat - und dafür ist die Wahrscheinlichkeit in jüngeren Jahren in der Regel deutlich höher.

Frau Greiners Tochter war elf Jahre alt, als sie zusammen mit ihrer Mutter in das Passivhausprojekt B eingezogen ist. Demnach hat sie das praktische Heizen und Lüften von mittlerer bis später Kindheit an im (Kontext des) Passivhaus(es) kennengelernt und bewusst erlernt. Frau Greiners Tochter ist gewissermaßen mit einer anderen, einer damals noch sehr seltenen ,Normalität', nämlich der des Passivhauses aufgewachsen. Dadurch hat sie schon sehr frühzeitig eine von der gängigen Heiz- und Lüftungspraxis abweichende Handhabung als ,normal' und alltäglich erfahren. Das heißt, als die Tochter in einem Alter war, in dem Kinder das selbständige Heizen und Lüften - häufig zunächst ihres eigenen Zimmers - normalerweise erstmals bewusst erlernen und übernehmen, war sie direkt mit der Passivhauspraxis konfrontiert.

Schon früh im Interview erzählt Frau Greiner, dass sie ihre einzige, mittlerweile erwachsene Tochter alleine großgezogen habe und sie damals, als ihre Tochter gerade im Grundschulalter war, ganz bewusst begonnen ha- 
be, sich nach einem Gemeinschaftswohnprojekt umzuschauen. Denn Frau Greiner hatte den Wunsch, dass ihre Tochter nicht nur mit ihr als enger Bezugsperson, sondern in größerer sozialer Gemeinschaft aufwächst und sie beide mehr enge, persönliche Kontakte in ihrem täglichen, nahen Umfeld haben, die eventuell auch ein fehlendes Familiennetz ersetzen: Frau Greiner war damals auf der Suche nach freundlichen, offenen Menschen, die wie sie Interesse daran hatten, sich etwas gemeinsam aufzubauen, Alltägliches zusammen zu teilen und eine Gemeinschaft zu gründen, in der man sich gegenseitig unterstützt. Der folgende Interviewauszug belegt, dass Frau Greiners ursprüngliche Motivation, sich dem zum damaligen Zeitpunkt noch in der Planung befindenden Bau- und Wohnprojekt B anzuschließen, keineswegs in dem Vorhaben eines Passivhauses bestand, sondern dass sie vorrangig die konkrete Aussicht auf Wohnen und Leben in einer Gemeinschaft begeisterte:

„Aber es stand eher im Vordergrund dass es ein Wohnprojekt ist und nicht dass es ein Passivhaus is. [...]. Dieses gemeinschaftliche Planen und Wohnen äh 'ne ge- frei gewählte Nachbarschaft das was es in- als Chance in sich birgt so Beziehungen entstehen zu lassen die auch Verwandtschaft ersetzen [...]. Also das war irgendwie was- was ganz Neues so. [...]. Und ich wohnte alleine mit meiner Tochter. Die war- wie alt war sie denn damals? (2) Weniger als zehn acht. Ich- ich wollte dass die- ich wollte nicht so 'ne allein erziehende Mutter sein in so 'nem blöden Mietshaus und wir hatten da wenig Kontakte. Und ich wollte dass sie da irgendwie Kontakte hat wo sie auch mal hingehen kann oder so oder wo ich wenn ich mal weggehe äh sie alleine lassen kann ohne 'nen Babysitter zu brauchen oder ohne mir Sorgen machen zu müssen. [...]. So und d- das war einfach- diese Hausgemeinschaft das war die Idee und auch dass wir alle sagten ,Ja wir- wir wollen Nachbarschaft aber nur bis zu 'ner bestimmten Grenze die auch jeder selbst definieren kann und nicht-' Es ist keine WG. [...]. Wir haben 'nen Gemeinschaftsraum. Aber wir haben keine gemeinsame Küche. So. Und das ist schon jeder wohnt für sich und sein Leben. [...]. Und das fand ich einfach sehr toll.“ (Bewohnerin PH, Interview 64: 5, 223-258)

Aus der Passage geht hervor, dass Frau Greiner in dem Bau- und Wohnprojekt $B$ genau das gefunden hat, was sie sich für sich und ihre Tochter zum damaligen Zeitpunkt vorgestellt hatte: eine eigene Wohnung haben, sein eigenes Leben leben, unabhängig sein und gleichzeitig in enger Gemeinschaft leben. 
Als sie in ihre Passivhauswohnung einzogen, war die Tochter elf Jahre alt. Dies ist ungefähr das Alter, in dem Kinder typischerweise in immer mehr alltägliche Aufgaben im Haushalt eingeführt und dann auch mit solch ,einfachen' Tätigkeiten bzw. Pflichten wie beispielsweise Aufräumen oder Fensterlüftung im eigenen Zimmer zunehmend betraut werden und diese bereits teilweise selbstständig übernehmen (können). Daraus lässt sich ableiten, dass der Tochter in den zentralen Lebensjahren, in denen normalerweise auch eine Heizpraxis erlernt wird, ,nur die zum damaligen Zeitpunkt innovative Heiz- und Lüftungspraxis des Passivhauses zur Verfügung stand. Dadurch war für die Tochter vorrangig ,passives' Heizen über eine Lüftungsanlage nichts Ungewöhnliches. Im Gegenteil, es ist anzunehmen, dass der Tochter die Heiz- und Lüftungspraxis des Passivhauses damals als ,normal' und selbstverständlich erschien, da sie im häuslichen Alltag stets mit dieser Art des Heizens und Lüftens konfrontiert war.

Als die Interviewerin bei Frau Greiner später im Interview nachfragt, ob sie ihrer Tochter den Umgang mit der Lüftungsanlage erklärt habe oder auch, wie man im Passivhaus heize, bejaht sie dies und erzählt dazu folgende Anekdote:

„Ja ja.@Und@für meine Tochter war das ganz@witzig@. Die zog hier ein da war sie zwölf elf genau- Ja und zog dann [in eine andere deutsche Großstadt] in 'ne normale Wohnung und sie sagte ,Bah Mama ich muss mich richtig dran gewöhnen Heizung abdrehen bevor ich das Fenster aufmach' und solche Sachen wenn ich lüfte'. Also die musste sich viel stärker umstellen." (Bewohnerin PH, Interview 64: 13, 683688)

Die Beschreibung macht deutlich, dass die Tochter im jungen Erwachsenenalter vollkommen an das Passivhaus gewöhnt war. Erst durch den Wechsel vom Passivhaus zu einem konventionellen Wohnkontext ist der Tochter bewusst geworden, wie ,normal' und selbstverständlich für sie die Heiz- und Lüftungspraxis des Passivhauses war. Der Schilderung ist zu entnehmen, dass sich Frau Greiners Tochter erst an das Heizen und Lüften im konventionellen Wohnkontext gewöhnen musste und ihr diese Umstellung offenbar nicht leichtfiel.

Auch Frau Greiners Kommentar im weiteren Gespräch dazu: „Gott man wohnt dann so und das- das ist einfach normal“ (ebd.: 13, 693-694) verdeutlicht den Routinecharakter des Heizens und Lüftens - einmal bewusst eingeübt, macht man sich im Alltag wenig bis keine Gedanken mehr über diese Tätigkeiten, sondern das einmal Gelernte wird - gleichsam einem standardisierten Programm - in gegebener Situation bzw. bei Bedarf ein- 
fach nur ,abgespult'. Typischerweise werden Routinen und gewohnheitsmäßige Abläufe nur dann wahrgenommen, wenn etwas schiefgeht oder die Routine gestört ist oder unterbrochen wird. Dies wird am Fall der Tochter Frau Greiners deutlich: Als diese damals „in 'ne normale Wohnung [zog]" (ebd.: 13, 685), passte ihre bisherige Heiz- und Lüftungspraxis nicht mehr zum neuen Wohnkontext und Heiz-Setting. Das, was die Tochter bisher über das Heizen und Lüften von Wohnräumen wusste, war im neuen Kontext auf einmal weitgehend unbrauchbar und sie musste die ,alte', für sie aber neue und ungewohnte Praxis erst bewusst erlernen. Hinzu kommt, dass die Tochter es vom Passivhaus gewohnt war, dass man kaum etwas aktiv dafür tun musste, um die Wohnräume grunderwärmt und gut gelüftet bewohnen zu können. Denn hier übernimmt die Technik das Heizen und Lüften fast vollständig. Im konventionellen Kontext liegen Verantwortung und Kontrolle über den Heiz- und den Lüftungsvorgang hingegen weitgehend in Nutzer"innenhand. Hier vollziehen die Nutzer*innen die zum Heizen und zum Lüften gehörigen Handlungen größtenteils aktiv selbst. An der von Frau Greiner wiedergegebenen Aussage der Tochter wird deutlich, dass die Tochter es sich nach ihrem Wechsel vom Passivhaus zum konventionellen Wohnkontext bewusst antrainieren musste, welche Aktivitäten zum ,richtigen' Heizen und Lüften im konventionellen Kontext dazugehören. Das heißt, in der Anfangszeit musste sie beim Heizen und Lüften alle dazugehörigen Schritte und Handgriffe sehr bewusst ausführen - wie eine Anleitung, die es bewusst aufzurufen und dann Schritt für Schritt zu befolgen gilt.

Abschließend möchte die Interviewerin von Frau Greiner noch wissen, ob ihre Tochter diese Umstellung vom Heizen und Lüften im Passivhaus zum Heizen und Lüften im konventionellen Wohnkontext lediglich festgestellt oder ob sie dies für sich auch irgendwie bewertet habe. Hier berichtet Frau Greiner dann, dass ihre Tochter „das hier [im Passivhaus, JM] dann ganz praktisch [fand]" (ebd.: 13, 699), was deutlich macht, dass die Tochter die weitgehende Abnahme des Heiz- und Lüftungsvorgangs durch die automatische Technik als willkommene Erleichterung und Entlastung empfunden hat. Demnach verhält es sich hinsichtlich des Kontroll- und Komforterlebens bei Frau Greiners Tochter genau umgekehrt zu dem Erleben vieler anderer älterer Passivhausbewohner*innen, die erst lange Zeit im konventionellen Wohnkontext gewohnt und dann in späteren Jahren in ein Passivhaus gezogen sind (vgl. Kap. 4.4.1.1 und 4.4.1.2). Während viele dieser ,späten“ Passivhausbezieher"innen - zumindest in der Anfangszeit - Probleme mit der für sie zunächst vollkommen ungewohnten Heizund Lüftungspraxis des Passivhauses hatten und manche sich bis heute nur 
schwerlich daran gewöhnt haben, im Passivhaus kaum noch etwas aktiv dafür tun zu müssen, dass ihre Wohnräume warm und gut gelüftet sind und viele genau diese Entwicklung als Kontrollverlust erleben, empfindet Frau Greiners Tochter demgegenüber die Situation im Passivhaus als "ganz praktisch“ (ebd.). Deutlich wird, die Tochter nimmt es so wahr, dass sie im Vergleich zu vorher nun im konventionellen Kontext an viel mehr denken und viel mehr aktiv machen muss, damit ihre Wohnung ausreichend beheizt und gelüftet ist. Die Entwicklung ihres Erlebens lässt sich demnach als Entwicklung von wenig Arbeit zu mehr Tätigkeiten, also als Arbeitszunahme bzw. Komfortverlust beschreiben.

Die positive Bewertung der Heiz- und Lüftungspraxis des Passivhauses durch die Tochter hängt ganz offensichtlich vor allem damit zusammen, dass sie es bereits seit ihrer Kindheit so kennengelernt hat, dass man sich im Passivhaus um Heizen und Lüften kaum kümmern muss. Deshalb hat sie es nicht so erlebt, dass ihr die Kontrolle über den Heiz- und Lüftungsvorgang von der Passivhaustechnik entzogen wurde. Hieraus lässt sich ableiten, dass sowohl für die Bewertung des Erlebens als auch für das tatsächliche Handeln entscheidend ist, mit welcher Praxis man aufwächst, was man zuerst bzw. von klein auf als ,normal' erlernt hat. Die meisten grundlegenden, alltäglichen Routinetätigkeiten, und so auch das Heizen und das Lüften, werden in der Kindheit verinnerlicht. Sind sie fest im Denken und Handeln verankert, sind sie häufig nur (noch) schwer zu verändern (vgl. Interview mit Dino Laufer in Dilk/Littger 2014: 25). Meist geht dies nur über die bewusste Reflexion und eine genauso bewusst-willentliche Neueinübung einer anderen Praktik.

\subsubsection{Die Rolle von Expert“innen im Entscheidungsfindungsprozess für ein Passivhaus}

Wie bereits in der zweiten Fallgeschichte dieses Kapitels des Herrn Barth angeklungen, spielt das Reden und Handeln von Expert*innen häufig eine entscheidende Rolle bei der Frage, ob Bewohner*innen von einem neuen Heizansatz erfasst werden und diesen für sich übernehmen.

Für gewöhnlich beschäftigen sich ,Normalverbraucher*innen' in ihrem Alltag weniger eingehend mit Heiztechnik. Dafür gibt es in unserer hochgradig ausdifferenzierten Gesellschaft ausgewiesene Expert*innen, die bei Bedarf um Rat gefragt werden können und sich gegebenenfalls um die Wartung der Heizungsanlage kümmern. Dementsprechend gering sind die Kenntnisse der meisten Verbraucher*innen hinsichtlich moderner Heiz- 
technik. Beratungsbedarf oder ein größeres Interesse an Heiztechnik kommt bei Normalverbraucher*innen in der Regel erst dann auf, wenn das aktuell verwendete Heizungssystem nicht ordentlich funktioniert oder wenn die Auswechselung bzw. Neuanschaffung eines Heizungssystems ansteht, beispielsweise beim Bau eines Hauses.

Geht es um den Bau eines Hauses und dementsprechend um die Realisierung einer neuen Heizlösung, so sind es in der Regel Architekt*innen, die die Bauherr*innen - meist sind dies auch die künftigen Bewohner*innen - zu der zur Auswahl stehendenden Heiztechnik beraten. Demensprechend ist davon auszugehen, dass Architekt*innen mit ihrem Fachwissen beträchtlichen Einfluss auf die Entscheidung der Bauherr*innen für einen Heizansatz nehmen und diese Expert"innen dadurch wesentlich am $\mathrm{Zu}-$ standekommen einer neuen Heizlösung beteiligt sind (vgl. Patow und Krienke 1972: 9).

Im Bereich ökologischen und energieeffizienten Bauens tätige Architekt"innen haben sich meist auf bestimmte Hausarten und Heizsysteme spezialisiert, da moderne energieeffiziente Bauweisen, wie zum Beispiel die Passivhausbauweise, noch nicht zur bauingenieurswissenschaftlichen Grundausbildung gehören. Das heißt, Architekt*innen, die sich diesbezüglich eigeninitiativ speziell weitergebildet haben, treten dann typischerweise als Promotor*innen dieser von ihnen zusätzlich erlernten Art des Bauens auf, von der sie in der Regel auch persönlich überzeugt sind. So bauen ausgebildete Passivhausarchitekt"innen meist nur noch Passiv- oder mindestens Niedrigenergiehäuser, also Häuser, die sich durch eine besonders hohe Energieeffizienz auszeichnen.

Mit bestimmten Bauweisen sind in der Regel ganz bestimmte Heizlösungen verknüpft. Beim Passivhaus bildet beispielsweise eine moderne Lüftungsanlage mit effizienter Wärmerückgewinnung das ,Kernstück ' ohne diese besondere Lüftungsanlage geht es im Passivhaus nicht. Hingegen ist eine aktive Zusatzheizung zur Deckung des nur noch geringen Restwärmebedarfs während der kalten Jahreszeit im Passivhaus nicht unbedingt erforderlich.

Geraten Bauherr"innen in der Planungsphase jetzt zufällig an eine"n auf Passivhäuser spezialisierte"n Architekt"in, wirkt diese*r kompetent und kann er bzw. sie das Vertrauen der bei ihm bzw. ihr Ratsuchenden gewinnen, und sind die Ratsuchenden zudem noch offen für energieeffizientes Bauen, so stehen die Chancen gut, dass sich die Bauherr*innen von dem bzw. der auf Passivhäuser spezialisierten Expert"in überzeugen lassen, ein modernes Passivhaus zu bauen. Denn häufig hören gewöhnliche Verbraucher*innen zum ersten Mal über ihre*n Architekt*in vom Passivhaus und 
beginnen erst daraufhin, sich zu dieser vom bzw. von der Expert*in vorgeschlagenen Technik näher zu informieren. Demnach lässt sich konstatieren, dass Architekt*innen beim Entscheidungsfindungsprozess für eine neu zu realisierende Heizlösung häufig als ,Gatekeeper ' fungieren, da bei einem Neubau die Heizlösung in der Regel eng mit dem gewählten Baustandard verknüpft ist.

In den vier für diese Studie untersuchten Mehrparteien-Passivhauswohnprojekten sehen die Wege, wie die Bauherr*innen, die auch künftige Bewohner*innen waren, zum Passivhaus gekommen sind, höchst unterschiedlich aus. Dementsprechend haben die betreffenden Architekt"innen in den jeweiligen Entscheidungsfindungsprozessen auch unterschiedliche Rollen eingenommen: So wurden die Hausprojekte C und D beide jeweils von den später auch für die Realisierung verantwortlichen Architektinnen initiiert. ${ }^{111}$ Das heißt, in beiden Fällen handelt es sich bei der Entscheidung für die Passivhausbauweise um eine grundlegende Vorentscheidung der jeweils verantwortlichen Architektin. Erst danach, auf Basis dieser Vorabentscheidung, wurden jeweils passende Mitglieder für diese beiden Baugemeinschaften gesucht. Während es sich bei den Passivhäusern C und D also um von Expertinnen angestoßene Bauprojekte handelt und hier von Anfang an feststand, dass dies Passivhäuser werden, ging bei den Projekten A und B der erste entscheidende Impuls für ein Passivhaus von den jeweils bereits zuvor gegründeten Baugemeinschaften aus. Bei diesen Bauprojekten kristallisierte sich die Entscheidung, dass das Wohnprojekt ein Passivhaus werden soll, also erst im gemeinsamen Planungsprozess heraus.

Im Folgenden werden die beiden unterschiedlichen Wege der Baugruppen A und B zum Passivhaus kurz skizziert. Dabei wird insbesondere da-

111 Das Passivhausprojekt C wurde hauptsächlich von der auch später mit der Umsetzung des Bauvorhabens beauftragten Architektin initiiert, die mit ihrer Familie selbst einige Jahre in der Reihenhaussiedlung gewohnt hat. Die komplette Baugemeinschaft bildete sich erst allmählich, nachdem die Entscheidung für das Passivhauskonzept bereits gefallen war.

Das Passivhausprojekt D geht auf einen Konzeptentwurf zurück, mit dem sich ein Architekturbüro erfolgreich bei einem Wettbewerb beworben hat und bei dem es um die Zusprechung einer Baugenehmigung für ein städtisches Grundstück ging. Hier hat das siegreiche Architekturbüro bzw. die federführende Architektin dann erst im Nachhinein nach Teilnehmer*innen für eine Baugemeinschaft gesucht, mit der sich das Bauvorhaben realisieren ließ. Das heißt, für die jetzigen Wohnungseigentümer*innen und Bewohner*innen war von Anfang an klar, dass sie sich um die Teilnahme an einem Passivhausbauprojekt bewerben und ihre zukünftige Eigentumswohnung bei erfolgreicher Bewerbung definitiv im Passivhausstandard erbaut wird. 
rauf eingegangen, welche Rolle der bzw. die leitende Architekt*in in diesem Entscheidungsprozess eingenommen hat.

\subsubsection{1 „[D]er größte gemeinsame Wunsch dieser Gruppe war ein Sonnenhaus zu planen" - Baugemeinschaft und Wohnprojektgruppe A}

Die Wohnprojektgruppe des Passivhausprojekts A ist damals eher auf indirektem Wege zum Passivhaus gekommen: Im Gespräch mit dem zusammenlebenden Paar Pfeiffer/Wirth wird deutlich, dass die Wohnprojektgruppe schon früh, circa fünf Jahre vor Baubeginn, damit begonnen hatte, sich regelmäßig zur gemeinsamen Planung zu treffen. Im Rahmen dieser regelmäßigen Treffen hat sich über einen längeren Zeitraum ein intuitivkreativer Ideenaustausch entwickelt, an dessen Ende das gemeinsame Vorhaben stand, ein Passivhaus zu bauen.

Der Kontakt mit Frau Pfeiffer kam über einen Workshop zustande. Eigentlich war ein Interview nur mit ihr vereinbart. Beim abendlichen Termin ist dann aber auch ihr Lebenspartner Herr Wirth in der gemeinsamen Wohnung anwesend. Aus Neugier und spontanem Interesse bleibt Herr Wirth im Raum. Sofort fängt er an, sich rege am Interview zu beteiligen, woraufhin sich ein langes, angeregtes Gespräch zu dritt entwickelt. Das Interview findet am Esstisch im zur Küche hin offenen Wohnzimmerbereich statt.

Auf die Eingangsfrage des Interviews, wie sie zum Passivhaus gekommen seien, holt Frau Pfeiffer etwas weiter aus und schildert zunächst kurz ihren gemeinsamen Weg in das Wohnprojekt:

„Ja weil also im Prinzip ist ' $n$ - ist 'ne Stadtteilinitiative ganz viele Leute die dann irgendwie hier einerseits 'nen Park wollten und dann gesagt haben okay dann sorgen wir auch dafür dass hier- hier 'n Wohnprojekt entsteht in dem auch Leute wohnen können mit nicht so viel Geld. [...]. Und wir jetzt speziell hier sind durch 'ne Anzeige dazu gekommen die die in [einer Tageszeitung] geschaltet haben dass sie noch Leute suchen." (Bewohnerin PH, Interview 56: 7, 362-369)

Herr Wirth knüpft hier direkt an Frau Pfeiffers Worte an und fährt mit dem Berichten von den Anfängen ihrer Zeit im Projekt fort. Dabei wird deutlich, dass bei ihrem Einstieg in die Baugruppe noch nicht entschieden war, dass das in Gemeinschaft zu bauende Haus ein Passivhaus werden 
soll; mehr noch, deutlich wird, dass zum damaligen Zeitpunkt das Konzept ,Passivhaus' noch nicht einmal im Gespräch war:

"Ja und das ging auch noch gar nicht um Passivhaus. Da war da war einfach nur 'ne Anzeige [...] und daraufhin haben wir uns gemeldet. Und dann gab's ja irgendwie schon- schon Grüppchen. [...]. Die hatten irgendwie im Vorfeld irgendwie schon Zukunftsplanungen und irgendwie überlegt wie sie wohnen wollen was- in- was für 'n Haus sie haben wollen wie das Haus aussehen soll in welcher Zusammensetzung. Und- und da war eine Wohnung frei. Und wir haben uns damals vorgestellt. Und dann ist das in so 'nem Wohnprojekt so dass- dass du da erst mal zu den Treffen gehst und so und dich vorstellst und sagst was du machst und ähm ja. Und dann hat- hat das Plenum quasi entschieden. [...] das Haus ist 2004 äh 2 oder 3 fertig geworden. Und wir haben uns schon getroffen irgendwie 1999 oder irgendwie oder 98 oder so.“ (Bewohner PH, Interview 56: 7f, 371-385)

Immer wieder ergänzen und korrigieren Frau Pfeiffer und Herr Wirth sich gegenseitig in ihren Angaben und rekonstruieren auf diesem Wege gemeinsam, im Dialog, wie die Idee für ein Passivhaus in der Gruppe erstmals aufgekommen ist:

Frau Pfeiffer: Das muss noch früher- $L$ denn ich hab gerad die- hab gerad die

Herr Wirth: die Gruppe hat vorher schon $\lrcorner$

Frau Pfeiffer: [...] ich hab meine Diplomarbeit 97 gemacht [...]. Das heißt das war ja noch im Studium das heißt 96 keine Ahnung also ewige Planung vorab und- und dann ist irgendwie im Laufe der Zeit ist so die- die Idee von 'nem Sonnenhaus entstanden und 'ne Idee dass man Energie sparen will natürlich wohnen will. Und dann kam dieses Passivhaus auch auf. Und ich kannte es halt vom Studium her und war total begeistert das zu machen und da - während so im Haus waren einige schon relativ skeptisch was das ist und ohne Heizung. Und das konnte man sich da ja noch nicht so richtig vorstellen wie das funktioniert.“

(Bewohnerin und Bewohner PH, Interview 56: 8, 387-402)

Aus dem Dialog zwischen Frau Pfeiffer und Herrn Wirth geht hervor, dass nicht sofort die Idee für ein Passivhaus im Raum stand, sondern dass sich die Baugemeinschaft vorher über einen längeren Zeitraum viel grundsätzlicher darüber verständigt hat, welche Vorstellungen die einzelnen Mitglieder davon haben, in was für einem Haus sie wohnen wollen und wie bzw. 
nach welchen Kriterien man überhaupt bauen und leben will. Frau Pfeiffers Beschreibung lässt sich entnehmen, dass sich im Laufe dieser recht lange andauernden Vorplanungsphase dann allmählich „die Idee von 'nem Sonnenhaus" (ebd., 396) herausentwickelt hat.

Vorausgesetzt das Passivhaus ist einem bekannt und man ist auch zumindest in Ansätzen mit seiner Funktionsweise vertraut, dann erscheint es tatsächlich naheliegend, die Haus- bzw. Wohnmetapher ,Sonnenhaus' der Baugruppenmitglieder mit dem Konzept des Passivhauses zu assoziieren. Denn neben der Nutzung der im Hausinneren erzeugten und zurückgehaltenen Abwärme, die durch die Bewohner*innen, Haushaltsgeräte usw. entsteht, ist ein Passivhaus zur Wärmeenergiegewinnung in erheblichem Maße auf solare Erträge angewiesen. Aus diesem Grund können Passivhäuser nur an Orten mit ausreichender Sonneneinstrahlung errichtet werden. Passivhäuser werden mit ihren großen, besonders beschichteten Fenstern nach Süden hin ausgerichtet, um auf diesem Wege das Maximum an Sonne einzufangen. Dafür muss die nach Süden ausgerichtete Front eines Passivhauses relativ frei sein, es dürfen zum Beispiel keine Bäume oder kein zu großes Haus davor stehen.

Die Metapher vom Sonnenhaus für das Passivhaus ist unabhängig vom Fall der Baugemeinschaft A noch in einem weiteren Interview aufgetaucht. Auch der Architekt Herr Freud wählt die Analogie des Sonnenhauses, um die prinzipielle Funktionsweise des Passivhauses zu beschreiben. In seinen Augen „[ist] 'n Passivhaus letztendlich [...]'n Sonnenhaus“ (Architekt PH, Interview 54: 17, 887-888), denn „wenn ich einfach nich genug Sonne hab dann funktioniert auch 'n Passivhaus nich" (ebd., 891-892).

Aus Frau Pfeiffers letzter Beschreibung lässt sich ableiten, dass zu einem unbekannten Zeitpunkt von jemandem die von den Wohnprojektmitgliedern geäußerten Wünsche und Vorstellungen, die offenbar in der Idee eines Sonnenhauses zusammenliefen, mit dem Konzept des Passivhauses übersetzt wurden. Welche Person diese Deutungs- bzw. Übersetzungsarbeit geleistet hat, geht aus ihrem Gesagten allerdings nicht hervor. Dies klärt sich jedoch in einem anderen Interview auf; und zwar im Gespräch mit dem damals für das Bauprojekt A hauptverantwortlichen Architekten Herrn Beckert. Auf das Interview mit Herrn Beckert wird gleich im Anschluss noch genauer eingegangen.

Zudem ist Frau Pfeiffers Schilderung zu entnehmen, dass sie zum damaligen Zeitpunkt der Vorplanungen, Mitte der 1990er Jahre, als das Passivhausprinzip noch relativ jung und in der allgemeinen Bevölkerung noch dementsprechend unbekannt war, bereits von diesem neuen Baukonzept während ihres Studiums gehört hatte. An anderer Stelle im Interview er- 
zählt Frau Pfeiffer, dass sie Umwelttechnik studiert hat. Vor diesem Hintergrund wird verständlich, dass sie eines der anscheinend wenigen Gruppenmitglieder war, das nicht erst einmal skeptisch, sondern offen und positiv auf den Vorschlag, ein Passivhaus zu bauen, reagierte. Da Frau Pfeiffer die dahintersteckende Technik bereits theoretisch bekannt war, wusste sie sofort, dass es sich beim Passivhaus um einen noch neuen, sehr energiesparenden Baustandard handelt. Sie war „total begeistert“ (ebd.: 8, 399), dass sich ihr nun mit dem eigenen Wohnprojekt die Möglichkeit bot, etwas unter Umweltgesichtspunkten so Innovatives und Modernes wie ein Haus ohne aktive Heizung, selbst frühzeitig praktisch mitzuerleben und zu erproben. Ihre Beschreibung lässt zudem erkennen, dass einige Baugruppenmitglieder eher skeptisch auf den Vorschlag eines Passivhauses reagierten. Bei ihnen dominierten die typischen Befürchtungen und Vorbehalte, die es insbesondere in der Anfangszeit häufig bei Verbraucher*innen gegenüber Passivhäusern gab. An der Formulierung „einige [waren] schon relativ skeptisch was das ist“ (ebd., 400) wird deutlich, dass viele der Wohnprojektmitglieder bei dieser Gelegenheit offenbar überhaupt zum ersten Mal vom Passivhaus hörten. Vor diesem Hintergrund erscheint ihre anfängliche Verunsicherung und kritische Haltung durchaus verständlich, da das Prinzip des Passivhauses von konventionellen Ansätzen, wie ein Haus beheizt werden kann, tatsächlich stark abweicht. Darüber hinaus handelt es sich bei der Passivhaustechnologie um eine relativ anspruchsvolle Technik und es ist anzunehmen, dass der Großteil der Wohnprojektmitglieder im Hinblick auf Heizungs- und Lüftungstechnik damals noch als vollkommene Lai*innen zu betrachten waren. Fehlendes technisches Wissen und Verständnis sowie keine erfahrungsweltliche Anknüpfung zum Vorschlag des Passivhauses gehabt zu haben, erschwerten es diesen Skeptiker"innen offenbar noch zusätzlich, zum damaligen Zeitpunkt eine erste realistische Vorstellung von der Passivhausfunktionsweise zu gewinnen.

Letztendlich wurde das Wohnprojekt A als Passivhaus realisiert. Das bedeutet, dass die anfänglichen Skeptiker"innen unter den Baugruppenmitgliedern während des langen Entscheidungsfindungsprozesses überzeugt werden konnten.

Im Fall des Wohnprojekts A lässt sich die Entscheidung fürs Passivhaus, neben der Bewohner*innenperspektive, auch aus der Expert"innenperspektive rekonstruieren, da der Architekt, der das Passivhausbauprojekt A damals hauptverantwortlich betreut hat, ebenfalls für ein Interview gewonnen werden konnte.

Im Interview mit dem Architekten Herrn Beckert kommt dieser von sich aus auf das Wohnprojekt $\mathrm{A}$ zu sprechen, als die Interviewerin ihn 
fragt, ob er aus seiner Berufspraxis einmal einen konkreten Fall schildern kann, wie bei diesem die Entscheidung für ein Passivhaus zustande gekommen ist. Hierbei wird deutlich, dass im Fall des Bauprojekts A er als Experte derjenige gewesen ist, der die ,Übersetzungsarbeit ' hinsichtlich der Wünsche der Baugemeinschaftsmitglieder in ein realweltliches Baukonzept geleistet hat. Im Interview liefert Herr Beckert eine detaillierte Schilderung des Ablaufs des gesamten Entscheidungsfindungsprozesses, während Frau Pfeiffer und Herr Wirth diesen in ihren Ausführungen nur allgemein beschrieben haben. Darüber hinaus nimmt Herr Beckert die Erzählaufforderung der Interviewerin zu seiner diesbezüglichen praktischen Erfahrung zum Anlass, um zunächst einmal ausführlich darzulegen, wie er bei größeren Hausbauprojekten grundsätzlich die Rollen- und Aufgabenverteilung zwischen Architekt"in und Bauherr"in bzw. Bauherr*innen sieht:

„Äh: (räuspern) es war 'ne Baugemeinschaft die sehr heterogen war und (2) die haben mich ausgesucht weil ich eben viel für Baugemeinschaften gemacht habe (.) auch schon Niedrigenergiehäuser geplant habe. Aber äh hauptsächlich weil ich ein kommunikativer Architekt bin (.) und die Wünsche erkenne. Und (husten) 'n Bauherr muss ja möglichst gut (.) seine Wünsche kennen. Die Aufgabe des Bauherrn ist es Wünsche zu äußern Entscheidungen zu treffen und Rechnungen zu bezahlen. Verkürzt gesagt. Die Aufgabe des Architekten ist (.) die Wünsche ernst zu nehmen (.) Alternativen vorzulegen (.) Kosten zu ermitteln und die Qualität in 'nem bestimmten Zeitraum herzustellen. So- das heißt die Rolle des Bauherren ist als erstes Wünsche zu äußern (.) was will er eigentlich? Je deutlicher er das formuliert umso einfacher ist die Planungsaufgabe. (1) Das heißt wir haben dann mit dieser Gruppe die sehr heterogen war äh ein- nachdem sie sich für mich entschieden hatten haben wir als erstes eine Zukunftswerkstatt gemacht. Weil wir wissen wollten was ist eigentlich was wollt ihr eigentlich als Gruppe? Was für ein Haus wollen wir bauen? Und wir haben dann die: Gruppe- das waren zwanzig Leute- gebeten doch erst mal ihr Traumhaus zu malen so 'n Zettel und dem einen Titel zu geben. Jeder hat sein Traumhaus gemalt- keine weiteren Vorgaben nur Traumhaus und Titel. Hat einen Titel gegeben wurde alles an die Wand gehängt konnten die Leute sich alles angucken. So was für Traumhäuser an der Wand hängen und wie sie hießen. Und dann hatte jeder drei Punkte und da konnte er die auf die Zettel, auf die Bilder beliebig verteilen. (.) Und das Bild, was die meisten Punkte bekommen hat das hieß das Sonnenhaus. [...]. Das heißt der größte gemeinsame (1) Wunsch dieser 
Gruppe(.) war ein Sonnenhaus zu planen. Da gab's noch weitere Kriterien aber das war sozusagen an- an oberster Stelle. (.) Bis dahin haben wir kein Wort geredet. Also alles nur (1) Verzeichnung. [...]. Das heißt nach einer Stunde wussten wir sie wünschen sich 'n Sonnenhaus. Und das habe ich eben dann übersetzt äh: in Passivhaus weil Passivhaus ist passiv (.) weil es von der Sonne lebt von der Sonneneinstrahlung. (.) Das heißt bei dieser Gruppe war es sehr eindeutig dass es sozusagen der- die Hauptaufgabe war ein Passivhaus zu planen." (Architekt PH, Interview 53: 4, 119-163)

Aus diesem längeren Zitat geht hervor, dass Herr Beckert überzeugt ist, dass er von der Baugemeinschaft damals aufgrund seiner reichlichen Erfahrung, sowohl was die Zusammenarbeit mit Baugemeinschaften als auch was energiesparendes Bauen angeht, ausgewählt wurde. Dass die Wahl auf ihn fiel, dafür war Herrn Beckert zufolge vor allem eine persönliche Eigenschaft bzw. eine seiner Stärken ausschlaggebend, nämlich die, „ein kommunikativer Architekt“" (ebd., 123) zu sein, der die Wünsche seiner Auftraggeber*innen erkennt und bemüht ist, diese so gut wie möglich in die Tat umzusetzen. Und im Falle, dass die Wünsche der Auftraggeber"innen nicht einfach zu realisieren sind, beispielsweise, weil sie den finanziellen Rahmen überschreiten, sei es die Aufgabe des bzw. der Architekt"in „Alternativen vorzulegen" (ebd., 129) bzw. vorschlagen. In jedem Falle liege aber die Zuständigkeit für die Gesamtplanung, inklusive der finanziellen und zeitlichen Kalkulation des Bauprojekts immer in der Hand des bzw. der beauftragten Architekt"in. Genau diese aus den entsprechenden Kompetenzen hervorgehenden Handlungen beschreibt Herr Beckert als die zentralen Aufgaben eines bzw. einer Architekt"in. Das zeigt, Herr Beckert ist ein selbstbewusster Architekt, der von sich, seinem Agieren und seiner Arbeit überzeugt ist.

Herr Beckert beschreibt die Baugemeinschaft in dieser Passage zweimal als „sehr heterogen“ (ebd., 120 und 133-134), was darauf schließen lässt, dass er damit zum Ausdruck bringen möchte, dass für ihn als leitender Architekt dieses Bauvorhabens die Führungs- und Vermittlungsarbeit in diesem Projekt keine leichte Aufgabe war. Seiner Schilderung lässt sich entnehmen, dass er einen einfachen, aber offenbar produktiven Ansatz gewählt hat, um die Baugruppenmitglieder in einem ersten Schritt dazu zu bewegen, ihren Träumen und Wünschen Ausdruck zu verleihen, um daraus in einem zweiten Schritt konkrete Ideen und Vorstellungen für die Gestaltung des Wohnprojekts abzuleiten. Deutlich wird, dass dieser Gruppenverständigungsprozess durch Herrn Beckert initiiert und moderiert wurde. Die Beschreibung verdeutlicht, dass der anfängliche kreative Grup- 
penprozess und die anschließende Abstimmung über die präsentierten Ideen sehr demokratisch organisiert waren. Zudem lässt sich seiner Schilderung entnehmen, dass die Idee von einem ,Sonnenhaus' die meiste $\mathrm{Zu}$ stimmung in der Baugruppe erhielt, was er als Experte dann so gedeutet hat, dass es „der größte gemeinsame (1) Wunsch dieser Gruppe(.) war ein Sonnenhaus zu planen“" (ebd., 150-151). Seine Leistung bei diesem Bauvorhaben bestand darin, die Gruppenprozesse, die für ihn als Architekt zu einem klaren Bauauftrag führten, veranlasst und moderiert zu haben.

Mit dem Hinweis „Bis dahin haben wir kein Wort geredet. Also alles nur (1) Verzeichnung" (ebd., 152-154) wird hier der Eindruck vermittelt, dass die Idee von einem Sonnenhaus ein reines, ,unverfälschtes' Produkt der Baugruppe ist. Herrn Beckerts Darstellung zufolge hat sich die „sehr heterogen[e]" (ebd., 120) Baugruppe binnen kürzester Zeit problemlos und ohne Einmischung des Architekten auf einen konsensfähigen Vorschlag geeinigt. Beziehungsweise, die Baugruppe hat für sich eine Vision von Wohnen entwickelt, die offenbar sofort geeignet erschien, den gesamten Prozess über zu tragen. Einmal angestoßen, so stellt Herr Beckert es dar, sei der Entscheidungsfindungsprozess wie von selbst abgelaufen. Er habe sich in diesem Prozess auf seine professionelle Rolle als Architekt beschränkt, so suggeriert Herr Beckert hier, und lediglich die mit dieser Rolle einhergehenden Aufgaben wahrgenommen und erfüllt. Diese bestanden seiner Ansicht nach in diesem konkreten Fall im Wesentlichen darin, den Entscheidungsfindungsprozess methodisch anzuleiten, die zentralen Wünsche bzw. den größten gemeinsamen Wunsch der vielen verschiedenen Bauherr*innen zu ermitteln sowie diesen Wunsch letztendlich in ein realweltliches Baukonzept zu überführen bzw. ,übersetzen' (vgl. ebd.: 4, 159). Seine Argumentation lässt erkennen, dass Herrn Beckert die Übersetzung von Sonnenhaus „in Passivhaus“ (ebd.) vollkommen logisch und plausibel erscheint. Darüber hinaus suggeriert er mit seiner Formulierung „bei dieser Gruppe war es sehr eindeutig dass es sozusagen [.] die Hauptaufgabe war ein Passivhaus zu planen“ (ebd., 161-163), dass für ihn in diesem Fall überhaupt kein Zweifel bestand, dass sich die Gruppe ein Passivhaus wünschte und dass er offenbar fest davon ausgeht, dass jede andere Person, der das Passivhaus geläufig ist, zum gleichen Ergebnis gekommen wäre. Hieraus lässt sich ableiten, dass Herr Beckert von seiner Arbeit, die er insgesamt im Rahmen dieses Projekts geleistet hat, nach wie vor überzeugt ist. Jedenfalls geht aus Herrn Beckers Schilderung hervor, dass der konkrete Vorschlag, das vorgestellte „Traumhaus“ (ebd., 139) als Passivhaus zu bauen, bei diesem Projekt eindeutig vom Architekten kam, womit noch 
einmal die zentrale Bedeutung des bzw. der Expert*in für die Hausbauplanung unterstrichen ist.

Ganz offensichtlich fühlt sich Herr Beckert in seinem Vorgehen und seiner Arbeit zusätzlich dadurch bestätigt, dass erstens die Entscheidung für ein Passivhaus bei dieser Wohnprojektgruppe schnell getroffen werden konnte und er zweitens als bauleitender Architekt in diesem Prozess praktisch kaum kommunikative Vermittlungsarbeit leisten musste. Mit dieser Darstellung wird der Eindruck vermittelt, dass der Plan für den Bau eines Passivhauses gleichsam schon vorher vorhanden gewesen ist, jedoch nur in den gedanklichen Vorstellungen der Mitglieder. Demnach hat die Baugemeinschaft im Grunde genommen nur noch jemand fachkundigen wie Herrn Beckert gebraucht, der ihre Wünsche und Vorstellungen versteht und erkennt, das heißt, sie zu ,lesen' und deuten vermag.

Mit seiner gesamten Darstellung des Entscheidungsfindungsprozesses der Bauprojektgruppe A vermittelt Herr Beckert ein eher bescheidenes Bild seiner Arbeit: Demnach hat er bei diesem Bauprojekt ,nur' Ergebnisse einsammeln müssen und diese zu einem konkreten gemeinsamen Bauvorhaben zusammengeführt. Dass die Wünsche und Vorstellungen der Baugruppe keineswegs von Anfang klar waren, sondern dass dem eindeutigen Gruppenergebnis Sonnen- bzw. Passivhaus viel Arbeit vorausging, die von den Baugruppenmitgliedern offenbar bereits in den Jahren zuvor geleistet worden war, geht aus der Beschreibung von Frau Pfeiffer hervor, die an einer Stelle von „ewige[r] Planung vorab“ (Bewohnerin PH, Interview 56: 8,395 ) spricht.

Auch wenn Herr Beckert bei dieser Baugruppe nicht viel konzeptionelle Arbeit zu erbringen hatte, verdeutlicht seine Schilderung insgesamt trotzdem, welch entscheidende Rolle die Person des bzw. der Architekt"in im Entscheidungsfindungsprozess und für die Verbreitung einer neuen Heizlösung häufig spielt. Im Fall der Baugruppe A erfuhren die Bauherr*innen tatsächlich erst durch ihren Architekten vom damals noch neuen Gebäudestandard ,Passivhaus' und entschieden sich daraufhin bewusst für die Übernahme dieses Ansatzes.

Für wie wichtig und wertvoll der Architekt Herr Beckert ein gemeinsames Leitbild, wie im Fall der Baugruppe A das Bild von einem Sonnenhaus, für das Durchhalten und ,Sich-Zusammenraufen' einer Baugemeinschaft über den langen Bauprozess hinweg erachtet, kommt in dem folgenden Zitat deutlich zum Ausdruck:

„Große Fenster Gewinne Wärme- also so 'n- so 'n Passivhaus is ja eigentlich 'n großer Sonnenkollektor der diese Sonne erntet die Wärme erntet und wiederverwendet. (1) Und das hat sehr getragen in dem 
Prozess. Für Baugemeinschaften is' es immer schwierig mit 'm Geld auszukommen man muss Kompromisse machen (.) man muss irgendwann von seinem Wunschdenken sozusagen auf die Realitätsebeneaber das haben wir durchgehalten. [...] dann haben wir Planungssysteme und- also damit können wir umgehen. Aber der Anker war immer (.) das Sonnenhaus (1). Das ist wichtig. So etwas." (Architekt PH, Interview 53: 5, 172-187)

Demnach scheint ein gemeinsames Leitbild, ein übergeordnetes visionäres Ziel wichtig, um den Gruppenzusammenhalt während des länger andauernden Realisierungsprozesses eines gemeinschaftlichen Hausbauprojekts zu sichern. Ein vereinigendes, die gemeinsamen Anstrengungen fokussierendes Leitbild wirkt auf alle Baugemeinschaftsmitglieder motivierend insbesondere wenn es im realen Bauprozess zu Verzögerungen oder Komplikationen kommt und/oder Kompromisse bei der Umsetzung erforderlich werden. Dann kann ein gemeinsam geteiltes Ziel helfen, diese schwierigen Phasen zu überbrücken, aufkommende Herausforderungen anzunehmen und Konflikte zu bewältigen.

\subsubsection{2 „[W]enn wir schon neu bauen dann für die Zukunft bauen und das sollte dann ein Passivhaus sein und auch nicht Niedrigenergie, sondern wirklich 'n Passivhaus" - Baugemeinschaft und Wohnprojektgruppe B}

Ein anderes Muster in der Konstellation zwischen Bauherr*in(nen) und Architekt*in wird im Fall der Bau- und Wohnprojektgruppe B deutlich. In diesem Fall ging die Initiative zum Bau eines Passivhauses eindeutig von der Gruppe der fünf „ursprünglichen Gründerinnen des Hauses“ (Bewohnerin PH, Interview 60: 25, 1297-1298) aus, die sich Anfang der 1990er Jahre für das gemeinschaftliche Wohnprojekt B offiziell zusammengeschlossen hatten. Erst nachdem die Entscheidung für ein Passivhaus in dieser Gruppe gefallen war, begann die Baugruppe, nach einem bzw. einer Architekt"in zu suchen, der bzw. die bereit war, ihr soziales Wohnprojektvorhaben als Passivhaus zu realisieren. Die Suche nach einem bzw. einer geeigneten Architekt"in stellte eine besondere Herausforderung dar, weil es in den frühen 1990er Jahren, als die Wohnprojektgruppe mit ihren Hausbauplanungen begann, noch kaum Architekt"innen gab, die mit der Passivhausbauweise vertraut waren. Dies lag vor allem daran, dass das Passivhauskonzept damals neu war. Im Jahr 1990 erfolgte der Schritt zum serienreifen Passivhaus. 1991 entstand dann das erste anerkannte Passivhaus in 
Deutschland, das in Darmstadt-Kranichstein errichtet und von Wolfgang Feist, dem offiziellen Begründer des Passivhaus-Energiestandards für Gebäude, geplant wurde. Das erste Mehrfamilien-Passivhaus steht seit 1999 in Freiburg und das erste im Sozialwohnungsbau errichtete Passivhaus befindet sich seit 2000 in Kassel. ${ }^{112}$

Frau Köhler, eine der Gründerinnen des Passivhausprojekts B, beschreibt es im Interview so, dass „das vordringlichste Motiv um so ein Wohnprojekt zu bauen und einzugehen" (Bewohnerin PH, Interview 60: 6, 309-310) der fünf ursprünglichen Gründerinnen war, dass sie „im Alter anders leben“ (ebd., 301) wollten, dass es nicht „irgendwann so weit geht dass [sie] irgendwo in 'nen Altenheim müssen" (ebd., 302-303) und dass sie „auch den Kontakt zu den anderen Generationen behalten [wollten]" (ebd., 308). Aus dieser Motivation heraus hätten sich die fünf Frauen damals noch während ihrer aktiven Berufszeit zusammengeschlossen und sich auf den Weg gemacht, um ihre Lebensphase nach ihrer Berufstätigkeit zu planen. Frau Köhler erklärt weiter, dass „das ganz langsam [ging]“ (ebd., 310) und gut zehn Jahre gedauert habe, bis ihre „Uridee“ (ebd., 312) dann tatsächlich verwirklicht gewesen sei und sie in ihr Passivhaus einziehen konnten.

Nachdem sich die fünf Frauen dafür entschieden hatten, ein gemeinsames Wohnprojekt zu gründen, fingen sie auch direkt an, sich „weiter Gedanken zu machen [...] wie [sie] denn dann dieses neue Wohnhaus gestalten" (ebd.: 6, 313-315) wollten. Dabei wurde schnell deutlich, dass sie sich - neben dem Zusammenleben von Jung und Alt - alle ein sozial-integratives Wohnprojekt wünschten. Als „Kompromissformel“ (ebd., 321) sei herausgekommen, dass es ,jetzt 'n sozialer Wohnungsbau geworden“ (ebd.: 7, 322 ) ist, wofür die Baugemeinschaft damals einer Wohnungsbaugenossenschaft beitrat.

Frau Köhler beschreibt, dass ihre Überlegungen und Planungen zur Gestaltung des Wohnprojekts noch weitergegangen seien und sie sich als Gruppe damals ganz bewusst gesagt hätten: „wir wollen gucken dass wir also möglichst [...] energiesparend [bauen]" (ebd.: 7, 337-344). Darüber hinaus sei es „eigentlich [...] von vornherein (.) so 'n Bedürfnis und 'n Wunsch [von ihr persönlich gewesen, JM] im Blick auf kommende Jahre und Jahrzehnte möglichst so zu (.) leben und zu wohnen um Ressourcen zu sparen“ (ebd., 353-356). Frau Köhler erzählt, dass zu der Zeit, als sie als Baugruppe gerade intensiv mit der Planung ihres Wohnprojekts beschäf-

112 Vgl. passipedia.de/grundlagen/anmerkungen_zur_geschichte, zuletzt geprüft am 11.08.2018. 
tigt gewesen seien, international und in der deutschen Bevölkerung die große Debatte um eine ,Nachhaltige Entwicklung' begonnen habe und dass auch sie von diesen Ideen buchstäblich ergriffen worden seien. Daraufhin hätten sie sich als Gruppe aufgemacht, sich zu informieren - zunächst hauptsächlich „über Fachzeitschriften“ (ebd., 342-243), da damals das „Internet noch gar nich so der Zugangsweg [war]“ (ebd., 341-342) und in der Folge sich in der gesamten Bundesrepublik umgesehen nach konkreten Projekten, „wo wird wie gebaut dass es möglichst energiesparend is“ (ebd., 343-344). Im Zuge dieser länger andauernden Recherchen und Planungen ist die ursprüngliche Gründerinnengruppe auch nach Freiburg und Kassel gefahren, um sich dort vor Ort die ersten gebauten Mehrgeschoss-Passivhäuser Deutschlands anzuschauen. Parallel dazu hatte die Baugruppe offenbar schon damit begonnen, sich nach einem bzw. einer geeigneten Architekt"in umzuschauen, mit dem bzw. der sich ein solches Passivhausbauvorhaben im Sozialwohnungsbau umsetzen ließ.

Die besichtigten Häuser haben die Frauen offenbar vollends überzeugt, denn nach dieser Besichtigungstour fasste die Gruppe endgültig den Entschluss, ihr eigenes Bau- und Wohnprojekt ebenfalls als Passivhaus zu realisieren. Frau Greiner, eine weitere Bewohnerin des Passivhausprojekts B, die nicht dem ursprünglichen fünfköpfigen Gründerinnenkreis angehört, sondern etwas später, aber noch während der Planungsphase zum Projekt dazu gestoßen ist, beschreibt den festen Entschluss der Gruppe zum Passivhaus folgendermaßen:

„Und zwar gab es Leute in der Gruppe die ökologisch ähm interessiert waren und aufgeschlossen waren. Und die sachten eigentlich sollten wir als Gr- wir als- als Gruppe äh wenn wir schon neu bauen dann für die Zukunft bauen und das sollte dann ein Passivhaus sein und auch nicht Niedrigenergie sondern wirklich 'n Passivhaus." (Bewohnerin $\mathrm{PH}$, Interview 64: 3, 114-119)

Das Zitat macht deutlich, dass die Baugruppe B damals sehr ambitioniert war, was den Gebäudeenergiestandard ihres zukünftigen Hauses betraf und bei ihrem eigenen Projekt unbedingt den höchsten Energiestandard für Gebäude, den es zum damaligen Zeitpunkt offiziell gab, verwirklicht haben wollte. Und dies war damals das Passivhaus.

Wie in Kapitel 4.2.4 bereits thematisiert, ist eine Frau daraufhin noch aus dem Projekt ausgestiegen, weil sie zu große Bedenken und Vorbehalte gegenüber der Passivhaustechnologie, insbesondere gegenüber der kontrollierten Be- und Entlüftung hatte und sich ein Leben im Passivhaus nicht vorstellen konnte. 
Aus Frau Greiners Antwort auf die Frage, inwieweit die Architektin in die Entscheidung für das Passivhaus involviert gewesen sei, geht noch einmal deutlich hervor, dass im Fall des Wohnprojekts B die Idee für ein Passivhaus definitiv von der Baugruppe ausging, die Architektin für dieses Vorhaben der Gruppe allerdings sehr aufgeschlossen war:

„Die- die Architektin (.) fand das interessant und hat es dann positiv unterstützt. Aber es war nicht die Idee der Architektin." (Bewohnerin $\mathrm{PH}$, Interview 64: 4, 174-175)

Frau Köhler räumt ein, dass es ihnen als Bauherr*innen und künftige Bewohner"innen damals wichtig gewesen sei, dass sie eine"n Architekt"in finden, der bzw. die selbst "auch Wert darauf [auf ökologisches, ressourcenschonendes Bauen, JM] legt“ (Bewohnerin PH, Interview 60: 7, 349) und sie deshalb auch von Anfang an „unter dem Gesichtspunkt [nach] jemand[em] suchten der das bauen sollte“ (ebd., 348-349). Das heißt, die ursprünglichen Baugruppenmitglieder, die damals noch als Pionier*innen im Bereich energiesparenden Bauens anzusehen waren, suchten nach einem oder einer gleichgesinnten Architekt"in, der bzw. die sich selbst auch auf den Weg in diese Richtung gemacht hatte und jetzt mit ihnen als Baugruppe das ,Abenteuer' Passivhaus wagen wollte. Aufgrund dieser Kriterien kam der Kontakt mit der Architektin zustande, die Frau Köhler zufolge, „eine der ersten [war] die [...] zunächst mehr bei der Sanierung von Niedrigenergiehäusern tätig war und dann so mit dieses Haus mit als eines der ersten [Passivhäuser im Geschosswohnungsbau, JM] plant[e]“" (ebd.: 5, 251-253).

Frau Köhlers Schilderungen lässt sich entnehmen, dass die Architektin, die das Passivhaus letztendlich für die Baugruppe B plante und die Umsetzung des Projekts leitend betreute, vorher zwar schon einiges im Bereich ,Niedrigenergiehausbau' gemacht hatte, vorab aber über keinerlei Erfahrungen im Planen und Bauen von Passivhäusern verfügte. Diese Deutung bestätigt sich sowohl im Interview mit Frau Greiner, die berichtet: „Und die Architektin war dann ganz aufgeschlossen. Die hatte so 'n Haus noch nie gebaut. Die hat gedacht super Chance so 'ne Erfahrung zu machen. Und dann haben wir das gemacht" (Bewohnerin PH, Interview 64: 3, 119122), als auch im Gespräch mit Frau Rosental, die argumentiert, dass die Architektin sich „praktisch ähm damit [...] ja auch sich was Neues erarbeitet [hat]“" (Bewohnerin PH, Interview 59: 2, 69-70).

Die Äußerungen der verschiedenen Bewohner*innen des Passivhausprojekts B machen deutlich, dass sich in diesem Fall Nutzer*innen und Expert"in gemeinsam auf den Weg ökologischen und ressourcenschonenden 
Bauens gemacht haben und dass hier die Nutzer*innen sogar die ersten Ideengeber*innen und die treibende Kraft des damals innovativen Passivhausbauvorhabens waren. Die Schilderungen der Bewohnerinnen zeigen, dass die von der Baugruppe B ausgewählte Architektin nicht nur von Anfang an offen für neue Ideen und Herausforderungen war, sondern dass sie in dem Projekt auch für sich selbst eine ,Chance' gesehen hat, neue Praxiserfahrungen auf dem Gebiet energieeffizienten Bauens zu sammeln und sich dadurch für die Planung von Passivhäusern weiter zu qualifizieren.

Der folgende Dialogausschnitt aus dem gemeinsamen Interview mit Frau Rosental und Frau Lutz verdeutlicht, dass die Realisierung des Passivhauses B zu einem wichtigen Lernprozess für die verantwortliche Architektin geworden ist:

Frau Lutz: Es lassen sich nich die Zimmer einzeln regulieren. In unserem nich. Ich glaube die Architektin hat inzwischen-

Frau Rosental: Genau.

Frau Lutz: gemerkt dass das 'n Defizit is und (.) dass man das anders Lbauen muss.

Frau Rosental: Ja die hat also ${ }^{\rfloor}$Lüftungen abgekoppelt und hat die Wärme dann durch Heizkörper ganz normal falls $L_{m a n}$ zuheizen will. Ja und dass

Interviewerin JM: Dass man dazu regulieren kann.」

Frau Rosental: das nich mit der Lüftung gekoppelt is. Und das is bei uns nich."

(Bewohnerinnen PH, Interview 59: 6, 292-305)

Dem Dialogausschnitt lässt sich entnehmen, dass im Passivhaus B - wie im ursprünglichen Passivhauskonzept vorgesehen - die Wärmeversorgung komplett an die Lüftung gekoppelt ist. Das heißt, dass die Wohnungen der Bewohner*innen des Passivhauses B über die Lüftungsanlage sowohl beund entlüftet als auch beheizt werden. Dadurch können die Bewohner*innen an ihrer jeweiligen Lüftung nur eine Temperatur für ihre gesamte Wohnung einstellen, so dass es in allen Wohnräumen immer gleich warm ist. Viele Bewohner*innen erleben dies offenbar als großes Manko. Die Passage verdeutlicht, dass die Architektin die Kritik der Bewohner*innen an der integrierten Luftheizung des Passivhauses registriert hat und diese offenbar nachvollziehen kann. An Frau Rosentals Beschreibung wird auf jeden Fall deutlich, dass die Architektin bei ihren darauffolgenden Passivhausprojekten dazu übergegangen ist, die Wärmeversorgung stärker von der Lüftung zu entkoppeln und stattdessen den Bewohner*innen standardmäßig zusätzliche Heizkörper in allen ihren Räumen für die Restwärme- 
versorgung und zum Dazuheizen, dem persönlichen Bedarf entsprechend, $\mathrm{zu}$ installieren.

Ganz offensichtlich hat die Architektin bei diesem, ihrem allerersten Passivhausbauprojekt erste wichtige Erfahrungen mit der Passivhausbauweise, vor allem aber in Bezug auf die Konzeption von Lüftung und Wärmeversorgung des Passivhauses gesammelt, die sie bei darauffolgenden Passivhausbauprojekten bereits erfolgreich umgesetzt $\mathrm{zu}$ haben scheint. Hieran wird deutlich, dass die Architektin anfangs nur über theoretische, aber keinerlei praktische Kenntnisse hinsichtlich der Passivhausbauweise verfügte, sondern sich ihr praktisches Wissen zum Passivhaus erst allmählich mit der Umsetzung konkreter Bauprojekte angeeignet hat (,learning by doing ${ }^{6}$. Diese Deutung wird durch eine Passage aus dem Interview mit Frau Köhler gestützt:

„also sie [die Architektin, JM] is grad speziell hat sie auch die Veränderungen und neu: (.) ja wie soll man sagen Verbesserungen dieses Passivenergiesystembaus hat sie sehr mit verfolgt und auch miteinbezogen. Sie hat zum Beispiel vor einiger Zeit mal gesacht, ihr Haus würde ich heut anders planen als ich's damals gemacht hab vor zwanzig knapp zwanzig Jahren'." (Bewohnerin PH, Interview 60: 5f, 267-272)

Dieser Punkt, dass viele der Architekt*innen von Passivhäusern der ersten Generation mit wenig Vorkenntnis in ihre ersten Bauprojekte gestartet sind und wichtiges praktisches Know-how zur Bau- und Funktionsweise des Passivhauses erst über die Jahre mit zunehmender Praxis gewonnen haben, war wesentlich mitentscheidend für den Umschwung hinsichtlich der Heizlösung von Passivhäusern der ersten zu Passivhäusern der zweiten Generation. Mit den ersten Passivhausbauprojekten wurde gewissermaßen Pionierarbeit geleistet. Diese Erfahrungen haben die Architekt*innen der ersten Generation Passivhäuser in ihre neuen Projekte hineingetragen bzw. dieses akkumulierte Praxiswissen wurde von nachfolgenden Architekt*innen übernommen, die es in ihre Arbeit einfließen lassen (haben) und es wiederum mit ihrem Erfahrungswissen immer weiter anreichern.

Heute wird nur noch selten das ursprüngliche Passivhauskonzept umgesetzt, welches kein zusätzliches aktives Heizungssystem, sondern nur eine reine Luftheizung mit eingebautem elektrischem Nachheizregister vorsieht. Zwar kann ein Passivhaus einen sehr großen Teil des Wärmebedarfs über die Nutzung solarer und interner Wärmegewinne decken, wobei die sehr gute Dämmung, die Wärmerückgewinnung und die solare Ausrichtung bzw. die solaren Erträge des Hauses hier sehr helfen. Dennoch verbleibt ein restlicher Wärmebedarf der möglichst ökonomisch wie auch 
ökologisch akzeptabel gedeckt werden sollte bzw. muss. Hinzu kommt, dass die Praxis gezeigt hat - dies klingt auch im obigen Zitat von Frau Lutz an -, dass die allermeisten Bewohner*innen aus Komfortgründen wünschen, die Temperatur weiterhin für jeden ihrer Wohnräume einzeln regulieren zu können und sie deshalb den Einbau zusätzlicher Heizkörper in allen ihren Wohnräumen präferieren. Vor allem aus Gründen der Akzeptanz und weil es den Nutzer*innen auch das Gefühl der Kontrolle lasse, so begründet es der Passivhausarchitekt Herr Lehmann, sei man deshalb (zumindest in Norddeutschland) mittlerweile dazu übergegangen, im Passivhaus die Wärmeversorgung grundsätzlich von der Lüftung zu entkoppeln und für die Deckung des Restwärmebedarfs und zur Nachtemperierung stattdessen wieder zusätzlich ein aktives Heizungssystem mit kleinen Heizkörpern in allen Wohnräumen einzubauen (vgl. hierzu Hacke 2009a: 11 sowie Kapitel 4.1.1, hier insbesondere Teilkapitel 4.1.1.7). Das zeigt, dass sich ein theoretisches, noch so gut durchdachtes Konzept letztendlich in der Praxis bewähren muss, um sich durchzusetzen und erfolgreich zu bestehen. Die potenziellen Anwender*innen bzw. Praktizierenden entscheiden demnach mit ihrem praktischen Handeln darüber, ob eine zunächst rein technische Innovation dann zu einer sozialen Innovation wird, also ob die Neuerung Eingang in die Praxis findet und dort hinreichende Verbreitung erfährt.

\subsubsection{6 Öffentliches Image des Passivhauses und cleveres Marketing}

Ein weiteres Thema, welches sowohl in den Gesprächen mit überzeugten Passivhausbewohner"innen als auch mit Expert"innen aufkam, ist der Name: Passivhaus-Anhänger*innen wie auch Expert"innen nehmen stark an, dass für das eher negative Image des Passivhauses in der allgemeinen Bevölkerung und dem bisher nur mäßigen Rekrutierungserfolg der Passivhauspraxis die Bezeichnung ,Passivhaus' wesentlich mitverantwortlich ist. Auch wenn der Name inhaltlich adäquat erscheint, gehen sie davon aus, dass er einer erfolgreichen Vermarktung des Passivhauskonzeptes erheblich im Wege steht. 
4.5.1.6.1 „Und Passivhaus ist sowieso [... ] so 'n blöder Name“ Herr Wirth

Im Interview mit dem zusammenlebenden Paar Pfeiffer/Wirth kommt Herr Wirth früh im Gespräch auf ein Thema zu sprechen, das auch schon in Expert*innenkreisen seit einiger Zeit viel diskutiert wird. Und zwar geht es um die Bezeichnung bzw. den Namen ,Passivhaus', der diesem Gebäudetyp sowohl aus Sicht vieler Lai*innen als auch mittlerweile aus Sicht vieler (Passivhaus-)Expert"innen ein eher negatives Image verleiht und dementsprechend unter Marketinggesichtspunkten eher hinderlich wirkt. Wie das folgende Zitat von Herrn Wirth deutlich macht, ist der Begriff ,passiv' für ihn - wie offenbar für viele Menschen - eindeutig negativ konnotiert, werden mit ihm offensichtlich Vorstellungen, wie ,untätig und (unfreiwillig) ruhiggestellt sein', ,selbst nicht aktiv mitgestalten können', ,keinen Einfluss haben', stattdessen ,fremdbestimmt sein' und ,etwas von außen Vorgegebenes ertragen müssen', assoziiert. Das Zitat zeigt allerdings auch, dass Herr Wirth diese negativen Assoziationen selbst bereits kritisch reflektiert hat:

„Und Passivhaus ist sowieso so 'n eng- so 'n [...] blöder Name eigentlich auch. Hmm. [...]. Weil das schreckt doch erst mal ab. Wenn=de Leute ansprichst irgendwie und von Passivhäusern erzählst dann heißt es immer, Äh ach so stimmt das sind- so komisch dann darf man eben nicht lüften und darf man die Fenster nicht aufmachen'. Und passiv hört sich erst mal negativ an. [...]. Ich würde lieber in so 'nem Aktivhaus wohnen als im Passivhaus. Nee klar gibt's ja auch Aktivhaus. Aber das wäre-“ (Bewohner PH, Interview 56: 1f, 41-58)

Dem Zitat lässt sich entnehmen, dass viele Menschen, wenn sie von Passivhäusern hören und diese nicht aus eigener Erfahrung kennen, erst einmal Einschränkungen und Handlungsverbote assoziieren, die für sie mit dem Gebäudetyp des Passivhauses in Verbindung stehen. Das Zitat macht deutlich, dass diese Menschen offenbar nicht vom Gebäude aus denken, sondern dass sie den Ausdruck ,passiv` zunächst auf sich übertragen und als erstes ihre eigene Rolle als potenzielle*r Bewohner*in solch eines Gebäudes reflektieren. Demnach stellen sie es sich so vor, dass sie in einem Passivhaus gewohnte Alltagsaktivitäten, wie etwa das Lüften mittels Fensteröffnung, nicht mehr ausführen dürfen. Aus dieser Perspektive können sie es nicht so sehen, dass ihnen im Passivhaus das Lüften durch die Technik abgenommen wird, sie also nicht mehr selbst aktiv lüften müssen, denn für die Versorgung mit ausreichend frischer Luft ist das Öffnen der Fenster 
im Passivhaus nicht mehr zwingend erforderlich. Offenbar verbinden sie mit Passivhäusern die Vorstellung eines Kontrollverlustes, etwa den Verlust der Kontrolle über den Lüftungsvorgang, und dass sie als Bewohner*innen eines solchen Gebäudes sehr ,passiv' gestellt sind. Dass diese Assoziationen und Vorstellungen nicht von ungefähr kommen, sondern dass solche Reglementierungen, vor allem was die Fensteröffnungs- und Lüftungspraxis im Passivhaus anbelangt, anfangs tatsächlich viel kursierten und von Expert*innen selbst kommuniziert wurden, wurde bereits in Teilkapitel 4.2.4 dargelegt. Obwohl längst widerlegt, gibt es nach wie vor diesen Mythos, der besagt, dass im Passivhaus die Fenster nicht geöffnet werden dürfen - und er hält sich offensichtlich hartnäckig.

Interessant ist, dass sich Herr Wirth direkt im Anschluss an seine Kritik am Namen ,Passivhaus' daran zu erinnern glaubt, dass es am Anfang innerhalb der Wohnprojektgruppe A ohnehin eine „große Debatte“ (Bewohner PH, Interview 56: 2, 63) darüber gegeben habe, ob man das gemeinschaftliche Wohnhaus tatsächlich als Passivhaus umsetzen möchte. Da es damals, Mitte der 1990er Jahre, praktisch noch keine Erfahrungen zur Planung und zum Wohnen in Mehrfamilien-Passivhäusern gab, war den Wohngruppenmitgliedern bewusst, dass sie damit Pionierarbeit leisten und zwangsläufig erste Erprober*innen des Lebens in einem größeren gemeinschaftlich bewohnten und organisierten Passivhaus sein würden. Das untenstehende Zitat Herrn Wirths macht deutlich, dass im Wohnprojekt A - genauso wie in dem ebenfalls der ersten Generation Passivhäuser angehörenden Wohnprojekt B - noch die „alte Lösung“ (ebd., 67) mit nur einer Lüftungsanlage für das gesamte Haus realisiert wurde. Dabei handelt es sich um den ursprünglichen Ansatz des Passivhauses, der vorsieht, dass es nur noch eine Lüftungsanlage mit hocheffizienter Wärmerückgewinnung und maximal kleinen Nachheizregistern vor den Zuluftkanälen gibt, so dass auf ein konventionelles Heizungssystem komplett verzichtet werden kann. Genau dieser ,alte' integrierte Heizungs- und Lüftungsansatz ist es, der von Anfang an für die größten Vorbehalte gegenüber dem Passivhaus in der allgemeinen Bevölkerung verantwortlich gewesen ist und deshalb, aufgrund von mangelnder Akzeptanz, heutzutage in MehrfamilienPassivhäusern kaum mehr umgesetzt wird. Welche Einschränkungen, die sich offenbar vor allem auf das Behaglichkeits- und Komforterleben der Bewohner*innen beziehen, mit dem ursprünglichen Ansatz verbunden sind und welche Antwort der ,neue', nun in der Regel in MehrfamilienPassivhäusern realisierte Heizungs- und Lüftungsansatz auf diese Probleme gibt, lässt sich Herrn Wirths folgender Schilderung entnehmen: 
„Und war damals glaube ich auch eben große Debatte hier ob man irgendwie das als Passivhaus plant oder nicht ob ob man jetzt unbedingt irgendwie so der erste Prototyp sein möchte von Bewohnern die in so 'nem Passivhaus einziehen weil du hast ja nur eine oder wir haben zumindest noch diese- diese alte Lösung hier mit- mit einer Lüftungsanlage für's ganze Haus. Und dann irgendwie ist das WG-tauglich oder nicht so WG-tauglich. Neuere Passivhäuser baut man ja immer irgendwie so dass- dass jede einzelne Wohneinheit so 'ne eigene Lüftungsanlage hat und dass du auch 'ne Steuerung hast weil ansonsten hast du ja in jedem Raum die gleiche Temperatur." (Bewohner PH, Interview 56: 2, 63-73)

Die Passage lässt erkennen, dass Herr Wirth meint, den zentralen technischen Unterschied zwischen den Mehrfamilien-Passivhäusern der ersten und denen der zweiten Generation zu kennen. Dieser besteht seiner Meinung nach in der Konzeption der Lüftungsanlage, über die in Passivhäusern entweder komplett oder zumindest wesentlich mitgeheizt wird: Während sich Bewohner*innen von Mehrfamilien-Passivhäusern der ersten Generation demnach meist eine Lüftungsanlage teilen und sich somit als Wohngemeinschaft auf eine Temperatur für alle ihre Wohnungen und Wohnräume einigen müssen, sei man bei der zweiten Generation Mehrfamilien-Passivhäuser offenbar dazu übergegangen, jede einzelne Wohneinheit mit einer separaten Lüftungsanlage auszustatten. In Mehrfamilien-Passivhäusern der zweiten Generation verfügt demnach jede einzelne Wohneinheit über eine eigene Lüftung bzw. eine Einzelsteuerungsmöglichkeit der größeren zusammengeschalteten Gesamthaus-Lüftungsanlage, so dass jede Wohnpartei unabhängig von anderen Wohnparteien die Temperatur für die eigene Wohnung bestimmen kann.

Offenbar ist Herr Wirth, aufgrund seiner eigenen Erfahrung vom Leben in einem Passivhaus erster Generation und dementsprechend mit der „alte[n] Lösung" (ebd., 67) vertraut und im Hinblick auf diesen Nutzungsaspekt besonders sensibel. Zudem macht die Passage deutlich, dass er, was die Technik des Passivhauses anbelangt, recht kompetent ist. Das, was Herr Wirth über die baulich-konzeptionellen Veränderungen von Mehrfamilien-Passivhäusern der ersten Generation zu denen der zweiten Generation sagt, zeigt, dass er die technische Weiterentwicklung des Passivhauses seit dem Entstehen des eigenen Wohnprojekts weiter mitverfolgt hat. Dies erklärt auch, warum er selbst dem zum Teil sehr negativen Image des Passivhauses keinen Glauben geschenkt hat: Durch das permanente Sich-Informieren und Weiterverfolgen konnte er die gängigen Vorbehalte von 
Anfang an nicht nur kritisch reflektieren, sondern ist offenbar auch imstande, sich die Weiterentwicklungen technisch herzuleiten.

Wie Herr Wirth richtig beschreibt, besteht der wesentliche technische Unterschied zwischen den Mehrfamilien-Passivhäusern der ersten und denen der zweiten Generation tatsächlich in der Konzeption und Umsetzung der zentralen Lüftungsanlage. Und wie in Kapitel 4.1.1, hier insbesondere in Teilkapitel 4.1.1.7 bereits erläutert, wird aus Akzeptanz- und Komfortgründen mittlerweile häufig zusätzlich ein aktives Heizungssystem mit Heizkörpern in jedem einzelnen Wohnraum installiert, so dass die Bewohner*innen dieser besser ausgestatteten Mehrfamilien-Passivhäuser zudem die Möglichkeit haben, durch entsprechendes Dazuheizen ihre einzelnen Wohnräume unterschiedlich zu temperieren.

\subsection{Der Name ,Passivhaus' geht auf Wissenschaftler*innenkreise zurück, Marketingspezialist"innen waren an der Namensgebung sicher nicht beteiligt - Frau Schulze}

Auch Frau Schulze, eine Passivhaus-Architektin, erzählt davon - allerdings erst nach dem offiziellen Interview, als die Tonbandaufnahme bereits beendet ist -, dass sie sowie zahlreiche ihrer Architekt*innen-Kolleg*innen in ihrem Arbeitsalltag, insbesondere bei ihrem Kontakt mit angehenden Bauherr"innen, schon vielfach die Erfahrung gemacht hätten, dass viele Menschen, wenn man ihnen das Konzept des Passivhauses erstmals vorstelle, allein schon bei der Nennung des Namens ,Passivhaus' erst einmal verschreckt und eher zurückhaltend reagierten. Frau Schulze berichtet, dass sie selbst es auch so erlebe, dass der Begriff ,Passivhaus' in der allgemeinen Bevölkerung eher negativ konnotiert sei und bei vielen Menschen deutlich negative Assoziationen hervorrufe. Sie räumt ein, dass mit der Bezeichnung ,Passivhaus` zwar adäquat die komplexe Funktionsweise dieses Gebäudetyps beschrieben sei, dass aber der Name für eine erfolgreiche Vermarktung dieses modernen, besonders energieeffizienten Gebäudestandards wegen der negativen Assoziationen, die er bei vielen Menschen auslöse, vollkommen ungeeignet sei. Ihrer Ansicht nach lässt das erkennen, dass die Namensgebung in reinen Fachkreisen durch Wissenschaftler*innen erfolgte, dass hier aber sicher keine Marketingspezialist"innen beteiligt gewesen seien. Weiter beschreibt sie im Nachgespräch, dass man dem von fachlicher Seite her ständig aktiv entgegenzuwirken versuche - zum Beispiel, indem die mittlerweile in neunter Auflage erschienene Infobroschüre der Informations-Gesellschaft Passivhaus Deutschland, die sich so- 
wohl an Bauherr*innen als auch Architekt*innen und Planer*innen richtet, bewusst mit dem Titel „Aktiv für mehr Behaglichkeit: Das Passivhaus“ (IG Passivhaus Deutschland 2016), überschrieben sei. Darüber hinaus, so erklärt Frau Schulze weiter, hätten die Fachleute aus diesen Erfahrungen gelernt, weshalb neuere energieeffiziente Gebäudetypen mittlerweile attraktiver klingende und häufig auch präzisere Namen wie ,Aktivhaus', ,Zero Emission Building', ,Nullenergiehaus' und ,Plusenergiehaus' erhalten würden.

Diese beiden Aspekte, dass beim Passivhaus die Namensgebung eher ungeschickt verlaufen ist und die Lüftungsanlage, das technische Kernstück des Passivhauses, zumindest in den ersten größeren Wohnprojekten nicht wirklich nutzer*innenfreundlich konzipiert war, haben sich offenbar nachhaltig auf das allgemeine Image des Passivhauses ausgewirkt und zu einem eher schlechten Ansehen und Ruf des Passivhauses in der breiten Öffentlichkeit geführt. Zwar gelten die technischen Mängel mittlerweile weitestgehend als behoben: Die Heizungs- und Lüftungstechnik wird mittlerweile deutlich nutzer*innenfreundlicher realisiert und es wird viel unternommen, um die breite Öffentlichkeit über die tatsächliche Funktionsweise und Handhabung des Passivhauses aufzuklären und sie für das Passivhaus zu begeistern - so gibt es heutzutage zum Beispiel zahlreiche Angebote zu eigener positiver Erfahrung, wie ,Tage der offenen Tür ${ }^{6113}$ oder ,Probewohnen'114. Zudem wird der Bau eines Passivhauses häufig mit öffentlichen Geldern gefördert. Dennoch konnte das Passivhaus sein negatives Image bisher nicht abschütteln. Trotz dieser zahlreichen Bemühungen ist weiterhin zu beobachten, dass das Passivhaus keine große Begeisterung in der deutschen Bevölkerung auslöst. Nach wie vor verbreitet sich die (Bau-)Praxis des Passivhauses in Deutschland eher langsam bis schleppend. Und mittlerweile sind bereits einige Gebäudestandards entwickelt worden, die die Idee des (Heiz-)Energiesparens noch deutlich weitertreiben als dies bereits im Passivhaus verwirklicht ist.

113 Z.B. „Tage der offenen Tür im Passivhaus. Passivhaus-Bewohner laden ein“ (www.ig-passivhaus.de/index.php?page_id=157\&, zuletzt geprüft am 02.10.2018).

114 Z.B. „Probewohnen im Passivhaus“" (www.ig-passivhaus.de/index.php?page_id= 183\&, zuletzt geprüft am 02.10.2018). 
4.5.2 Weg(e) zu einer intelligenten Heizungssteuerung oder wie intelligentes Heizen bisher Verbreitung findet

Im Fall der Heizungsautomationstechnik bzw. des intelligenten Heizens war die Ausgangslage eine gänzlich andere als bei der Passivhaus-Heizpraktik: Während sich die für diese Arbeit interviewten Passivhausbewohner*innen zwar aus unterschiedlichen Motivationen heraus, aber alle bewusst und freiwillig für den Einzug in ein Passivhaus und damit für eine neue Heizpraktik im Wohnkontext Passivhaus entschieden haben, sind die Teilnehmer*innen des Pilotprojekts zum intelligenten Heizen von ihrer Wohnungsgenossenschaft als Vermieterin verpflichtet worden. Das heißt, den von der Vermieterin ausgewählten Haushalten wurde die intelligente Heizungssteuerungstechnik eingebaut und diese Mieter*innen müssen nun - sie haben de facto keine andere Wahl - mittels der neuen Technik heizen. Die Praktik des intelligenten Heizens hat sich um diese Teilnehmer*innen nicht selbst aktiv bemühen müssen, sondern in diesem Fall wurde die Rekrutierung einer größeren Anzahl an Teilnehmer*innen von der die betreffenden Wohnungen vermietenden Genossenschaft übernommen. Es lässt sich hier von einer Herangehensweise in Form einer ,Zwangsbeglückung‘ oder ,Aufnötigung' sprechen.

Auch wenn anzunehmen ist, dass es einige Mieter*innen gegeben hat, die positiv auf die verpflichtende Teilnahme am Pilotprojekt reagiert haben, hatte keiner der von der Maßnahme betroffenen Haushalte vorher eigeninitiativ und unabhängig vom Pilotprojekt die Praktik des intelligenten Heizens übernommen - das heißt, sich schon vorher freiwillig rekrutieren lassen. Demnach lässt sich aus den Fällen der zwangsbeglückten Mieter*innen nur unzureichend ableiten, welche Aspekte und Faktoren es sind, die eine An- bzw. Übernahme dieses neuen Heizansatzes aus Sicht potenzieller Teilnehmer*innen attraktiv erscheinen lassen. Dass die Praktik des smarten Heizens zurzeit (noch) nicht erfolgreich darin ist, von sich aus, das heißt ohne massive Unterstützung in Form von Marketing und Werbung durch aktive Promotor*innen, neue potenzielle Teilnehmer *innen für sich zu gewinnen, wird auch im Interview mit Herrn Böhme deutlich. Herr Böhme arbeitet für einen großen deutschen Energieversorger und war in dem Unternehmen längere Zeit für den Aufbau der Produktsparte ,SmartHome-Lösungen für den Privatkundenbereich“ zuständig. Herr Böhme beschreibt, dass „der ganze SmartHome-Markt“ (Experte SH, Interview 58: 5, 233) in seinen Augen aktuell noch „mehr 'n Push-Markt als 'n Pull-Markt" (ebd., 235-236) sei, was seiner Ansicht nach zeigt, dass die SmartHome-Technik nicht hinreichend attraktiv für potenzielle 
Kund*innen zu sein scheint, so dass sie freiwillig und von sich aus, etwa auf Heizen mittels smarter Technik, umsteigen. Auf die Frage, von wem die Entscheidungsinitiative, ein Haus oder eine Wohnung mit SmartHome-Komponenten oder -Anwendungen aufzurüsten, meistens ausgehe, antwortet Herr Böhme:

„Äh: also der ganze SmartHome-Markt würde ich sagen is mehr 'n Markt das- wovon wir denken dass da einer is oder sein sollte und eines Tages hoffentlich auch einer is. Äh ich hab das Gefühl das is mehr 'n Push-Markt als 'n Pull-Markt. Also die Leute selber sind jetzt nich heiß drauf und wollen unbedingt das alles haben. (.) Deswegen glaube ich eigentlich mehr dass - (stammelt) wir können's ihnen ja nich aufdrängen aber wir sind glaub ich generell in der Energiewirtschaft mehr am aktiv Anbieten als dass der Kunde sacht ich hätte das alles gerne. (.) Deswegen is auch alles nich so besonders erfolgreich bisher." (Experte SH, Interview 58: 233-241)

Der Passage lässt sich entnehmen, dass Herr Böhme alle Unternehmen der deutschen Energiewirtschaft, die ihren Kund*innen zurzeit schon SmartHome-Produkte anbieten, im Moment noch mehr in der Rolle des aktiven Anbieters sieht, die damit beschäftigt sind, die Nachfrage bei den Kund*innen erst zu erzeugen, die sie mit ihren SmartHome-Produkten decken möchten. Deutlich wird, dass Herr Böhme dieses Unternehmensagieren, den Kund*innen SmartHome-Produkte und -Anwendungen mehr oder weniger ,aufzudrängen', für wenig sinnvoll und nicht sehr erfolgversprechend erachtet. Demnach wäre es für sein und andere am SmartHomeMarkt beteiligte Unternehmen einfacher und aussichtsreicher, wenn auf Seiten der Privatkund*innen bereits ein Interesse oder sogar ein Bedarf an SmartHome-Systemen bestünde, es also eine aktive Nachfrage gäbe, auf die man von Unternehmensseite mit entsprechenden Angeboten nur noch reagieren müsste.

Diese Einschätzung, dass sich in Deutschland bis jetzt noch keine rege aktive Nachfrage nach SmartHomes oder einzelnen SmartHome-Komponenten gebildet habe, wird auch von den anderen für diese Untersuchung interviewten SmartHome-Expert*innen geteilt. So berichtet auch Herr Thiel, ein Vertreter eines anderen großen deutschen Energieversorgungsunternehmens, dass „das Thema [SmartHome, JM] an sich noch nicht so bekannt ist" (Experte SH, Interview 63: 5, 223-224) und bisher auch immer nur aufgrund von massiver Werbung für kurze Zeit in der Bevölkerung präsent gewesen sei: 
„Also [Name des Energieversorgungsunternehmens] sind wir doch 'n größeres namhaftes Unternehmen in Deutschland. Aber die Marktmacht die Marktkapazität im Sinne einer von Werbemaßnahmen reichte doch nicht aus um so 'n Produkt oder so 'ne Idee bei den Leuten zu verankern. Also wir hatten zu Beginn 'ne sehr intensive Werbekampagne [...] das hm war interessant war gut wir haben auch gemerkt wie die Zugriffszahlen rasant gestiegen sind. Aber sobald der Werbedruck nachlässt sehen Sie auch wie die Zahlen wieder nach unten gehen. Also es ist noch kein Thema mit dem sich die Bevölkerung in dem Maße auseinandersetzt." (Experte SH, Interview 63: 3, 147157)

Deutlich wird, dass es im Fall der Praktik des intelligenten Heizens in Deutschland zurzeit in erster Linie die großen und mittelgroßen Energieversorgungsunternehmen sind, die bereits stark auf den Vertrieb von SmartHome-Technik setzen und die Rolle der aktiven Promotoren übernehmen. Dass diese sehr einflussreichen Akteure sich nicht uneigennützig für die Verbreitung der neuen Praktik des intelligenten Heizens intensiv engagieren, wird deutlich von den interviewten SmartHome-Expert*innen kommuniziert. Auf die Frage, was sein Unternehmen letztlich dazu bewogen habe, sich mittlerweile derart stark im Bereich SmartHome-Lösungen zu engagieren und diesen Geschäftsbereich derart umfassend auszubauen, antwortet Herr Koch, ein Mitarbeiter in führender Position bei einem regionalen mittelgroßen Energieversorgungsunternehmen, bei dem er zum Zeitpunkt des Interviews hauptverantwortlich für die SmartHome-Sparte ist, Folgendes:

„Dazu gekommen ist das eigentlich ähm darüber dass wir schon seit Langem wissen ich glaub seit dreizehn oder fünfzehn Jahren äh [...] dass dezentrale Energieerzeugung immer weiter zunimmt dass unser Bestandsprodukt die Kilowattstunde damit auch kontinuierlich ja sinkt und nicht mehr so nachgefragt wird wie das bisher der Fall war und dass man ja dadurch einen Market-Pull-Effekt im Prinzip hat man sagt wenn das Kerngeschäft der Besch- Bestandsmarkt nicht mehr so ist wie er vorher war da braucht man irgendwelche Neuerungen um das zu kompensieren oder dass das eben eine Antwort könnte da SmartHome sein.“ (Experte SH, Interview 57: 1, 20-29)

Die Argumentation macht deutlich, dass es den Energieversorgungsunternehmen bei ihrer Unterstützungsarbeit, die sie zur Verbreitung von SmartHome-Produkten und -Anwendungen leisten, vor allem um die Sicherung des eigenen Fortbestehens geht. Demnach bricht den großen Energiever- 
sorgungsunternehmen ihr „Kerngeschäft“ (ebd., 26) durch den Trend hin zu einer immer stärker dezentral organisierten Energieerzeugung massiv ein. Das heißt, das Basisprodukt, welches ihnen bisher die eigene Existenz absicherte, „die Kilowattstunde“ (ebd., 23) wird von den privaten Konsument"innen immer weniger nachgefragt - zum einen, weil Energie immer effizienter genutzt wird, zum anderen, weil offenbar immer mehr private Haushalte die von ihnen benötigte Energie von dezentralen (lokalen) Erzeugern beziehen oder diese zum Teil sogar selbst produzieren, beispielsweise über die Photovoltaikanlage auf dem Dach oder das Windrad auf dem Acker. Dadurch sinken die Unternehmensumsätze der großen zentralen Energieversorger kontinuierlich. Dementsprechend sehen sich die großen Energieversorger gezwungen, sich neue Geschäftsfelder zu erschließen, zum Beispiel indem sie neue Geschäftsmodelle entwickeln und neue gewinnbringende Produkte und Dienstleistungen vertreiben. Mit „MarketPull-Effekt" (ebd., 25) beschreibt Herr Koch genau dieses aktive Vorgehen seines und das anderer zentraler Energieversorgungsunternehmen im Fall der SmartHome-Produkte und -Anwendungen. Die Initiative für die ,Neuerung' geht in diesem Fall eindeutig von den Herstellern bzw. Anbietern aus. Diese versuchen, beispielsweise mit aufwendigen Werbemaßnahmen, die sich direkt an Kund"innen und potenzielle Konsument"innen richten, die Aufmerksamkeit der Endverbraucher*innen auf sich und ihr Produkt zu ziehen und dadurch eine entsprechende Kaufdruck-Situation auf dem Markt zu erzeugen. Damit ist Herr Koch der dritte Experte, der im Interview den aktuellen Markt für SmartHome-Lösungen in Deutschland als ,Pull-Markt' beschreibt.

\section{Die Unterstützung durch professionelle, einflussreiche und besonders enga- gierte Promotor*innen}

Da die beforschten Bewohner*innen für die Praktik des smarten Heizens, wie beschrieben, alle mehr oder weniger durch Zwang rekrutiert wurden und wegen dieses Vorgehens der Projektführung viele von ihnen verhalten bis ablehnend auf die neue Technik reagiert haben, konnte anhand der Gespräche mit Pilotprojektteilnehmer*innen kaum etwas darüber in Erfahrung gebracht werden, was smartes Heizen aus Sicht potenzieller Praktizierender für ein freiwilliges Engagement attraktiv machen könnte.

Dafür konnte in den Gesprächen mit SmartHome-Expert*innen etwas darüber herausgefunden werden, welcher Strategien sich die von ihnen vertretenen großen und mittelgroßen Energieversorgungsunternehmen bedienen, um die von ihnen angebotenen SmartHome-Produkte erfolgreich zu vermarkten. Gemeinsam ist allen diesen Unternehmen, dass sie bereits 
smarte Heizungssteuerungstechnik vertreiben und diesbezügliche Dienstleistungen anbieten und sie dieses Geschäft in Zukunft noch aktiver betreiben möchten. Deshalb sprechen sie ihre Kund*innen gezielt an, möchten sie dadurch zum Kauf von SmartHome-Technik anregen und sie auf diesem Wege zur Übernahme eines neuen Heizansatzes bewegen.

In den Interviews wurden von den SmartHome-Expert"innen viele Strategien genannt, die sich indirekt bereits im Fall des Passivhauses als grundlegend für die Entscheidung der Praktizierenden zu ihrem Engagement erwiesen haben. So beschreibt etwa Herr Thiel, dass sein Unternehmen bei der Vermarktung von SmartHome-Systemen bisher vor allem mit zwei Strategien durchaus erfolgreich arbeite. Zum einen ist dies die Kopplung der Technik an für Kund"innen bzw. potenzielle Nutzer"innen besonders wichtige Belange, wie zum Beispiel ,Komfort', ,Sicherheit' oder ,Status'. Das andere ist die anschauliche Präsentation der Handhabung von SmartHome-Technik im lebensweltlichen Kontext, wobei Herr Thiel sich hier noch eine deutliche Ausweitung des Engagements seines Unternehmens vorstellen kann.

\subsubsection{1 „So 'n bisschen von hinten durch die Brust [...] weil der direkte} Weg funktioniert äh doch nicht so einfach" - Herr Thiel

Herr Thiel ist Mitarbeiter eines großen deutschen Energieversorgungsunternehmens und bei diesem seit 2010 in leitender Position im Bereich „Effizienz' tätig, in dem auch das junge Geschäftsfeld ,SmartHome` angesiedelt ist.

Herrn Thiel zufolge bestand die ursprüngliche Idee seines Unternehmens, sich als „originäre[r] Energieversorger“ (Experte SH, Interview 63: 2, 72) in dem Geschäftsfeld ,SmartHome ' mit eigenen Produkten zu betätigen, darin, dass man die eigenen Kund"innen bei einem aktiven Energieverbrauchsmanagement und beim Energiesparen unterstützen wolle. Mittlerweile habe sich das Unternehmensangebot an SmartHome-Produkten allerdings deutlich verändert. Das folgende Zitat verdeutlicht, dass zum einen einige neue Themenfelder hinzugekommen sind, wie zum Beispiel ,Komfort', ,Sicherheit' und ,Entertainment', für die nun auch entsprechende Produkte entwickelt wurden. Zum anderen hat sich der thematische Fokus verlagert, nun steht nicht mehr das Thema ,Energiesparen` im Vordergrund, sondern eher ,Komfort':

„Also zu Beginn war der Ansatz dass wir sagten wir sind originäre Energieversorger. Und wir bringen 'n Produkt auf den Markt was dem 
Kunden erlaubt seine äh äh Energiemaßnahmen zu kontrollieren und und und sagen wir mal darüber 'ne- 'nen Einfluss auszuüben den er in dem Maße vorher nicht hatte. Also der Grundansatz von uns warum wir da rein gegangen sind war eigentlich so 'n- ja Energiesparen eigentlich. Ähm das Produkt hat sich dann aber im Laufe der Zeit doch erheblich weiterentwickelt. Also [...] wir haben momentan 'n Portfolio von achtzehn Geräten die eigentlich von Energiesparen bis Sicherheit zu Komfort eigentlich alles abdecken. [...] Überlegung is dassdass wir sagen jeder Kunde kauft so 'n System aus'm anderen Anlass. [...] was wir jetzt auch so 'n bisschen festgestellt haben dass ähm ich sag mal Energiesparen nicht die Hauptantriebsfeder ist für Kunden das zu kaufen. Es ist eher Komfort und Status so 'n bisschen." (Experte $\mathrm{SH}$, Interview 63: 2, 71-99)

Dem Zitat lässt sich entnehmen, dass das Unternehmen, in dem Herr Thiel tätig ist, hinsichtlich der Vermarktung von SmartHome-Produkten in seiner Geschäftsstrategie deutlich umgesteuert hat: Statt mit eigenen Produkten einzig bzw. hauptsächlich das Thema ,Energiesparen“ abzudecken, wird nun zusätzlich auf Themen wie, Sicherheit', ,Komfort' und ,Status' gesetzt. Deutlich wird, dass diese Ausweitung des Produkteportfolios daraus resultiert, dass Herr Thiels Unternehmen festgestellt hat, dass „Energiesparen nicht die Hauptantriebsfeder ist für Kunden das [SmartHomeSysteme bzw. -Geräte, JM] zu kaufen“ (ebd., 97-98), sondern dass es „eher [das Thema] Komfort" (ebd., 98) ist, an dem Käufer*innen interessiert sind und auch das Thema „Status so 'n bisschen“ (ebd., 98-99). Der Beschreibung lässt sich entnehmen, dass man in Herrn Thiels Unternehmen davon ausgeht, dass es nicht die eine „Hauptantriebsfeder“ (ebd., 97) gibt, warum sich Kund"innen dafür entscheiden, sich ein komplettes SmartHome-System anzuschaffen oder auch nur einzelne SmartHome-Komponenten zu kaufen, sondern dass dies von Kund"in zu Kund"in sehr verschieden sein kann. Deutlich wird aber, dass die Themen ,Komfort ${ }^{6}$ und ,Status ${ }^{6}$ an Wichtigkeit gewonnen haben, wobei ,Komfort' eine herausragende Rolle spielt. Dies wird an anderer Stelle im Interview ganz klar deutlich: Auf die direkte Frage der Interviewerin, welcher seiner Einschätzung nach „der im Moment größte bedeutendste [Verkaufs-]Faktor von diesem SmartHome“ (ebd.: 26, 1350-1351) sei, antwortet Herr Thiel einsilbig und bestimmt „Komfort“ (ebd., 1353). Zudem verdeutlicht die Beschreibung, dass es beim gesamten Thema ,SmartHome' aus Unternehmenssicht nicht vorrangig um die angesprochenen Themen geht, sondern vielmehr darum, sich ein neues Geschäftsfeld zu eröffnen und auf diesem möglichst gewinnbringend und in hoher Zahl die eigenen neuartigen Produkte zu verkaufen. 
Die Schilderung zeigt: Will ein Energieversorgungsunternehmen im Bereich ,SmartHome“ erfolgreich sein, so ist es nicht ausreichend, ausschließlich auf den eigenen bisherigen Kompetenzbereich und die eigenen Themen zu setzen, sondern es muss mit seinen Produkten auch die zentralen Belange und Interessen der Kund"innen bzw. potenzieller Nutzer*innen ansprechen und bedienen. Aus der Beschreibung von Herrn Thiel geht hervor, dass sein Unternehmen im Bereich ,SmartHome' mittlerweile relativ breit aufgestellt ist, offenbar mit dem Ziel, dadurch eine möglichst große Kundschaft bzw. viele potenzielle Anwender*innen zu erreichen.

Das Wichtigste sei aber, so erklärt Herr Thiel weiter, dass es einem gelinge, die neue SmartHome-Technik an Themen zu koppeln, die die Kund"innen entweder generell ,berührten', wie zum Beispiel das Thema ,Sicherheit', oder die sie aus einem saisonalen, ganz spezifischen Anlass heraus gerade aktuell beschäftigten, wie zum Beispiel ein nahender Sommeroder Winteranfang, Weihnachten oder der Eingang der jährlichen Stromoder Gasabrechnung. Herr Thiel beschreibt das diesbezügliche Vorgehen seines Unternehmens, das diese so genannten ,Gelegenheitsfenster ganz gezielt zur Bewerbung seiner SmartHome-Produkte und -Anwendungen nutzt, folgendermaßen:

„Sie benötigen so 'n bisschen 'n Vehikel um das Thema zu etablieren. Und wir äh versuchen's darüber dass wir uns Themen rausgreifen auch saisonal dass wir sagen wenn's warm ist müssen Sie keine Heizkörper verkaufen. Da hatten wir jetzt was- also zu Weihnachten haben wir dann die Lichterkette dazu gepackt. Machen Sie über den Zwischenstecker außen- steuern sie die Lichterkette. [...]. Sie müssen's so 'n bisschen verpacken mit Themen einfach auch sagen wir mal der Breitbandigkeit des Produkts geschuldet. Es ist- Sie brauchen mindestens drei bis vier Berührungspunkte mit dem Kunden bevor er sich überhaupt mal ansatzweise entscheidet sowas zu kaufen. [...]. Also nur mal zum Vorbeifliegen gucken SmartHome reicht nicht. [...] also der Kunde muss sich schon intensiver damit auseinandersetzen wollen. Und ähm um das zu erreichen brauchen Sie unheimlich viel Werbemittel. Sehen wir ja.“ (Experte SH, Interview 63: 4, 177-192)

An dieser Passage wird noch einmal deutlich, dass es der SmartHomeTechnik bis jetzt nicht gelungen ist, neue potenzielle Anwender*innen von sich aus neugierig zu machen und für sich zu begeistern. Im Gegenteil, zurzeit bedarf es noch erheblicher Unterstützung von außen, etwa in Form von besonderen Aktionen und viel prominent platzierter Werbung, dass die Kund"innen bzw. potenzielle Anwender"innen überhaupt dazu 
bereit sind, sich auf diese neue Technik einzulassen und diese einmal auszuprobieren.

Herr Thiels bisherige Ausführungen haben deutlich gemacht, dass potenzielle Anwender*innen im Moment noch sehr in Richtung SmartHome-Technik ,gepusht" werden müssen, etwa indem ihnen von den Anbietern (Herstellern und Vertriebsunternehmen) ständig attraktive Angebote gemacht werden. Demnach ist fraglich und bleibt abzuwarten, ob sich dies noch ändert und die Anwendung von SmartHome-Technik in Deutschland tatsächlich auch zu einer, sozialen Innovation' im Sinne einer weit verbreiteten und dadurch gut etablierten ,neuartigen' Praxis wird.

Von der Interviewerin konkret auf das Heizen angesprochen, beschreibt Herr Thiel sowohl die Produkte, die das von ihm vertretene Unternehmen seinen Bestandskund*innen und auch potenziellen Neukund"innen für diesen ausgewählten Tätigkeitsbereich anbietet, als auch wie sein Unternehmen auf diesem Feld vorgeht, um potenziellen Anwender*innen das eigene Angebot näher zu bringen:

Herr Thiel: [...]. Heizen zur Winterperiode ganz klar. Heizen dass man sagt Heizkörperther- thermostate wir haben 'ne Fußbodenheizungssteuerung für diejenigen die 'ne Fußbodenheizung haben. Raumthermostat ist natürlich dann Energiesparen angesagt. Ist auch 'n Produkt das natürlich ganz gut kommt wenn- wenn- wenn die Kunden die Stromabrechnung bekommen die Gasabrechnung die jährliche. Also ja wie gesagt themenbezogen versuchen wir das so 'n bisschen aufzusetzen.

Interviewerin JM: Wie schaffen Sie das genau? [...].

Herr Thiel: Also dadurch dass wir Strom- und Gasversorger sind haben wir natürlich die Möglichkeit über unsere Vertriebe Kunden auch anzusprechen ähm dass sie sagen wir hm bereiten den Kunden ähm Angebote dar in Form wenn sie eine Abrechnung bekommen 'ne Stromabrechnung oder irgendwie was dass man sagt wir versuchen da, Okay Sie haben jetzt die Möglichkeit Sie haben 'nen sehr hohen Ge- Energieverbrauch. Ähm kennen Sie schon das SmartHome-System? Ähm es spart Ihnen so und so viel Energie nachweislich'“"

(Experte SH, Interview 63: 5f, 257-281)

Das Zitat macht deutlich, dass Heizen ein typisch saisonales Thema darstellt. Zudem lässt sich der Beschreibung Herrn Thiels entnehmen, dass die privaten Verbraucher"innen insbesondere dann für das Thema, Energiesparen' offen und eher an möglichen Maßnahmen zur Senkung ihres Energieverbrauchs interessiert sind, wenn sie durch Erhalt ihrer jährlichen 
Gas- oder Stromrechnung konkret an ihren (hohen) Verbrauch erinnert werden. In dem Moment, in dem Energieverbrauch für die gewöhnlichen Verbraucher*innen nicht mehr nur im Abstrakten verbleibt, sondern beispielsweise in Form von Kosten konkrete Gestalt annimmt (vgl. Shove 1997a, 1997b), können und sind die Verbraucher*innen offenbar erst bereit, ihr Energieverbrauchsverhalten zu verändern. Die Motivation, etwas zu unternehmen, also zum praktischen Handeln, entsteht häufig erst infolge solch einer ,Übersetzung(sleistung) ${ }^{c}-$ in diesem Fall in eine ,Sprache (Preise), die die Verbraucher"innen gut verstehen, weil sie ihnen aus ihrem Alltag geläufig ist und sie bereits mit ihr vertraut sind.

In der Verhaltensforschung spricht man bei solch besonderen Ereignissen wie dem Erhalt der jährlichen Gas- bzw. Stromrechnung auch allgemein von "teachable moments" (Havighurst 1953; vgl. auch Sloman und Al Dowayan 2004; Dilk und Littger 2014: 21). Damit sind Gelegenheiten bzw. günstige Momente gemeint, in denen das Gehirn durch ein Ereignis oder eine Umbruchssituation ohnehin schon subtil auf Veränderung ausgerichtet ist und die sich deshalb besonders gut zur Einführung von größeren Neuerungen oder Verhaltensänderungen eignen. Genau solche, Gelegenheiten' oder ,günstigen Momente' versucht Herr Thiels Unternehmen zu erkennen und dann ganz bewusst als Anlass für das Offerieren von passend erscheinenden Angeboten wahrzunehmen.

Herr Thiel nennt im Interview noch weitere Wege wie gewöhnliche Verbraucher*innen häufig erstmalig mit SmartHome-Technik in Kontakt kommen oder bewusst gebracht werden können, zum Beispiel, sagt er, sei „viel auch Mundpropaganda“ (Experte SH, Interview 63: 5, 235-236). Er räumt aber auch ein, dass es für eine gelingende Rekrutierung neuer Anwender*innen immer wichtig und hilfreich sei, wenn die betreffende Person bereits "irgendwie 'ne gewisse Affinität“ (ebd., 234) zum Thema ,SmartHome" habe und nicht vollkommen technikavers eingestellt sei.

\subsubsection{2 „[S]o 'ne [...] Tupperparty [...] das würde die Zeit geben und wär 'n schöner Rahmen um das mal wirklich dezidiert vorzustellen“- Herr Thiel}

Eine weitere Strategie, die Herr Thiels Unternehmen bevorzugt zur Kund"innenwerbung anwendet, besteht darin, dass man potenziellen Anwender"innen die neue smarte Technik möglichst anschaulich und in einem passenden Rahmen, das heißt entweder im realen oder nachgebildeten lebensweltlichen Kontext präsentiert: „Also es kommt immer sehr gut 
an wenn wir Vorstellungen machen" (Experte SH, Interview 63: 5, 236237). Diesbezüglich kann sich Herr Thiel sehr gut eine Ausweitung der Aktivitäten seines Unternehmens vorstellen, etwa durch Verwendung von bisher nur aus anderen Bereichen bekannten Werbungs- und Verkaufsformaten:

„Also was auch ganz interessant ist wäre zum Beispiel so 'ne TupperTupperparty dass es mal vor- das würde die Zeit geben und wär 'n schöner Rahmen um das mal wirklich dezidiert vorzustellen." (Experte SH, Interview63: 5, 237-240)

Offenbar stellt sich Herr Thiel vor, dass sich ein privater und potenziellen neuen Anwender*innen bereits vertrauter Kontext besonders positiv auf die Präsentation und den Verkauf von SmartHome-Produkten auswirken könnte. Darüber hinaus nehmen an einer ,Tupperparty' normalerweise nur Personen teil, die entweder bereits überzeugte Anwender*innen der hier beworbenen Produkte sind oder bei denen bereits ein großes Interesse bzw. zumindest eine große Offenheit für die bei solch einer ,Party“ vorgeführten und zum Kauf angebotenen Produkte besteht. Dies hat für den bzw. die Verkäufer*in den Vorteil, dass er bzw. sie sich bei seinem bzw. ihrem Publikum nicht mehr um die grundsätzliche Akzeptanz der Produkte bemühen muss, sondern sich stärker auf die Verdeutlichung von Qualität und vor allem den Nutzen der Produkte im alltäglichen Gebrauch konzentrieren kann. Der wichtigste Punkt, weshalb sich Herr Thiel ausgerechnet (das Format) eine ,Tupperparty als geeigneten Rahmen für die Demonstration und den Verkauf von SmartHome-Produkten vorstellt, dürfte sein, dass der bzw. die geschulte*r Verkäufer*in im Rahmen solch einer Veranstaltung in aller Regel von einem erheblichen Vertrauensvorschuss ihm bzw. ihr gegenüber durch die Partygäste profitiert. Dieser ergibt sich daraus, dass die Partyteilnehmer*innen alle in einer vertrauensvollen Beziehung zum bzw. zur Gastgeber*in stehen, der bzw. die alle Teilnehmer*innen zu dieser Verkaufsveranstaltung in seinen bzw. ihren privaten Räumlichkeiten eingeladen hat.

Die Idee der ,Tupperparty' stammt ursprünglich aus den USA und wurde um 1950 von dem fast gleichnamigen US-Unternehmen „Tupperware $^{\text {"115 }}$ entwickelt, das mehrheitlich aus Kunststoff bestehende Küchenund Haushaltsprodukte sowie auch Kosmetik- und Körperpflegeprodukte

115 Vgl. www.tupperware.de/de-de/, zuletzt geprüft am 04.10.2018. 
vertreibt (vgl. Mühlestein und Niederhauser 2007: 24). ${ }^{116}$ Die ,Tupperparty' stellt ein spezielles Vertriebskonzept dar, bei dem Tupperprodukte von professionellen Verkäufer*innen bei Heimvorführungen an Privatpersonen verkauft werden (vgl. ebd.). Das Konzept sieht vor, dass persönliche Beziehungen und Freundschaften genutzt werden, um neue Kund"innen zu gewinnen. Dabei stellen in der Regel an einem Nebenverdienst interessierte firmenfremde Personen ihre privaten Räumlichkeiten für eine Verkaufsveranstaltung zur Verfügung, zu der sie dann Freund*innen, Kolleg*innen, Bekannte und/oder Verwandte einladen und bewirten. ${ }^{117} \mathrm{Im}$ ursprünglichen Konzept ist vorgesehen, dass die Gastgeber*innen - meistens bzw. typischerweise sind es (Haus-)Frauen (vgl. ebd.: 21ff) - für ihre Mühen eine Entlohnung in Form von Preisnachlässen, Bonuspunkten oder Gratis-Produkten erhalten. ${ }^{118}$ Bei diesen Veranstaltungen ist normalerweise immer ein"e geschulte"r Verkäufer"in anwesend, der bzw. die die Firmenprodukte vorstellt, vor allem aber einmal ,live' vorführt und die Bestellungen der neuen Kund"innen entgegennimmt oder - in seltenen Fällen - die Produkte sogar direkt vor Ort verkauft. Der entscheidende Faktor bei diesem Vertriebskonzept besteht in der direkten Ansprache der Bekannten des bzw. der Gastgeber*in, wobei der bzw. die geschulte Verkäufer"in hierbei meist sehr von den bereits bestehenden Vertrauensbeziehungen zwischen Gastgeber"in und Gästen profitiert.

Interessant ist, dass Herr Thiel mit ,Tupperparty' ein Verkaufsformat anspricht, das sich ursprünglich vorrangig an Frauen, meist Hausfrauen richtete und auch heute noch typischerweise bevorzugt Frauen als Hauptadressat"innen hat (vgl. Mühlestein und Niederhauser 2007). ${ }^{119}$ Es lässt sich hier allerdings nur spekulieren, ob der Vergleich tatsächlich so weit reicht, dass Herr Thiel diesen Aspekt bewusst mitbedacht hat - etwa, weil er davon ausgeht, dass die meisten Kaufentscheidungen, die die technische Ausstattung privater Haushalte betreffen, nicht von Männern, sondern nach wie vor wesentlich von Frauen getroffen werden.

Die beiden im Folgenden vorgestellten Fälle machen deutlich, dass die auf dem SmartHome-Markt engagierten Energieversorgungsunternehmen mittlerweile über sehr clevere und ausgefeilte Instrumente verfügen, um

116 Vgl. hierzu auch www.tupperware.de/de-de/uber-tupperware/unsere-geschicht e/, zuletzt geprüft am 04.10.2018.

117 Vgl. www.tupperware.de/de-de/mach-party/, zuletzt geprüft am 04.10.2018.

118 Vgl. www.tupperware.de/de-de/werde-aktiv/, zuletzt geprüft am 04.10.2018.

119 Vgl. hierzu auch www.tupperware.de/de-de/werde-aktiv/, zuletzt geprüft am 04.10.2018. 
sich gezielt das Erfahrungswissen ihrer Kund"innen einzuverleiben; sowie, dass sie bewusst besondere Methoden anwenden, um sich ebenfalls die Ideen und Konzepte für mögliche neue Produkt- oder Prozessinnovationen von ,Nicht-Kund"innen" - hiermit sind private Bastler*innen und Erfinder*innen bzw. ,Hobby-Tüftler*innen' gemeint - anzueignen.

\subsubsection{3 „[W]ir [als Energieversorgungsunternehmen] sagen wir wissen [nicht] alles. Also wir sind sehr intensiv auch auf das Feedback der Kunden angewiesen" - Herr Thiel}

Neben der Kopplung von SmartHome-Produkten an für Kund*innen bzw. potenzielle Anwender*innen interessante und wichtige Themen sowie der anschaulichen Präsentation der SmartHome-Produkte in einem ansprechenden, verkaufsanregenden Kontext wird im Interview mit Herrn Thiel noch eine weitere, ebenfalls verkaufsfördernde und der Kund"innenbindung dienende Unternehmensstrategie erkennbar. Und zwar arbeitet das Unternehmen, in dem Herr Thiel angestellt ist, bei der Entwicklung neuer SmartHome-Produkte und -Anwendungen mit seinen Privatkund"innen zusammen. Hierbei lässt es sich systematisch von besonders engagierten Nutzer"innen inspirieren und greift dann aussichtsreiche, lukrative Geschäftsideen für sich auf. Das heißt, das Unternehmen macht sich den Einfallsreichtum und die Kreativität privater Anwender*innen und allgemein das Feedback seiner Privatkund"innen gezielt zunutze, indem es die Anregungen und Vorschläge der Lai"innen und privaten ,Tüftler“innen' aufnimmt, sie auf Wirtschaftlichkeit überprüft und gegebenenfalls aktiv wird, um die eigenen SmartHome-Produkte zu optimieren, zu erweitern oder sogar neue smarte Produkte und Anwendungen zu entwickeln. Hierzu zwei, etwas längere Passagen aus dem Interview mit Herrn Thiel, die das diesbezügliche Vorgehen des Energieversorgers, bei dem Herr Thiel für die Geschäftssparte ,SmartHome“ leitend zuständig ist, gut veranschaulichen:

Herr Thiel: wir haben Foren und Themen wo die Kunden- es- es gibt ja Tüftler die die- die wirklich alles haben möchten. Und wir versuchen dem gerecht zu werden. @aber@wir können auch nur so viel entwickeln. Also wir wir nehmen das auf bei uns in die Liste versuchen das zu priorisieren und arbeiten die quasi so sukzessive ab was alles dazu kommen kann an neuen Geräten jetzt beispielsweise imKlimaanlage oder sowas. Versuchen wir dann halt auch immer ähm zu berechnen ist 'n Business-Case dahinter? Rechnet sich das? Weil die Entwicklungsaufwände sind jetzt nicht unerheblich. Da müssen wir 
auch sagen also hmm gewisse Dinge sind schön zu haben. Es ist aber vielleicht ein bisschen Liebhaberei. Wir können das bei uns intern schlecht verargumentieren wenn sich das überhaupt nicht rechnet. Vielleicht im Gesamtkontext. Aber wenn das nur 'ne Randgruppe von drei haben möchte dann ist das eher 'ne Priorität Stufe zwanzig alsInterviewerin JM: Mhm. Können Sie mal ein Beispiel geben was da schon so (.) war?

Herr Thiel: [...]. Also Themen die häufiger kommen sind äh Klimaanlage ähm Bewässerungsanlage für 'n Garten Videokamera ist ' $n$ sehr heißes Thema was immer kommt. Photovoltaikanlage-Anbindungen-“

(Experte SH, Interview 63: 15f, 794-816)

„[...] wenn's 'n gutes Gimmick ist das da vorge- wir nehmen auch nicht für uns ein dass wir sagen wir- wir wissen alles. Also wir sind sehr intensiv auch auf das Feedback der Kunden angewiesen. Und wenn wir sagen das ist was was wir nicht auf der Agenda hatten dann ähm bewerten wir das also gucken uns die Sache an Ist das sinnvoll? Können wir das umsetzen? Welchen Aufwand bedarf das? Und dann heißt's eben nun go oder no go bei uns. Aber wir prüfen das. Und dann ja in neunundneunzig Prozent der Fälle dass wir sagen wir gucken uns das an. Also es ist- es ist in unserem Interesse äh wenn's im Interesse der Kunden ist sagen wir so der Mehrheit der Kunden.“ (ebd.: 16, 836-845)

Aus beiden Zitaten geht deutlich hervor, dass Herr Thiels Unternehmen nur dann auf Anregungen, Vorschläge und Wünsche von Kund"innen tätig wird, wenn sich ein Engagement, besser gesagt eine Investition in die Entwicklung eines entsprechenden Produkts auch für sein Unternehmen lohnt. Mit anderen Worten: die Wünsche der Kund"innen werden bedient, wenn dabei gleichzeitig die Interessen des Unternehmens berücksichtigt werden, wenn sich aus der Unternehmenszusammenarbeit mit den Kund"innen also ein deutlicher Nutzen bzw. Mehrwert für das Unternehmen ergibt. Hat das neu zu entwickelnde Produkt ,Energiesparen' zum Ziel, könnten als Nebeneffekt die Umwelt und das Klima von der Anwendung bzw. Umsetzung der neuen, von Kund"innen inspirierten Problemlösung profitieren.

Deutlich wird, dass das Unternehmen, für das Herr Thiel tätig ist, mit den „Foren“ (ebd.: 15, 794), in die die Kund"innen ihre Anregungen, Ideen und Wünsche eintragen können, ein schlaues Instrument etabliert hat, um Kund"innenwünsche besonders effizient für sich zu erfassen. Die Beiträge der Kund"innen bearbeitet das Unternehmen offenbar ganz systema- 
tisch und nutzt attraktive Anregungen und Ideen gezielt zur Verbesserung, Weiterentwicklung und Erweiterung der eigenen Produktpalette. Hieran ist zu erkennen, wie weit der Einfluss der Anwender*innen reicht.

Von dieser Strategie, dass Anregungen, Ideen und Vorschläge von Kund"innen gezielt aufgenommen und für die unternehmenseigene Produktentwicklung verwendet werden, berichtet auch der SmartHome-Experte Herr Koch. Das Unternehmen, für das Herr Koch arbeitet, geht allerdings noch einen Schritt weiter. Es versucht, bei der Weiterentwicklung seiner Produkte nicht nur von seinen Bestandskund"innen zu lernen, sondern ist zudem bemüht, besonders kreative und selbstständig aktive Anwender*innen, so genannte „Lead-User“ (Hippel 1986) in den Entwicklungsprozess miteinzubinden. Wie diese Strategie im Einzelnen aussieht, verdeutlicht die folgende Fallgeschichte.

\subsubsection{4 „Wir suchen [...] aktiv nach Lead-Usern [...] das sind eher Nicht- Kunden [...] die sich dadurch auszeichnen dass sie selbst aktiv geworden sind" - Herr Koch}

Herr Koch sowie seine zwei Kollegen Herr Oster und Herr Drescher, die ebenfalls am Interview teilgenommen haben, sind bei einem regionalen, mittelgroßen Energieversorgungsunternehmen beschäftigt. Alle drei Experten arbeiten bei diesem Energieversorger im Bereich ,SmartHome' und hier schwerpunktmäßig zu Anwendungen und Produkten im Privatkundenbereich, die speziell das Heizen betreffen. Herr Koch ist als einziger der drei interviewten Unternehmensmitarbeiter in leitender Position tätig.

Auf die konkrete Nachfrage der Interviewerin, ob das Feedback der Kund"innen zu den vom Energieversorgungsunternehmen angebotenen Produkten zum ,smarten Energiemanagement ${ }^{\star}$ denn auch in die Forschungs- und Entwicklungsarbeit des Unternehmens einfließe, erklärt Herr Koch:

„Absolut. Klar. Und auch in die- man darf nicht nur Forschung und Entwicklung sagen sondern auch in die Produktentwicklung. Also auch in der Produktweiterentwicklung fließt das natürlich ein. Klar. Verständlich.“ (Experte SH, Interview 57: 20, 1062-1068)

Herr Koch fährt direkt im Anschluss damit fort, zu beschreiben, dass das Bemühen seines Unternehmens noch deutlich weiter reiche, wenn es darum geht, sich als Profianbieter für die Entwicklung neuer SmartHome- 
Produkte und -Problemlösungen gezielt von engagierten Lai“innen-Anwender*innen inspirieren zu lassen:

„Wir suchen beispielsweise auch jetzt gerade aktiv nach Lead-Usern. Ähm das sind aber jetzt nicht Kunden sondern das sind eher NichtKunden die eigene [...] ja äh Lösungen umgesetzt haben weil irgendwo der Schuh drückt. Also im Energiebereich zum Beispiel der AlmÖhi der sich selber versorgt. Und der möchte auch Fernsehgucken hat aber kein Stromkabel. So. Wie hat der das gelöst? So. Vielleicht so. Und- und wir suchen ganz gezielt nach diesen Lead-Usern so nennt man die die sich dadurch auszeichnen dass sie selbst aktiv geworden sind. Dummerweise sind das aber nicht die Kunden die man hat weil ähm das ja eher- eher die- die Nicht-Kunden. Und die muss man dann ganz systematisch suchen." (ebd.: 20f, 1073-1083)

Dem Zitat lässt sich entnehmen, dass das Unternehmen ganz gezielt und systematisch nach so genannten ,Lead-Usern' fahndet, die für ein Bedürfnis oder Problem bereits eigeninitiativ eine ,Lösung' entwickelt und implementiert haben, die es bisher so noch nicht am Markt gibt. Ganz offensichtlich sind solche kreativen Eigenlösungen auch für Unternehmen interessant, da sie eventuell für einen größeren Markt oder sogar den Massenmarkt tauglich sein können und somit möglicherweise über das Potenzial verfügen, von einem Unternehmen in Form eines neuen Produkts professionell und profitabel vermarktet zu werden.

Der Begriff „Lead-User“ wurde erstmals 1986 von Eric von Hippel eingeführt (vgl. Hippel 1986, 1988). Im Deutschen spricht man von fortschrittlichen bzw. trendführenden Nutzer*innen oder Anwender*innen, die sich dadurch auszeichnen, dass ihre Bedürfnisse den Anforderungen des Massenmarktes vorauseilen (vgl. Urban und Hippel 1988: 569f). Das Konzept des Lead-Users stammt aus dem Marketing. Als Lead-User bezeichnet man in der Marketingliteratur demnach „Personen, die sich in einem Anwendungsfeld intensiv mit einem Problem auseinandersetzen, für das es auf dem Markt noch keine passende Lösung gibt" (Wagner und Piller o.J.: 7). Und gleich weiter heißt es: „Diese Nutzer verspüren ein Bedürfnis wesentlich früher als die breite Masse beziehungsweise der Durchschnittskunde“ (ebd.). In dem Fall, dass es bisher noch keine passende Problemlösung oder nur ein unzureichendes Angebot auf ein von einem bzw. einer, gewöhnlichen' Konsument*in verspürtes Bedürfnis gibt, werden Lead-User selbst aktiv und erarbeiten sich eine eigene Lösung für dieses Problem. Damit bieten diese fortschrittlichen Anwender*innen einem Unternehmen im Kontrast zu den einfachen Kund"innen bzw. zu den ,nur' aktiven Pro- 
dukt-Anwender*innen tatsächlich neue Anregungen und konkrete Ideen für wirklich neuartige Innovationen. ,Lead-User ${ }^{6}$ sind also mehr als nur Trendsetter*innen, da sie das Produkt oder Verfahren, welches zum Trend wird, nicht nur vor der breiten Markteinführung aufgreifen, sondern es aus Eigenbedarf selbst neu ersonnen bzw. entwickelt haben. Demzufolge treten ,Lead-User" oftmals selbst als Innovator*innen auf. Durch den hohen Nutzen, den sie sich von einer Befriedigung ihrer Bedürfnisse versprechen, sind sie meist in höchstem Maße motiviert, möglichst schnell eine geeignete Problemlösung zu finden (vgl. Urban und Hippel 1988: 570). Bei der ,Lead-User-Methode‘ geht der erste Impuls für eine funktional neue Innovation also nicht vom Unternehmen, sondern von den fortschrittlichen Anwender*innen aus - und dies meist lange bevor die betreffende Neuerung überhaupt professionell ausgearbeitet und am Markt eingeführt ist (vgl. Wagner und Piller o.J.: 8f). Bei der Lead-User-Methode handelt es sich demnach um eine anerkannte und etablierte Form kooperativer Produktentwicklung, bei der ein Anbieter bzw. Unternehmen versucht, fortschrittliche Nutzer"innen gezielt in den Prozess der Produktentwicklung miteinzubinden oder zumindest gezielt von diesen trendführenden Anwender*innen für die Entwicklung neuer, möglichst massenmarkttauglicher Produkte zu lernen (vgl. Kleinaltenkamp und Staudt 1991; Lüthje und Herstatt 2004; sowie zur Erweiterung des Lead User-Konzeptes zum "Sustainable Lead User“ und zur „(Sustainable) Lead User Integration“, vgl. Springer et al. 2004: insbesondere Kapitel 2).

Gleich im Anschluss und ohne neue Aufforderung fährt Herr Koch in seiner Beschreibung fort und erzählt von zwei Beispielfällen, bei denen sich das von ihm vertretene Unternehmen etwas von gewöhnlichen Nutzer*innen abgeschaut hat. In der folgenden Passage berichtet er von einer von einem ,Lead-User' erdachten und erarbeiteten Heizlösung sowie von einer SmartHome-Anwendung, die eher dem Komforterleben der SmartHome-Bewohner"innen dient:

„Ja aber da gibt's alles Mögliche. [...]. Äh ein Fall war zum Beispiel dass ja ein Kunde gesagt hat ein Lead-User gesagt hat ,Mensch ich hab hier 'ne ähm 'n Wintergarten. Immer wenn der sich aufheizt pump ich die Wärme vom Wintergarten ins Haus wenn- wenn das Haus kälter ist als der Wintergarten. So und da spare ich Heizkosten' [...] solche Geschichten. Oder auch im Komfortbereich. Sitzt er auf'm Sofa und die Frau fragt abends ,Haben wir eigentlich abgeschlossen?` Das hört der sich einmal an und dann wird der aktiv. Dann sag ich ,Jetzt habe ich so LEDs da und sehe ob meine Türen abgeschlossen sind'. [...]. Also ob man's braucht oder nicht aber die werden selber aktiv 
und ähm ja hinsichtlich Komfort Sicherheit und Unterhaltung ähm. Also in dem ganzen SmartHome-Bereich gibt's also- Und im Sportiven und so sowieso gibt's Leute die eigentlich selber einfach Dinge umsetzen. Und davon kann man natürlich auch lernen. Und das machen wir auch ganz gezielt.“ (Experte SH, Interview 57: 21, 1087-1105)

Insgesamt verdeutlicht die Schilderung noch einmal den Einfluss der Anwender"innen für die Entwicklung neuer Produkte und Anwendungen im Bereich des privaten Energiekonsums, wobei erneut zum Ausdruck kommt, dass die (innovativen) Ideen und Entwicklungen privater ,Tüftler*innen' dann Eingang in die Forschungs- und Entwicklungsabteilungen der (Energieversorgungs-)Unternehmen finden, wenn diese dabei für sich eine rentable Investitionsmöglichkeit oder eine vielversprechende Geschäftsidee erkennen.

\subsubsection{Vergleichendes Kapitelfazit}

Die Bandbreite der in diesem Kapitel präsentierten Wege zum Passivhaus und zur Bekanntmachung und Verbreitung intelligenter Heizungssteuerungstechnik haben deutlich gemacht, wie viele verschiedene Möglichkeiten für die Praktiken des passiven und smarten Heizens derzeit schon bestehen, dass sie zu neuen, weiteren Träger*innen gelangen.

\section{Viele Wege führen zum Passivhaus}

Die Analyse des Datenmaterials zum Passivhaus hat gezeigt, dass es sich bei den erfolgreich rekrutierten Anhänger*innen nur in wenigen Fällen um explizit stark ökologisch motivierte Personen handelt, sondern dass die meisten der im Rahmen dieser Arbeit interviewten Bewohner*innen vorrangig aus anderen Gründen und Motiven an den jeweiligen Passivhausprojekten teilgenommen haben. Die allermeisten interviewten Passivhausbewohner*innen waren primär am Wohnen und Leben in sozialer Gemeinschaft interessiert. Bei einigen spielten zudem ökologische Beweggründe und Leitgedanken zu Nachhaltigkeit eine zentrale Rolle für ihre Entscheidung. Für einen erheblichen Teil der Interviewpartner*innen besaß das Merkmal „Passivhaus' im Entscheidungsprozess keine Relevanz (siehe hierzu auch Hacke 2009a: 10). Interessant ist, dass sich bemerkenswert viele von diesen anfänglich gleichgültig gegenüber dem Passivhaus eingestellten oder sogar tatsächlich skeptischen Personen durch eigene positive Erfahrungen regelrecht zu begeisterten Anhänger*innen des Lebens 
im Passivhaus entwickelt haben. Hieraus lässt sich ableiten, dass die Praktik des passiven Heizens nicht nur unter bereits ökologisch sensibilisierten und nachhaltig eingestellten Menschen neue Teilnehmer*innen rekrutieren kann, sondern dass ebenso ökologisch wenig oder nachrangig Interessierte als potenzielle neue Anhänger"innen in Frage kommen. Die Analyse hat ergeben, dass es bei diesen ,Erwartungslosen' und Skeptiker*innen keine nachträgliche Enttäuschung gibt, da sie in Bezug auf das Passivhaus meist ohne große Erwartungen in die Projekte eingestiegen sind. Stattdessen zeigen sich diese neuen Teilnehmer*innen häufig positiv überrascht, etwa davon, dass sie für behagliche Raumwärme und durchgehend gute Raumluft kaum noch etwas aktiv machen müssen, weil sie sich das vorher nur vom ,Hörensagen' her nicht vorstellen konnten. Das heißt, die Passivhaus-Praktik ist bei ihrer Verbreitung keineswegs auf ökologische Pionier*innen angewiesen. Wenn das Merkmal ,Passivhaus' mit anderen Belangen und Themen verknüpft ist oder bewusst an solche gekoppelt wird, die potenziellen Teilnehmer*innen besonders wichtig und für ihre Wohnortentscheidung von zentraler Bedeutung sind, so stehen die Chancen für eine erfolgreiche Verbreitung sehr gut.

Als weitere, besonders wichtige Kriterien im Entscheidungsprozess für ein Bau- und Wohnprojekt haben sich bei den für diese Arbeit interviewten Bewohnner*innen neben dem Wohnen in Gemeinschaft noch der Wohnort bzw. die Wohnlage, die Wohnungsgröße und die Finanzierbarkeit, also finanzielle Erwägungen erwiesen. Insbesondere der letzte Aspekt, die Finanzierung eines Passivhausbaus, spielt für die Entscheidung potenzieller neuen Teilnehmer*innen praktisch immer eine Rolle, da der Bau eines Passivhauses zu Beginn mit erheblichen Mehrkosten für die besondere Haustechnik verbunden ist. Diesen anfänglichen Mehrinvestitionen stehen allerdings bedeutende Einsparungen gegenüber, vor allem für das Heizen, aber auch in nicht unerheblichem Maße für Kühlung, so dass sich die anfänglichen Mehrkosten über die Zeitspanne von etwa 20 Jahren amortisiert haben (vgl. Sommer 2016*). Hierbei ist wichtig zu beachten, dass der Bau von Passivhäusern in starkem Maße mit öffentlichen Geldern gefördert wird. Beispielsweise gibt es zinsgünstige Darlehen und besondere $\mathrm{Zu}$ schüsse. Letztere gibt es aber nur für Gebäude in besonders energieeffizienter Bauweise, was auf Passivhäuser zutrifft. Diese besonderen Fördermittel haben für die meisten Beforschten eine wichtige Rolle gespielt und waren ausschlaggebend dafür, dass für sie eine Beteiligung am Bau eines Passivhauses überhaupt in Betracht kam und sie sich letztendlich dann auch dafür entscheiden konnten. 
Die unterschiedlichen Fallgeschichten einzelner Passivhausbewohner*innen und die ganzer Bau- und Wohngruppen haben deutlich gemacht, dass das eigene Handeln und das daraus resultierende persönliche Erleben die Faktoren waren, die am schnellsten und nachhaltigsten auf die neuen Praktizierenden gewirkt und sie für den neuen Heiz- und Lüftungsansatz des Passivhauses begeistert haben. Damit die Bewohner*innen diese subjektiven Erfahrungen überhaupt machen oder zumindest von Erfahrungen aus erster Hand profitieren können, ist es wichtig, dass sie zur richtigen Zeit bzw. in einem günstigen Moment auf für sie passende Art und Weise mit der neuen Praktik in Berührung kommen. Hierbei hat die Analyse der Passivhaus-Fälle gezeigt, dass sich Erfahrungen, die bereits in der Kindheit gesammelt werden, als besonders prägend erweisen - dies trifft insbesondere dann zu, wenn bei den Kindern in Bezug auf die betreffende Aktivität vorher noch keine (anderweitige) Routinebildung stattgefunden hat. Typisch ist auch der Weg, dass Heiz- und Wohnpraktiken von den Eltern an die Kinder ,stumm ' weitergegeben werden (vgl. Schmidt 2012: 215-222): Kinder nehmen sich für ihr alltägliches Handeln häufig die eigenen Eltern zum Vorbild und ahmen etwa deren alltägliche Heiz- und Wohnpraxis nach. Bei vielen Alltagstätigkeiten vollzieht sich dieser Prozess unbewusst - ohne Reflextion wird etwas auf die gleiche Art und Weise gemacht und durch ständige Wiederholung wird es dann zur Gewohnheit. Oder dieser Übertragungsprozess kann auch bewusst erfolgen - dies ist der Fall, wenn die elterliche Handhabung bewusst erlernt und reproduziert wird und die bei den Eltern beobachtete Routine auf diesem Wege über den Generationswechsel hinweg fortbesteht. Viele der interviewten erwachsenen Passivhausbewohner*innen haben Kinder, bei denen sich diese stumme Weitergabe durch Teilnahme an Praktiken bereits beobachten lässt. Diesen im Passivhaus sozialisierten Kindern erscheint die Heiz- und Lüftungspraxis des Passivhauses als ,normal'; sie zeigen sich wiederum irritiert und sind unsicher hinsichtlich des Heizens und Lüftens, wenn sie sich in konventionellen Wohnkontexten mit einer klassischen aktiven Gebäudeheizung aufhalten.

Für die für diese Arbeit interviewten erwachsenen Passivhausbewohner*innen bestand allerdings nicht die Möglichkeit, sich im Hinblick auf eine Teilnahme an der Passivhaus-Praxis am elterlichen Handeln zu orientieren, da sie überwiegend selbst die erste Teilnehmer*innengeneration des passiven Heizens bilden. Einige von ihnen waren von Anfang an dazu bereit, hier Pionierarbeit zu leisten. Sie haben sich aus ökologischer Überzeugung bewusst von dieser damals noch neuen und wenig bekannten und kaum verbreiteten Praktik ,mitreißen` bzw. überzeugen lassen. Andere 
sind wiederum mehr oder weniger zufällig an das Passivhaus ,geraten', haben sich daraufhin informiert und/oder hatten Vertrauen in das Reden und Handeln des bzw. der für ihr Hausbauprojekt verantwortlichen Architekt*in und haben sich auf diesem Wege von der Idee des Passivhauses einnehmen lassen.

Die Analyse der Passivhaus-Fälle hat überdies gezeigt, dass sich angehende Praktizierende bei ihrer Entscheidung für ein Passivhaus und damit zwangsläufig auch für die Praktik des passiven Heizens häufig auch am Handeln ihrer ,Peergroup', also beispielsweise den anderen Mitgliedern der Baugemeinschaft orientieren, sowie dass teilweise das Handeln und die Reaktionsweisen ihres engen sozialen Umfelds ihre Entscheidung für ein Passivhaus beeinflusst haben.

Nicht zuletzt sind der Name und das daraus resultierende Image entscheidend - was zeigt, dass Sprache ein sehr einflussreiches und wirkmächtiges (Werbe-)Instrument darstellt (vgl. Sachs und Finkelpearl 2010; Koesling 2014: 12).

Zusammenfassend lässt sich sagen, dass es in allen in diesem Kapitel dargestellten Fällen gelungener Teilnehmer*innenrekrutierung für die mit einem Passivhaus verbundenen Heiz- und Lüftungsaktivitäten immer ein Mix aus mehreren, verschiedenen Faktoren gewesen ist, der zum Resultat einer erfolgreichen Weiterverbreitung der Passivhauspraxis geführt hat.

\section{Noch mehr ein aktives, Anschieben' und angestrengtes, Hin(ein)ziehen' als ein wirklich begeistertes, leichtgängiges, Hineingesogen werden' - Teilneh- mer*innenrekrutierung im Fall des SmartHomes}

Ganz anders sieht es hingegen bei den für diese Arbeit untersuchten Fällen zum intelligenten Heizen aus. Hier war es nicht erforderlich, dass die Praktik des smarten Heizens von sich aus für diese neuen Teilnehmer*innen attraktiv erscheint. Denn den interviewten Mieter*innen, die ihre Wohnungen jetzt alle mittels intelligenter Heizungssteuerung beheizen, wurde die smarte Technik von ihrer Vermieterin aufoktroyiert. Das heißt, diese neuen Teilnehmenden an der Praktik des smarten Heizens wurden alle ,zwangsrekrutiert'. Die Wohnungsbaugenossenschaft hat also von ihrem Eigentumsrecht Gebrauch gemacht, wodurch sie bestimmen kann, welche Heizungstechnik in den ihr gehörenden und von ihr gemanagten Wohnobjekten verwendet wird. Mit dem Pilotprojekt zum intelligenten Heizen verfolgt die Wohnungsbaugenossenschaft das Ziel, die ihr von ihrem Dachverband (zunächst bis zum Jahr 2020) vorgegebenen Energie- und $\mathrm{CO}_{2}$-Einsparziele zu erreichen. Für das Pilotprojekt hat die Wohnungsgenossenschaft aus ihrem Hausbestand ganz bewusst denkmalgeschützte 
Häuser ausgewählt, da sie für solche Objekte gerne Alternativen zur Dämmung der Außenwände entwickeln möchte (vgl. HANSA Baugenossenschaft eG 2013: 6).

Die verpflichtende Teilnahme ist ein sehr effektiver Rekrutierungsweg, allerdings kommt für Heizpraktiken dieser Weg zur Gewinnung neuer Teilnehmer*innen nicht immer, sondern nur in ganz bestimmten Fällen in Frage. Für die Klärung dieser Frage sind in der Regel die Eigentumsverhältnisse des betreffenden Wohnobjekts entscheidend. Wenn die Heiztechnik für ein Haus oder eine Wohnung bereits feststeht, haben die Hausbzw. Wohnungsinteressent*innen die Wahl, ob sie in dieses Wohnobjekt zur Miete einziehen (möchten) oder nicht. Anders sieht es aus, wenn in Mietwohnungen im Nachhinein, also dann, wenn das Objekt bereits bewohnt ist, etwas an der Heiztechnik verändert wird. Hier haben die Mieter"innen meist kein Mitspracherecht, sondern müssen sich mit der Heizlösung arrangieren, die ihnen von ihrem bzw. ihrer Vermieter*in vorgesetzt wird. Für den Fall, dass die Mieter"innen mit der bei ihnen neu implementierten Heizlösung gänzlich nicht einverstanden sind, haben sie eigentlich nur die Möglichkeit, aus dem Haus bzw. der betreffenden Wohnung auszuziehen.

Zwar wurde von einigen von der Maßnahme betroffenen Mieter*innen Widerstand gegen die Einführung der neuen intelligenten Heizungssteuerungstechnik und den mit ihr verbunden neuen Heizansatz geleistet, den ,radikalen' Weg des Ausstiegs bzw. Auszugs aus der Wohnung hat aber keine"r von ihnen gewählt. Lediglich ein einziger, besonders vehement protestierender Mieter konnte durchsetzen, dass bei ihm in der Wohnung die neue Technik nicht eingebaut wurde.

Aufgrund der Tatsache, dass die für diese Untersuchung interviewten, nun im smarten Heizen engagierten Bewohner*innen alle gewissermaßen durch Zwang rekrutiert wurden, lässt sich aus den Bewohner"inneninterviews nicht viel dazu ermitteln, auf welchen Wegen es der Praktik des smarten Heizens zurzeit schon gelingt, erfolgreich neue Anhänger*innen ausfindig zu machen und zu werben. Hier waren stattdessen die Interviews, die mit Expert*innen für smarte (Heiz-)Technik geführt wurden, sehr aufschlussreich. Die von den befragten Expert"innen vertretenen großen und mittelgroßen Energieversorgungsunternehmen treten selbst als engagierte Promotoren smarter Heiztechnik auf. Das heißt, mit ihrem Agieren beabsichtigen diese Unternehmen der Praktik des smarten Heizens bei ihrer Weiterverbreitung zu helfen. Diese Unternehmensbetätigung erfolgt nicht uneigennützig, sondern der Nutzen besteht für die Unternehmen darin, dass sie erwarten, sich durch ihr Engagement im neuen, 
ihrer Erwartung und Prognose nach zukunftsweisenden und über enormes Wachstumspotenzial verfügenden Geschäftsfeld ,SmartHome` zu profilieren. ${ }^{120}$

Die Analyse der Interviews mit SmartHome-Expert*innen hat gezeigt, dass die im Vertrieb smarter Technik bereits intensiv engagierten Unternehmen vorrangig den Weg der Kopplung wählen, um private Verbraucher"innen zum Kauf smarter Produkte anzuregen. Das heißt, dass sie zum einen explizit technische Produkte und Anwendungen in ihr Portfolio aufnehmen oder selbst entwickeln, die explizit an die Wünsche und Interessen der Konsument"innen anknüpfen und diese abdecken. Zum anderen beinhaltet die Strategie der Kopplung, dass die Unternehmen versuchen, die eigenen Produkte mit Themen, Anlässen und besonderen Ereignissen zu verknüpfen, die für potenziellen Kund"innen gerade aktuell relevant sind. So steht etwa das Thema,(Heiz-)Energiesparen' immer klassisch zu Beginn der Heizperiode im Fokus. Dann gibt es besondere Werbe-, Vorführ- oder auch Rabattaktionen beispielsweise für programmierbare Heizungsthermostate oder eine intelligente Fußbodenheizungssteuerung. Darüber hinaus werden von den Unternehmen bewusst solche Gelegenheiten oder ,günstige' Anlässe wie die Versendung der jährlichen Strom- oder Gasabrechnung genutzt, um die Kund"innen gezielt anzusprechen und auf neue Produkte aufmerksam zu machen. Im Zuge dessen unterbreitet der Energieversorger seinen Kund"innen dann konkrete Angebote für smarte Heizungstechnik und entsprechende Heizungssteuerungsanwendungen, mit denen sich aus Unternehmenssicht nachweislich Energie und somit

120 Bestätigung für die Beobachtung, dass als treibende Kraft hinter der Entwicklung neuer SmartHome-Produkte und -Services meist (noch) die Interessen kommerzieller Anbieter stehen und eben nicht explizite Nutzer"innenbedürfnisse und -wünsche, findet sich auch in der wissenschaftlichen Literatur zu SmartHome-Technologien. So formulieren Haines et al. am Anfang ihrer Studie: "Smart home technology looks set to become an increasingly common feature of domestic life. However commercial desire for technical innovation rather than explicit user needs are often the driving force behind the development of Smart Home products and services" (Haines et al. 2007: 349). Und abschließend resümieren sie: „Smart Home technology looks set to become a feature of people's lives, whether it is wanted or not. The availability of technology and development of services with commercial benefits often means that the needs of the end user are treated secondary" (ebd.: 358f). Zwar ist die Studie von Haines et al. (2007) schon über zehn Jahre alt; die vorliegende Untersuchung hat allerdings gezeigt, dass die daraus zitierten Befunde zur Entwicklung und Verbreitung von SmartHome-Technologien und -Services für den Privatkundenbereich größtenteils noch Gültigkeit besitzen. 
auch Geld einsparen lässt. Allerdings, so hat die Analyse des Datenmaterials ergeben, sind die Unternehmen mit diesen sehr offensiven und zum Teil schon aufdringlichen Werbemaßnahmen bisher nur begrenzt erfolgreich. Bislang hat sich noch keine rege und stabile Nachfrage nach smarten Produkten und Anwendungen eingestellt, die Praktik des smarten Heizens hat also noch keine größere aktive Anhänger*innenschar für sich gewinnen können. Sobald der Werbedruck nachlässt, so beschreiben es die Expert"innen, nimmt auch das Interesse an SmartHome-Lösungen wieder ab, was zur Folge hat, dass die Zahl aktiv im smarten Heizen Engagierter wieder stagniert oder sogar zurückgeht.

Weil es hierbei um viel geht für die Energieversorgungsunternehmen, die mittlerweile massiv auf das Geschäft mit ,SmartHome، setzen (z.B. um die Erschließung neue Geschäftsfelder und die Entwicklung neuer Energiedienstleistungsangebote zu Zwecken der Neugewinnung sowie Bindung von Kund*innen) (vgl. Moritz 2014; Busching und Schlaak 2018), ist zu beobachten, dass diese Unternehmen es nicht alleine bei der aufwendigen und intensiven Bewerbung ihrer SmartHome-Produkte und -Services belassen. Auch sind sie nicht bereit, darauf zu warten bzw. sich darauf zu verlassen, ob bzw. dass die Produkte und Anwendungen das Potenzial haben, die Nutzer*innen irgendwann einmal selbst zu überzeugen. Deshalb sind die Unternehmen stark darum bemüht, mehr über die Bedürfnisse, Interessen und Wünsche ihrer Bestandskund"innen bezüglich SmartHome-Anwendungen herauszufinden, um dadurch neue Anregungen und attraktive Ideen für die Verbesserung, Weiter- sowie komplette Neuentwicklung eigener Produkte und -Anwendungen zu erhalten. Einige im Markt für SmartHome-Lösungen engagierte Energieversorgungsunternehmen gehen noch einen Schritt weiter, indem sie gezielt nach eigennützig und eigeninitiativ tätig gewordenen, kreativen Bastler*innen und innovativen Entwickler*innen, so genannten ,Lead-Usern' suchen. Die Unternehmen versuchen diese fortschrittlichen Nutzer*innen dafür zu gewinnen, sich am Produktentwicklungsprozess zu beteiligen, indem sie ihre innovativen Ideen von Anfang an miteinbringen (können), um gemeinsam neue Produkte oder Dienste zu erstellen. Hieran ist zu erkennen, wie weitreichend der Einfluss der Anwender“innen zum Teil ist - allerdings immer unter der Voraussetzung, dass sich diese Nutzer*innen-Beteiligung für das Unternehmen lohnt, das heißt sich ökonomisch auszahlt.

Die Analyse des Datenmaterials zum intelligenten Heizen hat deutlich gemacht, dass die Praktik des smarten Heizens in Deutschland bisher erst wenige Anhänger"innen rekrutieren konnte und die Verbreitung der Praktik trotz erheblicher Unterstützung durch zahlreiche Energieversorgungs- 
unternehmen bislang eher schleppend verläuft (vgl. Böttcher 2017*; Hofmann und Erichsen o.J.).

\section{Die beiden Heizansätze im Vergleich}

Die beiden, recht unterschiedlichen Heizansätze lassen sich hinsichtlich ihres Erfolgs bei der Teilnehmer*innenrekrutierung aus verschiedenen Gründen nur sehr begrenzt miteinander vergleichen. Zunächst einmal weisen sie eine sehr unterschiedliche Reichweite auf: Während der Ansatz des passiven Heizens für eine ganzheitliche und damit sehr umfangreiche Herangehensweise steht, denn das Passivhaus stellt einen Gebäudestandard dar, der sich praktisch auf alle Gebäudemanagement- und Wohnpraktiken auswirkt, handelt es sich bei der intelligenten Heizungssteuerung ,lediglich' um eine klassische Nachrüsttechnologie. Das heißt, hier verändert sich bei Anwendung primär und fast ausschließlich das Heizen, andere Alltagsbereiche und Praktiken sind von der Umgestaltung in der Regel nicht in größerem Umfang tangiert. Darüber hinaus gibt es das Passivhaus und zirkuliert die Praktik des passiven Heizens schon deutlich länger als der Ansatz des smarten Heizens existiert. In Deutschland ist das erste anerkannte private Passivwohnhaus bereits 1991 erbaut worden. SmartHomeLösungen zur Anwendung in Privathaushalten gibt es hingegen erst seit den späten 2000er Jahren serienmäßig und im normalen Fachhandel zu erwerben. Aufgrund dieser Einflussfaktoren unterscheiden sich die tatsächlichen Teilnehmer*innenzahlen sowie die bisherigen Dynamiken innerhalb der Anhänger*innenschaft der beiden Heizansätze deutlich.

Gemeinsam ist den Ansätzen aber, dass ihnen beiden ein hohes Verbreitungs- bzw. Rekrutierungspotenzial für die Zukunft vorausgesagt wird, was bedeutet, dass sowohl die Praktik des passiven als auch die des smarten Heizens als wichtige zukunftsweisende Ansätze betrachtet werden (können), bezüglich derer sich künftig sicher noch einiges ereignen wird. 


\section{Theoretische und praktische Schlussfolgerungen sowie Ausblick auf weiteren Forschungsbedarf}

In dieser Arbeit ging es darum, den bzw. das Energieverbrauch(shandeln) in Privathaushalten im Kontext der globalen Herausforderung des Klimawandels näher zu ergründen. Vor diesem Hintergrund wurde das alltägliche Heizgeschehen als Beispiel gewählt, weil - wie bereits in der Einleitung dargelegt - das Heizen aktuell mit Abstand die energieintensivste Alltagstätigkeit in deutschen Privathaushalten darstellt und ein dementsprechend großer Anteil der verursachten $\mathrm{CO}_{2}$-Emissionen auf Raumheizung zurückzuführen ist. Dafür wurde das alltägliche Heizgeschehen als soziale Praxis analysiert.

Ziel der Arbeit war es,

- erstens zu einem besseren Verständnis von der Beschaffenheit des alltäglichen Heizgeschehens in Privathaushalten beizutragen. Dafür galt es, das alltägliche Heizgeschehen möglichst detailliert zu erfassen, indem das Heizen als eine soziale Praktik betrachtet und untersucht wurde, die in gleicher Weise Wahrnehmen, Denken und Handeln umfasst, um

- zweitens eine umfassende Analyse und Darstellung verschiedener typischer Praktiken-Wandlungsprozesse leisten zu können.

- drittens, aus den zuvor erarbeiteten Detailanalysen Ansatzpunkte für mögliche absichtsvolle Interventionen zu identifizieren, um Heizpraktiken in privaten Haushalten zukünftig energiesparender zu gestalten. Insbesondere im Hinblick auf das dritte Forschungsziel wurden zwei möglicherweise zukunftsweisende Heizansätze zur Untersuchung gewählt: Heizen in Passivhäusern und Heizen in so genannten SmartHomes. In beiden Fällen liegt der Schwerpunkt auf der Einsparung von Heizenergie durch den Einsatz neuer Technik.

In dieser Studie wurde mit einem qualitativen Forschungsdesign analysiert, ob und wie diese zur Energieeinsparung neu eingeführten Heiz-Technologien von den Bewohner*innen in ihrem Alltag praktisch genutzt werden und inwiefern sich dadurch die alltägliche Heizpraxis der Bewohner*innen verändert (hat).

In diesem Kapitel werden nun die zentralen Ergebnisse und Schlussfolgerungen der Untersuchung dargestellt. Die Gliederung der Schlussbetrachtungen folgt im Wesentlichen den drei oben genannten Forschungs- 
zielen der Arbeit. Bevor jedoch die Darstellung der inhaltlichen Ergebnisse dieser Arbeit erfolgt (Teilkapitel 5.2), wird mit einer Reflextion der Anwendung des Praktiken-Ansatzes als theoretischer Bezugspunkt der Arbeit sowie des praktischen Vorgehens bei der Analyse begonnen (Teilkapitel 5.1). Im Anschluss an die Präsentation der inhaltlichen Erkenntnisse zur Praxis des Heizens erfolgt eine kurze Auflistung zentraler Aspekte, die in der Untersuchung herausgearbeitet werden konnten, die es bei absichtsvoller politischer Intervention in alltägliche Praktiken zu berücksichtigen gilt (Teilkapitel 5.3). In Teilkapitel 5.4 wird dann die in der Öffentlichkeit sehr kontrovers diskutierte Frage nach der Verantwortung für nachhaltigen Konsum aufgegriffen. Ziel hierbei ist, noch einmal die Spezifika eines streng auf Praktiken fokussierten Ansatzes sowie den sich daraus ergebenden Mehrwert für die Erforschung alltäglichen Konsums zu verdeutlichen. Abschließend wird in Teilkapitel 5.5 ein kurzer Ausblick auf weiteren Forschungsbedarf und mögliche Forschungsthemen gegeben.

\subsection{Soziale Praktiken: Ein aufschlussreicher analytischer Rahmen zur Untersuchung des Energiekonsums in Privathaushalten}

In Bezug auf den in dieser Arbeit angewendeten Forschungsansatz der sozialen Praktiken sowie des dadurch angeleiteten Vorgehens bei der Analyse des alltäglichen Heizgeschehens werden im Folgenden fünf Punkte eingehender reflektiert, die sich als besonders gewinnbringend für die Bearbeitung des Forschungsthemas herausgestellt haben: (1.) die Praktiken-Elemente, (2.) die (historischen) Entwicklungsverläufe von Praktiken, (3.) die Verflechtung von Praktiken, (4.) die Klassifikation von Praktiken und (5.) unterschiedliche Formen und das Ausmaß von Praktikenwandel.

\subsubsection{Arbeiten mit dem (Drei-)Elemente-Modell}

Bei der Analyse alltäglicher Heizpraktiken habe ich das vereinfachte DreiElemente-Schema Shoves et al. (2012) genutzt, wonach jedwede Praktik ein spezifisches Ensemble aus den drei grundlegenden Elementen Materialien (alle physischen Objekte), Wissen/Kompetenz(en) und Bedeutungsgehalte darstellt.

Diese Unterteilung von Praktiken in einzelne elementare Bestandteile war hilfreich, weil dadurch leicht(er) zu identifizieren war, welche Technologien, Gegenstände, Infrastrukturen, Akteure, Wissensbestände, prakti- 
schen Erfahrungen, Aktivitäten, Handgriffe, Körperbewegungen, Sinnbilder, Deutungen usw. tatsächlich zu den konkret untersuchten Heizpraktiken gehören. Anhand des Elemente-Schemas ließ sich ermitteln, wodurch sich Heizen im Passivhaus und Heizen im SmartHome jeweils auszeichnet und von anderen (konventionellen) Heizformen unterscheidet sowie von welchen Einflüssen das alltägliche Heizgeschehen maßgeblich bestimmt wird.

Die Vorstellung von einer Praktik als ein spezifisches Zusammenspiel unterschiedlicher Elemente ist hilfreich dafür, den Praktiken-Ansatz bzw. die Brauchbarkeit des Praktiken-Ansatzes anderen Akteuren sowie politischen Entscheidungsträger*innen, z.B. Architekt*innen, Stadtplaner*innen, Energie- und Klimaschutzbeauftragten, verständlich vermitteln zu können. Die Möglichkeiten für praktikenbasierte Interventionen in die alltägliche Praxis werden in Teilkapitel 5.3 eingehender erörtert.

Zudem hat sich der Grundsatz, dass alle Elemente als gleichwertig anzusehen sind und Wandel in den Praktikenperformances von jedem Element ausgehen kann, als nützlich erwiesen und ist daher unbedingt zu beachten - etwa um politische Interventionsmaßnahmen sinnvoll planen sowie deren wahrscheinliche Auswirkungen im Vorhinein abwägen zu können. Demnach kann prinzipiell jede Veränderung eines Elements sich darauf auswirken, wie die betreffende Praktik performt wird. So können nichttechnische Veränderungen einen deutlichen Effekt auf Praktiken haben. Beispielsweise hatte die Erblindung einer Passivhausbewohnerin zur Folge, dass sie viele Aktivitäten wie Fernsehen oder Beleuchtung, die im Passivhaus eigentlich zur Wärmegewinnung beitragen, nicht mehr ausübt, weshalb bei ihr zusätzliche Heizkörper installiert wurden.

Die Arbeit hat deutlich gemacht, dass die Beziehungen zwischen den Elementen entscheidend dafür sind, ob und wie sich Veränderungen bzw. Interventionen bei einzelnen Elementen auf die anderen Elemente sowie die Gesamtperformance auswirken.

Bei den zwei untersuchten Fallbeispielen stand die Änderung der (Heiz-)Technik am Anfang. Wie in Kapitel 4.3 gezeigt wurde, wirkt sich die neue Passivhaustechnologie nicht nur direkt auf die Heizpraktikenperformances aus, sondern sie hat bei vielen Bewohner*innen auch zu einem geänderten Verständnis von ,Wohnkomfort' und ,Wärmebehaglichkeit ${ }^{\star}$ geführt. Die diesbezüglichen Ansprüche und Erwartungen sind deutlich gestiegen. Im Fall der SmartHomes hat die neu installierte automatische Heizungssteuerung hingegen dazu geführt, dass bei den meisten Bewohner*innen eher negative Gefühle von zunehmender Technikdominanz, 
Kontrollverlust und Diskomfort aufkamen oder noch verstärkt wurden (vgl. z.B. die Kapitel 4.4.1 und 4.4.2).

Darüber hinaus war es durch den Elemente-Ansatz möglich, den Werdegang einzelner Elemente zu untersuchen. Diese Vorgehensweise hat sich beispielsweise als nützlich zur näheren Untersuchung des Heizkörpers erwiesen (vgl. Kapitel 4.1). Lange war der Heizkörper obligatorisches Element des Heizens. Im Idealfall macht die Einführung der Passivhaustechnologie ein aktives Heizungssystem und damit auch Heizkörper zur Wärmeverteilung obsolet. Viele Passivhausbewohner"innen bestehen dennoch auf deren Einbau, weil sie sich das Heizen ohne solche nicht vorstellen können. Das macht deutlich, wie einzelne Elemente auch ohne direkte Anbindung an die anderen Elemente einer Praktik weiter fortbestehen können.

Das Elemente-Schema wurde unterstützend genutzt, um den empirischen Analyseteil dieser Arbeit sinnvoll zu strukturieren (vgl. Kapitel 4). Jedes Teilkapitel fokussiert ein wichtiges Element des Heizens, um von dieser Thematik aus weitere Konsequenzen neu eingeführter Heiztechnik auf die alltäglichen Heizpraktikenperformances zu untersuchen.

In diesem Zusammenhang ist zu betonen, dass das Elemente-Schema nicht zum Ausgangspunkt für diese Forschung gemacht wurde - weder wurden die Fallbeispiele noch die konkreten einzelnen Untersuchungsfälle auf Basis des Elemente-Modells ausgewählt. Vielmehr wurde die Durchführung der Untersuchung vorrangig von den empirischen Daten geleitet, insbesondere von den Berichten und Erzählungen der Interviewpartner*innen von ihrer alltäglichen Heizpraxis. Erst bei der Analyse und Aufbereitung der Daten wurde das Elemente-Schema angewendet, weil es sich als ein adäquates Instrument für die Auswertung und Interpretation der Daten erwiesen hat.

\subsubsection{Die (historischen) Entwicklungsverläufe von Praktiken}

In der einschlägigen Literatur zu sozialen Praktiken wird betont, dass jede Praktik eine Geschichte hat und sich auf einer ständig sich weiter entfaltenden Verlaufskurve befindet (vgl. z.B. Schmidt 2012; Warde und Southerton 2012a; Shove et al. 2012; Spurling et al. 2013; und siehe auch Kapitel 2.2.4). Daraus wurde abgeleitet, dass alltägliche Praktiken(performances) nur begrenzt für sich alleine zu verstehen sind. Für ein umfassendes Verständnis bedarf es der Kenntnis ihrer historischen Entwicklung. Dies hat dazu geführt, dass die Geschichte des Heizens und künstlicher Gebäu- 
deheizung in der westlichen Welt, mit Schwerpunkt auf Mitteleuropa, respektive Deutschland nachvollzogen wurde (vgl. Kapitel 2.2.4.1). Dabei zeigte sich, dass es zu einzelnen Entwicklungsphasen kaum verlässliche wissenschaftliche Quellen gibt. Im Nachhinein ist die aufwendige Erforschung der Heizgeschichte aber als lohnenswert zu beurteilen. Viele Entwicklungen und Erscheinungen im gegenwärtigen Heizen erschlossen sich erst vor dem Hintergrund vergangener Heizpraxis und früherer Heizformen. Zum Beispiel hatten viele Passivhausbewohner*innen am Anfang große Probleme mit der Regulierung ihrer Lüftung, was erst vor dem Hintergrund ehemals genutzter Heizsysteme verständlich wurde. Und auch die überwiegende Zahl der SmartHome-Bewohner"innen tat sich schwer mit der Umstellung, die Raumtemperaturen aller Wohnräume zentral von einem Tablet aus zu regulieren, anstatt direkt am einzelnen Heizkörperthermostat zu drehen (vgl. die Teilkapitel 4.1.2.1 und 4.4.1.3).

Auch ließen sich einige größere aktuelle Entwicklungen und Trends im Heizen vor dem Hintergrund der gesamten Heizgeschichte einfacher sinnhaft deuten und hinsichtlich ihrer Bedeutung nicht nur für modernes, sondern auch für zukünftiges Heizen fundierter bewerten. So führt etwa die hocheffiziente Wärmedämmung des Passivhauses dazu, dass zur Gewährleistung einer angemessenen Raumluftqualität eine kompakte Lüftungsanlage unbedingt erforderlich wird, wobei aufgrund eines nur noch geringen Restwärmebedarfs auf ein Extra-Heizungssystem verzichtet werden kann. Im Passivhaus verschmelzen Heizung und Lüftung - ehemals eigenständige Tätigkeiten - zu einer Hybridaktivität (vgl. Kap. 4.2).

Folgendes Zitat fasst noch einmal den besonderen Mehrwert zusammen, der sich aus der umfassenden Erforschung der historischen Werdegänge einzelner Praktiken ergibt:

„While empirical studies of relatively simple examples of practices changing within a short time span may disclose detailed aspects of practice dynamics, historical studies of long-term changes of domestic practices highlight the importance of wider social changes involved in practice changes." (Røpke 2009: 2494)

Dieser Mehrwert wurde auch in dieser Arbeit zur Alltagstätigkeit des Heizens deutlich.

Zudem können aus der Kenntnis und einem soliden Verständnis der bisherigen Verlaufs- und Wandlungsgeschichte einer Praktik Annahmen abgeleitet werden, wie sich die betreffende Praktik in Zukunft weiterentwickeln könnte. So zeichnet sich heute bereits ab, dass die Passivhaustechnologie, trotz enormer Energieeinsparungen, mit hoher Wahrscheinlich- 
keit zu einer Steigerung der Wärmebehaglichkeitskonventionen führen wird, was wiederum geringere Einsparungen zur Folge hätte - ein klassischer Rebound-Effekt (vgl. Kapitelfazit 4.3.8).

Wird die prognostizierte Weiterentwicklung einer Handlungspraxis als nicht erstrebenswert beurteilt, dann ermöglicht eine plausible gedankliche Vorwegnahme umgekehrt genauso, dass schon frühzeitig interveniert werden kann.

\subsubsection{Die Verflechtung von Praktiken}

Im realen Leben steht keine Praktik für sich, sondern Praktiken sind grundsätzlich mit anderen Praktiken verflochten (vgl. Teilkapitel 2.3.2.1). Themen des Ineinandergreifens von unterschiedlichen Praktiken haben sich als sehr nützlich erwiesen, um die Auswirkungen von modernen Hausdesign- und Heiztechnologien etwa auf abgestimmte Alltagsarrangements und für die Koordinierung des alltäglichen Lebens in den Blick zu bekommen. Dabei wurde deutlich, dass Heizen und Lüften - zwei Tätigkeiten, die schon immer eng miteinander verbunden waren - durch die Passivhaustechnologie und - auf andere Art und Weise und in geringerem Ausmaß - auch durch die smarte Heizungssteuerung nun praktisch untrennbar miteinander verknüpft sind (vgl. Kapitel. 4.2). Darüber hinaus hat die Arbeit gezeigt, mit welchen anderen alltäglichen Praktiken Heizen und Lüften im Alltag der Bewohner*innen noch verflochten sind und was bei ihren alltäglichen Routinen neu koordiniert werden muss, wenn sich ihre alltägliche Heizpraxis aufgrund neuer Technik verändert. Wie Teilkapitel 4.2.2 verdeutlicht, besitzt die Passivhaustechnologie das Potenzial, Praktiken zu entflechten (z.B. Lüften und Frühstücken), die sich vorher zeitlich überschnitten haben und deshalb immer genau aufeinander abzustimmen waren. Und in Teilkapitel 4.2.3 wurde anschaulich gezeigt, wie sich die Programmierung der intelligenten Heizungssteuerungstechnik, also die Praktiken der Technikkonstrukteur*innen und Softwareentwickler*innen, die eigentlich nur das Heizen und Lüften adressieren sollte(n), auch noch auf ganz andere Routinen (z.B. Rauchen) auswirken kann.

Aus einer Forschungsperspektive, die soziale Praktiken als Analysefokus hat, handelt es sich bei der Verzahnung von Praktiken um einen Aspekt von grundlegender Bedeutung. Denn es ist tatsächlich fast immer so, dass Änderungen bei einer Praktik auch zu Modifikationen bei anderen Praktiken führen. Die Untersuchung hat gezeigt, dass Veränderungen in der Performance alltäglicher Heizpraktiken praktisch unvermeidbar manchmal 
,Dominoeffekte' auslösen. So sorgen etwa viele Passivhausbewohner*innen in ihren Wohnungen für zusätzliche Luftfeuchtigkeit (z.B. durch Aufstellen von Wasserschalen oder Aufhängen feuchter Tücher oder feuchter Wäsche), da ihnen die Raumluft im Passivhaus ansonsten zu trocken ist (vgl. Teilkapitel 4.3.6).

Die Analyse, wie Praktiken auf komplexe Weise miteinander verzahnt, koordiniert und synchronisiert sind, stellt somit auch ein (wirk-)mächtiges Instrument zur absichtsvollen Intervention und Veränderung bestimmter Praktiken oder Praktikengefüge dar (vgl. Spurling et al. 2013: 14). Mit einer Praktiken-Perspektive ist das netzwerkartige (Alltags-)Gefüge aus multiplen ,doings ${ }^{6}$ und Praktizierenden gut in den Blick zu bekommen, auch wenn - wie in dieser Arbeit geschehen - der Analysefokus auf Aktivitäten auf der Mikroebene liegt.

Die Perspektive, die über eine Betrachtung der isolierten, als problematisch eingeschätzten Praktik hinausgeht, ermöglicht frühzeitig mögliche Rebound-Effekte abzusehen und gegebenenfalls zu verhindern. Mit dem Praktiken-Ansatz lässt sich die Komplexität des Alltagsgeschehens sehr gut einfangen und analysieren (vgl. ebd.: 51).

\subsubsection{Die Klassifizierung von Praktiken}

Schon frühzeitig im Forschungsprozess wurde deutlich, dass die Analyse alltäglichen Heizens als eine soziale Praktik es erforderlich macht, die Grenzen des Heizens zu bestimmen, um Heizaktivität(en) möglichst eindeutig identifizieren und von anderen Praktiken unterscheiden zu können; vor allem war eine genauere Eingrenzung und Einordnung des Heizens notwendig, um zu wissen, welche ,doings and sayings' empirisch zu untersuchen sind. Von den drei bisher aus der Literatur bekannten Konzepten zur ontologischen und methodologischen Beschreibung und Unterscheidung von Praktiken, erscheint mir für den Untersuchungsfall Heizen die von Warde stammende Idee von einer „compound practice“ (Warde 2013) am geeignetsten (vgl. Teilkapitel 2.1.3). Der Kerngedanke des Konzepts besteht, wie dargelegt, darin, dass sich mehrere eigenständige Praktiken um oder sogar innerhalb bzw. unter einer anderen umfassenden Praktik bündeln bzw. sammeln. Die Konzeption von einer komplexen, zusammengesetzten Praktik war insbesondere hilfreich, um das Heizen im Passivhaus angemessen erfassen zu können. Mit Einführung der Passivhaustechnologie ist Heizen tatsächlich zu einer nahezu allumfassenden ,compound practice' geworden: Durch das Prinzip der Wärmerückgewin- 
nung tragen im Passivhaus beinahe alle Tätigkeiten (z.B. Kochen, Staubsaugen) zur Erwärmung der Raumluft bei. Aber auch im Fall der SmartHomes sind Heizen und Lüften mittels Technik jetzt deutlich enger verknüpft: Hier sorgen smarte Fenstersensoren dafür, dass die Heizung entsprechend automatisch reguliert wird.

Die Praktikentypologie und insbesondere das Konzept der ,compound practice' waren demnach nützlich, um Wandlungsprozesse erfassen zu können, bei denen sich durch bestimmte Interventionen aus zuvor unabhängigen oder nur lose miteinander verbundenen Praktiken ein Aktivitätenkomplex von nun deutlich stärker integrierten und ko-abhängigen Praktiken bildet.

\subsubsection{Unterschiedliche Formen und das Ausmaß von Praktikenwandel}

Bei dem theoretischen Modell ,soziale Praktiken' handelt es sich keineswegs um einen statischen, sondern im Gegenteil, um einen äußerst flexiblen und facettenreichen theoretischen Ansatz zur Beschreibung und Analyse von Sozialleben. Die vorliegende Arbeit hat verdeutlicht, dass der Praktiken-Ansatz bestens geeignet ist, um (nicht nur Kontinuität und sich ständig wiederholende Routineaktivität, sondern auch) kleine alltägliche Veränderungsprozesse sowie größeren abrupten Wandel (innerhalb) von Praktiken einzufangen, zu klassifizieren und angemessen zu interpretieren.

Durch die Analyse zweier relativ neuartiger Heizformen konnte bestätigt werden, dass es sich um zwei deutlich unterschiedliche Wandlungsformen handelt (vgl. Teilkapitel 2.3.2.2).

Das Passivhausprinzip ist als eine radikale bzw. Basisinnovation zu bezeichnen, weil die Aktivität des Heizens in den entsprechenden Haushalten tatsächlich fundamental gewandelt wird. Das Heizen im Passivhaus beinhaltet im Kern eine neuartige Aktivität, nämlich die Bedienung der kompakten Lüftungsanlage. Andere Aktivitäten, die schon vorher Teil des Heizens waren und auch im Passivhaus weiterhin dazuzählen und erhalten bleiben, sind nun aber stark verändert: die klassische Fensterlüftung wird weitgehend durch eine automatisch kontrollierte Be- und Entlüftung ersetzt, die Raumtemperaturen werden vorrangig über die Lüftungsanlage reguliert, die nur in Ausnahmefällen durch eine aktive Heizung ergänzt wird. Darüber hinaus dienen viele im Haus vollzogene Alltagsaktivitäten nun auch der internen Wärmegewinnung. Im Kontext Passivhaus erfährt die Alltagstätigkeit Heizen demnach eine grundlegende Transformation. 
Hingegen stellt die smarte Heizungssteuerung im Hinblick auf das Heizgeschehen lediglich eine inkrementelle Veränderung dar. Die mit Heizen verbundenen Handgriffe und Aktivitäten (z.B. Bedienen der Heizungsanlage, Drehen am Thermostat, Fensteröffnung) bleiben im Prinzip alle erhalten, werden aber in ein zentrales Steuerungsgerät verlagert und dabei nur geringfügig transformiert: Um die Raumtemperaturen einzustellen, müssen die Bewohner*innen ihre Wunschtemperaturen nun an einem Tablet eingeben bzw. sie können ihre gewünschten Temperaturen für die einzelnen Räume in Form von Nutzungsprofilen am Tablet fest ein- und vorprogrammieren.

Des Weiteren hat die Untersuchung deutlich gemacht, dass unterschiedliche Formen von Wandel auch andersartige Anstöße benötigen. Und ebenso erfordern die angestoßenen Veränderungen ein deutlich unterschiedliches Veränderungsmanagement, sollen sie tatsächlich längerfristig erfolgreich sein.

Während im Fall des Passivhauses der Anstoß in der Regel ein geplanter Hausbau oder -kauf ist, reicht für den Wechsel zum smarten Heizen bereits ein deutlich weniger umfängliches Modernisierungs- oder Sanierungsvorhaben im bestehenden Zuhause.

Hinzu kommt: das Passivhaus bedarf in jedem Falle der fachlichen Planung sowie Umsetzung; und nach der Realisierung muss die Technik weiterhin regelmäßig von entsprechenden Expert"innen kontrolliert und gewartet werden. Hingegen handelt es sich bei der intelligenten Heizungssteuerung um eine relativ ,einfache ${ }^{6}$ Nachrüsttechnologie. Man benötigt keine professionelle Installation und im Prinzip kein besonderes technisches Wissen, um diese Technik zu nutzen. Die smarte Technik ist selbsterklärend und alles Notwendige stehe in der Bedienungsanleitung, so die Expert*innen. Verschieden aufwendige Ausführungen smarter Heizungsteuerungssysteme können im normalen Elektrohandel oder im Baumarkt gekauft werden oder lassen sich teilweise direkt vom Energieversorger beziehen. Der Einbau bedarf keiner Erlaubnis des bzw. der Vermieter*in.

Die Untersuchung hat gezeigt, dass all die unterschiedlichen Facetten von Wandel (Auslöser, Form, Ausmaß, Ablauf, usw.) anhand des Praktiken-Ansatzes für die beiden Fallbeispiele sehr gut zu analysieren waren.

\section{Alltägliches Heizen - eine facettenreiche, komplexe Praxis}

Wie anhand der fünf dargelegten Aspekte einzeln ausgeführt, hat sich die Anwendung des Praktiken-Ansatzes zur Analyse des alltäglichen Heizgeschehens in Privathaushalten insgesamt als produktiv erwiesen, um die Komplexität des Untersuchungsgegenstandes einzufangen. Mit der Analy- 
seperspektive ,soziale Praktiken' konnte aufgezeigt werden, wie facettenreich und vielschichtig gewöhnliches Heizen ist - und somit, was für gelungene Intervention alles zu berücksichtigen wäre, damit Heizen in $\mathrm{Zu}$ kunft einen deutlich geringeren Energieverbrauch und weniger $\mathrm{CO}_{2}$-Emissionen impliziert.

Welche Aspekte für den Wandel von Heizpraktiken besonders relevant sind und was demnach für effektive Intervention in die alltägliche Heizpraxis unbedingt berücksichtigt werden sollte, ist Thema der folgenden Ausführungen zu den inhaltlichen Erkenntnissen bezogen auf die Praxis des Heizens.

\subsection{Inhaltliche Erkenntnisse zur Praxis des Heizens}

Aus der Rekonstruktion und Analyse einzelner konkreter Entwicklungsverläufe von Heizpraktiken im Übergang von konventionellen Wohnkontexten zum Passivhaus und SmartHome wurde deutlich, wie es im Einzelnen zu bestimmten Dynamiken und Veränderungen im alltäglichen Heizgeschehen gekommen ist. Im Folgenden werden sechs zentrale Punkte ausführlicher erläutert. Dies sind:

1. ,History matters'

2. Entkopplung und die Wandlung von Elementen mit unterschiedlicher Geschwindigkeit

3. Koevolution

4. ,Distributed agency ${ }^{6}$ (ungleich) verteilte Wirkmacht

5. ,Heterogeneous engineers' und , heterogeneous engineering

6. Nicht-intendierte Folgen

Die erfolgreiche Verbreitung von bestimmten Praktiken oder ihr länger andauerndes Fortbestehen stellt im Grunde genommen nichts anderes dar als ein erfolgreiches ,Matching ' zwischen den Erfordernissen einer Praktik und den allgemeinen, persönlichen Ressourcen (z.B. Motivation, Interessen, Zeit, Kompetenzen, usw.) des bzw. der sich (in der jeweiligen Praktik) engagierenden Teilnehmer*innen.

Daraus folgt, dass jeder Weg, der eingeschlagen wird, um nachhaltigen bzw. unter Nachhaltigkeitsgesichtspunkten, günstigen' Praktiken zum Durchbruch zu verhelfen, stets von diesen beiden Standpunkten aus zu betrachten ist. 


\subsection{1 ,History matters ${ }^{6}$}

In diesem Sinne trifft auch der allgemein bekannte Ausspruch, history matters' stets sowohl aus der Perspektive der Praktiken als auch aus der ihrer (neuen, potenziellen und bereits vorhandenen) Teilnehmer*innen zu. In Abschnitt 5.1.2 wurde bereits auf die Bedeutung des historischen Verlaufs von Praktiken hingewiesen. In diesem Abschnitt soll nun am konkreten Beispiel aufgezeigt werden, wie sich die Geschichte der Praktik-als-Einheit und genauso die vergangenen individuellen (Heiz-)Erfahrungen der einzelnen Praktizierenden auf ihre aktuelle Heizpraxis in Passivhäusern und SmartHomes auswirken. Welche Folgeentwicklungen, Kontinuitäten, Pfadabhängigkeiten und/oder Brüche sind hier erkennbar?

Die ausführliche Darstellung des Entwicklungspfades der Gebäudeheizung in Deutschland hat gezeigt, dass die Tätigkeit des Heizens eine lange Geschichte hat (vgl. Teilkapitel 2.2.4.1). Was heutzutage in Bezug auf das Heizen und den Energieverbrauch als problematischer, state of the $\operatorname{art}^{6}$ und bedenkliche, weil klimaschädigende gesellschaftliche Norm gilt nämlich die weit verbreitete zentrale Gebäudeerwärmung mittels fossiler Energieträger - diese spezifische Kombination gibt es dagegen erst seit ungefähr einem Jahrhundert. Und erst seit den 1970er Jahren gehört die in der Regel auf der Verbrennung von Öl oder Gas basierende zentrale Wärmeversorgung zum Standard. Daran wird deutlich, welche Beschleunigung die Entwicklung der Heizungstechnik alleine in den letzten hundert Jahren erfahren hat und wie rasant sich dadurch die künstliche Beheizung von Wohnräumen insbesondere in den letzten Jahrzehnten gewandelt hat.

\section{Pfadabbängigkeiten und die längeren Entwicklungsverläufe (,trajecto- ries') von Praktiken}

Die Geschichte einer Praktik bestimmt sowohl ihr gegenwärtiges Erscheinungsbild, als auch bildet sie die Grundlage für die Zukunft derselben Praktik. Aus diesem Grund ist es wichtig, die Entwicklungsgeschichte einer Praktik nachzuvollziehen und ihre Vergangenheit aufzuarbeiten (vgl. Abschnitt 5.1.2). Dies gilt nicht nur für die im Mittelpunkt des Interesses stehende Praktik, sondern auch für den Gesamtzusammenhang, in dem die Praktik entstanden ist und sich erfolgreich verbreiten konnte. Denn erst, wenn man auch um die zentralen Entwicklungen weiß, die sich in der kritischen Phase der Entstehung und anfänglichen Verbreitung ereignet und wesentlich zum entscheidenden Umbruch beigetragen haben, lässt sich die Bedeutung der aktuellen Herausforderung(en) sowie das Ausmaß 
notwendiger Veränderungen angemessen abschätzen, die für eine Reduzierung des Energieverbrauchs in Privathaushalten erforderlich erscheinen.

Durch das Nachvollziehen der historischen Entwicklung künstlicher Gebäudeheizung wurde deutlich, welche technischen und soziokulturellen Entwicklungen im Deutschland der Nachkriegsjahre der mittlerweile als problematisch angesehenen Öl- und Gaszentralheizung den Weg für ihre Verbreitung ebneten (vgl. Teilkapitel 2.2.4.1).

Wie bei einem Wegenetz gibt es auch in den Entwicklungsverläufen von Praktiken Anfänge und Kreuzungen, an denen mehrere Alternativen zur Auswahl stehen und somit die Chance besteht, den aktuell beschrittenen Pfad (wieder) zu verlassen und auf eine Alternative auszuweichen. Eine einmal eingeschlagene Entwicklungsrichtung wird in der Regel jedoch nicht ohne weiteres geändert, sondern meist wird - wenn überhaupt - nur an solch einem Kreuzungspunkt umgesteuert. Häufig braucht es jedoch ein kritisches Ereignis bzw. der Kreuzungspunkt an sich muss selbst einen solchen kritischen Zeitpunkt (,critical juncture') darstellen, damit es tatsächlich zur Pfadabkehr und damit zur Umstellung im praktischen Geschehen kommt.

Die Lage nach dem Zweiten Weltkrieg mit der weitgehenden Zerstörung der (Versorgungs-)Infrastrukturen ist als ein solch kritischer Wendepunkt auf dem gesellschaftlichen sowie technisch-infrastrukturellen Entwicklungspfad anzusehen. Die Nachkriegssituation sorgte dafür, dass eine neue Grundlage für das Heizen geschaffen werden konnte: viele Wohnhäuser mussten neu gebaut werden und die Versorgungsinfrastruktursysteme für Gas, Elektrizität, Wasser usw. mussten weitestgehend neu verlegt werden. Eine neue Heizungsform erlangte den Durchbruch: die öl- oder gasbefeuerte Zentralheizung.

Es stellt sich nun die Frage, ob die Herausforderung des Klimawandels aktuell wieder solch einen entscheidenden Wendepunkt darstellt.

Zwar lässt sich auf der Bewusstseinsebene bereits antizipieren, dass mit dem anthropogenen Klimawandel ein kataklystisches Ereignis bevorsteht, aber physisch erlebt, haben die allermeisten Menschen die möglichen Konsequenzen des Klimawandels noch nicht. Zwar sind bereits erste Ereignisse aufgetreten, die dem anthropogenen Klimawandel zugerechnet werden und Auswirkungen wie Schäden infolge von Extremwettereignissen waren auch in Deutschland schon spürbar. Allerdings steht der größte Teil der Veränderungen, die der Klimawandel verursachen wird, noch aus. Und auch dann werden die meisten Folgen nur mittelbar dem Klimawandel zuzurechnen sein (z.B. Migration). Die für den Menschen spürbaren Auswirkungen und Folgen liegen aber (größtenteils noch) in der Zukunft und da- 
mit im Bereich des Unsicheren und noch Nicht-Fassbaren. Wie die Analyse der Heizpraktiken in gewandelten Wohnkontexten verdeutlicht hat, ist es in den meisten Fällen aber offenbar genau diese reale persönliche Erfahrung mit allen Sinnen, die die Menschen dazu bewegt, bewusst über ihre bisherige(n) Verhaltensroutine(n) zu reflektieren und diese gegebenenfalls abzuändern (vgl. Ilmonen 2001; Wilk 2009).

In Deutschland ist das Energieversorgungsnetz für die ,alten' fossilen Energien gut ausgebaut und die Versorgungssicherheit ist auf einem hohen Niveau. Nur äußerst selten kommt es zu großflächigeren Ausfällen in der Wärmeversorgung, und wenn, sind diese meist nur von kurzer Dauer. Die Menschen in Deutschland sind diesbezüglich an einen hohen Komfortstandard gewöhnt. Das bedeutet, dass die Infrastrukturen des auf fossilen Energieträgern beruhenden Versorgungssystems voll funktionsfähig sind. Die mangelnde ,Erlebbarkeit' eines kritischen Wendepunktes und die aktuelle Versorgungslage auf hohem Niveau erzeugen somit (vielseitige) so genannte Lock-in-Effekte - das heißt, die Abkehr vom bisherigen Pfad bzw. der Wechsel zu einem neuen Pfad ist für die betroffenen, involvieren Akteure mit erheblichen (Wechsel-)Kosten unterschiedlichster Art verbunden.

Diese ,Pfadabhängigkeiten', ,kritischen (Zeit-)Punkte“ und ,Lock-in-Effekte' sowie daraus resultierende Wechselkosten sind für den Bereich des Heizens auch auf der Ebene der Haushalte zu identifizieren: So gilt ein Heizungssystem nach etwa 15 Jahren als alt und es wird allgemein eine Generalinspektion empfohlen. Als generelle Richtlinie gilt, dass das Heizungssystem etwa alle 20 Jahre erneuert bzw. grundlegend modernisiert werden sollte. Nach 30 Jahren besteht laut EnEV eine Austauschpflicht (vgl. z.B. Rosenkranz 2017*). ${ }^{121}$ Demnach stellt dieser Zeitpunkt für Hauseigentümer*innen solch einen kritischen Moment dar, an dem dem bisher verfolgten technisch-infrastrukturellen Pfad eine neue (Aus-)Richtung gegeben werden kann. Im Umkehrschluss bedeutet dies, dass mit der (neuerlichen) Entscheidung für ein bestimmtes Heizungssystem der technischmaterielle Pfad des Heizens für die nächsten 20 Jahre weitestgehend festgelegt ist. Ein vorzeitiger Wechsel wäre mit sehr hohen Investitions- bzw. Wechselkosten verbunden.

Aus dem bisher Geschilderten ergibt sich die Tragweite der Entscheidung für die erste Heizlösung bei einem Neubau(projekt). Unterschiedli-

$121 \mathrm{Vgl}$. auch www.verbraucherzentrale.de/wissen/energie/heizen-und-warmwasser/ austauschpflicht-fuer-heizkessel-11902, zuletzt aktualisiert am 20.07.2016, zuletzt geprüft am 13.04.2018. 
che Heizlösungen erfordern unterschiedliche technische Vorrichtungen, Infrastrukturen sowie Rahmenbedingungen. So ist es zum Beispiel relativ einfach, einen Neubau als Passivhaus zu realisieren. Ein bereits 20 oder sogar 40 Jahre altes Haus bei anstehendem Wechsel der Heizung durch eine umfassende energetische Sanierung auf den Energiestandard des Passivhauses zu bringen, ist hingegen äußerst schwierig, in vielen Fällen nicht mehr möglich. Dies ist der Grund, weshalb für den Untersuchungsfall des passiven Heizens die Bewohner*innen im Interview zunächst danach gefragt wurden, wie sie zu ihrem Passivhaus gekommen sind, weil es für diese Form des Heizens tatsächlich erforderlich ist, dass die Entscheidung für ein Passivhaus möglichst früh im Planungs- und Bauprozess gefällt wird. Darüber hinaus braucht es für die Realisierung eines Passivhauses die entsprechenden Expert"innen. Demnach ist entscheidend, welche*r Architekt"in die Hausbauherr"innen während ihrer Planungen berät. Je nach Kenntnisstand und Interesse der Bauherr*innen sowie besonderer Ausbzw. Weiterbildung des bzw. der Architekt"in werden den angehenden Bauherr*innen unterschiedliche Heizungslösungen vorgeschlagen und zur Auswahl vorgestellt. Der bzw. die beratende Architekt"in stellt somit eine wichtige Vermittlungsinstanz dar, was die Auswahl einer ersten Heizlösung bei dem Bau eines Hauses anbelangt.

Pfadabhängigkeiten anderer Art wurden bei dem untersuchten Projekt zum intelligenten Heizen sichtbar: Bei der betroffenen Liegenschaft handelt es sich um ein altes Wohngebäude aus rotem Backstein, das in den 1920er Jahren errichtet wurde. Diese so genannten Rotklinker-Häuser werden in Hamburg mittlerweile als zu schützendes Kulturgut angesehen. Weil immer mehr dieser stadtbildprägenden Backsteinhausfassaden hinter Dämmung und Putz verschwinden, hat sie die Stadt inzwischen größtenteils unter Denkmalschutz gestellt und für diese Häuser die Außendämmung verboten. Dies gilt auch für die untersuchte Genossenschaftsimmobilie, weshalb die Genossenschaft nach Alternativen zur Dämmung der Außenfassaden suchen musste, um Heizenergie und $\mathrm{CO}_{2}$-Emissionen einzusparen. Die Genossenschaft hat sich daraufhin dazu entschieden, testweise ein intelligentes Heizungssteuerungssystem in einem ihrer Mietwohnblöcke installieren zu lassen. Dadurch sahen sich die von dieser Entscheidung betroffenen Mieter"innen mit einer neuen Heiztechnik konfrontiert, die bisher nicht Teil ihrer alltäglichen Heizpraxis gewesen ist. Das heißt, sie waren gezwungen den Umgang mit der intelligenten Heizungssteuerung direkt im Feldversuch zu erlernen (,learning by doing ${ }^{6}$ ) und mussten die neue Technik kurzfristig in ihre Heizpraxis integrieren. Bezogen auf die bildliche Darstellung der Pfadabhängigkeit könnte man 
konstatieren, dass sich für die Genossenschaft eine Kreuzung mit der Möglichkeit zur Wahl unterschiedlicher Pfade ergab. Die Bewohner*innen hingegen wurden damit konfrontiert, dass sich der für sie vorgezeichnete Pfad - ohne Wahlmöglichkeit - veränderte.

\section{Prägung durch die individuelle, persönliche Wohn- und Heiz-Vergangen- beit}

Die bisher geschilderten Pfadabhängigkeiten bezogen sich vor allem auf die materielle Basis von Heizpraktiken und der Praktik des Heizens als ein schon über lange Zeit als Einheit bestehendes Aktivitätenbündel (,practiceas-entity ${ }^{6}$ ). Die Untersuchung konkreter alltäglicher Heizpraktikenperformances in Passivhäusern und in SmartHomes hat außerdem gezeigt, dass solche Pfadabhängigkeiten auch auf der Ebene der Praktiken-als-Performances zahlreich vorhanden sind und sich deren Effekte nicht nur im praktischen Tun niederschlagen, sondern teilweise sogar materiellen Ausdruck finden, also wiederum auf die gegenständliche Ausgestaltung des Heizens rückwirken.

So wichtig wie die Kenntnis der (Gebäude-)Heizungshistorie für das Verstehen des heutigen Erscheinungsbildes des Heizens ist, so wichtig ist auch die Berücksichtigung der jeweiligen persönlichen Wohn- und Heizgeschichte der einzelnen Beforschten, wenn es um die Rekonstruktion und Interpretation der individuellen Heizpraktikenperformances geht (vgl. Kapitel 4.1 bis 4.3). In einigen Fällen ist die Prägung durch in der Vergangenheit gemachte Erfahrungen so nachhaltig, dass von Anfang an kaum ein wirkliches Einlassen auf die neue Situation und Konstellation stattgefunden hat, sondern die alte Handlungsroutine nahezu unverändert beibehalten wurde. So ist zu erklären, dass zentrale materielle Elemente der früheren Heizpraxis wie etwa der Heizkörper in das neue (Wohn- und Heiz-)Setting übertragen wurden.

Die Untersuchung hat gezeigt, dass die Fortsetzung alter Heizpraxis augenscheinlich vor allem bei denjenigen Bewohner*innen zu beobachten ist, bei denen der neue Heizansatz sehr stark von ihrer vorher praktizierten Heizroutine abweicht. Diesen Bewohner*innen fehlt im Vorhinein die Vorstellung davon, welches ,neue ' Heizen sie in einem Passivhaus erwartet. Für einige Bewohner*innen stellt der Übergang von einem konventionellen Wohngebäude in ein Passivhaus einen buchstäblichen ,Quantensprung', also eine ungewöhnlich große Veränderung im Hinblick auf das Heizen und den allgemeinen Wärmekomfort, dar (vgl. Teilkapitel 4.1.1.1 und 4.1.1.2). Die detaillierte Analyse hat ergeben, dass dies vor allem auf diejenigen Passivhausbewohner*innen zutrifft, die direkt zuvor in einem 
klassischen (unsanierten) Altbau gelebt haben. Vor allem sind es unangenehme Kälteerlebnisse, die Skepsis gegenüber dem Passivhaus erzeugen; den bisherigen Altbau-Bewohner*innen fehlt die Erfahrung einer guten Isolierung - das unterscheidet sie von den Bewohner*innen, die zwar ebenfalls aus einem konventionellen Wohnkontext kommen, aber vor ihrem Einzug ins Passivhaus bereits in einem Neubau bzw. relativ modernen Wohngebäude gelebt haben.

Die fehlende Kenntnis des neuen Heizansatzes wird in den meisten Fällen allerdings nicht einfach durch Vertrauen in die neue moderne Technik und/oder Expert"innenrat kompensiert. Die Analyse hat vielmehr erbracht, dass sich die Bewohner*innen im Heizen vorrangig auf ihre persönlichen bisher gesammelten Erfahrungen stützen und in diesem Bereich kein Risiko eingehen (möchten). Und so kommt es, wie in Kapitel 4.1 anhand mehrerer Fallgeschichten anschaulich dargestellt, dass an vertrauten Elementen wie dem (Platten-)Heizkörper oder im SmartHome dem manuell regelbaren Heizkörperthermostat festgehalten wird und diese materiellen Elemente in den gewandelten Kontext übertragen, das heißt wieder eingebaut werden.

Im Hinblick auf die Heizpraxis der Bewohner*innen von Passivhäusern der ersten Generation stellt der Heizkörper demnach eine Art ,Brücke' dar; er fungiert als Bindeglied zwischen konventionellem Heizen und dem (neuartigen) Heizen im Passivhaus.

Im Hinblick auf die Bedeutung der konkreten (Entwicklungs-)Geschichte von Praktik und Praktizierenden lässt sich für den Bereich des alltäglichen Heizens zusammenfassend festhalten: Zum einen sind es die historisch gewachsene Infrastruktur und das grundlegende Setting, in dem Heizen stattfindet, wodurch das alltägliche Heizgeschehen sowie die Richtung seines weiteren (Wandlungs-)Verlaufs wesentlich bestimmt werden. Zum anderen sind die alltäglichen Heizpraktikenperformances entscheidend durch die persönliche Wohn- und Heizgeschichte der Bewohner"innen beeinflusst. Historische Kontexte sind also in zweierlei Hinsicht mitgestaltend für die gegenwärtige, sichtbare Heizpraxis und sie bedingen und begrenzen die Richtung des (weiteren) Wandels von Heizen-als-Einheit. 


\subsubsection{Entkopplung und die Wandlung von Elementen mit unterschiedlicher Geschwindigkeit}

Mit Entkopplung ist ganz allgemein der Vorgang des Aufbrechens oder Lösens ehemals stabiler Verknüpfungen zwischen den elementaren Komponenten einer Praktik gemeint (vgl. Teilkapitel 2.3.2.1).

Nochmal zur Erinnerung: Die wesentlichen Komponenten, aus denen sich jedwede Praktik und damit auch das alltägliche Heizen in Privathaushalten ,zusammensetzt ${ }^{6}$, sind (1.) Materialien - hierzu gehören Dinge und technische Artefakte, aber auch (menschliche) Körper/leibliche Akteure werden dieser Kategorie zugerechnet, (2.) Wissen/Kompetenz(en), im Sinne von internalisierten Fähig- und Fertigkeiten sowie (3.) Sinn-Bilder, (Be-)Deutungs- und Verstehensweisen. Für eine Praktik braucht es immer Elemente aus allen drei Kategorien. Dennoch steht bisher fast ausschließlich die Materialien-Komponente im Fokus, wenn es um eine Reduzierung des Energieverbrauchs und davon abhängiger $\mathrm{CO}_{2}$-Emissionen privater Haushalte im Bedarfsfeld, Wohnen und Heizung' geht. Das heißt, es wird überwiegend isoliert, an nur einer Komponente interveniert - meist wird auf neue effiziente Technik gesetzt, zudem wird teilweise mit moralischen Appellen gearbeitet, um Verhaltensänderungen herbeizuführen. In einzelnen Fällen wird an zwei Komponenten gleichzeitig angesetzt - dann handelt es sich zumeist um die Hereingabe neuer Technik und die Verbreitung von Informationen. Was dabei allerdings häufig vergessen oder außer Acht gelassen wird, ist, dass die Variation einzelner Elemente immer Auswirkungen auf das Gesamtgefüge einer Praktik hat. In Fällen einseitigen Vorgehens kommt es häufig zu einer mehr oder minder abrupten Entkopplung von ursprünglich fest miteinander verknüpften zentralen Praktikenelementen - oftmals mit der Folge, dass sich die ehemals zu einer Praktik wie dem Heizen stabil integrierten Elemente (plötzlich) aus ihrer Verbindung lösen und sich daraufhin getrennt voneinander mit unterschiedlicher Geschwindigkeit weiterentwickeln und ändern.

Dieses (typische) Wandlungsmuster wurde bei den zwei in dieser Arbeit untersuchten Fällen an mehreren Stellen deutlich: Technischer Wandel stand auch bei den zwei gewählten Untersuchungsfällen am Anfang. In beiden Fällen sahen sich die Bewohner*innen für ihre alltägliche Heizpraxis mit einer neuen Technologie konfrontiert. Die Studie verdeutlicht: Es macht für die Akzeptanz und die Bereitschaft zur Integration der neuen Heiztechnik in die alltägliche Heizpraxis einen Unterschied, ob die neue Technik bewusst gewählt oder ob sie einem aufoktroyiert wurde (vgl. Kapitel 4.4). Aus diesem Grund wurde im Fall der SmartHomes, um die Mie- 
ter*innen von der Technik zu überzeugen, noch an einer zweiten Stelle interveniert. Und zwar wurden die betroffenen Mieter*innen vor Beginn der Veränderungsmaßnahmen von Expert*innenseite mit theoretischem Wissen versorgt. Sie wurden demnach vorrangig bzw. ausschließlich auf der technisch-rationalen Ebene adressiert, jedoch wurde dabei die praktisch-lebensweltliche Ebene weitgehend außer Acht gelassen. Das heißt, auf die Emotionen, Sorgen und Ängste der betroffenen Mieter*innen wurde nicht eingegangen; ihr Sinnverstehen, ihre Bereitschaft, ihre Motivation(en) und Interessenlagen wurden weitestgehend ausgeblendet. Die Analyse hat deutlich gezeigt, dass die Bedeutungen-Komponente systematisch vernachlässigt wurde. Eine typische Reaktion der von der Veränderungsmaßnahme betroffenen Mieter"innen war es, subtilen bzw. mehr oder weniger offenen Widerstand zu leisten (vgl. exemplarisch Teilkapitel 4.4.1.3, 4.4.2.2 sowie 4.4.3.2).

Bei dem in dieser Arbeit herausgearbeiteten Verlauf von technischer Intervention mit anschließendem Reaktions- bzw. Folgegeschehen handelt es sich um ein typisches und relativ häufig auftretendes Muster. In der Praxis wird das komplexe Zusammenwirken aller drei Komponenten insbesondere von Technik-Expert*innen sowie von politischen Entscheidungsträger*innen allerdings häufig noch kaum beachtet. Vor allem die Bilder/ Bedeutungen-Komponente wird bislang noch sehr wenig in den Blick genommen, wenn es um absichtsvolle Intervention in alltägliche (Heizenergiekonsum-)Praktiken in Privathaushalten geht.

Die sich aus einseitiger Intervention typisch ergebende Wandlungsdynamik (der einzelnen Elemente innerhalb einer Praktik) wird neben dem oben angeführten Beispiel noch an einer weiteren Stelle bei den zwei in dieser Arbeit untersuchten Fällen erkennbar: In Teilkapitel 4.2.5 wurde verdeutlicht, dass sich die Verhaltensänderung bzw. Anpassung vom manuellen Lüften durch das geöffnete Fenster hin zu kontrollierter Be- und Entlüftung mittels Lüftungsanlage in vielen Fällen als schleichender Gewöhnungsprozess ereignet hat. So waren die neuen Passivhausbewohner*innen zwar darüber informiert, dass aktives Lüften im Passivhaus nicht mehr erforderlich ist. Das heißt, neue Technik und das entsprechende technische Wissen waren von Anfang an vorhanden. Dennoch behielten einige Bewohner*innen zunächst noch ihre an den alten, vorherigen Wohnkontext angepasste Fensterlüftungspraxis bei.

Der geschilderte Verlauf hinsichtlich des Wohnraumlüftens im Übergang von konventionellen Wohnkontexten zum Passivhaus ist demnach ein anschauliches Beispiel dafür, dass sich hier die Inhalte (aus) der Bedeutungen-Komponente merklich langsamer gewandelt haben als es die ande- 
ren zentralen Elemente der alltäglichen Heizpraktiken aus Technologie und aus Wissen getan haben.

Diese Entwicklung wurde in theoretisch-abstrakter Form bereits von Schatzki beschrieben. Er weist darauf hin, dass sich das praktische Verstehen bzw. die Sinndeutungen, die in den vollzogenen körperlichen Routinen zum Ausdruck kommen, häufig deutlich langsamer ändern, als sich beispielsweise abstraktes Wissen oder in Praktiken involvierte Artefakte wandeln (vgl. Schatzki 2013: 40f).

\section{Die freie Zirkulation oder das, Eigenleben' einzelner Elemente}

Der ungleichzeitige oder unterschiedlich schnelle bzw. langsame Wandel von grundlegenden Elementen einer Praktik wird durch eine weitere besondere Gegebenheit begünstigt, auf die im Theorieteil, in Teilkapitel 2.3.2.1 zu den Ausgangspunkten für Wandel bereits kurz eingegangen wurde. Dabei handelt es sich um die vergleichsweise große Stabilität und raumzeitliche Unabhängigkeit von Elementen. Während Praktiken für ihr Fortbestehen auf regelmäßigen Vollzug angewiesen und die einzelnen konkreten (Praktiken-)Performances stets raumzeitlich situiert sind, gilt für die zu einer Praktik verknüpfen Elemente gewissermaßen genau das Gegenteil: Die einzelnen Elemente sind in ihrer Existenz weitgehend unabhängig von Raum und Zeit. Praktiken(arrangements) wandeln sich praktisch permanent. Hingegen sind die einzelnen Elemente in der Regel relativ stabil. Dadurch sind sie in der Lage, eine Art ,Eigenleben' zu führen. Shove et al. beschreiben diesen Sachverhalt wie folgt:

„[...] elements do seem to travel in ways that practices do not. As structured and situated arrangements, practices are always in the process of formation, re-formation and de-formation. By contrast, elements are comparatively stable and are, as such, capable of circulating between places and enduring over time. We are consequently surrounded by things that have outlived the practices of which they were once a vital part." (Shove et al. 2012: 44)

Die Entwicklungsdynamik, dass ein einzelnes oder mehrere Elemente die Praktik, in die sie einst fest integriert waren, ,überleben' und alleine weiter existieren, konnte auch in dieser Untersuchung festgestellt werden: Obwohl im Passivhaus ein herkömmliches aktives Heizungssystem eigentlich nicht mehr erforderlich ist, wird in den meisten (Mehrfamilien-)Passivhäusern eine Heizung mit Heizkörpern in allen Wohnräumen eingebaut (vgl. Kapitel 4.1.1). 
Eigenen Angaben nach haben die interviewten Bewohner*innen die $\mathrm{Zu}$ satzheizmöglichkeiten bisher noch nie bzw. kaum genutzt und einige wohnen bereits mehr als zwölf Jahre in ihrer Passivhauswohnung. Wie in Teilkapitel 4.1.1.5 herausgearbeitet wurde, handelt es sich bei diesen ungenutzten konventionellen Heizkörpern gewissermaßen um ein materielles Relikt, aus Sicht der Passivhausbewohner*innen um ein Überbleibsel einer längst vergangenen Heizpraxis. Shove und Pantzar sprechen in diesem $\mathrm{Zu}$ sammenhang von ,social fossils', die bei Bedarf allerdings auch jederzeit wieder ,zum Leben erweckt' werden können (vgl. Shove und Pantzar 2006, siehe auch Teilkapitel 2.3.2.2). Die Absicherung für den möglicherweise irgendwann einmal eintretenden ,Ernstfall ${ }^{`}$ spielt für einige Passivhausbewohner*innen eine entscheidende Rolle, weshalb sie trotz des Nicht-Gebrauchs weiterhin am Verbleib der Heizkörper in ihren Räumlichkeiten festhalten und diese Position auch in Diskussionen anderen Hausbewohner*innen gegenüber entschieden vertreten (vgl. Teilkapitel 4.1.1.1 und 4.4.1.1). Praktikentheoretiker"innen sprechen hier von übertriebener Ausstattung bzw. von Überdimensionierung als Strategie im Umgang mit so genannten ,just in case'-Szenarien (vgl. Wilhite und Lutzenhiser 1999).

Eine weitere Entwicklung in Richtung Umnutzung der nicht (mehr) zum Heizen verwendeten Heizkörper im Passivhaus wurde in Teilkapitel 4.1.1.5 aufgezeigt. All dies veranschaulicht das unabhängige Zirkulieren und eigenständige ,(Fort-)Leben' eines einzelnen Elements - hier konkret des materiellen Artefakts, Heizkörper`.

\subsubsection{Koevolution}

Eine weitere typische Wandlungsdynamik zwischen und innerhalb von Praktiken, die an mehreren Stellen der vorliegenden Studie deutlich wurde, ist die Koevolution. Von einer Form der Koevolution war im vorherigen Abschnitt zu Entkopplung bereits indirekt die Rede, als auf das unbedingt zu beachtende Zusammenspiel der unterschiedlichen, zu einer Praktik integrierten Elemente hingewiesen wurde. Koevolution stellt gewissermaßen das Komplement zu Desintegrations- und Entkopplungsphänomenen dar (vgl. Teilkapitel 2.3.2.1). Auf Ebene der Praktiken beschreibt es den sich über einen längeren Zeitraum erstreckenden Prozess gemeinsamer, paralleler Entwicklung bzw. die wechselseitige Anpassung von zwei oder mehreren stark miteinander interagierenden Elementen einer Praktik oder von einzelnen Elementen unterschiedlicher Praktiken. Aber auch die interdependente Fortentwicklung verschiedener Praktiken oder sogar gan- 
zer Komplexe sozialer Praktiken, die gemeinsam größere sozio-materielle Ordnungssysteme bilden, werden als Koevolution erfasst.

Die Analyse der Heizpraktiken in Passivhäusern und SmartHomes hat gezeigt, dass ko-evolutionäre Prozesse beim Wandel des alltäglichen Heizgeschehens in Privathaushalten in zweierlei Ausprägung eine zentrale Rolle spielen:

Zum einen können sich ko-evolutionäre Prozesse aufgrund von Abhängigkeiten zwischen den unterschiedlichen, zu einer einheitlichen Praktik integrierten Elementen ereignen. Abhängigkeiten können sowohl zwischen Elementen unterschiedlicher Kategorien bestehen, als auch zwischen Elementen derselben Kategorie (vgl. Schweighofer 2015: 130). Diese Art wechselseitig beeinflusster Veränderung innerhalb unterschiedlicher, für alltägliches Heizen konstitutiver Elemente hat es bei den untersuchten Fällen besonders deutlich zwischen den beiden zentralen Elementen Heizungstechnik und Behaglichkeitskonventionen gegeben. Ganz offensichtlich hat die Passivhaustechnik einen deutlichen Wandel der Wärmebehaglichkeitskonventionen bewirkt (vgl. Teilkapitel 4.3.4 und 4.3.5). Viele Passivhausbewohner*innen haben sich derart an den (innerräumlichen) Wärmekomfort des Passivhauses gewöhnt, dass sie sich mittlerweile bei deutlich höheren Raumtemperaturen wohlfühlen. Das heißt, eine Technik, die mit der Absicht eingeführt wurde, Energie zu Heizzwecken einzusparen, hat dazu geführt, dass sich die thermischen Komforterwartungen und das dementsprechende Handeln dergestalt gewandelt haben, dass sie einen höheren Energieverbrauch implizieren - ein typischer Rebound-Effekt (vgl. Shove 2003).

Zum anderen ereignen sich vielfältige ko-evolutionäre Prozesse zwischen unterschiedlichen Praktiken, die nur lose miteinander gekoppelt sind, oder zwischen einzelnen Praktiken innerhalb größerer PraktikenKonstellationen. Hier geht es um wechselseitige Anpassungen und abhängige Wandlungsprozesse zwischen Praktiken und ihrem Kontext. So wurden bei den Analysen des alltäglichen Heizgeschehens im Passivhaus und im SmartHome interessante Interdependenzen und wechselseitige Anpassungsprozesse des Heizens (und Lüftens) mit ganz anderen alltäglichen Praktiken sichtbar (vgl. Teilkapitel 4.2.2 und 4.2.3). Dabei hat sich beispielsweise herausgestellt, dass die Interventionsmaßnahme der Installation intelligenter Heizungssteuerungstechnik, die eigentlich nur das Heizen verändern sollte, gleich die Umstellung mehrerer Praktiken bzw. die Neuanordnung eines kleinen Praktikengefüges, nämlich das aus Heizen, Lüften und Rauchen, erforderlich gemacht hat (vgl. Teilkapitel 4.2.3). 


\subsection{4 ,Distributed agency ${ }^{6}$ (ungleich) verteilte Wirkmacht}

Wie in Teilkapitel 2.3.2.1 dargelegt, kann jedes der unterschiedlichen, zu einer Praktik gehörenden Elemente Ausgangspunkt für Wandel sein. Der Wandel einer bestimmten Praktik kann aber auch von außen angestoßen werden, z.B. durch Veränderungen (im Elementegefüge) bei mit der im Fokus stehenden Praktik verflochtenen Praktiken oder durch das Aufkommen gänzlich neuer, bisher nicht integrierter Elemente. Alle in einem betrachteten Setting vorhandenen Elemente verfügen somit über Wirkmächtigkeit.

Einzelne Praktikentheoretiker*innen haben sich diesbezüglich durch Arbeiten aus dem Bereich der ,Social Science and Technology Studies (SSTS) inspirieren lassen und deren Konzept der ,distributed agency übernommen, um die Verteilung von Wirkmacht auf die verschiedenen Elemente einer Praktik zu beschreiben (vgl. Wilhite 2008): „Distributed agency draws attention to the sources and sites of agency in consumption habits" (Wilhite 2012: 88).

In diesem Zusammenhang ist noch einmal zu betonen, dass Praxistheoretiker"innen ,agency' nicht im herkömmlichen (Wort-)Sinne als ,Handlungsträgerschaft' bzw. ,Handlungsmacht' verstehen und verwenden, das heißt als Bezeichnung einer Eigenschaft bzw. Fähigkeit, die normalerweise nur menschlichen Akteuren zugerechnet wird. Aus einer praxistheoretischen Perspektive, die zugleich eine Dezentrierung des Subjekts bedeutet und stattdessen primär von sozialen Praktiken ausgeht (vgl. Teilkapitel 2.1.1.4), resultiert vielmehr ein leicht abweichendes Verständnis von ,agency‘. Hier bedeutet ,agency` so viel wie (primärer) Anstoß für Aktivität bzw. Dynamik (innerhalb) von Praktiken (gewesen) zu sein; bzw. ,agency' bezeichnet das Potenzial, Veränderung bewirken zu können bzw. einen Unterschied zu machen. Infolgedessen können neben menschlichen Akteuren nun auch gleichwertig Dinge sowie sozio-kulturelle Kontextgegebenheiten über, agency', also Wirkung(smacht) verfügen .

"If we take account of these perspectives on both embodied and material agency, we can say that agency in habits is distributed between body and objects. However, we must not forget that embodiment and material scripts result from exposure to the social world. Should there be a change in socio-cultural context of a habit, either over time in the same place or due to a displacement of the habit to a different place, the new socio-cultural context can be agentive in changing or reforming the habit. Thus we can say that body, object and social context are each agentive in consumption habits; or, that agency in consumption 
habits is distributed among body, material context and social context." (ebd.: 90)

Häufig ist diese Wirkmächtigkeit allerdings nicht gleichmäßig auf die zahlreichen an einer Praktik beteiligten Elemente verteilt. ,Agency ' kann sogar höchst ungleich zwischen den beteiligten Elementen aufgeteilt sein - wobei sich auch diese Verteilung in ständiger Entwicklung befindet und somit laufend verändern kann. ${ }^{122}$

Im Rahmen des gesamten Untersuchungsprozesses wurde deutlich, wie zentral die jeweils involvierte Heizungstechnologie für den Vollzug alltäglichen Heizens ist. Während Wohnraumbeheizung für die Akteure früher vor allem viel körperliche Arbeit bedeutete, sind heutzutage in der Regel nur noch kleine, wenig anstrengende Handgriffe und Betätigungen für Heizen nötig (vgl. Teilkapitel 2.2.4.1). Über die Jahrzehnte wurden demnach von den ursprünglich zum Heizen gehörenden körperlichen Routineaktivitäten immer mehr an technische Artefakte delegiert. Die beiden in dieser Arbeit untersuchten Heizansätze mit modernen Technologien folgen ebenfalls dieser Entwicklung, besser gesagt: mit ihnen setzt sich der Trend zunehmender Technisierung und Automatisierung im Bereich alltäglichen Heizens deutlich weiter fort.

Wallenborn (2013) zufolge, hat die generell zunehmende Beteiligung technischer Artefakte beim Vollzug von alltäglichen, einst relativ einfachen und ,unbelasteten' Aktivitäten wie Sich-Fortbewegen, Kommunizieren oder eben Heizen dazu geführt, dass diese Tätigkeiten immer komplizierter und ,(ressourcen-)belasteter' geworden sind. ${ }^{123}$ So hat sich das Heizen durch den verstärkten Rückgriff auf technische Artefakte (wie z.B. moderne Heizungssysteme, elektrische Wärmepumpen, automatisierte Thermostate, usw.) zum einen zu einer technisch enorm anspruchsvollen, das heißt sehr komplexen und mittlerweile auch extrem voraussetzungsvollen Tätigkeit gewandelt. Zum anderen haben die nahezu vollständige Delega-

122 Zur grundsätzlichen Diskussion rund um die Frage nach der, agency von Technik innerhalb der (Technik-)Soziologie, siehe Matsuzaki 2011.

123 Wallenborn selbst spricht bei diesen Veränderungsprozessen in Richtung einer immer extensiveren Delegation von körperlichen Betätigungen auf technische Artefakte, für deren Betrieb in der Regel mehr (elektrische) Energie erforderlich ist, von einer (künstlichen),Erweiterung' bzw. ,Verlängerung des (menschlichen) Körpers' (,extension of bodies ${ }^{6}$ bzw. ,extended bodies ${ }^{6}$ ). Dementsprechend definiert er ,practice' - und zwar meint Wallenborn hier mit ,practice' das, was man im Deutschen mit konkreter ,Handlungspraxis' übersetzen würde - als ,die Performance bzw. das Agieren eines erweiterten/verlängerten Körpers` (vgl. Wallenborn 2013: 149). 
tion von körperlicher Aktivität/Arbeit, die einst für die Erzeugung von angenehmer Raumwärme erforderlich gewesen ist, und damit einhergehend die Übertragung von wichtigem praktischen Wissen auf technische Artefakte dazu geführt, dass sich die in Privathaushalten heizend betätigenden Akteure auch kognitiv immer weiter von ihrem mit dem Heizen verbundenen Energiekonsum distanziert haben. Zudem wird größtenteils nicht wahrgenommen oder manchmal sogar bewusst ausgeblendet, welche Konsequenzen mit der mittlerweile hochgradig technisierten künstlichen Raumheizung, -lüftung und -klimatisierung für Mensch, Umwelt und Klima verbunden sind. Insbesondere die zunehmende Entfremdung, den immer weitergehenden Kontaktverlust zur (materiellen) Realität, sehen viele Praktikentheoretiker"innen als eine der größten Herausforderungen auf dem Weg der Transformation alltäglicher Praktiken hin zu mehr Nachhaltigkeit. Denn aus praxistheoretischer Perspektive ist eine starke, intensive körperliche Beteiligung und die bewusste unmittelbare und echte Erfahrung ein sehr wichtiger Faktor, um signifikante Veränderungen im Energieverbrauchshandeln in Privathaushalten anzuregen (vgl. z.B. Wilhite 2012: 94f; Walker 2014; Wallenborn und Wilhite 2014: 61).

Die inzwischen weit vorangeschrittene Technisierung und Automatisierung des Heizens war eines der Hauptthemen in den Bewohner*innengesprächen. Wie in Kapitel 4.4 verdeutlicht wurde, beurteilen etwa die Hälfte der Passivhaus- und der Großteil der SmartHome-Bewohner*innen diesen Delegationsprozess des Heizens nicht positiv als Arbeitsentlastung und Komfortsteigerung, sondern die meisten erleben diese Veränderungen als zunehmenden Kontroll- und Einflussverlust und sehen damit gleichzeitig ihre Technikabhängigkeit kontinuierlich größer werden. Einigen Bewohner*innen bereitet diese Entwicklung sogar Sorge. Somit versinnbildlicht das Festhalten einiger Bewohner*innen am Heizkörper bzw. an manuell regelbaren Heizkörperthermostaten ihren dringenden Wunsch, weiterhin die Kontrolle über den Heizvorgang zu behalten (vgl. Teilkapitel 4.4.1).

Die Thematik, welchen Bezug die Menschen zu dem durch ihr Handeln verursachten Energieverbrauch in Zukunft haben sollen, wird in Teilkapitel 5.4 aufgegriffen, wenn es um die Diskussion der Frage nach der Verantwortung(szuschreibung) für nachhaltigen Konsum geht.

\subsection{5 ,Heterogeneous engineers ${ }^{6}$ und ,heterogeneous engineering ${ }^{6}$}

Zentrales Thema dieses Abschnitts sind die heterogenen Akteure bzw. deren vielfältige Aktivitäten, die zum Zustandekommen der technischen 
Heizlösungen beigetragen haben und die das alltägliche Heizgeschehen ausmachen. Dafür lassen sich aus dem vorherigen Abschnitt drei wichtige Erkenntnisse ableiten, die auch für den im Folgenden auszuführenden Kernpunkt von zentraler Bedeutung sind:

Erstens stellt das alltägliche Heizgeschehen in Privathaushalten einen Tätigkeitsbereich dar, der wesentlich durch das dazugehörige materielle Arrangement konstituiert ist. Zweitens lässt sich der allgemeine Entwicklungstrend hin zu einer immer weitergehenden Technisierung und Digitalisierung auch eindeutig für den Bereich des alltäglichen Heizens konstatieren. Und drittens wird diese Entwicklung von den involvierten Akteuren äußerst unterschiedlich aufgenommen und bewertet. Die beiden in dieser Arbeit untersuchten Heizansätze und Technologien sind gewissermaßen als Musterbeispiele dieses sich sehr wahrscheinlich in Zukunft noch weiter fortsetzenden Entwicklungstrends anzusehen. Hier hat die Untersuchung deutlich gezeigt, dass eine große Diskrepanz in der Bewertung moderner Heiztechnik zwischen Expert*innen und gewöhnlichen Nutzer*innen besteht (vgl. Kapitel 4.4).

Diese Erkenntnisse leiten über zu einer weiteren zentralen Forschungsfrage hinsichtlich des Wandels alltäglicher Heizpraktiken. Und zwar ist dies die Frage nach den zentralen Akteuren, die Einfluss auf die Ausgestaltung und den Ablauf des alltäglichen Heizgeschehens in Privathaushalten haben. Die Frage begleitete praktisch den gesamten Forschungsprozess und wurde an verschiedenen Stellen - manchmal direkt, manchmal auch nur unterschwellig - adressiert. Eine Beantwortung erscheint hilfreich, um besser abschätzen zu können, an welcher Stelle im Prozess alltäglicher Heizpraxis eine absichtsvolle Intervention Sinn ergibt, damit eine Reduktion des mit Heizen verbundenen Energieverbrauchs und klimaschädigender $\mathrm{CO}_{2}$-Emissionen erreicht werden kann.

Auf den ersten Blick könnte konstatiert werden, dass die größte Gestaltungsmacht bei den sich tagtäglich in Privathaushalten heizend betätigenden Personen liegt. Diese Annahme ist auch schlüssig, die Praktizierenden haben einen Spielraum, was die Ausgestaltung ihrer Heizpraktikenperformances angeht. Dieser Einfluss der Bewohner*innen sollte nicht geringgeschätzt werden. Allerdings sollten ihre Einflussmöglichkeiten auch nicht überschätzt werden. Bezieht man die oben geschilderten Entwicklungen mit ein, so wird verständlich, dass der Einfluss der Praktizierenden auf ihre alltägliche Heizpraxis in ihrem Zuhause relativ begrenzt ist. In noch stärkerem Maße trifft dies auf das praktizierte Heizen in modernen, hochtechnisierten Wohn- und Heizsettings wie dem Passivhaus und dem SmartHome zu. Verglichen mit konventionellen Wohn- und Heizkontexten wird, 
wie die Untersuchung gezeigt hat, das Heizgeschehen in Passivhäusern und SmartHomes sehr stark durch die installierte Technik konstituiert (vgl. Teilkapitel 4.4.1.2, 4.4.2.3 und 4.4.2.4). Daraus lässt sich ableiten, dass in technisch besonders fortschrittlichen Wohn- und Heizkontexten mittlerweile neben den Bewohner*innen noch weitere Akteure das alltägliche Heizgeschehen wesentlich beeinflussen.

Für den Bereich des alltäglichen Heizens sind dies an erster Stelle die mit dem (Haus-)Neubau beauftragten Architekt*innen, zu deren zentralen professionellen Aufgaben es gehört, erstens die Bauherr"innen bei ihrer Entscheidung bzw. Wahl einer geeigneten Heizlösung kompetent zu beraten und zweitens die gewünschte Heizlösung gemeinsam mit den entsprechenden Haus- bzw. Heizungstechnik-Expert“innen und Fachleuten zu planen und umzusetzen (vgl. Patow und Krienke 1972: 9).

Ein entscheidender Einfluss für das Erscheinungsbild alltäglicher Heizpraxis geht auch von den Ingenieur*innen und Hersteller*innen der jeweils zur Anwendung kommenden Heizungstechnik aus. Ihre Vorstellungen von effizienter Heizung, von den Nutzer*innen sowie deren praktischem Umgang mit der Technik im Alltag und auch ihre persönlichen Heiz-Erfahrungen - all das fließt in die Technik mit ein und bestimmt deren endgültige Ausgestaltung und Funktionsweise in entscheidendem Maße (vgl. Braun-Thürmann 2006; Rammert 2006). ${ }^{124}$

Aufgrund der besonderen Bedeutung von Materialität für alltägliches Heizen sind viel mehr Akteure als auf den ersten Blick ersichtlich an der Ausgestaltung des Heizgeschehens in Privathaushalten beteiligt. Denn heutzutage handelt es sich nicht mehr nur um einfache, einzelne zum Heizen verwendete Artefakte wie den alten Zimmerofen, sondern um äußerst komplexe Technologiegefüge - nicht umsonst ist in der Regel nur noch von Heizungsanlagen bzw. Heizsystemen die Rede. John Law (2012 [1987]) hat für die Beschreibung dieser vielfältigen Akteurskonstellationen und deren vielgestaltiges Zusammenwirken im Konstruktionsprozess von komplexen Infrastruktursystemen die - wie ich finde sehr passenden - Begriffe ,heterogeneous engineers' und ,heterogeneous engineering' geprägt. Diese Konzepte eignen sich sehr gut, um den Konstruktions- und Implementationsprozess moderner Heizungstechnik sowie die Zusammensetzung und die Performances entsprechender Heizpraktiken angemessen zu erfassen.

124 Diese Perspektiven wurden in der vorliegenden Studie nicht ermittelt bzw. direkt erfragt. Rückschlüsse auf die Perspektiven der Technik-Konstrukteur*innen wurden wenn ,nur' aufgrund der in den Untersuchungshaushalten installierten Heiztechnik gezogen. 
Um die konkreten Akteurskonstellationen im Bereich alltäglichen Heizens in Passivhäusern und SmartHomes sowie deren vielfältige ,Arbeit bzw. deren unterschiedliches Mitwirken am Beheizungsprozess angemessen zu erfassen, wurden nicht nur Bewohner*innen von Passivhäusern und SmartHomes interviewt, sondern auch mit den entsprechenden Expert"innen (bzw. mit Vertreter*innen entsprechender Expert*innengruppen) für die beiden analysierten Heizansätze gesprochen (vgl. Teilkapitel 3.5 und 3.6). Diese Kombination aus Interviews mit Technik-Anwender*innen und Technik-Expert"innen sowie im Fall der SmartHomes noch ergänzend die Teilnahme an den regelmäßigen Bauteambesprechungen zwischen den Hauptverantwortlichen aller beteiligten Projektparteien (Hauseigentümer*in/Bauherr*in, Gebäudeverwaltung, Energieversorger und Technikfirma) hat sich als äußerst fruchtbar erwiesen. Dadurch ist eine Multiperspektivität auf die beiden Untersuchungsfälle entstanden, die es ermöglichte, ein Bild von der tatsächlichen Verantwortungs-, Macht- und Einfluss- sowie der Wissens- und Kompetenzverteilung zwischen den verschiedenen, am Heizgeschehen beteiligten Akteuren gewinnen zu können (siehe hierzu auch Chappells und Shove 2005: 33).

So wurde durch dieses multiperspektivische Vorgehen sehr gut deutlich, dass - ganz klassisch - nach wie vor und auch weiterhin vor allem die Eigentumsverhältnisse entscheidend dafür sind, welche Heizlösung implementiert wird bzw. wer bei einem Wechsel des Heizungssystems oder auch im Falle einer größeren Nach- bzw. Umrüstung der Heizung darüber entscheidet, welche technische Lösung umgesetzt wird (vgl. ebd.: 35). Während bei den untersuchten Passivhausprojekten die jetzigen Bewohner*innen auch gleichzeitig die Bauherr*innen gewesen sind (in der Regel ein Zusammenschluss von Privatpersonen zu einer Baugemeinschaft) und sich diese Bewohner*innen dementsprechend bewusst für den Bau eines Passivhauses entschieden und damit über die konkrete Ausgestaltung der entsprechenden Heizlösung selbst bestimmt haben, hatten die im Fall der SmartHomes betroffenen Miethaushalte kein Mitspracherecht bei dem Implementationsprozess der intelligenten Heizungssteuerungstechnik. In ihrem Fall hat die Genossenschaft als Hauseigentümerin die Installation der smarten Heizungssteuerung beschlossen (vgl. Teilkapitel 4.1.2.1 sowie die Teilkapitel 4.4.1.3 4.4.2.2 und 4.4.2.4). Das alleinbestimmte Vorgehen der Vermieterin war möglich, weil für diese Gebäudezentralheizungsanlage die Genossenschaft als Hauseigentümerin die alleinige Verantwortung trägt. Hätte sich dagegen eine Mietpartei alleine dafür entschieden, den eigenen Heizenergieverbrauch intelligent steuern zu wollen und sich dafür beispielsweise ein SmartHome-Starterset mit smarten Heizkörperthermo- 
staten angeschafft, so müsste dafür umgekehrt nicht die vermieterseitige Einwilligung eingeholt werden, da die zentrale Heizungsanlage von dieser Veränderungsmaßnahme nicht betroffen wäre und die Mieter*innen damit auch keine größeren und/oder irreversiblen baulichen Eingriffe vornehmen würden. Das zeigt, dass vor allem auch das Ausmaß der zur Anwendung kommenden Technologie eine wichtige Rolle dafür spielt, welche Akteure am Entscheidungsprozess über eine neue Heizlösung oder über Änderungen an einer bereits bestehenden Heizform zu beteiligen sind (vgl. Teilkapitel 2.3.2.2).

\section{Divergierende Vorstellungen, Deutungen und Verstehensweisen}

Die Untersuchung hat gezeigt, dass die verschiedenen, an der alltäglichen Heizpraxis in Passivhaus- und SmartHome-Haushalten beteiligten Akteure aus ganz unterschiedlichen (Sinn-)Welten kommen. Somit haben sie zum Teil sehr unterschiedliche Perspektiven auf ein und dasselbe Phänomen; sie verstehen und legen für das Beheizen von Wohnräumen zentrale Konzepte wie Behaglichkeit oder Wärmekomfort divergierend aus und sprechen folglich auch deutlich unterschiedliche ,Sprachen'. Dass die Vorstellungen von Expert*innen und gewöhnlichen Nutzer*innen etwa davon, was ein behagliches Wohnraumklima ausmacht, weit auseinanderliegen, äußert sich beispielsweise dadurch, dass Architekt"innen und Haus-/ Heizungsplaner"innen in der Praxis immer wieder erstaunt oder enttäuscht feststellen, dass die meisten Bewohner*innen nicht gemäß DINorm EN ISO 7730 heizen und deshalb die vorher von den Planer"innen theoretisch errechneten Energieverbrauchs- und -einsparungswerte realiter nicht erreicht werden (vgl. Kapitelfazit 4.3.8). Umgekehrt machen die gewöhnlichen Nutzer"innen häufig die Erfahrung, dass die zur Beratung aufgesuchten oder zugeteilten fachlichen Expert"innen keinerlei Verständnis für die individuellen Wünsche einzelner Kund"innen aufbringen können, wie in Kapitel 4.4 dargelegt wurde. Oftmals bewerten die Expert"innen diese (Sonder-)Wünsche der Bewohner"innen sogar als unsinnig und irrational, was häufig dazu führt, dass die weitere Interaktion zwischen den Expert"innen und den Bewohner"innen wenig erfolgreich verläuft (vgl. Teilkapitel 4.4.1.3 und 4.4.2.2). Der Abstand zwischen den zwei (Sinn-)Welten von ,Behaglichkeits-Theoretiker"innen“ und ,Gemütlichkeits-Praktiker*innen' ist häufig so groß, dass eine Überbrückung dieser Diskrepanz in der Praxis oftmals nicht gelingt. 


\subsubsection{Nicht-intendierte Folgen}

An verschiedenen Stellen der Untersuchung wurde deutlich, dass sich die Entwicklung einzelner Praktiken nur begrenzt kontrollieren oder gar gezielt steuern lässt. ${ }^{125}$ Vielmehr hat absichtsvolle Intervention häufig unbeabsichtigte (Neben-)Effekte zur Folge, durch die neue oder Folgeprobleme erzeugt werden. Genauso gut ist möglich und dies passiert auch, dass bewusste Veränderung interessante unerwartete Nebenfolgen nach sich zieht. Wie in Kapitel 4.3 aufgezeigt, haben die zum Passivhauskonzept gehörende hocheffiziente Wärmedämmung und die Luftdichtheit der Gebäudehülle unter anderem dazu geführt, dass die Menschen im Inneren eines Passivhauses effektiv von jeglichen äußeren Einflüssen und der natürlichen Umgebung abgeschirmt sind - dies betrifft abgesehen von den Temperaturen (primär beabsichtigter Effekt), z.B. auch Geräusche, Düfte, Luftbewegungen, usw. Dieser Zustand wird innerhalb der Gruppe der interviewten Bewohner*innen höchst unterschiedlich bewertet: Einige Bewohner*innen bedauern und beklagen das Abgetrenntsein von natürlichen sowie sozialen Einflüssen und Geräuschen aus der Umgebung; andere Bewohner*innen erleben und beschreiben das Leben im Passivhaus dagegen als „Oase der Ruhe“ (Bewohner PH, Interview 67: 11, 567) und genießen es, kaum etwas von draußen ,mitzubekommen'.

Ergänzend zu den ausgeführten gegensätzlichen Sichtweisen der Bewohner*innen lässt sich hier anführen, dass es, laut Literatur, auch unter Expert*innen beide Sichtweisen gibt: Während die meisten Passivhaus-Expert*innen die Geräuschabschirmung sowie die effektive Abschirmung natürlicher Einflüsse positiv sehen, sie als Gewinn an Lebensqualität anpreisen und als großen (Komfort-)Vorteil loben, gibt es einige Bau- und Energie-Expert*innen, die diesen Abgrenzungseffekt negativ bewerten. Sie befürchten, dass die komplette Abschottung nach außen und der dadurch unterbundene Austausch der Menschen sowohl untereinander als auch mit der natürlichen Umwelt auf lange Sicht negative Folgen für beide Seiten, also für Mensch und Natur haben könnte - beispielsweise, dass diese künstliche Trennung auf materieller Ebene die Menschen gleichgültiger und distanzierter sowohl gegenüber ihren Mitmenschen als auch gegenüber der Natur macht (vgl. Koesling 2014). Darüber hinaus befürchten einige Energie-Expert"innen, dass den Menschen infolge der immer besseren, verfügbaren Wärmedämmung für Wohngebäude mehr und mehr das

125 Entsprechendes gilt auch für die Entwicklung von Gesellschaften als Ganzes (vgl. Schatzki 2002). 
Gefühl für die Diversität und Variabilität des natürlichen Klimas abhandenkommen könnte und dadurch auch ihre Bereitschaft sinkt, diese natürliche Klima-Diversität und -Variabilität zu akzeptieren und sich dieser auch weiterhin in gewissem Maße anzupassen, das heißt, mit den Jahreszeiten zu leben. Als ein Indiz dafür, dass diese Befürchtung bereits Realität geworden ist, könnte die in vielen westlichen Industrieländern aktuell zu beobachtende Entwicklung in Richtung immer weitergehender Standardisierung des Innenraumklimas gewertet werden (vgl. Chappells und Shove 2005). Dieser Trend zeigt, dass Expert"innen in den Planungen heutzutage überwiegend davon ausgehen, dass sich nahezu alle Menschen bei annährend gleichen Temperaturen und Raumklimaverhältnissen wohlfühlen (Stichwort: Behaglichkeitsdiagramm, vgl. Kapitel 4.3) und von ihnen die ,Ausschaltung' bzw. ,Eindämmung' der Diversität und Variabilität des natürlichen Klimas häufig einseitig als Fortschritt gesehen wird. Untersuchungen haben hingegen gezeigt, dass das Spektrum an Raumtemperaturen, bei denen sich die Menschen wohlfühlen, deutlich breiter ist als die zum Standard festgelegten und bei Planungen aktuell zugrunde gelegten einheitlichen 19-22 Grad Celsius (vgl. ebd.: 38f; vgl. auch Shove 2014: 421). Und auch die vorliegende Untersuchung hat erwiesen, dass bei einem Großteil der Bewohner*innen durchaus die Bereitschaft vorhanden ist, sich auch weiterhin den natürlichen saisonalen Temperaturschwankungen sowie den lokal unterschiedlichen Klimabedingungen bis zu einem gewissen Grad anzupassen, z.B. durch wärmere Kleidung im Winter. Wie Teilkapitel 4.3.2 verdeutlicht, bevorzugen manche Bewohner*innen bei nur mäßiger Kälte sogar die alternative Erwärmung mittels Decke oder warmer Kleidung gegenüber intensiver künstlicher Gebäudeheizung.

Darüber hinaus können auch die bereits mehrfach aufgegriffenen Beispiele von Rebound-Effekten nach Effizienzsteigerungen (vgl. Teilkapitel 4.3.4 und 4.3.5) sowie von Umnutzung (vgl. Teilkapitel 4.1.1.5) als nichtintendierte Folgen (der Einführung der Passivhaustechnologie) betrachtet werden.

\subsection{Ableitungen für politische Interventionen}

Aufbauend auf den Ergebnissen und Erkenntnissen dieser Arbeit, werden in diesem Teilkapitel einige praktische Anregungen für politische Entscheidungsträger*innen gegeben, die planen, steuernd in die alltäglichen Praktiken einzugreifen. Hinter den im Folgenden gemachten Hinweisen und Vorschlägen, steht zudem die allgemeinere Frage, wie künftige Ener- 
giepolitik von der Anwendung einer Praktiken-Perspektive profitieren könnte. Bislang ist in der Praktiken-Literatur vergleichsweise wenig zum Thema aktiver Praktiken-Governance zu finden (siehe aber Shove 2010a, 2010b, 2014; Shove et al. 2012: 146-164; Shove und Spurling 2013; Spurling et al. 2013; Evans et al. 2012; Thøgersen 2012). Dies hängt damit zusammen, dass Praktikentheoretiker*innen sozialen Wandel als einen komplexen und im Wesentlichen emergenten Prozess verstehen, über den kein einzelner Akteur die Kontrolle innehat (vgl. Shove et al. 2012: 143f). Aus praxistheoretischer Sicht stellt Wandel vielmehr ein „weitgehend ungesteuertes Produkt der Dynamik sozialer Praktiken, ihrer Verknüpfungen und Nebenfolgen" (Brand 2011: 190) dar. So wie in dieser Perspektive die gesamte Sozialwelt und die Geschehnisse in ihr als bestehend aus sozialen Praktiken sowie das Resultat ihrer ständigen Dynamiken aufgefasst werden, gilt dies selbstverständlich auch für staatliche Politik und das Handeln politischer Entscheidungsträger*innen:

"Whether they recognize it to be so or not, policy makers are by implication themselves part of the patterns, systems and social arrangements they hope to govern: they do not intervene from the outside, nor do their actions have effect in isolation." (Shove et al. 2012: 145) ${ }^{126}$

Demnach sind grundsätzlich Verlauf und Folgen absichtsvoller Intervention größtenteils als nicht plan- und steuerbar und somit als kaum voraussehbar anzusehen:

„[...] human activity cannot be controlled. The best that designers of lives and institutions can do is to create contexts that, as experience and thought show, make certain activities very more likely. Since activities are events that befall people, people themselves likewise cannot control them. People do have intimate experience of themselves and might know better than others which contexts increase the likelihood of their performing certain activities. [...]. One can never be sure how people will respond. [...]. Once practices and bundles are established, moreover, they assume lives of their own and unfold in unforseen ways.“ (Schatzki 2012: 22f)

126 Für diese Art von Politikgestaltung und des Regierens, from within` wird in der ,transition management-Forschung und -Literatur die Bezeichnung, reflexive governance' verwendet (vgl. z.B. Voß und Kemp 2005; Voß et al. 2006; hierzu kritisch Shove und Walker 2007). 
Dies ist mit Begründung dafür, weshalb Praktikentheoretiker*innen - wie bereits in Abschnitt 5.2.4 erwähnt - dem klassischen Konzept von ,agency skeptisch bis ablehnend gegenüberstehen.

Um aus Praktiken-Perspektive tatsächlich eine Sinnhaftigkeit für politische Intervention zu erkennen, ist neben einem (primär verantwortlichen, aktiv handelnden) Akteur eine Wirksamkeitserwartung für dessen Tätigwerden notwendig. Aus diesem Grund arbeiten einige Praktikentheoretiker*innen mit einer „illusion of agency“ (Rip 2006: 94), auch wenn dies eine Art ,Behelfskonstruktion“ darstellt:

„However, we are with Rip (2006) in recognizing the value, productivity, and everyday necessity of an 'illusion of agency', and of the working expectation that a difference can be made even in the face of so much evidence to the contrary. The outcomes of actions are unknowable, the system unsteerable, and the effects of deliberate intervention inherently unpredictable, and, ironically, it is this that sustains concepts of agency and management." (Shove und Walker 2007: 468f)

Die vorliegende Untersuchung liefert zahlreiche Anknüpfungspunkte, die zeigen, dass der Ansatz sozialer Praktiken nicht nur geeignet ist, Alltagsgeschehen sozialwissenschaftlich fundiert zu analysieren, sondern gegebenenfalls auch, um politische Interventionen zielführend zu gestalten. Oder wie Rip es ausdrückt: „illusions are productive because they motivate action and repair work, and thus something (whatever) is achieved" (Rip 2006 : 94; vgl. heirzu - auf die konkrete Handlungspraxis bezogen - auch Hacke 2009b: 10).

Im Folgenden werden beispielhaft fünf Handlungsempfehlungen ausgeführt, die sich aus dieser Untersuchung ableiten lassen.

\subsubsection{Komplexität berücksichtigen}

Politik sollte in jedem Falle die Komplexität des alltäglichen Geschehens beachten. So wird etwa alleiniger Technologiewechsel immer auch die anderen Praktikenelemente verändern; ebenso kann sich Technologiewandel auf andere benachbarte oder angekoppelte Praktiken auswirken und diese verändern. Darüber hinaus beeinflussen und modifizieren rein technologische Veränderungen stets auch die Verbindungen und Verknüpfungen zwischen den einzelnen Elementen sowohl innerhalb einzelner Praktiken als auch zwischen unterschiedlichen Praktiken. 
Am konkreten Beispiel wurde diese interne Komplexität und die darüberhinausgehende Komplexität des Heizens als ,compound practice' dargelegt. Will man profunde Veränderungen erreichen, so empfiehlt es sich, statt nur an einem oder zwei Elementen isoliert, an multiplen Elementen gleichzeitig zu intervenieren (vgl. Spurling et al. 2013: 51; vgl. hierzu auch Hacke 2009b: 11). Weiter sollte bedacht werden, dass jegliches politische Eingreifen nicht nur direkte Auswirkungen auf die fokussierte Alltagspraktik (und deren Elemente) hat, sondern auch Effekte auf weitere, nicht unmittelbar adressierte, angrenzende Praktiken haben kann.

\subsubsection{Richtiges Timing und Gelegenheitsfenster schaffen}

Will Politik in alltägliche Abläufe lenkend eingreifen, obwohl keine gravierende Zäsur zu erkennen ist, so ist auf das richtige Timing ihrer Interventionsmaßnahmen zu achten. Dafür gilt es, die lokal-spezifische Geschichte einzubeziehen und zu ermitteln, ob aus der Vergangenheit eventuell noch relevante Elemente vorhanden sind, an welche sich für eine nachhaltige Gestaltung von Alltagspraktiken heute wieder anknüpfen lässt.

Auf Haushaltsebene bedeutet das richtige Timing etwa die Nutzung, vor allem aber die aktive Schaffung von Gelegenheitsfenstern und günstigen Zeitpunkten, so genannter "teachable moments" (vgl. Schäfer und Bamberg 2008; Schäfer et al. 2012; Dilk und Littger 2014: 21; Thøgersen 2012). Bezogen auf das Beispiel des Heizens ließe sich durch strengere nationale Gesetze und Restriktionen, was z.B. den Energieverbrauch und/oder $\mathrm{CO}_{2-}$ Emissionsausstoß von Gebäudeheizungssystemen anbelangt, sowie durch gezielte staatliche Subventionen für den Wechsel zu und die Verwendung von energie- und emissionsarmen Heizungen, auf Ebene der Privathaushalte sicher ein rascheres Umsteuern auf deutlich nachhaltigere Heizformen forcieren. Politik sollte gezielt neue Pfade aufzeigen und aktiv schaffen. Bezogen auf das Heizen hieße dies beispielsweise, dass sie die Erforschung innovativer energiearmer Heizansätze sowie den Ausbau der (öffentlichen) Infrastrukturen für aussichtsreiche alternative Heizformen veranlasst und parallel den Rückbau energieintensiver Infrastrukturen anordnet.

Richtlinien können Handlungsdruck erzeugen und verknüpft mit der Gestaltung nachhaltigkeitsfördernder Rahmenbedingungen und Anreizstrukturen können Gelegenheitsfenster aktiv geschaffen werden, die Konsument*innen wahr- und annehmen können. 


\subsubsection{Die Bedeutung der Bedeutungen-Komponente}

Politik sollte nicht alleine auf Technik setzen, sondern Intervention unbedingt auch in anderen Praktikenelementen verankern, denn "governments have [also] a hand in reproducing versions of normal and acceptable ways of life" (Shove et al. 2012: 157). Wie diese Arbeit gezeigt hat, ist die Bedeutungen-Komponente äußerst wirkmächtig und entscheidend dafür, ob es weiterhin ,nur' zu Reproduktion oder tatsächlich zu grundlegender Transformation der gegenwärtigen Heizpraxis in Privathaushalten kommt. Bisher wurde die Sinndimension von Praktiken (im Vergleich zu Technik und Wissen) allerdings - auch im hier dargelegten Beispiel - am wenigsten beachtet und bei Interventionsvorhaben nicht systematisch einbezogen. Hier könnte Politik ansetzen, indem sie damit beginnt, von nun an so etwas wie ,cultural engineering' zu betreiben (vgl. Assadourian 2010). Gemeint ist, dass Politik den mutigen Versuch unternehmen könnte, gezielt in zentrale kulturelle Normvorstellungen verändernd einzugreifen, um auch mittels einer neuen Sinnfundierung sowie Zielausrichtung nachhaltige Konsummuster auf kollektiver Ebene zu etablieren. Z. B. könnte Politik systematisch (neue) positive Leitbilder für suffiziente Alltagspraktiken verbreiten und nachhaltige Lebensstile in Imagekampagnen als attraktiv darstellen und mit steuerlichen Vorteilen stützen (vgl. Monkhouse und Dibb 2011: 8, 26-30). Ein gesamtgesellschaftlicher Paradigmenwechsel stellt vermutlich den wohl wirkmächtigsten Ansatzpunkt dar, um grundlegenden (System-)Wandel zu forcieren (vgl. Meadows 1999: 17). Suffiziente Lebensstile würden dadurch immer attraktiver. Mit der Zeit würde das heute noch Neue (und daher noch Unübliche), normal' werden. Auf das Heizen heruntergebrochen würden das Energiesparen, die Verwendung nachwachsender, umweltverträglicher Energiequellen sowie die weitgehende Vermeidung gesundheits-, umwelt- und klimaschädlicher Folgen dann oberste Priorität erlangen und nachhaltige Heizformen könnten sich mittelfristig durchsetzen.

\subsubsection{Allianzen aufbauen}

Regierungen kommt eine wichtige Rolle zu, wenn es darum geht, Netzwerke und Allianzen aufzubauen, die häufig die geeigneten Rahmenbedingungen für eine bestimmte neuartige Praxis in einem Bereich wie dem 
Heizen erst erschaffen. ${ }^{127}$ Bei diesen Kooperationsprozessen sollte Politik als dirigierender Akteur in Erscheinung treten, indem sie die verschiedenen relevanten Akteure und Interessengruppen/Parteien zusammenbringt und eine Plattform für deren Austausch bietet bzw. schafft. Gleichzeitig sollte Politik sich nicht als den anderen involvierten Akteuren überlegen, sondern vielmehr als eine teilnehmende Partei begreifen, in dem konzertierten strategisch-aktiven Bemühen, „to reconfigure the character and the distribution of the elements of which more sustainable practices could be made, and in seeking to break the ties that hold other less sustainable arrangements in place" (Shove et al. 2012: 161, Hervorh. im Original). Aus dieser Sicht besteht effektive Politikgestaltung darin, Prozesse von Selektion und Variation anzuleiten und zu begleiten, sich an neu entwickelnde Praktikenkomplexe anzupassen, sowie all diese Prozesse permanent reflexiv zu beobachten und zu begleiten.

\subsubsection{Als Vorbild agieren}

Nicht zuletzt kann und sollte Politik selbst stets mit gutem Beispiel vorangehen $^{128}$ : In eigenen Gebäuden und im staatlich geförderten Wohnungsbau sollte auf energiesparende und klimaschonende Heizlösungen gesetzt werden. Zum einen verfolgt der Staat ein vitales Eigeninteresse damit, dass

127 Für den Gegenstandsbereich des alltäglichen Energiekonsums zu Heizzwecken in Privathaushalten sind neben den politischen Rahmensetzungen insbesondere die Aktivitäten der für dieses Thema relevanten Akteure aus der Energie- und Wohnungswirtschaft entscheidend. Demnach könnten Bündnisse und Gemeinschaftsaktionen von Energieversorgungsunternehmen, Vermieter*innen- und Mieter*innenverbänden sowie der entsprechenden politischen Ebenen bzw. Akteure einen wesentlichen Beitrag zur Veränderung der Energiekonsumpraxis in privaten Haushalten leisten (vgl. Hacke 2009b: 25). Das im Rahmen dieser Arbeit wissenschaftlich begleitete Pilotprojekt zum smarten Heizen stellt den Versuch solch eines Bündnisses dar: Hier haben ein großes Energieversorgungsunternehmen, eine Wohnungsbaugenossenschaft als Vermietungsgesellschaft und eine Technikfirma aus dem Bereich Gebäudeautomation kooperiert, mit dem gemeinsamen Ziel, den (Heiz-)Energieverbrauch in ausgewählten Miethaushalten effektiv zu senken. Die politische Ebene war in Gestalt der verantwortlichen städtischen Behörde ebenfalls involviert; sie hat sich bemüht, das Projekt öffentlichkeitswirksam bekannt zu machen und hat es mit finanziellen Mitteln unterstützt.

$128 \mathrm{Zu}$ diesem Ergebnis kommen auch andere sozialwissenschaftliche Studien zur Nutzung verschiedener SmartHome-Technologien (vgl. z.B. Balta-Ozkan et al. 2013: 372). 
die Heizkosten im Sozialwohnungsbereich möglichst geringgehalten werden, da die Warmmiete in diesem Bereich für die betreffenden Haushalte eine staatliche Transferleistung darstellt. Zum anderen erfüllt der soziale Wohnungsbau(-sektor) aus staatlicher Sicht eine wichtige (Wegbereiter-)Funktion für den Klimaschutz: konsequentes und ambitioniertes energiesparendes Bauen, Sanieren und Modernisieren im gemeinnützigen Wohnungsbaubereich trägt entscheidend dazu bei, dass Deutschland seine im Rahmen der weltweit diskutierten Klimaschutz-Strategie zugesagten nationalen Energieeinsparziele erreichen kann. Darüber hinaus stellt der Bereich des öffentlichen Wohnungsbaus eine gute Möglichkeit dar, eine breite Öffentlichkeit auf die Themen ,Klimaschutz im Gebäudebereich und ,alternative Heizformen' aufmerksam zu machen, indem sie für alle Schichten zugänglich werden.

Diese Liste mit Vorschlägen, wie (aussichtsreiche und wirkungsvolle) politische Intervention aussehen könnte, erhebt keinen Anspruch auf Vollständigkeit. Vielmehr wurde die Absicht verfolgt, anhand einiger beispielhafter Maßnahmen aufzuzeigen, welche Formen von Intervention aus einer praxistheoretischen Perspektive gegenwärtig sinnvoll und vielversprechend erscheinen.

\subsection{Praktiken - die Transzendierung von Verantwortung}

Wie bereits erwähnt, sind die beiden in dieser Arbeit untersuchten Heizansätze im Grunde genommen nicht zu vergleichen, da es sich um sehr unterschiedliche Herangehensweisen zur Veränderung des Heizgeschehens in Privathaushalten handelt. Und durch die Untersuchung hat sich bestätigt, dass der Ansatz des passiven Heizens und das smarte Heizen deutlich unterschiedliche Anforderungen haben und dass sich beide bei unterschiedlichen Herausforderungen eignen. Dementsprechend haben sie sehr unterschiedliche Effekte auf das allgemeine Wohngefühl und Wärme(komfort-)erleben sowie auf den Energieverbrauch und den damit einhergehenden $\mathrm{CO}_{2}$-Ausstoß. Allerdings gibt es einen für das Heizen sehr zentralen Aspekt, für den eine vergleichende Betrachtung der beiden Heizansätze lohnenswert erscheint, macht er doch deutlich, für welche Richtungen die beiden Technik-Ansätze stehen. Und zwar geht es um die Frage, wie Energiekonsum(handeln) in Privathaushalten grundsätzlich verstanden und konzipiert wird. Hier hat die Analyse nämlich erbracht, dass dem Heizen im Passivhaus und dem Heizen im SmartHome deutlich divergierende Konzepte zugrunde liegen, die sich sehr gut anhand des Begriffspaares pas- 
siv - aktiv bzw. anhand der namensgebenden Bezeichnungen „passiv“ und „smart“" kontrastierend aufzeigen lassen.

Im Folgenden wird dafür noch einmal kurz auf die unterschiedlichen Funktionsweisen und die damit verbundenen Zielsetzungen der Heizungstechnologien eingegangen. Sie werden einander gegenübergestellt, um deutlich zu machen, dass die Namensgebung für die beiden Heiztechniken augenscheinlich passend erfolgt ist.

\section{Passiv versus smart}

Während der Ansatz des passiven Heizens gewissermaßen den in den letzten Jahrzehnten dominanten Trend im Heizen weiter fortsetzt, nämlich, dass moderne Technik den Menschen möglichst viele der mit Raumbeheizung verbundenen Aktivitäten abnimmt und die dafür erforderlichen technischen Operationen weitgehend im Verborgenen oder im Hintergrund ablaufen (sollen), wird mit dem Ansatz des smarten Heizens die nahezu gegenteilige Idee verfolgt. Die smarte Heizungssteuerungstechnologie zielt darauf ab, den Energiekonsum für Raumheizung für die Menschen nicht nur wieder deutlich sichtbar zu machen und damit wieder ins Bewusstsein zu rücken, sondern sie soll die Nutzer*innen gleichzeitig dazu anregen, ihren Energiekonsum zu Heizzwecken selbst aktiv zu managen.

Das heißt, mit dem Ansatz der Passivhaustechnologie verbindet sich zentral der Gedanke, dass der Energiekonsum für Raumheizung auch zukünftig unbemerkt stattfinden kann. Energieflüsse und -verbräuche dürfen in dieser Logik ,unsichtbar' und damit für die Menschen in ihrem Alltag nebensächlich bleiben. Mit der grundsätzlichen Entscheidung für ein Passivhaus wird der Energieverbrauch automatisch so weit verringert, dass sich die Nutzer*innen praktisch keine Gedanken mehr um ihren heizungsbedingten Energieverbrauch machen müssen. ${ }^{129}$ Dadurch wird die gesamte Energieverbrauchsthematik von der tatsächlichen Heiztätigkeit weitgehend abgekoppelt.

Aufgrund der geringen Gesamtheizkosten in Passivhäusern erfolgt in Passivmehrfamilienhäusern in der Regel keine individuelle verbrauchsabhängige Abrechnung von Heizkosten mehr; stattdessen werden die Kosten für Heizwärme gleichmäßig auf alle Wohnungen umgelegt (vgl. Rasch

129 In den meisten Fällen kann in Passivhäusern der verbleibende äußerst geringe Restwärmebedarf größtenteils oder sogar vollständig über erneuerbare Energiequellen abgedeckt werden (vgl. Feist et al. 2005: 1188). 
2009: 8). Daher handelt es sich beim Ansatz des passiven Heizens somit um einen ,solidarischen' Heizansatz.

Im Kontrast dazu geht es beim Ansatz des smarten Heizens darum, dass die Nutzer*innen durch Verwendung smarter Heizungssteuerungstechnik ihren individuellen Heizenergieverbrauch permanent visualisiert und nahezu in Echtzeit in Form von verbrauchten Kilowattstunden sowie durch Anzeige der entsprechend dafür anfallenden Kosten genau gespiegelt bekommen. Dadurch soll das Thema Energie(konsum) wieder ins Bewusstsein gebracht werden. Durch die smarte Technik sind die Menschen aufgefordert, ihren (Heiz-)Energieverbrauch aktiv und überlegt zu organisieren. Allerdings muss dies im Umkehrschluss nicht bedeuten, dass der Energiekonsum dabei auch effektiv gesenkt wird. Durch Visualisierung vermittelt die smarte Technik dem bzw. der Nutzer*in zwar einen guten Eindruck über den eigenen (Heiz-)Energieverbrauch. Aber die Auswertung und Bewertung der visualisierten Verbräuche sowie die Beantwortung der Frage, ob und wenn ja, welche Konsequenzen aus den angezeigten Verbrauchszahlen für das alltägliche Konsumverhalten resultieren, werden ebenfalls vollständig in den individuellen Verantwortungsbereich der Verbraucher*innen verschoben. Beim smarten Heizen handelt es sich also um einen individualisierenden Ansatz, der stark auf den bzw. die einzelne*n Konsument*in und dessen bzw. deren individuelles Energieverbrauchshandeln ausgerichtet ist. Hinzu kommt, je mehr individuelle Heiz-Daten die Nutzer*innen in das der Heizungssteuerungstechnik zugrundeliegende Computerprogramm eingeben, desto schneller und effektiver erkennt und ,(er-)lernt' der Algorithmus die Heizroutinen seiner Nutzer*innen. Dadurch ist die smarte Heizungssteuerung letztendlich binnen kurzer Zeit imstande, den Nutzer*innen ihre routinemäßigen Wohnraumheizaktivitäten abzunehmen. Gleichzeitig bleibt die Konstruktion von aktiv eingebundenen Nutzer*innen bestehen, da die ,smarte' Technik wesentlich auf der kontinuierlichen Einbindung von Nutzer*innenverhalten und neuen Nutzer*innendaten basiert. Diese Eigenschaft ist es letztendlich auch, für die die Technik vor allem die Bezeichnung, smart` erhalten hat.

Meist erfolgt eine erste (vorläufige) Bewertung des Heizansatzes auf Basis der namentlichen Bezeichnung, smart', vor allem wenn die Technik den Nutzer*innen noch relativ unbekannt ist. Bei mangelnder Kenntnis schließen die Menschen dann offenbar von den Bezeichnungen intuitiv auf die Funktionsweise und Zielsetzung der jeweiligen Heiztechnik. Dieser Zusammenhang konnte auch im Rahmen der vorliegenden Untersuchung festgestellt werden: So ist das Passivhaus wegen seines Namens bzw. vorrangig wegen der Vorsilbe ,passiv ${ }^{`}$ eher negativ besetzt und die breite 
Öffentlichkeit, gewöhnliche Nutzer*innen begegnen dem Passivhaus(ansatz) anfangs häufig verhalten bis skeptisch (vgl. Teilkapitel 4.5.1.6). Im Gegensatz dazu ruft die Bezeichnung, smart sowie deren im Deutschen hauptsächlich verwendete Übersetzung, intelligent ' bei potenziellen Anwender"innen anscheinend deutlich positivere Assoziationen hervor. Im Unterschied zum Passivhaus wird der smarte Heizansatz abstrakt eher mit positiven Bildern in Zusammenhang gebracht. Es entsteht der Eindruck, dass die Menschen mit der Bezeichnung ,smart die Vorstellung verbinden, den Heizvorgang aktiv kontrollieren zu können. Und aktiv Handelnde" $r$ zu sein sowie die Kontrolle zu haben, erscheint attraktiver als passiv beheizt zu werden.

Hierbei handelt es sich um eine interessante Erkenntnis, gibt sie doch einen Hinweis darauf, wie wirkmächtig Sprache für die alltägliche Wahrnehmung und die erste Einordnung von neuen Phänomenen ist. Zudem macht der beschriebene Zusammenhang deutlich, dass wir Menschen größtenteils in (Sinn-)Bildern denken oder ,in Metaphern leben', wie Lakoff und Johnson es ausdrücken (Lakoff und Johnson 2004).

Die Bedeutung von Bildern und Metaphern sowie ihre emotionale Aufladung durch vergangene Erfahrungen könnte in Zukunft noch umfassender genutzt werden, indem die Konsument*innen bei ihren alltäglichen Konsumentscheidungen mithilfe von "choice editing"130 (Sustainable Consumption Roundtable (SCR) 2006; Maniates 2010a) und „social mar-

130 Mit ,choice editing ist das Prinzip der Konsument*innensteuerung (durch Bearbeitung der Auswahlmöglichkeiten) umschrieben. Es geht bei ,choice editing also um das, was sinngemäß als ,gelenkte Wahl' bezeichnet werden kann. Der Sustainable Consumption Roundtable (SCR) - eine gemeinsame Initiative des britischen National Consumer Council (NCC) und der Sustainable Development Commission (SDC) der britischen Regierung - definiert "choice editing " als „shifting the field of choice for mainstream consumers: cutting out unnecessarily damaging products and getting real sustainable choices on the shelves" (Sustainable Consumption Roundtable (SCR) 2006: 2). Der Begriff hat vor allem im Rahmen der Nachhaltigkeitsdebatte verstärkt an Bedeutung gewonnen. Im Prozess des ,choice editing' werden die Wahlmöglichkeiten der Konsument*innen bewusst kontrolliert bzw. limitiert, etwa durch Verbote, Verteuerungen, Steuern oder Zölle. Dies geschieht immer mit dem Ziel, durch diese Beeinflussung bei den Konsument*innen bestimmte gewünschte Entscheidungen zu bewirken. Maniates schreibt hierzu: „Choice editors remove environmentally offensive products from commercial consideration [...]. Or they make such products expensive to use [...]. But like any good editor, choice editors cannot just chop. They must offer options, at the very least [...] a sufficiently compelling illusion of choice" (Maniates 2010a: 119f). 
keting"131 (Sachs und Finkelpearl 2010) verstärkt in Richtung Nachhaltigkeit gelenkt werden (vgl. Ölander und Thøgersen 2014).

\section{Verantwortlichkeit für nachbaltigen Konsum?}

In Zusammenhang mit rigiden staatlichen Eingriffen in Konsumoptionen werden immer wieder kritische Stimmen laut, die vor einer, Öko-Diktatur ${ }^{6}$ warnen. Und es steht die ethische Frage im Raum: Darf der bzw. die Konsument"in von dem Kauf bestimmter Produkte aufgrund deren umweltschädlicher oder anderer gesellschaftlicher unerwünschter Eigenschaften aktiv abgehalten werden, ist es tatsächlich legitim ihm bzw. ihr solche Produkte z.T. einfach vorzuenthalten? Und wenn ja, wer entscheidet dann über die Produkte, die zum Kauf angeboten werden oder nicht? Sollte nicht vielmehr dem bzw. der Verbraucher*in das Recht auf freie Auswahl vorbehalten sein? (Maniates 2010b).

Wenn man letzteres mit ja beantwortet, würde das bedeuten, dass man die (Haupt-)Zuständigkeit für nachhaltigen Konsum bei den privaten Kon-

131 Unter ,social marketing' werden Werbungs- und Vermarktungsstrategien verstanden, die darauf abzielen, einen gesellschaftlichen Bewusstseinswandel herbeizuführen und gesellschaftlich relevante Werte, Einstellungen sowie Verhaltensweisen absichtsvoll zu beeinflussen. Im Gabler Wirtschaftslexikon findet sich folgende Begriffsdefinition: „Gebrauch von Marketingtechniken mit dem Ziel, eine Zielgruppe dahingehend zu beeinflussen, dass diese freiwillig ein Verhalten akzeptiert, ablehnt, verändert oder aufgibt. Dies geschieht zum eigenen Wohl, zum Wohl für bestimmte Personengruppen oder zum Wohl der Gesellschaft als Ganzes“ (Helmig und Kirchgeorg 2018*). Im Gegensatz zum Konsumgütermarketing werden beim ,social marketing' keine materiellen Produkte angeboten, sondern (gesundheitsbezogene, umweltschonende bzw. nachhaltige) Verhaltensweisen angepriesen (z.B. Nichtrauchen, verminderter Fleischkonsum, Energiesparen, Bahnreisen). Das Konzept des, social marketing' beinhaltet im Wesentlichen den Kerngedanken, durch das Erzählen attraktiver Geschichten über nachhaltige Praktiken und das Verbreiten positiver, fiktiver Zukunftsvisionen einen gesellschaftlichen Bewusstseinswandel und die dafür notwendigen Verhaltensänderungen (in Richtung mehr Nachhaltigkeit) bei einer bestimmten Zielgruppe zu bewirken. Laut Sachs und Finkelpearl stehen "social marketers" damit vorrangig vor folgender Herausforderung: „to play a role in the transition from consumerism to sustainability, they will need to draw on the main lesson learned by consumer marketing in the 1950s: facts alone do not sell behavior change. Instead, people working to foster sustainable behavior must use storytelling to reach audiences on a human, personal scale. As social marketers craft a strategy for this critical next decade, understanding and harnessing the power of emotional storytelling may be their most important task" (Sachs und Finkelpearl 2010: 152). 
sument*innen sieht - damit bürdet man ihnen letztendlich wiederum die vorrangige Verantwortung auf, mit ihren Konsumentscheidungen die notwendigen gesellschaftlichen Veränderungen zu bewirken. Und tatsächlich taucht in der öffentlichen Diskussion um den Klimawandel dieses Kommunikationsmuster immer wieder auf: „die Moralisierung des umweltrelevanten Handelns der Individuen, verbunden mit der Aufforderung, dieses in ökologischer Absicht zu ändern (so jüngst Leggewie/Welzer 2009)“ (Grunwald 2010: 231).

Es besteht mittlerweile gesellschaftlicher Konsens, dass eine nachhaltigere Gesellschaft auch eines nachhaltigeren Konsums bedarf. Die Frage allerdings, wie die große Transformation herbeigeführt werden könnte und sollte - ob etwa der Staat in zentralen Nachhaltigkeitsbelangen noch stärker limitierend eingreifen oder ob man eher mittels Appellen und Information für einen umweltverträglicheren Konsum werben sollte -, scheint weiterhin ein großes Streitthema zu sein (vgl. Grunwald 2013: 7; Ölander und Thøgersen 2014).

$\mathrm{Zu}$ beobachten ist, dass Konsument*innen „seit einigen Jahren verstärkt mit der Erwartung konfrontiert [werden], aktiv und von sich aus ihr Konsumverhalten umzustellen" (Grunwald 2013: 9, Hervorh. im Original). Vertreter"innen dieser Haltung leiten ihre Position von dem Verursacherprinzip ab, nach dem diejenige Person, die durch ihr Verhalten oder Vorgehen Schäden bzw. Kosten verursacht, diese auch zu beseitigen bzw. zu tragen hat. Mit diesem Standpunkt verbindet sich die Hoffnung, „dass die ganze Wirtschaftsweise auf Nachhaltigkeit und Umweltverträglichkeit umgepolt werden könnte, wenn alle nachhaltig konsumieren würden und die Wirtschaft auf diese Weise dazu zwingen würden, nachhaltige Produkte und Dienstleistungen anzubieten“ (ebd.: 7).

An dieser Position wird kritisiert, dass die Konsument*innen damit systematisch überfordert werden. Zum einen wird grundlegend in Frage gestellt, ob die gewünschte Umsteuerung angesichts der Komplexität von Nachhaltigkeitsbewertungen, Wissensdefiziten, Mobilisierungsproblemen, bekannten Rebound-Effekten usw. überhaupt über einen (vermeintlich) nachhaltigeren Konsum auf individueller Ebene zu bewerkstelligen ist Grunwald spricht hier von „funktionaler Überforderung“ (ebd.: 9) der Konsument"innen (vgl. ebd.: 10-13). Zum anderen wird die aus dem Verursacherprinzip abgeleitete Schlussfolgerung der (ausschließlichen bzw. überwiegenden) Verantwortung der Konsument"innen für aus ihrem Konsumhandeln resultierende Umweltprobleme stark in Zweifel gezogen Grunwald beschreibt dies als „attributive Überforderung“ (ebd.: 13) der Konsument*innen (vgl. ebd.: 13-15). Die vollständige Verantwortungszu- 
schreibung nach kausalen Zurechnungen verstärke das, was als einer der am stärksten hinderlichen politischen Mythen zu bezeichnen ist: den Mythos vom bzw. von der souveränen Konsument*in (Princen zitiert nach Maniates 2010a: 125). Allerdings lässt die Vorstellung, dass die Verursacher*innen respektive Konsument*innen in ihren Handlungs- und Wahlmöglichkeiten völlig frei sind, so die zentrale Kritik, die ganz realen Rahmenbedingungen, inmitten derer Konsumhandeln stattfindet, außer Acht (vgl. Grunwald 2013: 14). Zudem werde dadurch der Einfluss sowie die Verantwortung des Staates und der Wirtschaft auf bzw. für Umfang und Struktur der den Verbraucher*innen zur Verfügung stehenden Optionen geleugnet (Maniates 2010a: 125).

In Abgrenzung zu obiger Position des Verursacherprinzips gibt es noch einen anderen, alternativen Vorschlag zur Verantwortungszuschreibung, der schlüssiger erscheint. Hierbei wird vorrangig an die Verantwortung angeknüpft, die jeder einzelne Mensch in seiner Rolle als Bürger*in für eine nachhaltigkeitsförderliche Ausgestaltung der allgemein verbindlichen Rahmenbedingungen für den Konsum trägt (vgl. Grunwald 2013: 15). Dadurch werden die Individuen keineswegs aus ihrer subjektiven Verantwortung als Konsument"innen entlassen, aber durch ihre vorrangige Adressierung als verantwortliche Bürger*innen wird ihre Konsument*innenverantwortung gleichsam stark relativiert:

„Das bedeutet, das Verursacherprinzip zwar ernst zu nehmen, aber die Einseitigkeit einer Attribution von Verantwortung ohne Ansehung der politisch gestaltbaren Rahmenbedingungen des Konsums zu überwinden. Sicher tragen die Konsumenten einen Teil der Verantwortung und können wohl auch durch bewussten Konsum hier und da etwas ändern. Aber es gibt eben auch einen anderen Teil der Verantwortung, und dieser liegt nicht im privaten Bereich, sondern in den öffentlichen Aspekten des Konsums.“ (ebd., Hervorh. im Original)

Denn in einem demokratischen System sind die Rahmenbedingungen für Konsum Gegenstand der öffentlichen Debatte und bedürfen der demokratischen Legitimierung. Und diesen für alle gleichermaßen verbindlichen politischen Rahmen für den Konsum gelte es, als engagierte Bürger*innen eines Gemeinwesens aktiv mitzugestalten. Demnach verteilt sich die Verantwortung, die jeder als individueller Mensch für den Konsum trägt, auf diese zwei unterschiedlichen Rollen.

„Die Sichtbarmachung der, politischen' Seite der Verantwortung für den Konsum [...] ist von daher zentral, weil die Umorientierung in Richtung Nachhaltigkeit zum Bereich der Polis, zu den öffentlich zu 
behandelnden Angelegenheiten gehört und eben nicht eine Sache ist, die individuellem Handeln überlassen werden sollte." (ebd.: 15)

Damit schließt sich der Kreis zum anfangs kurz erwähnten Prinzip des ,choice editing'. Der ,choice editing'-Ansatz und das Konzept der Konsument"innenverantwortung nach dem Verursacherprinzip stellen somit keine absoluten oder echten Gegensätze dar. Vielmehr gehören die beiden Herangehensweisen untrennbar zusammen und können sich sinnvoll ergänzen (vgl. Bossy 2014: 194f).

Die Wirksamkeit von Rahmenbedingungen und ihre Verschränkung mit individuellen Konsumentscheidungen zeigt sich im Untersuchungsfall des Heizens beispielsweise durch die seit 2017 gültige verpflichtende Energieverbrauchskennzeichnung für Heizungsanlagen. Diese besagt, dass der Energieverbrauch der Heizungsanlage mittels eines Effizienzlabels an der Anlage deutlich sichtbar gemacht werden muss. Während moderne Heizungsanlagen mit Elektro-Wärmepumpe, Holz, Solar- oder Geothermie dabei die Effizienzklassen A+ und A++ erzielen, erreichen fossil befeuerte Heizkessel nur die Klassen A bis G. Das Energielabel soll zur Unterstützung bei der Kaufentscheidung dienen. Zudem ist geplant, dass im Jahr 2019 eine zusätzliche Effizienzklasse A+++ hinzukommt und die Klassen E bis $G$ gleichzeitig wegfallen. Hauseigentümer*innen sollen dadurch zum Austausch ihrer Heizungsanlage motiviert werden (vgl. Umweltbundesamt (UBA) 2018a").

Das Problem ist jedoch nicht die Einflussnahme des Staates auf das den Verbraucher*innen zur Verfügung stehende Auswahlspektrum an sich dabei handelt es sich, wie dargelegt, um nichts Neues. Und auch die Instrumente und Wege, derer sich der Staat dafür bevorzugt bedient, wie etwa Festlegung von Standards, Preise, Steuern und Subventionen, sowie Entscheidungen über Infrastrukturprojekte und unterschiedliche Fördermaßnahmen, sind weder besonders heikel noch neuartig. Allerdings war staatliche Lenkungspolitik die letzten Jahrzehnte überwiegend auf Grundlage einer Wachstumsorientierung ausgerichtet, das heißt, es ging um die ständige Ausweitung von Konsum:

„Consumerism [...] is a cultural paradigm where 'the possession and use of an increasing number and variety of goods and services is the principal cultural aspiration and the surest perceived route to personal happiness, social status and national success'." (Ekins 1991: 245, zitiert nach Assadourian 2010: 187)

Ein zentraler Bestandteil dieser Strategie, die praktisch in der gesamten westlichen Welt seit dem Ende des Zweiten Weltkriegs bis annähernd in 
die Gegenwart konsequent verfolgt wurde, war, energieintensive, ressourcenverbrauchende Massenkonsumoptionen als selbstverständlich und unvermeidbar, eben als normal erscheinen zu lassen (vgl. Maniates 2010a: 121).

Und auch heute werden noch häufig die ungesunden, nicht nachhaltigen oder sogar gesundheits- und umweltschädlichen Konsumoptionen öffentlich stark beworben, ohne dass der Staat hier eingreift: Beispielsweise werden stark gesüßte und stark verarbeitete Speisen und Getränke positiv beworben; und meistens sind diese Produkte auch deutlich günstiger als gesündere Alternativen, obwohl man mittlerweile weiß, dass sehr zuckerhaltige und verarbeitete Nahrungsmittel wesentlich zur epidemischen Verbreitung von Übergewicht und Krankheiten wie Diabetes beitragen. Oder blickt man auf den Bereich Mobilität: Immer noch ist Fliegen oftmals deutlich günstiger als die gleiche Strecke mit der Bahn zu reisen. Auch hier hat die Politik bisher kaum im Sinne der Nachhaltigkeit interveniert. Im Gegenteil, bisher fördert und subventioniert der deutsche Staat das Fliegen (gegenüber dem Bahnreisen) sogar noch: So erhebt er beispielsweise auf Auslandsflüge keine Mehrwertsteuer, rechnet sie jedoch bei Bahntickets und an Tankstellen ab. Auch gibt es bislang keine Kerosinsteuer, eine Mineralölsteuer für Autos aber schon. Darüber hinaus werden manche Flughäfen, von denen man erwartet, dass sie Wirtschafswachstum, Arbeitsplätze, Tourismus und Messegäste begünstigen, vom Staat bezuschusst und/oder teilweise von Flughafengebühren befreit (Ahr et al. 2018: 14). Und dies alles, obwohl bekannt ist, dass es sich beim Fliegen um eine sehr klimaschädliche Aktivität handelt. ${ }^{132}$

Wenn das Ziel tatsächlich ,nachhaltiger Konsum' lautet, erscheint es geboten, dass der Staat zukünftig stärker durch Setzung entsprechender Rahmen darauf hinwirkt. Mindestens aber ,verlangt [...] die Umstellung auf nachhaltigere Konsummuster [...] ein ähnliches Maß an Engagement und Raffinesse seitens des Staates und der Wirtschaft" (Maniates 2010b*: 3), wie sie es bisher bei der Förderung des (kulturellen) Massenkonsum(paradigma)s demonstriert haben.

132 Eine deutliche Mahnung, dass es mit dem Flugverkehr und der Praxis des Fliegens in derzeitiger Form in Deutschland so nicht weitergehen kann und die Gesellschaft sich hier in gänzlich andere Richtung bewegen bzw. dass im Bereich Verkehr deutlich umgesteuert werden muss, sprach zuletzt der Mobilitätsforscher Andreas Knie aus. Im Interview mit der Zeit (vom 9. August 2018) forderte Knie den Staat auf, das Fliegen entschieden zu limitieren (vgl. Pinzler 2018). „Seine radikale Forderung lautet: ,Das Fliegen innerhalb Deutschlands muss verboten werden!““ (Ahr et al. 2018). 
Gleichzeitig kommt den Verbraucher*innen selbstverständlich weiterhin eine bedeutende Verantwortung zu, da sie mit ihren Kaufentscheidungen immer auch für oder gegen Nachhaltigkeit votieren (können) (Maniates 2010a: 123; Bossy 2014). Setzt man allerdings hauptsächlich oder entscheidend auf ein verändertes Kaufverhalten, so wird die Transformation nicht zeitnah und umfassend gelingen.

Für ein effektives Umsteuern wird aber auch (zusätzliches) klassisches ,choice editing' nicht ausreichen, da Konsumsteuerung meist darauf abzielt, die Verbraucher*innen zum Kauf umweltfreundlicherer Produkte und Dienstleistungen zu animieren.

Vielmehr sollte es neben dem ,anders konsumieren' verstärkt auch um ,weniger Konsum', also Konsumverzicht gehen. Wenn lediglich , anders konsumiert' wird, kann und wird es aller Voraussicht nach immer wieder zu „Rebound-“ oder sogar „Backfire-Effekten“133 kommen, wie es für das Thema Heizen in dieser Arbeit beispielhaft gezeigt wurde (vgl. auch Hens et al. 2010). Und auch für andere Konsumbereiche wird in diesem Zusammenhang auf mögliche Rebound- und Backfire-Effekte hingewiesen (vgl. z.B. Brännlund et al. 2007; Druckman et al. 2011; Murray 2013).

Der wirkliche Verzicht auf Energiekonsum als effektive Nachhaltigkeitsstrategie wird in Fachkreisen bereits seit vielen Jahren u.a. unter dem Stichwort ,Negawatt' diskutiert. Der Begriff ,Negawatt ${ }^{\star}$ ist eine Wortschöpfung des US-amerikanischen Physikers und Umweltaktivisten Amory Lovins. ${ }^{134}$,Negawatt ${ }^{6}$ bedeutet eingesparte bzw. nicht erzeugte Energie und stellt Lovins zufolge - neben der unbedingt notwendigen kompletten Umstellung auf erneuerbare Energien -, die effektivste Strategie zur Umsteuerung auf ein nachhaltiges Energiesystem und somit auf eine nachhaltige gesamtgesellschaftliche Entwicklung dar (vgl. z.B. Lovins 1978 [1977], 1990, 1996; Weizsäcker et al. 1997; Hawken et al. 2000; sowie über den ,Nega-Watt-Guru' Lovins und seine Gesellschaftsvision, siehe Widmann

133 Für eine Erklärung von Rebound-als auch Backfire-Effekten siehe Fußnote 90.

134 Amory Lovins (*13. November 1947) ist Mitbegründer und (aktuell) wissenschaftlicher Leiter des Rocky Mountain Institute (RMI). Er war mehrere Jahrzehnte in der Energiepolitik und in ähnlichen Bereichen in den USA tätig. Lovins ist Autor zahlreicher Bücher, die sich alle mit einer effizienteren Nutzung von Energie im Privatbereich und in der Industrie beschäftigen. $\mathrm{Zu}$ seinen bekanntesten Veröffentlichungen zählen „Factor Four. Doubling Wealth, Halving Resource Use" (1997) (zusammen mit seiner damaligen Frau L. Hunter Lovins und Ernst Ulrich von Weizsäcker), „Natural Capitalism. The Next Industrial Revolution" (2000) (zusammen mit Paul Hawken und L. Hunter Lovins) und „Soft Energy Paths. Towards A Durable Peace“ (1977). 
1995). Bislang wurde dieses Thema jedoch nicht in nennenswertem Maße politisch rezipiert.

Die zentrale Frage müsste aus einer Perspektive zu forcierender Nachhaltigkeit daher lauten: „Wie kann der [allgemeine] Kontext, innerhalb dessen die Mehrheit der Menschen alltägliche Konsumentscheidungen trifft, so verändert werden, dass er einen Konsumverzicht unterstützt?" (Maniates 2010b*: 6; vgl. auch Dilk und Littger 2014: 18).

Diese Transformation stellt eine große Herausforderung dar:

„Shifting cultural systems is a long process measured in decades, not years. Even consumerism, with sophisticated technological advances and many devoted resources, took centuries to become dominant. However, as the spread of consumerism also demonstrates, leading cultural institutions can be harnessed by specific actors and can play a central role in redirecting cultural norms." (Assadourian 2010: 189, Hervorh. $\mathrm{JM})$

\section{Beyond responsibility - oder wie kann aus einer praktikenzentrierten Sicht nachbaltiger Konsum gelingen?}

Aber selbst wenn man mit, verteilter Verantwortung ${ }^{6}$ argumentiert und stärker auf ,Nicht-Konsum' fokussiert, so würde man dennoch den gängigen und weit verbreiteten Argumentationslogiken verhaftet bleiben. Nach wie vor hätte man sich nicht von der (dualistischen) Auffassung gelöst, dass für einen nachhaltigeren Konsum entweder vorrangig bei den Auswahloptionen oder bei den Individuen und deren Konsumverhalten anzusetzen ist. In der ersten Logik sind die Konsument*innen vor allem in ihrer Rolle als Bürger*innen, das heißt als aktiv beteiligte ,Architekt*innen' eines Gemeinwesens angesprochen. Die zweite Herangehensweise entspricht der Position, die Konsument"innen vor allem als (ökonomisch oder psychologisch) rational motivierte, autonome Entscheider*innen zu betrachten. Beiden Ansätzen ist gemein, dass sie von einem linearen $\mathrm{Zu}-$ sammenhang bzw. einer klaren Ursache-Wirkung-Korrelation ausgehen. Demzufolge wird angenommen, dass eine gezielte (politische) Intervention(smaßnahme) in der Regel zu gewünschtem Ergebnis führt.

Davon abgesehen, dass die Praxis solch einen linearen Zusammenhang ständig widerlegt, ist aus einer praktikenzentrierten Perspektive dagegen einzuwenden, dass nicht-intendierte Folgen und Rebound-Effekte damit nicht ausreichend Berücksichtigung finden. Diese spielen allerdings gerade im Bereich alltäglichen (Energie-)Konsums eine herausragende Rolle, wie 
an mehreren Stellen in dieser Arbeit aufgezeigt wurde (vgl. z.B. Teilkapitel 4.3.1, 4.3.3 und 4.3.4).

Wenn man aber Praktiken zentral setzt und von hier aus (neu) denkt und über gesellschaftlichen Energiekonsum und die Herausforderungen des Klimawandels reflektiert, so ergeben sich zum einen ganz andere denkbar mögliche und sinnvolle Ansatzpunkte für Interventionen. Zum anderen ergibt sich eine andere, aber deutlich realistischere Sichtweise auf Einflussmöglichkeiten in Praktiken als komplexe Gefüge. Nicht zuletzt müsste aus einer praktikenzentrierten Perspektive schon anders gefragt werden bzw. es wären bereits ganz andere Fragen zu stellen, wenn es darum geht, herauszufinden, wie die gesellschaftliche Transformation hin $\mathrm{zu}$ mehr Nachhaltigkeit gelingen kann (vgl. Shove 2010a, 2010b). Dies sei an einem Beispiel zum Untersuchungsfall verdeutlicht: Statt danach zu fragen, wie die Wünsche und Bedürfnisse der Menschen (z.B. 23 Grad Celsius Raumtemperatur während der Winterzeit/Heizperiode) mit einem geringeren Ressourceneinsatz erfüllt werden können, erscheint es aus praktikentheoretischer Sicht eher interessant und relevant zu fragen, wo diese Bedürfnisse, Wünsche, Ansprüche und Erwartungshaltungen eigentlich herrühren, die von vielen Menschen westlicher Gesellschaften geteilt werden. Wie ist es dazu gekommen, dass sich gesellschaftliche Konventionen, wie beispielsweise die Wohnräume während der Heizperiode auf durchschnittlich 22 Grad Celsius zu erwärmen, als normal etabliert haben? Und was führt dazu, dass viele Menschen weiterhin ein energieintensives und umweltschädliches Heizen im Winter praktizieren?

Mir ist wichtig, an dieser Stelle noch einmal herauszustreichen, dass sich für die vorliegende Untersuchung an einer "'strong' interpretation of practice theory“ (Shove 2014: 415) orientiert wurde. In dieser Version wird tatsächlich konsequent und streng von den Praktiken her gedacht und argumentiert. Anders als diejenigen ,Praktikentheoretiker*innen', „who talk of practices as a means of talking about materialised, situated moments of performance“ (ebd.: 418), wird bei einer strengen Auslegung des Ansatzes sozialer Praktiken vorrangig auf die Entwicklung sowie raumzeitliche Verteilung von ,practices-as-entities' fokussiert (vgl. Teilkapitel 2.3.2). Dieser Unterschied in der Auslegung und Anwendung des Praktiken-Ansatzes ist äußerst wichtig, da nur die Fokussierung auf ,practices-as-entities ${ }^{6}$ impliziert, dass es um größere Transformationsprozesse geht - um solche, die sich tatsächlich in stabiler Weise auf gesamtgesellschaftlicher Ebene manifestieren. Damit unterscheidet sich diese strengere und vielleicht etwas ,anspruchsvollere' Lesart (vgl. Shove 2010a: 1279) auch deutlich von jenen Auslegungen, bei denen (die), Theorien sozialer Praktiken' lediglich zur 
Erlangung eines besseren Verständnisses des Konsum(ent*innen)verhaltens herangezogen werden (Shove 2014: 419).

Bei einer praktikenzentrierten Betrachtung von (Energie-)Konsum geht es im Kern also darum, „the trajectories and careers of variously resource intensive practices (as entities)“ (ebd.) zu verstehen. Es geht zudem darum, wie in dieser Arbeit sowohl theoretisch als auch empirisch umfassend umgesetzt, die Elemente zu identifizieren, aus denen solche Praktiken zusammengesetzt sind (vgl. Teilkapitel 2.2.1), ihre Geschichte nachzuvollziehen (vgl. Teilkapitel 2.2.4.1), da Elemente selbst wiederum (nur) Resultate vergangener Praktiken darstellen. Und genauso gilt es, Näheres über die entscheidenden Prozesse der Rekrutierung von Teilnehmer*innen und des Lossagens bzw. Abwerbens von Träger*innen in Erfahrung zu bringen (vgl. Kapitel 4.5). In einer Frage zusammengefasst: „how are people drawn into more or less sustainable practices and how do their lives and careers sustain the lives and careers of the practices they reproduce?" (Shove 2014: 419).

Darüber hinaus ist mir wichtig, zu betonen, dass auch in dieser Sicht einer strengen Auslegung des Praktiken-Ansatzes davon ausgegangen wird, dass politische Entscheidungsträger*innen Einflussmöglichkeiten haben und ihnen Mittel und Wege zur Verfügung stehen, um effektiv in Praktiken zu intervenieren. Zum Beispiel können sie die unterschiedlichen Praktikenelemente gestalten und verändern, die Beziehungen zwischen Praktiken neu ausrichten und/oder ordnen sowie die zentralen Institutionen und Systeme und die mit ihnen assoziierten Modelle normaler und akzeptierter Lebensstandards umgestalten (ebd.: 425). Dabei sollten sie sich stets darüber bewusst sein, dass sich die tatsächlichen Konsequenzen ihres Eingreifens (vorher) nicht vollständig absehen lassen, da Praktiken(gefüge) komplexe Gebilde darstellen, die zudem eine spezifische Eigendynamik aufweisen. Das hat letztlich häufig zur Folge, dass sie sich eher zufällig und ungeplant wandeln als sich durch absichtsvolle, gezielte Intervention in gewünschte Richtung verändern zu lassen (vgl. ebd.: 427).

Um auf die Eingangsfrage dieses Teilkapitels zurückzukommen: Anstatt danach zu fragen, bei wem die vorrangige Verantwortung für nachhaltigen Konsum liegt, geht es aus einer auf Praktiken (als Einheiten) fokussierten Perspektive vielmehr darum, herauszufinden und zu verstehen, welche als selbstverständlich erachteten alltäglichen Routinen, Konventionen und Erwartungen, welche Normalitätsstandards und damit verbundenen komplexen sozio-technischen Versorgungs- und Infrastruktursysteme bislang dafür gesorgt haben, dass eher nicht-nachhaltige Konsummuster performt werden. Diese Normalitätskonzepte und die entsprechendnen Institutio- 
nen und Strukturen, auf denen das Alltagsleben aufbaut sowie ihre Konstruktion und alltägliche Reproduktion gilt es aus einer auf Praktiken orientierten Perspektive sichtbar zu machen, infrage zu stellen und gegebenenfalls zu verändern.

Eine praktikenzentrierte Herangehensweise ermöglicht eine deutlich differenziertere Betrachtung und ein komplexeres Verständis alltäglicher (Konsum-)Praxis als die bisher vorwiegend zur Erforschung alltäglichen Konsums angewandten sozialwissenschaftlichen Theorieansätze (vgl. Kapitel 1.4). Indem sie auf monokausale Verantwortungszuschreibungen verzichtet, bietet diese alternative Herangehensweise vermutlich auch eine bessere Grundlage zur Ermittlung geeigneter Ansatzpunkte für Interventionen und ermöglicht dadurch letztendlich ein effektiveres Intervenieren.

Was also braucht es, damit nachhaltige Lebensweisen erstarken und künftig führend werden? Welches sind die notwendigen Voraussetzungen und begünstigenden Bedingungen dafür, dass weniger energieintensive und kohlenstoffärmere Lebensweisen fortan (noch stärker) prosperieren und sich dauerhaft und endgültig gegenüber deutlich weniger nachhaltigen Lebensweisen durchsetzen (können)? Wie also sind die ko-evolvierenden sozio-technischen Regime bzw. Rahmenbedingungen zu gestalten und gegebenenfalls zu verändern, dass die Umweltbelastung alltäglichen Praktizierens und normaler Lebensführung (vor allem der Menschen westlicher Industrienationen) deutlich geringer ausfällt als bislang?

Die Anliegen und Themen bezüglich der Herausforderung eines nachhaltigen Konsums sind im Prinzip also ähnlich; ein praktikenorientiertes Vorgehen impliziert jedoch eine radikale Änderung des Herangehens an derartige Fragestellungen.

Für den Gegenstandsbereich des alltäglichen Heizens in Privathaushalten konnten in dieser Arbeit bereits einige Antworten auf diese entscheidenden Fragen gegeben werden.

\subsection{Bedarf und Potenzial für weitere Forschung}

Die vorliegende Studie hat erkennbar wertvolle Erkenntnisse über den Forschungsgegenstand, das alltägliche Heizen in Privathaushalten, hervorgebracht. Es konnte aufgezeigt werden, wie der Konsum von Energie (zu Heizzwecken) durch die Einbettung in die komplexe Praxis alltäglichen Heizens bedingt ist. Zugleich bin ich im Laufe des Forschungsprozesses auf zahlreiche weitere interessante Themen aufmerksam geworden und haben sich neue oder anschließende Ideen und Fragen ergeben, für die ich 
weiteren Forschungsbedarf sehe oder die mir für eine weitere Erforschung (als) lohnenswert erscheinen. Eine kleine Auswahl dieser Themen und Ideen möchte ich im Folgenden kurz skizzieren.

1. Die Auswirkungen der Anwendung neuer Heiztechnik auf zwischenmenschliche, innerfamiliäre Beziehungen - In den konkreten Gesprächssituationen mit Bewohner*innen und bei der späteren Analyse des Datenmaterials ist mir immer wieder aufgefallen, dass die Integration neuer Technik in alltägliche Heizpraktiken auch zu vielfältigen Dynamiken in den Sozialbeziehungen der betroffenen Bewohner*innen führt. So erübrigten sich im Passivhaus typische Konflikte, etwa um ausreichendes Lüften oder das Geschlossenhalten von Zimmertüren und Fenstern während der Heizperiode, oftmals von selbst. Und im SmartHome zeigte sich, dass einige Bewohner*innen, die vor der Installation der Heizungssteuerung von dem unkontrollierten Heizen ihrer Nachbarn in angrenzenden Wohnungen passiv profitiert haben, nun deutlich mehr selbst aktiv heizen müssen, da die Heizung ihrer Nachbarn aufgrund der neuen Technik nur noch angeschaltet ist, wenn diese auch tatsächlich zuhause sind. Die vielfältigen zwischenmenschlichen Beziehungsdynamiken und -konstellationen, die sich offenbar auch aus der Anwendung neuer Heiztechnik ergeben (können), wären näher zu untersuchen.

2. Genderspezifische Betrachtung häuslichen Energiekonsums zu HeizzweckenDarüber hinaus stelle ich mir auch eine gendersensible Perspektive auf heizungsbedingten Energiekonsum als interessant und aufschlussreich vor. Da sich das Wärme- und Behaglichkeitsempfinden von Männern und Frauen bekanntlich signifikant unterscheidet, hat dies somit aller Voraussicht nach auch einen Effekt auf das alltägliche Heizverhalten und den dadurch bedingten Energiekonsum.

3. Praxistheoretische Analyse weiterer energieintensiver Alltagstätigkeiten Wie diese Arbeit verdeutlicht hat, passten Theorie und das gewählte Forschungsthema ausgezeichnet zusammen. Die Mikroperspektive auf Heiztätigkeiten in Privathaushalten war enorm ergiebig und sollte unbedingt auf noch weitere Handlungsbereiche und Alltagsphänomene angewendet werden. Für einige Gegenstandsbereiche und typische Alltagsaktivitäten wurde dies, eine praxistheoretisch angeleitete Detailanalyse gegenstandsbasierter sozio-technischer Kopplungen, bereits geleistet, z.B. für das Duschen (Hand et al. 2005), das Wäschewaschen (Shove 2004c) oder die zunehmende Nutzung von Klimaanlagen sowohl in Privathaushalten als auch in öffentlichen Gebäuden (Healy 2008; Parkhurst und Parnaby 2008; Hitchings 2011). Für viele ressourcenin- 
tensive Aktivitäten steht solch eine detaillierte Analyse noch aus (z.B. (Flug-)Reisen, Plastikverbrauch, Beleuchtung, intensivierter Gebrauch moderner Informations- und Kommunikationstechnologien). Auch beziehen sich viele der oben genannten Studien auf den anglo-amerikanischen Raum. Wie diese Untersuchung jedoch verdeutlicht hat, spielt der spezifische soziokulturelle und regional-lokale Kontext für die Ausgestaltung von Praktiken eine zentrale Rolle. Annahmen und Erkenntnisse lassen sich demnach nicht so ohne Weiteres auf andere Länderkontexte übertragen. Deshalb wären für europäische und andere Länderkontexte auch noch einmal eigene Analysen der oben genannten Gegenstandsbereiche durchzuführen.

4. Kombination quantitativer und qualitativer Methoden - In dieser Untersuchung wurde ein qualitativer Ansatz verwendet, der es ermöglichte, das Handlungsfeld des alltäglichen Heizens in Privathaushalten besonders umfassend zu ergründen. Sicher wäre es spannend, z.B. in einem weiteren Forschungsprojekt zum Energieverbrauch zu Heizzwecken, die Daten aus qualitativen Interviews und teilnehmender Beobachtung mit tatsächlich gemessenen Verbrauchszahlen zu kombinieren. Die tatsächlichen Energie- und $\mathrm{CO}_{2}$-Einsparungen wären den versprochenen bzw. erwarteten Einsparungen gegenüberzustellen. Auf diese Weise ließe sich eine valide Gesamtbilanz für den Energie- und $\mathrm{CO}_{2}$-Output erstellen und auf dieser Grundlage könnte ein geeigneter Ansatz oder eine geeignete Kombination aus verschiedenen Ansätzen entwickelt werden, um den tatsächlichen Energieverbrauch zu Heizzwecken nachhaltig zu senken. Durch qualitative Interviews wäre es möglich, die genaueren Hintergründe für effektive Einsparungen zu ergründen, das heißt, inhaltlich zu eruieren, welche Maßnahmen und Aktivitäten sich (aus Sicht der Praktizierenden) letztendlich als besonders wirkungsvoll erwiesen haben und worauf sie als Hauptbetroffene von derartigen Interventionen besonders Wert legen.

5. Impulse für die Theorieentwicklung - Im Hinblick auf die Theorieentwicklung halte ich es für notwendig, dass die in dieser Arbeit angewandte Praktikentypologie sowie die Konzepte, um unterschiedliche (auch eher komplexe) Formen von Praktikenwandel zu beschreiben und zu erfassen, weiter ausgearbeitet werden. Meines Erachtens ist das Thema ,Wandel von Praktiken' bislang noch zu wenig theoretisiert. Mit seinem Konzept der ,compound practice‘ für komplexe, umfassendere Praktiken hat Warde $(2013,2016)$ einen nützlichen Anfang gemacht, an den sich gut anknüpfen lässt. Und auch Schatzkis Aufzählung von „loci and forms that change can take“ (Schatzki 2013: 44) ent- 
hält vielversprechende Anregungen und Ideen, die allerdings noch ausgearbeitet werden müssen, damit die gegebenenfalls auch praktische Anwendbarkeit gegeben ist. Mit dieser Arbeit wurde mit der näheren Erforschung und theoretischen Einordnung von Praktikenwandlungsprozessen begonnen, indem - wie sich in der Untersuchung bestätigt hat - mit den ausgewählten Fallbeispielen zwei unterschiedliche Wandlungsmodi infolge absichtsvoller Intervention detailliert analysiert werden konnten. Hierbei wurde deutlich, dass einer der zentralen Drehund Angelpunkte für Interventionen und entscheidende Veränderungen in alltäglichen Praktiken die Verbindungen zwischen Praktiken bzw. die Koevolution von Praktiken und sozio-materiellen Ordnungen sind. Hier fände ich beispielsweise interessant (noch weiter) zu untersuchen, wie durch bestimmte Interventionen (z.B. Automatisierungstechnologien) neue Praktikenbündel bzw. -hybride entstehen oder bereits bestehende Praktikenbündel in noch komplexere Arrangements transformiert werden (können). Oder umgekehrt: die Untersuchung, wie sich bereits bestehende mehr oder weniger fest verknüpfte Praktikenkomplexe durch gezieltes Eingreifen (wiederum) diversifizieren (lassen) und wie sich all diese Praktiken-Metamorphosen auf das Alltagsleben bzw. das alltägliche ,doing' auswirken.

6. Verbreitung der praxistheoretischen Perspektive sowie verstärkte und engere Zusammenarbeit mit anderen Forschungsdisziplinen - Diese Studie hat die Relevanz und den Nutzen (einer spezifischen sozialwissenschaftlichen Herangehensweise, respektive) des Praktiken-Ansatzes für absichtsvolle politische Intervention aufgezeigt. Ich könnte mir vorstellen, dass es mit steigender Anzahl unterschiedlicher praktikenzentrierter Fallstudien immer attraktiver wird, in Zukunft deutlich häufiger, wenn nicht gar regelmäßig, eine praktikenzentrierte Betrachtungs- und Vorgehensweise in (Prozesse der) Politikplanung und -gestaltung zu integrieren. Darüber hinaus stelle ich mir vor, dass das ,Denken in sozialen Praktiken' auch für Forscher*innen anderer Disziplinen (wie z.B. der Umweltökonomie, der Umweltphysik oder der Umweltphilosophie), die ebenfalls stark mit Konsum- und Nachhaltigkeitsthemen befasst sind, Anregungen und Ideen für ihre diesbezüglichen Forschungen geben könnte. Und die auf diesem Wege zustande kommenden, also in unterschiedlichen Forschungskontexten und aus verschiedenen disziplinären Sichtweisen generierten, aber eben alle auf Praktiken konzentrierten Analysen und detaillierten Fallstudien würden sicherlich auch erfahrenen Praktikentheoretiker*innen neue Einblicke und Erkenntnisse in die Gestalt, Logik, Struktur sowie Dynamik sozialer Praktiken liefern 
(können). Dies gilt insbesondere für komplexe Forschungsthemen wie Klimawandel, die zunehmende Erschöpfung natürlicher Ressourcen, soziale Ungleichheit und (Armuts-)Migration.

Diese Fragestellungen lassen sich letztendlich nur durch empirische Forschung beantworten. Insbesondere qualitative Forschung kann hierzu einen bedeutenden Beitrag leisten und es ist zu erwarten, dass sie zu all diesen Themen und Fragen wertvolle Einblicke und Ansätze liefern wird.

Maßnahmen(vorschläge) zur Energieeinsparung und beabsichtigte Interventionen in Praktiken sollten immer auf einer derart detailreichen Analyse fundiert sein, wie sie in dieser Arbeit für den Gegenstandsbereich des alltäglichen Heizens in Privathaushalten geleistet wurde. 


\section{Literaturverzeichnis}

Abrahamse, Wokje; Steg, Linda; Vlek, Charles; Rothengatter, Talib (2005): A review of intervention studies aimed at household energy conservation. In: Journal of Environmental Psychology 25, S. 273-291.

Achtnicht, Martin (2011): Do environmental benefits matter? Evidence from a choice experiment among houseowners in Germany. In: Ecological Economics 70 (11), S. 2191-2200.

Aderhold, Jens (2005): Gesellschaftsentwicklung am Tropf technischer Neuerungen? In: Jens Aderhold und René John (Hg.): Innovation. Sozialwissenschaftliche Perspektiven. Konstanz: UVK Verlagsgesellschaft mbH, S. 13-32.

Adolf, Jörg; Bräuninger, Michael (2012): Energiewende im Wohnungssektor - Fakten, Trends und Realisierungsmöglichkeiten. In: Wirtschaftsdienst 92 (3), S. $185-$ 192. DOI: $10.1007 / \mathrm{s} 10273-012-1360-9$.

AGEB (2016): Anwendungsbilanzen für die Endenergiesektoren in Deutschland in den Jahren 2013 bis 2015. Studie beauftragt vom Bundesministerium für Wirtschaft und Energie. Hg. v. Arbeitsgemeinschaft Energiebilanzen e.V. (AGEB). Berlin.

AGEB (2017): Auswertungstabellen zur Energiebilanz Deutschland 1990 bis 2016. Unter Mitarbeit von DIW Berlin und Energy Environment Forecast Analysis (EEFA). Hg. v. Arbeitsgemeinschaft Energiebilanzen e.V. (AGEB).

Ahr, Nadine; Asendorpf, Dirk; Pinzler, Petra (2018): Die Hölle am Himmel. Dossier Titelthema. In: Die Zeit 73, 09.08.2018 (33), S. 13-14.

Andreasen, Alan R. (1995): Marketing Social Change: Changing Behaviour to Promote Health, Social Development and the Environment. San Francisco: JosseyBass.

Annunziata, Eleonora; Frey, Marco; Rizzi, Francesco (2013): Towards nearly zeroenergy buildings: The state-of-art of national regulations in Europe. In: Energy 57, S. 125-133. DOI: 10.1016/j.energy.2012.11.049.

Arnold, Anika; David, Martin; Hanke, Gerolf; Sonnberger, Marco (2015): Einleitung. In: Anika Arnold, Martin David, Gerolf Hanke und Marco Sonnberger (Hg.): Innovation - Exnovation: Über Prozesse des Abschaffens und Erneuerns in der Nachhaltigkeitstransformation. Marburg: Metropolis-Verlag (Ökologie und Wirtschaftsforschung), S. 7-11.

Assadourian, Erik (2010): Transforming Cultures: From Consumerism to Sustainability. In: Journal of Macromarketing 30 (2), S. 186-191.

Atteslander, Peter (2010): Methoden der empirischen Sozialforschung. 13., neu bearbeitete und erweiterte Auflage. Berlin: Erich Schmidt Verlag (ESV basics).

Balkowski, Jan (2006): Die „optimale“ Beheizung eines Passivhauses (Teil II). In: Holzbau (4), S. 43-46. 
Balta-Ozkan, Nazmiye; Davidson, Rosemary; Bicket, Martha; Whitmarsh, Lorraine (2013): Social barriers to the adoption of smart homes. In: Energy Policy 63, S. 363-374. DOI: 10.1016/j.enpol.2013.08.043.

Barnett, Homer G. (1953): Innovation: The Basis of Cultural Change. New York [u.a.]: Mc Graw-Hill Book Company.

Barr, Stewart (2006): Environmental Action in the Home: Investigating the 'ValueAction' Gap. In: Geography 91 (1), S. 43-54.

Barr, Stewart; Gilg, Andrew W.; Ford, Nicholas (2005): The household energy gap: examining the divide between habitual- and purchase-related conservation behaviours. In: Energy Policy 33 (11), S. 1425-1444.

Bauman, Zygmunt (2000): Vom Nutzen der Soziologie. Aus dem Englischen von Christian Rochow. 1. Aufl., Dt. Erstausg. Frankfurt am Main: Suhrkamp (Edition Suhrkamp, 984).

BDEW (2015): Wie heizt Deutschland? BDEW-Studie zum Heizungsmarkt. Hg. v. Bundesverband der Energie- und Wasserwirtschaft e. V. (BDEW). Bonn.

Bean, Robert; Olesen, Bjarne W.; Kim, Kwang Woo (2010): Part 2: History of Radiant Heating \& Cooling Systems. In: ASHRAE Journal, S. 50-54.

Berker, Thomas (2008): Energienutzung im Heim als sozio-technische Praxis. In: Corinna Fischer (Hg.): Strom sparen im Haushalt. Trends, Einsparpotenziale und neue Instrumente für eine nachhaltige Energiewirtschaft. 1. Aufl. München: oekom verlag, S. 175-192.

Black, J. Stanley; Stern, Paul C.; Elworth, Julie T. (1985): Personal and contextual influences on househould energy adaptations. In: Journal of Applied Psychology 70 (1), S. 3-21.

Blake, James (1999): Overcoming the 'value-action gap' in environmental policy: tensions between national policy and local experience. In: Local Environment: The International Journal of Justice and Sustainability 4 (3), S. 257-278.

Blazejczak, Jürgen; Edler, Dietmar; Schill, Wolf-Peter (2014): Steigerung der Energieeffizienz: Ein Muss für die Energiewende, ein Wachstumsimpuls für die Wirtschaft. In: DIW-Wochenbericht 81 (4), S. 47-60. Online verfügbar unter https://www.econstor.eu/bitstream/10419/91605/1/777077590.pdf.

BMU (2018): Klimaschutz in Zahlen. Fakten, Trends und Impulse deutscher Klimapolitik. Ausgabe 2018. Hg. v. Bundesministerium für Umwelt, Naturschutz und nukleare Sicherheit (BMU). Frankfurt am Main. Online verfügbar unter https:/www.bmu.de/publikation/klimaschutz-in-zahlen-2018/, zuletzt geprüft am 01.08.2018.

Bohnsack, Ralf (1989): Generation, Milieu und Geschlecht. Ergebnisse aus Gruppendiskussionen mit Jugendlichen. Zugl.: Erlangen-Nürnberg, Univ., Habil.Schr. Opladen: Leske + Budrich (Biographie und Gesellschaft, 8).

Bohnsack, Ralf (1998): Rekonstruktive Sozialforschung und der Grundbegriff des Orientierungsmusters. In: Dirk Siefkes, Peter Eulenhöfer, Heike Stach und Klaus Städtler (Hg.): Sozialgeschichte der Informatik. Kulturelle Praktiken und Orientierungen. Wiesbaden: DUV Dt. Univ.-Verl. (DUV Sozialwissenschaft), S. 105-121. 
Bohnsack, Ralf (2001): Dokumentarische Methode. Theorie und Praxis wissenssoziologischer Interpretation. In: Theo Hug (Hg.): Einführung in die Methodologie der Sozial- und Kulturwissenschaften, Bd. 3. 4 Bände. Baltmannsweiler: Schneider-Verlag, Hohengehren (Wie kommt Wissenschaft zu Wissen?, 3), S. 326-345.

Bohnsack, Ralf (2011a): Fokussierungsmetapher. In: Ralf Bohnsack, Winfried Marotzki und Michael Meuser (Hg.): Hauptbegriffe qualitativer Sozialforschung. 3. Aufl. Opladen [u.a.]: Barbara Budrich (UTB), S. 67-68.

Bohnsack, Ralf (2011b): Praxeologische Wissenssoziologie. In: Ralf Bohnsack, Winfried Marotzki und Michael Meuser (Hg.): Hauptbegriffe qualitativer Sozialforschung. 3. Aufl. Opladen [u.a.]: Barbara Budrich (UTB), S. 137-138.

Bohnsack, Ralf (2013): Typenbildung, Generalisierung und komparative Analyse: Grundprinzipien der dokumentarischen Methode. In: Ralf Bohnsack, Iris Nentwig-Gesemann und Arnd-Michael Nohl (Hg.): Die dokumentarische Methode und ihre Forschungspraxis. Grundlagen qualitativer Sozialforschung. 3., erw. und aktualisierte Aufl. Wiesbaden: VS, Verl. für Sozialwiss, S. 241-270.

Bohnsack, Ralf (2014): Rekonstruktive Sozialforschung: Einführung in qualitative Methoden. 9., überarbeitete und erweiterte Auflage. Opladen [u.a.]: Barbara Budrich.

Bohnsack, Ralf; Loos, Peter; Schäffer, Burkhard; Städtler, Klaus; Wild, Bodo (1995): Die Suche nach Gemeinsamkeit und die Gewalt der Gruppe: Hooligans, Musikgruppen und andere Jugendcliquen. Opladen: Leske + Budrich.

Bohnsack, Ralf; Nentwig-Gesemann, Iris; Nohl, Arnd-Michael (2013): Einleitung: Die dokumentarische Methode und ihre Forschungspraxis. In: Ralf Bohnsack, Iris Nentwig-Gesemann und Arnd-Michael Nohl (Hg.): Die dokumentarische Methode und ihre Forschungspraxis. Grundlagen qualitativer Sozialforschung. 3., erw. und aktualisierte Aufl. Wiesbaden: VS, Verl. für Sozialwiss, S. 7-32.

Bongaerts, Gregor (2007): Soziale Praxis und Verhalten - Überlegungen zum Practice Turn in Social Theory. In: Zeitschrift für Soziologie 36 (4), S. 246-260.

Bordass, Bill; Cohen, Robert; Standeven, Mark; Leaman, Adrian (2001): Assessing building performance in use 3: energy performance of the Probe buildings. In: Building Research \& Information 29 (2), S. 114-128. DOI: 10.1080/0961321001000 8036.

Bossy, Sophie (2014): The utopias of political consumerism: The search of alternatives to mass consumption. In: Journal of Consumer Culture 14 (2), S. 179-198. DOI: $10.1177 / 1469540514526238$.

Bourdieu, Pierre (1976): Entwurf einer Theorie der Praxis auf der ethnologischen Grundlage der kabylischen Gesellschaft. Aus dem Französischen von Cordula Pialoux und Bernd Schwibs. 1. Aufl. Frankfurt am Main: Suhrkamp.

Bourdieu, Pierre (1977): Outline of a Theory of Practice. Cambridge: Cambridge Univ. Press.

Bourdieu, Pierre (1982): Die feinen Unterschiede. Kritik der gesellschaftlichen Urteilskraft. Übersetzt von Bernd Schwibs und Achim Russer. 1. Aufl. Frankfurt am Main: Suhrkamp (Suhrkamp-Taschenbuch Wissenschaft). 


\section{Literaturverzeichnis}

Bourdieu, Pierre (1984): Distinction: A Social Critique of the Judgement of Taste. London: Routledge.

Bourdieu, Pierre (1990): The Logic of Practice. Cambridge: Polity Press.

Bourdieu, Pierre (1993): Sozialer Sinn. Kritik der theoretischen Vernunft. Übersetzt von Günter Seib. 1. Aufl. Frankfurt am Main: Suhrkamp (Suhrkamp-Taschenbuch Wissenschaft, 1066).

Brager, G. S.; Dear, R. J. de (2003): Historical and Cultural Influences on Comfort Expectations. In: Raymond J. Cole und Richard Lorch (Hg.): Buildings, Culture and Environment: Informing Local and Global Practices.

Brand, Karl-Werner (2011): Umweltsoziologie und der praxistheoretische Zugang. In: Matthias Groß (Hg.): Handbuch Umweltsoziologie. Wiesbaden: Verlag für Sozialwissenschaften, S. 173-198.

Brand, Ralf (2005): Synchronizing Science and Technology with Human Behaviour. London [u.a.]: Earthscan.

Brandon, Gwendolyn; Lewis, Alan (1999): Reducing Household Energy Consumption: A Qualitative And Quantitative Field Study. In: Journal of Environmental Psychology 19, S. 75-85.

Brännlund, Runar; Ghalwash, Tarek; Nordström, Jonas (2007): Increased energy efficiency and the rebound effect: Effects on consumption and emissions. In: Energy Economics 29 (1), S. 1-17. DOI: 10.1016/j.eneco.2005.09.003.

Braun-Thürmann, Holger (2006): Ethnografische Perspektiven: Technische Artefakte in ihrer symbolisch-kommunikativen und praktisch-materiellen Dimension. In: Werner Rammert und Cornelius Schubert (Hg.): Technografie. Zur Mikrosoziologie der Technik. Frankfurt am Main [u.a.]: Campus Verlag, S. 199222.

Brohmann, Bettina; Heinzle, Stefanie; Rennings, Klaus; Schleich, Joachim; Wüstenhagen, Rolf (2009): What's Driving Sustainable Energy Consumption? A Survey of the Empirical Literature. Zentrum für Europäische Wirtschaftsforschung GmbH (Mannheim) (Discussion Paper, 09-013). Online verfügbar unter ftp://ftp.zew.de/pub/zew-docs/dp/dp09013.pdf.

Brom, Paula van den; Meijer, Arjen; Visscher, Henk (2018): Performance gaps in energy consumption: household groups and building characteristics. In: Building Research \& Information 46 (1), S. 54-70. DOI: 10.1080/09613218.2017.13128 97.

Bruegmann, Robert (1978): Central Heating and Forced Ventilation: Origins and Effects on Architectural Design. In: Journal of the Society of Architectual Historians 37 (3), S. 143-160.

Brulle, Robert J.; Dunlap, Riley E. (2015): Sociology and Global Climate Change: Introduction. In: Riley E. Dunlap und Robert J. Brulle (Hg.): Climate Change and Society. Sociological Perspectives. Oxford: Oxford University Press, S. 1-31.

Brunner, Karl-Michael; Spitzer, Markus; Christianell, Anja (2011): Energiekonsum und Armut. In: Gertraude Mikl-Horke (Hg.): Sozioökonomie. Die Rückkehr der Wirtschaft in die Gesellschaft. Marburg: Metropolis-Verlag, S. 319-348. 
Bundesministerium für Umwelt, Naturschutz, Bau und Reaktorsicherheit (BMUB) (Hg.) (2016): Klimaschutzplan 2050. Klimaschutzpolitische Grundsätze und Ziele der Bundesregierung. Broschüre. Stand November 2016 (Nr. 2261). Online verfügbar unter https://www.bmu.de/publikation/klimaschutzplan-2050-kli maschutzpolitische-grundsaetze-und-ziele-der-bundesregierung/.

Bundesministerium für Wirtschaft und Energie (BMWi) (Hg.) (2015a): Energieeffizienzstrategie Gebäude. Wege zu einem klimaneutralen Gebäudebestand. Berlin. Online verfügbar unter https://www.bmwi.de/Redaktion/DE/Publikationen/ Energie/energieeffizienzstrategie-gebaeude.html, zuletzt geprüft am 10.10.2015.

Burgess, Jacquelin; Nye, Michael (2008): Re-materialising energy use through transparent monitoring systems. In: Energy Policy 36 (12), S. 4454-4459. DOI: 10.1016 /j.enpol.2008.09.039.

Busching, Dominik; Schlaak, Thomas (Monitor Deloitte) (2018): Commodities \& Dienstleistungen: Smart Home vom Energieversorger. Aus Stromabnahmestellen werden Kunden. Auszug aus Ausgabe 4 (August 2018). In: energate GmbH (Hg.): emw. Energie.Markt.Wettbewerb. Ausgabe 4. con energy Gruppe, S. 2-5.

Butler, Catherine; Parkhill, Karen A.; Pidgeon, Nicholas F. (2014): Energy consumption and everyday life: Choice, values and agency through a practice theoretical lens. In: Journal of Consumer Culture 0 (0), S. 1-21.

Castleton, Holly F.; Stovin, Virginia; Beck, Stephen B. M.; Davison, John Buick (2010): Green roofs; building energy savings and the potential for retrofit. In: Energy and Buildings 42 (10), S. 1582-1591.

Chappells, Heather; Shove, Elizabeth (2005): Debating the future of comfort: Environmental sustainability, energy consumption and the indoor environment. In: Building Research \& Information 33 (1), S. 32-40. DOI: 10.1080/096132104200032 2762.

Christensen, Clayton M. (1997): The Innovator's Dilemma: When New Technologies Cause Great Firms to Fail. Boston: Harvard Business School Press.

Clausnitzer, Klaus-Dieter (2014): Alternativen zur konventionellen Heizung. Heizen im Haus von morgen. In: Die Wohnungswirtschaft (DW) 67 (2), S. 30-32.

Cook, Diane J. (2012): Computer science. How smart is your home? In: Science (New York, N.Y.) 335 (6076), S. 1579-1581. DOI: 10.1126/science.1217640.

Cooper, Gail (1998): Air-conditioning America. Engineers and the controlled environment, 1900-1960. Baltimore: Johns Hopkins Univ. Press (Johns Hopkins studies in the history of technology, N.S., 23). Online verfügbar unter http://ww w.loc.gov/catdir/description/jhu052/97037148.html.

Crowley, John E. (1999): The Sensibility of Comfort. In: The American Historical Review 104 (3), S. 749.

Crowley, John E. (2001): The Invention of Comfort: Sensibilities \& Design in Early Modern Britain \& Early America. Baltimore, London: The Johns Hopkins University Press.

Day, John W.; Hall, Charles A.; Yáñez-Arancibia, Alejandro; Pimentel, David; Ibáñez Martí, Carles; Mitsch, William J. (2009): Ecology in Times of Scarcity. In: BioScience 59 (4), S. 321-331. 


\section{Literaturverzeichnis}

Dentel, Arno; Dietrich, Udo (o. J.): Thermische Behaglichkeit - Komfort in Gebäuden. HafenCity Universität Hamburg, Institut für Energie und Gebäude. Online verfügbar unter http://rom-umwelt-stiftung.de/wp-content/uploads/2006/02/Do kumentation_Thermische_Behaglichkeit.pdf, zuletzt geprüft am 20.10.2016.

Destatis (Hg.) (2017): Bauen und Wohnen. Baugenehmigungen / Baufertigstellungen von Wohn- und Nichtwohngebäuden (Neubau) nach Art der Beheizung und Art der verwendeten Heizenergie, Lange Reihen ab 1980. Statistisches Bundesamt Deutschland.

Deutsch, Karl W. (1985): On Theory and Research in Innovation. In: Richard L. Merritt und Anna J. Merritt (Hg.): Innovation in the Public Sector. Beverly Hills, California [u.a.]: Sage, S. 17-35.

Deutsche Energieagentur GmbH (dena) (2017): Gebäudestudie. Szenarien für eine marktwirtschaftliche Klima- und Ressourcenschutzpolitik 2050 im Gebäudesektor. dena.

Deutsche Energie-Agentur GmbH (dena) (Hg.) (2016): Der dena-Gebäudereport 2016. Statistiken und Analysen zur Energieeffizienz im Gebäudestand. Broschüre (pdf-Fassung). Wittenberg.

Di Giulio, Roberto (Hg.) (2012): Suburbanscapes. COST Action TU0701. Improving the Quality of Suburban Building Stocks. Unter Mitarbeit von (Editorial Board): Borg, Ruben Paul, Silvia Brunoro, Vince Buhagiar, Jaana Nevalainen, Emanuele Piaia, Jana Selih et al. Florenz: Alinea Editrice.

Diekmann, Andreas (2003): Empirische Sozialforschung. Grundlagen, Methoden, Anwendungen. 10. Aufl. Hamburg: Rowohlt Taschenbuch Verlag (rowohlts enzyklopädie).

Dilk, Anja; Littger, Heike (2014): Raus aus der Routine. In: enorm. Wirtschaft für den Menschen (1), S. 18-26.

Druckman, Angela; Chitnis, Mona; Sorrell, Steve; Jackson, Tim (2011): Missing carbon reductions? Exploring rebound and backfire effects in UK households. In: Energy Policy 39 (6), S. 3572-3581. DOI: 10.1016/j.enpol.2011.03.058.

Dubin, J. A.; McFadden, D. L. (1984): An economometric analysis of residential electric appliance holdings and consumption. In: Econometrica 52, S. 118-131.

Duhigg, Charles (2012): The power of habit. Why we do what we do in life and business. New York, NY: Random House.

Dunlap, Riley E.; Brulle, Robert J. (2015): Bringing Sociology into Climate Change Research and Climate Change into Sociology: Concluding Observations. In: Riley E. Dunlap und Robert J. Brulle (Hg.): Climate Change and Society. Sociological Perspectives. Oxford: Oxford University Press, S. 412-436.

Ebrecht, Jörg; Hillebrandt, Frank (Hg.) (2004): Bourdieus Theorie der Praxis. Erklärungskraft - Anwendung - Perspektiven. 2. durchgesehene Auflage. Wiesbaden: VS Verlag für Sozialwissenschaften / GWV Fachverlage GmbH Wiesbaden. 
Edenhofer, Ottmar (Hg.) (2010): Global aber gerecht. Klimawandel bekämpfen, Entwicklung ermöglichen. Ein Report des Potsdam-Instituts für Klimafolgenforschung und des Instituts für Gesellschaftspolitik München im Auftrag von Misereor und der Münchener Rück Stiftung. Unter Leitung von Ottmar Edenhofer, Johannes Wallacher, Michael Reder und Hermann Lotze-Campen. Potsdam-Institut für Klimafolgenforschung. München: Beck.

Elzen, Boelie; Geels, Frank W.; Green, Ken (Hg.) (2004): System Innovation and the Transition to Sustainability. Cheltenham, UK, Northampton, MA, USA: Edward Elgar.

Elzen, Boelie; Wieczorek, Anna (2005): Transitions towards sustainability through system innovation. In: Technological Forecasting and Social Change 72 (6), S. 651661. DOI: 10.1016/j.techfore.2005.04.002.

Ester, Peter (1984): Consumer Behavior and Energy Conservation. A policy-oriented field experimental study on the effectiveness of behavioral interventions promoting residential energy conservation. Amsterdam: Kanters B. V.

Evans, David; McMeekin, Andrew; Southerton, Dale (2012): Sustainable Consumption, Behaviour Change Policies and Theories of Practice. In: Alan Warde und Dale Southerton (Hg.): The Habits of Consumption. 12 Bände. Helsinki: Helsinki Collegium for Advanced Studies (Collegium. Studies Across Disciplines in the Humanities and Social Sciences, 12).

Faber, Alfred (1957): Entwicklungsstufen der häuslichen Heizung. München: R. Oldenbourg.

Fanger, Ole (1970): Thermal Comfort: Analysis and Application in Environmental Engineering. Copenhagen: Danish Technical Press.

Featherstone, Mike (1991): Consumer Culture and Postmodernism. London [u.a.]: Sage.

Feist, Wolfgang; Schnieders, Jürgen; Dorer, Viktor; Haas, Anne (2005): Re-inventing air heating: Convenient and comfortable within the frame of the Passive House concept. In: Energy and Buildings 37 (11), S. 1186-1203.

Ferguson, M. R. (1993): Energy-saving housing improvements in Canada (197982): A nested logit analysis. In: Environment and Planning A 25, S. 609-625.

Fischer, Corinna (2008): Feedback on household electricity consumption: a tool for saving energy? In: Energy Efficiency 1, S. 79-104.

Flick, Uwe; Kardorff, Ernst von; Steinke, Ines (2010): 1. Was ist qualitative Forschung? Einleitung und Überblick. In: Uwe Flick, Ernst von Kardorff und Ines Steinke (Hg.): Qualitative Forschung. Ein Handbuch. 8. Aufl. Hamburg: Rowohlt Taschenbuch Verlag, S. 13-29.

Flynn, Rob; Bellaby, Paul; Ricci, Miriam (2009): The 'Value-Action Gap' in Public Attitudes towards Sustainable Energy: The Case of Hydrogen Energy. In: The Sociological Review 57 (2), S. 159-180. 


\section{Literaturverzeichnis}

Fokaides, Paris A.; Kanarachos, Andreas; Kanarachos, Georgette; Kanarachos, Stratis; Björk, Folke; Gohardani, Navid et al. (2013): Promotion of Sustainable Renovation in Europe. In: ELCAS (Hg.): Exergy and Buildings. $3^{\text {rd }}$ International Exergy, Life Cycle Assessment, and Sustainability Workshop \& Symposium (ELCAS3). Nisyros, Greece, 07-09 July 2013, S. 225-234.

Foucault, Michel (1976): Überwachen und Strafen. Die Geburt des Gefängnisses. Übersetzt von Walter Seitter. 1. Aufl. Frankfurt am Main: Suhrkamp.

Foulds, Chris (2013): Practices and technological change. The unintended consequences of low energy dwelling design. School of Environmental Sciences, University of East Anglia, UK.

Foulds, Chris; Powell, Jane; Seyfang, Gill (2012): Domestic practices perspective on Passivhaus living. 3S Working Paper 2012-09. School of Environmental Sciences, University of East Anglia, UK (Science, Society and Sustainability (3S)).

Frondel, Manuel (2012): Der Rebound-Effekt von Energieeffizienz-Verbesserungen. In: Energiewirtschaftliche Tagesfragen 62 (8), S. 12-17.

Gallo, Emmanuelle (2008): Lessons Drawn From the History of Heating: A French Perspective. In: Mogens Rüdiger (Hg.): The Culture of Energy. Newcastle upon Tyne: Cambridge Scholars Publishing, S. 268-280.

Garfinkel, Harold (1967): Studies in Ethnomethodology. Englewood Cliffs, NJ: Prentice-Hall.

Gasparrini, Antonio; Guo, Yuming; Hashizume, Masahiro; Lavigne, Eric; Zanobetti, Antonella; Schwartz, Joel et al. (2015): Mortality risk attributable to high and low ambient temperature: a multicountry observational study. In: Lancet 386, S. 369-375.

Gekle, Michael; Singer, Dominique (2014): Wärmehaushalt und Temperaturregulation. In: Hans-Christian Pape, Armin Kurtz und Stefan Silbernagl (Hg.): Physiologie. 7. Aufl. Stuttgart: Georg Thieme Verlag, S. 567-584.

Gerber, Sophie; Lorkowski, Nina; Möllers, Nina (2012): Kabelsalat - Energiekonsum im Haushalt. Begleitkatalog zur Sonderausstellung. Deutsches Museum. München.

Giddens, Anthony (1979): Central Problems in Social Theory. Action, Structure and Contradiction in Social Analysis. London [u. a.]: Macmillan (Contemporary Social Theory).

Giddens, Anthony (1984): The Constitution of Society: Outline of the Theory of Structuration. Cambridge: Polity Press.

Giddens, Anthony (1991): Modernity and Self-Identity: Self and Society in the Late Modern Age. Cambridge: Polity Press.

Giddens, Anthony (1997 [1984]): Die Konstitution der Gesellschaft. Grundzüge einer Theorie der Strukturierung. Mit einer Einführung von Hans Joas. Aus dem Englischen von Wolf-Hagen Krauth und Wilfried Spohn-. 3. Aufl. Frankfurt am Main: Campus Verlag (Theorie und Gesellschaft, 1).

Gill, Zachary M.; Tierney, Michael J.; Pegg, Ian M.; Allan, Neil (2010): Low-energy dwellings: the contribution of behaviours to actual performance. In: Building Research \& Information 38 (5), S. 491-508. DOI: 10.1080/09613218.2010.505371. 
Gladhart, Peter M.; Maas Morrison, Bonnies; Long, Brenda R. (1987a): Housing and Energy. In: Peter M. Gladhart, Bonnie Maas Morrison und James J. Zuiches (Hg.): Energy and Families: Lifestyles and Energy Consumption in Lansing. Michigan, S. 86-134.

Gladhart, Peter M.; Morrison, Bonnie Maas; Zuiches, James J. (Hg.) (1987b): Energy and Families: Lifestyles and Energy Consumption in Lansing. Michigan.

Gladhart, Peter M.; Roosa, Mark W. (1987): Family Lifestyle and Energy Consumption: An Energy Adaption Model. In: Peter M. Gladhart, Bonnie Maas Morrison und James J. Zuiches (Hg.): Energy and Families: Lifestyles and Energy Consumption in Lansing. Michigan, S. 17-43.

Gladhart, Peter M.; Tortorici, Joseph (1987): Energy and Family Transportation. In: Peter M. Gladhart, Bonnie Maas Morrison und James J. Zuiches (Hg.): Energy and Families: Lifestyles and Energy Consumption in Lansing. Michigan, S. 157192.

Gladhart, Peter M.; Zuiches, James J. (1987): Energy Conservation. In: Peter M. Gladhart, Bonnie Maas Morrison und James J. Zuiches (Hg.): Energy and Families: Lifestyles and Energy Consumption in Lansing. Michigan, S. 134-157.

GMSH (2013): Energiebericht 2013 für die landesgenutzten Liegenschaften in Schleswig-Holstein. 40 Jahre Betriebsüberwachung und Energiemanagement. pdf-Dokument. Hg. v. Gebäudemanagement Schleswig-Holstein AöR (GMSH). Kiel. Online verfügbar unter www.gmsh.de.

Gram-Hanssen, Kirsten (2010): Residential heat comfort practices: understanding users. In: Building Research \& Information 38 (2), S. 175-186.

Gram-Hanssen, Kirsten (2011): Understanding change and continuity in residential energy consumption. In: Journal of Consumer Culture 11 (1), S. 61-78.

Gram-Hanssen, Kirsten; Georg, Susse (2018): Energy performance gaps: promises, people, practices. In: Building Research \& Information 46 (1), S. 1-9. DOI: 10.108 0/09613218.2017.1356127.

Gram-Hanssen, Kirsten; Georg, Susse; Christiansen, Ellen; Heiselberg, Per (2017): How building regulations ignore the use of buildings, what that means for energy consumption and what to do about it. In: Therese Laitinen Lindström (Hg.): ECEEE 2017 Summer Study - consumption, efficiency and limits. 29 May-3 June 2017, Belambra Les Criques, Toulon/Hyères, France: ECEEE Summer Study Proceedings. Stockholm, Sweden: eceee secretariat, S. 2095-2104.

Groba, Felix; Traber, Thure (2010): Increasing energy efficiency in private households in Germany. Overview of existing and proposed policy measures. DIW Berlin. Berlin (Workshop Report, 12).

Gronow, Jukka; Warde, Alan (2001a): Introduction. In: Jukka Gronow und Alan Warde (Hg.): Ordinary Consumption. London, New York: Routledge (Studies in Consumption and Markets Series, 2), S. 1-8.

Gronow, Jukka; Warde, Alan (Hg.) (2001b): Ordinary Consumption. London, New York: Routledge (Studies in Consumption and Markets Series, 2). 


\section{Literaturverzeichnis}

Grotelüschen, Frank (2010): Energie intelligent nutzen (1) Hundert Prozent sparen - Wohnen ohne Strom- und Heizungskosten. Manuskript Hessischer Rundfunk hr2-kultur 11.01.2010, zuletzt geprüft am 26.02.2013.

Grund-Ludwig, Pia (18.04.2009): Dämmung und Fassade Passivhaus. enbausa.de. Interview mit Wolfgang Feist.

Grunwald, Armin (2010): Die Ökologie der Individuen. Erwartungen an individuelles Umwelthandeln. In: Christian Büscher und Klaus Peter Japp (Hg.): Ökologische Aufklärung. 25 Jahre „Ökologische Kommunikation“. Wiesbaden: Verlag für Sozialwissenschaften, S. 231-257.

Grunwald, Armin (2013): Überforderte Verbraucher - Warum ökologischer Konsum die Umwelt nicht rettet. In: Umweltbundesamt (UBA) (Hg.): Umweltverträglicher Konsum durch rechtliche Steuerung. Dokumentation des Symposiums in der Landesvertretung Sachsen-Anhalt in Berlin am 27. November 2012. Umweltbundesamt. Berlin, S. 6-18.

Guy, Simon; Shove, Elizabeth (2000): A Sociology of Energy, Buildings and the Environment. Constructing Knowledge, Designing Practice. 9 Bände. London, New York: Routledge (Routledge Research Global Environmental Change Series, 5).

Hacke, Ulrike (2009a): Nutzerzufriedenheit im Passivhaus - eine Bestandsaufnahme. In: wohnbund-informationen (1), S. 10-12.

Hacke, Ulrike (2009b): Thesenpapier: Nutzerverhalten im Mietwohnbereich. Im Auftrag des VdW südwest e.V. Institut Wohnen und Umwelt GmbH. Darmstadt.

Haines, Victoria; Mitchell, Val; Cooper, Catherine; Maguire, Martin (2007): Probing user values in the home environment within a technology driven Smart Home project. In: Personal and Ubiquitous Computing 11 (5), S.349-359. DOI: 10.1007/s00779-006-0075-6.

Hanc, Madalina; McAndrew, Claire; Ucci, Marcella (2018): Conceptual approaches to wellbeing in buildings: a scoping review. In: Building Research \& Information 1 (1), S. 1-17. DOI: 10.1080/09613218.2018.1513695.

Hand, Martin; Shove, Elizabeth (2007): Condensing practices. Ways of living with a freezer. In: Journal of Consumer Culture 7, S. 79-104.

Hand, Martin; Shove, Elizabeth; Southerton, Dale (2005): Explaining showering: A discussion of the material, conventional and temporal dimensions of practice. In: Sociological Research Online 10 (2).

HANSA Baugenossenschaft eG (Hg.) (2013): Bei Uns. Wohnen mit Hamburger Genossenschaften. Mitgliederzeitschrift der HANSA Baugenossenschaft. HaufeLexware GmbH \& Co KG. Hamburg (Ausgabe 4/2013).

Hargreaves, Tom (2011): Practice-ing behaviour change: Applying social practice theory to pro-environmental behaviour change. In: Journal of Consumer Culture 11 (1), S. 79-99. 
Hargreaves, Tom; Hauxwell-Baldwin, Richard; Coleman, Michael; Wilson, Charlie; Stankovic, Lina; Stankovic, Vladimir et al. (2015): Smart homes, control and energy management: how do smart home technologies influence control over energy use and domestic life? Paper presented at the ECEEE 2015. In: ECEEE Summer Study Proceedings. ECEEE 2015 Summer Study; first fuel now; 1-6 June 2015, Belambra les Criques, Toulon/Hyères, France. European Council for an Energy Efficient Economy; ECEEE Summer Study on Energy Efficiency. Stockholm: eceee secretariat, S. 1021-1032.

Hargreaves, Tom; Wilson, Charlie (2017): Smart Homes and Their Users: Springer (Human-Computer Interaction Series).

Hargreaves, Tom; Wilson, Charlie; Hauxwell-Baldwin, Richard (2016): Control in The Smart Home. Paper presented at the DEMAND Centre Conference, Lancaster, UK, 13-15 April 2016.

Häußler, Franz (2008): Johannes Haag erwärmte zuerst den Adel. In: Augsburger Allgemeine, 18.12.2008. Online verfügbar unter http:/www.augsburger-allgemei ne.de/augsburg/Johannes-Haag-erwaermte-zuerst-den-Adel-id4770966.html, zuletzt geprüft am 08.01.2018.

Havighurst, Robert James (1953): Human Development and Education. Oxford: Longmans Green.

Hawken, Paul; Lovins, Amory B.; Lovins, L. Hunter (2000): Öko-Kapitalismus. Die industrielle Revolution des 21. Jahrhunderts; Wohlstand im Einklang mit der Natur. 1. Aufl. München: Riemann.

Healy, Stephen (2008): Air-conditioning and the 'homogenization' of people and built environments. In: Building Research \& Information 36 (4), S. 312-322. DOI: 10.1080/09613210802076351.

Heintz, Bettina (2004): EMERGENZ UND REDUKTION. Neue Perspektiven auf das Mikro-Makro-Problem. In: Kölner Zeitschrift für Soziologie und Sozialpsychologie 56 (1), S. 1-31.

Helfferich, Cornelia (2004): Die Qualität qualitativer Daten. Manual für die Durchführung qualitativer Interviews. Wiesbaden: VS Verlag für Sozialwissenschaften / GWV Fachverlage GmbH Wiesbaden.

Hens, Hugo; Parijs, Wout; Deurinck, Mieke (2010): Energy consumption for heating and rebound effects. In: Energy and Buildings 42 (1), S. 105-110. DOI: 10.1016/j.enbuild.2009.07.017.

Hermelink, Andreas; Schimschar, Sven; Boermans, Thomas; Pagliano, Lorenzo; Zangheri, Paolo; Armani, Roberto et al. (2013): Towards nearly zero-energy buildings. Definition of common principles under the EPBD. Final report. Hg. v. European Commission. Ecofys, Köln (Germany), by order of: European Commission. Online verfügbar unter https://ec.europa.eu/energy/en/topics/energy-eff iciency/buildings/nearly-zero-energy-buildings, zuletzt geprüft am 11.09.2018.

Herrmann, Sebastian (2014): Hilflos vor der Maschine. Artikel aus der App der Süddeutschen Zeitung. Ressort Wissen, 10.05.2014.

Heyen, Dirk Arne (2016): Working Paper. Exnovation: Herausforderungen und politische Gestaltungsansätze für den Ausstieg aus nicht-nachhaltigen. Öko-Institut e.V., Germany (Öko-Institut Working Paper, 3/2016). 


\section{Literaturverzeichnis}

Hippel, Eric von (1986): Lead users: a source of novel product concepts. In: Management Science 32 (7), S. 791-805.

Hippel, Eric von (1988): On the Sources of Innovation. Oxford [u.a.]: Oxford University Press.

Hirschauer, Stefan (2001): Ethnografisches Schreiben und die Schweigsamkeit des Sozialen. Zu einer Methodologie der Beschreibung. In: Zeitschrift für Soziologie 30 (6), S. 429-451.

Hirschauer, Stefan (2008): Körper macht Wissen - Für eine Somatisierung des Wissensbegriffs. In: Karl-Siegbert Rehberg (Hg.): Die Natur der Gesellschaft. Verhandlungen des 33. Kongresses der Deutschen Gesellschaft für Soziologie in Kassel 2006, Bd. 2. 2 Bände. Frankfurt am Main: Campus Verlag, 974-984.

Hitchings, Russell (2011): Researching air-conditioning addiction and ways of puncturing practice. Professional office workers and the decision to go outside. In: Environ. Plann. A 43 (12), S. 2838-2856. DOI: 10.1068/a43574.

Hitchings, Russell (2012): People can talk about their practices. In: Area 44 (1), S. 61-67. DOI: 10.1111/j.1475 - 4762.2011.01060.x.

Hoffmann-Riem, Christa (1980): Die Sozialforschung einer interpretativen Soziologie. Der Datengewinn. In: Kölner Zeitschrift für Soziologie und Sozialpsychologie 32, 339-372.

Hofmann, David B.; Erichsen, Olaf (o.J.): Smart Home Angebote erfolgreich vermarkten. Ein Whitepaper der Innovations-Experten von mm1 Consulting \& Management. Hg. v. mm1 Consulting \& Management.

Hörning, Karl Heinz (2001): Experten des Alltags. Die Wiederentdeckung des praktischen Wissens. 1. Aufl. Weilerswist: Velbrück Wissenschaft.

Hörning, Karl-Heinz; Reuter, Julia (Hg.) (2004): Doing Culture: neue Positionen zum Verhältnis von Kultur und sozialer Praxis. Bielefeld: Transcript-Verl.

IG Passivhaus Deutschland (Hg.) (2016): Aktiv für mehr Behaglichkeit: Das Passivhaus. Informationsbroschüre. 9. Aufl. Darmstadt. Online verfügbar unter https:/ /www.ig-passivhaus.de/index.php?page_id=73\&level1_id=70, zuletzt geprüft am 02.10.2018.

Ilmonen, Kaj (2001): Sociology, Consumption and Routine. In: Jukka Gronow und Alan Warde (Hg.): Ordinary Consumption. London, New York: Routledge (Studies in Consumption and Markets Series, 2), S. 9-25.

IPCC (2013): Climate Change 2013: The Physical Science Basis. Contribution of Working Group I to the Fifth Assessment Report of the Intergovernmental Panel on Climate Change [Stocker, Thomas F.; Qin, D.; Plattner, G.-K.; Tignor, M. Allen, S. K.; Boschung, J.; Nauels, A.; Xia, Y.; Bex, V.; Midgley, P. M. (eds.)]. Hg. v. Stocker, Thomas F. [u.a.] (Working Group I). Intergovernmental Panel on Climate Change (IPCC). Cambridge, United Kingdom and New York, NY, USA. 
Jaeger-Erben, Melanie (2010): Zwischen Routine, Reflektion und Transformation die Veränderung von alltäglichem Konsum durch Lebensereignisse und die Rolle von Nachhaltigkeit. eine empirische Untersuchung unter Berücksichtigung praxistheoretischer Konzepte. Doktorarbeit. Fakultät VI Planen Bauen Umwelt. Technische Universität Berlin. Berlin, Deutschland.

Johann, Sebastian (2015): Energieeffizienz bei Wohngebäuden - (k)ein Zusammenspiel zwischen Mensch und Technik. In: Anika Arnold, Martin David, Gerolf Hanke und Marco Sonnberger (Hg.): Innovation - Exnovation: Über Prozesse des Abschaffens und Erneuerns in der Nachhaltigkeitstransformation. Marburg: Metropolis-Verlag (Ökologie und Wirtschaftsforschung), S. 171-184.

John, René (2013): Alltägliche Nachhaltigkeit: Zur Innovativität von Praktiken. In: Jana Rückert-John (Hg.): Soziale Innovation und Nachhaltigkeit: Perspektiven sozialen Wandels. Wiesbaden: Springer VS, S. 103-132.

Kallmeyer, Werner; Schütze, Fritz (1977): Zur Konstitution von Kommunikationsschemata der Sachverhaltsdarstellung. In: Dirk Wegner (Hg.): Gesprächsanalysen. Vorträge gehalten anläßlich des 5. Kolloquiums des Instituts für Kommunikationsforschung und Phonetik, Bonn, 14.-16. Oktober 1976. 5. Kolloquiums des Instituts für Kommunikationsforschung und Phonetik. Bonn, 14.-16. Oktober 1976. Hamburg: Buske, S. 159-274.

Kalthoff, Herbert (2008): Einleitung: Zur Dialektik qualitativer Forschung und soziologischer Theoriebildung. In: Herbert Kalthoff, Stefan Hirschauer und Gesa Lindemann (Hg.): Theoretische Empirie. Zur Relevanz qualitativer Forschung. Frankfurt am Main: Suhrkamp, S. 8-32.

Kalthoff, Herbert; Hirschauer, Stefan; Lindemann, Gesa (Hg.) (2008): Theoretische Empirie. Zur Relevanz qualitativer Forschung. Frankfurt am Main: Suhrkamp.

Kelle, Udo (2008): Die Integration qualitativer und quantitativer Methoden in der empirischen Sozialforschung. Theoretische Grundlagen und methodologische Konzepte. 2. Aufl. Wiesbaden: VS Verlag für Sozialwissenschaften / GWV Fachverlage GmbH Wiesbaden.

Kempton, Willett; Neiman, Max (Hg.) (1987): Energy Efficiency: Perspectives on Individual Behavior.

Kennedy, Emily Huddart; Beckeley, Thomas M.; McFarlane, Bonita L.; Nadeau, Solange (2009): Why We Don't "Walk the Talk": Understanding the Environmental Values/Behaviour Gap in Canada. In: Human Ecology Review 16 (2), S. 151-160.

Kleinaltenkamp, Michael; Staudt, Maike (1991): Kooperation zwischen Investitionsgüter-Herstellern und führenden Anwendern („Lead User“). In: Josef Hilbert, Michael Kleinaltenkamp, Jürgen Nordhause-Janz und Brigitta Widmaier (Hg.): Neue Kooperationsformen in der Wirtschaft. Können Konkurrenten Partner werden? Wiesbaden: VS Verlag für Sozialwissenschaften (Schriften des Institut Arbeit und Technik), S. 59-70.

Klusendick, Martina (2011): Kognitionspsychologie: Einblicke in mentale Prozesse. In: Gabriele Naderer (Hg.): Qualitative Marktforschung in Theorie und Praxis. Grundlagen, Methoden, Anwendungen. 2., überarbeitete Auflage. Wiesbaden: Gabler, S. 111-126. 


\section{Literaturverzeichnis}

Koesling, Brigitte (2014): Wie sich die Energiewende auf unser Zusammenleben und Wohnen auswirkt. In: Nordstern (03), S. 11-12.

Kollmuss, Anja; Agyeman, Julian (2002): Mind the Gap: Why do people act environmentally and what are the barriers to pro-environmental behavior? In: Environmental Education Research 8 (3), S. 239-260.

König, Wolfgang (2000): Geschichte der Konsumgesellschaft. Stuttgart: Steiner.

Krödel, Michael (2013): Was will mein Kunde wirklich. Kundenanalysen und Umfragen zur Raumautomation. In: Bussysteme 20 (3), S. 158-159.

Kuijer, Lenneke; Jong, Annelise de (2012): Identifying design opportunities for reduced household resource consumption: exploring practices of thermal comfort. In: Journal of Design Research 10 (1/2), S. 67-85.

Lakoff, George; Johnson, Mark (2004): Leben in Metaphern. Konstruktion und Gebrauch von Sprachbildern. 4. Aufl. Heidelberg: Carl-Auer-Systeme.

Latif, Mojib (2006): Der menschliche Einfluss auf das Klima. In: Bundeszentrale für politische Bildung (bpb) (Hg.): Aus Politik und Zeitgeschichte. 20 Jahre Tschernobyl. Beilage zur Wochenzeitung Das Parlament 13 (27. März 2006). Frankfurt am Main: Frankfurter Societäts-Druckerei GmbH, S. 26-31.

Lave, Jean; Wenger, Etienne (2011 [1991]): Situated learning. Legitimate peripheral participation. 24. print. Cambridge: Cambridge Univ. Press (Learning in doing).

Law, John (2012 [1987]): Technology and Heterogeneous Engineering: The Case of Portuguese Expansion. In: Wiebe E. Bijker, Thomas P. Hughes und Trevor J. Pinch (Hg.): The Social Construction of Technological Systems: New Directions in the Sociology and History of Technology. Anniversary edition. Cambridge, Massachusetts [u.a.]: MIT Press, S. 105-128.

Leonard-Barton, Dorothy (1981a): Diffusion of energy conservation and technologies. In: John D. Claxton, C. Dennis Anderson, J.R Brent Ritchie und Gordon H.G McDougall (Hg.): Consumers and Energy Conservation. International Perspectives on Research and Policy Options. New York, USA: Praeger Publishers, S. 97-107.

Leonard-Barton, Dorothy (1981b): Voluntary Simplicity Lifestyles and Energy Conservation. In: The Journal of Consumer Research 8 (3), S. 243-252.

Lewis, Simon C. R. (2011): Energy in the Smart Home. In: Richard Harper (Hg.): The Connected Home: The Future of Domestic Life. 1. Aufl. s.l.: Springer Verlag London Limited, S. 281-300.

Lindemann, Gesa (2008): Theoriekonstruktion und empirische Forschung. In: Herbert Kalthoff, Stefan Hirschauer und Gesa Lindemann (Hg.): Theoretische Empirie. Zur Relevanz qualitativer Forschung. Frankfurt am Main: Suhrkamp, S. 107-128.

Lipp, Bernhard (2006): Thermische Behaglichkeit. In: IBO - Österreichisches Institut für Bauen und Ökologie $\mathrm{GmbH}$ (Hg.): IBO magazin 3/06. Österreichisches Institut für Baubiologie und -ökologie, S. 6-16. Online verfügbar unter https://d ocplayer.org/42653557-Thermische-behaglichkeit.html, zuletzt geprüft am 13.08.2018. 
Loewer, Harald (1968): Klimatechnik. Grundlagen und Anwendungen der Luftkonditionierung. Berlin, Heidelberg: Springer.

Long, James E. (1993): An econometric analysis of residental expenditures on energy conservation and renewable energy sources. In: Energy Economics 15 (4), S. 232-238.

Loos, Peter; Schäffer, Burkhard (2001): Das Gruppendiskussionsverfahren. Theoretische Grundlagen und empirische Anwendung. Opladen: Leske + Budrich.

Louis, Jean-Nicolas; Calo, Antonio; Leiviskä, Kauko; Pongrácz, Eva (2015): Environmental Impacts and Benefits of Smart Home Automation: Life Cycle Assessment of Home Energy Management System. In: IFAC-PapersOnLine 48 (1), S. 880-885. DOI: 10.1016/j.ifacol.2015.05.158.

Lovins, Amory B. (1978 [1977]): Sanfte Energie. Das Programm für die energieund industriepolitische Umrüstung unserer Gesellschaft. ins Deutsche übersetzt von Karl A. Klewer, Klaus Traube und Volker Hauff. 1. Aufl. Reinbek bei Hamburg: Rowohlt.

Lovins, Amory B. (1990): The Negawatt Revolution. In: Across the Board: The Conference Board Magazine XXVII (9), S. 18-23.

Lovins, Amory B. (1996): Negawatts. In: Energy Policy 24 (4), S. 331-343. DOI: 10.1016/0301-4215(95)00138-7.

Luhmann, Niklas (1990): Die Wissenschaft der Gesellschaft. Frankfurt am Main: Suhrkamp.

Lüthje, Christian; Herstatt, Cornelius (2004): The Lead User method: an outline of empirical findings and issues for future research. In: RむD Management 34 (5), S. 553-568. DOI: 10.1111/j.1467 - 9310.2004.00362.x.

Lutzenhiser, Loren (1992): A Cultural Model of Household Energy Consumption. In: Energy 17 (1), S. 47-60.

Lutzenhiser, Loren (1993): Social and Behavioral Aspects of Energy Use. In: Annual Review of Energy and the Environment 18, S. 247-289.

Lutzenhiser, Loren (2002): Greening the Economy from the Bottom up? Lessons in Consumption in the Energy Case. In: Nicole Woolsey Biggart (Hg.): Readings in Economic Sociology, Bd. 8. Malden, Mass. u. a.: Blackwell (Blackwell Readers in Sociology, 8), S. 345-356.

Lutzenhiser, Loren; Hill Gossard, Marcia (2000): Lifestyle, Status and Energy Consumption. In: American Council for an Energy-Efficient Economy (Hg.): Efficiency and sustainability. Washington, DC, S. 207-221.

Lutzenhiser, Loren; Moezzi, Mithra; Hungerford, David; Friedmann, Rafael (2010): Sticky Points in Modeling Household Energy Consumption. In: American Council for an Energy-Efficient Economy (ACEEE) (Hg.): Proceedings of the ACEEE Summer Study on Energy Efficiency in Buildings. The Climate for Efficiency is Now. Summer Study on Energy Efficiency in Buildings. Pacific Grove, CA, 15.-20.08.2010, S. 167-182. Online verfügbar unter https://pdxschola r.library.pdx.edu/cus_pubs/152, zuletzt geprüft am 12.10.2018. 
Ma, Zhenjun; Cooper, Paul; Daly, Daniel; Ledo, Laia (2012): Existing building retrofits: Methodology and state-of-the-art. In: Energy and Buildings 55, S. 889902.

Madigan, Ruth; Munro, Moira (1996): 'House Beautiful': Style and Consumption in the Home. In: Sociology 30 (1), S. 41-57.

Majcen, D.; Itard, L. C. M.; Visscher, H. (2013): Theoretical vs. actual energy consumption of labelled dwellings in the Netherlands: Discrepancies and policy implications. In: Energy Policy 54, S. 125-136.

Mangold, Werner; Bohnsack, Ralf (1983): Kollektive Orientierungen in Gruppen Jugendlicher. Antrag für ein Forschungsprojekt. Erlangen.

Mangold, Werner; Bohnsack, Ralf (1988): Kollektive Orientierungen in Gruppen Jugendlicher. Bericht für die Deutsche Forschungsgesellschaft. Erlangen.

Maniates, Michael (2010a): Editing Out Unsustainable Behavior. In: The Worldwatch Institute (Hg.): State of the World 2010. Transforming Cultures: From Consumerism to Sustainability. New York [u.a.]: W. W. Norton \& Company (State of the World), S. 119-126.

Mannheim, Karl (1964): Wissenssoziologie. Auswahl aus dem Werk. Eingeleitet und herausgegeben von Kurt H. Wolff. Berlin [u.a.]: Luchterhand.

Mannheim, Karl (1980): Strukturen des Denkens. Herausgegeben von David Kettler, Volker Meja und Nico Stehr. Frankfurt am Main: Suhrkamp.

Mannheim, Karl (1985): Ideologie und Utopie. 7. Aufl. Frankfurt/Main: Klostermann.

Matsuzaki, Hironori (2011): Die Frage nach der „Agency“ von Technik und die Normenvergessenheit der Techniksoziologie. In: Nico Lüdtke und Hironori Matsuzaki (Hg.): Akteur - Individuum - Subjekt. Fragen zu Personalität und Sozialität. 1. Aufl. Wiesbaden: VS Verl. für Sozialwiss, S. 301-325.

Matzat, Johanna Sophie (2008): Von der wilden Ehe zur nichtehelichen Lebensgemeinschaft. Die nichteheliche Lebensgemeinschaft als soziale Innovation in der zweiten Hälfte des 20. Jahrhunderts. Unveröffentlichte Diplomarbeit. Fachbereich Sozialwissenschaften. Universität Hamburg. Hamburg, Deutschland.

McCracken, Grant David (1990): Culture and Consumption: New Approaches to the Symbolic Character of Consumer Goods and Activities. Bloomington [u.a.]: Indiana University Press.

McKenzie-Mohr, Doug (2000): Promoting Sustainable Behavior: An Introduction to Community-Based Social Marketing. In: Journal of Social Issues 56 (3), S. 543554.

McMeekin, Andrew; Southerton, Dale (2007): Innovation and final consumption: social practices, instituted modes of provision and intermediation. Discussion Paper 79. Centre for Research on Innovation and Competition (CRIC), University of Manchester. Manchester.

McMeekin, Andrew; Southerton, Dale (2012): Sustainability transitions and final consumption: practices and socio-technical systems. In: Technology Analysis \& Strategic Management 24 (345-361). 
Meadows, Dennis; Meadows, Donella; Zahn, Erich; Milling, Peter (1972): Die Grenzen des Wachstums. Bericht des Club of Rome zur Lage der Menschheit. Stuttgart: Deutsche Verlags-Anstalt.

Meadows, Donella; Randers, Jørgen; Meadows, Dennis (2016): Grenzen des Wachstums - das 30-Jahre-Update: Signal zum Kurswechsel. 5. Auflage. Mit einem Geleitwort von Ernst Ulrich von Weizsäcker, Ko-Präsident des Club of Rome. Stuttgart: S. Hirzel.

Meadows, Donella H. (1999): Leverage Points: Places to Intervene in a System. Hg. v. Sustainability Institute. Hartland, VT.

Messari-Becker, Lamia (2016): Energiewende im Bausektor. Interview. In: Energiewirtschaftliche Tagesfragen 66 (9), S. 28-29.

Meuser, Michael; Nagel, Ulrike (1991): ExpertInneninterviews - vielfach erprobt, wenig bedacht. Ein Beitrag zur qualitativen Methodendiskussion. In: Detlef Garz und Klaus Kraimer (Hg.): Qualitativ-empirische Sozialforschung. Konzepte, Methoden, Analysen. Wiesbaden: VS Verlag für Sozialwissenschaften, S. 441471.

Meuser, Michael; Nagel, Ulrike (2005): Vom Nutzen der Expertise. ExpertInneninterviews in der Sozialberichterstattung. In: Alexander Bogner, Beate Littig und Wolfgang Menz (Hg.): Das Experteninterview. Theorie, Methode, Anwendung. 2. Aufl. Wiesbaden: VS, Verl. für Sozialwiss., S. 257-272.

Meuser, Michael; Nagel, Ulrike (2011): Experteninterview. In: Ralf Bohnsack, Winfried Marotzki und Michael Meuser (Hg.): Hauptbegriffe qualitativer Sozialforschung. 3. Aufl. Opladen [u.a.]: Barbara Budrich (UTB), S. 57-58.

Moezzi, Mithra; Lutzenhiser, Loren (2010): What's Missing in Theories of the Residential Energy User. In: American Council for an Energy-Efficient Economy (ACEEE) (Hg.): Proceedings of the ACEEE Summer Study on Energy Efficiency in Buildings. The Climate for Efficiency is Now. Summer Study on Energy Efficiency in Buildings. Pacific Grove, CA, 15.-20.08.2010, S. 207-221. Online verfügbar unter https://pdxscholar.library.pdx.edu/cus_pubs/151, zuletzt geprüft am 12.10.2018.

Monkhouse, Claire; Dibb, Sue (2011): Making sustainable lives easier: a priority for governments, business and society. Hg. v. Sustainable Development Commission (SDC) (Great Britain) (Sustainable Development Commission Reports). Online verfügbar unter https://research-repository.st-andrews.ac.uk/handle/1002 3/2288, zuletzt geprüft am 30.07.2018.

Moritz, Wolfram (2014): Der Markt für Smart Energy Services bis 2020. In: MPW Institute LLC (Hg.): smart.ER. Ausgabe II. Brooklyn/New York, S. 37-41.

Mühlestein, Helene; Niederhauser, Rebecca (2007): Tupperware: Ordnung, Sauberkeit und Hygiene im Haushalt. In: Schweizerisches Archiv für Volkskunde 103 (1), S. 21-59. DOI: 10.5169/SEALS-118222.

Murray, Cameron K. (2013): What if consumers decided to all 'go green'? Environmental rebound effects from consumption decisions. In: Energy Policy 54, S. 240-256. DOI: 10.1016/j.enpol.2012.11.025. 


\section{Literaturverzeichnis}

Nemoz, Sophie (2010): The meaning of rebound effects in the energy-related practices of households. In: $7^{\text {th }}$ Biennial International Workshop Advances in Energy Studies 2010. $7^{\text {th }}$ Biennial International Workshop "Advances in Energy Studies 2010. Barcelona. Centre d'Etudes du Développement durable (CEDD).

Nentwig-Gesemann, Iris (2013): Die Typenbildung der dokumentarischen Methode. In: Ralf Bohnsack, Iris Nentwig-Gesemann und Arnd-Michael Nohl (Hg.): Die dokumentarische Methode und ihre Forschungspraxis. Grundlagen qualitativer Sozialforschung. 3., erw. und aktualisierte Aufl. Wiesbaden: VS, Verl. für Sozialwiss, S. 295-323.

Neuloh, Otto (1977): Zum Bezugsrahmen von sozialer Innovation und sozialem Konflikt. In: Otto Neuloh (Hg.): Soziale Innovation und sozialer Konflikt. Göttingen: Vandenhoeck \& Ruprecht, S. 9-30.

Nohl, Arnd-Michael (2005): Dokumentarische Interpretation narrativer Interviews. PDF-Dokument. In: bildungsforschung (frei zugängliche Online-Zeitschrift), Bd. 2 (2005): Bildungsbiographien und Bildungsverläufe. DOI: 10.25539/BILDU NGSFORSCHUN.V2I0.13.

Nohl, Arnd-Michael (2013): Komparative Analyse: Forschungspraxis und Methodologie dokumentarischer Interpretation. In: Ralf Bohnsack, Iris Nentwig-Gesemann und Arnd-Michael Nohl (Hg.): Die dokumentarische Methode und ihre Forschungspraxis. Grundlagen qualitativer Sozialforschung. 3., erw. und aktualisierte Aufl. Wiesbaden: VS, Verl. für Sozialwiss, S. 271-293.

Nohl, Arnd-Michael (2017): Interview und dokumentarische Methode. Anleitungen für die Forschungspraxis. 5., aktualisierte und erweiterte Auflage. Wiesbaden: Springer VS.

Norman, Donald A. (1994): How might people interact with agents. In: Communications of the ACM 37 (7), S. 68-71. DOI: 10.1145/176789.176796.

Norman, Donald A. (2004): Emotional Design. Why we love (or hate) everyday things. New York: Basic Books. Online verfügbar unter http://www.loc.gov/catd ir/enhancements/fy0830/2003010123-b.html.

Norman, Donald A. (2011): Living with Complexity. Cambridge, Mass.: MIT Press.

Norman, Donald A. (2013): The Design of Everyday Things. Revised and expanded edition. New York, NY: Basic Books.

Norton, Michael I.; Mochon, Daniel; Ariely, Dan (2012): The IKEA effect: When labor leads to love. In: Journal of Consumer Psychology 22, S. 453-460.

Nyborg, Sophie; Røpke, Inge (2011): Energy impacts of the smart home - conflicting visions. In: ECEEE 2011 Summer Study (Hg.): Energy Efficiency First: The Foundation of a Low-Carbon Society, S. 1849-1860.

Ölander, Folke; Thøgersen, John (2014): Informing Versus Nudging in Environmental Policy. In: Journal of Consumer Policy 37 (3), S. 341-356. DOI: 10.1007/s1 0603-014-9256-2.

Olsen, Marvin E. (1981): Consumers' Attitudes Toward Energy Conservation. In: The Journal of Social Issues 37 (2), S. 108-131.

Osche, Günther (1974): Evolution. Grundlagen, Erkenntnisse, Entwicklungen der Abstammungslehre. 3. Aufl. Freiburg, Basel, Wien: Herder (Studio visuell). 
Paech, Niko (2006): Wirtschaften ohne Wachstumszwang. In: Ökologisches Wirtschaften 21 (3), S. 30-33.

Pantzar, Mika; Shove, Elizabeth (2006): Circuits of reproduction and the dynamics of practice in everyday life. In: Proceedings of the Second Organization Studies Summer Workshop on "Re-turn to Practice: Understanding Organization As It Happens". Proceedings of the Second Organization Studies Summer Workshop on "Re-turn to Practice: Understanding Organization As It Happens". Mykonos, Greece, 15-16 June.

Pantzar, Mika; Shove, Elizabeth (2010): Understanding innovation in practice: a discussion of the production and re-production of Nordic Walking. In: Technology Analysis \& Strategic Management 22 (4), S. 447-461.

Parkhurst, Graham; Parnaby, Richard (2008): Growth in mobile air-conditioning: a socio-technical research agenda. In: Building Research \& Information 36 (4), S. 351-362. DOI: 10.1080/09613210802076500.

Patow, Otto; Krienke, Carl Friedrich (1972): Die Ölheizung im Wohnhaus. eine Arbeits- und Informationsunterlage für Planung und Auswahl moderner Heizungen. 2. Aufl. Düsseldorf: Werner-Verlag.

Peattie, Ken (2010): Green Consumption: Behavior and Norms. In: Annual Review of Environment and Resources 35, S. 195-228.

Pinzler, Petra (2018): »In der Luft ist noch Platz. Leider«. Dossier Titelthema. Interview mit Andreas Knie. Das Gespräch führte Petra Pinzler. In: Die Zeit 73, 09.08.2018 (33), S. 15.

Polanyi, Michael (1985): Implizites Wissen. Michael Polanyi. Übersetzt von Horst Brühmann. Frankfurt am Main: Suhrkamp.

Postill, John (2010): Introduction: Theorising Media and Practice. In: Birgit Bräuchler und John Postill (Hg.): Theorising Media and Practice. New York, USA, Oxford: Berghahn Books, S. 1-33.

Power, Anne (2010): Housing and sustainability: demolition or refurbishment? In: Urban Design and Planning 163 (4), S. 205-216.

Przyborski, Aglaja; Wohlrab-Sahr, Monika (2013): Qualitative Sozialforschung. Ein Arbeitsbuch. München: Oldenbourg.

Rammert, Werner (2006): Technik in Aktion: Verteiltes Handeln in soziotechnischen Konstellationen. In: Werner Rammert und Cornelius Schubert (Hg.): Technografie. Zur Mikrosoziologie der Technik. Frankfurt am Main [u.a.]: Campus Verlag, S. 163-196.

Randall, Dave (2003): Living Inside a Smart Home: A Case Study. In: Richard Harper (Hg.): Inside the Smart Home. London: Springer-Verlag London Limited, S. 227-246.

Randles, Sally; Warde, Alan (2006): Consumption: the view from theories of practice. In: Ken Green und Sally Randles (Hg.): Industrial ecology and spaces of innovation. Cheltenham: Elgar, S. 220-237.

Rasch, Folkmer (2009): Das Ende der Verbrauchsabrechnung? Die Warmmiete und ihre Vorteile. In: wohnbund-informationen (1), S. 8.

Recknagel, Hermann (1915): Lüftung und Heizung. Leipzig: Hirzel. 
Reckwitz, Andreas (2000a): Der Status des ,Mentalen' in kulturtheoretischen Handlungserklärungen. Zum Problem der Relation von Verhalten und Wissen nach Stephen Turner und Theodore Schatzki. In: Zeitschrift für Soziologie 29 (3), S. $167-185$.

Reckwitz, Andreas (2000b): Die Transformation der Kulturtheorien: Zur Entwicklung eines Theorieprogramms. Weilerswist: Velbrück Wissenschaft.

Reckwitz, Andreas (2002a): The Status of the "Material" in Theories of Culture: From "Social Structure" to "Artefacts". In: Journal of the Theory of Social Behaviour 32 (2), S. 195-217.

Reckwitz, Andreas (2002b): Toward a Theory of Social Practices. A Development in Culturalist Theorizing. In: European Journal of Social Theory 5 (2), S. 243-263.

Reckwitz, Andreas (2003): Grundelemente einer Theorie sozialer Praktiken. Eine sozialtheoretische Perspektive. In: Zeitschrift für Soziologie 32 (4), S. 282-301.

Reckwitz, Andreas (2004): Die Entwicklung des Vokabulars der Handlungstheorien: Von den zweck- und normorientierten Modellen zu den Kultur- und Praxistheorien. In: Manfred Gabriel (Hg.): Paradigmen der akteurszentrierten Soziologie. Wiesbaden: VS Verlag, S. 303-328.

Reisch, Lucia A.; Hagen, Kornelia (2011): Kann der Konsumwandel gelingen? Chancen und Grenzen einer verhaltensökonomisch basierten sozialen Regulierung. In: Ludger Heidbrink, Imke Schmidt und Björn Ahaus (Hg.): Die Verantwortung des Konsumenten. Über das Verhältnis von Markt, Moral und Konsum. Frankfurt am Main: Campus Verlag, S. 221-244.

Richter, Wolfgang (2003): Handbuch der thermischen Behaglichkeit - Heizperiode. Bremerhaven: Wirtschaftsverl. NW Verl. für neue Wiss (Schriftenreihe der Bundesanstalt für Arbeitsschutz und Arbeitsmedizin Forschung Arbeitsschutz, 991).

Rip, Arie (2006): A co-evolutionary approach to reflexive governance - and its ironies. In: Jan-Peter Voß, Dierk Bauknecht und Rene Kemp (Hg.): Reflexive Governance for Sustainable Development. Cheltenham, UK, Northampton, MA, USA: Edward Elgar, S. 82-100.

Roberts, Brian M. (1995): A History of Heating in Europe (ASHRAE Transactions: Symposia), S. 773-785.

Røpke, Inge (2009): Theories of practice - New inspiration for ecological economic studies on consumption. In: Ecological Economics 68 (10), S. 2490-2497.

Rosa, Eugene A.; Machlis, Gary E.; Keating, Kenneth M. (1988): Energy and Society. In: Annual Review of Sociology 14, S. 149-172.

Rosa, Hartmut (2011): Über die Verwechselung von Kauf und Konsum: Paradoxien der spätmodernen Konsumkultur. In: Ludger Heidbrink, Imke Schmidt und Björn Ahaus (Hg.): Die Verantwortung des Konsumenten. Über das Verhältnis von Markt, Moral und Konsum. 1. Aufl. Frankfurt am Main: Campus Verlag $\mathrm{GmbH}$ (Sozialwissenschaften 2011), S. 115-132.

Rosenthal, Gabriele (2011): Interpretative Sozialforschung. Eine Einführung. 3., aktualisierte und ergänzte Auflage. Weinheim und München: Juventa (Grundlagentexte Soziologie). 
Rybczynski, Witold (1991): Verlust der Behaglichkeit. Wohnkultur im Wandel der Zeit. München: Deutscher Taschenbuch Verlag.

Ryle, Gilbert (1969): Der Begriff des Geistes. Ditzingen: Reclam (Reclams Universal-Bibliothek).

Sachs, Jonah; Finkelpearl, Susan (2010): From Selling Soap to Selling Sustainability. In: The Worldwatch Institute (Hg.): State of the World 2010. Transforming Cultures: From Consumerism to Sustainability. New York [u.a.]: W. W. Norton \& Company (State of the World), S. 151-156.

Sahakian, Marlyne; Wilhite, Harold (2014): Making practice theory practicable: Towards more sustainable forms of consumption. In: Journal of Consumer Culture 14 (1), S. 25-44.

Santarius, Tilman (2012): Der Rebound-Effekt. Über die unerwünschten Folgen der erwünschten Energieeffizienz. Hg. v. Umwelt Energie GmbH Wuppertal Institut für Klima. Wuppertal (Impulse zur WachstumsWende).

Schäfer, Martina; Bamberg, Sebastian (2008): Breaking habits: Linking sustainable consumption campaigns to sensitive life events. In: Theo Geer Ken, Arnold Tukker, Carlo Vezzoli und Fabrizio Ceschin (Hg.): Sustainable Consumption and Production: Framework for Action. $2^{\text {nd }}$ Conference of the Sustainable Consumption Research Exchange (SCORE!) Network. Score! Sustainable Consumption Research Exchange, S. 213-229.

Schäfer, Martina; Jaeger-Erben, Melanie; Bamberg, Sebastian (2012): Life Events as Windows of Opportunity for Changing Towards Sustainable Consumption Patterns? In: Journal of Consumer Policy 35 (1), S. 65-84. DOI: 10.1007/s10603-011-9 181-6.

Schaffrin, André; Reibling, Nadine (2015): Household energy and climate mitigation policies: Investigation energy practices in the housing sector. In: Energy Policy 77, S. 1-10.

Schatzki, Theodore R. (1996): Social practices. A Wittgensteinian approach to human activity and the social. Cambridge: Cambridge Univ. Press.

Schatzki, Theodore R. (2001): Introduction: practice theory. In: Theodore R. Schatzki, Knorr Cetina Karin und Eike von Savigny (Hg.): The Practice Turn in Contemporary Theory. London [u. a.]: Routledge, S. 1-14.

Schatzki, Theodore R. (2002): The Site of the Social. A Philosophical Account of the Constitution of Social Life and Change. Pennsylvania, US: The Pennsylvania State University Press.

Schatzki, Theodore R. (2005): Peripheral Vision: The Sites of Organizations. In: Organization Studies 26 (3), S. 465-484. DOI: 10.1177/0170840605050876.

Schatzki, Theodore R. (2010): Materiality and social life. In: Nature and Culture 5 (2), S. 123-149.

Schatzki, Theodore R. (2012): A Primer on Practices. In: Joy Higgs, Ronald Barnett, Stephen Billet, Maggie Hutchings und Franziska Trede (Hg.): PracticeBased Education. Perspectives and Strategies. Rotterdam, New York, Taipei: Sense Publisher, S. 13-26. 


\section{Literaturverzeichnis}

Schatzki, Theodore R. (2013): The Edge of Change. On the emergence, persistence and dissolution of practices. In: Elizabeth Shove und Nicola Spurling (Hg.): Sustainable Practices. Social Theory and Climate Change. New York, USA, London, UK: Routledge, S. 31-46.

Schatzki, Theodore R.; Knorr Cetina Karin; Savigny, Eike von (Hg.) (2001): The Practice Turn in Contemporary Theory. London [u.a.]: Routledge.

Schimschar, Sven; Blok, Kornelis; Boermans, Thomas; Hermelink, Andreas (2011): Germany's path towards nearly zero-energy buildings-Enabling the greenhouse gas mitigation potential in the building stock. In: Energy Policy 39 (6), S. 3346-3360. DOI: 10.1016/j.enpol.2011.03.029.

Schmidt, Robert (2012): Soziologie der Praktiken. konzeptionelle Studien und empirische Analysen. Berlin: Suhrkamp.

Schnell, Rainer; Hill, Paul B.; Esser, Elke (2011): Methoden der empirischen Sozialforschung. 9., aktualisierte Aufl. München: Oldenbourg.

Schnieders, Jürgen; Hermelink, Andreas (2006): CEPHEUS results: measurements and occupants' satisfaction provide evidence for Passive Houses being an option for sustainable building. In: Energy Policy 34 (2), S. 151-171.

Schulz, Christian; Rosenfeld, Martin T.W. (2011): Im Fokus: Wie fördern Bund und Länder die Energieeffizienz im Gebäudebestand? In: Wirtschaft im Wandel 17 (11), S. 376-390. Online verfügbar unter https://www.econstor.eu/bitstream/1 0419/143940/1/2011-11-03.pdf.

Schumpeter, Joseph A. (1943): Capitalism, Socialism, and Democracy. London [u.a.]: Allen \& Unwin.

Schumpeter, Joseph A. (1947): The Creative Response in Economic History. In: The Journal of Economic History 7 (2), S. 149-159.

Schütze, Fritz (1987): Das narratative Interview in Interaktionsfeldstudien. Hagen: Fernuniversität, Gesamthochschule.

Schütze, Fritz; Meinefeld, Werner; Springer, Werner; Weymann, Ansgar (1973): Grundlagentheoretische Voraussetzungen methodisch kontrollierten Fremdverstehens. In: Arbeitsgruppe Bielefelder Soziologen (Hg.): Alltagswissen, Interaktion und gesellschaftliche Wirklichkeit/ 2 Ethnotheorie und Ethnographie des Sprechens, Bd. 2. 2 Bände. Reinbek bei Hamburg: Rowohlt (Alltagswissen, Interaktion und gesellschaftliche Wirklichkeit, 2), S. 433-495.

Schwartz Cowan, Ruth (1976): The "Industrial Revolution" in the Home: Household Technology and Social Change in the $20^{\text {th }}$ Century. In: Technology and Culture 17 (1), S. 1-23.

Schwartz Cowan, Ruth (1983): More Work for Mother: The Ironies of Household Technology from the Open Hearth to the Microwave. New York: Basic Books.

Schweighofer, Martin (2015): Die Elimination sozialer Praktiken. Eine Herausforderung auf dem Weg zu suffizienten Alltagskulturen. In: Anika Arnold, Martin David, Gerolf Hanke und Marco Sonnberger (Hg.): Innovation - Exnovation: Über Prozesse des Abschaffens und Erneuerns in der Nachhaltigkeitstransformation. Marburg: Metropolis-Verlag (Ökologie und Wirtschaftsforschung), S. 127143. 
Shove, Elizabeth (1997a): Energy Knowledges. In: European Council for an Energy Efficient Economy (ECEEE) (Hg.): Panels of the eceee 1997 Summer Study.

Shove, Elizabeth (1997b): Revealing the invisible: sociology, energy and the environment. In: Michael Redclift und Graham Woodgate (Hg.): The International Handbook on Environmental Sociology. Cheltenham, UK, Northhampton, MA, USA, S. 261-273.

Shove, Elizabeth (2003): Converging Conventions of Comfort, Cleanliness and Convenience. In: Journal of Consumer Policy 26, S. 395-418.

Shove, Elizabeth (2004a): Changing human behaviour and lifestyle: A challenge for sustainable consumption? In: Lucia A. Reisch und Inge Røpke (Hg.): The Ecological Economics of Consumption. Cheltenham, UK, Northampton, MA, USA: Edward Elgar, S. 111-131.

Shove, Elizabeth (2004b): Efficiency and Consumption: Technology and Practice. In: Energy \& Environment 15 (6), S. 1053-1065.

Shove, Elizabeth (2004c): Sustainability, system innovation and the laundry. In: Boelie Elzen, Frank W. Geels und Ken Green (Hg.): System Innovation and the Transition to Sustainability. Cheltenham, UK, Northampton, MA, USA: Edward Elgar, S. 76-94.

Shove, Elizabeth (2010a): Beyond the ABC. Climate change policy and theories of social change. In: Environ. Plann. A 42 (6), S. 1273-1285. DOI: 10.1068/a42282.

Shove, Elizabeth (2010b): Social Theory and Climate Change. Questions Often, Sometimes and Not Yet Asked. In: Theory, Culture and Society 27 (2-3), S. 277288.

Shove, Elizabeth (2012): Habits and Their Creatures. In: Alan Warde und Dale Southerton (Hg.): The Habits of Consumption, Bd. 12. 12 Bände. Helsinki: Helsinki Collegium for Advanced Studies (Collegium. Studies Across Disciplines in the Humanities and Social Sciences, 12), S. 100-112.

Shove, Elizabeth (2014): Putting practice into policy: reconfiguring questions of consumption and climate change. In: Contemporary Social Science: Journal of the Academy of Social Sciences 9 (4), S. 415-429. DOI: 10.1080/21582041.2012.69248 4.

Shove, Elizabeth; Chappells, Heather (2001): Ordinary Consumption and Extraordinary Relationships: Utilities and their Users. In: Jukka Gronow und Alan Warde (Hg.): Ordinary Consumption, Bd. 2. London, New York: Routledge (Studies in Consumption and Markets Series, 2), S. 45-58.

Shove, Elizabeth; Chappells, Heather; Lutzenhiser, Loren; Hackett, Bruce (2008): Editorial. Comfort in a lower carbon society. In: Building Research \& Information (Special Issue) 36 (4), S. 307-311.

Shove, Elizabeth; Lutzenhiser, Loren; Guy, Simon; Hackett, Bruce; Wilhite, Harold (1998): Energy and social systems. In: Steve Rayner und Elizabeth L. Malone (Hg.): Human choice and climate change. Resources and technology, Bd. 2. 4 Bände. Columbus, Ohio u. a.: Battelle Press (Human choice and climate change, 2), S. 291-325. 
Shove, Elizabeth; Pantzar, Mika (2005): Consumers, Producers and Practices. Understanding the invention and reinvention of Nordic Walking. In: Journal of Consumer Culture 5 (1), S. 43-64.

Shove, Elizabeth; Pantzar, Mika (2006): Fossilisation. In: Orvar Löfgren und Richard R. Wilk (Hg.): Off the Edge. Experiements in Cultural Analysis. Copenhagen: Museum Tusculanum Press, S. 59-62.

Shove, Elizabeth; Pantzar, Mika (2007): Recruitment and Reproduction: The Careers and Carriers of Digital Photography and Floorball. In: Human Affairs 17, S. $154-167$.

Shove, Elizabeth; Pantzar, Mika; Watson, Matt (2012): The Dynamics of Social Practice. Everyday Life and how it changes. London [u. a.]: Sage.

Shove, Elizabeth; Southerton, Dale (2000): Defrosting the freezer: From novelty to convenience - A narrative of normalisation. In: Journal of Material Culture 5 (3), S. 301-319.

Shove, Elizabeth; Spurling, Nicola (Hg.) (2013): Sustainable Practices. Social Theory and Climate Change. New York, USA, London, UK: Routledge.

Shove, Elizabeth; Trentmann, Frank; Wilk, Richard R. (Hg.) (2009): Time, Consumption and Everyday Life. Practice, Materiality and Culture. Oxford, New York: Berg (Cultures of Consumption Series).

Shove, Elizabeth; Walker, Gordon (2007): CAUTION! Transitions ahead: politics, practice, and sustainable transition management. In: Environment and Planning A 39 (4), S. 763-770.

Shove, Elizabeth; Walker, Gordon (2014): What Is Energy For? Social Practice and Energy Demand. In: Theory, Culture \& Society 31 (5), S. 41-58.

Shove, Elizabeth; Warde, Alan (2002): Inconspicuous Consumption: The Sociology of Consumption, Lifestyles, and the Environment. In: Riley E. Dunlap, Frederick H. Buttel, Peter Dickens und August Gijswijt (Hg.): Sociological Theory and the Environment. Classical Foundations, Contemporary Insights. Lanham, Md. [u.a.]: Rowman \& Littlefield, S. 230-251.

Shove, Elizabeth; Watson, Matthew; Hand, Martin; Ingram, Jack (2007): The Design of Everyday Life. Oxford [u.a.]: Berg (Cultures of Consumption Series).

Sloman, Martyn; Al Dowayan, Maram (2004): Learning interventions. In: Development and Learning in Organizations: An International Journal 18 (3), S. 13-15. DOI: $10.1108 / 14777280410699104$.

Sonnberger, Marco; Zwick, Michael M. (2016): Der Energieverbrauch in Privathaushalten soziologisch betrachtet. In: SuN Soziologie und Nachhaltigkeit - Beiträge zur sozial-ökologischen Transformationsforschung 2 (2), S. 1-28. Online verfügbar unter http://nbn-resolving.de/urn:nbn:de:hbz:6:3-sun-2016-16530.

Southerton, Dale; Vliet, Bas van; Chappells, Heather (2004): Introduction: consumption, infrastructures and environmental sustainability. In: Dale Southerton, Heather Chappells und Bas van Vliet (Hg.): Sustainable Consumption: The Implications of Changing Infrastructures of Provision. Cheltenham, UK, Northampton, MA, USA: Edward Elgar, S. 1-11. 
Spaargaren, Gert; Vliet, Bas van (2000): Liefestyles, consumption and the environment: The ecological modernisation of domestic consumption. In: Environmental Politics 9 (1), S. 50-76.

Springer, Stefanie; Beucker, Severin; Lang, Claus; Bierter, Willy (2004): Lead User Integration. nova-net Konsortium. Stuttgart.

Spurling, Nicola; McMeekin, Andrew; Shove, Elizabeth; Southerton, Dale; Welch, Daniel (2013): Sustainable Practices Research Group Report. Interventions in practice: re-framing policy approaches to consumer behaviour. Hg. v. Sustainable Practices Research Group.

Staats, Henk; Harland, Paul; Wilke, Henk A. M. (2004): Effecting durable Change. A Team Approach to Improve Environmental Behavior in the Household. In: Environment and Behavior 36 (3), S. 341-367.

Statistisches Bundesamt (2017): Nachhaltige Entwicklung in Deutschland. Indikatorenbericht 2016. Destatis (Statistisches Bundesamt Deutschland).

Statistisches Bundesamt; Umweltbundesamt (2015): Daten zur Umwelt: Umwelt, Haushalte und Konsum. Ausgabe 2015. Broschüre (PDF). Hg. v. Umweltbundesamt (UBA). Online verfügbar unter https://www.umweltbundesamt.de/publi kationen/daten-zur-umwelt-umwelt-haushalte-konsum-0, zuletzt geprüft am 05.08.2018.

Statistisches Bundesamt (Destatis) (Hg.) (2018a): Bautätigkeit und Wohnungen. Bautätigkeit. Fachserie 5 Reihe 1-2017. Online verfügbar unter https://www.des tatis.de/DE/Publikationen/Thematisch/Bauen/BautaetigkeitWohnungsbau/Baut aetigkeit.html, zuletzt geprüft am 07.09.2018.

Statistisches Bundesamt (Destatis) (Hg.) (2018b): Bautätigkeit und Wohnungen. Bestand an Wohnungen. Fachserie 5 Reihe 3-31. Dezember 2017. Online verfügbar unter https://www.destatis.de/DE/Publikationen/Thematisch/Bauen/Wo hnsituation/BestandWohnungen.html, zuletzt geprüft am 07.09.2018.

Stebbins, Robert A. (1992): Amateurs, professionals, and serious leisure. Montreal: McGill-Queen's Univ. Press.

Stebbins, Robert A. (1999): EDUCATING FOR SERIOUS LEISURE: LEISURE EDUCATION IN THEORY AND PRACTICE. In: World Leisure \& Recreation 41 (4), S. 14-19. DOI: 10.1080/10261133.1999.9674163.

Stern, Paul C. (1985): Energy Efficiency in Buildings: Behavioral Issues. Washington, DC: National Academy Press.

Stern, Paul C. (1986): Blind spots in policy analysis: What economics doesn't say about energy use. In: Journal of Policy Analysis and Management 5, S. 200-227.

Stern, Paul C. (1992): What Psychology knows about Energy Conservation. In: American Psychologist 47 (10), S. 1224-1232.

Stern, Paul C. (2000): Toward a Coherent Theory of Environmentally Significant Behavior. In: Journal of Social Issues 56 (3), S. 407-424.

Stern, Paul C.; Dietz, Thomas; Abel, Troy; Guagnano, Gregory A.; Kalof, Linda (1999): A Value-Belief-Norm Theory of Support for Social Movements: The Case of Environmentalism. In: Human Ecology Review 6 (2), S. 81-97. 
Stern, Paul C.; Gardner, Gerald T. (1981): Psychological Research and Energy Policy 36 (4), S. 329-342.

Strauss, Anselm; Corbin, Juliet (1990): Basics of Qualitative Research: Grounded Theory Procedures and Techniques. Newbury Park, California [u.a.]: Sage.

Strengers, Yolande (2008): Comfort expectations: the impact of demand-management strategies in Australia. In: Building Research \& Information 36 (4), S.381391. DOI: $10.1080 / 09613210802087648$.

Strengers, Yolande (2013): Smart energy technologies in everyday life. Smart utopia? [Basingstoke]: Palgrave Macmillan (Consumption and public life).

Strese, Hartmut; Seidel, Uwe; Knape, Thorsten; Botthof, Alfons (2010): Smart Home in Deutschland. Untersuchung im Rahmen der wissenschaftlichen Begleitung zum Programm Next Generation Media (NGM) des Bundesministeriums für Wirtschaft und Technologie. Hg. v. Institut für Innovation und Technik (iit). Berlin.

Stringer, Mark; Fitzpatrick, Geraldine; Harris, Eric (2006): Lessons for the Future: Experiences with the Installation and Use of Today's Domestic Sensors and Technologies. In: Kenneth P. Fishkin, Bernt Schiele, Paddy Nixon und Aaron Quigley (Hg.): Pervasive computing. $4^{\text {th }}$ international conference, PERVASIVE 2006, Dublin, Ireland, May 7-10, 2006; proceedings. Berlin: Springer (Lecture notes in computer science, 3968), S. 383-399.

Sunikka-Blank, Minna; Galvin, Ray (2012): Introducing the prebound effect: the gap between performance and actual energy consumption. In: Building Research \& Information 40 (3), S. 260-273. DOI: 10.1080/09613218.2012.690952.

Sustainable Consumption Roundtable (SCR) (2006): Looking back, looking forward. Lessons in choice editing for sustainability. 19 case studies into drivers and barriers to mainstreaming more sustainable products. Hg. v. Sustainable Development Commission (SDC). SCR (Great Britain) - a joint initiative of the National Consumer Council (NCC) and the Sustainable Development Commission (SDC). London, UK (Sustainable Development Commission Reports). Online verfügbar unter https://research-repository.st-andrews.ac.uk/handle/10023/2 314, zuletzt geprüft am 30.07.2018.

Szerszynski, Bronislaw; Urry, John (2010): Changing Climates: Introduction. In: Theory, Culture \& Society 27 (2-3), S. 1-8.

Thøgersen, John (2012): The Importance of Timing for Breaking Commuters' Car Driving Habits. In: Alan Warde und Dale Southerton (Hg.): The Habits of Consumption. 12 Bände. Helsinki: Helsinki Collegium for Advanced Studies (Collegium. Studies Across Disciplines in the Humanities and Social Sciences, 12), S. 130-140.

Tuschinski, Melita (2018): EnEV 2020: Energieeinsparverordnung auf dem Weg zu klimaneutralen Bauten. Intelligente Architektur: Niedrigst-, Null- und PlusEnergie-Gebäude. Projekte, Bauten und Informationen für Architekten, Energieberater, Planer, Sachverständige, Bauherrn und Verwalter. Ergänzte Ausgabe: 21. Juni 2018. Hg. v. Institut für Energie-Effiziente Architektur mit Internet-Medien. Online verfügbar unter http://service.enev-online.de/bestellen/index.htm, zuletzt geprüft am 11.10.2018. 
Umweltbundesamt (UBA); GdW - Bundesverband deutscher Wohnungsunternehmen e.V. (Hg.) (2003): Energiemanagement in Wohnungsunternehmen. Chancen nutzen - Klimaschutz und Wirtschaftlichkeit verbinden. Berlin.

UNEP (2015): Sustainable Consumption and Production. A Handbook for Policymakers. Global Edition. Hg. v. United Nations Environment Programme (UNEP).

Urban, Glen L.; Hippel, Eric von (1988): Lead User Analyses for the Development of New Industrial Products. In: Management Science 34 (5), S. 569-582. DOI: 10.1287/mnsc.34.5.569.

Vaage, K. (2002): Heating technology and energy use: A discrete / continuos choice approach to Norwegian household energy demand. In: Energy Economics 22, S. 649-666.

Valkila, Noora; Saari, Arto (2013): Attitude-behaviour gap in energy issues: Case study of three different Finnish residential areas. In: Energy for Sustainable Development 17 (1), S. 24-34.

Vliet, Bas van (2002): Greening the grid. The ecological modernisation of networkbound systems. PhD-Thesis Wageningen University.

Vliet, Bas van; Chappells, Heather; Shove, Elizabeth (2005): Infrastructures of Consumption. Environmental Innovation in the Utility Industries. London, Sterling, VA: Earthscan.

Voß, Jan-Peter; Kemp, Rene (2005): Reflexive governance for sustainable development - incorporation feedback in social problem solving. Paper for ESEE Conference, Lisbon, 14-17 June 2005.

Voß, Jan-Peter; Truffer, Bernhard; Konrad, Kornelia (2006): Sustainability foresight: reflexive governance in the transformation of utility systems. In: Jan-Peter Voß, Dierk Bauknecht und Rene Kemp (Hg.): Reflexive Governance for Sustainable Development. Cheltenham, UK, Northampton, MA, USA: Edward Elgar, S. 162-188.

Wagner, Philipp; Piller, Frank (o.J.): Mit der Lead-User-Methode zum Innovationserfolg. Ein Leitfaden zur praktischen Umsetzung. Hg. v. Ralf Reichwald und Kathrin M. Möslein. CLIC - Center for Leading Innovation \& Coorporation, Handelshochschule Leipzig GmbH (CLIC Executive Briefing, 020). Online verfügbar unter http://clicresearch.org/wp-content/uploads/2011/11/20_de_lead_us er_handbuch.pdf, zuletzt geprüft am 06.04.2017.

Walker, Gordon (2014): The dynamics of energy demand: Change, rhythm and synchronicity. In: Energy Research \& Social Science 1, S. 49-55.

Walker, Gordon; Shove, Elizabeth; Brown, Sam (2014): How does air conditioning become 'needed'? A case study of routes, rationales and dynamics. In: Energy Research \& Social Science 4, S. 1-9. DOI: 10.1016/j.erss.2014.08.002.

Wallenborn, Grégoire (2013): Extended bodies and the geometry of practices. In: Elizabeth Shove und Nicola Spurling (Hg.): Sustainable Practices. Social Theory and Climate Change. New York, USA, London, UK: Routledge, S. 146-164. 
Wallenborn, Grégoire; Orsini, Marco; Vanhaverbeke, Jérémie; Velghe, Jan; Zaccai, E.; Rousseau, C. et al. (2011): Integration of Standards, Ecodesign and Users in energy-using Products - ISEU. Final Report. Belgian Science Policy. Brüssel.

Wallenborn, Grégoire; Wilhite, Harold (2014): Rethinking embodied knowledge and household consumption. In: Energy Research \& Social Science 1, S. 56-64.

Warde, Alan (2005): Consumption and Theories of Practice. In: Journal of Consumer Culture 5 (2), S. 131-153.

Warde, Alan (2013): What Sort of a Practice Is Eating. In: Elizabeth Shove und Nicola Spurling (Hg.): Sustainable Practices. Social Theory and Climate Change. New York, USA, London, UK: Routledge, S. 17-30.

Warde, Alan (2016): The Practice of Eating. Cambridge: Polity.

Warde, Alan; Southerton, Dale (2012a): Introduction. In: Alan Warde und Dale Southerton (Hg.): The Habits of Consumption. 12 Bände. Helsinki: Helsinki Collegium for Advanced Studies (Collegium. Studies Across Disciplines in the Humanities and Social Sciences, 12), S. 1-25.

Warde, Alan; Southerton, Dale (Hg.) (2012b): The Habits of Consumption. Collegium for Advanced Studies. 12 Bände. Helsinki: Helsinki Collegium for Advanced Studies (Collegium. Studies Across Disciplines in the Humanities and Social Sciences, 12).

Weizsäcker, Ernst Ulrich von; Lovins, Amory B.; Lovins, L. Hunter (1997): Faktor Vier. Doppelter Wohlstand - halbierter Naturverbrauch; der neue Bericht an den Club of Rome. 10. Aufl. München: Droemer Knaur.

Widmann, Carlos (1995): Der Nega-Watt-Guru. Energiewende. In: Spiegel special (7), S. 96-99.

Wilhite, Harold (2007): Will efficient technologies save the world? A call for new thinking on the ways that end-use technologies affect energy using practices. In: ECEEE 2007 Summer Study (Hg.): Saving Energy - Just do it! ECEEE. Stockholm, Schweden: ABA Intercopy, S. 23-30.

Wilhite, Harold (2008): New thinking on the agentive relationship between enduse technologies and energy-using practices. In: Energy Efficiency 1 (2), S. 121130. DOI: $10.1007 / \mathrm{s} 12053-008-9006-x$.

Wilhite, Harold (2012): Towards a Better Accounting of the Roles of Body, Things and Habits in Consumption. In: Alan Warde und Dale Southerton (Hg.): The Habits of Consumption, Bd. 12. 12 Bände. Helsinki: Helsinki Collegium for Advanced Studies (Collegium. Studies Across Disciplines in the Humanities and Social Sciences, 12), S. 87-99.

Wilhite, Harold; Lutzenhiser, Loren (1999): Social Loading and Sustainable Consumption. In: Advances in Consumer Research 26 (1), S. 281-287. Online verfügbar unter http://search.ebscohost.com/login.aspx?direct=true $\& \mathrm{db}=\mathrm{bth} \& \mathrm{~A}$ $\mathrm{N}=83144326 \&$ site=ehost-live. 
Wilhite, Harold; Shove, Elizabeth; Lutzenhiser, Loren; Kempton, Willett (2000): The Legacy of Twenty Years of Energy Demand Management: we know more about Individual Behaviour but next to Nothing about Demand. In: Eberhard Jochem, Jayant Sathaye und Daniel Bouille (Hg.): Society, Behaviour, And Climate Change Mitigation, Bd. 8. Dordrecht, Boston, London: Kluwer Academic Publishers (Advances in Global Change Research, 8), S. 109-126.

Wilk, Richard R. (2009): The Edge of Agency. Routines, Habits and Volition. In: Elizabeth Shove, Frank Trentmann und Richard R. Wilk (Hg.): Time, Consumption and Everyday Life. Practice, Materiality and Culture. Oxford, New York: Berg (Cultures of Consumption Series), S. 143-154.

Wilson, Charlie; Hargreaves, Tom; Hauxwell-Baldwin, Richard (2017): Benefits and risks of smart home technologies. In: Energy Policy 103, S. 72-83. DOI: 10.1016/j.enpol.2016.12.047.

Witzel, Andreas (1982): Verfahren der qualitativen Sozialforschung. Überblick und Alternativen. Frankfurt, New York: Campus Verlag. 


\title{
Online-Quellen
}

\author{
(im Text mit * gekennzeichnet)
}

Bendel, Oliver (2017): Smart Home. Definition. Gabler Wirtschaftslexikon. Online verfügbar unter https:/wirtschaftslexikon.gabler.de/definition/smart-home-5413 7/version-188420, zuletzt aktualisiert am 26.01.2017, zuletzt geprüft am 29.07.2018.

Böttcher, Sarah (2017): Smart Home Index 2017. So smart ist das deutsche Zuhause vernetzt. Website-Artikel auf www.it-business.de. Hg. v. Vogel IT-Medien $\mathrm{GmbH}$. Online verfügbar unter https:/www.it-business.de/so-smart-ist-das-deuts che-zuhause-vernetzt-a-650590/, zuletzt aktualisiert am 06.10.2017, zuletzt geprüft am 04.09.2018.

Brönnimann, Stefan (2010): Wie beeinflussen natürliche Faktoren den Klimawandel? Eidgenössische Technische Hochschule Zürich (ETH). ETH-Klimablog. Online verfügbar unter https://blogs.ethz.ch/klimablog-archive/2010/04/08/wie-beei nflussen-naturliche-faktoren-den-klimawandel/, zuletzt aktualisiert am 08.04.2010, zuletzt geprüft am 27.07.2018.

Bundesministerium der Justiz und für Verbraucherschutz (Hg.) (2007): Verordnung über energiesparenden Wärmeschutz und energiesparende Anlagentechnik bei Gebäuden (Energieeinsparverordnung - EnEV). Gesamtausgabe der Norm im HTML-Format. Online verfügbar unter https:/www.gesetze-im-intern et.de/enev_2007/BJNR151900007.html, zuletzt aktualisiert am 24.10.2015, zuletzt geprüft am 12.08.2018.

Bundesministerium für Wirtschaft und Energie (BMWi) (Hg.) (2015b): So heizt Deutschland heute. Artikel im Newsletter des BMWi „Energiewende direkt“ vom 8. September 2015, Ausgabe 15/2015. Online verfügbar unter https://www. bmwi-energiewende.de/EWD/Redaktion/Newsletter/2015/15/Meldung/infografi k-so-heizt-deutschland-heute.html, zuletzt aktualisiert am 08.09.2015, zuletzt geprüft am 07.08.2018.

Bundesministerium für Wirtschaft und Energie (BMWi) (Hg.) (2017): Verwendung von Fernwärme in Deutschland. Infografik. Online verfügbar unter https:/ /www.bmwi.de/Redaktion/DE/Infografiken/Energie/Energiedaten/Energietraege r/energiedaten-energietraeger-32.html, zuletzt aktualisiert am 04.10.2017, zuletzt geprüft am 07.08.2018.

Bundesministerium für Wirtschaft und Energie (BMWi) (Hg.) (2018): Was sind eigentlich „Flexibilitätsoptionen“? Artikel im Newsletter des BMWi „Energiewende direkt" vom 16. Januar 2018, Ausgabe 01/2018. Online verfügbar unter https: //www.bmwi-energiewende.de/EWD/Redaktion/Newsletter/2018/01/Meldung/d irekt-erklaert.html, zuletzt aktualisiert am 16.01.2018, zuletzt geprüft am 28.08.2018. 
Burgdorf, Markus (2009): Definition KfW Effizienzhaus 55. Website-Artikel. Hg. v. OKAL Haus GmbH. Online verfügbar unter www.effizienzhaus55.info/2009/04/ 13/definition-kfw-effizienzhaus-55/, zuletzt aktualisiert am 13.04.2009, zuletzt geprüft am 29.08.2018.

Deloitte; Bitcom (Hg.) (2014): Vor dem Boom - Marktaussichten für Smart Home. Fokusgruppe Connected Home des Nationalen IT-Gipfels. Studie erschienen als PDF-Dokument. Online verfügbar unter https://www.bitkom.org/Bitkom/Publi kationen/Marktaussichten-fuer-Smart-Home.html, zuletzt aktualisiert am 23.10.2014, zuletzt geprüft am 06.09.2018.

Deutsche Energie-Agentur GmbH (dena) (Hg.) (o.J.): Gesund Wohnen durch richtiges Lüften und Heizen. Broschüre als pdf-Dokument. Online verfügbar unter www.komfortlüftung.at/fileadmin/komfortlueftung/EFH/GesundWohn_dena.p df, zuletzt geprüft am 13.08.2018.

Deutscher Mieterbund e.V. (dmb) (Hg.) (o.J.): Heizung. Mindesttemperaturen. Mietrecht A - Z. Website-Artikel. Online verfügbar unter https://www.mieterbu nd.de/index.php?id=442, zuletzt geprüft am 06.08.2018.

Forschungsstelle für Energiewirtschaft e.V. (FfE) (Hg.) (2017): Basisdaten von Energieträgern. Basisdaten zur Bereitstellung elektrischer Energie. Website-Artikel. Online verfügbar unter https://www.ffe.de/themen-und-methoden/erzeugung-u nd-markt/186-basisdaten-energietraeger, zuletzt aktualisiert am 20.02.2017, zuletzt geprüft am 05.08.2018.

Grobe, Carsten (2016): Passivhaus Grundlagen. [Gebäudetechnik in Passivhäusern. Wärmerückgewinnung]. Artikel auf Website www.passivhaus.de. Hg. v. Architektur- und TGA-Planungsbüro. Carsten Grobe Passivhaus. Online verfügbar unter https:/www.passivhaus.de/passivhaus-alt/passivhaus-grundlagen/, zuletzt geprüft am 08.08.2018.

Helmig, Bernd; Kirchgeorg, Manfred (2018): Social Marketing. Ausführliche Definition. Gabler Wirtschaftslexikon. Online verfügbar unter https://wirtschaftslexi kon.gabler.de/definition/social-marketing-43356/version-266687, zuletzt aktualisiert am 19.02.2018, zuletzt geprüft am 30.07.2018.

Hockenos, Paul (2012): The Energiewende. Aus dem Englischen von Michael Adrian. Erschienen in Zeit Online / Wissen. ZEIT Online (47). Online verfügbar unter http://www.zeit.de/2012/47/Energiewende-Deutsche-Begriffe-Englisch, zuletzt aktualisiert am 15.11.2012, zuletzt geprüft am 14.12.2017.

Krennerich, Michael (2018): Ein Recht auf (menschenwürdiges) Wohnen? Hg. v. Bundeszentrale für politische Bildung (bpb) (Aus Politik und Zeitgeschichte (APUZ), 25-26/2018). Online verfügbar unter http://www.bpb.de/apuz/270880/ ein-recht-auf-menschenwuerdiges-wohnen, zuletzt aktualisiert am 15.06.2018, zuletzt geprüft am 11.10.2018. 
Maniates, Michael (2010b): Ist nachhaltiges Verhalten steuerbar? [Zur Lage der Welt 2010 - Michael Maniates über Choice Editing]. Gekürzte Fassung eines Beitrags im Bericht „Zur Lage der Welt 2010 - Einfach besser leben“, herausgegeben vom Worldwatch Institute (Washington, D.C.) in Zusammenarbeit mit der Heinrich-Böll-Stiftung und Germanwatch. Erschienen im Oekom Verlag, München 2010. Online verfügbar unter https://utopia.de/0/magazin/michael-ma niates-nachhaltiges-verhalten-steuerbar-bericht-lage-der-welt-2010-konsum-choic e-editing, zuletzt aktualisiert am 03.03.2010, zuletzt geprüft am 16.08.2018.

Mietrechtslexikon.de - Redaktion (Hg.) (2014): Mietrecht: Raumtemperatur, Heizperiode, Hitze. 2004-2017 mietrechtslexikon.de - Mietrecht von A bis Z. Website-Artikel. Online verfügbar unter http:/www.mietrechtslexikon.de/a1lexikon 2/h1/heizung.htm, zuletzt aktualisiert am Mietrecht 11-2014 Mietrechtslexikon, zuletzt geprüft am 06.08.2018.

Nagengast, Bernard (2001): An Early History Of Comfort Heating. Online-Artikel. The News (Magazine) - Digital Edition. Online verfügbar unter https:/www.ac hrnews.com/articles/87035-an-early-history-of-comfort-heating, zuletzt aktualisiert am 11.12.2001, zuletzt geprüft am 06.08.2018.

o. A. (2000-2018): Heizung: Eine brennend heiße Geschichte. wissen.de Artikel. Hg. v. Konradien Medien GmbH. wissen.de - das Wissensportal von bild der wissenschaft. Online verfügbar unter https://www.wissen.de/heizung-eine-brenn end-heisse-geschichte, zuletzt geprüft am 06.08.2018.

Online-Redaktion von mietrecht-lexikon.net (o.J.): Zentralheizung (Miete). pdfDokument. Hg. v. mietrecht-lexikon.net. Online verfügbar unter http://mietrec ht-lexikon.net/download/C5fbe4e4fX125075b991eXY4773/Zentralheizung_Mi ete_.pdf, zuletzt geprüft am 06.08.2018.

Paschotta, Rüdiger (2010): Elektroheizung. Blog-Artikel im RP-Energie-Lexikon. Online verfügbar unter https://www.energie-lexikon.info/elektroheizung.html, zuletzt aktualisiert am 23.01.2018, zuletzt geprüft am 07.08.2018.

Paschotta, Rüdiger (2012): Heizkurve. Blog-Artikel im RP-Energie-Lexikon. Online verfügbar unter https://www.energie-lexikon.info/heizkurve.html, zuletzt aktualisiert am 21.02.2017, zuletzt geprüft am 11.10.2018.

Redaktion von energie-experten.org (2016): Schwerkraftheizung modernisieren oder umrüsten? Blog-Artikel. energie-experten.org ist ein unabhängiges Expert*innenportal und Fachmedium zu allen Themen der Energieeffizienz und Erneuerbaren Energien. Online verfügbar unter http:/www.energie-experten.or g/heizung/heizungstechnik/heizungsarten/schwerkraftheizung.html, zuletzt aktualisiert am 10.06.2016, zuletzt geprüft am 06.08.2018.

Rosenkranz, Alexander (2017): Die eigene Heizung nach 30 Jahren erneuern. BlogArtikel. Hg. v. VC/O GmbH - Viessmann Group. Online verfügbar unter https:/ /heizung.de/heizung/tipps/die-eigene-heizung-nach-30-jahren-erneuern/, zuletzt aktualisiert am 20.09.2017, zuletzt geprüft am 22.08.2018.

Sommer, Adolf (2016): Kostenvergleich zwischen EnEV und Passivhaus / Stand 2016. pdf-Dokument. Hg. v. Sommer Passivhaus GmbH. www.sommer-passivha us.de. Online verfügbar unter https://docplayer.org/23045639-Kostenvergleich-z wischen-enev-und-passivhaus-stand-2016.html, zuletzt geprüft am 22.08.2018. 
The Editors of Encyclopædia Britannica (1998): Heating. Process or System. Hg. v. inc. Encyclopædia Britannica. Online verfügbar unter https://www.britannica.co $\mathrm{m} /$ technology/heating-process-or-system, zuletzt aktualisiert am 22.07.2008, zuletzt geprüft am 09.01.2018.

Umweltbundesamt (UBA) (Hg.) (2013): Richtig Heizen, Schimmelbildung vermeiden. Website. Online verfügbar unter https://www.umweltbundesamt.de/theme $\mathrm{n}$ /gesundheit/umwelteinfluesse-auf-den-menschen/schimmel/richtig-heizen-schi mmelbildung-vermeiden, zuletzt aktualisiert am 14.10.2013, zuletzt geprüft am 03.08.2018.

Umweltbundesamt (UBA) (Hg.) (2015): Konsum und Umwelt: Zentrale Handlungsfelder. Website-Artikel. Online verfügbar unter https://www.umweltbunde samt.de/themen/wirtschaft-konsum/konsum-umwelt-zentrale-handlungsfelder, zuletzt aktualisiert am 01.04.2015, zuletzt geprüft am 26.07.2018.

Umweltbundesamt (UBA) (Hg.) (2017): Richtig Lüften, Schimmelbildung vermeiden. Webseite-Artikel. Online verfügbar unter https://www.umweltbundesamt.d e/themen/gesundheit/umwelteinfluesse-auf-den-menschen/schimmel/richtig-lue ften-schimmelbildung-vermeiden, zuletzt aktualisiert am 07.11.2017, zuletzt geprüft am 03.08.2018.

Umweltbundesamt (UBA) (Hg.) (2018a): Energieverbrauchskennzeichnung. Heizgeräte. Website-Artikel. Online verfügbar unter https://www.umweltbundesamt. de/themen/klima-energie/energiesparen/energieverbrauchskennzeichnung/heizg eraete\#textpart-1, zuletzt aktualisiert am 06.02.2018, zuletzt geprüft am 31.07.2018.

Umweltbundesamt (UBA) (Hg.) (2018b): Treibhausgas-Emissionen in Deutschland. Website-Artikel. Online verfügbar unter https:/www.umweltbundesamt.d e/daten/klima/treibhausgas-emissionen-in-deutschland, zuletzt aktualisiert am 30.07.2018, zuletzt geprüft am 07.08.2018.

Utopia Team (2018): Richtig lüften: 10 Tipps gegen Schimmel in der Wohnung. Ratgeber-Artikel auf utopia.de. Online verfügbar unter https://utopia.de/ratgebe r/richtig-lueften-gegen-schimmel/, zuletzt aktualisiert am 31.01.2018, zuletzt geprüft am 07.08.2018.

Verbraucherzentrale Bundesverband e.V. (VZBV) (Hg.) (2017): Gesundes Raumklima. Heizen, Lüften, Feuchtigkeit und Schimmel. Broschüre als pdf-Dokument. Stand März 2017. Online verfügbar unter https:/www.verbraucherzentral e-energieberatung.de/assets/downloads/flyer/Flyer_Gesundes_Raumklima.pdf, zuletzt geprüft am 03.08.2018. 


\section{Anhang}

\section{A: Kurzbeschreibung der untersuchten Passivhaus-Wohnprojekte}

\begin{tabular}{|l|l|}
\hline $\begin{array}{l}\text { Untersuchte } \\
\text { Passivhausprojekte }\end{array}$ & Kurzbeschreibung \\
\hline \multirow{5}{*}{ Passivhausprojekt A } & $\begin{array}{l}\text { Bei dem Hausprojekt A handelt es sich um ein Mehrgeschoss-Passiv- } \\
\text { haus mit knapp 20 Wohneinheiten (Mietwohnungen), die sich hin- } \\
\text { sichtlich Größe, Zuschnitt und Ausstattung deutlich unterscheiden. } \\
\text { Das Bauprojekt ist genossenschaftlich getragen. Darüber hinaus han- } \\
\text { delt es sich um ein baulich und sozial integratives Wohnprojekt. , Bau- } \\
\text { lich integrativ' meint, dass das gesamte Haus barrierefrei gebaut wor- } \\
\text { den ist. Zudem gibt es einige komplett rollstuhlgerechte Wohnungen. } \\
\text {,Sozial integrativ' bedeutet, dass es sich bei einem Teil der Wohnun- } \\
\text { gen um so genannte Sozialwohnungen handelt. }{ }^{135} \text { Das mit öffentli- } \\
\text { chen Mitteln geförderte Bauprojekt A wurde in den frühen 2000er } \\
\text { Jahren fertiggestellt (Passivhaus der ersten Generation). Das Haus- } \\
\text { und Wohnprojekt ist weitestgehend gemeinschaftlich selbstverwaltet. } \\
\text { Die meisten Wohneinheiten werden fast ausschließlich mit vorhande- } \\
\text { ner Wärme über das Lüftungssystem beheizt (Luftheizung) - eine zen- } \\
\text { trale Lüftungsanlage versorgt alle Wohneinheiten. Falls noch eine } \\
\text { kleine, Restheizung erforderlich ist, kann die Zuluft leicht nacher- } \\
\text { wärmt werden. In der Regel ist nur ein vorgeschriebener (zusätzli- } \\
\text { cher) Heizkörper im Badezimmer vorhanden. Einige Wohneinheiten } \\
\text { dieses Projekts verfügen aber über eine konventionelle Zusatzheizung } \\
\text { mit zusätzlichen Heizkörpern in anderen Wohnäumen. Bei der kon- } \\
\text { ventionellen Heizungsanlage handelt es sich um eine Gas-Zentralhei- } \\
\text { zung. Das Passivhausprojekt A verfügt zusätzlich noch über eine So- } \\
\text { laranlage, die nachträglich installiert wurde. }\end{array}$ \\
\hline
\end{tabular}

135 Bei Sozialwohnungen handelt es sich um Wohnungen, die im sozialen Wohnungsbau errichtet, d.h. mit öffentlichen Mitteln gebaut wurden. Sozialwohnungen sind in der Miete vergleichsweise günstig, da die Mieten einer Preisbindung unterliegen. Sozialwohnungen stehen ausschließlich einkommensschwachen Personen und Haushalten zur Verfügung, die ihren Wohnungsbedarf nicht am freien Markt decken können. Für den Bezug einer Sozialwohnung ist eine amtliche Bescheinigung, ein so genannter Wohnberechtigungsschein erforderlich, mit deren Hilfe ein*e Mieter*in nachweisen kann, dass er bzw. sie aufgrund seines bzw. ihres niedrigen Einkommens dazu berechtigt ist, eine mit öffentlichen Mitteln geförderte Wohnung zu beziehen. 


\begin{tabular}{|c|c|}
\hline Passivhausprojekt B & $\begin{array}{l}\text { Bei dem Hausprojekt B handelt es sich um ein Mehrgeschoss-Passiv- } \\
\text { haus mit knapp } 20 \text { Wohneinheiten (Mietwohnungen), die sich hin- } \\
\text { sichtlich Größe, Zuschnitt und Ausstattung unterscheiden. Das Bau- } \\
\text { projekt ist ein genossenschaftlich getragenes Projekt. Das Wohnpro- } \\
\text { jekt ist sozial integrativ, was bedeutet, dass es sich bei einigen der } \\
\text { Wohnungen um Sozialwohnungen handelt. Darüber hinaus liegt bei } \\
\text { diesem Wohnprojekt ein besonderer Schwerpunkt auf dem Zusam- } \\
\text { menwohnen von Jung und Alt. Das Wohnprojekt befindet sich in ge- } \\
\text { meinschaftlicher Selbstverwaltung. Das mit offentlichen Mitteln ge- } \\
\text { förderte Bauprojekt B wurde in den frühen 2000er Jahren fertiggestellt } \\
\text { (Passivhaus der ersten Generation). Der überwiegende Teil der Wohn- } \\
\text { einheiten wird fast ausschließlich mit vorhandener, d.h. aus der Ab- } \\
\text { luft zurückgewonnener Wärme über das Lüftungssystem beheizt } \\
\text { (Luftheizung); bei Bedarf wird die Zuluft leicht (elektrisch) nacher- } \\
\text { wärmt. In der Mehrheit der Wohnungen ist nur ein zusätzlicher Heiz- } \\
\text { körper im Badezimmer vorhanden. Einige Wohneinheiten dieses Pro- } \\
\text { jekts verfügen jedoch über eine konventionelle Zusatzheizung mit zu- } \\
\text { sätzlichen Heizkörpern in anderen Wohnräumen. Bei dem konventio- } \\
\text { nellen aktiven Heizungssystem handelt es sich um eine Gas-Zentral- } \\
\text { heizung. }\end{array}$ \\
\hline Passivhausprojekt C & $\begin{array}{l}\text { Bei dem Hausprojekt C handelt es sich um eine Passivhaus-Reihen- } \\
\text { hauskette mit ca. zehn Wohneinheiten. Die Passivhausreihenhäuser } \\
\text { sind Teil einer größeren Wohnsiedlung, die überwiegend aus Niedrig- } \\
\text { energiehäusern mit ca. } 35 \text { Wohneinheiten besteht. Das genossen- } \\
\text { schaftlich getragene und mit öffentlichen Mitteln geförderte Baupro- } \\
\text { jekt wurde in den frühen 2000er Jahren fertiggestellt (Passivhaus der } \\
\text { ersten Generation). Das Wohnprojekt befindet sich in gemeinschaftli- } \\
\text { cher Selbstverwaltung. In diesem Wohnprojekt verfügen alle Wohn- } \\
\text { einheiten über eine Zusatzheizung mit Heizkörpern zur Wärmevertei- } \\
\text { lung in allen Wohnräumen. Das Hausprojekt ist an das städtische } \\
\text { Fernwärmenetz angebunden, das heißt die Wärmeversorgung der ein- } \\
\text { zelnen Wohngebäude des Passivhausprojekts C erfolgt über Fernwär- } \\
\text { me. }\end{array}$ \\
\hline Passivhausprojekt D & $\begin{array}{l}\text { Bei dem Hausprojekt D handelt es sich um ein Mehrgeschoss-Passiv- } \\
\text { haus mit knapp } 20 \text { Wohneinheiten (Eigentumswohnungen), die sich } \\
\text { hinsichtlich Größe und Zuschnitt unterscheiden. Die Besonderheit } \\
\text { dieses Bau-und Wohnprojekts besteht darin, dass die Initiative für ein } \\
\text { Passivhaus von einem Architekturbüro ausging. Das Büro machte im } \\
\text { Rahmen eines Konzeptwettbewerbs ein öffentlich ausgeschriebenes } \\
\text { Baugrundstück zu einem Baugemeinschaftsgrundstück in Passivhaus- } \\
\text { bauweise und gewann damit den Wettbewerb. Erst daraufhin wurden } \\
\text { die teilnehmenden Parteien für die Baugemeinschaft gesucht. Das ge- } \\
\text { meinschaftsgetragene und mit öffentlichen Mitteln geförderte Baupro- } \\
\text { jekt wurde in den frühen 2010er Jahren fertiggestellt (Passivhaus der } \\
\text { zweiten Generation). In diesem Hausprojekt ist ein kleines Blockheiz- } \\
\text { kraftwerk (BHKW) installiert, das das gesamte Mehrfamilien-Wohnge- } \\
\text { bäude mit Strom und Wärme versorgt. Alle Wohneinheiten sind an } \\
\text { dieses aktive Zusatzheizungssystem angeschlossen und haben in der } \\
\text { Regel (zusätzliche) Heizkörper zur Wärmeverteilung in allen Wohn- } \\
\text { räumen. }\end{array}$ \\
\hline
\end{tabular}




\section{B: Interviewübersicht}

Insgesamt wurden 27 Interviews mit insgesamt 33 Personen geführt. Davon entfallen 17 Interviews mit insgesamt 21 Personen auf den Untersuchungsfall ,Passivhaus' (PH) (sechs Architekt*innengespräche und elf Bewohner*innengespräche) und zehn Interviews mit insgesamt zwölf Personen auf den Untersuchungsfall ,SmartHome' (SH) (vier Expert*innengespräche und sechs Bewohner*innengespräche).

\begin{tabular}{|c|c|c|c|c|}
\hline Audioaufnahme & \begin{tabular}{|l|} 
Interview- \\
nummer
\end{tabular} & Datum & Fall & Interviewpartner*innen \\
\hline DM550048 & 48 & 17.12 .2012 & $\mathrm{PH}$ & Expert"in: Architekt"in \\
\hline DM550049 & 49 & 18.12 .2012 & $\mathrm{PH}$ & Expert*in: Architekt"in \\
\hline DM550051 & 51 & 14.01 .2013 & $\mathrm{PH}$ & Expert"in: Architekt"in \\
\hline DM550052 & 52 & 17.01 .2013 & $\mathrm{PH}$ & Expert*in: Architekt"in \\
\hline DM550053 & 53 & 23.01 .2013 & $\mathrm{PH}$ & Expert"in: Architekt"in \\
\hline DM550054 & 54 & 28.01 .2013 & $\mathrm{PH}$ & Expert*in: Architekt"in \\
\hline DM550055 & 55 & 14.02 .2013 & $\mathrm{PH}$ & $\begin{array}{l}\text { Bewohner" in } 1 \text { und } 2 \text { des Passiv- } \\
\text { hausprojekts D (Doppelinterview) }\end{array}$ \\
\hline DM550056 & 56 & 14.03 .2013 & $\mathrm{PH}$ & $\begin{array}{l}\text { Bewohner*in } 1 \text { und } 2 \text { des Passiv- } \\
\text { hausprojekts A (Doppelinterview) }\end{array}$ \\
\hline DM550057 & 57 & 20.03 .2013 & $\mathrm{SH}$ & $\begin{array}{l}\text { Expert*innen: drei Mitarbeiter*in- } \\
\text { nen (Expert*in } 1,2 \text { und } 3 \text { ) eines } \\
\text { regionalen Energieversorgungs- } \\
\text { unternehmens (gemeinsames } \\
\text { Interview) }\end{array}$ \\
\hline DM550058 & 58 & 25.03 .2013 & $\mathrm{SH}$ & $\begin{array}{l}\text { Expert*in: Mitarbeiter*in eines } \\
\text { großen Energieversorgungsunter- } \\
\text { nehmens }\end{array}$ \\
\hline DM550059 & 59 & 03.04 .2013 & $\mathrm{PH}$ & $\begin{array}{l}\text { Bewohner"in } 1 \text { und } 2 \text { des Passiv- } \\
\text { hausprojekts B (Doppelinterview) }\end{array}$ \\
\hline DM550060 & 60 & 04.04.2013 & $\mathrm{PH}$ & $\begin{array}{l}\text { Bewohner"in des Passivhaus- } \\
\text { projekts B }\end{array}$ \\
\hline DM550061 & 61 & 09.04 .2013 & $\mathrm{PH}$ & \begin{tabular}{|l}
$\begin{array}{l}\text { Bewohner"in des Passivhaus- } \\
\text { projekts C }\end{array}$ \\
\end{tabular} \\
\hline DM550062 & 62 & 22.04 .2013 & $\mathrm{PH}$ & $\begin{array}{l}\text { Bewohner"in des Passivhaus- } \\
\text { projekts C }\end{array}$ \\
\hline DM550063 & 63 & 24.04 .2013 & $\mathrm{SH}$ & $\begin{array}{l}\text { Expert"in: Mitarbeiter*in eines } \\
\text { großen Energieversorgungsunter- } \\
\text { nehmens }\end{array}$ \\
\hline DM550064 & 64 & 29.04 .2013 & $\mathrm{PH}$ & $\begin{array}{l}\text { Bewohner*in } 1 \text { und } 2 \text { des Passiv- } \\
\text { hausprojekts B (Doppelinterview) }\end{array}$ \\
\hline DM550066 & 66 & 29.05 .2013 & $\mathrm{PH}$ & $\begin{array}{l}\text { Bewohner"in des Passivhaus- } \\
\text { projekts D }\end{array}$ \\
\hline
\end{tabular}


Anhang

\begin{tabular}{|l|l|l|l|l|}
\hline DM550067 & 67 & 03.06 .2013 & PH & $\begin{array}{l}\text { Bewohner*in des Passivhaus- } \\
\text { projekts D }\end{array}$ \\
\hline DM550068 & 68 & 19.06 .2013 & PH & $\begin{array}{l}\text { Bewohner*in des Passivhaus- } \\
\text { projekts D }\end{array}$ \\
\hline DM550069 & 69 & 16.07 .2013 & PH & $\begin{array}{l}\text { Bewohner*in des Passivhaus- } \\
\text { projekts D }\end{array}$ \\
\hline DM550070 & 70 & 19.07 .2013 & SH & $\begin{array}{l}\text { Expert*in: Mit-Urheber*in und } \\
\text { Betreuer*in eines SH-Modell- } \\
\text { hauses (LivingLab) }\end{array}$ \\
\hline DM550071 & 71 & 22.11 .2013 & SH & Bewohner*in \\
\hline DM550072 & 72 & 10.01 .2014 & SH & Bewohner*in \\
\hline DM550073 & 73 & 20.01 .2014 & SH & Bewohner*in \\
\hline DM550074 & 74 & 28.01 .2014 & SH) & Bewohner*in \\
\hline DM550075 & 75 & 28.01 .2014 & SH & Bewohner*in \\
\hline DM550076 & 76 & 26.03 .2014 & SH & Bewohner*in \\
\hline
\end{tabular}

